JORGE CRUCES CERRO

APLICAÇÃO DE NANOCELULOSES EM FIBRAS NÃO BRANQUEADAS PARA OBTENÇÃO DE PAPÉIS

São Paulo

2016 
JORGE CRUCES CERRO

\section{APLICAÇÃO DE NANOCELULOSES EM FIBRAS NÃO BRANQUEADAS PARA OBTENÇÃO DE PAPÉIS}

Dissertação apresentada à Escola Politécnica da Universidade de São Paulo para obtenção do título de Mestre em Ciências

Área de Concentração:

Engenharia Química

Orientador:

Prof. Dr. Song Won Park

São Paulo 
Catalogação-na-publicação

CRUCES-CERRO, JORGE

APLICAÇÃO DE NANOCELULOSES EM FIBRAS NÃO BRANQUEADAS

PARA OBTENÇÃO DE PAPÉIS / J. CRUCES-CERRO -- São Paulo, 2016.

$178 \mathrm{p}$.

Dissertação (Mestrado) - Escola Politécnica da Universidade de São Paulo. Departamento de Engenharia Química.

1.Fabricação de Papel 2.Propriedades Mecânicas de Papel 3.Nanocelulose 4.Fibras Curtas de Eucalipto 5.Kraftliner I.Universidade de São Paulo. Escola Politécnica. Departamento de Engenharia Química II.t. 


\section{AGRADECIMENTOS}

Me resulta gracioso el pensar como comenzó este proyecto, el cual, inicialmente, seria en "Tissue" y, que, por azar o por tener una "bocaza", acabo en papeles de embalaje y uso de nanocelulosas. De la misma forma, durante las diferentes cooperaciones necesarias para la realización del trabajo, ocurrieron situaciones, dicho sea, cómicas o inesperadas, pero, que al final de cuentas, llevaron a la finalización de un trabajo de más de dos años y "sabe Dios" cuantas horas, lecturas, sufrimientos o desesperos pasaron para un estudio que, en mi más sincera opinión, intenta dar un foco totalmente diferente a lo "típico".

Es difícil o imposible, poder listar a todas las personas que colaboraron directa o indirectamente en la realización de este trabajo, citarlos llevaría a escribir, por lo menos, otra monografía. A todos, sin excepción, quiero mostrar mi agradecimiento. Solamente con su contribución ha sido posible concretar y finalizar el trabajo aquí presentado.

Desde luego, mi más sincera gratitud al Profesor Doctor Song Won Park de la "Universidade de São Paulo", mi orientador y amigo, por la supervisión científica, por las sugestiones dadas en el corredor, por la ayuda en el desarrollo de este estudio y por la gran y cuidada revisión en este trabajo. Aún más importante es agradecer las risas, su disponibilidad incondicional ante todas las dificultades y dudas tenidas, no sólo de la ejecución del trabajo, sino de otros aspectos no académicos.

A la Doctora Maria Luiza Otero D'Almeida, jefa del laboratorio de papel y celulosa del IPT, por la constante y tortuosa labor de enderezar el camino a seguir en la realización del trabajo, así como a las sugestiones, ayuda, disponibilidad de medios y estar presente cuando fue necesario.

A Fernando Henrique Pescatori da Silva, Gerente de "Desenvolvimento Técnico" de la empresa Eldorado Brasil Celulose S.A., por la colaboración a la realización de este estudio, por el incentivo, por la ayuda, por los consejos, por el financiamiento y por el apoyo al presente trabajo, el cual no 
podría haber sido realizado sin su colaboración este manuscrito no hubiera sido posible.

A mis compañeras y compañeros del IPT: Arlet, Carol, Dani, Jonathan, Karina, Marcia, Mariza, Paty, Pris, Renato y Tonino por porque no solamente me acogieron durante mi estancia en el laboratorio, también me ayudaron en la realización de los ensayos, por su amistad, así como por el apoyo durante la ejecución del proyecto.

A Ana Carolina Alves do Carvalho, de Eldorado Brasil Celulose S.A., por su ayuda en la ejecución y realización de ensayos.

Especial agradecimiento al Profesor Doctor, de la Universidad de Coimbra, Paulo Jorge Tavares Ferreira, por la obtención de nanofibras. Además de mostrar mi gratitud por la cooperación, caracterización y sugestiones en el uso de estos nanomateriales.

A las Doctoras Graziela Muniz y Lívia Cassia de la Universidad de Paraná, por dejarme utilizar sus equipamientos e instalaciones para obtener microfibras para el desarrollo de esta investigación.

Al Doctor Pedro Silva, por la ayuda en la obtención de datos, insumos y materias primas de Kraftliner.

Al Doctor Juan Carlos Villar, por ayudarme a venir a Brasil, por lo cual continué mis estudios en la gran área de los materiales lignocelulósicos.

Agradecer a la Doctora Nuria y a Chema, por conseguir que un pésimo escritor consiguiese poder, al menos en parte, desarrollar capacidad para poder expresar sus ideas, experiencias y conocimientos en un papel de una manera más "adecuada".

Al laboratorio de papel y celulosa del IPT, así como a todos sus colaboradores, por haberme acogido tan calurosamente además de haberme permitido usar su centro y equipamientos para la ejecución de este trabajo. 
A la empresa Eldorado Brasil Celulose S.A., por subministrar el apoyo económico y formación en este proyecto así como en el área de celulosa y papel.

Es obligado por mi parte no olvidarme de todos mis amigos y amigas, tengan aportado algo o no en este proyecto. No obstante, ellos y ellas estuvieron siempre presentes. A mis amigos de Brasil y España, estén aquí o en otra región. Pido perdón a todos ellos por no listarlos, a mi favor sea dicho que supondría colocar innúmeros nombres.

A mi familia, por su apoyo en mi formación así como por la comprensión del estar tan lejos de casa. A pesar de los kilómetros, siempre que necesite de ellos estuvieron presentes.

A todos, Muito Obrigado! 
A mis padres y mi hermano, sin su ayuda y su apoyo este trabajo no hubiera sido posible 


\title{
RESUMO
}

\author{
CRUCES-CERRO, J. Aplicação de nanoceluloses em fibras não branqueadas \\ para obtenção de papéis. São Paulo, 2016. 178p. Dissertação (Mestrado em \\ Ciências - Engenharia Química) - Escola Politécnica da Universidade de São \\ Paulo, 2016.
}

\begin{abstract}
Atualmente, o Brasil é o maior fabricante de celulose branqueada de eucalipto do mundo. Geralmente as fibras virgens de Eucalyptus spp. são utilizadas na fabricação de papéis para imprimir, tissue e especiais. Papéis para embalagens, tipicamente Kraftliners, precisam de uma grande resistência mecânica e são produzidos principalmente a partir de pastas Kraft de coníferas não branqueadas. Por outro lado, nanoceluloses fabricadas a partir de biomassa são consideradas um dos materiais sustentáveis mais interessantes para o século, com excelentes propriedades como baixa densidade, elevadas propriedades mecânicas, alta hidrofilicidade, grande área superficial com reatividade química e elevado valor econômico. Desde 2012 o uso de nanoceluloses na fabricação de papel ganhou impulso. As nanoceluloses têm sido adicionadas em pastas mecânicas e Kraft branqueadas para fabricação do papel, incrementando notavelmente as suas propriedades mecânicas, mas há preocupações sobre a diminuição da drenabilidade, da porosidade e da opacidade do papel. Poucos estudos foram desenvolvidos visando a aplicação de nanoceluloses em fibras não branqueadas, ainda que tenham aplicações em pastas branqueadas e/ou mecânicas. Portanto, o presente trabalho visa desenvolver 0 uso de nanoceluloses para melhorar as propriedades mecânicas em fibras não branqueadas. Em primeiro lugar, tomaram-se os finos primários do branqueamento de celulose de Pasta Kraft de Eucalipto como a matéria-prima para produzir dois tipos de nanocelulose. A celulose microfibrilada (MFC) é produzida diretamente por homogeneização mecânica utilizando equipamento Masuko. A celulose nanofibrilada (CNF) é produzida por oxidação mediada por TEMPO e homogeneizada por GEA. Em segundo lugar, selecionaram-se com as fibras virgens de Pasta Kraft Marrom de Pinho (PKPM) com número Kappa 36,1 e Pasta Kraft de Eucalipto Não Branqueada (PKEP), obtida na saída de estágio de deslignificação com oxigênio, com número Kappa 9,21, e todas as fibras foram refinadas até atingir o mesmo grau Shopper-Riegler ( $33 \pm 1 \mathrm{SR}$ ). Os experimentos com PKPM são conduzidas como uma referência a papéis Kraftliners tradicionais, com ou sem nanocelluloses. Também obteve folhas manuais com pasta branqueada Kraft de eucalipto, adicionando nanoceluloses, para compreender o efeito da lignina presente em PKEP. A receita e os aditivos químicos aplicados aqui são os mesmos que na produção industrial. Os principais resultados são: o uso de CNF (ou MFC) e agentes químicos, separadamente, na pasta PKEP, aumenta as resistências mecânicas dos papéis, no entanto, quando aplicadas CNF (ou MFC) em PKMP sem aditivos químicos, as resistências à tração e a estouro diminuem, e a resistência ao rasgo permanece constante.
\end{abstract}

Como a terceira parte do estudo, delineamento de experimentos teve a configuração composto central com 0 ponto central em 1\% de CNF (ou MFC) e 1\% de agentes químicos (polímero+amido+cola), e seus pontos axiais foram $0,3 \%-1,7 \%$ de CNF (ou MFC), e 0,15\%-0,85\% de agentes químicos. 0 ponto ótimo de equilíbrio dos índices de rasgo $\left(\mathrm{mN} . \mathrm{m}^{2} / \mathrm{g}\right) /$ estouro $\left(\mathrm{kPa} . \mathrm{m}^{2} / \mathrm{g}\right) /$ tração $(\mathrm{N} . \mathrm{m} / \mathrm{g})$ de $(10,00 / 2,25 / 36,56$ para CNF e 12,88/4,25/57,62 para MFC), obteve-se com a adição de 1,03\% de CNF e 0,65\% de amido, ou com a adição de menos de $0,01 \%$ de MFC e de $1 \%$ de amido.

Finalmente, foram aplicadas CNF ou MFC por impregnação direta no centro da direção-z, considerando que 0 papel tem forças que interagem em 3D. Os resultados mostram que a PKEP atinge a qualidade do Kraftliner de pinus obtendo um índice de tração de $52,58 \mathrm{~N} . \mathrm{m} / \mathrm{g}$ utilizando $1 \%$ de CNF, ou $47,40 \mathrm{~N} . \mathrm{m} / \mathrm{g}$ utilizando $1 \%$ de MFC.

Também, o custo de utilização do CNF ou MFC na fabricação do papel é avaliado, resultando em estimativas de 0,9494 US $\$ \mathrm{~kg}$ ou 0,3036 US $\$ \mathrm{~kg}$, com a adição de $1 \%$ de CNF ou $1 \%$ de MFC, respectivamente, em pasta PKEP.

Este trabalho mostra que a aplicação de nanocelulose em Kraftliner tradicional com fibras de pinus com todos os agentes químicos não tem vantagens reais. No entanto, o uso de CNF e MFC tecnicamente e economicamente tem vantagens superiores em pasta Kraft de eucalipto não branqueada (e deslignificada com oxigênio), obtendose propriedades superiores às de fibras longas.

PALAVRAS CHAVE: Kraftliner; Fibras Curtas de Eucalipto; Nanocelulose; Propriedades Mecânicas do Papel; Fabricação de papel; CNF; MFC. 


\section{ABSTRACT}

CRUCES-CERRO, J. Application of nancellulose in unbleached fibres for papermaking. São Paulo, 2016. 178p. MSc Thesis (Master in Chemical Engineering at Polytechnic School of the University of Sao Paulo), Brazil, 2016.

Nowadays, Brazil is the largest manufacturer of Bleached Eucalyptus Kraft Pulp in the world. Mostly the Eucalyptus spp. virgin fibres are used in papermaking to manufacture printing, tissue and specialty papers. Packaging papers, typically Kraftliners, have high demands for mechanical strength and are made mostly from Unbleached Softwood Kraft Pulp. Other side, nanocelluloses from biomass are considered one of the most interesting sustainable materials for the Century, with excel properties such as low density, high mechanical properties, high hydrophilicity, large surface area with chemical reactivity and high economic value. Since 2012 the use of nanocellulose in papermaking experienced a great momentum. Nanocelluloses are added in bleached or mechanical pulp in papermaking to increase significantly the mechanical properties, but there are concerns about the decreasing of the drainability, the porosity and the opacity of the paper. A very few studies were developed on the application of nanocelluloses in an unbleached Kraft pulp, even there are its applications on bleached pulps and mechanical pulps. Therefore, the present work aims to develop the application of nanocelluloses to increase the mechanical properties of the unbleached fibers, specifically for Kraftliners, and show the way to replace the softwood fibers with the low-cost hardwood fibers. Firstly, the primary fines from bleaching area of Eucalyptus Kraft pulp, obtained from an industrial residue, was the raw material for nanocellulose production of two nanocelluloses. The microfibrillated celluloses (MFC) are produced with direct mechanical homogenization using Masuko. The nanofibrillated cellulose (NCF) is produced with oxidation mediated by TEMPO and homogenization using GEA. Secondly, as virgin fibers were selected the Unbleached Pine Kraft Pulp (USKP) with Kappa number 36.1 and the Unbleached Eucalyptus Kraft Pulp (UEKP) just after the oxygen delignification stage with the Kappa number 9.21. All the fibres (USKP and UEKP) was refining at the same Shopper-Riegler ( $33 \pm 1$ SR). USKP experiments are conducted as reference to traditional Kraftliners, with or without nanocelluloses. Also the virgin bleached Eucalyptus Kraft pulp with nanocelluloses addition for the handsheet paper helps to understand the role of lignin in UEKP. The recipe and chemicals applied here are the same of the industrial production. The main results are: the use CNF (or MFC) and chemical agents, separately, in UEKP, promote the mechanical resistances, however when applied CNF (or MFC) in UPKP without chemicals, the tensile and burst properties decreased and tear remains constant.

As the third group of the study, the design of the experiments was conducted in the star configuration with centre point as 1\% CNF (or MFC) and 1.00\% chemical agents (polymers+starch+chemical agents) and, the axial points were $0.3 \%-1.7 \%$ NCF (or MFC) and $0.15 \%-0.85$ of chemical agents. The optimum point from the balanced tear $\left(\mathrm{mN} . \mathrm{m}^{2} / \mathrm{g}\right) / \mathrm{burst}\left(\mathrm{kPa} \cdot \mathrm{m}^{2} / \mathrm{g}\right) / \mathrm{tensile}(\mathrm{N} . \mathrm{m} / \mathrm{g})$ index point of view with 10.00/2.25/36.56 for (1.03\% CNF and 0.65\% starch) and 12.88/4.25/57.62 for (<0.001\% MFC and $1 \%$ starch).

Finally, it is applied here the direct impregnation of the center of z-direction with $1 \%$ of CNF and MFC, considering that the paper has 3D interacting forces. The results show that the UEKP reaches the pinus Kraftliner quality with $52.58 \mathrm{~N} . \mathrm{m} / \mathrm{g}$ (Tensile Index) using 1\% CNF or $47.40 \mathrm{~N} . \mathrm{m} / \mathrm{g}$ using 1\% MFC.

Also, the cost of use CNF or MFC in papermaking is evaluated, resulting in the estimates of 0.9494 US $\$ / \mathrm{kg}$ or 0.3036 US $\$ \mathrm{~kg}$, the addition of $1 \%$ CNF or $1 \%$ MFC in UEKP.

This work shows that the application of nanocellulose in traditional Kraftliner with pinus fibres with all chemical agents has no real advantages. However, the use of CNF and MFC technically and economically has superior advantages in Eucalyptus unbleached (and oxygen delignified) Kraft pulp, resulting in such properties superior to those of long fibres.

KEYWORDS: Kraftliner; Eucalyptus Short Fibers; Nanocellulose; Mechanical Properties of Paper; Papermaking, NCF, MFC. 


\section{LISTA DE FIGURAS}

Página

Figura 4.1: Estrutura da madeira e da parede celular das fibras vegetais, $\mathrm{P}$ : parede primária, S1: parede secundária externa, S2: parede secundária média, S3: parede secundária interna e LM: lamela média.

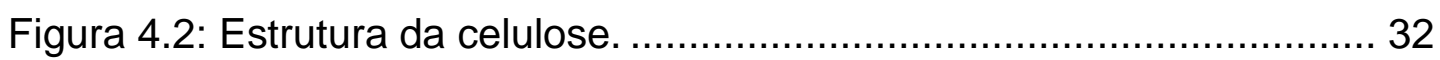

Figura 4.3: Ilustração esquemática da formação da fibra celulósica............ 33

Figura 4.4: Principais açúcares que compõem as hemiceluloses............... 35

Figura 4.5: Alcoóis precursores da lignina ............................................ 36

Figura 4.6: Máquina de Papel ........................................................ 45

Figura 5.1: Ligação de partícula na fibra por ação de polímero ..................6 69

Figura 5.2: Esquema ilustrando o modelo patch....................................69 69

Figura 6.1: Planejamentos compostos centrais do estudo ........................ 86

Figura 7.1: Curvas de refinação das pastas celulósicas .......................... 93

Figura 7.2: Índice de resistência à tração versus Schopper-Riegler ............ 95

Figura 7.3: Índice de resistência a rasgo versus Schopper-Riegler ............. 95

Figura 7.4: Índice de resistência a estouro versus Schopper-Riegler ........... 96

Figura 7.5: Resistência ao ar Gurley versus Schopper-Riegler.................. 97

Figura 7.6: Opacidade ............................................................ 98

Figura 7.7: Índice de resistência à tração - Testes em pasta branqueada (PKEB) ................................................................. 100

Figura 7.8: Índice de resistência a estouro - Testes em Pasta branqueada (PKEB) ..................................................... 101

Figura 7.9: Índice de resistência à tração - Pasta branqueada (PKEB) ..... 103

Figura 7.10: Índice de resistência à tração - Pasta pré-branqueada (PKEP) .................................................................. 103

Figura 7.11: Índice de resistência à tração - Pasta marrom de pinus (PKPM) ................................................................. 104

Figura 7.12: Índice de resistência a rasgo - Pasta branqueada (PKEB) .... 106

Figura 7.13: Índice de resistência a rasgo - Pasta pré-branqueada

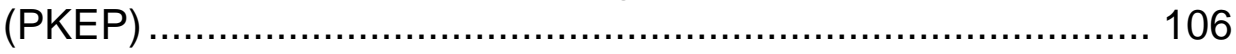

Figura 7.14: Índice de resistência a rasgo - Pasta marrom de pinus (PKPM) ................................................................ 107

Figura 7.15: Índice de resistência a estouro - Pasta branqueada (PKEB) . 108 
Figura 7.16: Índice de resistência a estouro - Pasta pré-branqueada (PKEP)

Figura 7.17: Índice de resistência a estouro - Pasta marrom de pinus (PKPM)

Figura 7.18: Resistência ao ar Gurley - Pasta branqueada (PKEB) .......... 110

Figura 7.19: Resistência ao ar Gurley - Pasta pré-branqueada (PKEP) .... 110

Figura 7.20: Resistência ao ar Gurley - Pasta marrom de pinus (PKPM) .. 111

Figura 7.21: Opacidade - Pasta branqueada (PKEB) ............................. 112

Figura 7.22: Opacidade - Pasta pré-branqueada (PKEP) ........................ 113

Figura 7.23: Opacidade - Pasta marrom de pinus (PKPM) ....................... 113

Figura 7.24: Gráficos de contorno e de superfície para os índices de resistência a tração (Tensile), rasgo (Tear) e estouro (Burst) com CNF

Figura 7.25: Gráfico de otimização da quantidade de CNF e de (amido + cola) adicionar para os índices de tração (Tensile), rasgo (Tear) e estouro (Burst) com CNF

Figura 7.26: Gráficos de contorno e de superfície para os índices de resistência a tração (Tensile), rasgo (Tear) e estouro (Burst) com MFC (MCF)

Figura 7.27: Gráfico de otimização da quantidade de CNF e de (amido + cola) adicionar para os índices de tração (Tensile), rasgo (Tear) e estouro (Burst) com MCF (MFC)

Figura 7.28: SEM realizados no planejamento de experimentos com CNF.

Figura 7.29: SEM realizados no planejamento de experimentos com MFC

Figura 7.30: SEM de amostra referência (PKEP). A1: aumento de 200x; B1: aumento de 5000x

Figura 7.31: SEM PKEP realizada com adição de aditivo. A2: aumento de 200x; B2: aumento de 1000x; C3: aumento de 5000x

Figura 7.32: SEM de PKEP realizada com adição de CNF em duas regiões (A, B e C, e D,E e F). A4: aumento de 1000x, B4: aumento de 5000x e C4: aumento de 10000x. D3: aumento de 1000x; E3: aumento de 5000x; F3: aumento de 10000x...... 138

Figura 7.33: SEM de PKEP realizada com adição de aditivo e CNF. A4: aumento de 200x; B4: aumento de 1000x; C4: aumento de 5000x; D4; aumento de 10000x.

Figura 7.34: SEM de PKEP realizada com adição de MFC. A5: aumento de 200x, B5: aumento de 5000x e C5 e D5: aumento de $10000 x$ 
Figura 7.35: SEM de PKEP realizada com adição de aditivo e MFC. A6: aumento de 1000x; B6: aumento de 5000x; C6: aumento de 10000x; D6; aumento de 20000x

Figura 7.36: SEM de PKPM realizada com adição de 1\% CNF. A7: aumento de 200x, B7: aumento de 1000x e C7: aumento de 5000x. D7: aumento de 10000x

Figura 7.37: SEM de PKPM realizada com adição de $2 \%$ CNF em duas regiões. A8: aumento de 200x, B8: aumento de 1000x e C7: aumento de 5000x. D7: aumento de 1000x; E8: aumento de 1000x; F8: aumento de 10000x

Figura 7.38: SEM de PKPM realizada com adição de MFC. A9: aumento de 200x; B9: aumento de 1000x; C9: aumento de 5000x

Figura 7.39: SEM de PKEB realizada com adição de $1 \%$ de CNF em diferentes regiões. A10: aumento de 1000x, B10: aumento de 5000x e C10: aumento de 10000x. D10: aumento de 1000x; E10: aumento de 10000x; F10: aumento de 20000x. 


\section{LISTA DE TABELAS}

Página

Tabela 4.1: Diferenças dimensionais entre fibras curtas (FC) e fibras longas (FL)

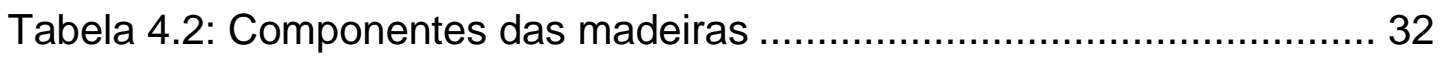

Tabela 5.1: Terminologia das unidades de celulose por diversos autores... 51

Tabela 6.1: Teor de cinzas antes e depois do tratamento de lavagem ........ 71

Tabela 6.2: Propriedades das CNF................................................ 74

Tabela 6.3: Teor Seco das MCF e CNF .............................................. 75

Tabela 6.4: Número Kappa das pastas celulósicas ................................. 75

Tabela 6.5: Viscosidade Intrínseca das pastas celulósicas ....................... 76

Tabela 6.6: $\mathrm{pH}$ do formador e do purificador ao longo do dia .................... 79

Tabela 6.7: Condutividade do formador e do purificador ao longo do dia.... 79

Tabela 6.8: Amostras selecionadas para realização de SEM .................... 91

Tabela 7.1: Morfologia das fibras das Pastas Celulósicas ......................... 99

Tabela 7.2: Resultados obtidos para os índices de tração, rasgo e

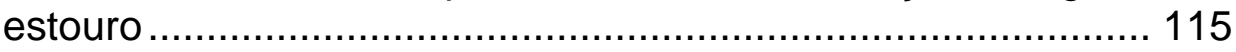

Tabela 7.3: Grau Schopper-Riegler da pasta PKEP com 1\% de CNF e $1 \%$ de MFC ................................................................... 116

Tabela 7.4: Resultados dos testes realizados para os índices ${ }^{[]}$de tração, estouro e rasgo, com as diferentes adições de CNF

Tabela 7.5: Resultados estatísticos da análise da resposta do índice de tração (Tensile) usando CNF

Tabela 7.6: Resultados estatísticos da análise da resposta do índice de rasgo ( Tear) usando CNF

Tabela 7.7: Resultados estatísticos da análise da resposta do índice de estouro (Burst) usando CNF

Tabela 7.8: Resultados dos testes realizados para os índices de tração, estouro e rasgo, com as diferentes adições de MFC (ou MCF) 126

Tabela 7.9: Resultados estatísticos da análise da resposta do índice de tração (Tensile) usando MFC (ou MCF)

Tabela 7.10: Resultados estatísticos da análise da resposta do índice de rasgo (Tear) usando MFC (ou MCF)

Tabela 7.11: Resultados estatísticos da análise da resposta do índice de estouro (Burst) usando MFC (ou MCF)

Tabela 7.12: Custo de obtenção das CNF e MFC 152 
Tabela 7.13: Custos de Produção das Pastas

Tabela 7.14: Custo de $1 \mathrm{~kg}$ de pasta UHKP com $1 \%$ de CNF ou $1 \%$ de MFC adicionada

Tabela 7.15: Resultados obtidos para o índice de tração em folhas produzidas em dupla camada e em outras condições

Tabela 7.16: Resultados obtidos para o índice de rasgo em folhas produzidas em dupla camada e em outras condições

Tabela 7.17: Resultados obtidos para o índice de estouro em folhas produzidas em dupla camada e em outras condições 158 


\section{LISTA DE SIGLAS E ABREVIATURAS}

Ácidos

hexenurônicos

ABNT

AKD

Alvura

ASA

BEKP

BHKP

BSKP

CAR

CEPI

CNC

CNF ou NFC

Cleaner

Container liner

C-PAM

DP

EKP

FEG-SEM

Fluting

GEA
HexA são grupos ácidos 4-deoxihex-4-enurônicos formados através de reação de álcali, (reagentes geralmente presentes na polpação Kraft) com os grupos ácidos 4-O-metil-a-D-glicurônicos (MeGlcA) presentes como componentes da madeira, principalmente eucalipto, através da reação de beta eliminação da radical metoxila. Quando os HexA estão presentes na pasta pré-branqueada aumentam 0 consumo de agentes químicos do branqueamente, e portanto, número Kappa não pode ser considerada como representante direto de lignina residual sem levar em conta HexA

Associação Brasileira de Normas Técnicas

Alkylketene dimer

É o fator de reflectância intrínseco do papel, determinado a um comprimento de onda efetivo de $457 \mathrm{~nm}$ (azul)

Alkenylsuccinic anhydride

Bleached Eucalyptus Kraft Pulp

Bleached Hardwood Kraft pulp

Bleached Softwood Kraft Pulp

Comprimento de auto-ruptura

Confederation of European Paper Industry

Cellulose nanocrystal

Cellulose nanofibers

Equipamento utilizado no processo de fabricação da pasta celulósica que visa a remoção de contaminantes mediante forças centrífugas que separam a fibra dos contaminantes baseadas as diferenças de densidade e forma

Cartão (papel) inserido como bucha em container cobrindo todas as paredes, para obter resistência adicional

Poliacrilamida catiônica

Grau de polimerização

Eucalyptus Kraft Pulp

Field Emission Gun Scanning Electron Microscopy

Miolo do corrugado

Equipamento utilizado para obtenção de nanoceluloses que mediante homogeneização por impacto direto em choque a um anteparo 
IPT

ISO

Kraftliner

LDS

Linerboard

MCC

MFC ou MCF

NBR

Número Kappa

PDADMAC

PEI

PKEB

PKEP

PKPM

Pitch

Potencial zeta

Pulper

Scott-Bond
Instituto de Pesquisas Tecnológicas do Estado de São Paulo

International Organization for Standardization

Um linerboard que contenha mais de $80 \%$ de fibras virgens provenientes de processo Kraft com gramatura de 26-90 lb por $1000 \mathrm{ft}^{2}$.

Laser Diffraction Spectometry, para distribuição de tamanho de partículas. DLS é Dynamic Light Scattering, um outro princípio para medição das partículas.

Papel produzido em máquina de papel e utilizado como face na produção de papel corrugado ou de papel para embalagem sólida

Microcrystalline cellulose

Microfibrillated cellulose

Norma Brasileira

Valor do teste que relaciona linearmente a quantidade de lignina remanescente na pasta depois de polpação (grau de deslignificação) e da uma estimativa da demanda química de branqueamento, através de oxidação da lignina por permanganato. Ver Ácidos hexenurônicos.

Cloreto de polidialilmetilamonio

High molecular polyethylenimine

Pasta Kraft de Eucalipto Branqueada

Pasta Kraft de Eucalipto Pré-Branqueada com Deslignificação por Oxigênio

Pasta Kraft de Pinus Marrom

Depósitos de compostos presentes nos extrativos da madeira e/ou em alguns aditivos utilizados no processamento. Os pitch depositam-se na maquinaria industrial ou no papel, aumentando, portanto, o custo de manutenção e operação dos equipamentos e os defeitos no papel

O potencial eletrocinético, também conhecido como potencial zeta mede, em $\mathrm{mV}$, a carga superficial líquida das superfícies dos substratos. O balanço de cargas de uma suspensão de fibras, para a fabricação do papel, pode ser avaliado de duas maneiras: através da demanda iônica e da carga superficial.

Equipamento utilizado no início do processo de fabricação do papel, com a finalidade de desagregar a matéria prima fibrosa, a celulose, a pasta mecânica ou as aparas

Ensaio do papel que prevê a energia requerida para delaminar uma folha de papel na direcção $z$ sob ação de um pêndulo de massa e velocidade controlada 
SEM

Short-span

TAPPI

TEMPO

Testliner

TOCN

UHKP

USKP
Scanning Electron Microscopy, também conhecida como MEV - Microscopia Eletrônica de Varredura.

Força de compressão máxima, no plano do papel, que uma tira de $15 \mathrm{~mm}$ de papel pode suportar quando é apertada entre duas garras com uma distância entre elas de 0,7 milímetros. O ensaio permite prever a resistência à compressão de coluna do papelão ondulado

Technical association of the pulp and paper industry

2,2,6-6-tetrametilpiperdina-1-10xyl

Linerboard fabricado com papel reciclado ou com fibras secundárias que atenda a requisitos de teste de aplicabilidade aos regulamentos de transporte de materiais.

2,2,6,6-tetramethylpiperidine-1-oxyl (TEMPO)-oxidized cellulose nanofibril

Unbleached Hardwood Kraft Pulp

Unbleached Softwood Kraft Pulp 


\section{LISTA DE SÍMBOLOS E NOMENCLATURA}

\begin{tabular}{|c|c|c|}
\hline EP & Erro padrão & \\
\hline $\mathrm{F}$ & Relação de quadrados médios & \\
\hline$G$ & Gramatura de uma amostra & $\mathrm{g} / \mathrm{m}^{2}$ \\
\hline $\mathrm{GL}$ & Graus de liberdade & \\
\hline IC & Intervalo de confiança & \\
\hline IP & Intervalo de predição & \\
\hline It & Índice de Resistência à tração & $\mathrm{Nm} / \mathrm{g}$ \\
\hline Lc & Largura de um corpo-de-prova & $\mathrm{mm}$ \\
\hline $\mathrm{P}_{\mathrm{h}}$ & Massa úmida & $g$ \\
\hline $\mathrm{P}_{\mathrm{s}}$ & Massa seca & $g$ \\
\hline QM & Quadrado médio & \\
\hline $\mathrm{R}$ & Resíduo & \\
\hline $\mathrm{R}_{\mathrm{t}}$ & Resistência à tração & $\mathrm{kN} / \mathrm{m}$ \\
\hline $\mathrm{R}_{0}$ & Fator de refletância de somente uma folha de papel & \\
\hline $\mathrm{R} 2$ & Coeficiente de determinação & \\
\hline R2 (aj) & Coeficiente de determinação ajustado & \\
\hline $\mathrm{R} 2$ (pred) & Coeficiente de determinação predito & \\
\hline $\mathrm{R}_{\infty}$ & Fator de refletância intrínseco & \\
\hline S & Desvio padrão & \\
\hline SQ & Soma de quadrados & \\
\hline TS & Teor seco & $\%$ \\
\hline Valor $\mathrm{P}$ & Grau de significância & \\
\hline Valor T & $\begin{array}{l}\text { Diferença entre uma estatística observada e seu parâmetro } \\
\text { de população em unidades de erro padrão }\end{array}$ & \\
\hline VIF & Fator de inflação de variância & \\
\hline
\end{tabular}




\section{NORMAS UTILIZADAS}

\section{Ensaio \\ NORMA ABNT}

Determinação do resíduo (cinza) após a incineração a $525^{\circ} \mathrm{C}$

Método por secagem em estufa

Determinação do número de viscosidade-limite em solução de etilenodiamina cúprica (CED)

Refinação em laboratório - Método do refinador $\mathrm{PFI}$

Preparação de folhas em laboratório para ensaios físicos. Parte 1: Método do formador de folhas convencional

Determinação da resistência à drenagem pelo aparelho SchopperRiegler

Refinação em laboratório - Método Valley

Atmosfera normalizada para condicionamento e ensaio e procedimento de controle da atmosfera e condicionamento das amostras

Determinação da gramatura

Determinação da permeância e resistência ao ar (faixa média)

Parte 5: Método Gurley

Determinação das propriedades de tração. Parte 2: Método da velocidade constante de alongamento $(20 \mathrm{~mm} / \mathrm{min})$

Determinação da resistência ao arrebentamento

Determinação da opacidade (fundo de papel) - Método da refletância difusa
ABNT NBR 13999: 2003

ABNT NBR NM ISO 287: 2012

ABNT NBR ISO 5351: 2012

ISO 5351: 2010

ABNT NBR ISO 5264-2: 2012

ISO 5264-2: 2011

ABNT NBR ISO 5269-1: 2006

ISO 5269-1: 2005

ABNT NBR 14031: 2004

ISO 5267-1

ABNT NBR 14347:1999

Versão Corrigida: 2013

ABNT NBR NM ISO 187:2000 Versão Corrigida: 2000

ABNT NBR NM ISO 536:2000 Versão Corrigida: 2002

ABNT NBR NM ISO 5636-5: 2006

ABNT NBR NM ISO 1924-2: 2012

ABNT NBR NM ISO 2758: 2007

ABNT NBR NM ISO 2471: 2001
ISO 2758: 2014

ISO 5264-2: 2011

ISO 187:1990

ISO 536:2012

ISO 5636-5: 2013

ISO 1924-2: 2008

ISO 2471: 2008

\section{Ensaio}

Método TAPPI

Kappa number of pulp

TAPPI T236

Fiber length of pulp and paper

by automated optical analyzer using polarized light 


\section{SUMÁRIO}

Página

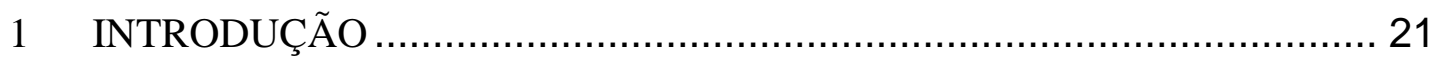

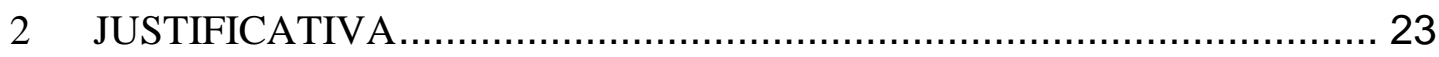

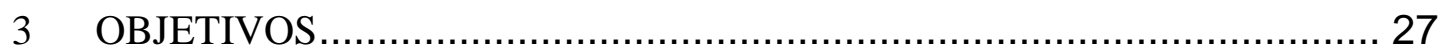

4 DESCRIÇÃO DOS OBJETOS DO ESTUDO .................................. 28

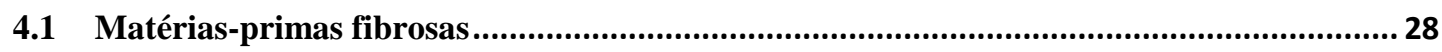

4.2 Composição química das fibras ………………….......................................................... 31

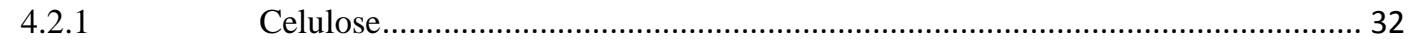

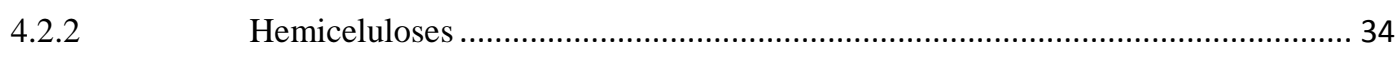

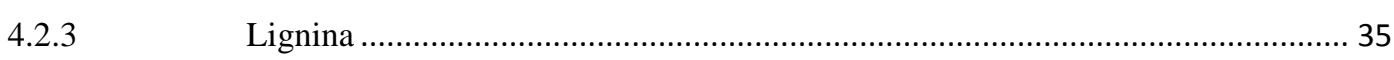

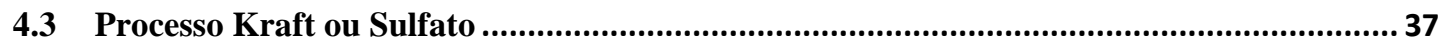

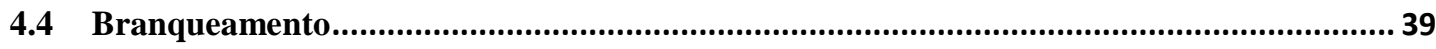

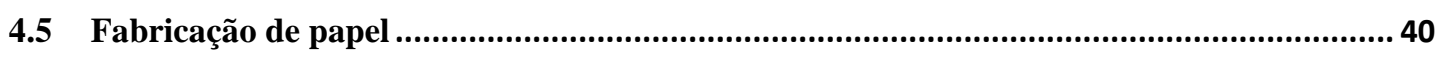

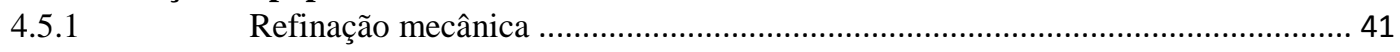

4.5.2 Matérias-primas não fibrosas ………………………………………….... 42

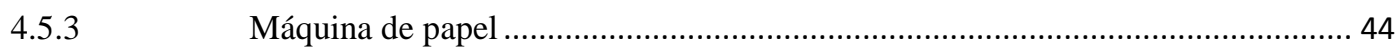

4.5.4 Papéis para embalagem: Kraftliners ……………………………….................. 46

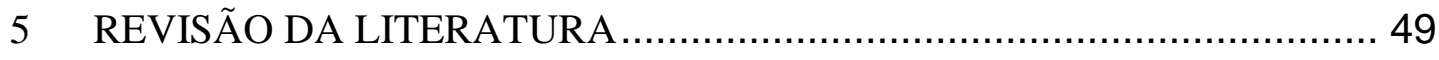

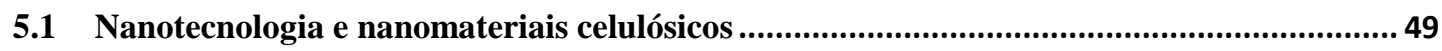

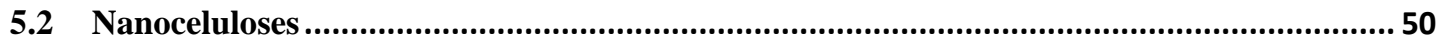

5.2.1 Obtenção de nanoceluloses ..................................................................... 52

5.2.2 Aplicações de nanoceluloses na fabricação do papel ........................................... 57

5.3 Métodos de caracterização.....................................................................................................67

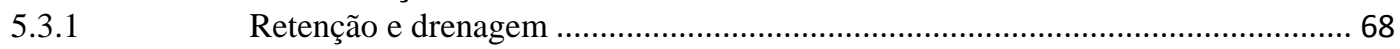

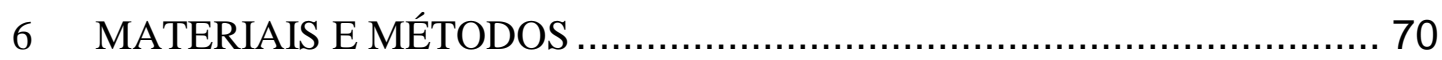

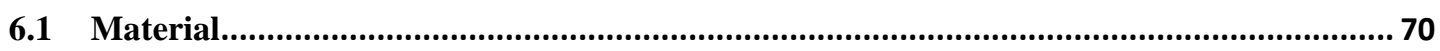

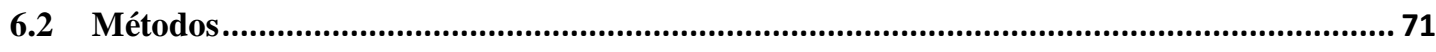

6.2.1 Obtenção de Nanoceluloses ...................................................................... 71 


\begin{tabular}{|c|c|}
\hline .2 .2 & 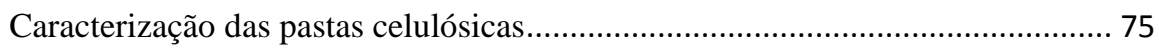 \\
\hline 6.2 .3 & Refinação ... \\
\hline 6.2 .4 & Formação de folhas ... \\
\hline 6.2 .5 & Preparação das amostras - Refinador Valley............................. \\
\hline 6.2 .6 & Formação de folhas com nanoceluloses ...... \\
\hline 5.2 .7 & Ensaios para caracterização das pastas/folhas formadas .............................. \\
\hline
\end{tabular}

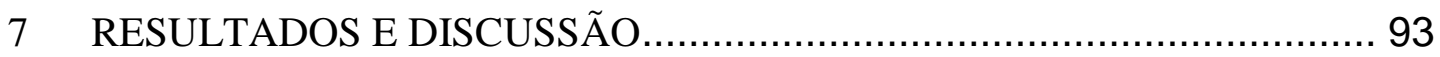

7.1 Caracterização das matérias primas .................................................................. 93

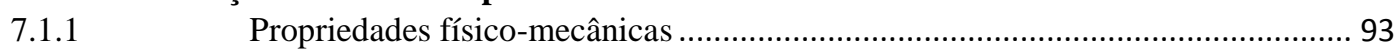

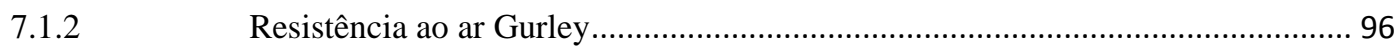

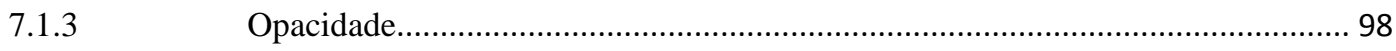

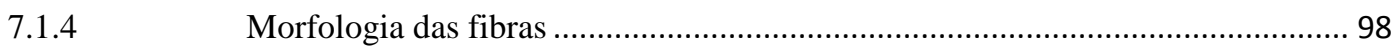

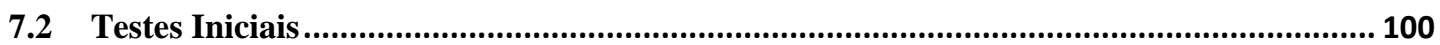

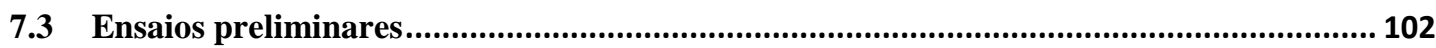

P.3.1 Propriedades Físico-Mecânicas ................................................................... 102

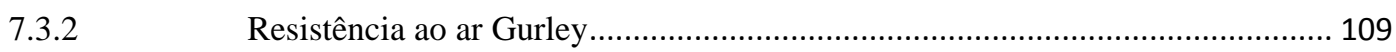

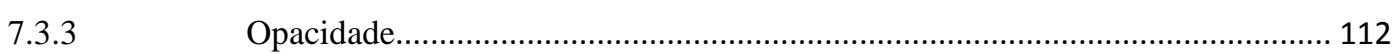

7.4 Resultados do delineamento dos experimentos da pasta pré-branqueada com adição de nanoceluloses, amido, cola e polímero de retenção........................................................... 114

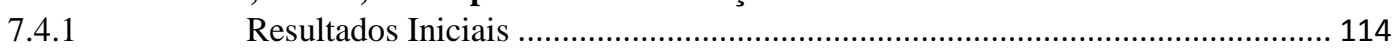

7.4.2 Grau Schopper-Riegler da pasta pré-branqueada com nanoceluloses ................. 116

7.4.3 Resultados em propriedades físico-mecânicas com CNF................................ 116

7.4.4 Resultados em propriedades físico-mecânicas com MFC ................................. 126

7.5 Microscopia Eletrônica de Varredura (MEV) ....................................................... 134

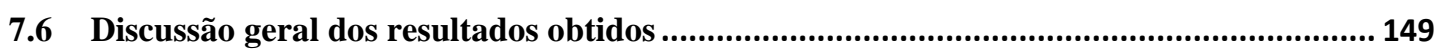

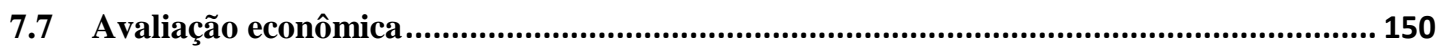

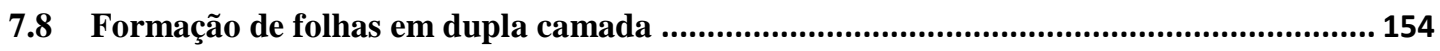

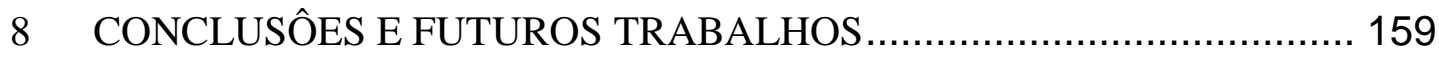

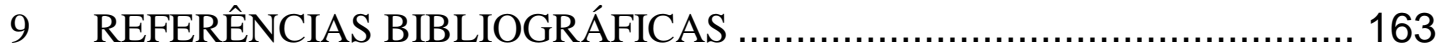


APÊNDICE B - MORFOLOGÍA DAS FIBRAS DAS PASTAS

CELULÓSICAS UTILIZADAS ……………………....... 209

APÊNDICE C - LAVAGEM PASTA KRAFT DE EUCALIPTO PRÉ-

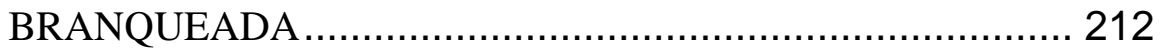

APÊNDICE D - CARACTERÍSTICAS DAS CNF....................................... 213

APÊNDICE E - MICROSCOPIA ELECTRÔNICA DE VARREDURA (SEM).. 214 


\section{INTRODUÇÃO}

A indústria mundial tem passado por inúmeras mudanças em busca de matérias primas, processos e produtos mais sustentáveis. A utilização de materiais biodegradáveis e/ou com potencial de reuso na cadeia produtiva ganha espaço e, lentamente, torna-se realidade para muitas indústrias de transformação e conversão. Biorrefinarias, que visam integrar processos e equipamentos para geração de bioprodutos de maneira sustentável, têm-se desenvolvido nos últimos anos e tem sido foco ativo de estudos.

A busca crescente por matérias-primas renováveis coloca a celulose em destaque, como um material renovável, biodegradável, de baixo custo, mostrando ainda excelentes propriedades físico-mecânicas. Dentre os produtos obtidos a partir da celulose têm-se as chamadas microfibras e nanofibras de celulose, que podem ser produzidas a partir de qualquer fonte de biomassa lignocelulósica.

O uso e a obtenção de micro e nanofibras de celulose e suas aplicações em materiais compósitos despertam a atenção de pesquisadores por se apresentarem como um material com alta resistência e rigidez, aliado ao fato do ter baixo peso (SIRÓ e PLACKETT, 2010). Além das suas excelentes propriedades mecânicas, as micro e nanofibras de celulose mostram outras interessantes propriedades para reforços em compósitos.

As micro e nanofibras de celulose conquistam espaço nos meios industriais, principalmente por suas características ópticas e de resistência mecânica. Quando são aplicadas na produção de materiais estruturados, elas não somente alteram o comportamento físico-mecânico exibido pelos materiais, mas também afetam suas propriedades ópticas. Além disso, as micro e nanofibras de celulose são materiais biodegradáveis.

Na fabricação de papéis, as fibras celulósicas são a matéria-prima principal. Elas podem ser extraídas de biomassa lignocelulósica por processo mecânico ou químico e podem ser longas, por exemplo, quando procedente de árvores de coníferas como o pinus, ou curtas, por exemplo, quando 
procedentes de árvores de folhosas como o eucalipto. As fibras curtas de eucalipto são, usualmente, utilizadas para a fabricação de papéis para imprimir e escrever, e de papéis tissue [1], e as fibras longas de pinus são utilizadas na fabricação de papéis para embalagens. Neste contexto, os papéis cartão e sacos de embalagem possuem diferentes características em relação aos produtos destinados à higiene e ao processo de imprimir e escrever. Apesar dos fundamentos de processos serem os mesmos (EK et al., 2009), a sua finalidade como produto requer atenções diferentes em suas propriedades (NISKANEN, 2012).

O Brasil é um grande produtor de fibras celulósicas procedentes do Eucalipto com $66,30 \%$ da produção total mundial de celulose Kraft de eucalipto[2]. Deste modo, toda e qualquer pesquisa para desenvolvimento do mercado para fibras curtas de eucalipto é relevante para as empresas brasileiras de EKP (Eucalyptus Kraft Pulp). Considerando este fato, o objeto do estudo é "conhecer quais são as limitações ou vantagens da substituição de fibras longas não branqueadas em papel para embalagem por fibras curtas de eucalipto, e quanto o uso de micro e nanofibras de celulose podem influir na melhoria das propriedades do papel quando se usam fibras curtas".

${ }^{1}$ Papéis sanitários, também chamados de papéis tissue, são folhas ou rolos de papéis de baixa gramatura, usados para higiene pessoal e limpeza doméstica, como papel higiênico, lenços faciais, papel-toalha e guardanapos. Além das fibras virgens, eles podem ter, como característica de sua composição, o uso de aparas recicladas.

${ }^{2}$ HAWKINS WRIGHT. The outlook for paper grade pulp demand, supply, cost and prices. Dezember, 2015. <http://www.hawkinswright.com> Relatórios desta empresa de consultoria independente de informação de negócios e inteligência de mercado são acessíveis para assinantes 


\section{JUSTIFICATIVA}

Estimativas recentes apontam para uma tendência do aumento da demanda mundial de produtos florestais para energia, celulose e papel, e produtos da madeira sólida e seus derivados. Ainda, os programas governamentais brasileiros, como o Programa de Aceleração do Crescimento (PAC), com a ênfase na infraestrutura e construção civil, aumentaram a demanda nacional por madeira e aqueceram o mercado madeireiro nacional.

$\mathrm{Na}$ indústria papeleira brasileira a principal fonte de fibras são os eucaliptos. Isto por eles terem maior adaptabilidade, maior crescimento por hectare e por ano, e o corte poder ser efetuado em tempos menores.

O uso de micro e nano-compostos apresenta um grande campo de aplicações, entre eles a adição de nanoceluloses, CNF (cellulose nanofibers) e MFC (microfibrillated cellulose) ao papel, as quais podem aumentar as propriedades de resistência mecânica, a printabilidade (imprimibilidade em papel) e atuar como barreira para líquidos e gases.

A escassez de recursos florestais, o aumento da demanda de produtos do papel e a vocação e a experiência do Brasil pelo plantio de madeira de fibras curtas (eucalipto) tornam importante a realização de estudos referentes à utilização dessas fibras em substituição às fibras longas, tais como nos papéis Kraftliner[3] que são fabricados principalmente a partir destas fibras longas de coníferas.

Pelo exposto, justifica-se o escopo do estudo, que leva a um desafio de compreensão das oportunidades e restrições técnicas e tecnológicas de substituição de fibras longas na produção de papéis para embalagens, especialmente na linha de Kraftliners, e como a aplicação de nanotecnologia

3 Kraftliner, também chamado de capa ou papel Kraft de cobertura, mas também podendo ser utilizada nas folhas externas de papel multicamada, usualmente é fabricado com pasta não branqueada (ou eventualmente branqueada) de fibras longas de pinus com gramatura de 100-120 $\mathrm{g} / \mathrm{m}^{2}$ para obter resistência física. Uma definição mais restritiva é encontrada em M. KOURIS. Dictionary of Paper. Atlanta. TAPPI Press, 1996 onde exige que haja mais de $80 \%$ de fibras virgens, mas não define que seja com fibras longas de celulose. 
pode modificar as propriedades do papel. Folhas foram formadas em laboratório com pastas de eucalipto e pinus em diferentes condições de aplicação de MCF e CNF, como ou sem os aditivos químicos comumente utilizados na fabricação de Kraftliners. Assim, mediram-se as propriedades físico-mecânicas das folhas fabricadas manualmente em laboratório, além das folhas industriais para referência, para avaliar a substituição das fibras longas por fibras curtas na fabricação de papéis Kraftliners.

\section{Estrutura da tese}

A presente Dissertação na sua estrutura contém:

Capítulo 1 que explica o contexto técnico e o mercado para a importância de melhorias na produção de papel de embalagens;

Capítulo 2 que descreve a relevância de estudos de aplicação de nanofibras e microfibras de celulose na produção de papel para embalagens;

Capítulo 3 que define os objetivos da Dissertação;

Capítulo 4 que contém uma breve descrição dos objetos do estudo, desde as características de matérias primas fibrosas e sua composição química, o processo de fabricação de fibras de celulose que são utilizadas para produção de papel, o eventual processo de branqueamento de fibras quando necessário, e o processo de fabricação de papel, com destaque para Kraftliner e as propriedades mais relevantes em papéis para embalagem;

Capítulo 5 que apresenta a revisão bibliográfica dos aspectos mais relevantes para a Dissertação, subdivididos em nanoceluloses para o uso em papéis e os métodos da sua caracterização;

Capítulo 6 que descreve os materiais e os métodos para desenvolvimento experimental dos estudos, os materiais obtidos para ensaios experimentais, métodos de obtenção de nanoceluloses; normas de caracterização das pastas celulósicas, procedimentos para 
refinação de fibras em moinho PFI e refinador Valley, formação de folhas manuais, planejamento e execução da formação de folhas com nanocelulose e aditivos químicos e os ensaios de caracterização das fibras e folhas produzidas;

Capítulo 7 que apresenta e discute os resultados dos experimentos;

Capítulo 8 que conclui com os principais achados da discussão dos resultados da Dissertação e sugere futuros trabalhos;

Referências Bibliográficas com as citações dos trabalhos utilizados na Dissertação, e finalmente, com os Apêndices e Anexos necessários para eventual detalhamento das informações nessa Dissertação. As referências auxiliares, que não são diretamente relevantes para o escopo da Dissertação, são anunciadas em notas de rodapé.

Como resultados diretos da Monografia, foram submetidos dois trabalhos em CIADICYP 2016 (Iberoamerican Congress on Pulp and Paper Research), um congresso internacional trilíngue, que será preferencialmente em Inglês por ser realizado em 4-9 de Setembro de 2016 em Helsinki, Finlândia.

- CRUCES-CERRO, J.; D'ALMEIDA, M.L.O.; FERREIRA, P.J.T.; PARK, S.W. Effect of nanofibrils (NFC) added with cationic polielectrolyte in paper formation with unbleached fibers. In: CIADICYP 2016 (Iberoamerican Congress on Pulp and Paper Research). September, 4-9, 2016. Helsinki. Finland.

- CRUCES-CERRO, J.; D'ALMEIDA, M.L.O.; SILVA, P.L.F.; PARK, S.W. Use of nanofibers in brown pinus fibers for packaging. In: CIADICYP 2016 (Iberoamerican Congress on Pulp and Paper Research). September, 4-9, 2016. Helsinki. Finland.

Além desses trabalhos, como resultados do processo de aprendizado, estudo em Programa de Pós-graduação em Engenharia Química, que necessita do entendimento em diferentes aspectos de caracterização de madeira brasileira e dos aspectos de fabricação do papel, incluindo fibras recicladas, foram publicados em Congressos Internacionais e Nacionais os seguintes trabalhos: 
- CRUCES-CERRO, J; CARBAJO, J.M.; GÓMEZ, N.; REVILLA, E.; VILLAR, J.C. Estudio de la influencia del estuco en la reciclabilidad de papeles revista. In: VII Congreso Iberoamericano de Investigación en Celulosa y Papel, 2012, Sâo Paulo, Brazil.

- CARBAJO, J.M.; CRUCES-CERRO, J.; GÓMEZ, N.; QUINTANA, E; REVILLA, E.; VILLAR, J.C. Influencia de la Cantidad de Estuco en el Reciclado de Papeles de Impresión. In: $13^{\text {er }}$ Congreso Internacional en Ciencia y Tecnología de Metalurgía y Materiales, 2013, Puerto Iguazú, Argentina.

- CRUCES-CERRO, J.; BASTOS, N.R.; FERREIRA, D.C.; CARDOSO, M.B.; D'ALMEIDA, M.L.O; PARK, S.W.; VILLAR, J.C. Influência da biodeterioração por fungos xilófagos nas características de eucalipto. In: Iberomerican Congress on Pulp and Paper Research, 2014, Medellin, Colombia, 2014.

- CRUCES-CERRO, J.; CARDOSO, M. B.; FIORITTI, R.R.; FERREIRA, D. C.; D'ALMEIDA, M. L. O.; PARK, S.W.; VILLAR, J.C. Influência de cozimentos químicos sobre as propriedades calorimétricas de madeira fungada. In: The 48th Pulp and Paper International Congress / BEM2015. The 1st lberoamerican Conference on the Bio-economy, 2015, São Paulo. (Held jointly)

- CRUCES-CERRO, J.; CARDOSO, M.B.; FERREIRA, D.C.; D'ALMEIDA, M.L.O.; PARK, S.W.; VILLAR, J.C. Lignin extraction from wood attacked by fungi. In: Third International Symposium on Lignocelulosic Materials, 2015. Concepción, Chile.

O autor da presente Dissertação está trabalhando para que, a médio prazo, a maioria destes trabalhos possa ser acessível na literatura aberta em periódicos do setor de celulose e papel. 


\section{OBJETIVOS}

O objetivo principal deste trabalho consiste em produzir Kraftliners a partir de fibra curta de eucalipto com características semelhantes a fibras longas de pinus.

Para avaliar a viabilidade da substituição das fibras longas pelas fibras curtas, foram utilizadas uma pasta de pinus não branqueada, uma pasta de eucalipto não branqueada e uma pasta de eucalipto branqueada.

Para aumentar as propriedades mecânicas das fibras, são utilizados os aditivos químicos para produção de papéis Kraftliner e as microfibras celulose (MFC ou MCF) e as nanoceluloses (CNF) obtidas a partir de finos de fibra curta de eucalipto branqueada.

Os objetivos específicos são:

- Verificar as limitações ou as vantagens das fibras de eucalipto para substituição de fibra longa não branqueada na produção de papéis da linha de Kraftliners;

- Verificar as possibilidades para superar as eventuais limitações das fibras curtas de eucalipto em relação às fibras longas na produção de papéis da linha de Kraftliners, mantendo adequados os custos de produção de papéis. 


\section{DESCRIÇÃO DOS OBJETOS DO ESTUDO}

\subsection{Matérias-primas fibrosas}

As fibras naturais são classificadas em mineral, animal ou vegetal, de acordo com sua origem. As fibras vegetais, as de madeira e as de não-madeira[4], são formadas principalmente por uma matriz lignocelulósica.

A grande maioria das fibras utilizadas na fabricação de pastas celulósicas e papéis pertencem ao reino vegetal, com destaque para as fibras de madeira provenientes de árvores constituintes de dois grandes grupos, as dicotiledôneas (Angiospermae) e as coníferas (Gymnospermae). Estas madeiras são também conhecidas por folhosas (porosas, duras ou hardwoods, e usualmente identificadas como fibras mais curtas) e resinosas (não porosas, branda ou softwood, usualmente fibras mais longas), respectivamente.

As fibras de madeira são células vegetais compridas e são os elementos anatômicos majoritários que constituem a madeira. Uma fibra é capaz de estabelecer uniões e conformar-se sob uma superfície de maneira "uniforme" para formar o papel.

As fibras são compostas basicamente por parede primária e parede secundária (Figura 4.1). A parede secundária divide-se em parede secundária média e parede secundária interna. Cada uma das camadas da fibra possui sua própria organização e difere uma das outras em espessura, estrutura, composição química e orientação das microfibras com respeito ao eixo da fibra. Finalmente, rodeando a fibra encontra-se a lamela média que une as fibras entre si.

\footnotetext{
${ }^{4}$ Não-madeira é um neologismo amplamente aceito pela comunidade industrial de celulose e papel, porque nonwood fiber consegue sintetizar uma denominação genérica para fibras naturais obtidas de plantas fibrosas de importância comercial, sazonais ou não, que incluem bambu, capim-elefante, sisal, palhas de cereais, bagaço de cana-de-açúcar.
} 


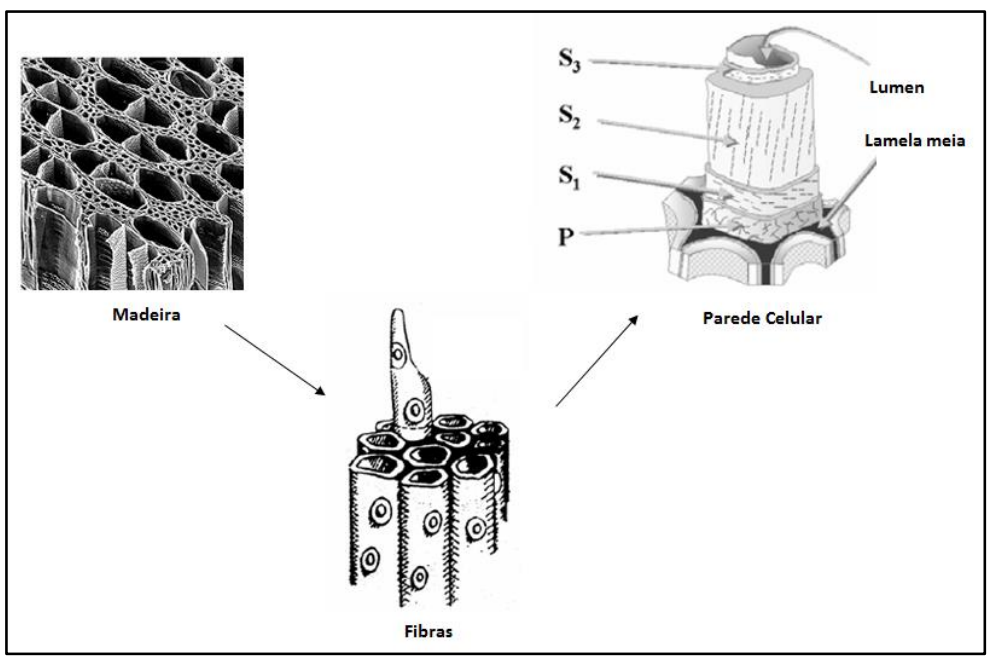

Figura 4.1: Estrutura da madeira e da parede celular das fibras vegetais,

P: parede primária, S1: parede secundária externa, S2: parede secundária média, S3: parede secundária interna e LM: lamela média. Fonte: extraído de Kirk e Cullen (1998)[5]

As principais espécies arbóreas fornecedoras das fibras de resinosas no Brasil são os pinhos e as araucárias. Estas fibras são conhecidas como "fibras longas", uma vez que seu comprimento médio na árvore é maior que $2 \mathrm{~mm}$, tipicamente entre $3 \mathrm{~mm}$ e $5 \mathrm{~mm}$. As fibras são estreitas e alongadas, apresentando uma estrutura tubular, da onde se origina sua denominação "traqueídeos".

A principal fonte das fibras de folhosas na indústria papeleira brasileira são os eucaliptos. Nestas fibras, aparecem dois elementos celulares principais, as fibras, e os elementos de vasos.

$\mathrm{Na}$ madeira, a grosso modo, existem xilema (responsável principalmente pela condução de água e sais minerais) e floema (responsável pela condução de material orgânico em solução). O xilema tem como elementos traqueais (na maior parte os traquídeos, ou traquíedes, em Gymnospermae e os derivados de traquídeos, chamados de vasos em Angiospermae),

\footnotetext{
5 Essa figura esquemática, com suas variantes, tornou-se clássica e perdeu-se a origem da idéia. Há muito tempo, já se tem a sua comprovação com topoquímica e microtomografia $2 \mathrm{D}$ e $3 \mathrm{D}$. A presente figura foi extraída de: KIRK, T.K. e CULLEN, D. Enzymology and Molecular Genetics of Wood Degradation by White-Rot Fungi. Environmentally Friendly Technologies for the Pulp and Paper Industry. Hoboken, NJ: John Wiley \& Sons, 1998.
} 
células de sustentação e as células de parênquima que armazenam substâncias. As fibras de folhosas[6], são, em geral, de dimensões menores que as resinosas. O comprimento destas fibras na árvore está entre $1 \mathrm{~mm}$ e 2 mm, e são popularmente conhecidas como "fibras curtas". Os vasos são caracteristicamente maiores do que as fibras. A proporção em volume dos vasos pode ser superior a $50 \%$, mas proporção em peso é, em geral, inferior a $10 \%$.

As fibras de folhosas, por serem menores que as de coníferas, no passado foram consideradas menos adequadas para fabricação do papel, uma vez que o parâmetro em voga era principalmente a resistência. Entretanto, as fibras curtas dão a certos produtos as características melhores do que as fibras longas, como no caso de papéis para imprimir e escrever, e fornecem melhor volume específico (bulk) e maciez para papéis sanitários. As fibras curtas conferem a estes papéis uma formação mais uniforme, imprescindível para uma boa impressão.

$\mathrm{Na}$ tabela 4.1 estão relacionadas as principais diferenças dimensionais entre as fibras curtas (FC) e as fibras longas (FL). As características dimensionais explicam muito das diferenças entre as propriedades de fibras, e tem-se analisado em várias literaturas, como em Ververis et al. (2004), mas a tabela 4.1 fornece uma ideia geral, suficiente para o presente texto.

A madeira de coníferas é utilizada, geralmente, na produção de papéis para embalagens, devido a maior resistência física proporcionada por essas fibras.

\footnotetext{
6 As fibras em madeira podem ser vistas em ILVESSALO-PFÄFFLI, M-S. Fiber Atlas. Springer, 1995. As fibras de celulose produzidas industrialmente podem ser vistas em NANKO, H.; BUTTON, A.; HILlMAN, D. The World of Market Pulp. TAPPI Press, 2010, que contém uma boa análise da morfologia, características perante refino PFI e fotografia eletrônica de varredura de mais de 35 empresas de 22 países.
} 
Tabela 4.1: Diferenças dimensionais entre fibras curtas (FC) e fibras longas (FL).

Fonte: Stenius (2004)

\begin{tabular}{|c|c|c|c|c|c|}
\hline $\begin{array}{l}\text { Tipo de } \\
\text { célula }\end{array}$ & $\begin{array}{l}\text { Orientação } \\
\text { na árvore }\end{array}$ & $\begin{array}{l}\text { Função } \\
\text { principal }\end{array}$ & $\begin{array}{c}\text { Fração no } \\
\text { xilema } \\
\text { (\% vol.) }\end{array}$ & $\begin{array}{l}\text { Comprimento } \\
(\mathrm{mm})\end{array}$ & $\begin{array}{c}\text { Espessura } \\
(\mu \mathrm{m})\end{array}$ \\
\hline \multicolumn{6}{|l|}{ softwood } \\
\hline $\begin{array}{l}\text { Traquídeos } \\
\text { (fibras) }\end{array}$ & vertical & $\begin{array}{l}\text { suporte e } \\
\text { condução }\end{array}$ & 90 & $1.5-6.0$ & $20-50$ \\
\hline $\begin{array}{l}\text { Traquídeo } \\
\text { radicular }\end{array}$ & horizontal & condução & $<5$ & $0.01-0,16$ & $2-50$ \\
\hline $\begin{array}{l}\text { Parênquima } \\
\text { radicular }\end{array}$ & horizontal & estocagem & $<10$ & $0.01-0,16$ & $2-50$ \\
\hline $\begin{array}{l}\text { Parênquima } \\
\text { epitelial }\end{array}$ & $\begin{array}{l}\text { vertical e } \\
\text { horizontal }\end{array}$ & $\begin{array}{l}\text { excreção } \\
\text { de resinas }\end{array}$ & $<1$ & $0.01-0,16$ & $2-50$ \\
\hline \multicolumn{6}{|l|}{ hardwood } \\
\hline Fibras & vertical & suporte & 55 & $0.4-1.6$ & $10-40$ \\
\hline $\begin{array}{l}\text { Elementos } \\
\text { de vasos }\end{array}$ & vertical & condução & 30 & $0.2-0.6$ & $10-300$ \\
\hline $\begin{array}{l}\text { Parênquima } \\
\text { longitudinal }\end{array}$ & vertical & condução & $<5$ & $<0.1$ & $<30$ \\
\hline $\begin{array}{l}\text { Parênquima } \\
\text { radicular }\end{array}$ & horizontal & estocagem & 15 & $<0.1$ & $<30$ \\
\hline
\end{tabular}

\subsection{Composição química das fibras}

As condições climáticas, idade e o processo de nutrição digestiva influenciam não só a estrutura da fibra vegetal, mas também sua composição química. Uma revisão mais abrangente sobre fibras naturais e suas aplicações encontra-se em Bledzki e Gassan (1999).

Os materiais lignocelulósicos são compostos basicamente por celulose, hemiceluloses, lignina e constituintes menores. $\mathrm{Na}$ Tabela 4.2 são mostradas as porcentagens das estruturas moleculares típicas dos constituintes na madeira em geral. 
Tabela 4.2: Componentes das madeiras Fonte: D'Almeida (1988)

\begin{tabular}{lr}
\hline \multicolumn{1}{c}{ Componente } & Presença (\%) \\
\hline Celulose & $\sim 50$ \\
Hemiceluloses & $\sim 20$ \\
Lignina & 15 a 35 \\
Constituintes menores & até $~ 10$ \\
\hline
\end{tabular}

\subsubsection{Celulose}

O componente principal dos vegetais é a celulose, a qual constitui $50 \%$ da matéria orgânica da biosfera (ROJAS, 2003). A celulose é um polissacarídeo formado por unidades de $\beta$-D-glucose, que se ligam entre si através dos carbonos 1 e 4, dando origem a um polímero linear (D'ALMEIDA, 1988) com uma estrutura cíclica formada por seis átomos de carbono (Figura 4.2).

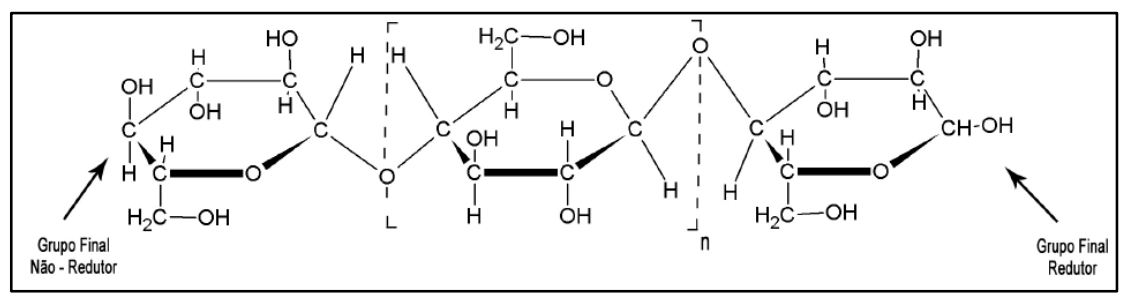

Figura 4.2: Estrutura da celulose.

Fonte: D'Almeida (1988)

D'Almeida (1988) descreve que as moléculas de celulose tendem a formar pontes de hidrogênio intramoleculares (entre unidades de glicose da mesma molécula) e intermoleculares (entre unidades de glicose de moléculas adjacentes). O primeiro tipo de interação é responsável por certa rigidez das cadeias unitárias, e o segundo pela formação da fibra vegetal, ou seja, as moléculas de celulose se alinham, formando as microfibras, as quais formam as fibrilas que, por sua vez, ordenam-se para formar as sucessivas paredes celulares da fibra (Figura 4.3).

Cada fibra de celulose tem de 10.000 até 15.000 monômeros. A estrutura estabiliza-se por pontes de hidrogênio intra e intercatenários (SJÖSTRÖM, 2010; ROJAS, 2003). As ligações de hidrogênio intramoleculares e 
intermoleculares fazem com que a fibra de celulose seja um polímero estável e apreciado como reforço em compósitos.

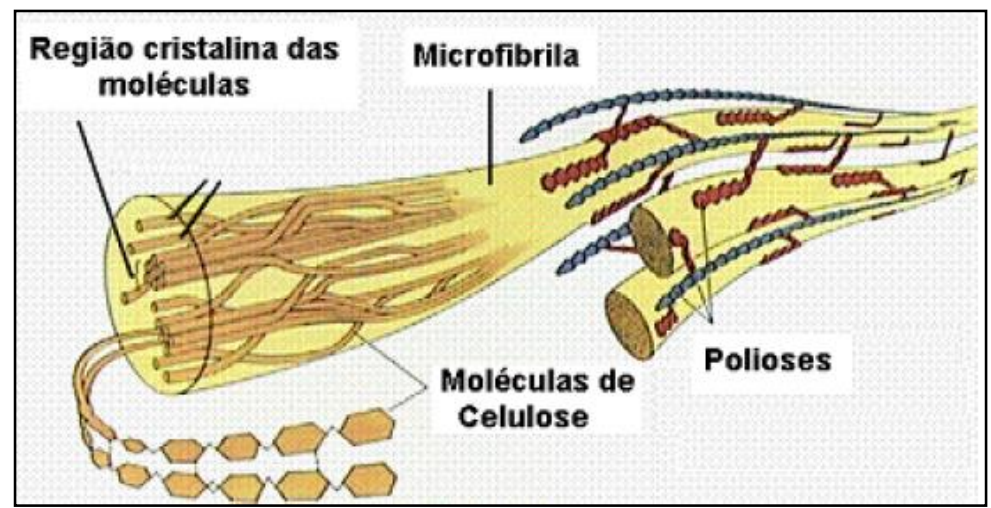

Figura 4.3: llustração esquemática da formação da fibra celulósica Fonte: Extraído de Klock, et al. (2005) ${ }^{[7]}$

A roseta, uma estrutura de seis lobos onde tem-se a produção de celulose pelo complexo multimérico transmembrana celulose sintase (CESA), foi observada por microscopia eletrônica (KIMURA et al., 1999). Déjardin et al. $(2010)^{[8]}$ revê a formação da madeira como um processo biológico complexo, envolvendo cinco maiores etapas de desenvolvimento, incluindo a divisão celular a partir de um meristema secundário (tecidos embrionários formadores das diversas partes da planta) chamado de câmbio vascular, a expansão das células (o alongamento das células e o alargamento radial), a deposição da parede celular secundária, a morte celular programada, e a formação do cerne. O xilema divide-se em duas regiões distintas: o alburno que é a parte externa formada por células vivas e o cerne formado por células mortas. A produção de celulose em cristalitos (tipo I), ou nativa, é intercalado de regiões amorfas fazem parte do processo de biossíntese.

${ }^{7}$ Essa figura esquemática também tornou-se clássica e perdeu-se a origem da idéia. Presente figura foi extraída de apostila de curso da Prof. Graciela Muñiz em Engenharia Florestal de UFPr. Ver KLOCK, MUÑIZ, G.I.B.; HERNANDEZ, J.A.; ANDRADE, A.S. Química da madeira. 3.ed. UFPr. Curitiba, 2005. 86p. (Apostila).

${ }^{8}$ Esses autores descrevem o desenvolvimento de estudos genômicos em espécies lenhosas, bem como a engenharia genética, e o recente progresso na compreensão dos mecanismos moleculares subjacentes à formação da madeira, em dois aspectos diferentes: o processo de lignificação e o controle do ângulo de microfibrilas na parede celular das fibras de madeira e suas principais características Ambas são propriedades dos materiais de madeira. 
Outro tipo de celulose, mais estável, é chamado de tipo II, ou chamado de regenerado por ser celulose precipitada de solução alcalina, tem estrutura também cristalina. A celulose exibe um polimorfismo, devendo ser destacado sete polimorfos $\left(I_{\alpha}, I_{\beta}, I I, I I I_{I}, I I_{\|}, I V_{I}\right.$ e IV $\left.V_{\|}\right)$que podem ser interconvertidos. (SIQUEIRA et al., 2010). As fibras de celulose apresentam regiões cristalinas altamente organizadas e também regiões amorfas, onde as cadeias de celulose estão agrupadas de maneira irregular. Essas regiões não possuem delimitações e a razão entre elas pode variar de acordo com a origem da celulose (ALMEIDA et al., 2010). A celulose pode ser convertida em amorfo através de ataques químicos (EL SEOUD et al., 2008).

\subsubsection{Hemiceluloses}

Segundo D'Almeida (1988), o termo hemiceluloses refere-se a uma mistura de polímeros polissacarídeos de baixa massa molar, os quais estão intimamente associados com a celulose no tecido das plantas. $\mathrm{Na}$ composição das hemiceluloses podem aparecer as seguintes unidades de açúcar: $\beta$-D-xilose, $\beta$-D-manose, $\beta$-D-glucose, $\alpha$-L-arabinose, $\alpha$-D-galactose, ácido $\beta$-D-glucorônico, ácido $\beta$-D-galacturônico e ácido $\alpha$-D-4-0metilglucourônico (Figura 4.4).

As hemiceluloses podem ter cinco átomos de carbono, sendo denominadas pentoses ou seis átomos de carbono, sendo denominadas hexoses. Pentosanas e hexosanas são, por conseguinte, anidridos poliméricos de pentoses e hexoses com as formulas gerais $\left(\mathrm{C}_{5} \mathrm{H}_{8} \mathrm{O}_{4}\right)_{\mathrm{n}}$ e $\left(\mathrm{C}_{6} \mathrm{H}_{10} \mathrm{O}_{5}\right)_{n}$, respectivamente, onde $n$ é o grau de polimerização (D'ALMEIDA, 1988). Portanto, as hemiceluloses são polímeros nos quais participam pelo menos dois tipos de unidades de açúcar. As hemiceluloses são muito mais solúveis e instáveis que a celulose (BIERMAN, 1996). Elas são solúveis em hidróxido de sódio $(\mathrm{NaOH})$ e seus baixos pesos moleculares as tornam parcialmente solúveis em álcali a elevadas temperaturas, tal como acontece no processo Kraft. 


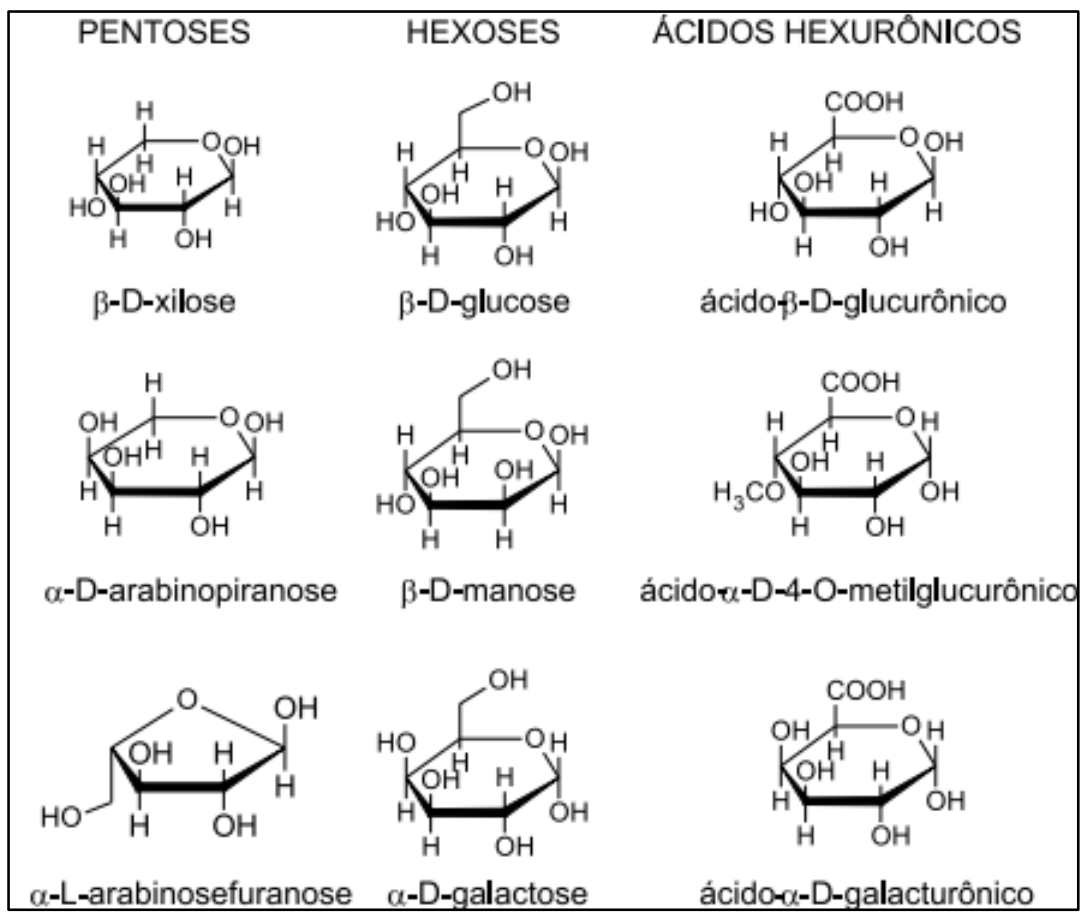

Figura 4.4: Principais açúcares que compõem as hemiceluloses Fonte: D'Almeida (1988)

\subsubsection{Lignina}

A lignina confere rigidez á parede da célula e age como um agente permanente de ligação entre as células vegetais, gerando uma estrutura resistente ao impacto, compressão e dobra.

As ligninas presentes nas paredes celulares das plantas estão sempre associadas com as hemiceluloses. A maioria das ligninas contém quantidades variáveis de ligações covalentes.

As moléculas de lignina estão compostas por um sistema aromático de fenilpropano (EK et al., 2005)[9]. A lignina é hidrofóbica e tem uma estrutura tridimensional, altamente ramificada, podendo ser classificada como um polifenol.

9 HENRIKSSON, G.; LENNHOLM, H. Cellulose and Carbohydrate Chemistry. cap. 4, p.71-100. TELEMAN, A. Hemicelluloses and Pectins. Cap.5, p.. 101-120. Henriksson, G. Lignin. cap. 5, p.121-146. In: EK, M.; GELLERSTEDT, G.; HENRIKSSON, G. Pulp and Paper Chemistry and Tecnology. Volume 1: Wood Chemistry and Wood Biotechnology. Berlin. De Gruyter, 2009. 
A estrutura principal da lignina provém da polimerização de precursores primários: álcool trans-coniferílico; álcool trans-sinapílico; e álcool trans-paracumárico (Figura 4.5). A constituição da lignina muda dependendo da planta. Portanto, esse polímero natural amorfo é complexo e não deve ser considerado como uma substância química única. No caso das madeiras, a lignina pode ser dividida em dois tipos: ligninas guaiacil e ligninas guaiacilsiringil. A primeira classe corresponde às ligninas predominantes nas coníferas e a segunda às predominantes nas folhosas (D'AMEIDA, 1988). As coníferas apresentam maior teor de lignina em comparação com as folhosas, além de apresentar diferenças estruturais.

A lignina siringil apresenta estrutura menos condensada do que a lignina guaicil, não possuindo o carbono reativo cinco (C5) disponível para reação na etapa de polimerização da biossíntese da lignina, consequentemente são mais favoráveis à deslignificação pelo processo Kraft (GOMES et al., 2008). Segundo os mesmos autores, a lignina guaicil, por possuir o grupo C5 disponível para reação com outros anéis de fenilpropano, torna-se um componente de maior massa molecular.

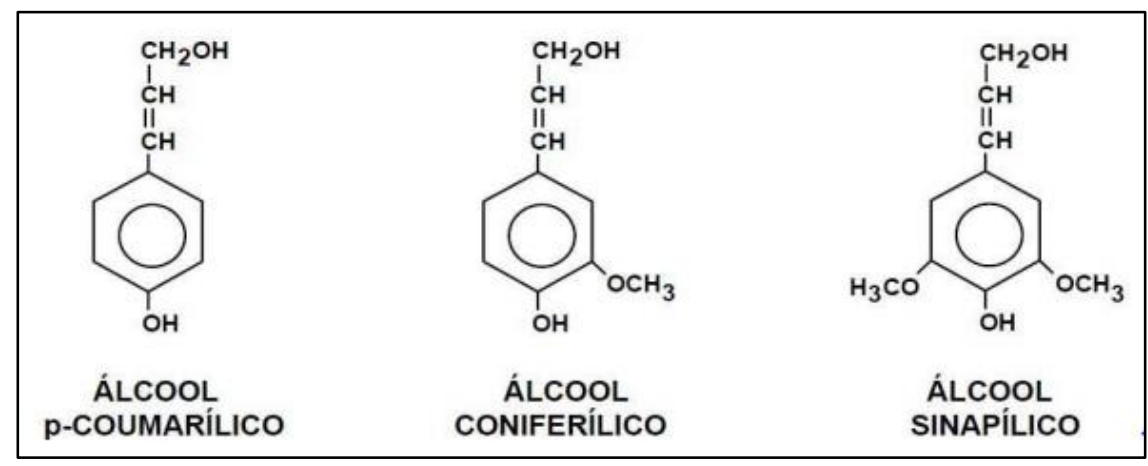

Figura 4.5: Alcoóis precursores da lignina Fonte: D'Almeida (1988)

A relação dos tipos de lignina siringil/guaicil varia em folhosas e coníferas. Foelkel (2009) [10], em seu e-book de divulgação do conhecimento no setor de celulose e papel, descreve que a relação de ligninas siringil/guaiacil para

10 FOELKEL, C.E.B. Propriedades papeleiras das árvores, madeiras e fibras celulósicas dos eucaliptos. 2009. 111p. Eucalyptus Online Book \& Newsletter. Disponível em: <http://www.eucalyptus.com.br> Acesso em: 09 jan. 2016. 
madeira de clones de eucalipto varia de 3 a 3,5. O mesmo autor cita que a relação para Eucalyptus urophylla apresenta valores de 2 e o Eucalyptus globulus apresenta uma relação de 4 a 6 . Gomes et al. (2008) observam uma relação de 2,7 a 2,9 para clones de eucalipto. Para Eucalyptus grandis $x$ Eucalyptus urophylla uma relação de 2,07 tem sido observada por Júnior e Colodette (2011).

\subsection{Processo Kraft ou Sulfato}

O processo químico de cozimento, ou polpação, da madeira para a obtenção de pasta celulósica denominado Kraft envolve o cozimento de cavacos de madeira com produtos químicos a altas temperaturas e a altas pressões. Hoje, Kraft é o processo mais utilizado no mundo para produção de pasta celulósica e em processos contínuos existem várias modalidades ${ }^{[11]} \mathrm{em}$ que através de melhor perfil de concentração de reagentes $\mathrm{NaOH}$ e $\mathrm{Na}_{2} \mathrm{~S}$ utilizase um perfil de temperatura menor com a sua correspondente pressão menor, em conceitos de deslignificação estendida e seus variantes.

Nesse licor reagente contendo hidróxido de sódio $(\mathrm{NaOH})$ e sulfeto de sódio $\left(\mathrm{Na}_{2} \mathrm{~S}\right)$, estão envolvidos os seguintes equilíbrios que dependem da temperatura, concentração e as suas características termodinâmicas (GULLICHSEN e FOGELHOM, 1999):

$$
\begin{array}{ll}
\mathrm{NaOH}+\mathrm{H}_{2} \mathrm{O} \leftrightarrow \mathrm{Na}^{+}+\mathrm{OH}^{-}+\mathrm{H}_{2} \mathrm{O} & \text { Reação 1 } \\
\mathrm{Na}_{2} \mathrm{~S}+\mathrm{H}_{2} \mathrm{O} \leftrightarrow 2 \mathrm{Na}^{+}+\mathrm{S}^{2-}+\mathrm{H}_{2} \mathrm{O} & \text { Reação 2 } \\
\mathrm{S}^{2-}+\mathrm{H}_{2} \mathrm{O} \leftrightarrow \mathrm{HS}^{-}+\mathrm{OH}^{-} & \text {Reação 3 } \\
\mathrm{HS}^{-}+\mathrm{H}_{2} \mathrm{O} \leftrightarrow \mathrm{H}_{2} \mathrm{~S}+\mathrm{OH}^{-} & \text {Reação 4 } \\
\mathrm{Na}_{2} \mathrm{CO}_{3}+\mathrm{H}_{2} \mathrm{O} \leftrightarrow 2 \mathrm{Na}^{+}+\mathrm{CO}_{3}^{2-}+\mathrm{H}_{2} \mathrm{O} & \text { Reação 5 } \\
\mathrm{CO}_{3}^{2-}+\mathrm{H}_{2} \mathrm{O} \leftrightarrow \mathrm{CO}_{3}^{-}+\mathrm{OH}^{-} & \text {Reação 6 }
\end{array}
$$

${ }^{11}$ A tecnologia de polpação Kraft pode ser vista em de forma sumária em EK, M.; GELLERSTEDT, G.; HENRIKSSON, G. Pulp and Paper Chemistry and Tecnology. Volume 2: Pulping Chemistry and Technology. Berlin. De Gruyter, 2009. A descrição de diferentes processos e suas operações pode ser visto em GULLICHSEN, J.; FOGELHOLM, C.J. Book 6A: Chemical Pulping. In: Papermaking Science and Technology Series. FI \& TAPPI Publ. 1999. (volume 6B trata de equipamentos e operação do ciclo de recuperação dos reagentes $\mathrm{NaOH}$ e $\mathrm{Na}_{2} \mathrm{~S}$ ). 
Hidróxido de sódio $(\mathrm{NaOH})$ é um reagente mais abrangente para ataque aos carboidratos (celulose e hemicelulose) e às diferentes ligninas, mas sulfeto de sódio $\left(\mathrm{Na}_{2} \mathrm{~S}\right)$ torna essas reações mais seletivas, o que antigamente era coloquialmente dito que sulfeto "protege" carboidratos ${ }^{[12]}$. Por isso o cozimento ou polpação também é chamado com mais enfaticamente de deslignificação. Lembrando-se da topoquímica da madeira, onde a lignina concentra-se mais em lamela média e depois em parede primária, a deslignificação se dará significativamente nessas partes. Também lembrando que "lignina" é uma designação genérica para diferentes e complexas configurações deste polímero natural, desde o ponto de vista tecnológico considera-se que existe uma fase de ataque inicial, seguida de período principal e a parte mais resistente ao ataque às ligninas, denominada período final. Os modelos mecanísticos de ataque nas estruturas da lignina são revisados em Park e Pinto (1990) e o modelo cinético de deslignificação de eucalipto é detalhado em Giudici e Park (1996). O número Kappa é o grau de oxidação por permanganato das fibras celulósicas e é uma indicação de ligninas ainda existentes nas fibras, ou seja, grau de deslignificação é importante para estimar ligninas residuais depois do período final de polpação. Recentemente verificou-se a existência de ácidos hexenurônicos que concorrem com a lignina na determinação do número Kappa e no consumo de reagentes, o que é relevante para a fase de branqueamento das fibras. Portanto, pode-se ver em Sixta e Rutkowska (2007) um trabalho de cinética de eucalipto considerando esses ácidos hexenurônicos ${ }^{[13]}$.

\footnotetext{
12 Também é interessante ver a descrição de reações de carbohidratos tal como se conhecia em 1979, em GOMIDE, J.L. Reação dos carboidratos e dissolução dos constituintes da madeira, durante pasteado alcalina. O Papel, São Paulo, v.40, n.11, p.119-128, nov. 1979.

13 Descrição abrangente e detalhada de deslignificação encontra-se em SIXTA, H. Handbook of Pulp. 2 volumes. Berlin. Wiley-VCH. 2006.
} 


\subsection{Branqueamento}

$\mathrm{Na}$ maioria dos produtos de polpação de eucalipto, interessa como valor comercial as fibras branqueadas BEKP (Bleached Eucalyptus Kraft Pulp). Portanto, os agentes cromóforos, na maior parte devido à lignina residual e de condensação (fragmentos de lignina que se recombinam e permanecem na fibra) devem ser removidos por agentes mais agressivos. Desse modo, o branqueamento da pasta celulósica tem como o principal objetivo aumentar a alvura, seja por eliminação ou modificação da lignina residual do cozimento.

A utilização do cloro elementar $\left(\mathrm{Cl}_{2}\right)$ tem sido cada vez menor por questões ambientais, sendo substituído por dióxido de cloro $\left(\mathrm{Cl}_{2} \mathrm{O}\right)$ nos processos ECF (Elemental Chlorine Free). Outros oxidantes utilizados em branqueamento são hipocloritos, oxigênio, peróxido de oxigênio, ozônio, perácidos e hidróxido de sódio. Dependendo da sua natureza química, esses reagentes fazem ataque nucleofílico ou eletrofílico, e dependendo de reagentes, o meio deve ser alcalino ou ácido. Assim, pode-se ter uma sequência de torres com esses reagentes e suas combinações intercaladas de lavagem (alcalina) com diferentes condições operacionais. Uma boa referência para detalhes de tecnologia encontra-se em Colodette e Gomes (2015).

A inserção de uma etapa de oxidação de lignina residual por oxigênio logo após a polpação pode ser entendida como uma extensão de deslignificação e, ao mesmo tempo, por se localizar antes da sequência das etapas de branqueamento, pode ser entendida como início de branqueamento. Assim, essa etapa é denominada de pré-branqueamento por oxigênio ou

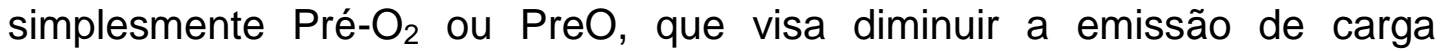
poluente, aumentar rendimento e facilitar o branqueamento posterior. As fibras que saem dessa etapa ainda é "marrom claro", o que indica alto conteúdo de lignina residual em relação às pastas branqueadas. 


\subsection{Fabricação de papel}

O papel consiste em uma trama de fibras, formada sobre uma tela, a partir de uma suspensão aquosa, mantida unida por pontes de hidrogênio. Além das fibras, no papel encontram-se minerais adicionados na massa (na suspensão da pasta antes da fabricação do papel) ou na superfície (na forma de revestimentos). Igualmente, no papel encontram-se aditivos químicos na massa ou na superfície, utilizados para melhorar as propriedades do papel ou para facilitar o processo de formação.

$\mathrm{Na}$ atualidade encontram-se mais de 500 tipos de papel no mercado, geralmente classificados em quatro grandes grupos (CRUCES-CERRO, 2013):

- Papéis para imprimir e escrever: Destinados ao uso como suporte de impressão e escritura (jornais, "cut-size”, papéis revestidos, etc.);

- Papéis para fins sanitários: Fabricados para a higiene e a limpeza em geral (papel higiênico, papel toalha, etc.);

- Papéis para embalagens: Destinados a envolver, transportar e proteger diferentes produtos (caixas de cartão corrugado, sacos, etc.);

- Papéis especiais: Engloba-se nesta categoria os que, por seu uso ou peculiaridades, não entram em nenhuma das categorias dos outros papéis (papel seda, papel filtro, etc.).

As principais operações na formação dos papéis são a refinação mecânica das fibras celulósicas (com eventual refino enzimático), adição das matériasprimas não fibrosas, e a operação da máquina de papel em si mesma, composta, a grosso modo, da formação ou a consolidação da folha de papel, drenagem de "água", prensagem para remoção mecânica da água, e a secagem, podendo ter uma seção intermediária de colagem superficial quando for o caso. O acabamento desses papéis podem ter calandragem, supercalandragem, colagem superficial e revestimento, que são tratamentos da superfície do papel. 


\subsubsection{Refinação mecânica}

A refinação é uma operação de preparação da pasta celulósica, na qual, por intermédio da ação de um trabalho mecânico e um meio aquoso, modifica a morfologia das fibras, visando conferir, ao papel ou ao produto a que se destinam, determinadas propriedades desejáveis.

Industrialmente, o processo de refinação consiste em fazer passar uma suspensão de fibras através de dois discos, um fixo (estator) e um em movimento (rotor). Desta forma, ao passar as fibras entre os discos de refinação as fibras sofrem um efeito de corte, esmagamento entre si e entre as ranhuras dos discos. Existem variantes tais como duplo discos rotores, discos cônicos, e outros. Existem diferenças fundamentais entre o processo de refinação industrial, que atualmente migrou para discos, com os princípios de cisalhamento de fibras (CUBEROS-MARTINEZ e PARK, 2012), e a refinação em laboratório, com os princípios de batimento contínuo das fibras, tal como antigamente, (YASUMURA et al., 2008) e ainda hoje é largamente utilizada para analisar as qualidades de fibras (YASUMURA et al., 2012).

Devido ao trabalho mecânico durante a refinação, rompem-se e eliminam-se parcialmente as paredes primárias e secundárias, externas da fibra, permitindo a penetração de água que provocará seu inchamento e possibilitará a fibrilação interna. Devido a estes efeitos mecânicos, a fibra adquirirá um aspecto desfibrilado, aumentando sensivelmente sua superfície e volume específico, tornando-se ainda mais flexível e macia, porém diminuí o bulk total da folha de papel devido ao colapso das fibras.

Alguns efeitos não desejáveis podem ocorrer, como uma diminuição das fibras por fratura e a produção de finos (desprendimento das capas externas e de microfibras).

Os efeitos principais da refinação[14] na pasta de celulose são:

\footnotetext{
14 Para ver os efeitos do refino das fibras celulósicas e a geração, e morfologia, dos finos, uma boa referência é FERREIRA, P.J.T. Estudos de pastas Kraft de Eucalyptus globulus: características
} 
- Ruptura das pontes de hidrogênio intra-fibra e sua substituição por pontes de hidrogênio fibra-água (fibrilação interna);

- Fibrilação externa;

- Formação de finos;

- Diminuição do tamanho das fibras.

Por outra parte, os parâmetros que tem maior influência na refinação da pasta celulósica são: tipo de pasta, $\mathrm{pH}$, temperatura, consistência, velocidade de rotação dos discos, características dos discos e a intensidade (energia) de refinação.

\subsubsection{Matérias-primas não fibrosas}

As principais matérias-primas não fibrosas[15] utilizadas na fabricação de papéis podem-se dividir em:

- Cargas minerais: Minerais brancos adicionados para melhorar as propriedades óticas e de impressão;

- Aditivos funcionais: Incrementam as propriedades existentes ou conferem uma nova propriedade ao papel e seus exemplos são os agentes de colagem interna, agentes de resistência a seco, agentes de resistência a úmido, alvejantes óticos, e outros;

estruturais e aptidão papeleira. Coimbra, 2000. 361p. Tese (Doutor em Engenharia Química) Faculdade de Ciência e Tecnologia, Universidade de Coimbra, 2000, incluindo o seu capítulo de revisão bibliográfica.

15 A Química da Parte Úmida no processo de fabricação do papel é por si só uma grande área de conhecimento, e o presente texto deve ser considerado como uma ilustração. A introdução da tecnologia pode ser encontrada em HOLIK, H. Handbook of Paper and Board. 2 volumes. 2nd ed. Berlin. Wiley-VCH 2013 e EK, M.; GELLERSTEDT, G.; HENRIKSSON, G. Pulp and paper chemistry and tecnology. Volume 3: Paper Chemistry and Technology. Berlin. De Gruyter, 2009. Um livro com maiores referências é de R. ALÉN. Papermaking Chemistry. Volume 4. ( $2^{\text {nd }}$ edition) In: Papermaking Science and Technology Series. Finnish paper engineer's association and TAPPI Publ. 2007. Em Português pode ser visto em SILVA, D.J. Química da parte úmida em processo de fabricação de papel - Interações em interfaces sólido-líquido. São Paulo, 2010. 293p. Tese (Doutor em Engenharia Química) - Escola Politécnica, Universidade de São Paulo, 2010 e FERNANDES, E.T. Nanopartículas de sílica coloidal como agente da parte úmida na fabricação de papel. São Paulo, 151p. Dissertação (Mestrado em Engenharia Química) - Escola Politénica, Universidade de São Paulo, 2013. 
- Aditivos de processo: Auxiliam na limpeza e desempenho da fabricação do papel, e seus exemplos são os agentes de retenção, agentes de controle microbiológicos, agentes de drenagem, controladores de pitch e agentes anti-espumantes.

Nos papéis para embalagens Kraftliner não se utilizam cargas minerais, e as principais matérias-primas não fibrosas empregadas são:

- Agentes de colagem: As fibras celulósicas são extremadamente absorventes. A colagem deve conferir ao papel resistência à penetração da água. O sistema mais empregado no caso de papéis para embalagem é a colagem a pH ácido $(4,5-5,0)$, com colas de breu, e as resinas modificadas para condições alcalinas, tais como ASA (alkenylsuccinic anhydride) e AKD (alkylketene dimer);

- Agentes de resistência a seco: São agentes empregados para aumentar a resistência do papel após a secagem, geralmente aumentam as propriedades como estouro, tração, coesão interna, e para prevenir a geração de pó ou a soltura de fibras superficiais. Os aditivos mais empregados são amidos catiônicos. Estes agem aumentando a resistência das ligações inter-fibras. Por outro lado, o amido necessita ser cationizado, pois amido também é um carboidrato, logo é aniônico como as fibras celulósicas. Incorporandose ao amido os grupos catiônicos, estes lhes conferirão carga positiva, e assim poderá unir-se fortemente às fibras. As fibras branqueadas possuem carga aniônica. As fibras de pastas mecânicas, por ter lignina, e pastas marrons, por ter lignina residual da polpação, possuem essa carga aniônica em maior grau do que as pastas branqueadas;

- Agentes de resistência a úmido: São importantes para aqueles papéis que devem resistir a uma alta umidade. São usados para reforçar as ligações inter-fibras contra a ação da água. Tipicamente, são usados agentes catiônicos tais como ureia formaldeído, melanina formaldeído e poliamina, e outros polímeros. Deve-se lembrar de que 
agentes de colagem são também agentes que aumentam a resistência a seco e a úmido;

- Agentes de retenção: O uso de agentes de retenção e drenagem tem como principal objetivo fixar as partículas, tais como cargas minerais e finos, de pequenas dimensões, e com a consequente micro-floculação das fibras e o aumento da drenagem. Geralmente são usados agentes floculantes, como polímeros sintéticos (polieletrólitos) e/ou sulfato de alumínio, e outros polímeros.

\subsubsection{Máquina de papel}

A formação do papel envolve as etapas abaixo descritas:

- Formação: Deposição de fibras de uma suspensão aquosa sobre uma tela;

- Drenagem: Retirada de água por forças como a gravidade ou diferença de pressão mantida por vácuo;

- Prensagem: Remoção da maior quantidade possível de água da folha de papel antes de submetê-la à secagem por calor;

- Secagem: Secagem por ar ou secagem da folha de papel sobre uma superfície aquecida (com eventual colagem superficial entre as secagens).

A máquina de papel é um equipamento para formação contínua, retirada de água, prensagem e secagem do papel (Figura 4.6). O tipo mais comum de máquina de papel é a de mesa plana, onde uma suspensão diluída de fibras (tipicamente $0,3 \%$ a $0,6 \%$ de consistência) é depositada sobre uma mesa de tela metálica ou sintética. A água é removida por gravidade ou pela diferença de pressão desenvolvida por rolos da mesa, ou por equipamentos de sucção. Mais água é retirada na seção de prensas até a consistência de $35 \%-55 \%$. Finalmente, a folha é seca por aquecimento com vapor na seção de secagem. 


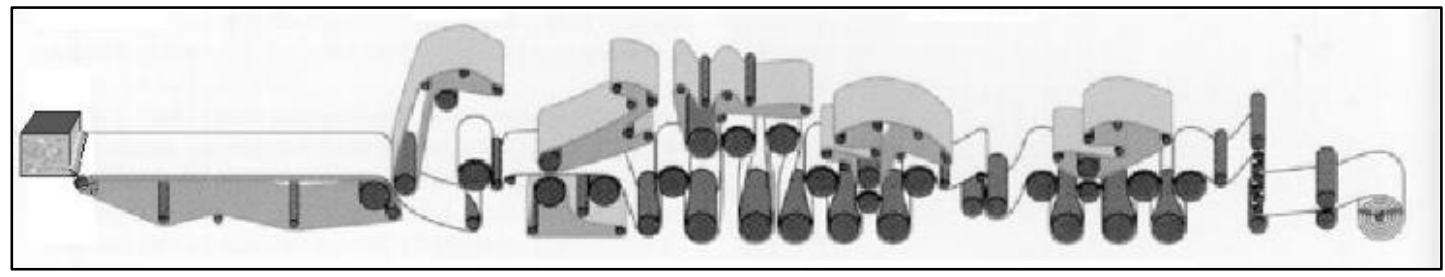

Figura 4.6: Máquina de Papel

Extraído de Cruces-Cerro, 2013

As fibras celulósicas devem ser depositadas na tela em uma consistência muito baixa, para garantir a boa formação do papel, ou seja, para que haja uma distribuição uniforme das fibras, desenvolvendo uma espessura constante. A função da máquina de papel é retirar a água que foi adicionada para garantir a uniformidade do papel.

As etapas mais importantes após a formação do papel são (YASUMURA, 2012):

- Calandragem: Depois da seção de secagem, o papel é pressionado por cilindros de aço aquecidos para se obter qualidade superficial, um processo chamado de calandragem. O papel é então enrolado em grandes bobinas chamadas de rolo jumbo;

- Supercalandragem: A supercalandragem é uma operação de acabamento de papel, geralmente como uma operação independente após a fabricação, que consiste em um grau adicional de calandragem realizado em uma máquina especial, que não está ligada à máquina de papel;

- Colagem superficial: Os processos de calandragem e supercalandragem são tratamentos que alteram a natureza das fibras da superfície, sem adição de nenhum composto. Já a colagem superficial e o revestimento envolvem a adição de outras substâncias à superfície do papel;

- Revestimento: Em papel para imprimir e escrever o revestimento mais comum é de pigmento mineral, ou seja, adição ao papel de uma camada fina de minerais emulsionados em polímero. Em papéis para embalagem podem existir outros tipos de revestimento de acordo com 
a finalidade da embalagem. O processo de revestimento pode ocorrer em máquina (linha) ou em uma operação fora de máquina.

\subsubsection{Papéis para embalagem: Kraftliners}

Os papéis para embalagem são aqueles destinados a conter, proteger e viabilizar o transporte dos produtos. Trata-se de um produto do setor de base florestal que é produzido com pastas celulósicas de fibras longas, tanto de fibras virgens como de fibras recicladas.

Existe uma grande variedade de papéis para embalagens. Segundo Kiviranta (2000) eles podem ser classificados em três categorias principais: "cartonboards", "containerboards" e "specially boards".

Entre os papéis "containerboard" encontram-se os "lineardboards" ou papéis ondulados[16] Basicamente são papéis formados por uma placa composta externamente por duas folhas de papel lisas, denominadas capas ou liners. Por dentro, entre as capas, há um meio interno ondulado (o miolo do papelão), que pode ser constituído de uma ou mais camadas de papéis em onda colados aos liners externos ou mesmo a liners interiores (no caso de papelão multicamadas).

Quando a capa é fabricada com grande proporção de fibras virgens, essa capa denomina-se Kraftliner. Se for fabricada principalmente com fibras recicladas, chama-se Testliner. Apesar do grande uso de aparas de papel como fonte de fibra para a produção de papéis ondulados, fazem-se necessários aportes de fibras virgens, mais resistentes, para melhorar a qualidade. Tanto no Kraftliner como no Testliner, a predominância é para fibras longas de pinus, mas existem também percentagens significativas de fibras curtas de celulose de eucalipto. Já o papel miolo (fluting), com o qual se produz a onda, por questões de custos é invariavelmente produzido com

16 H. PAUlaPURO. Paper and Board Grades. Volume 18. In: Papermaking Science and Technology Series. Finnish paper engineer's association and TAPPI Publ. 2000. 
papel reciclado, contendo fibras longas e curtas misturadas, podendo também ser produzido com pasta mecânical ${ }^{[17]}$.

Os papéis Kraftliner devem reunir uma série de propriedades que garantam o desempenho para atender os requisitos do produto. De maneira geral, essas propriedades podem ser classificadas em: propriedades de aparência, propriedades químicas, propriedades estruturais, propriedades mecânicas e propriedades superficiais.

Como o papel deve resistir à ação das forças externas, da umidade e do calor, depende de sua composição fibrosa e de sua formação. A resistência do papel é muito importante nos casos onde o papel deve resistir a um esforço aplicado. Dentre as variáveis que mais influenciam a qualidade do papel produzido estão o comprimento das fibras, a espessura da parede celular, os danos físicos durante o processo de refinação, os danos químicos durante o processo de polpação e a deslignificação.

As propriedades dos papéis são determinadas em ambiente padronizado por serem muito dependentes do conteúdo de umidade. Os ensaios podem ser de natureza mecânica tais como a gramatura e as resistências à tração, ao arrebentamento, ao rasgo, à rigidez, e à absorção da energia de tensão (TEA); de natureza ótica (alvura, opacidade, brilho e cor); de natureza química ( $\mathrm{pH}$, umidade); de natureza elétrica (rigidez dielétrica, condutividade); e de propriedades como superficiais (lisura) e permeabilidade a fluidos ${ }^{[18]}$.

As propriedades que dependem da ligação entre fibras (tração, e arrebentamento) são melhoradas quanto maior são o entrelaçamento entre as fibras, o contato fibra-fibra, e a colapsabilidade das fibras e dos lúmens. Esta última, o colapso das fibras, está associada com o refino das fibras e a

${ }^{17}$ VIDAL, A.C.F. O mercado de papelão ondulado e os desafios da competitividade da indústria brasileira. BNDES Setorial, n. 35, p. 5-46, 2012.

18 Ver em SMOOK, G. A.; Handbook for Pulp and Paper Technologists, Tappi Press: Atlanta, 1982 e SANJUAN, D. R.; Obtención de Pulpas y Propiedades de las Fibras para Papel, Guadalajara: México, 1997. 
compactação da folha úmida, que coloca as paredes celulares mais próximas umas das outras. Fatores como o comprimento médio das fibras, a espessura da parede celular das fibras, a formação e estrutura da folha e a resistência individual das fibras tem grande influência na tração de um papel. Por outra parte, uma baixa resistência ao arrebentamento pode ser atribuída, em parte, ao corte das fibras. O uso de aditivos e colas afetam consideravelmente o comportamento do papel e o resultado dos ensaios de propriedades físicas do papel.

A resistência ao rasgo depende principalmente do tipo da fibra utilizada na fabricação do papel. A integridade das fibras também afeta resistência ao rasgo, portanto um aumento exagerado no processo de refinação provoca decréscimo da resistência ao rasgo, devido ao aumento do número de cortes nas fibras, mesmo que se aumente a resistência ao arrebentamento e à tração, como consequência do aumento da área de contato entre as fibras.

As propriedades mais importantes ${ }^{[19]}$ para os papéis Kraftliner são as propriedades de resistência mecânica, em especial a resistência ao estouro e a resistência à compressão short-span. A importância destas propriedades é devido ao fato de serem indicadores do desenvolvimento da resistência de uma caixa, da flexibilidade durante a transformação do produto e do uso da placa de papelão. No entanto, além da resistência a estouro e a resistência a compressão short-span, a resistência à tração e o alongamento da fibra são indicadores muito usados para o cálculo do desempenho de uma caixa.

19 CONFEDERAÇÃO EUROPEIA DE INDÚSTRIAS DE PAPEL PARA CARTÃO (CEPI CONTAINERBOARD). Lista europea de papeles para carton ondulado. Disponível em: <www.cepi-containerboard.org>. Acesso em: 10 jul. 2015. 


\section{REVISÃO DA LITERATURA}

\subsection{Nanotecnologia e nanomateriais celulósicos}

No setor papeleiro, a palavra celulose é aplicada, dentro de cada contexto, ou como polímero natural de glicose-glicose onde a ligação C-1 é feita em C4 , ou como o conjunto de fibras que se conformam em torno de um conjunto de materiais desta maior componente da madeira. É difícil imaginar um biomaterial mais abundante na natureza, e ao mesmo tempo mais ambientalmente adequado do que a celulose da base florestal plantada. Dada a diversidade de morfologia e suas características químicas e estruturais, consegue-se obter diferentes matérias-primas a partir das diferentes celuloses, ou seja, tanto no sentido químico do polímero quanto no sentido de matéria-prima, têm-se diferentes "celuloses". Nanocelulose é um produto há 50 anos já imaginado, mas teve um grande impulso nos últimos vinte anos, e é um produto onde o sentido de polímero e o sentido de matéria-prima industrial mais se convergem. Ainda assim, existem diferentes "nanoceluloses" que dependem da fonte da biomassa e do processo de produção. Nanocelulose já é considerada como um dos grandes materiais do século, tal a diversidade da sua aplicação, cujo panorama pode ser visto em Postek et al. (2013). Dado o tamanho interesse nesse material, a quantidade de publicações cresce de forma espetacular neste último ano, e portanto, o presente texto terá que ser seletivo.

A presente revisão bibliográfica trata diretamente de nanomateriais celulósicos específicos, das nanofibrilas e microfibrilas de celulose, da sua obtenção e da sua aplicação na produção de papel. Não se trata aqui de nanocristais de celulose (SILVA e D'ALMEIDA, 2009). Não se aborda aqui de toda e qualquer aplicação de nanofibrilas, tais como filmes e espumas.

Para conceitos amplamente aceitos na área de pesquisa e aplicação, não se remete a nenhuma referência específica, e sim, explica-se e define-se aqui no texto, utilizando o máximo de trabalhos de revisão sobre os assuntos. 


\subsection{Nanoceluloses}

Sob o nome genérico do material nanocelulose, existem nanocristais que o setor informalmente diz que se parece com "grãos de arroz", e nanofibrilas e microfibrilas que se parecem com "spaghetti", entendido que é em escala nanométrica. Ainda os termos nanofibrilas e microfibrilas de celulose se confundem na literatura, e cada uma delas ainda são denominadas com diferentes nomes, tais como nanofibras e microfibras de celulose, ou celulose nanofibrilada e microfibrilada, com seus acrônimos NFC, MFC, CNF, CMF, MCF, NCF. As normas internacionais ainda estão na fase de discussão pela comunidade de interesse.

Para ser considerada nanocelulose, ao menos uma das suas dimensões precisa ter uma escala nanométrica, ou seja, entre 1-100 nm (nanômetro). As celuloses nano e micro fibriladas possuem espessura entre 2-100 nm, e comprimento na escala de 100 nanometros a alguns micrômetros, o que faz com que tenha alta razão de aspecto (100-150), grande área superficial $\left(100-200 \mathrm{~g} / \mathrm{m}^{2}\right)$, alta resistência e rigidez, boa elasticidade (VISHTAL e RETULAINEN, 2014), alta hidrofilicidade com tendência à formação de gel com água, pseudoplasticidade, e superfície facilmente modificável por reações químicas.

A tendência é denominar como nanofibras de celulose as que possuem espessura de 5-30 nm, o que, em termos práticos das técnicas de produção, significa que a massa total tem quase metade do seu material dentro dessas dimensões, e são pouco ramificadas. Considera-se microfibrilas de celulose as de espessura $25-100 \mathrm{~nm}$, o que significa que a massa tem uma faixa muito grande de diferentes tamanhos, desde 5 nanômetros a um pouco mais de décimo de micrômetro, e apresenta várias ramificações de fibrilas.

Existem diferentes terminologias para descrever as nanoceluloses. $\mathrm{Na}$ literatura estes termos acabam sendo um pouco confusos, visto que se podem entender como nanocelulose aquelas estruturas de celulose com diâmetro inferior a 100 nanómetros. Segundo Machena et al. (2011) o termo nanocelulose utiliza-se geralmente para descrever estruturas com 2-10 nm 
de espessura e várias dezenas de micrômetros de comprimento, as quais são formadas durante a biossíntese de celulose em plantas superiores. Segundo os mesmos autores, os termos "nanofibrilas" e "nanofibras" também são utilizados como sinônimos de "microfibrilas". Na Tabela 5.1 relatam-se as diferentes terminologias para as unidades de nanoceluloses.

Tabela 5.1: Terminologia das unidades de celulose por diversos autores Fonte: Sehaqui. et al. (2011)

\begin{tabular}{|c|c|}
\hline Terminologia & Diâmetro \\
\hline Microfibrilas de celulose & $\begin{array}{l}3 \mathrm{~nm} \text { de espessura em plantas e mais do que } 20 \mathrm{~nm} \text {, em } \\
\text { certas algas e tunicados }\end{array}$ \\
\hline Celulose Microcristalina (MCC) & 15-30 nm até cerca de $5 \mu \mathrm{m}$ devido à agregação \\
\hline Nanocristais de cellulose (CNC) & a partir de $3 \mathrm{~nm}$ até $50 \mathrm{~nm}$, dependendo da literatura \\
\hline Whiskers de celulose & $10-20 \mathrm{~nm}$ proveniente do manto tunicado \\
\hline $\begin{array}{l}\text { Celulose Microfibrilada (MFC ou } \\
\text { MCF) }\end{array}$ & $\begin{array}{l}25-100 \mathrm{~nm} \text { a partir de fibras de pastas celulósicas da } \\
\text { madeira }\end{array}$ \\
\hline $\begin{array}{l}\text { Celulose Nanofibrilada (NFC ou } \\
\text { CNF) }\end{array}$ & $\begin{array}{l}5-30 \mathrm{~nm} \text { a partir de fibras de pastas celulósicas da } \\
\text { madeira }\end{array}$ \\
\hline
\end{tabular}

Sehaqui et al. (2011) descrevem o termo MFC como as fibras com diâmetro compreendido entre 20 e 100 nanómetros. Segundo os mesmos autores o termo NFC (ou CNF) serve para descrever as fibras de celulose com diâmetro compreendido entre 5 e 20 nanómetros e comprimento variável, entre 2 e 10 micrômetros. O termo nanofibras é também utilizado para referir fibras com as suas dimensões inferiores a 100 nanómetros.

As CNF e as MCF, também são conhecidas como celulose nanofibrilada (CNF) e celulose microfibrilada (MCF). Ambas são dois tipos de nanomateriais de celulose que contêm regiões cristalinas e regiões amorfas e tipicamente têm comprimentos de mais do que $1 \mu \mathrm{m}$ (EICHHORN et al., 2010).

As nanofibrilas de celulose são originalmente criadas durante a biossíntese de celulose. A introdução de cada nanocelulose com um pouco do seu histórico pode ser vista na extensa revisão de Nechyporchuk et al.(2016). 


\subsubsection{Obtenção de nanoceluloses}

Para produção de nanocristais de celulose a rota geralmente é química de ataque às fibras por hidrólise ácida (SILVA e D'ALMEIDA, 2009). Nanocelulose bacteriana (GAO et al., 2010; ESA et al., 2014; SANTOS et al., 2015), obviamente, é produzida em um cultivo contendo substrato de açúcar, e nanocelulose por eletrosspin é feita a partir de celulose dissolvida para posterior aplicação de alta voltagem elétrica.

A produção de nanoceluloses a partir da madeira inicia geralmente com a remoção de lignina, por cozimento e posterior branqueamento, seguido por diferentes técnicas. Estas podem ser por desintegração mecânica, tal como homogeneização por impacto direto em choque a um anteparo (GEA), ou por microfluidizador em microcanais (Microfluidizer), e moagem (Masuko), que tem um disco de pedra rotativo a uma folga micrométrica. Existem outras técnicas não convencionais, tais como refino excessivo, extrusão, explosão a vapor, ultrasonificação, moinho de bolas, crioesmagamento, colisão aquosa, etc., de menor interesse industrial.

Nessas fibras pode-se ter etapas de pré-tratamento por hidrólise enzimática, carboxilação por oxidação mediada por TEMPO (2,2,6,6-tetrametilpiperdina$\mathrm{N}$-oxil), substância que é já conhecida na área de floculação em massa de celulose, carboxilação por oxidação com periodato e clorito, já conhecida na área de branqueamento, sulfonação, carbometilação já conhecida nos processos de fabricação de CMC (carboximetilcelulose), quartenização (cationização de celulose) e solventes. Os pós-tratamentos não são muito praticados, tanto na pesquisa quanto em testes industriais, ainda que 0 fracionamento por escoamento microfluídico seja amplamente conhecido em outras áreas de Engenharia Química. A morfologia e reologia de nanocelulose é revisitada por Colson et al. (2016), que apresentam as melhores técnicas práticas de caracterização, exceto uma falta de detalhes em outra técnica poderosa e prática de cromatografia inversa, que foi explorada por Gamelas et al. (2015 a, b) . 
Recomenda-se ver a revisão exaustiva e atualizada de Nechyporchuk et al. (2016), além de Brodin et al. (2014), Ahola et al. (2008), Lavoine et al. (2012), Siqueira et al. (2010), Siró e Placket (2010), Osong et al. (2016) e Chayhan e Chakr-abarti (2016). Onde se tem revisão de técnicas de caracterização de nanocelulose, necessariamente tem-se abordagem das diferentes técnicas de obtenção de nanocelulose, por enquanto, devido ao fato de que este produto depende da matéria-prima e de processo de fabricação. Portanto pode-se acompanhar essas revisões por Kangas et al. (2014), além de loelovich e Figovsky (2010) e de Besbes et al. (2011). Têm-se a comparação do consumo de energia na produção de nanocelulose em Spence et al. (2011), a influência da composição química na caracterização de nanocelulose em Spence et al. (2010), e a caracterização de nanoceluloses provenientes de diferentes madeiras em Besbes etal. (2011) e Stelte e Samadi (2009).

\subsubsection{Processo de desintegração mecânica}

Essa subseção segue literalmente a Vianna (2013), pois para o presente trabalho a MCF (ou MFC) em MASUKO (homogeneizador mecânico de disco de pedra) foi produzida junto com esta autora no seu laboratório. $O$ processo de desintegração mecânica para obtenção de celulose microfibrilada (MCF) é um processo mecânico de homogeneização, onde a celulose é degradada, promovendo a exposição e abertura das superfícies anteriormente situadas no interior das fibras, as fibrilas e as microfibras (ANDRESEN et al., 2006; GARDNER et al., 2008; KOLAKOVIC et al., 2011; SYVERUD et al ., 2011). No processo de desfibrilação mecânica ocorre uma diminuição significativa no tamanho das fibras e um consequente aumento da área específica das mesmas. Uma maior área específica permite uma maior ligação entre as microfibras de celulose, assim as folhas formadas apenas por MCF (chamadas aqui de filmes) tem menor espaço vazio (ou menor tamanho dos poros entre elas), e resulta em uma maior densidade e maior transparência. Conforme observado por Jonoobi et al. (2012), filmes nanocelulósicos mais densos apresentaram menor opacidade e maior transparência. 
O equipamento Masuko consiste em um disco rotatório e um disco fixo com uma abertura ajustável entre eles para que por meio do contato mecânico as fibras de celulose sejam desfibriladas por forças de cisalhamento geradas pelas pedras de desfibrilação.

A celulose a partir da madeira tem sido a principal fonte explorada para a produção de celulose microfibrilada (CARRASCO, 2011). A obtenção e separação de nanofibras de celulose a partir do processo mecânico produz um gel com elevado teor de água, que pode ainda ser transformado em pó, por secagem por aspersão (KOLAKOVIC et al., 2011).

Autores têm medido as transmitâncias regulares de luz de filmes e compósitos de celulose microfibrilada para avaliar o grau de fibrilação (ABE et al., 2009; UETANI e YANO, 2011; WANG et al., 2013). Segundo Carrasco (2011) o aumento nas transparências dos materiais de MCF pode ser um indicativo do grau de fibrilação, uma vez que fibrilas apresentam potencial de espalhamento de luz baixa. Desta forma um aumento na transmissão de luz indica aumento da transparência dos filmes nanoestruturados e um maior grau de fibrilação do material.

As microfibras obtidas por processo mecânico apresentam regiões com elevada intensidade de fibrilações devido às forças de cisalhamento em que as fibras são submetidas no processo de obtenção, enquanto os nanocristais são exclusivamente as regiões cristalinas da molécula de celulose. Esta microfibra apresenta regiões amorfas e cristalinas que compõem sua cadeia mais alongada no sentido longitudinal. Dessa forma, o longo comprimento das cadeias de celulose microfibrilada, associado à sua superfície que contém vasta gama de grupos hidroxílicos expostos, acaba potencializando a formação de inúmeras ligações de hidrogênio (PÄÄKKÖ et al., 2007).

Quanto às dimensões, o comprimento das cadeias de celulose microfibrilada por processos mecânicos tem vários micrômetros, ou seja, muito maiores que o seu diâmetro. A microfibrila apresenta diâmetro entre 5 e $60 \mathrm{~nm}$ e seu comprimento varia na escala micrométrica (KLEMM et al., 2011). 
Em relação às hemiceluloses, pesquisas realizadas indicam que é possível a obtenção de microfibras de celulose a partir de pasta celulósica com a presença ou ausência destes polissacarídeos. De acordo com alguns trabalhos, a presença de hemiceluloses pode facilitar a obtenção de microfibras de celulose durante o tratamento mecânico da pasta e aumentam as propriedades físicas de nanocompósitos. No processo de secagem, a presença de hemiceluloses impede a formação de ligações de hidrogênio irreversíveis entre as microfibras impedindo seu contato direto (IWAMOTO et al., 2008).

Para a obtenção de microfibras de celulose os autores enfatizam que a pasta celulósica, ou serragem de madeira, que será submetida ao processo de fabricação não deve ser completamente seca (ABE et al., 2009; JONOOBI et al., 2012). A natureza hidrofílica da celulose provoca aglomeração irreversível durante a secagem. O processo de secagem gera fortes ligações de hidrogênio entre as fibras, o que torna difícil a obtenção de microfibras de celulose finas e uniformes ( $A B E$ et al., 2007). As dimensões, a morfologia e as características das microfibras de celulose obtidas em um processo dependem de alguns fatores como a fonte de celulose e o tipo de tratamento aplicado, conforme estudado por alguns autores (TONOLI et al., 2012).

O elevado consumo de energia de refinação e a obtenção do material na forma de gel com grande porcentagem em água, podendo tornar mais difícil a sua aplicabilidade e funcionalização, conforme são apontadas por alguns autores como desvantagens do processo mecânico de desfibrilação (VARTIAINEN et al., 2011; SPENCE et al., 2011).

\subsubsection{Processo de oxidação mediada TEMPO}

Atualmente, o pré-tratamento mais frequentemente usado é a oxidação mediada por TEMPO. De fato, microfibras obtidas por oxidação mediada por TEMPO representam uma categoria inteira de nanoceluloses dignas de consideração, denominando-se CNF (BRODIN et al., 2014; LAVOINE et al., 2012; ISOGAI et al., 2011). 
O processo de oxidação mediada por TEMPO consiste na a oxidação das fibras de celulose através de um sistema reacional constituído por 2,2,6,6tetramethylpiperidine-1-oxyl radical (TEMPO), brometo de sódio ( $\mathrm{NaBr})$ e hipoclorito de sódio $(\mathrm{NaClO})$. O princípio básico deste mecanismo consiste em oxidar de forma altamente seletiva o carbono 6 (C6) dos grupos hidroxilos primários da celulose em meio aquoso introduzindo grupos funcionais carboxílicos e grupos aldeídos com carga iônica. Desta forma são criadas repulsões electroestáticas fortes entre as fibrilas, levando as a se separarem. Caso se verifique uma agitação homogênea do sistema, os grupos aldeídos são completamente oxidados em grupos carboxílicos (SAITO e ISOGAI, 2004).

A oxidação mediada por TEMPO é realizada com pH alcalino de 10 a 11, a temperatura ambiente e pressão atmosférica (ISOGAl et al., 2011; PEREZ et al., 2003). Durante a oxidação catalítica, é adicionado hidróxido de sódio para manter o pH constante em torno de 10. À medida que a reação ocorre, a cor da mistura fica amarelada devido à libertação de cloro livre (BESBES et al., 2011). Quanto ao tempo de reação, Saito e Isogai (2004) testaram de 15 minutos a 24 horas, aplicando $4,84 \mathrm{mmol}$ de $\mathrm{NaClO}$ por grama de celulose. A concentração de grupos aldeídos e carboxílicos vai aumentando ao longo do tempo de reação e, a partir de 4 horas, estas concentrações permanecem quase constantes. Neste estudo, para 2 horas de tempo de reação, obtiveram-se concentrações de $0,7 \mathrm{mmol} / \mathrm{g}$ de celulose de grupos carboxílicos e $0,3 \mathrm{mmol} / \mathrm{g}$ de celulose de aldeídos.

Por outro lado, o processo de oxidação por TEMPO tem aberto um novo campo eficiente de conversão química seletiva de grupos hidroxilo alcoólicos para aldeídos, cetonas e grupos carbóxilo sob condições suaves (BRODIN et al., 2014).

Segundo autores, existem duas características importantes das nanoceluloses obtidas por oxidação TEMPO: podem ser dispersos sem água como fibrilas completamente individuais com larguras homogêneas de 3-4 nm (ISOGAl et al., 2011), e abundantes grupos de carboxilato de sódio estão 
presentes na superfície cristalina da fibrila de celulose ( 1.7 grupos carboxilato $\mathrm{nm}^{-2}$ ), com repulsão eletrostática e/ou comportamento osmótico trabalho efetivo entre as CNF carregadas anionicamente em água (FUKUZUMI et al., 2010).

As propriedades óticas e mecânicas de filmes de nanocellulose são influenciadas pelo grau de polimerização (DP), a cristalinidade e a composição química das pastas de celulose utilizadas (HENRIKSSON et al., 2008). Segundo os mesmos autores, no caso das CNF o comprimento da fibrila pode influenciar as propriedades ópticas, mecânicas e de barreira ao gás. Por outra parte, embora as CNF preparadas a partir de celuloses de madeira tenham larguras quase homogêneas (3-4 nm), os seus comprimentos e distribuições de comprimento podem variar, dependendo das condições de preparação. O comprimento das CNF pode ser controlada pelo $\mathrm{pH}$ do sistema de oxidação mediada TEMPO (SAITO et al., 2009) ou a quantidade de $\mathrm{NaClO}$ adicionado na oxidação mediada TEMPO em água a pH 10 (SHINODA et al., 2012).

Em comparação com o consumo de energia no processo de obtenção de MCF, de um homogeneizador de alta pressão (700-1400 MJ/Kg), o processo com oxidação por TEMPO diminui dramaticamente o consumo para valores inferiores a $7 \mathrm{MJ} / \mathrm{Kg}$ (ISOGAl et al., 2011).

Assim como as MFC, as CNF têm propriedades intrínsecas interessantes que as tornam atraentes para muitas aplicações. Têm uma área específica, uma flexibilidade, uma cristalinidade e uma quantidade elevada de grupos hidroxilo. Todas estas propriedades influenciam as suas interações, quer como uma suspensão no estado líquido, ou como um filme (LAVOINE et al., 2012).

\subsubsection{Aplicações de nanoceluloses na fabricação do papel}

Deve ser lembrado aqui que, como característica marcante dessa área setorial florestal, as novidades tecnológicas são apresentadas e discutidas em Congressos e Conferências em torno de cinco anos antes de publicação em journals. Portanto as referências citadas no presente texto foram 
escolhidas para melhor ilustrar e analisar os resultados do presente trabalho, e não são indicativos da primazia do desenvolvimento dos conceitos.

No início, as aplicações de nanoceluloses na área do papel vinham de duas vertentes, a primeira era a utilização geral do nanomaterial em si como classicamente era procurada: emulsificador, material de recobrimento, filmes, reforço ou tratamento superficial em papel de imprimir e de embalagens, modificador de reologia, e outros. A segunda vinha da idéia decorrente da experiência da utilização de superfinos na formação de papel e de algum modo de diminuir o esforço de energia dos refinadores.

A convergência da utilização direta de nanocelulose na fabricação do papel começa a ganhar impulso a partir de aproximadamente 2012, e com isso, a busca do entendimento para além de uma simples substituição de refino mecânico. Ver Joseleau et al. (2012) a respeito de interação entre finos microfibrilados e as fibras, e Magnusson e Ostlund (2011) sobre as forças interfibras. Na revisão de Bardet e Bras (2013) apresenta-se o uso de nanocelulose (CNF) na adição direta à massa de celulose, o uso como agente de tratamento superficial (barreira por recobrimento ou impregnação ou composto híbrido), o recobrimento puro ou composto com polímero para impressão, a funcionalização para tornar superfície hidrófoba (lembrando que a superfície de nanocelulose é suscetível de reações, apesar de originalmente ser hidrofílica), o uso antibacteriano e a aplicação para aumentar a condutividade elétrica da superfície por composto híbrido com metais. O corpo principal de Bardet e Bras (2013) revê os trabalhos publicados sobre a adição na massa da celulose, através da adição direta na pasta, o uso superficial em papel cartão multicamada, a integração de CNF em química da parte úmida como agentes de retenção e o desenvolvimento de novos materiais híbridos.

Uma pasta celulósica não é composta apenas de fibras "usuais" de celulose, pois contém também seus finos chamados de primários quando vem da polpação, ou secundários quando decorrentes do refino dessas fibras celulósicas. O material decorrente das fibras de celulose é classificado de 
finos, se passarem através de peneira de 100 mesh $(150 \mu \mathrm{m})$, sendo aceitos muitas vezes, de modo mais restritivos, como finos o material que passa em peneira de 200 mesh $(75 \mu \mathrm{m})$. Denominar-se-á de superfinos, no presente texto, ao material que tem dimensão intermediária de espessura entre 10-50 $\mu \mathrm{m}$, porque já houve vários testes industriais de super-refino que não chegam a produzir nanocelulose, e sim, fibras com dimensões menores do que os finos. Ferreira et al. $(1999,2000)$ caracterizaram os finos e fibras de Eucalyptus Globulus de polpação Kraft, em laboratório, não branqueada com $8,1 \%$ de finos (primários) e com 10,1\% de finos totais após refino PFI de 2000 revoluções com aumento substancial das propriedades mecânicas, e chama-se atenção, nas fibras não refinadas com papel manual, o seu índice de tração que passa de 48,0 sem finos, para 70,9 (N.m/g), com adição de finos. Seth (2003) revisita a ideia, medindo várias propriedades da folha manual com ganhos em resistência mecânica, e explicitando a dramática queda em drenabilidade e a mudança nas características correlatas de permeabilidade e opacidade.

Refino é uma das ações consideradas importantes para fabricação de papel (GHAREHKHANI, 2015). Já houve experiência industrial no Brasil da utilização de finos secundários que eram descartados para seu super-refino e adição na massa da fabricação de papel, balanceando sua quantidade em relação à drenabilidade e operabilidade da máquina de papel. Muitos centros de pesquisa estudaram esses microfibrilas e finos, incluindo superfinos como aditivo à massa de celulose, como pode ser visto em Tapaile et al. (2010). Portanto a ideia inicial de uso de microfibrilas de celulose segue analogia com a utilização de finos e superfinos para redução do esforço de refinadores, com entendimento de que as forças de uma rede de fibras se dá pelas ligações de ponte de hidrogênio entre fibras e fibrilas (TAPAILE et al., 2010; RETULAINEN et al.,1993). A adição de 6\% de nanocelulose, a grosso modo, aumenta em torno de $30 \%$ a resistência à tração em papel de gramatura $40 \mathrm{~g} / \mathrm{m}^{2}$, sendo mais significativo em gramatura de $60 \mathrm{~g} / \mathrm{m}^{2}$, na qual a adição de $10 \%$ de nanocelulose aumenta a resistência, aproximadamente, em $70 \%$ (esses percentuais em base do valor inicial da 
resistência sem nanocelulose). Ver as revisões de Brodin et al. (2014) e Hubbe (2014) .

Destaca-se aqui uma novidade a ser explorada: em Hassan et al. (2011) ao adicionar CNF nas fibras aumenta-se a resistência à tração a úmido e a seco, entretanto, resistência ao rasgo e ao estouro diminui. Contudo, com as fibras longas de madeira branqueadas, as resistências ao rasgo e ao estouro também são maiores do que sem a adição de CNF.

Praticamente não se encontra literatura de aplicação de nanocelulose em Kraftliner de fibras de processo Kraft, ou seja, a chamada folha de capa para embalagens, que possuem alto teor de lignina. Em cartões multicamadas, Mörseburg e Chinga-Carrasco (2009) aplicaram uma camada simples no interior da folha de papel-cartão de fibras de pastas mecânicas como reforço às propriedades mecânicas.

As questões abertas ainda são: se o uso de nanocelulose em substituição de aditivos químicos e colagem interna traz reais vantagens ao reuso das fibras, e como em Kangas et al. (2004), se a quantificação industrial das vantagens de redução de energia de refino de pastas mecânicas são efetivas.

Já é conhecida a questão de retenção pobre de nanocelulose na matériaprima fibrosa, ainda que os autores não citem esse problema diretamente (não é ainda seguramente mensurável), e o presente trabalho analisará essa questão de modo inferencial em resultados das propriedades. Outra questão trata de alto custo de nanocelulose comparado a agentes químicos e aditivos os quais se deseja substituir na formação da folha. Como os seus custos estão se alterando continuamente, em lugar de citar no escopo da revisão bibliográfica, será tratada diretamente na análise de custos junto com citação dos autores que abordam esse assunto. Já foi colocado aqui que a obtenção de nanocelulose e da sua fonte de matéria-prima tem influência direta na sua caracterização. Como serragem de eucalipto é um resíduo de pouco valor econômico, Vallejos et al. (2016) investigam a deslignificação e branqueamento desse material para produção de nanocelulose por oxidação mediada TEMPO e homogeneização mecânica e seu uso como substitutivo de 
refinação de fibras para fabricação de papel, obtendo equivalente ao refino de 1600 revoluções com a adição de $9 \%$ deste CNF. Deve-se lembrar aqui que os gráficos de propriedades mecânicas em relação ao revolução PFI não são lineares, e que esse resultado é apenas indicativo. Ainda na linha de busca de matérias primas de menor custo, agregando valor ao produzir nanocelulose, tem-se o trabalho de Adel et al. (2016) investigando diferentes resíduos agrícolas e os trabalhos Leão et al. (2012), Jonoobi et al. (2012) e Gottumukkala et al. (2016) utilizando lama primária de fábrica de papel. Portanto a utilização de finos primários descartados na linha de branqueamento da fábrica de celulose, no presente trabalho, não é nova (lembrar o uso de finos primários para super-refino citado anteriormente), porém, tem atrativo de agregar alto valor a esses resíduos.

O conceito de extensibilidade do papel, geralmente observada como resistência à tração, resistência ao rasgo e outras propriedades em pesquisa de papel usual de imprimir, torna-se importante como um conceito composto para papéis para embalagem. Vishtal e Retulainen (2014) fizeram uma extensa revisão sobre o assunto, que envolve um conjunto maior de características de papel incluindo a estrutura da fibra, ligações interfibras e a estrutura da rede de fibras. Portanto o conceito de RBA (relative bonded area) é importante para a extensibilidade. A nanocelulose, por características já citadas, é diferente de fibras usuais, e possuem extensibilidade significativamente maior. $\mathrm{Na}$ adição de $10 \%$ de nanocelulose tem-se demonstrado um aumento geral de extensibilidade (em termos de tensão de ruptura) de 5\%. Entretanto deve-se usar essa revisão como um guia, sempre lembrando de que extensibilidade é um conceito ainda difuso devido a múltiplos fatores que o envolvem, e por isso as teorias clássicas de módulo de elasticidade deve ser revisitadas antes de buscar explicações testemunhais de experimentos (ver CUBEROS-MARTINEZ ,2005)

A terceira questão é a dificuldade industrial perante a drenabilidade, com consequência direta em seção de prensas e de secagem. Apesar dos diferentes dados da literatura, ressalva-se aqui que é muito diferente o uso de nanocelulose na faixa de $1-3 \%$ com a literatura com exagero de $6-10 \%$ 
para substituição de aditivos. As considerações sobre a química da parte úmida da fabricação do papel, antes de iniciar a formação de folhas nas telas, devem incluir os aspectos de retenção e drenagem, cuja boa revisão é apresentada por Blanco et al. (2001) e por Hubbe (2007). As diferentes teorias e o papel de polieletrólitos e polímeros são exaustivamente descritas em Silva (2010) e o uso de nanopartículas de sílica coloidal (não é nanocelulose) como agente da química da parte úmida na fabricação de papel é abordada em Fernandes (2013). Um bom trabalho sobre poliacrilamidas catiônicas pode ser visto em Antunes et al. (2008). Os finos e a celulose microfibrilada (MFC ou MCF) possuem algumas matérias em comum, mas as propriedades físicas de MFC diferem muito das fibras tradicionais de celulose, e a alta capacidade de retenção da água em MFC pode ter efeito não desejado na fabricação de papel. O entendimento da interação coloidal e ligação mecânica entre as fibrilas, seja de MFC ou da superfície das fibras tradicionais, junto com este efeito de ligações diretas de pontes de hidrogênio na drenagem em formação de folhas deve ser buscada desde Campbell (1959). Uma excelente revisão é apresentada no trabalho de Taipale et al.(2010), que descrevem diferentes finos e nanoceluloses com aditivos químicos, amidos e polímeros catiônicos (devido a natureza aniônica da alta superfície do nanocelulose), e polieletrólitos na folha manual de fibra branqueada de pinus. A drenagem em laboratório medido em SR (Schopper Riegler) ou CSF (Canadian Standard Freeness) é obviamente diferente de drenagem a vácuo em formação de folhas, mas é um bom indicativo e mostra o aumento do tempo de drenagem em relação à adição de nanoceluloses. Neste trabalho, pouco notado pelos leitores, é que os experimentos vão ao extremo de $10 \%$ de MFC, mas os dois pontos entre 0 a $2 \%$ mostram-se "constantes" que não é ruído experimental. Outro aspecto que não é muito notado nesse trabalho (que é muito utilizado pelos outros autores), é que o aumento do teor de nanocelulose aumenta as propriedades mecânicas, coerente com todos os trabalhos publicados, mas quando se trata de forças que não dependem de estiramento da fibra individual (que tem resistência sempre maior do que resistência intertravada 
de fibras), um aumento excessivo de nanocelulose dificultará contato interfibras, o que se evidencia por queda de propriedades de rasgo, estouro e "scott bond". Portanto tem-se em torno de 3-4\% como máximo e depois a propriedade de "scott bond" começa a decair. Tudo isso será evidenciado na discussão do presente trabalho. Permeabilidade ao ar em papel reflete não apenas a porosidade, mas também a complexidade do modo como as fibras se conformaram. Portanto, diferente de finos, o pequeno percentual de nanocelulose não deve alterar porosidade por preenchimento de vazios, e sim refletir a mudança na rede de fibras. O trabalho de Tapaile et al.(2010), por descrever gráfico da relação de permeabilidade em relação à drenagem, não esclarece completamente o papel da adição de nanocelulose. Deve-se lembrar de que aditivos químicos, agentes de retenção e de drenagem, sem existência de finos, resulta em comportamento totalmente diferente em relação a pasta com finos, até mesmo porque não tem sentido ter aditivos sem os finos. Entretanto, é interessante notar em Taipale et al. (2010), que CPAM (poliacrilamida catiônica) forma uma camada viscoelástica grossa na presença de nanocelulose, e também PDADMAC (cloreto de polidialilmetilamonio) pode consumir cargas de nanocelulose (ou pode-se interpretar que nanocelulose pode consumir cargas de PDADMAC), e raciocínio similar pode ser feito em relação ao amido catiônico. Assim, descrevem-se os resultados de TAPAILE et al.(2010), para além das conclusões dos autores e das citações comuns na literatura, analisando diretamente as informações deste trabalho, que tem um grande mérito de não ser apenas uma publicação testemunhal de resultados medidos, e se preocupa em interpretar com mecanismos.

A tendência de floculação de nanofibrilas deve ser maior do que as fibras clássicas, mas devido a sua hidrofilicidade que produz gel a $1 \%$ puro em água, é um dos aspectos não abordados pelos pesquisadores de fabricação de papel, mesmo porque a observação direta dentro da massa diluída é muito difícil. Sim et al. (2015) apresenta um trabalho inovador a esse respeito, cujos experimentos deverão ser melhor analisados sob a luz de teorias de floculação e aglomeração coloidal correntes na área de celulose e papel, 
pois sabe-se que aqui existem várias implicações importantes porém muito acima do presente trabalho.

Agentes de colagem (de resistência a úmido e a seco), comuns na fabricação de papel, apresentam grandes aumentos de resultados na presença de nanocelulose (AHOLA et al., 2008; MISSOUM et al., 2013). Ao verificar os resultados experimentais desses trabalhos, a ação mais provável é que nanocelulose melhora a dispersão e a distribuição desses agentes na formação de folhas. Portanto conclusões simples de que adição de nanocelulose em aditivos de colagem interna melhoram, ou pioram, a resistência devem ser vistas com cuidado. Como se quantifica a influência de nanocelulose junto com vários aditivos na fabricação do papel em termos de resistência a desaguamento (drenagem) e de permeabilidade, encontrasse em um trabalho muito original de Li et al. (2016), ainda que a formação de folha manual puramente de MFC e de adição de químicos sejam de forma usual.

Como a formação de papel com cargas minerais não faz parte do presente escopo, apesar da sua importância para fabricação de papel, podem ser vistos em Bardet e Bras (2013), Nunes et al. (2015), e Nunes et al. (2016) .

Quando usadas em massa, a aplicação das nanoceluloses no papel também podem modificar as propriedades de retenção e drenagem, a densidade e a permeabilidade ao ar. Pesquisadores observaram que 0 uso de nanoceluloses obtidas com o processo TEMPO aumentavam a retenção e drenagem e o numero de enlaces de hidrogênio entre as fibras, aumentando portanto a resistência à tração (FUKUZUMl et al., 2013; ÄMMÄLÄ et al., 2013; MANNINEN et al., 2011). Sehaqui et al. (2013) adicionaram 10\% CNF em celulose de fibra longa, encontrando um incremento da densidade de 30-50\%. Taipale et al. (2010) relataram que a permeabilidade ao ar cai rapidamente de $1450 \mathrm{~mL} / \mathrm{min}$ para $450 \mathrm{~mL} / \mathrm{min}$ quando se aumenta o teor de CNF de $0 \%$ a $30 \%$.

Vários estudos de investigação concluíram que as CNF funcionam bem como um aditivo de resistência em seco. Também tem sido mostrado que as 
CNF podem ser utilizadas para ligar mais partículas de carga no papel sem reduzir as propriedades de resistência. Na literatura, quantidades que variam de $2,5 \%$ a $10 \%$ de CNF por folha têm sido utilizadas. Lin et al. (2007) prémisturaram cargas minerais com finos e posteriormente adicionaram a mistura no acabamento do papel e descobriram que resistência mecânica e as propriedades ópticas da folha de papel melhoraram.

O uso de microfibras em revestimentos de papel começou apenas há alguns anos, com o objetivo de investigar a influência de uma camada de microfibras nas propriedades de superfície de papel. O método escolhido para a preparação das nanoceluloses, bem como a formulação de revestimento e a espessura de revestimento, são fatores importantes para a compreensão dos efeitos das nanoceluloses em revestimentos de papel diferentes. Em algumas aplicações uma camada fina é suficiente para alterar as propriedades de superfície, enquanto em outros casos a aplicação de barreira uma camada mais espessa pode ser necessária para obter uma camada contínua de microfibras (BRODIN et al., 2014).

As MCF e as CNF, quando aplicadas como revestimento no papel, podem modificar as propriedades óticas, a reologia, a maciez superficial, a resistência mecânica, a printabilidade (imprimibilidade) e atuar como barreira para líquidos e gases. Comparando revestimentos de caulim com revestimentos de CNF, Hamada et al. (2010) concluíram que os revestimentos de CNF tiveram uma baixa absorção da tinta e uma densidade de impressão alta em relação aos de caulim.

Destaca-se que é importante aperfeiçoar o uso de MCF e CNF. Na literatura pesquisada, não existe uma otimização do uso de MCF ou CNF. A maioria dos trabalhos utiliza um percentual de nanoceluloses muito alto em relação ao percentual de fibras (pastas de celulose tem uma relação de custo/preço baixo), tal como folhas de laboratório contendo $4 \%$ de CNF (ERIKSEN et al., 2008), ou 10\% (SEHAQUI et al., 2013) e entre 7\% e 10\%, (MANNINEN et al., 2011). 
Ahola et al. (2008) relataram que o maior valor de resistência à tração foi obtido quando as CNF foram depositados na parede da fibra como uma dupla camada ligada por uma camada de amido catiônico. Outros (HII et al., 2012; TAIPALE et al., 2010) se auxiliam de um agente de retenção, para depositar as MCF ou as CNF na fibra, antes da formação da folha.

Embora na literatura (HII et al., 2012; TAIPALE et al., 2010; ERIKSEN et al., 2008) exista adição de nanoceluloses junto com agentes de retenção, cargas ou amidos, não tem sido claramente avaliados os mecanismos de agregação das nanoceluloses no papel.

Os "patchs" ou "mosaicos" são regiões de carga oposta à superfície da partícula, criada através da absorção de polímeros. Segundo Rojas e Hubbe (2004), este tipo de interação ocorre quando são usados polieletrólitos com baixos pesos moleculares. A interação tem que ser ainda melhor avaliada.

De forma geral, as nanoceluloses são utilizadas junto com fibras branqueadas na formação de papéis (MANNINEN et al., 2008; SEHAQUI et al., 2013). No entanto, é importante avaliar interação das nanoceluloses com a lignina, isto é, o uso de nanoceluloses em pastas que não estejam branqueadas.

Outro parâmetro a ser avaliado é o custo das nanoceluloses em relação ao papel. Segundo Brodin et al. (2014) o papel tem custos baixo em relação ao alto volume de produção. O custo das nanoceluloses, ainda não totalmente comercializadas, irá determinar se os resultados promissores a respeito do uso em aplicações de papel podem ser colocados em prática. Os desafios neste caso são os custos totais de produção de microfibras, incluindo a energia, os custos de produtos químicos e investimentos em equipamentos de produção, além de investimentos na máquina de papel. Ao mesmo tempo, a operabilidade é um desafio, além da necessidade de produção de CNF e MCF perto da máquina de papel porque, caso contrário, envolveria a questão logística de transporte de 99\% de água. Também, pelo menos em alguns casos, um aumento dos custos de secagem na máquina de papel 
também deve ser esperado com a adição de nanocelulose no papel, o que ainda não foi estudado.

Outro parâmetro a avaliar é a qualidade das CNF ou das MCF, a fim de otimizar os custos Os pré-tratamentos enzimáticos reduzem a demanda de energia na produção CNF, mas isso também requer um processo mais complexo, com maior investimento. Portanto, não é certo que um prétratamento irá reduzir os custos totais.

Finalmente, a seleção da qualidade das nanoceluloses para a aplicação a que se destina também é importante, a fim de aperfeiçoar a função e a produção dos custos com base em requisitos de produto. Portanto, ainda que os pré-tratamentos consigam diminuir o custo de produção, o processo de obtenção também é mais complexo que por simples energia mecânica, e ainda tem que avaliar se os custos são suficientes como para que seja rentável o seu uso no papel.

\subsection{Métodos de caracterização}

Definir as propriedades papeleiras e seus métodos de caracterização do papel formado tem a finalidade de caracterizar qualidade das fibras celulósicas. As propriedades, de uma maneira geral, fazem parte do processo de melhoria de produtos, processos e de rentabilidade para toda indústria, incluindo a de celulose e papel. Por isso, faz-se importante o conhecimento das propriedades físicas da pasta celulósica e do papel, e a sua dependência com as variáveis do processo.

Como comentado anteriormente, o papel é formado por uma rede de fibras individuais, aditivos e outros componentes. Assim as propriedades do papel dependem fortemente das propriedades das fibras individuais e do seu conjunto, caracterizadas geralmente por ensaios físicos, mecânicos, ópticos e de superfície. Técnicas estatísticas, tais como, a metodologia de superfície de resposta são úteis para a otimização de processos. O planejamento composto central é um tipo de experimento para a construção de um modelo de $2^{\text {a }}$ ordem para a variável resposta, sem a necessidade de usar um 
modelo com três níveis completo. Além disso, é uma composição entre o planejamento fatorial $2^{k}$ (com um ou mais pontos centrais) e uma parte axial. Por outra parte, os mecanismos de retenção e drenagem hão de ser avaliados. Técnicas de microscopia, tais como microscopia eletrônica de varredura, ajudam a conhecer os mecanismos de adesão de partículas.

\subsubsection{Retenção e drenagem}

Segundo Silva (2010) o termo retenção refere-se à fixação das partículas de pequenas dimensões, presentes na suspensão aquosa, em elementos com dimensões maiores como as fibras ou seus fragmentos (finos). $\mathrm{Na}$ fabricação de papel, geralmente, a retenção ocorre de duas maneiras: mecanicamente (a manta da folha na máquina de papel funciona como um filtro para retenção de elementos de pequenas dimensões) e quimicamente (fixação de partículas através de agentes químicos de retenção).

Por outra parte, as fibras apresentam uma tendência natural a agregar-se mecanicamente numa suspensão aquosa. Segundo Swanson(2003) e Hubbe (2007) as fibras celulósicas em suspensão aquosa estão sujeitas a dois efeitos de retenção ou floculação: mecânicos, quando as fibras se agregam naturalmente; e química, o agregado de fibras se forma a partir de um polieletrólito.

Os polieletrólitos ou polímeros sintéticos são agentes floculantes que têm como principal objetivo fixar as partículas de pequenas dimensões nas fibras por absorção Os mecanismos envolvidos na retenção e agregação de partículas por polímeros são denominados como "patch" ou mosaicos (TRIPATTHARANAN, 2004; HUBBE, 2007; SILVA, 2010).

Segundo Aloi e Trksak (1998), Blanco et al. (2001) e Rojas e Hubbe (2005) "patchs" ou mosaicos são regiões da carga oposta à da superfície da partícula, criada através da absorção de polímeros. Khosravani et al. (2010) concluíram que amidos de alta massa molecular incrementa a retenção de partículas. Segundo Hubbe (2007) a adição de polieletrólitos de alta massa molecular 
tende a aumentar a ligação entre as fibrilas de uma fibra celulósica com as partículas pequenas (Figura 5.1).

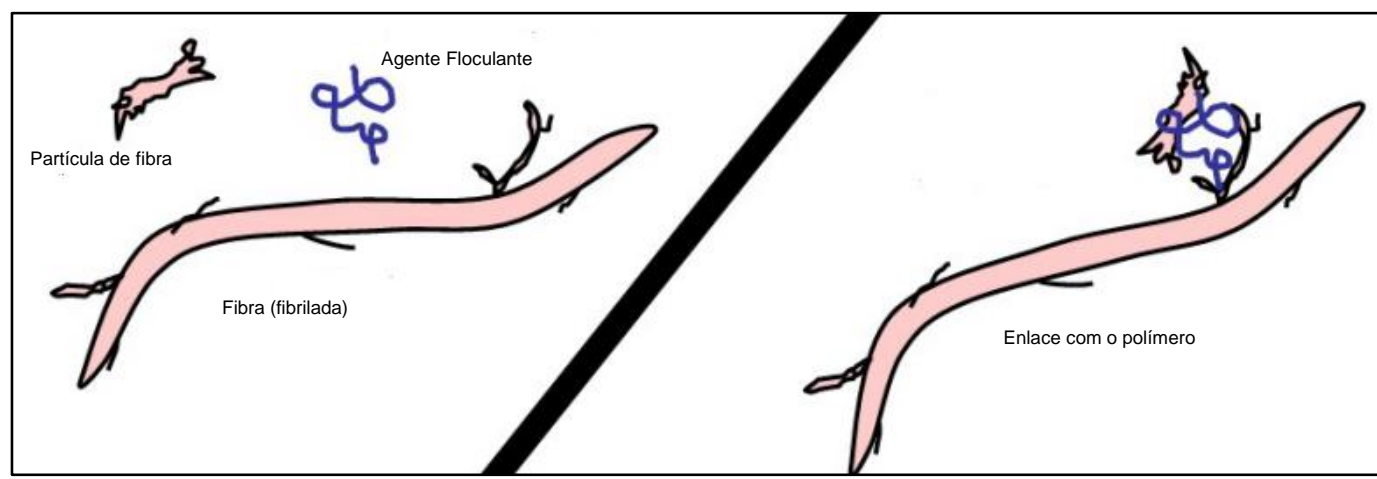

Figura 5.1: Ligação de partícula na fibra por ação de polímero Fonte: Hubbe (2007)

Nas fibras celulósicas, o polieletrólito é absorvido em regiões planas, na superfície da fibra ou partes de fibras (finos e partículas pequenas de fibras). A existência de regiões com cargas positivas e negativas na superfície da fibra, ou de seus fragmentos promove as forças atrativas entre os substratos, as fibras e as partículas (Figura 5.2).

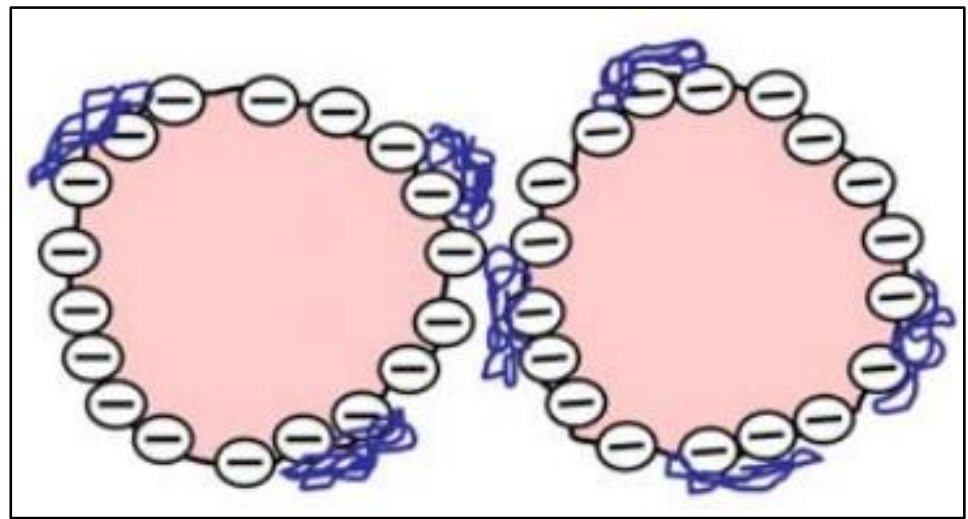

Figura 5.2: Esquema ilustrando o modelo patch Fonte: Hubbe (2007)

Baseando-se no exposto na literatura, Hubbe (2007) descreve que, em teoria, a presença de "manchas" de carga oposta (positiva e negativa) sobre as superfícies dentro uma suspensão promove a aglomeração dentro da suspensão. 


\section{MATERIAIS E MÉTODOS}

\subsection{Material}

Para realização deste trabalho foram utilizados diferentes materiais, listados a seguir:

a) Pasta Kraft de Eucalipto Branqueada (PKEB), com alvura comercial (90\% ISO), coletada em fábrica de celulose após a etapa de branqueamento. A pasta foi fornecida por um fabricante de celulose na região de Três Lagoas, Mato Grosso do Sul;

b) Pasta Kraft Pré-branqueada de Eucalipto (PKEP), deslignificada com oxigênio $\left(\mathrm{O}_{2}\right)$, coletada em fábrica de celulose na saída da torre de pasta marrom. A pasta foi fornecida pelo mesmo fabricante de pasta Kraft de eucalipto;

c) Pasta Kraft de Pinus Marrom (PKPM), coletada em fábrica de celulose e papel após refinador industrial. Essa pasta celulósica não passou por deslignificação por oxigênio. A pasta foi fornecida por um fabricante de celulose e papel na região de Chapecó, Santa Catarina;

d) Papel Kraftliner industrial (100\% fibra virgem) de $70 \mathrm{~g} / \mathrm{m}^{2}$, obtido após máquina de papel. O papel foi subministrado pelo mesmo fornecedor de pasta Kraft de pinus marrom;

e) Rejeito dos "cleaners" da terceira linha da depuração. O rejeito é composto na sua maioria por finos primários da pasta branqueada de eucalipto e foi subministrado pelo fornecedor de pasta Kraft de eucalipto;

f) Amido catiônico - foi utilizado amido catiônico de milho usado na fabricação de papel Kraftliner industrial. Este produto foi subministrado pelo fornecedor de pasta Kraft de pinus marrom;

g) Cola sintética - foi utilizada cola sintética de breu usada na fabricação de papel Kraftliner industrial. Este produto foi subministrado pelo fornecedor de pasta Kraft de pinus marrom; 
h) Polímero catiônico de retenção de alto peso molecular (poliacrilamida catiônica) - foi utilizado como agente de retenção, o mesmo usado na indústria celulósica para retenção, drenagem e recuperação de fibras. Este produto foi subministrado pelo fornecedor de pasta Kraft de pinus marrom.

\subsection{Métodos}

\subsubsection{Obtenção de Nanoceluloses}

\subsubsection{Obtenção dos finos}

O rejeito dos cleaners foi submetido a tratamento de separação por densidade, lavagem e peneirado em equipamento Somerville para eliminação dos possíveis contaminantes e minerais e obtenção dos finos de celulose branqueados. Antes e depois do tratamento de separação por densidade, lavagem e peneiramento, foi determinado o teor de cinzas (norma Papel, cartão, pastas celulósicas e madeira - Determinação do resíduo (cinza) após a incineração a $525^{\circ} \mathrm{C}$ ) para conhecer a eficiência da limpeza. Na Tabela 6.1 apresenta o teor de cinzas antes e depois do tratamento.

Tabela 6.1: Teor de cinzas antes e depois do tratamento de lavagem

\begin{tabular}{cc}
\hline $\begin{array}{c}\text { Teor de Cinzas (\%) antes } \\
\text { do Tratamento }\end{array}$ & $\begin{array}{c}\text { Teor de Cinzas (\%) } \\
\text { após do Tratamento }\end{array}$ \\
\hline $22,38(0,71)$ & $3,34(0,05)$ \\
\hline Nota: O número entre parênteses refere-se ao desvio padrão do ensaio.
\end{tabular}

\subsubsection{Processo Masuko}

No laboratório de Pasta e Papel da Universidade Federal de Paraná (UFPr), os finos e a pasta Kraft de eucalipto branqueada (PKEB) foram dispersos em água destilada utilizando um pulper, durante o tempo de vinte minutos, para obtenção de uma suspensão de fibras homogeneizadas. Assim obteve-se duas microfibrilas de celulose, uma a partir dos finos primários (resíduos do 
branqueamento) e outra da polpa de celulose de eucalipto branqueada, utilizando-se no presente trabalho dos finos.

Os finos, e a pasta PKEB, formando uma suspensão juntamente com água destilada na concentração $1 \%$ base massa seca, tal como em Iwamoto et al. (2008), seguiram para o processo mecânico de desfibrilação no moinho Super Masscolloider Masuko Sangyo (MKCA6-3; Masuko Sangyo Co., Ltd.) para obtenção de microfibrilas de celulose mediante 10 passagens pelo moinho.

O moinho desfibrilador Super Masscolloider Masuko Sangyo consiste em duas pedras de desfibrilação com um diâmetro de 150 mm, sendo a pedra inferior rotativa e a superior estacionária. A região periférica da pedra é bastante plana e a parte interior cônica apresenta sulcos.

O ajuste das pedras de desfibrilação por meio da distância entre elas permite o controle do tamanho das partículas produzidas. A aproximação das pedras foi feita com o equipamento desligado e sem a suspensão de fibras. Contudo, é importante ressaltar que quando o moinho desfibrilador for ligado, com as pedras próximas, que este deve estar carregado de material. A presença da suspensão celulósica no moinho desfibrilador permite a "lubrificação" das pedras evitando desta forma o chamado "vazio de moagem" que pode causar o desgaste das mesmas podendo resultar numa futura contaminação do material.

A separação das microfibras da parede das fibras ocorre no moinho desfibrilador por meio de um processo mecânico de compressão e forças de cisalhamento geradas quando a pasta passa através da abertura entre as pedras. A distância entre os discos foi ajustada em cerca de 0,1 mm (NAKAGAITO e YANO, 2005; STELTE e SANADI, 2009).

Além da regulagem das distâncias entre as mós, o moinho desfibrilador também permite o controle da frequência que pode ser de até 3000 rpm. Nesta pesquisa adotou-se a frequência de 1500 rpm conforme sugerido por outros autores (IWAMOTO et al., 2008; IFUKU et al., 2009; IFUKU et al., 2010). 
Após 10 passagens pelo moinho desfibrilador a suspensão celulósica transforma-se numa suspensão estabilizada, adquirindo aspecto de gel similar ao observado por Besbes et al. (2011), sendo chamada neste trabalho MCF ou MFC.

\subsubsection{Processo de oxidação mediada TEMPO}

Neste estudo foram utilizadas nancoceluloses (CNF), provenientes dos finos, também foram obtidas CNF a partir da pasta PKEB e de uma pasta celulósica comercial proveniente de Portugal. Os finos primários (resíduos do branqueamento) e a pasta celulósica branqueada de eucalipto forma enviadas à Universidade de Coimbra, Portugal, onde foram produzidas as nanoceluloses.

Os finos de celulose e as pastas de celulose, foram pré-tratados com $\mathrm{NaClO}$ e mediadas catalíticamente por TEMPO (2,2,6-6-tetrametilpiperdina-1-1oxyl) com adição de $\mathrm{NaBr}$, de acordo com o método descrito na literatura (SAITO et al., 2007). No experimento, $15 \mathrm{~g}$ dos finos e das pastas de celulose, separadamente, foram dispersos em água destilada contendo TEMPO $(0,016 \mathrm{~g}$ por $\mathrm{g}$ de finos) e $\mathrm{NaBr}(0,1 \mathrm{~g}$ por $\mathrm{g}$ de finos) em consistência de $1 \%$. A mistura foi agitada durante 15 minutos a temperatura ambiente, a fim de assegurar uma boa dispersão de todas as substâncias. Posteriormente, uma solução de $15 \%$ de hipoclorito de sódio foi adicionada gota a gota à suspensão. $\mathrm{O}$ volume de $\mathrm{NaClO}$ foi calculado para ter $4 \mathrm{mmol}$ por grama de celulose. $\mathrm{O}$ pH foi mantido a 10 pela adição de gotas de uma solução 0,5 M de $\mathrm{NaOH}$. A oxidação foi considerada concluída quando o $\mathrm{pH}$ foi estabilizado a 10.

Os finos e as pastas, separadamente, foram oxidados, e depois, filtrado e lavado com água destilada. Os finos e as pastas foram posteriormente passados através de um homogeneizador (GEA Niro Soavi Panda Plus 2000, Itália) uma vez a 500 bar e posteriormente outra vez a 1000 bar. A homogeneização foi realizada a temperatura ambiente com os finos e as pastas a uma consistência de 1,5\%. Assim foram obtidas três nanoceluloses, uma a partir dos finos primários da área de branqueamento, 
outra da pasta celulósica de eucalipto branqueada do Brasil, e terceira das fibras de celulose branqueada de Eucalyptus globulus de Portugal. Utilizouse aqui a nanocelulose produzida com os finos.

As nanoceluloses (CNF) produzidas foram recebidas junto com os dados das suas principais propriedades: concentração do "gel" (dispersão) ou consistência; rendimento (ou porcentagem de nanofibras de celulose após centrifugação); quantidade de grupos carboxílicos (por titulação); carga superficial (potencial zeta); e tamanho equivalente (LDS Laser Diffraction Spectrometry). As propriedades das CNF obtidas com os finos mostram-se na Tabela 6.2 (no apêndice D mostram-se todas as propriedades das CNF obtidas).

Tabela 6.2: Propriedades das CNF

\begin{tabular}{|c|c|c|c|c|c|c|}
\hline \multirow[b]{2}{*}{$\begin{array}{c}\text { Consistência } \\
(\%)\end{array}$} & \multicolumn{2}{|c|}{ Rendimento (\%) } & \multirow{2}{*}{$\begin{array}{l}\text { Concentração } \\
\text { de grupos } \\
\text { carboxílicos }^{(\mathrm{c})} \\
(\mathrm{mmol} / \mathrm{g})\end{array}$} & \multicolumn{3}{|c|}{$\begin{array}{l}\text { Distribução de tamanho de } \\
\text { partículas (LDS), nm }\end{array}$} \\
\hline & produção $^{(a)}$ & nanofibrilação $^{(b)}$ & & $\begin{array}{l}\text { Potencial zeta, } \\
\text { mV }\end{array}$ & $\begin{array}{l}10 \\
\text { Pico }\end{array}$ & $\begin{array}{l}20 \\
\text { Pico }\end{array}$ \\
\hline 1,11 & 78,7 & 86 & 1,56 & -82 & 1751 & 42,23 \\
\hline $\begin{array}{l}\text { (a) Porcent } \\
\text { (b) Porcent } \\
\text { (c) ver Gan }\end{array}$ & $\begin{array}{l}\text { gem de gel obtid } \\
\text { gem do gel nano } \\
\text { elas et al. ( } 2015\end{array}$ & $\begin{array}{l}\text { ós obtenção CNF } \\
\text { ado }\end{array}$ & & & & \\
\hline
\end{tabular}

\subsubsection{Determinação do teor seco das nanoceluloses}

O teor seco de uma amostra é a relação entre a massa de uma amostra após ser submetida a secagem até massa constante e sua massa no momento da toma de amostra.

A determinação do teor seco realiza-se segundo a equação:

$T S=\frac{P_{S}}{P_{h}} \times 100$

Onde:

TS, teor seco da amostra, em porcentagem;

$P_{\mathrm{s}}$, massa seca da amostra, em gramas;

$P_{h}$, massa úmida da amostra, em gramas.

Na Tabela 6.3 apresenta-se o teor seco das MCF e das CNF. 
Tabela 6.3: Teor Seco das MCF e CNF

\begin{tabular}{cc}
\hline Material & Teor Seco (\%) \\
\hline MCF & $1,10(0,01)$ \\
CNF & $1,15(0,00)$ \\
\hline
\end{tabular}

Nota: O número entre parênteses refere-se ao desvio padrão do ensaio.

\subsubsection{Caracterização das pastas celulósicas}

Foi determinado o teor seco de todas as segundo norma ABNT NBR NMISO 287: Papel e cartão - Determinação do teor de umidade de um lote Método por secagem em estufa (ISO 287: 2009, IDT).

\subsubsection{Número Kappa}

A determinação do Número Kappa realiza-se segundo a norma TAPPI T236 om-85: Kappa number of Pulp.

O número Kappa é um ensaio utilizado para medir o grau de deslignificação de uma pasta celulósica, é uma medida indireta do teor de lignina da pasta. No entanto o número Kappa não representa a quantidade de lignina residual na pasta devido a existência de ácidos hexerunônicos.

$\mathrm{Na}$ Tabela 6.4 apresenta o número Kappa para as pastas utilizadas no estudo:

Tabela 6.4: Número Kappa das pastas celulósicas

\begin{tabular}{lcc}
\hline \multicolumn{1}{c}{ Amostra } & Nomenclatura & Número Kappa \\
\hline $\begin{array}{l}\text { Pasta Branqueada de } \\
\text { eucalipto }\end{array}$ & PKEB & --- (a) \\
$\begin{array}{l}\text { Pasta Pré-branqueada de } \\
\text { eucalipto }\end{array}$ & PKEP & 9,21 \\
Pasta marrom de pinus & PKPM & 36,1 \\
\hline
\end{tabular}

(a) Trata-se de pasta branqueada final, portanto não se mede número Kappa 


\subsubsection{Viscosidade Intrínseca}

A determinação da viscosidade intrínseca das pastas realiza-se segundo norma ABNT NBR ISO 5351: Pastas celulósicas - Determinação do número de viscosidade-limite em solução de etilenodiamina cúprica (CED).

A viscosidade intrínseca relaciona o comprimento das cadeias de celulose existentes na polpa e seu grau de polimerização, é um indicador de degradação dos carboidratos das pastas celulósicas.

$\mathrm{Na}$ Tabela 6.5 são apresentados os valores obtidos para as pastas utilizadas no estudo.

Tabela 6.5: Viscosidade Intrínseca das pastas celulósicas

\begin{tabular}{lcc}
\hline \multicolumn{1}{c}{ Amostra } & Nomenclatura & $\begin{array}{c}\text { Viscosidade } \\
\text { Intrínseca }\left(\mathbf{d m}^{\mathbf{3}} \mathbf{k g}\right)\end{array}$ \\
\hline $\begin{array}{l}\text { Pasta Branqueada de } \\
\text { eucalipto } \\
\begin{array}{l}\text { Pasta Pré-branqueada de } \\
\text { eucalipto }\end{array}\end{array}$ & PKEB & 786 \\
Pasta marrom de pinus & PKEP & 845 \\
\hline
\end{tabular}

\subsubsection{Morfologia da fibra}

As caracterizações morfológicas das pastas de celulose foram efetuadas em um analisador de morfologia de laboratório Fiber Tester segundo método Tappi T 271 (Fiber length of pulp and paper by automated optical analyzer using polarized light).

A morfologia das fibras foi determinada nas pastas de celulose de eucaliptos e pinus. As dimensões de fibras avaliadas foram: comprimento, largura, diâmetro do lúmen e espessura da parede. As relações determinadas entre dimensões de fibras foram: a fração da parede da fibra (definida como peso por unidade de comprimento da fibra) e diâmetro de lúmen. As outras determinações analisadas foram o "coarseness" (definida como peso por unidade de comprimento da fibra), a população fibrosa, deformação das 
fibras ("curl" ou curvatura da fibra e "kink" ou torção da fibra) e teor de finos (fibras compreendidas entre $0,1 \mathrm{~mm}$ e $0,2 \mathrm{~mm}$ ).

No Fiber Tester foram determinados uma quantidade maior de dados morfológicos, não listadas no presente texto: comprimento da fibra, largura da fibra, índice de curvatura da fibra (curl), índice de torção da fibra (kink), comprimento do vaso, largura do vaso (para todas estas análises obteve-se resultados aritmético, ponderado por comprimento e ponderado por peso), teor de finos (aritmético e ponderado por comprimento), população fibrosa (milhões grama), "coarseness" das fibras e número de vasos (por metro de fibra ou por peso de fibra).

\subsubsection{Refinação}

O procedimento para a refinação de pastas celulósicas em laboratório, em moinho PFI é normalizada pela norma ABNT NBR ISO 5264-2: 2012: Pasta celulósica - Refinação em laboratório - Método PFI. O procedimento utiliza $(30,0 \pm 0,5) \mathrm{g}$ de pasta celulósica seca em estufa em uma consistência de $10 \%$ para cada ensaio no moinho PFI.

Para poder conhecer o desempenho das pastas celulósicas, é elaborada a curva de refino, ou seja, a refinação a diferentes revoluções no moinho PFI e a determinação do seu teste de drenagem (SR - grau Schopper-Riegler). $O$ PFI consiste basicamente de um rotor, uma panela de refinação com tampa e um dispositivo para exercer uma pressão durante a refinação. O rotor e a panela giram sobre um eixo vertical.

O rotor possui 33 barras, cada uma com $50 \mathrm{~mm}$ de comprimento e $5 \mathrm{~mm}$ de largura. As barras são dispostas radialmente, paralelas ao eixo do rotor. 0 diâmetro do rotor é de $200 \mathrm{~mm}$, medido através das barras, e a profundidade das cavidades entre as barras é de $30 \mathrm{~mm}$. O rotor é movido por um motor de aproximadamente $1 \mathrm{~kW}$ e a frequência rotacional é de $(24,3 \pm 0,5) \mathrm{s}^{-1}$, quando nenhuma pressão é aplicada. O número de revoluções do rotor é indicado pelo contador. 
A panela de refinação, com um diâmetro interno de $250 \mathrm{~mm}$, é movida por um motor de $400 \mathrm{~W}$. A velocidade da panela deve ser ajustada para que a diferença na velocidade periférica de $(6,0 \pm 0,2) \mathrm{m} / \mathrm{s}$ entre os elementos de refinação seja obtida, com carga zero e uma frequência rotacional do rotor de $(24,3 \pm 0,5) \mathrm{s}^{-1}$.

A pressão de refinação é obtida por uma carga aplicada por uma alavanca, que pressiona o rotor contra a parede da panela. $O$ refinador possui um parafuso usado para regular a distância entre o rotor e a panela quando se afia e condiciona o moinho.

Neste estudo foram realizados três pontos de refinação, ponto 1: $0 \mathrm{PFI}$ (sem refinar); ponto 2: $2000 \mathrm{PFI}$ e ponto 3: $4000 \mathrm{PFI}$. Para cada um dos pontos foi medido o grau de refinação (SR) e formadas folhas, das que foram analisadas as propriedades físico-mecânicas e a opacidade.

\subsubsection{Formação de folhas}

A formação de folhas de laboratório segue o procedimento descrito na norma ABNT NBR ISO 5269-1: 2006: Pastas celulósicas - Preparação de folhas em laboratório para ensaios físicos. Parte 1: Método do formador de folhas convencional.

Para poder medir as propriedades físico-mecânicas e óticas das pastas (PKEB, PKEP e PKPM) folhas de $90 \mathrm{~g} / \mathrm{m}^{2}$ foram formadas em laboratório, empregando um formador da Mecatécnica.

Previamente à formação de folhas, 20 gramas de pasta seca foram desagregadas, 20 minutos para pastas não refinadas e 5 minutos para pastas refinadas. Posteriormente, as pastas foram diluídas em água até obter uma fração de massa (consistência) entre 0,2 \% e 0,5\%. Partindo da diluição da pasta, obtém-se uma folha quadrada de ensaio em uma tela metálica mediante sucção. A folha é submetida duas vezes à pressão de $410 \mathrm{kPa}$ e seca em ambiente condicionado e em contato com uma chapa de secagem, na qual se adere a modo de não encolher. 


\subsubsection{Determinação do $\mathrm{pH}$}

Para conhecer se houve mudanças significativas no $\mathrm{pH}$ da água durante a formação de folhas, determinou-se o valor do $\mathrm{pH}$ da água do formador e da água do purificador (água usada na desagregação das pastas) ao longo do dia em um pHmetro digital Metrohm 827 pH LAB.

$\mathrm{Na}$ Tabela 6.6 apresenta-se $\mathrm{o} \mathrm{pH}$ da água do purificador e do formador durante a manha e a tarde.

Tabela 6.6: $\mathrm{pH}$ do formador e do purificador ao longo do dia

\begin{tabular}{ccc}
\hline Período do dia & $\begin{array}{c}\text { pH - água do } \\
\text { formador }\end{array}$ & $\begin{array}{c}\text { pH - água do } \\
\text { purificador }\end{array}$ \\
\hline Manhã & $7,5(0,4)$ & $8,2(0,3)$ \\
Tarde & $7,8(0,2)$ & $8,6(0,2)$ \\
\hline
\end{tabular}

Nota: O número entre parênteses refere-se ao desvio padrão do ensaio.

\subsubsection{Determinação da condutividade}

Para conhecer se houve mudanças significativas na condutividade da água durante a formação de folhas, determinou-se a condutividade da água do formador e da água do purificador (água usada na desagregação das pastas) ao longo do dia com um condutivímetro digital Mettler Toledo modelo 8603. Na Tabela 6.7 apresenta-se a condutividade da água do purificador e do formador durante a manha e a tarde.

Tabela 6.7: Condutividade do formador e do purificador ao longo do dia

\begin{tabular}{ccc}
\hline $\begin{array}{c}\text { Período do } \\
\text { dia }\end{array}$ & $\begin{array}{c}\text { Condutividade }(\boldsymbol{\mu s} / \mathbf{c m}) \text { - água } \\
\text { do formador }\end{array}$ & $\begin{array}{c}\text { Condutividade }(\boldsymbol{\mu s} / \mathbf{c m})-\text { água do } \\
\text { purificador }\end{array}$ \\
\hline Manhã & $238,5(8,9)$ & $1,4(0,4)$ \\
Tarde & $235,5(6,2)$ & $1,1(0,1)$ \\
\hline
\end{tabular}




\subsubsection{Determinação da resistência à drenagem}

A determinação da resistência à drenagem se realiza segundo a norma ABNT NBR 14031:2004: Pasta celulósica - Determinação da resistência a drenagem pelo aparelho Schopper-Riegler.

A resistência à drenagem é a propriedade da pasta celulósica, em suspensão aquosa, de resistir à separação da água, quando drenada por gravidade e determinada sob as condições normalizadas. $O$ resultado obtido na determinação da resistência à drenagem pelo aparelho Schopper-Riegler fornece uma indicação da velocidade com que uma suspensão aquosa diluída de pasta celulósica pode ser desaguada. É relacionado com as condições da superfície e do inchamento das fibras, sendo um índice prático do grau de tratamento mecânico dado à pasta celulósica. A determinação da drenagem foi realizada em um aparelho Schopper-Riegler Regmed.

A determinação é feita através da drenagem de um determinado volume de suspensão aquosa, através de uma camada de fibras formada durante o ensaio e depositada sobre uma tela, para um funil que possui dois orifícios. $\mathrm{O}$ volume drenado e o escoado através do orifício lateral é medido em um cilindro graduado em números Schopper-Riegler (SR). Nesta escala, um volume de $1000 \mathrm{~mL}$ corresponde a $0 \mathrm{SR}$ e $0 \mathrm{~mL}$ corresponde a $100 \mathrm{SR}$.

\subsubsection{Preparação das amostras - Refinador Valley}

A refinação Valley realiza-se em um refinador de laboratório Valley, marca Voith Allis segundo a norma ABNT NBR 14347:1999 Versão Corrigida: 2013: Pasta celulósica - Refinação em laboratório - Método Valley.

Para poder ter a maior reprodutividade de ensaios em todas as pastas celulósicas, procedeu-se à refinação das pastas de eucalipto (PKEB e PKEP), em refinador Valley até atingir o mesmo grau de refino que a pasta de pinus.

O Refinador Valley consiste em uma reprodução do chamado moinho "holandesa", ambos utilizados em tempos muito antigos, mas de contribuição 
muito importante. Tratava-se de um vaso aberto recirculante, com um rotor fixado horizontalmente e separado do estator.

No ensaio, 360 gramas secas de pasta celulósica com consistência de $1,57 \%$ são refinadas em uma carga de refinação de $(54 \pm 1) \mathrm{N}$ (Newton) entre as barras do rotor e a placa de apoio do refinador Valley. Durante a refinação, amostras de pasta celulósica são retiradas em intervalos determinados e determinado seu grau Schopper-Riegler até atingir o grau de refinação procurado.

\subsubsection{Formação de folhas com nanoceluloses}

Os principais constituintes de um papel Kraftlinner industrial são as fibras de celulose. Igualmente importantes são aditivos usados tais como os agentes de retenção e colagem. Assim, neste trabalho, foram utilizadas pasta Kraft de eucalipto e/ou de pinus, CNF, MFC, amido catiônico e cola de breu como agentes de colagem e agente floculante (poliacrilamida cationica) como agente de retenção. Deste modo, previamente à formação de folhas foi necessário preparar também todos estes constituintes conforme se descreve em detalhe a continuação.

\subsubsection{Preparação do amido e a cola:}

A preparação da mistura de (amido + cola) consiste em adicionar 20 gramas de amido em $800 \mathrm{ml}$ de água em um béquer de vidro com uma barra magnética dentro, previamente tarados. Posteriormente, com ajuda de uma chapa de agitação magnética com aquecimento inicia-se a agitação até dissolver completamente o amido. Em seguida se inicia o aquecimento até $80^{\circ} \mathrm{C}$ junto com agitação. Uma vez atingida à temperatura de $80^{\circ} \mathrm{C}$ se transferem 2 gramas de cola e se mantém a temperatura constante durante 5 minutos. Após o tempo, se diminui a temperatura até $60^{\circ} \mathrm{C}$ mantendo-a constante. 
6.2.6.2 Formação de folhas com adição de nanoceluloses na massa

Na metodologia desenvolvida para produção de folhas constituídas por fibras e nanoceluloses (CNF ou MCF), é realizada também a adição de (amido + cola) e agente floculante (polímero de retenção) para reproduzir em laboratório a formação de papel Krafliner. A formação das folhas a nível laboratorial cumpriu os requisitos da norma ABNT NBR ISO 5269-1: 2006 : Pastas celulósicas - Preparação de folhas em laboratório para ensaios físicos. Parte 1: Método do formador de folhas convencional formando-se folhas quadradas de $90 \mathrm{~g} / \mathrm{m}^{2}$.

A soma em pesos com todos os constituintes da folha deve ser 90 gramas por metro quadrado. Para conhecer a quantidade a ser adicionada de cada um deles, começou-se por fixar a percentagem de nanoceluloses que se pretendia adicionar (esta percentagem é relativa ao peso total da folha). Da quantidade restante, fixou-se a percentagem amido, cola e polímero a serem adicionados e determinou-se a quantidade da fibra correspondente.

Desta forma, ao variar a quantidade de nanoceluloses ou de (amido + cola), a porcentagem de polímero foi mantido constante. $O$ polímero, quando adicionado à massa, sempre é em proporção de 0,02\% em relação a 90 $\mathrm{g} / \mathrm{m}^{2}$, e (amido + cola) cuja quantidade adicionada varia em relação a cada experimento, tem a sua proporção entre si de (amido/cola=1/0,12). Tanto as nanoceluloses como o amido, a cola e o polímero são adicionados em percentagem do peso total da folha.

Para formar folhas proporcionais à gramatura $90 \mathrm{~g} / \mathrm{m}^{2}$, em laboratório, uma suspensão de fibras determinada é colocada em um béquer de laboratório, junto com uma barra magnética. A solução é agitada mediante agitador magnético e adicionam-se (se for o caso) a proporção desejada de nanoceluloses, mantendo-se em contato a suspensão durante 5 minutos. Após dois minutos, adicionam-se a quantidade requerida da mistura de (amido + cola), mantendo em contato com as fibras durante 3 minutos. Finalmente, nos últimos segundos adiciona-se (se for o caso) o agente floculante ou polímero de retenção. 


\subsubsection{Formação de folhas em dupla camada}

Visando desenvolver novos métodos de produção de papéis com CNF e MFC, neste estudo realizou-se a formação de folhas de laboratório denominada aqui simplesmente de técnica laboratorial de "dupla camada", na pasta Kraft de eucalipto pré-branqueada (PKEP). Entretanto, não é realmente uma dupla camada no sentido de multiply.

$\mathrm{Na}$ metodologia desenvolvida deposita-se (quando ainda úmidas), entre duas camadas de papel de laboratório de $45 \mathrm{~g} / \mathrm{m}^{2}$ realizadas conforme 0 item 6.2.6.2 (Formação de folhas com adição de nanoceluloses na massa) com $0,5 \%$ de amido, $0,06 \%$ de cola e $0,02 \%$ de polímero de retenção, uma fina camada de $1 \%$ de CNF ou MFC por aspersão (spray). Fizeram-se sete folhas de laboratório com adição de CNF e MFC. Ressalta-se que todas as formações cumprem os requisitos da norma ABNT NBR ISO 5269-1: 2006: Pastas celulósicas - Preparação de folhas em laboratório para ensaios físicos. Parte 1: Método do formador de folhas convencional formando-se folhas quadradas de $90 \mathrm{~g} / \mathrm{m}^{2}$.

Para depositar as CNF ou MFC entre camadas, $1 \%$ de nanocelulose é disperso em $100 \mathrm{~mL}$ de água destilada e depositada mediante aspersão acima de uma das caras do papel. Posteriormente, as folhas são unidas e somente depois são prensadas e secas conforme norma ABNT citada. A soma de ambas as folhas deve ter $90 \mathrm{~g} / \mathrm{m}^{2}$.

\subsubsection{Ensaios preliminares (prospecção de experimentos)}

Inicialmente foram testadas diferentes condições de formação de folhas com CNF, amido, cola e polímero analisando-se as práticas do fabricante de papel Kraftliner e a literatura. Na Tabela 6.8 apresentam-se as porcentagens de CNF, amido, cola e polímero usada em cada tipo de formação assim como a pasta celulósica usada. 
Tabela 6.8: Diferentes tipos de pastas de celulose usadas em cada condição

\begin{tabular}{|c|c|c|c|c|c|c|}
\hline Condição & $\begin{array}{c}\text { Pastas } \\
\text { Celulósicas }\end{array}$ & $\begin{array}{l}\text { CNF } \\
(\%)\end{array}$ & $\begin{array}{l}\% \text { amido } \\
+\% \text { cola }\end{array}$ & $\begin{array}{c}\% \\
\text { polímero } \\
\text { (5 s tempo } \\
\text { contato) }\end{array}$ & $\begin{array}{c}\text { \% polímero } \\
\text { ( } 30 \text { s de } \\
\text { tempo de } \\
\text { contato) }\end{array}$ & $\begin{array}{c}\text { \% polímero } \\
\text { diluído (5 s } \\
\text { de tempo de } \\
\text { contato) }\end{array}$ \\
\hline & PKEB & - & - & - & - & - \\
\hline \multirow[t]{3}{*}{0} & - & - & - & - & - & - \\
\hline & - & - & - & - & - & - \\
\hline & - & - & - & - & - & - \\
\hline \multirow[t]{3}{*}{1} & PKEP & $1 \%$ & - & - & - & - \\
\hline & PKPM & $1 \%$ & - & - & - & - \\
\hline & PKEB & $2 \%$ & - & - & - & - \\
\hline \multirow[t]{3}{*}{2} & PKEP & $2 \%$ & - & - & - & - \\
\hline & PKPM & $2 \%$ & - & - & - & - \\
\hline & - & - & - & - & - & - \\
\hline \multirow[t]{3}{*}{3} & PKEP & $3 \%$ & - & - & - & - \\
\hline & PKPM & $3 \%$ & - & - & - & - \\
\hline & PKEB & - & $1+0,12$ & 0,02 & - & - \\
\hline \multirow[t]{3}{*}{4} & PKEP & - & $1+0,12$ & 0,02 & - & - \\
\hline & PKPM & - & $1+0,12$ & 0,02 & - & - \\
\hline & - & - & - & - & - & - \\
\hline \multirow[t]{3}{*}{5} & PKEP & - & $0,5+0,06$ & 0,02 & - & - \\
\hline & PKPM & - & $0,5+0,06$ & 0,02 & - & - \\
\hline & PKEB & - & $1+0,12$ & - & 0,02 & - \\
\hline \multirow[t]{3}{*}{6} & - & - & $1+0,12$ & - & - & - \\
\hline & - & - & $1+0,12$ & - & - & - \\
\hline & PKEB & $2 \%$ & $1+0,12$ & 0,02 & - & - \\
\hline \multirow[t]{3}{*}{7} & PKEP & $2 \%$ & $1+0,12$ & 0,02 & - & - \\
\hline & PKPM & $2 \%$ & $1+0,12$ & 0,02 & - & - \\
\hline & PKEB & $2 \%$ & $1+0,12$ & - & 0,02 & - \\
\hline \multirow[t]{3}{*}{8} & - & - & - & - & - & - \\
\hline & - & - & - & - & - & - \\
\hline & PKEB & $2 \%$ & $1 \%+0,12$ & - & - & 0,02 \\
\hline \multirow[t]{3}{*}{9} & - & - & - & - & - & - \\
\hline & - & - & - & - & - & - \\
\hline & - & - & - & - & - & - \\
\hline \multirow[t]{3}{*}{10} & PKEP & $2 \%$ & $0,5+0,06$ & 0,02 & - & - \\
\hline & PKPM & $2 \%$ & $0,5+0,06$ & 0,02 & - & - \\
\hline & PKEB & $2 \%$ & $1+0,12$ & - & - & - \\
\hline \multirow[t]{2}{*}{11} & - & - & - & - & - & - \\
\hline & - & - & - & - & - & - \\
\hline
\end{tabular}


Cabe destacar que inicialmente foi formada somente uma folha de laboratório, com pasta branqueada, nas condições 0, 2, 4, 6, 7, 8, 9 e 10 para escolher as melhores condições de formação. Nas condições restantes, assim como com nas pastas PKEP e PKPM, fizeram-se 7 folhas de laboratório em cada condição. Ressalta-se que todas as formações cumprem os requisitos da norma ABNT NBR ISO 5269-1: 2006: Pastas celulósicas - Preparação de folhas em laboratório para ensaios físicos. Parte 1: Método do formador de folhas convencional formando-se folhas quadradas com uma massa total de $90 \mathrm{~g} / \mathrm{m}^{2}$.

\subsubsection{Planejamento de experimentos composto central $2^{2}$}

Basicamente, estes experimentos são compostos de um ponto central, que será executado com réplicas e dará uma estimativa interna do erro puro e de pontos axiais, que irão determinar os termos quadráticos. Esses experimentos são de dois níveis totais ou fatoriais fracionados que foram aumentados com um pequeno número de tratamentos, cuidadosamente escolhidos, para permitir a estimativa do modelo de superfície de resposta de segunda ordem.

Neste estudo optou-se por realizar dois experimentos fatoriais $2^{2}$ compostos centrais (um com CNF e outro com MFC) apenas na pasta PKEP (objeto de estudo), onde variou-se a quantidade a adicionar, em folhas de laboratório, de nanoceluloses e de (amido + cola), mantendo constante o polímero (agente floculante). As variáveis resposta foram os índices de tração, rasgo e estouro. Na Figura 6.1 apresentam-se os planejamentos de experimentos realizados $[20]$.

Os pontos da estrela (star) estão localizados a uma distância $\alpha=$ V2 à partir do centro. O ponto em branco representa a referência (folhas de laboratório

\footnotetext{
20 O "ponto em branco" não é necessário para superfície de resposta e análise estatística, mas importante como referência entendimento de pesquisa. Igualmente, foi do interesse do presente trabalho obter experimentos adicionais nos quatro vértices do quadrado da Figura 6.1 (não indicados como pontos nessa figura), que foram utilizados pelo Minitab ${ }^{\circledR} 17$, mesmo que a configuração star de delineamento não exija esses pontos.
} 
formadas somente com fibras). Análise estatística foi realizada com software Minitab ${ }^{\circledR} 17$.

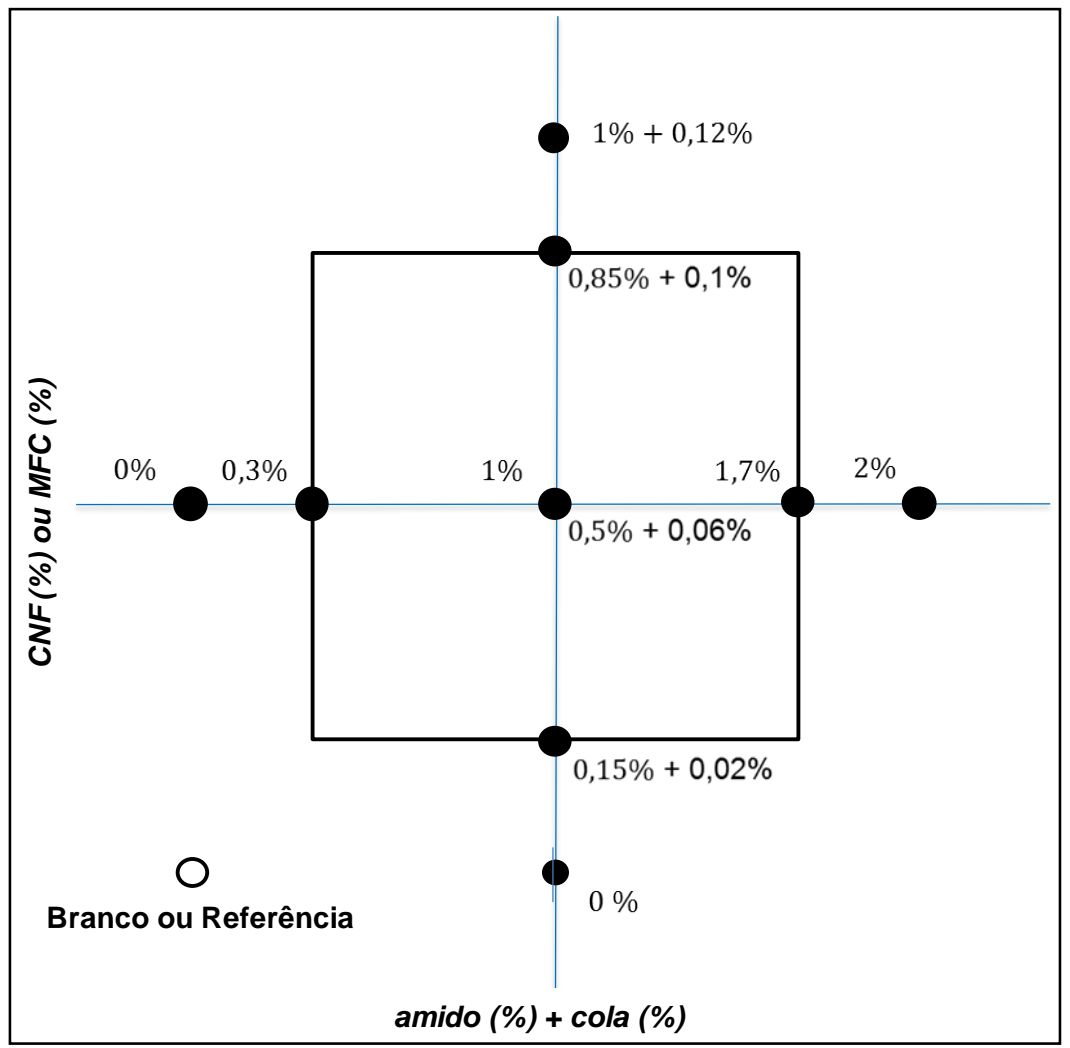

Figura 6.1: Planejamentos compostos centrais do estudo

\subsubsection{Drenabilidade}

Tal como foi explicado anteriormente, a drenabilidade é um fator muito importante na indústria do papel, uma vez que está fortemente relacionado com a velocidade de perda de água da folha em formação, especialmente nas fases de drenagem e prensagem. Assim, é importante estudar de que forma a drenabilidade é afetada pela adição das nanoceluloses.

No ensaio, duas gramas secas da pasta PKEP foram colocadas em suspensão aquosa com agitação constante e adicionadas $1 \%$ de nanoceluloses em proporção à fibra. A solução foi agitada durante 5 minutos e posteriormente diluída até 1 litro com água destilada. Posteriormente foi determinado o grau Schopper-Riegler. 


\subsubsection{Ensaios para caracterização das pastas/folhas formadas}

O papel Kraftliner industrial e as folhas de laboratório realizadas foram acondicionados conforme norma ABNT NBR NM ISO 187:2000 Versão Corrigida: 2000: Papel, cartão e pastas celulósicas - Atmosfera normalizada para condicionamento e ensaio e procedimento de controle da atmosfera e condicionamento das amostras, a $(23 \pm 1)^{\circ} \mathrm{C} \mathrm{e}(50 \pm 2)^{\circ}$ de umidade relativa, previamente e durante a realização dos ensaios que se executam sobre elas.

\subsubsection{Determinação da gramatura}

A determinação da gramatura se realiza segundo a norma ABNT NBR NM ISO 536:2000 Versão corrigida: 2002: Papel e cartão - Determinação da gramatura.

A gramatura pode ser descrita como a massa do papel expressa em gramas por metro quadrado. A medição é feita em corpos-de-prova, através da pesagem dos mesmos em balança. Os ensaios foram realizados em uma Balança analítica AB 204-S/FACT Mettler.

\subsubsection{Resistência ao ar Gurley}

A determinação da resistência ao ar Gurley realiza-se em um Densímetro Gurley Regmed PGH segundo a norma ABNT NBR NM ISO 5636-5: 2006: Papel e cartão - Determinação da permeância e resistência ao ar (faixa média). Parte 5: Método Gurley.

O termo porosidade utiliza-se para descrever o volume total de poros e capilares de uma folha de papel. Por não ser a porosidade uma variável fácil de medir, emprega-se a permeância ao ar, a qual esta relacionada com a porosidade.

A permeância ao ar é definida como a propriedade que permite a passagem de ar através do papel sob uma diferença de pressão e tempo, expressandose em micrômetros por pascal por segundo ( $\mu \mathrm{m} / \mathrm{Pa}$.s). É uma propriedade estrutural do papel que depende do número, tamanho, formato e distribuição 
dos poros no papel. A permeância ao ar não deve confundida com a porosidade, que é a razão entre o volume de poros e o volume total do papel.

Como estas unidades resultam-se complexas, na indústria do papel é habitual usar como resultado o valor obtido pelo equipamento. Neste estudo utiliza-se para medir a permeância ao ar a resistência ao ar Gurley, definida como o tempo que tardam em passar $100 \mathrm{~cm}^{3}$ de ar através de uma folha de papel, expressado em segundos.

O ensaio baseia-se em fixar uma folha de papel entre as mordaças de um equipamento Gurley. Uma vez fixada a folha, faz-se descer o ar que contém um cilindro vertical através do papel. O tempo que tarda em descer o cilindro é a resistência ao ar Gurley.

\subsubsection{Determinação da resistência à tração e índice de tração}

A determinação da resistência à tração e índice de tração realiza-se segundo a norma ABNT NBR NM ISO 1924-2: 2012: Papel e cartão Determinação das propriedades de tração. Parte 2: Método da velocidade constante de alongamento $(20 \mathrm{~mm} / \mathrm{min})$.

Para a determinação da resistência à tração, o corpo-de-prova de largura e comprimento especificados é fixado através de duas garras. Estas garras são então separadas para exercer um esforço de tração. Um mecanismo indica a força de tração quando da ruptura do corpo-de-prova. O aparelho empregado para a medição da resistência à tração é o dinamômetro DL-500 EMIC, e os valores reportados referem-se à carga de ruptura dividida pela largura do corpo-de-prova.

A resistência à tração pode ser expressa também pelo comprimento de autoruptura (CAR), definido como o comprimento de uma tira de papel que, quando suspensa, rompe-se sob seu próprio peso. A resistência à tração também pode ser expressa pelo índice de tração, que é dado pelo quociente entre a resistência e a gramatura. 
O índice de tração em $\mathrm{Nm} / \mathrm{g}$ é dado pela expressão:

$$
I t=\frac{R_{t} \times 1000}{G \times L_{c}}
$$

Onde:

$R_{t}$, resistência à tração em $\mathrm{kN} / \mathrm{m}$;

$G$, gramatura da amostra em $\mathrm{g} / \mathrm{m}^{2}$;

Lc, largura do corpo-de-prova em $\mathrm{mm}$.

A resistência à tração é controlada por fatores como:

- Resistência individual das fibras;

- Comprimento médio das fibras;

- Formação e estrutura da folha.

6.2.7.4 Determinação da resistência ao rasgo e índice de rasgo

A determinação da resistência a rasgo e índice de rasgo realiza-se segundo a norma ABNT NBR NM ISO 2471:2001: Papel - Determinação da resistência ao rasgo - Método Elmendorf.

A resistência ao rasgo é um ensaio muito utilizado na avaliação das propriedades mecânicas do papel. $O$ ensaio de rasgo mais comumente encontrado é o ensaio tipo Elmendorf. Este ensaio mede o trabalho mecânico necessário para se prolongar um rasgo, já iniciado por uma faca adaptada ao aparelho Elmendorf, em um corpo-de-prova de dimensões conhecidas. A resistência ao rasgo é dada pelo trabalho despendido nesta operação.

O índice de rasgo é dado pelo quociente entre a resistência ao rasgo e a gramatura e é dado em $\mathrm{mN} \cdot \mathrm{m}^{2} / \mathrm{g}$ (no Sistema Internacional).

Entre os fatores que podem influenciar a resistência ao rasgo tem-se o comprimento das fibras, a ligação entre elas e a integridade das mesmas. 
6.2.7.5 Determinação da resistência ao estouro e índice de estouro

A determinação da resistência a estouro e índice de estouro realiza-se segundo a norma ABNT NBR NM ISO 2758:2007: Papel - Determinação da resistência ao arrebentamento.

O ensaio de resistência ao estouro ou arrebentamento é um dos mais antigos ensaios utilizados pela indústria, e é relativamente simples e baixo custo.

A resistência ao estouro é definida como a pressão necessária para produzir o estouro do material, ao se aplicar uma pressão uniformemente crescente, transmitida por um diafragma elástico, de área circular. O corpo de prova, submetido ao ensaio, é preso rigidamente entre dois anéis concêntricos. A pressão limite no momento da ruptura é a chamada de resistência ao estouro ou resistência a arrebentamento. O aparelho empregado para medição de resistência a estouro é o Mullentester - Regmed MTA-2000P.

O índice de estouro é dado pelo quociente entre a resistência ao arrebentamento e a gramatura e é dado no Sistema Internacional por $\mathrm{kPa} \cdot \mathrm{m}^{2} / \mathrm{g}$.

A resistência ao estouro é controlada por diversos fatores como:

- A resistência ao estouro aumenta com crescente refinação, para decrescer com 0 excesso desta. A baixa resistência ao arrebentamento pode ser atribuída, em parte, ao corte das fibras;

- As variações na gramatura e na espessura causam comumente variação na resistência ao estouro;

- O uso de aditivos e colas afeta consideravelmente o comportamento do papel e o resultado do ensaio.

\subsubsection{Opacidade}

A determinação da opacidade realiza-se segundo a norma ABNT NBR NM ISO 2471:2001: Papel e cartão - Determinação da opacidade (fundo de papel) - Método da refletância difusa. Realiza-se em um Espectrofotômetro Datacolor Elrepho 450. 
A opacidade é a propriedade relacionada com a quantidade de luz transmitida através do papel. Um papel perfeitamente opaco é aquele que impede por completo a passagem de luz visível. Define-se como a relação, expressada em porcentagem, entre o fator de refletância luminosa de uma folha só $\left(R_{0}\right)$ com uma cavidade preta como fundo, e o fator de refletância luminoso intrínseco $\left(R_{\infty}\right)$ de um conjunto de folhas de uma espessura tal que seja opaco.

A opacidade do papel é influenciada pela gramatura, uso de alvejantes, refinação, uso de cargas e tipos de fibras.

\subsubsection{Microscopia eletrônica de varredura (SEM)}

A microscopia eletrônica (SEM Scanning Electron Microscopy) de varredura foi utilizada para caracterizar a superfície dos papéis escolhidos (Tabela 6.8). Para a análise das amostras no equipamento utilizado, é necessário um recobrimento das amostras com uma fina camada de ouro para evitar o acúmulo de cargas elétricas na superfície que poderiam afetar o sinal.

Tabela 6.8: Amostras selecionadas para realização de SEM

\begin{tabular}{lccc}
\hline \multicolumn{1}{c}{ Aditivos } & PKEB & PKEP & PKPM \\
\hline Branco ou referência & & $\mathrm{X}$ & \\
$0,6 \%$ amido, $0,06 \%$ cola, $0,02 \%$ polímero de retenção & & $\mathrm{X}$ & \\
$1 \% \mathrm{CNF}$ & $\mathrm{X}$ & $\mathrm{X}$ \\
$2 \% \mathrm{CNF}$ & & $\mathrm{X}$ & $\mathrm{X}$ \\
$1 \% \mathrm{MCF}$ & & & \\
Ponto central do planejamento com CNF & $\mathrm{X}$ & & \\
Ponto central do planejamento com MCF & $\mathrm{X}$ & & \\
\hline
\end{tabular}

O equipamento utilizado foi um microscópio eletrônico de varredura de emissão de campo (FEG-SEM), marca FEI modelo QUANTA 400, com detector INCA PentaFETx3 do Laboratório de Corrosão e Proteção do IPT. 
Das folhas de cada amostra foram extraídos corpos de prova quadrados com cerca de $1 \mathrm{~cm}$ de lado. Os corpos de prova foram introduzidos na câmara do equipamento simultaneamente.

Os ensaios de SEM foram realizados nos pontos centrais do planejamento de experimentos com a PKEP, em papéis com $1 \%$ de nanoceluloses de CNF e de MCF, com o ponto de referência do delineamento de experimentos e em um papel com $1 \%$ de amido, $0,12 \%$ de cola e $0,02 \%$ de agente floculante (polímero de retenção). Na PKEB e na PKPM foi realizado SEM em uma folha com $2 \%$ de CNF e na PKPM foi realizado em folhas com $1 \%$ de nanoceluloses CNF e MCF, e $2 \%$ de CNF. 


\section{RESULTADOS E DISCUSSÃO}

\subsection{Caracterização das matérias primas}

Para atingir os objetivos propostos, inicialmente as pastas de celulose foram submetidas à refinação a 2000 e 4000 revoluções em PFI. Foi determinado o grau de refino das pastas celulósicas, antes e depois da refinação, e com as folhas obtidas foram determinadas as propriedades físico-mecânicas, a resistência ao ar Gurley e a opacidade das pastas celulósicas.

\subsubsection{Propriedades físico-mecânicas}

$\mathrm{Na}$ Figura 7.1 apresentam-se as curvas de refino[21] da Pasta Kraft de Eucalipto Branqueada (PKEB), da Pasta Kraft de Eucalipto Pré-branqueada (PKEP) e da Pasta Kraft de Pinus Marrom sem nenhum branqueamento (PKPM).

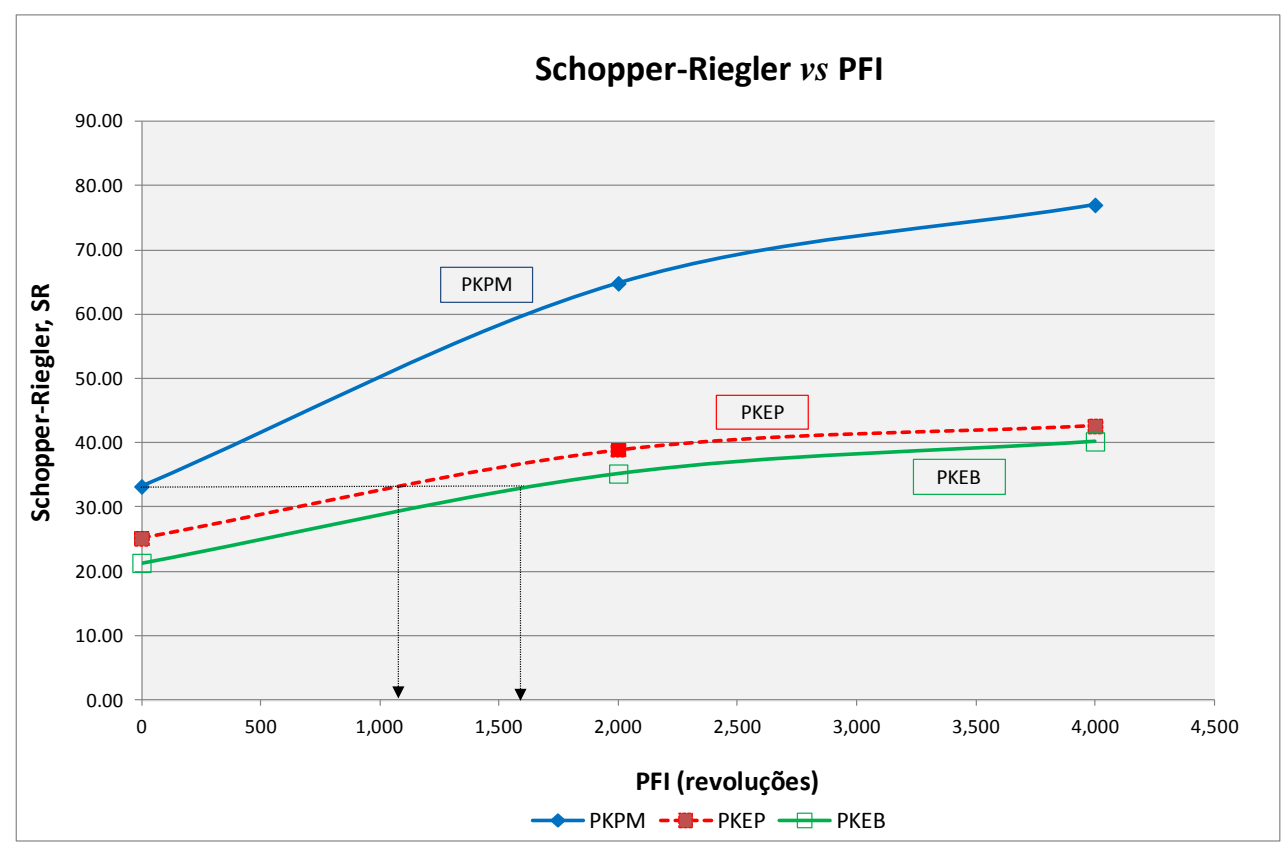

Figura 7.1: Curvas de refinação das pastas celulósicas

\footnotetext{
${ }^{21}$ Curvas de refinação $\quad \mathrm{y}_{\text {PKPM }}=-2.10^{-6} \mathrm{x}^{2}+0.0206 \mathrm{x}+33.2 ; \mathrm{y}_{\mathrm{PKEP}}=-1.10^{-6} \mathrm{x}^{2}+0.0093 \mathrm{x}+25.125$; $\mathrm{y}_{\text {PKEB }}=-1.10^{-6} \mathrm{x}^{2}+0.0092 \mathrm{x}+21.3$.
} 
Na Figura 7.1 observa-se que:

- As pastas PKEB e PKEP apresentam curvas de refinação semelhantes entre si. No entanto, a curva da pasta pré-branqueada (PKEP), tem um grau de refinação, relativamente, maior à da pasta branqueada. $O$ maior grau Schopper-Riegler da PKEP respeito PKEB, provavelmente se deve a fato de que é uma pasta não branqueada, ou seja, menos degradada;

- A curva da PKPM tem um grau Schopper inicial maior que as pastas de eucalipto (PKEB e PKEP), devido ao fato de ser coletada na saída de um refinador industrial e por ser fibra longa. Por outra parte, a medida que a pasta é refinada desenvolve mais o grau de refinação que as pastas PKEB e PKEP.

Nas Figuras 7.2, 7.3 e 7.4 apresentam-se as curvas dos índices de resistência à tração, resistência a rasgo e resistência a estouro com respeito ao grau de refino (Shopper-Riegler, SR) para as pastas de eucalipto branqueada (PKEB) e pré-branqueada (PKEP) e para a pasta marrom de pinus (PKPM). 


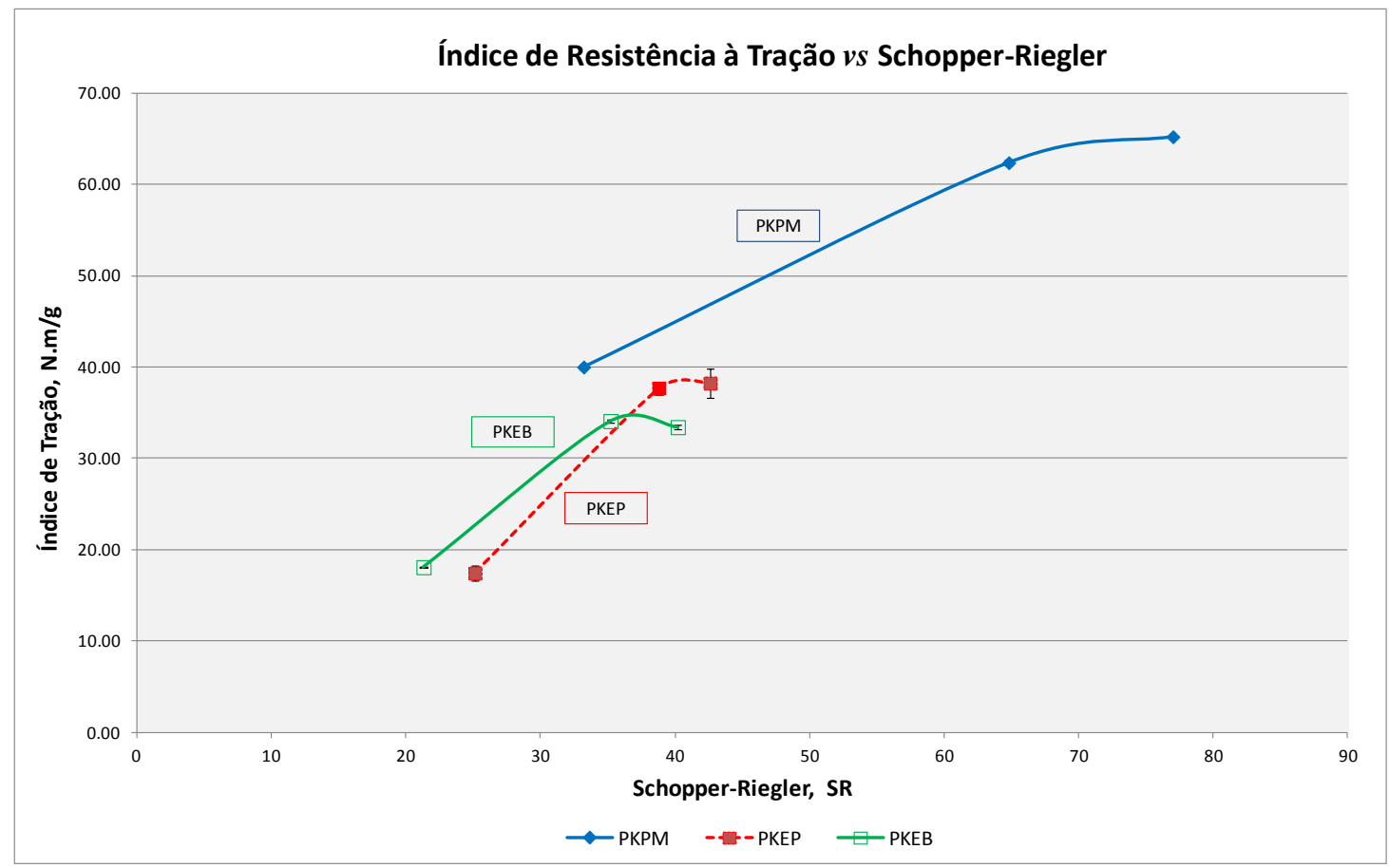

Figura 7.2: Índice de resistência à tração versus Schopper-Riegler

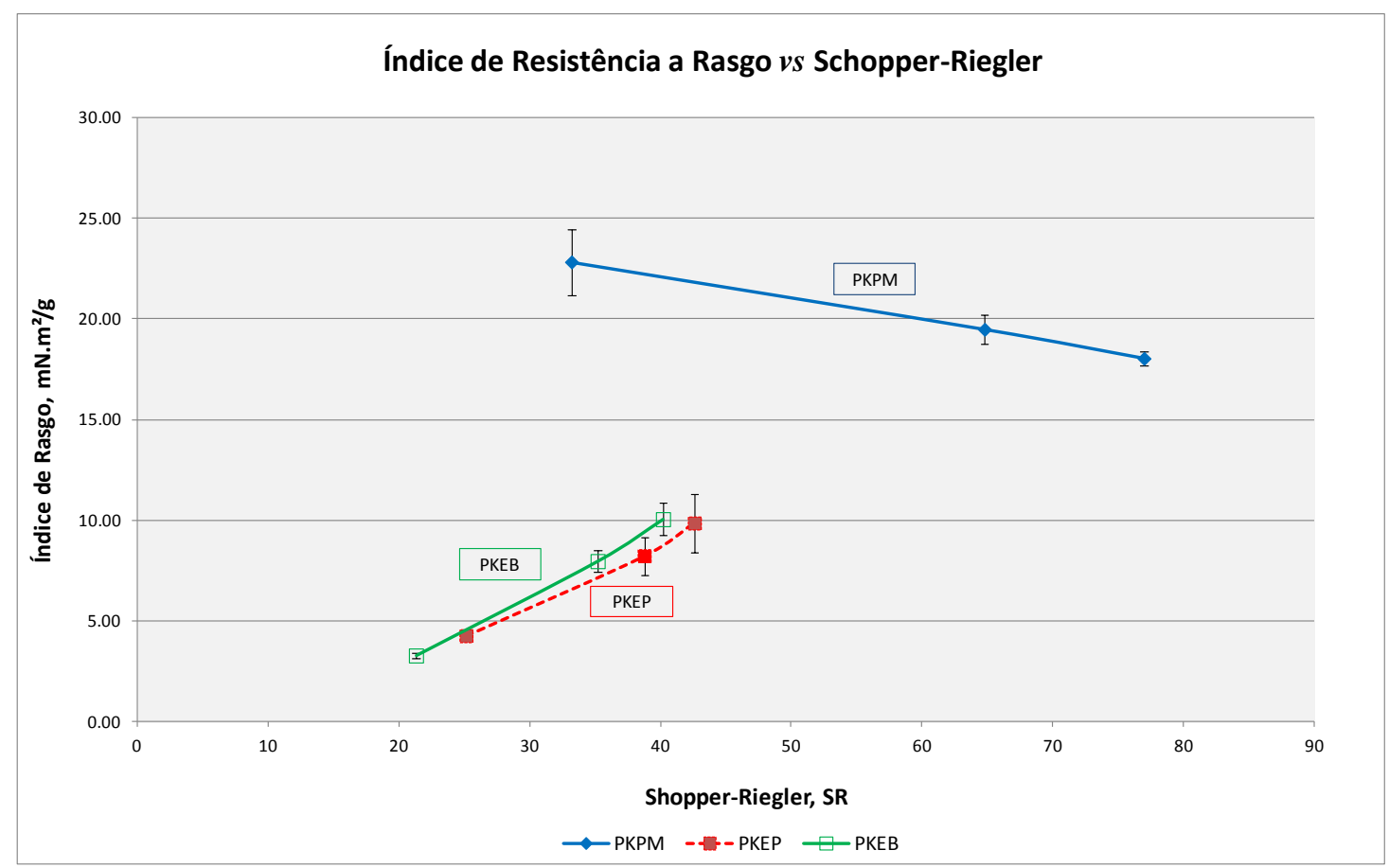

Figura 7.3: Índice de resistência a rasgo versus Schopper-Riegler 


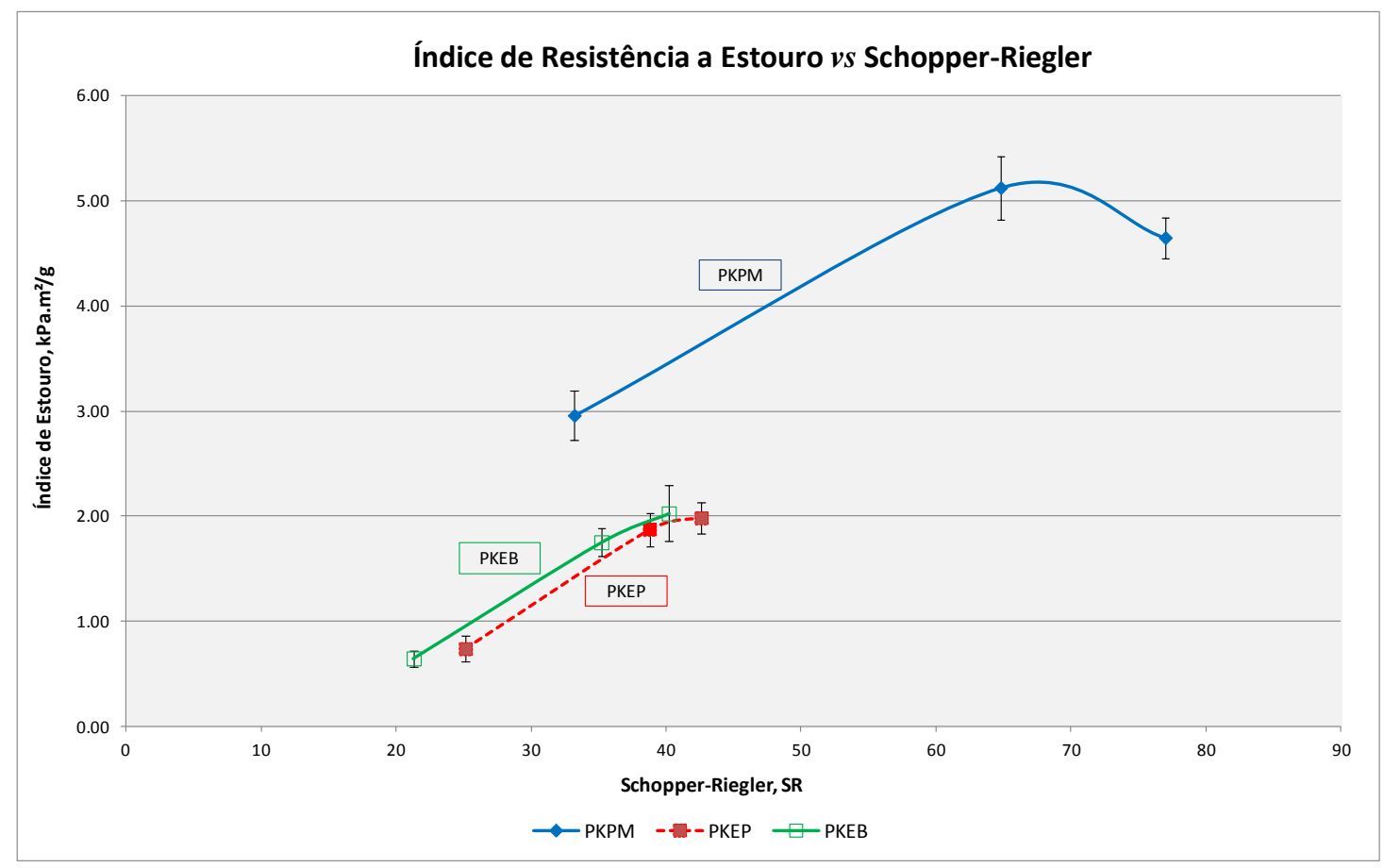

Figura 7.4: Índice de resistência a estouro versus Schopper-Riegler

Nas Figuras 7.2, 7.3 e 7.4 observa-se que:

- A pasta PKEP tem valores dos índices de tração, rasgo e estouro maiores que a PKEB, para o mesmo grau de refinação. Isto possivelmente se deve ao fato de ser pasta celulósica não branqueada. Durante o branqueamento, geralmente, acontece uma degradação dos carboidratos (ver, por exemplo, Jardim e Colodette (2015));

- A pasta PKPM desenvolve umas propriedades de tração e de estouro maiores que as pastas de eucalipto (PKEB e PKEP), como esperado por ser fibra longa. Porém, o índice de rasgo a 2000 PFI e 4000 PFI é inferior ao ponto 0 PFI. A pasta PKPM (no ponto inicial) já está refinada tal como recebida da fábrica, e ao continuar refinando, as fibras começam a ser cortadas, diminuindo a resistência ao rasgo que depende principalmente da integridade das mesmas.

\subsubsection{Resistência ao ar Gurley}

Foi determinada a resistência ao ar Gurley das pastas PKEB, PKEP e PKPM antes e depois da refinação. Na Figura 7.5 apresentam-se os resultados da 
resistência ao ar Gurley para as pastas celulósicas a 0 PFI, 2000 PFI e 4000 PFI.

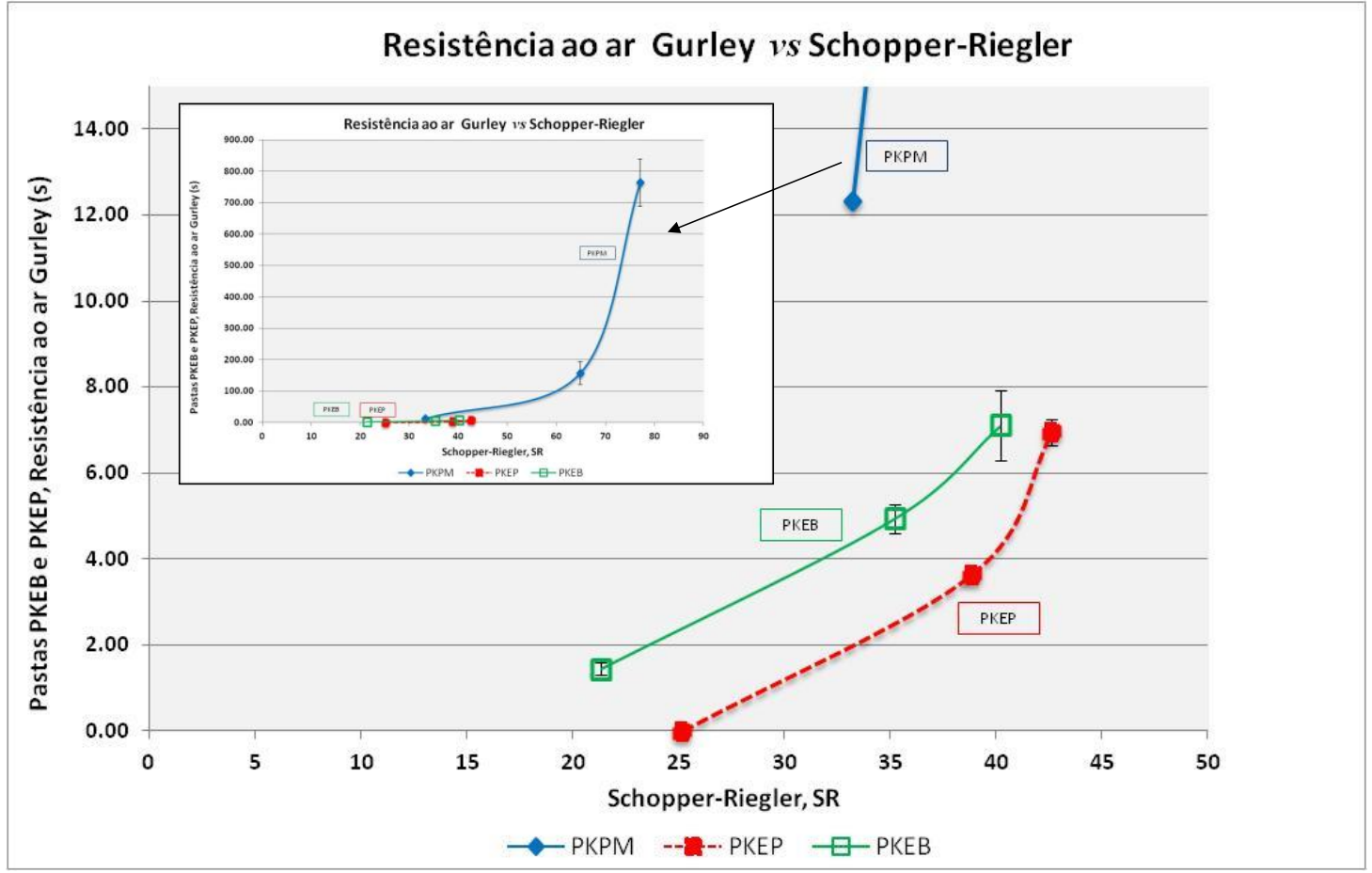

Figura 7.5: Resistência ao ar Gurley versus Schopper-Riegler

Observa-se na Figura 7.5 que a pasta com menor valor resistência ao ar Gurley é a PKEP, sem refinar. Após refinação os valores de resistência ao ar Gurley da pasta branqueada (PKEB) são similares aos da polpa prébranqueada (PKEP). A pasta de pinus (PKPM) é a que maior valor de resistência ao ar Gurley apresenta, em todos os casos. A explicação mais provável é o alto teor de finos, por ser uma pasta refinada, os quais fecham os poros da folha formada diminuindo a porosidade. Por outro lado, Ferreira (2000) descreve que a lignina funciona como agente aglutinador das fibras, impedindo, mesmo na presença de água, que estas incorporem as alterações induzidas pela refinação e se liguem de modo eficaz. A Figura 7.3 relativo ao índice de resistência a rasgo, e a Figura 7.5 relativa à resistência ao ar Gurley em conjunto reforçam a evidência da pasta PKPM, já refinada originalmente, ter geração de finos no presente refino adicional. 


\subsubsection{Opacidade}

Na Figura 7.6 apresentam-se os resultados obtidos para a opacidade nas pastas PKEB, PKEP e PKPM, antes e após refinar.

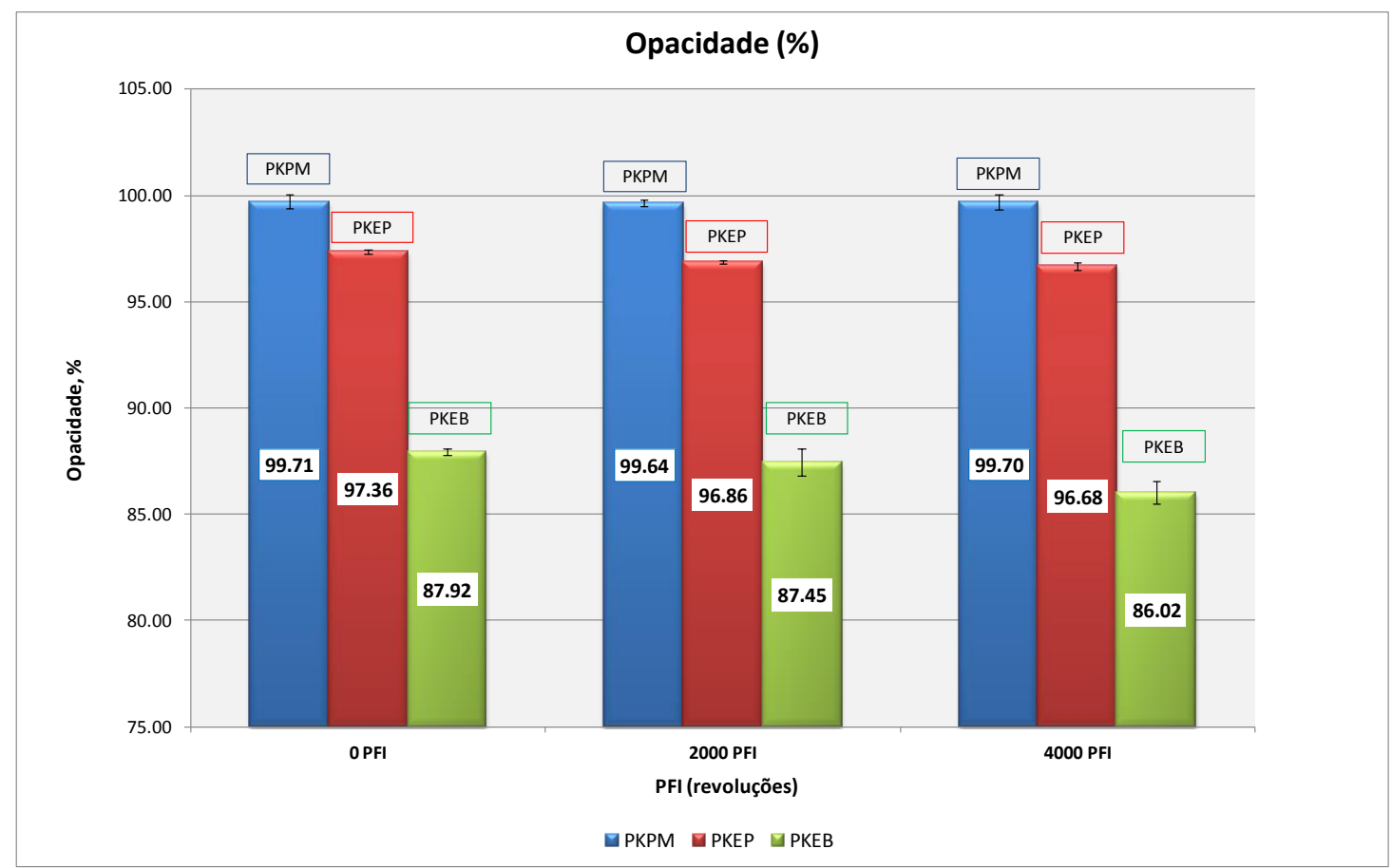

Figura 7.6: Opacidade

Se comparados os valores de opacidade (Fig. 7.6) nas pastas, antes e após refinação, observa-se que a opacidade é semelhante no ponto sem refinar ( 0 PFI) e depois de refinar (2000 PFI e 4000 PFI).

Comparando todas as pastas entre si, observa-se que os valores de opacidade decrescem com a diminuição do conteúdo de lignina, concordando com o exposto por Scott (1995). Portanto, a pasta PKPM (maior conteúdo de lignina) tem uns valores de opacidade maiores que a pastas pré-branqueada (PKEP) e esta, por sua vez, maiores que a branqueada (PKEB).

\subsubsection{Morfologia das fibras}

$\mathrm{Na}$ Tabela 7.1, apresentam-se os resultados da morfologia das fibras das pastas de eucalipto branqueada (PKEB) e pré-branqueada (PKEP) e da pasta marrom de pinus (PKPM). Nas pastas PKEB e PKEP, também se apresentam os valores após refinação Valley. 
Tabela 7.1: Morfologia das fibras das Pastas Celulósicas

\begin{tabular}{lc|cc|cc}
\hline \multirow{2}{*}{ Parâmetro } & \multirow{2}{*}{ PKPM } & \multicolumn{3}{c|}{ Antes de Refinar } & \multicolumn{2}{c}{ Depois de Refinar } \\
\cline { 3 - 6 } & & PKEP & PKEB & PKEP & PKEB \\
\hline População de fibras, milhões/g & 2.10 & 19.77 & 19.47 & 20.88 & 21.75 \\
Comprimento aritmético, mm & 1.19 & 0.70 & 0.66 & 0.66 & 0.64 \\
Comprimento ponderado, mm & 2.65 & 0.87 & 0.83 & 0.87 & 0.82 \\
Largura da Fibra, $\boldsymbol{\mu m}$ & 34.95 & 18.05 & 16.60 & 17.50 & 17.00 \\
Fração parede, \% & 25.08 & 33.28 & 45.37 & 34.70 & 37.43 \\
Diâmetro do lúmen, $\boldsymbol{\mu m}$ & 26.22 & 12.04 & 9.07 & 11.43 & 10.64 \\
Coarseness, mg/100.m & 17.67 & 6.20 & 6.63 & 6.03 & 6.03 \\
Kink angle, ${ }^{\circ}$ & 128.28 & 128.00 & 128.80 & 131.70 & 131.05 \\
Kink, \% & 86.05 & 53.90 & 62.10 & 49.45 & 58.70 \\
Curl, \% & 16.75 & 10.62 & 11.54 & 9.95 & 11.73 \\
\hline
\end{tabular}

Observa-se na Tabela 7.1 que, como esperado, por ser fibra longa a pasta PKPM tem os maiores valores de comprimento das fibras largura de fibra fração de parede e coarseness. Além disso, a pasta PKPM apresenta os maiores valores de curl por estar refinada industrialmente.

Se comparados entre si as pastas PKEP e PKEB, observa-se na Tabela 7.1 que a pasta PKEP tem valores maiores de comprimento das fibras, largura de fibra, diâmetro de lúmen e coarseness. Possivelmente é devido ao fato de ser uma pasta não branqueada, confirmando o exposto anteriormente. 0 branqueamento da celulose degrada a fibra, diminuindo os valores da morfologia.

Comparando as pastas PKEP e PKPB antes e depois de refinar, observa-se que, como esperado, o comprimento e a largura da fibra diminuem por ação do refino. O percentual de fibras fibriladas (Kink, \%) e o curl (grau de torção da fibra) aumentam. Durante a refinação da pasta aumenta a fibrilação externa, a formação de finos e a diminuição do tamanho das fibras. Yasumura et al. (2008) observaram que as fibras refinadas em PFI, comparadas ao refino em disco, apresentam-se mais colapsadas, mas com um menor grau de torção. Os mesmos autores mostram que à medida que a fibra é refinada, esta é cortada diminuindo o comprimento e a largura da fibra. 
Em relação ao coarseness, ou seja, a massa de fibras por unidade de comprimento observa-se que após refinação este aumenta devido à fibrilação externa que causa o arrancamento das camadas externas das fibras.

\subsection{Testes Iniciais}

Inicialmente foram testadas diferentes condições de formação de folhas com nanoceluloses (CNF), amido, cola e polímero de retenção na pasta de eucalipto branqueada (PKEB) para escolher as melhores condições de adição de aditivos (CNF, amido, cola e polímero). Ver Tabela 6.8 relativo a diferentes tipos de pastas de celulose usadas em cada condição. Fez-se uma folha de laboratório na qual se determinaram as propriedades de tração e estouro. Os resultados apresentam-se nas Figuras 7.7 e 7.8 .

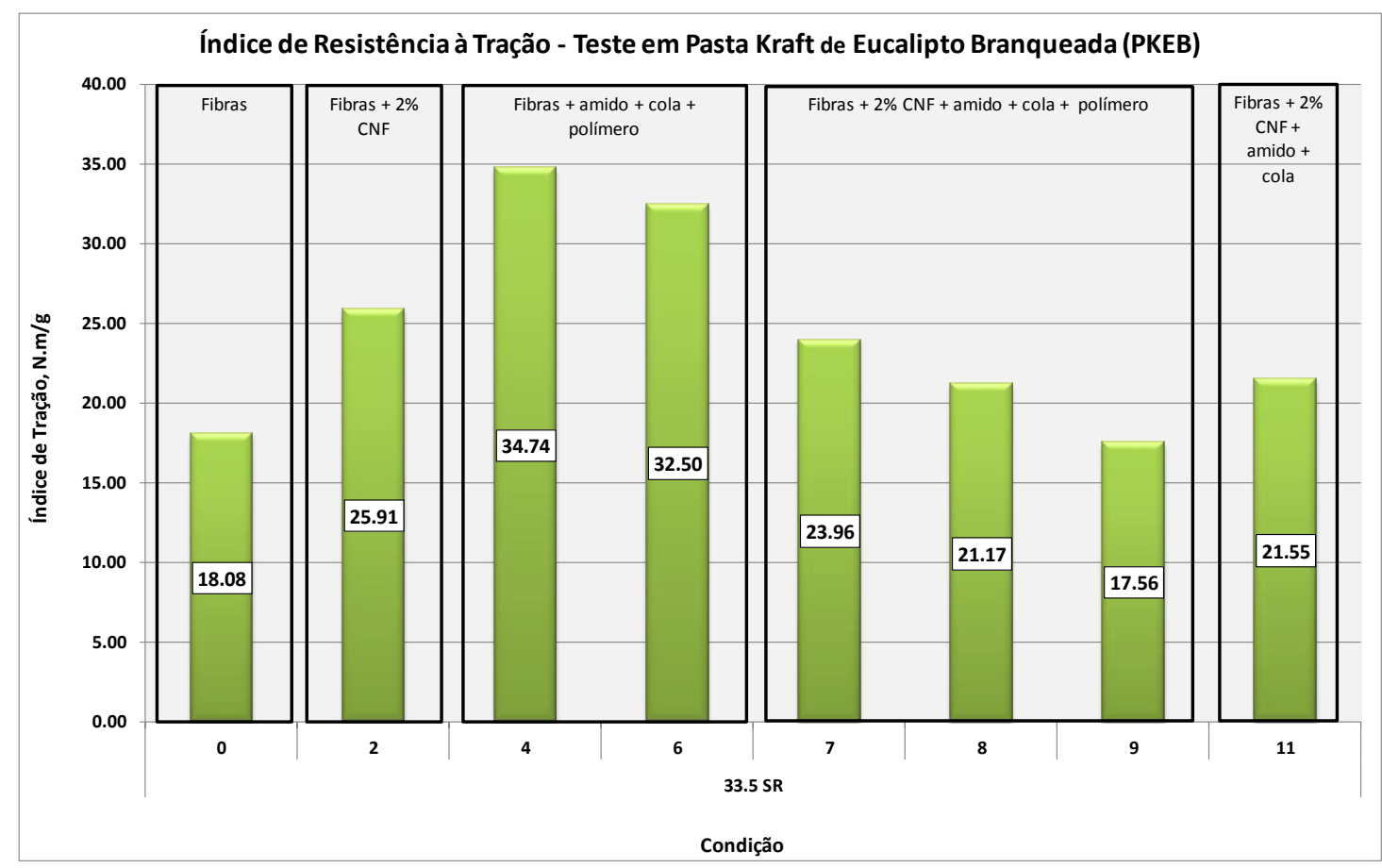

Figura 7.7: Índice de resistência à tração - Testes em pasta branqueada (PKEB) 


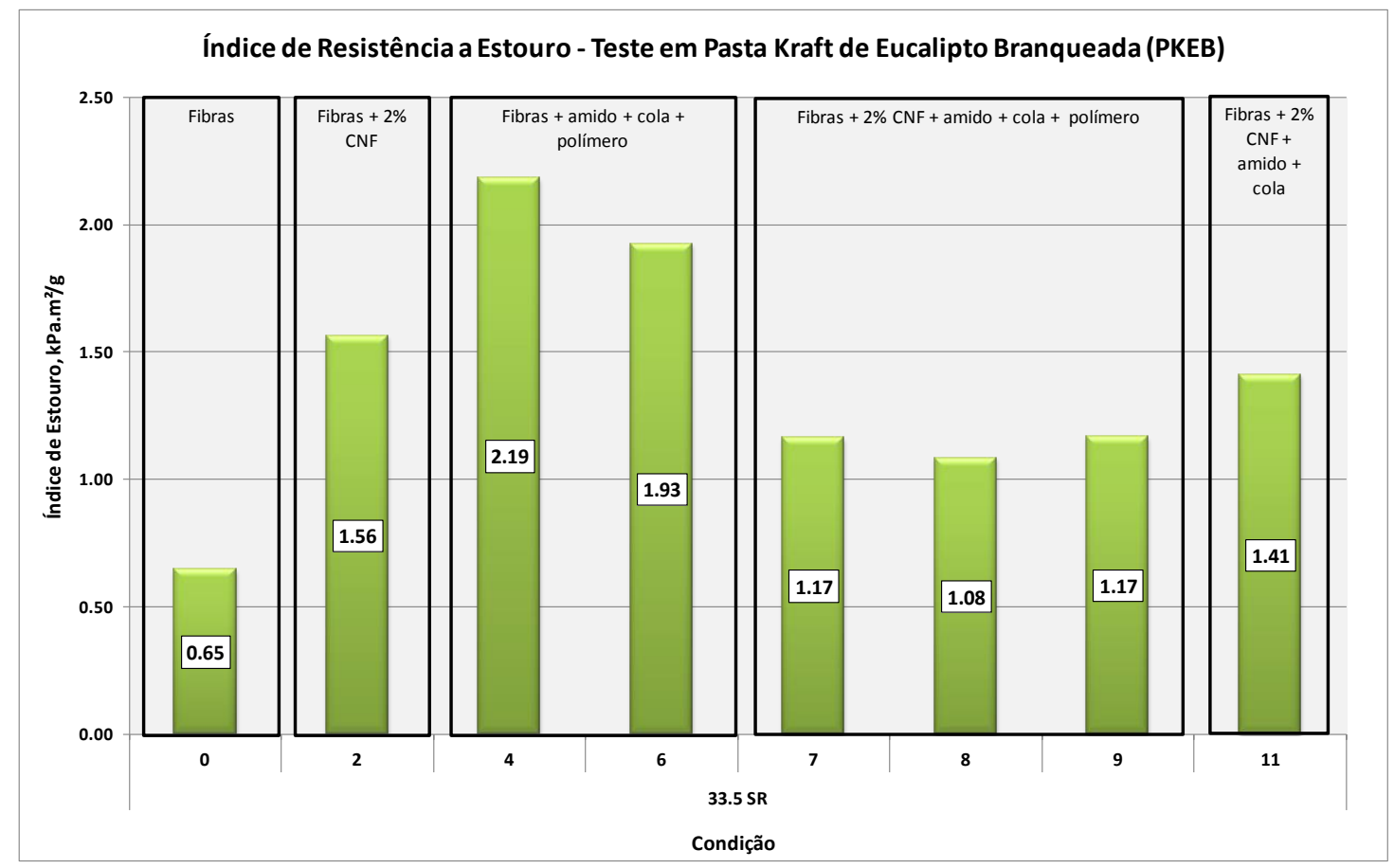

Figura 7.8: Índice de resistência a estouro - Testes em Pasta branqueada (PKEB) Nas Figuras 7.7 e 7.8 observa-se:

- A condição 4 (adição de químicos sem nanocelulose) é a que obtiveram maiores valores de resistência. Porém, a adição da metade de (amido + cola) (condição 6) proporciona propriedades semelhantes, diminuindo custos e material;

- A adição de nanoceluloses (CNF) na pasta aumenta consideravelmente a resistência mecânica (condição 2), se comparados com respeito a condição 0 (uso de fibras). Estes resultados estão de acordo com a literatura. Brodin et al. (2014) citam que com o uso de $4 \%$ de CNF em folhas de laboratório fabricadas com pasta TMP obteve-se um aumento significativo do índice de tração. Kajanto e Kosonen (2012) adicionando ao papel celulose nanofibrilada tiveram um aumento significativo da resistência à tração, o que permitiu uma redução na gramatura do papel de $8 \mathrm{~g} / \mathrm{m}^{2}$. No entanto, uma vez que se adicionam CNF e os químicos (amido, cola e polímero) as propriedades físico-mecânicas da pasta diminuem. Uma possível causa é que os aditivos atuem como aglutinadores das CNF impedindo sua adesão nas fibras. Além disso, pode-se observar que 
não usando polímero (condição 11) os índices de tração e estouro aumentam. O polímero pode aumentar, ainda mais, a aglomeração das CNF, e ao retirá-lo, esta aglomeração diminui, portanto, aumentando a resistência da folha.

Tendo em conta os resultados observados nas Figuras 7.7 e 7.8, nas polpas marrons (PKEP e PKPM) foram realizadas folhas de laboratório nas condições: 1, 2, 3 (adição de $1 \%, 2$ e $3 \%$ de CNF), para poder avaliar como influencia o conteúdo de CNF na pasta; nas condições 4 e 5 (adição de amido, cola e polímero), para avaliar o conteúdo de aditivos químicos de Kraftliner; e nas condições 7 e 10 (adição de CNF e aditivos químicos), para avaliar a mistura dos aditivos e das CNF na pasta ao mesmo tempo.

\subsection{Ensaios preliminares}

Conforme comentados nos objetivos do trabalho (item 3), a finalidade do estudo consiste em conhecer quais são as principais limitações ou vantagens das fibras de eucalipto na substituição da fibra longa não branqueada na produção de papéis na linha de Kraftliners. Por este motivo, nos ensaios preliminares ou prospecção de experimentos, na pasta branqueada (PKEB), somente foi realizada a condição 2 e na pasta pré-branqueada de eucalipto (PKEP), objeto do trabalho, e na pasta marrom de pinus (PKPM) realizaramse as melhores condições de adição a partir dos resultados obtidos no item 7.2 (Testes Iniciais).

\subsubsection{Propriedades Físico-Mecânicas}

Nas Figuras 7.9, 7.10 e 7.11 apresenta-se os índices de resistência à tração dos resultados obtidos para os ensaios preliminares das pastas PKEB, PKEP e PKPM. Nestas figuras, também apresentam-se os índices de resistência à tração a 0 PFI, 2000 PFI e 4000 PFI e dos índices de resistência a tração longitudinal e transversal do papel Kraftliner industrial para comparação. 


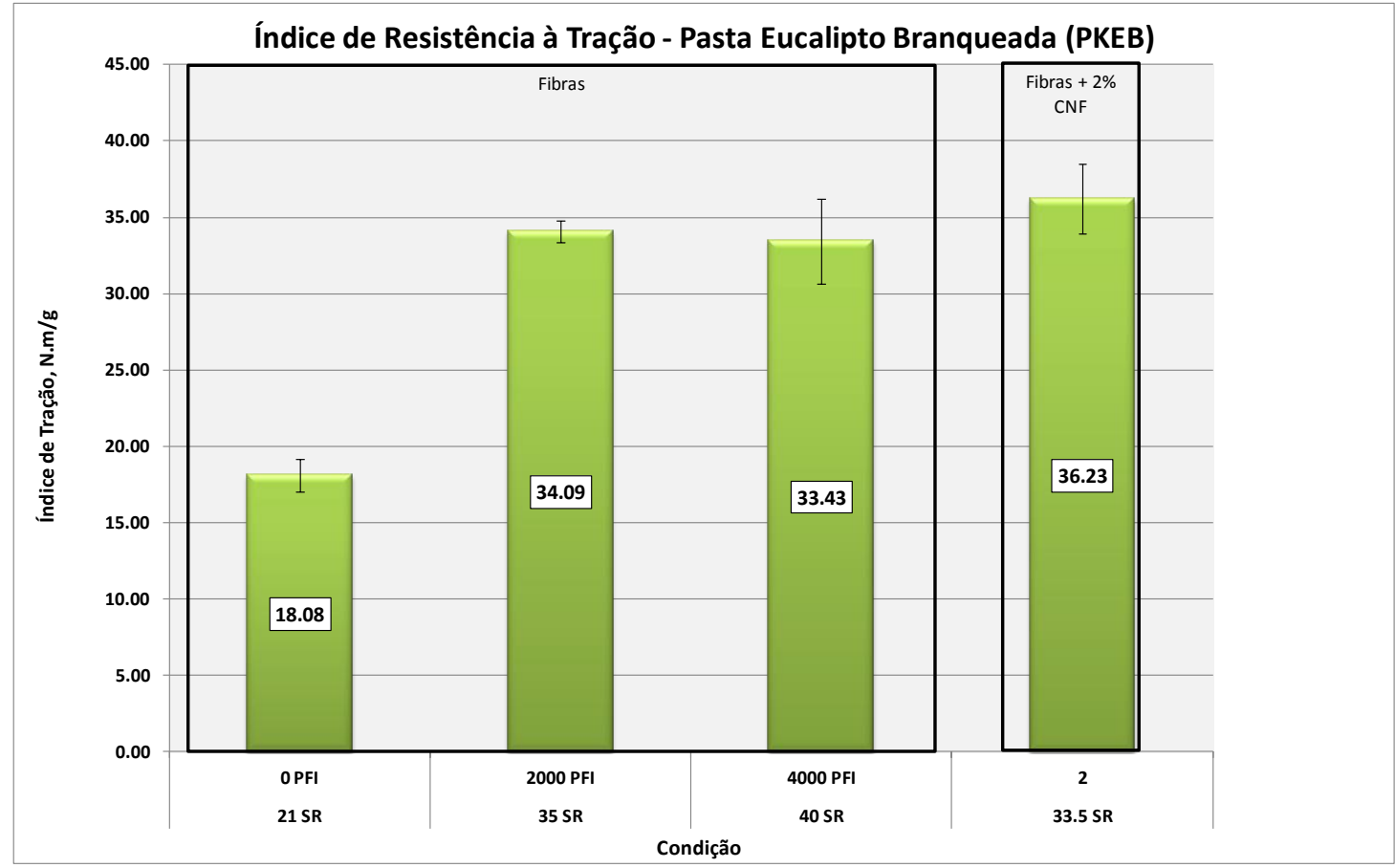

Figura 7.9: Índice de resistência à tração - Pasta branqueada (PKEB)

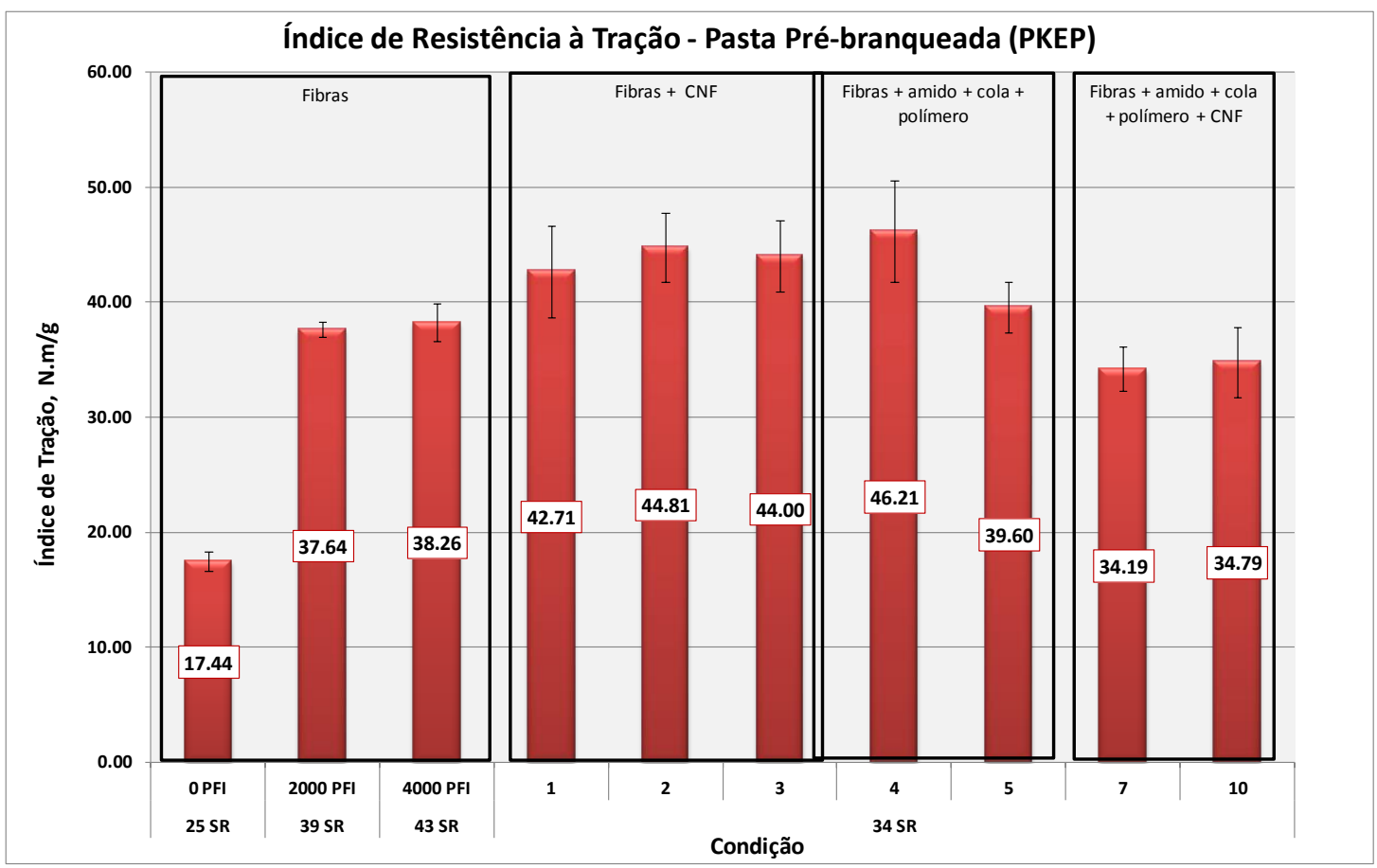

Figura 7.10: Índice de resistência à tração - Pasta pré-branqueada (PKEP) 


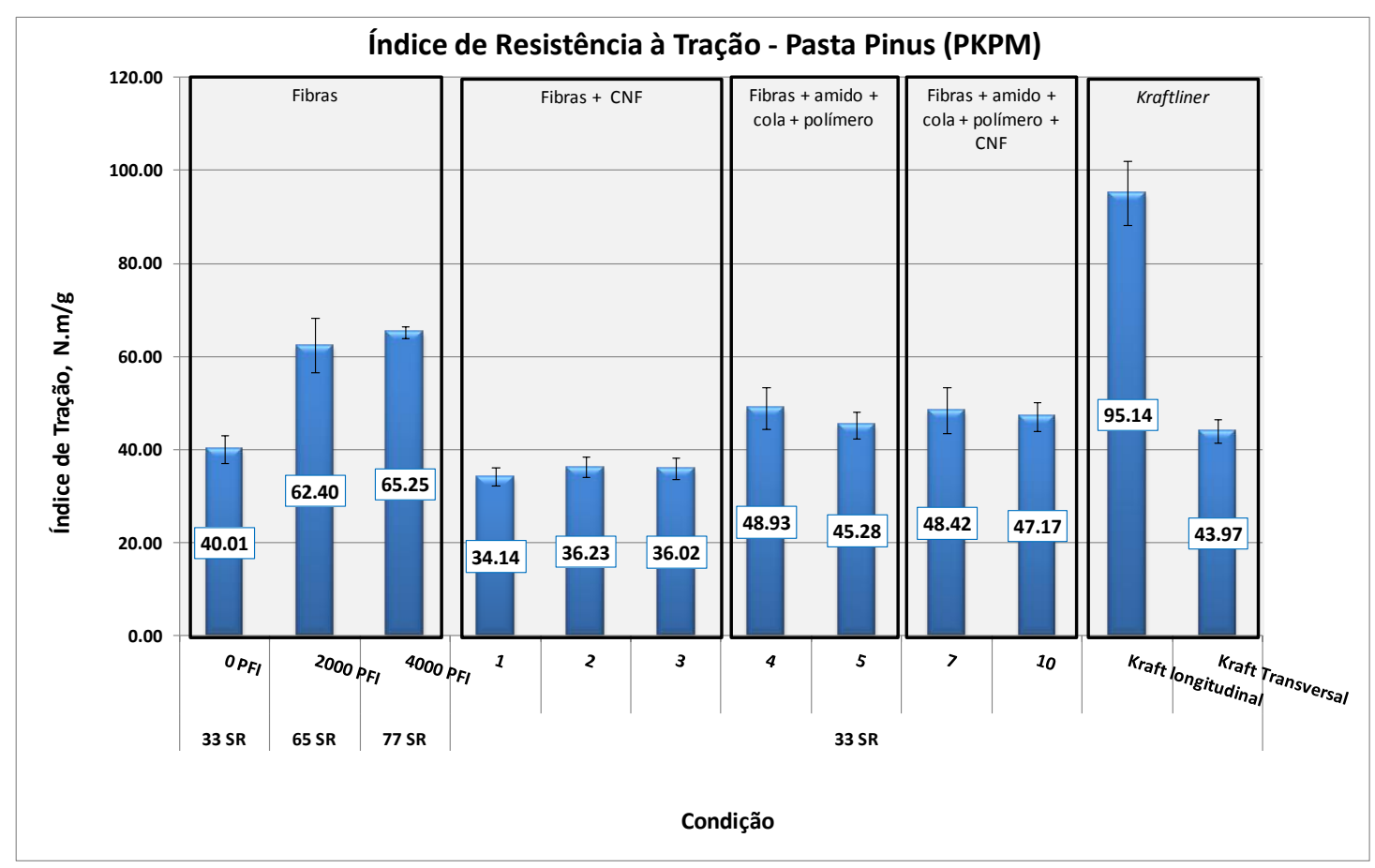

Figura 7.11: Índice de resistência à tração - Pasta marrom de pinus (PKPM)

Analisando os resultados apresentados nas Figuras 7.9, 7.10, 7.11 observase:

- A adição de nanoceluloses (CNF) aumenta as propriedades de tração na pasta PKEP, concordado com a literatura (BRODIN et al., 2014; KAJANTO e KOSONEN, 2012; FUKUZUMI et al., 2013; ÄMMÄLÄ et al., 2013), incrementando os valores de resistência com a adição de 1 $\%, 2 \%$ e $3 \%$ (condições 1,2 e 3 ). No entanto, como se observa na Figura 7.10 e 7.11 , a adição de $2 \%$ e $3 \%$ de CNF não modifica significativamente os valores do índice de tração da pasta com respeito à adição de $1 \%$ de CNF (condição 4). Na pasta PKPM, a adição de CNF diminui o índice de tração, provavelmente devido ao alto teor de lignina da pasta de pinus (PKPM) o qual faz com que as CNF não se adiram às fibras;

- De igual forma que na Figura 7.8 (item 7.2), observa-se que a média da condição 4 tem os maiores valores para 0 índice de resistência a tração (46,21 Nm/g, pasta PKEP; 48,93 Nm/g, pasta PKPM);

- Na Figura 7.10 observa-se que as misturas de químicos com CNF (condições 7 e 10) têm valores inferiores aos obtidos com adição 
apenas de CNF e de químicos (condições 1, 2, 3, 4 e 5, respectivamente). Esta tendência não se observa na pasta PKPM (Figura 7.11) na qual a adição de químicos e/ou de misturas de ambos, apresenta valores semelhantes. Por outra parte, não se observam (Figuras 7.10 e 7.11) diferenças significativas ao adicionar a metade de amido mais cola junto com CNF (condições 7 e 10);

- Como esperado, o índice de resistência à tração longitudinal do papel Kraftliner industrial, tem o maior valor $(95,14 \mathrm{~N} . \mathrm{m} / \mathrm{g})$. No sentido transversal o valor do índice de tração é semelhante às condições utilizadas. Possivelmente, se deve ao direcionamento das fibras, no ensaio de tração a quebra do papel produz-se perpendicularmente à força aplicada, opondo mais resistência no sentido longitudinal;

- Comparando a pasta de eucalipto pré-branquada (PKEP) com a pasta de pinus (PKPM), observa-se que, ao adicionar exclusivamente CNF o índice de tração têm valores superiores na pasta de eucalipto. Isto pode ser devido ao maior conteúdo de lignina na pasta PKPM que na PKEP, números Kappa 9,21 (PKEP) e 36,1 (PKPM), aderindo-se melhor na pasta de eucalipto (menor conteúdo de lignina) e aumentando o índice de tração. Ao contrario que nas condições 1, 2 e 3, nas condições 4, 5, 7 e 10, o índice de tração tem valores superiores na pasta PKPM. Conforme comentado anteriormente, pode ser que ao adicionar aditivos químicos junto com CNF, as nanoceluloses aglomeram-se entre si, diminuindo a adesão destas no papel.

Nas Figuras 7.12, 7.13 e 7.14 apresenta-se o índice de resistência a rasgo dos resultados obtidos para os ensaios preliminares das pastas PKEB, PKEP e PKPM. Nas Figuras, também apresentam-se os índices de resistência à tração a 0 PFI, 2000 PFI e 4000 PFI e dos índices de resistência a rasgo longitudinal e transversal do papel Kraftliner industrial para comparação. 


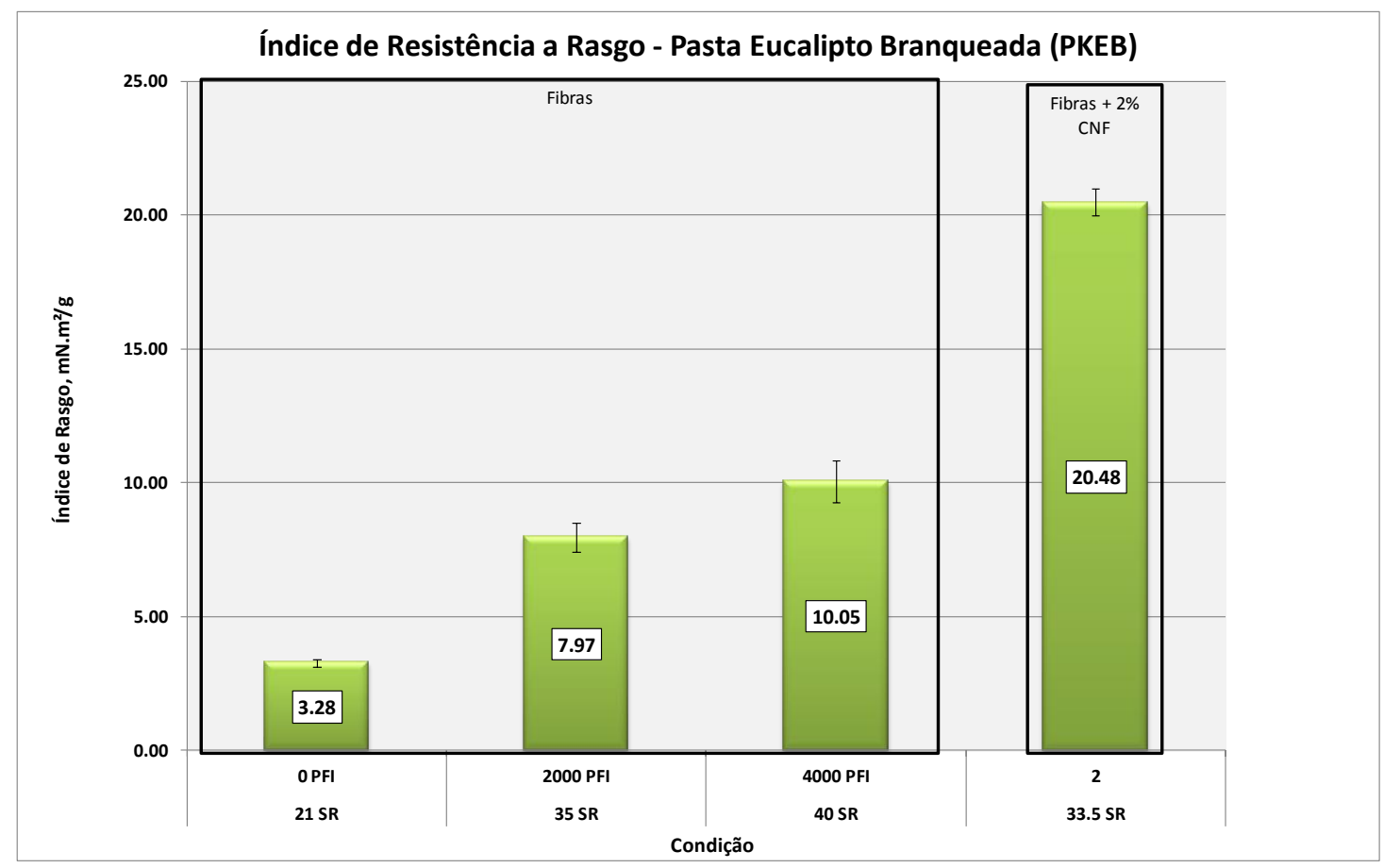

Figura 7.12: Índice de resistência a rasgo - Pasta branqueada (PKEB)

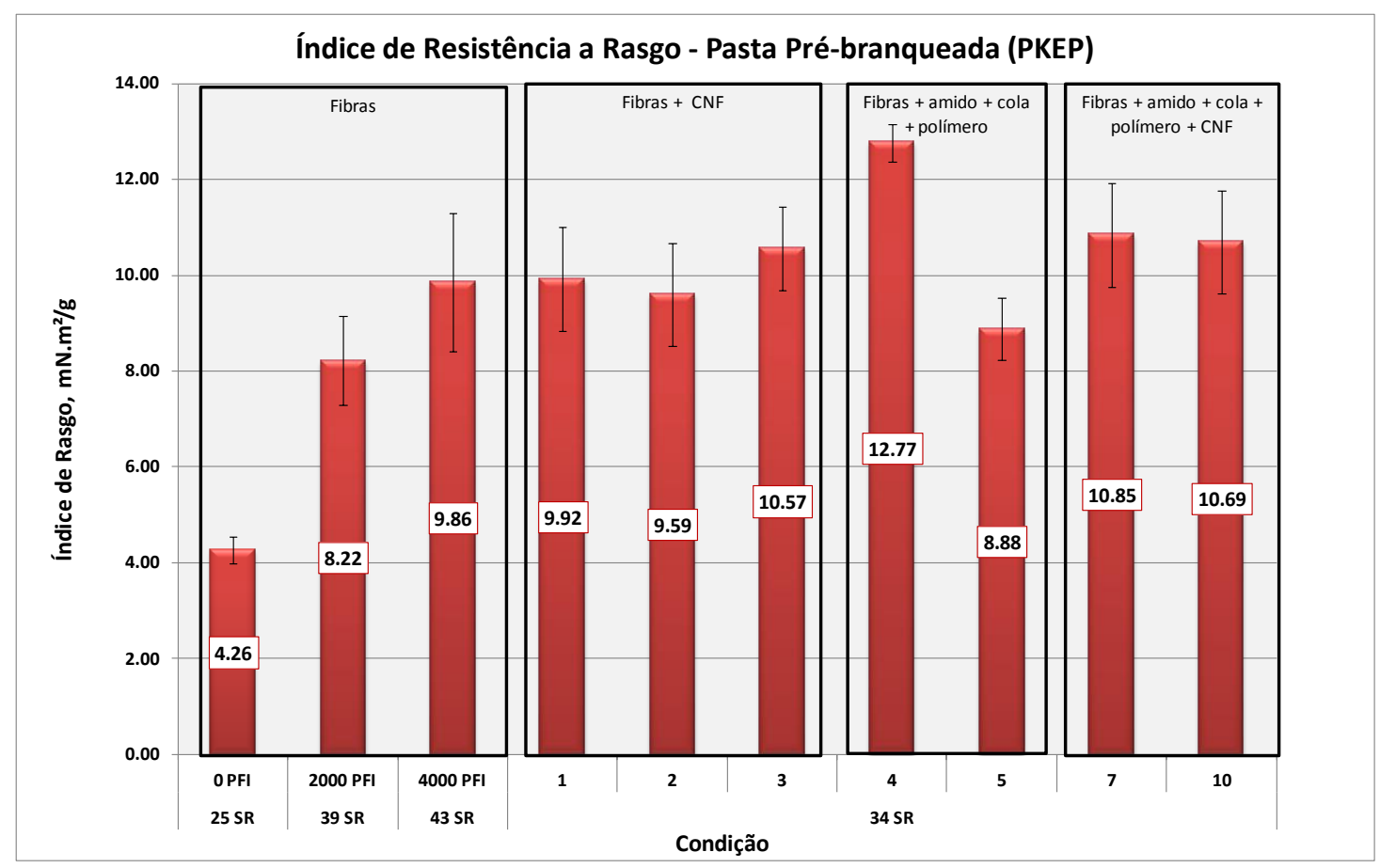

Figura 7.13: Índice de resistência a rasgo - Pasta pré-branqueada (PKEP) 


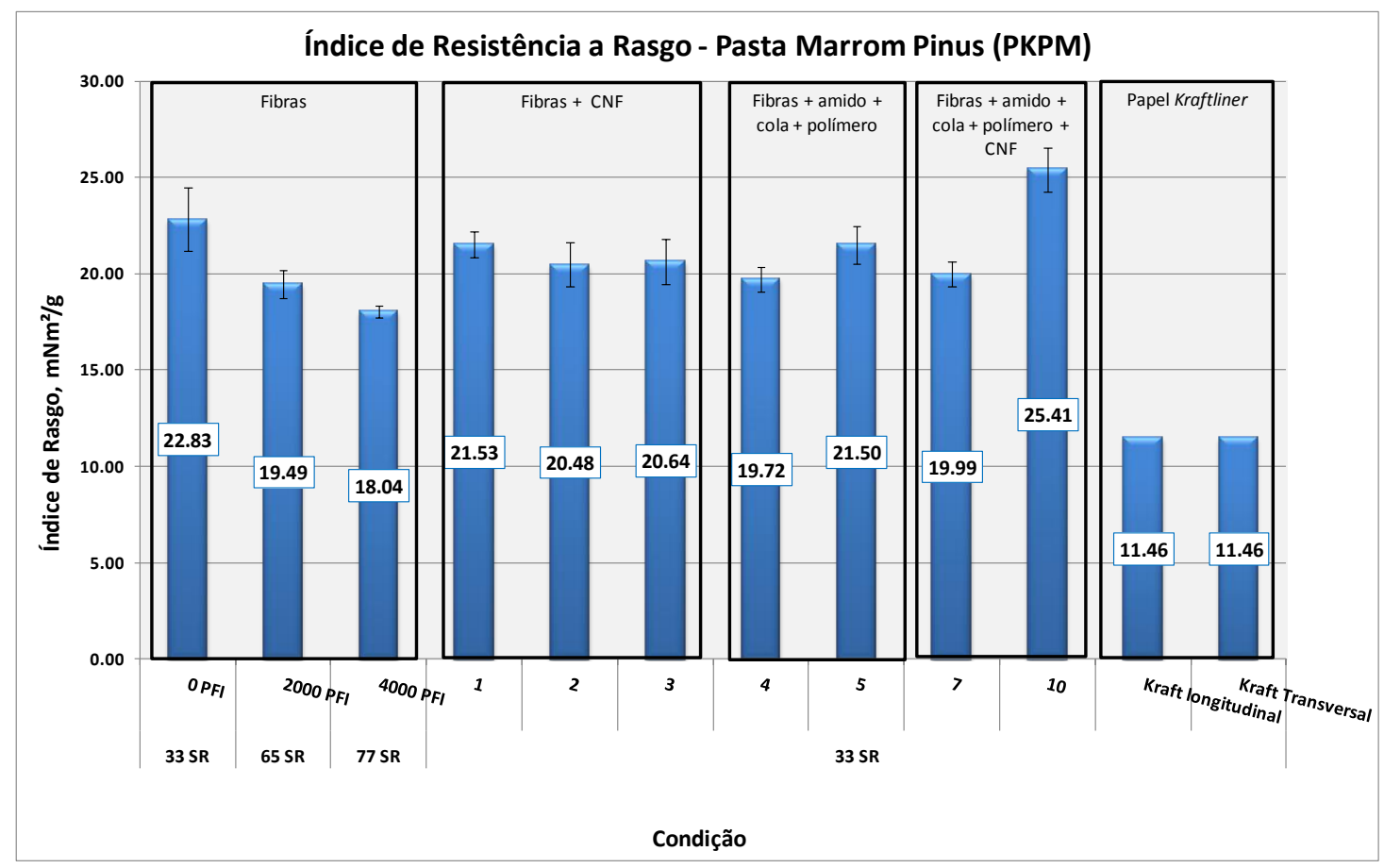

Figura 7.14: Índice de resistência a rasgo - Pasta marrom de pinus (PKPM)

Os resultados mais importantes das Figuras 7.12, 7.13 e 7.14 são:

- Similar ao observado para o índice de resistência a tração (Figuras 7.9, 7.10), a adição de CNF aumenta o índice de rasgo das pastas de eucalipto (Figuras 7.12 e 7.13). Por outro lado, na pasta PKPM (Figura 7.13) a exceção da condição 10 não existem diferenças significativas entre os valores do índice de rasgo nas condições utilizadas neste estudo;

- Na Figura 7.14 observa-se que o índice de resistência a rasgo tem uns valores inferiores no papel Kraftliner industrial que nas folhas de laboratório. Em folhas industriais as fibras são direcionadas no papel, diminuindo o rasgo;

- Comparando a Figura 7.13 com a Figura 7.14 observa-se que em todos os casos, a pasta de pinus (PKPM) tem valores maiores que a pasta pré-branqueada de eucalipto, por ser fibra longa.

Nas Figuras 7.15, 7.16 e 7.17 apresenta-se o índice de resistência a estouro dos resultados obtidos para os ensaios preliminares das pastas PKEB, PKEP e PKPM. Nas Figuras, também apresentam-se os índices de resistência a 
estouro a 0 PFI, 2000 PFI e 4000 PFI e dos índices de resistência à tração longitudinal e transversal do papel Kraftliner industrial para comparação.

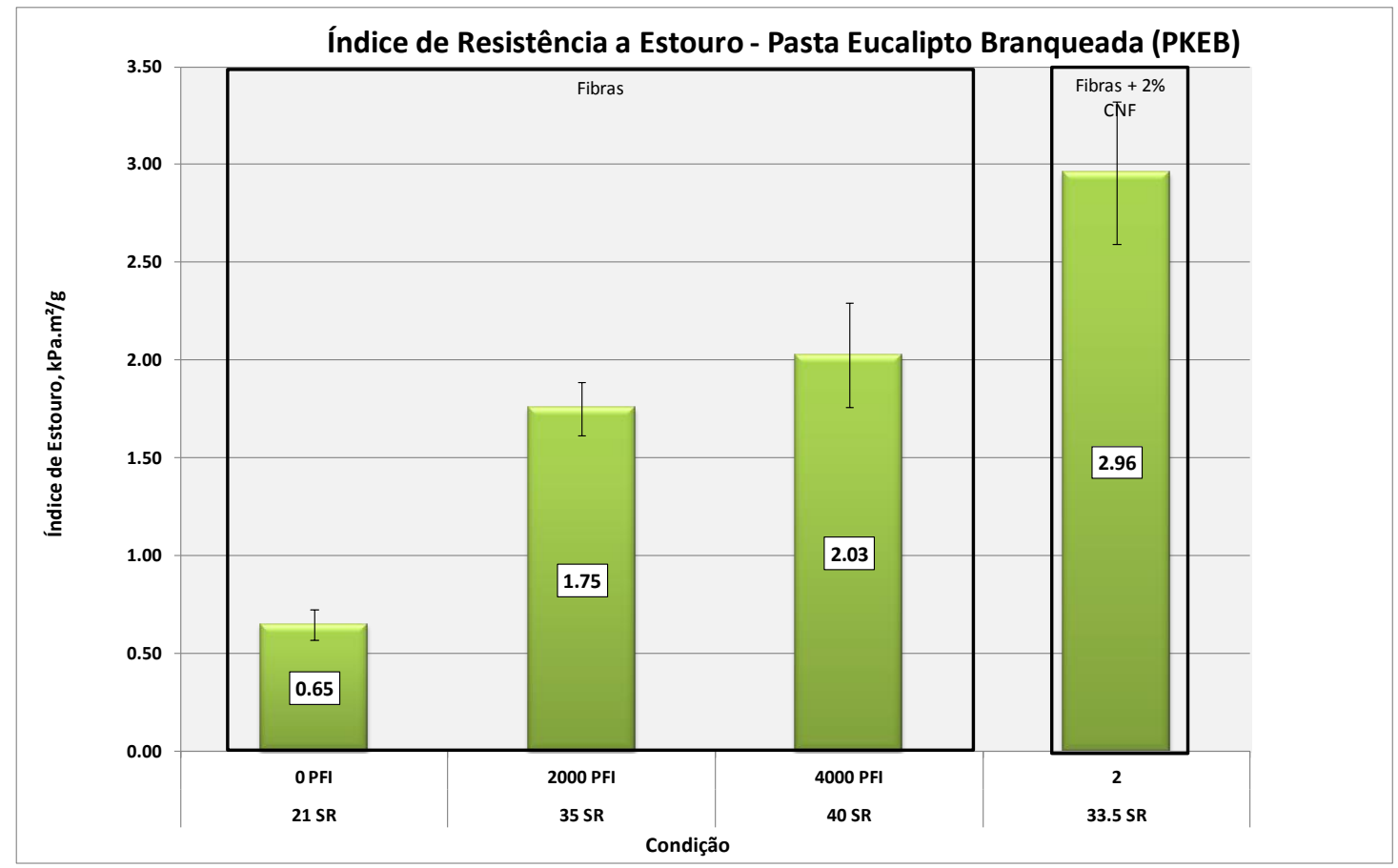

Figura 7.15: Índice de resistência a estouro - Pasta branqueada (PKEB)

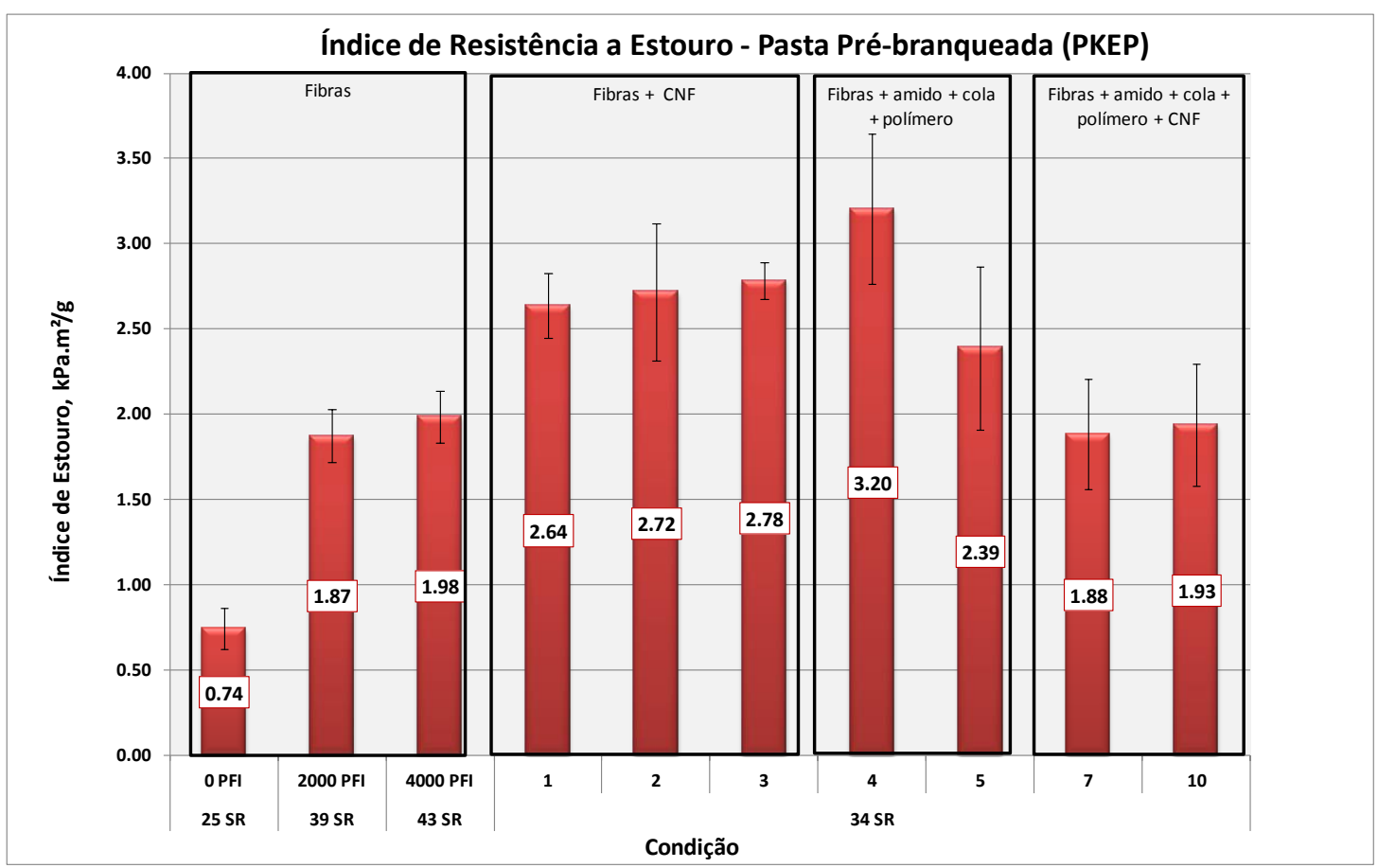

Figura 7.16: Índice de resistência a estouro - Pasta pré-branqueada (PKEP) 


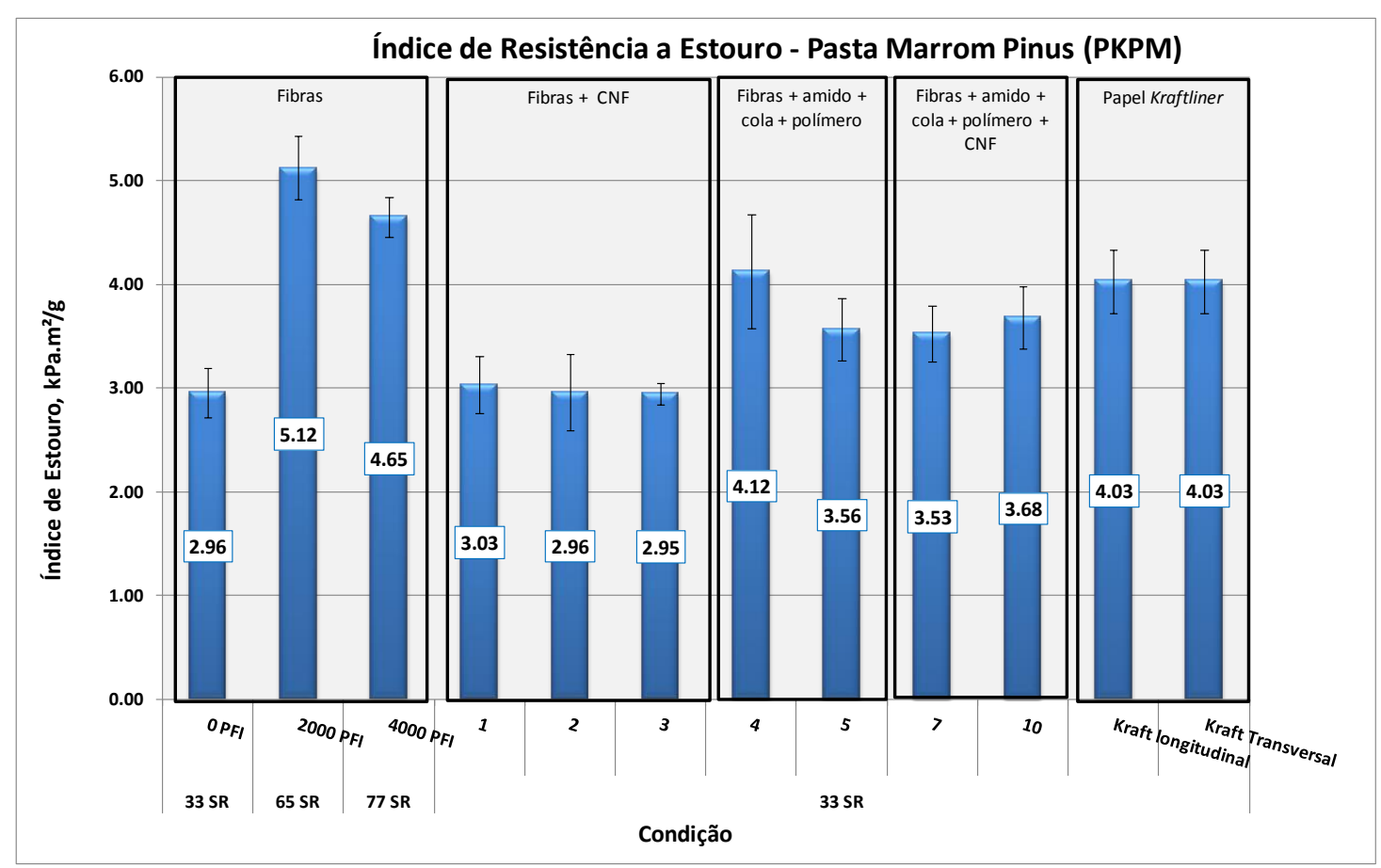

Figura 7.17: Índice de resistência a estouro - Pasta marrom de pinus (PKPM)

Observando as figuras $7.15,7.16$ e 7.17 nota-se que de forma análoga às propriedades de tração (Figuras 7.9, 7.10 e 7.11), encontram-se as mesmas diferenças para o índice de resistência a estouro (Figuras 7.15, 7.16 e 7.17) nas condições utilizadas. O papel Kraftliner industrial apresenta uns valores do índice de estouro longitudinal e transversal semelhantes, devido à resistência a estouro não depender da orientação das fibras no papel.

\subsubsection{Resistência ao ar Gurley}

Nas Figuras 7.18, 7.19 e 7.20 apresenta-se a resistência ao ar Gurley dos resultados obtidos para os ensaios preliminares das pastas PKEB, PKEP e PKPM. Nestas figuras, também apresentam-se a resistência ao ar Gurley a 0 PFI, 2000 PFI e 4000 PFI e da resistência ao ar Gurley do papel Kraftliner industrial para comparação. 


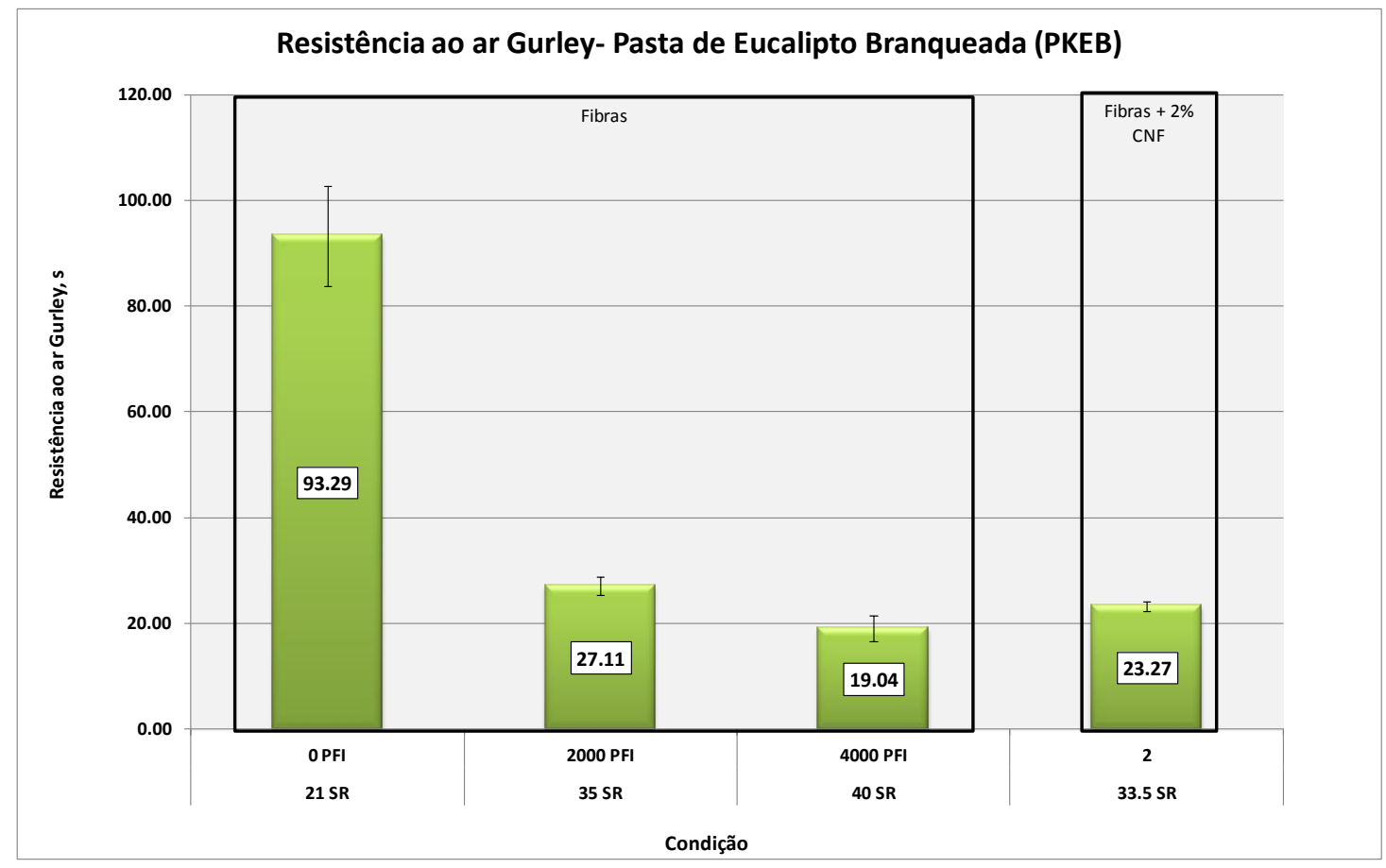

Figura 7.18: Resistência ao ar Gurley - Pasta branqueada (PKEB)

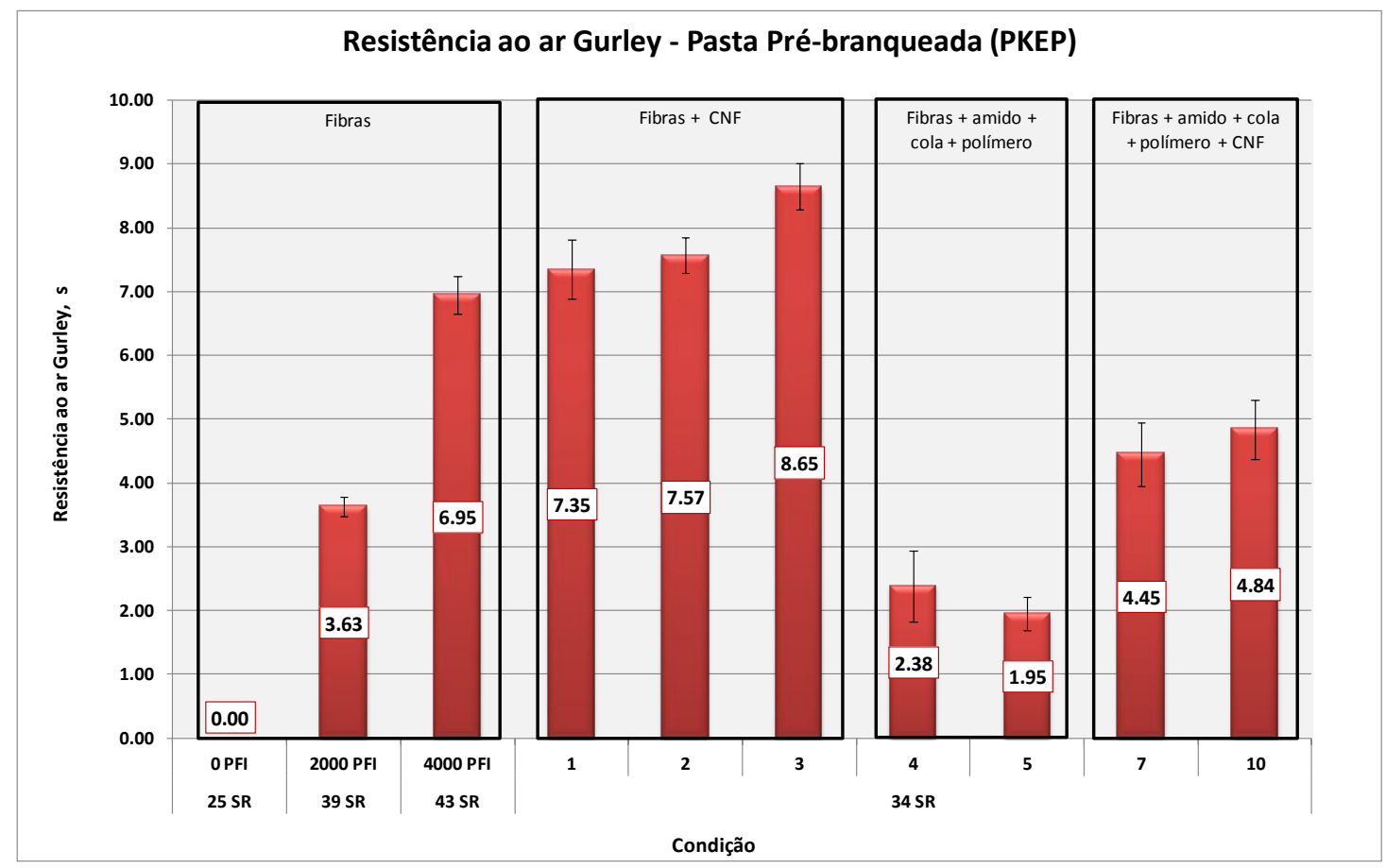

Figura 7.19: Resistência ao ar Gurley - Pasta pré-branqueada (PKEP) 


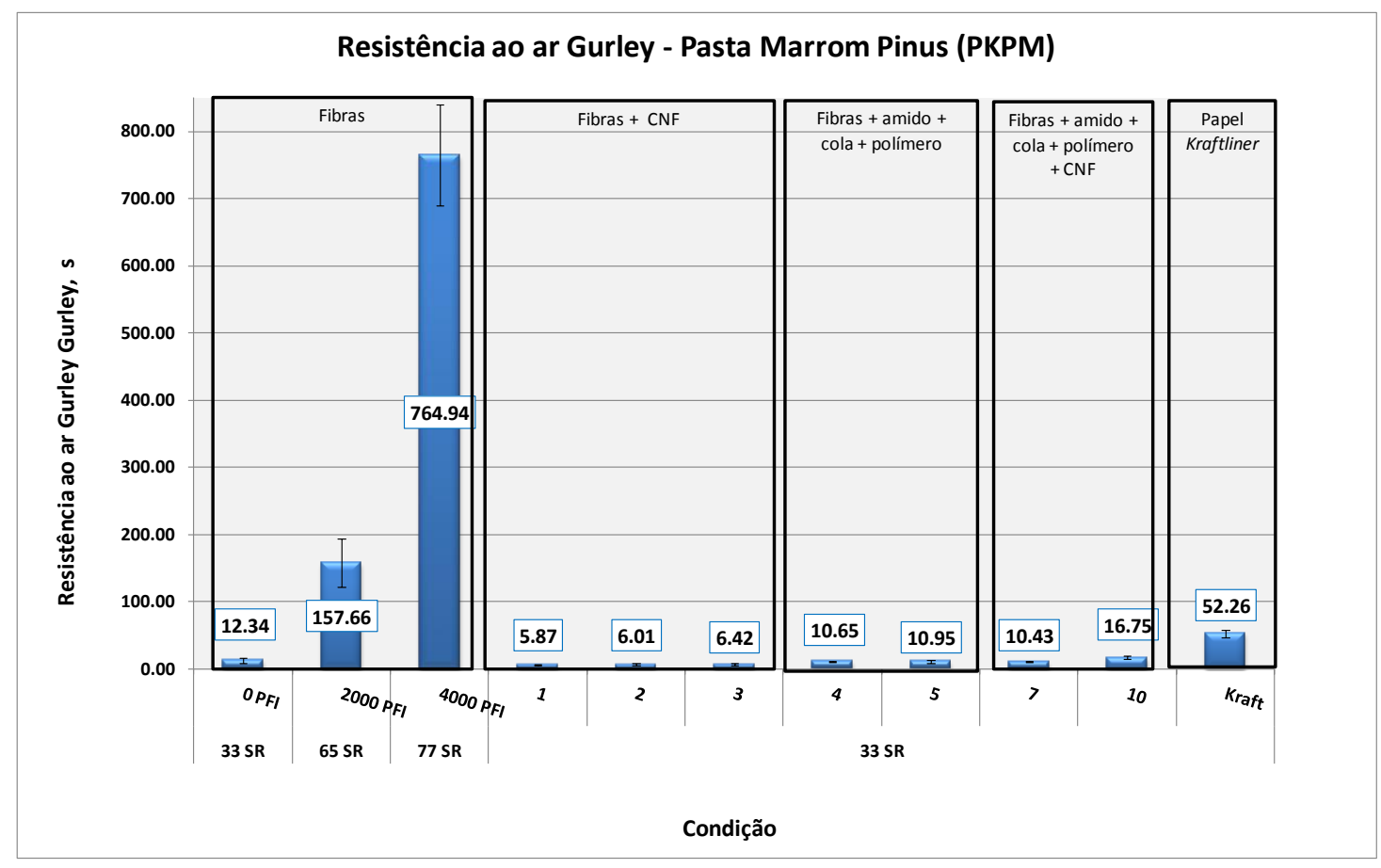

Figura 7.20: Resistência ao ar Gurley - Pasta marrom de pinus (PKPM)

Observando as Figuras 7.18, 7.19 e 7.20, a adição de nanoceluloses (CNF) aumenta os valores da resistência ao ar Gurley da pasta PKEP, mantém-se constante na pasta PKEB e diminui na pasta PKMP. Taipale et al. (2010), observou uma diminuição da permeabilidade ao ar incrementando o conteúdo de CNF $(0 \%$ até $30 \%)$ na pasta de celulose. Eriksen et al. (2008) obtiveram uma diminuição da permeância ao ar adicionando 4\% de CNF. Subramaniam (2008) descobriu que a permeabilidade ao ar cai rapidamente com o aumento do conteúdo CNF. Ele conclui que a permeabilidade da rede microfinos/pigmentos, a varias gramaturas, é muito baixa. Ao contrario da adição de CNF, ao adicionar os aditivos químicos ou a mistura de CNF com os químicos, a resistência ao ar Gurley da pasta pré-branqueada de eucalipto (PKEP) cai. Brodin et al. (2014) expõe que a adição de CNF no papel reduz a permeabilidade ao ar (porosidade). Na pasta de pinus (PKPM) diminui, ao contrario que na pasta PKEP, se comparados com os valores obtidos para as pastas sem CNF e aumenta com respeito as condições de adição de CNF.

Os valores de resistência ao ar são (Figuras 7.18, 7.19 e 7.20), praticamente, semelhantes entre condições 1,2 e 3, independentemente do tipo de pasta. 
Na pasta PKEP a resistência ao ar resultados similares entre as condições 4 e 5, e entre as condições 7 e 10. Por outro lado, na pasta PKPM, os valores de resistência ao ar Gurley são similares entre as condições 4, 5 e 7. No papel Kraftliner industrial, o valor da resistência ao ar Gurley é menor que nas condições de adição utilizadas. Lembra-se aqui que a permeância ao ar é inversamente proporcional à resistência ao ar, e que todos dão indicação parcial da "porosidade" do papel. Análise de diferentes métodos pode ser visto em Yasumura e Park (2012).

\subsubsection{Opacidade}

Nas Figuras 7.21, 7.22 e 7.23 apresenta-se a opacidade dos resultados obtidos para os ensaios preliminares das pastas PKEB, PKEP e PKPM. Nestas figuras, também se apresenta a opacidade a 0 PFI, 2000 PFI e 4000 PFI e da opacidade do Papel Kraftliner industrial para comparação.

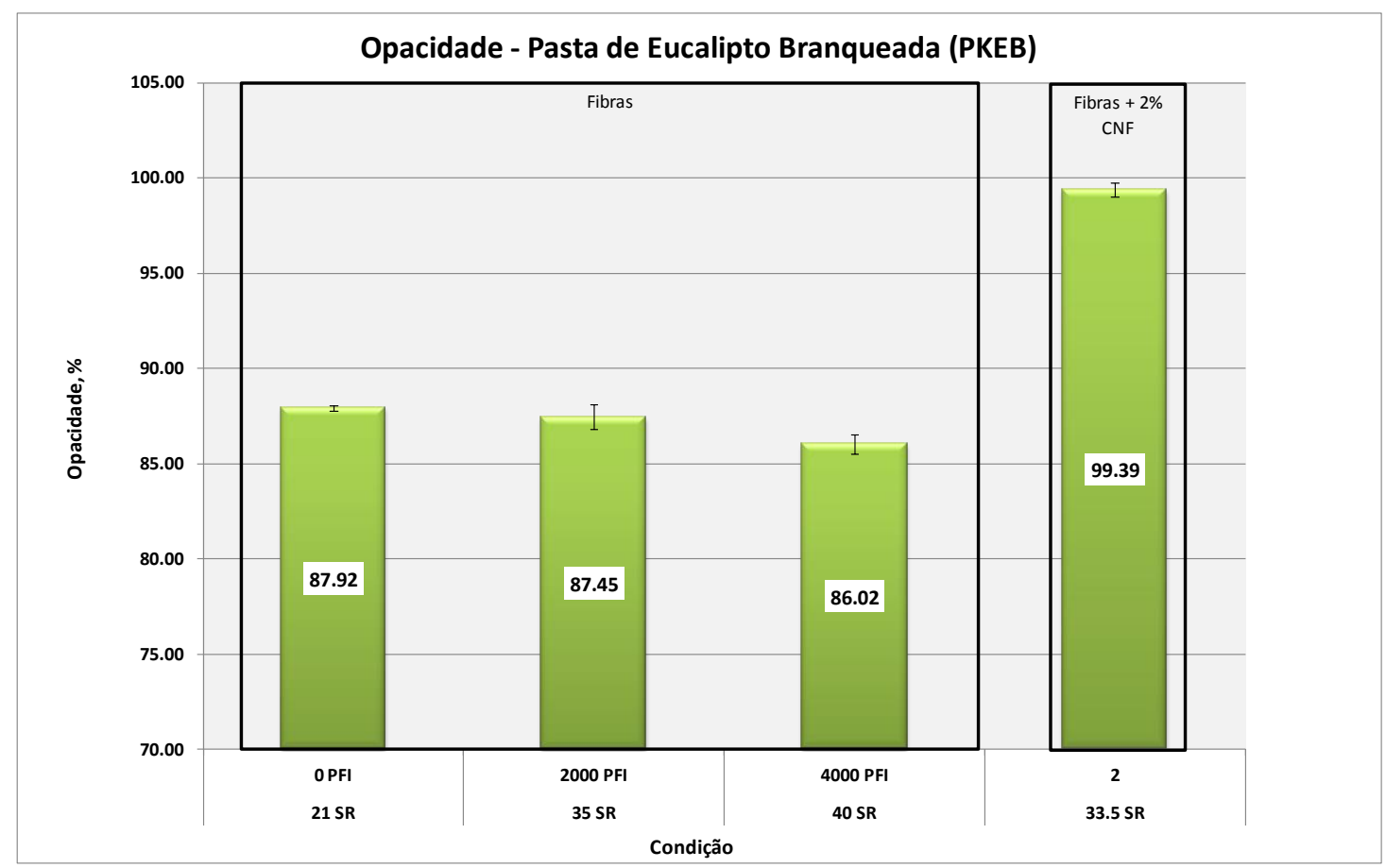

Figura 7.21: Opacidade - Pasta branqueada (PKEB) 


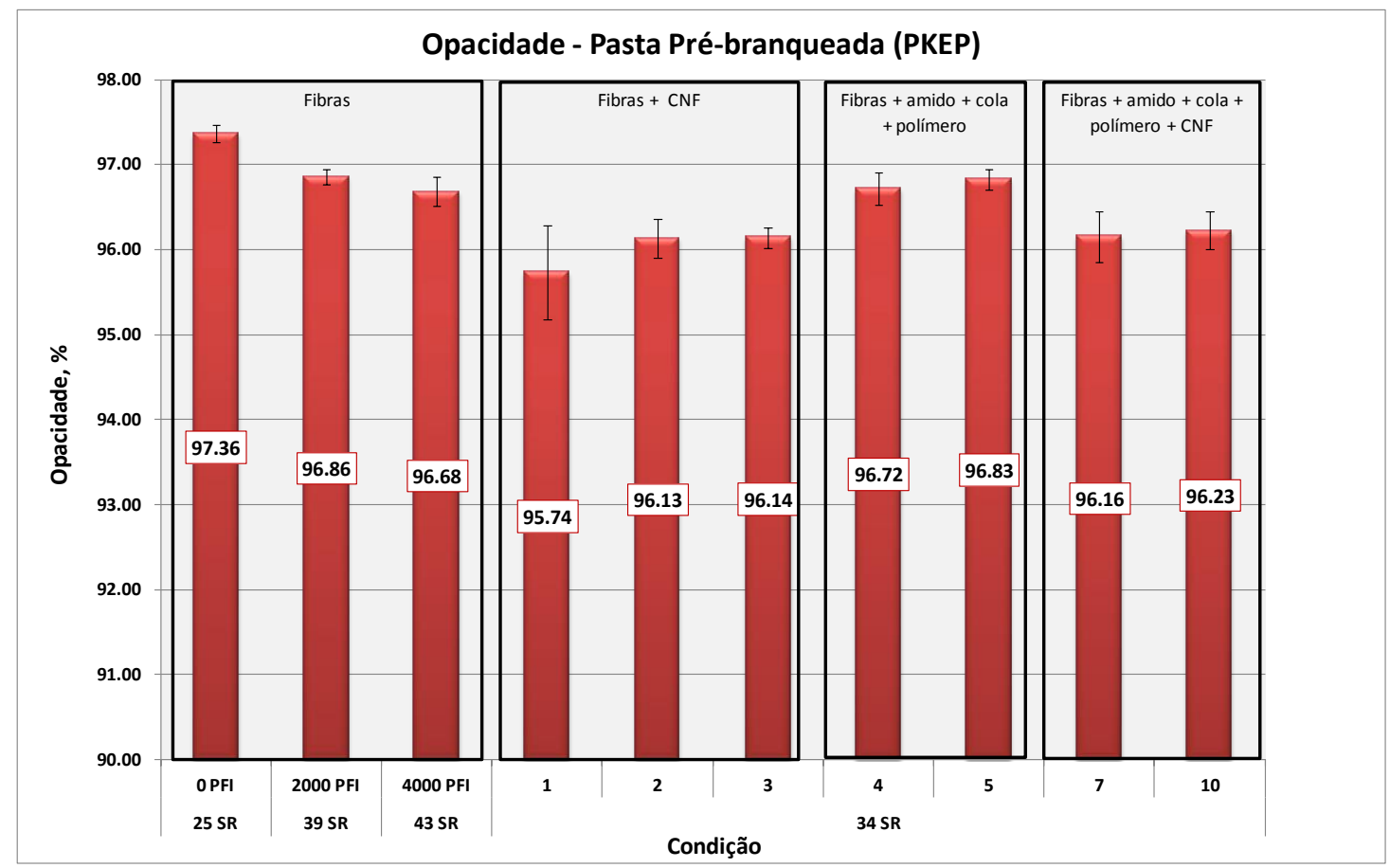

Figura 7.22: Opacidade - Pasta pré-branqueada (PKEP)

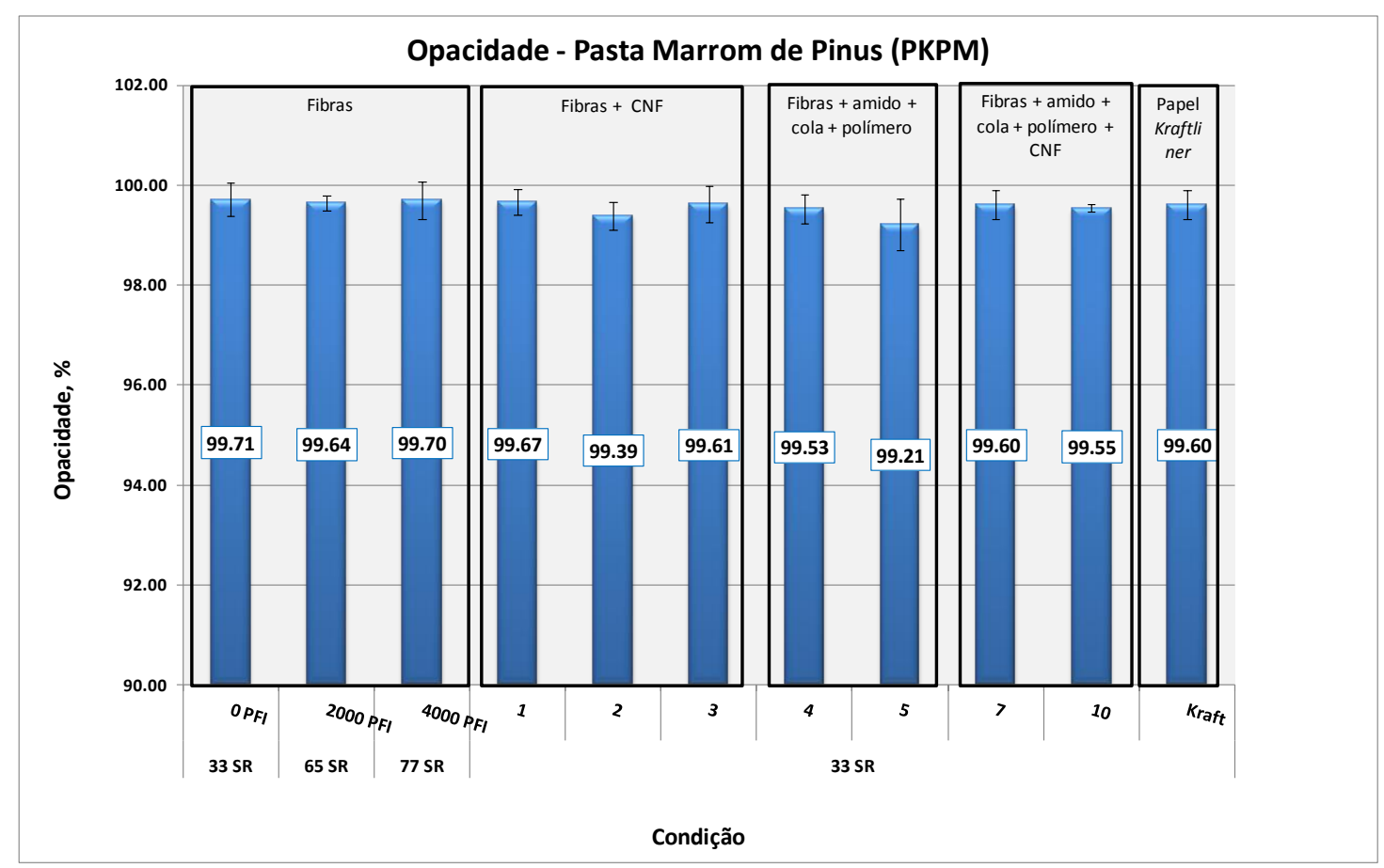

Figura 7.23: Opacidade - Pasta marrom de pinus (PKPM)

Os resultados mais importantes das Figuras 7.21, 7.22 e 7.23 são:

- A adição de nanoceluloses (CNF) na pasta de eucalipto branqueada (Figura 7.21) aumenta consideravelmente a opacidade do papel. 
Possivelmente, a adição de nanoceluloses no papel aumenta o espalhamento da luz, portanto, aumenta a opacidade do papel. No entanto, na pasta PKEP observa-se uma pequena diminuição, concordando com a literatura (BRODIN et al., 2014);

- Na pasta pré-branqueada de eucalipto (PKEP) e na pasta de pinus marrom (PKPM), não se observam mudanças significativas nos valores de opacidade, nas condições utilizadas. Além disso, na Figura 7.14 observa-se que o valor de opacidade do papel Kraftliner industrial (Kraft) é semelhante ao das condições realizadas.

\subsection{Resultados do delineamento dos experimentos da pasta pré-branqueada com adição de nanoceluloses, amido, cola e polímero de retenção.}

\subsubsection{Resultados Iniciais}

Para poder comparar os resultados dos experimentos, inicialmente realizaram-se folhas de laboratório com a pasta PKEP e PKPM, com adição de CNF ou MFC, com adição de amido, cola e polímero, e com CNF ou MFC ${ }^{[22]}$ junto com amido, cola e polímero. Na Tabela 7.2 apresentam-se os resultados obtidos para folhas de laboratório formadas (nas pastas PKEP e PKPM) sem aditivos químicos, para $1 \%$ de CNF e $1 \%$ de MFC, com amido, cola e polímero e nos pontos centrais do planejamento de experimentos composto central.

22 Nesta parte da monografia, para as nanoceluloses obtidas por processo Masuko às vezes se utiliza o termo MFC e/ou MCF. A evidência concreta de que a nanocelulose produzida para o presente trabalho, por tratamento puramente mecânico é microfibrilas de celulose, pode ser encontrada em POTULSKI, D.C. Influência da Nanocelulose nas Propriedades Físicas Mecânicas de Papel Primário e Reciclado de Pinus e Eucalyptus. Tese DR. UFPr, 2016 e VIANA, L.C. Desenvolvimento de filmes celulósicos nanoestruturados a partir da polpa Kraft de Pinus sp. Tese DR. UFPr, 2013. Nanocelulose produzida para o presente trabalho, por oxidação TEMPO seguida de homogeneização GEA, é celulose nanofibrilada (CNF), conforme pode ser visto em GAMELAS et al. On the morphology of cellulose nanofibrils obtained by TEMPO-mediated oxidation and mechanical treatment. Micron, v.72, p.28-33. 2015. 
Tabela 7.2: Resultados obtidos para os índices de tração, rasgo e estouro

\begin{tabular}{|c|c|c|c|c|c|c|}
\hline Pasta & $\begin{array}{l}\text { Referência } \\
\text { (Branco) }\end{array}$ & $1 \% \mathrm{CNF}$ & $1 \% \mathrm{MCF}$ & $\begin{array}{c}0,5 \% \text { amido } \\
+0,06 \% \text { cola } \\
+0,02 \% \\
\text { polímero }\end{array}$ & $\begin{array}{c}1 \% \text { CNF }+0,5 \% \\
\text { amido+0,06\% } \\
+0,02 \% \\
\text { polímero }\end{array}$ & $\begin{array}{c}1 \% \text { MFC+0,5\% } \\
\text { amido+0,06\% } \\
\text { cola+0,02\% } \\
\text { polímero }\end{array}$ \\
\hline \multicolumn{7}{|c|}{ Índice de Resistência à Tração, N.m/g } \\
\hline PKEP & $32,14(2,50)$ & $42,71(3,99)$ & $39,42(2,61)$ & $39,60(2,20)$ & $33,02(1,08)$ & $37,26(2,97)$ \\
\hline PKPM & $40,01(3,02)$ & $34,14(1,98)$ & $32,28(2,88)$ & $45,28(2,90)$ & $32,68(1,20)$ & $33,21(1,47)$ \\
\hline \multicolumn{7}{|c|}{ Índice de Resistência a Rasgo, $\mathrm{mN} \cdot \mathrm{m}^{2} / \mathrm{g}$} \\
\hline PKEP & $7,24(0,73)$ & $9,92(1,08)$ & $9,82(0,99)$ & $8,88(0,65)$ & $9,53(0,77)$ & $9,89(0,64)$ \\
\hline PKPM & $22,83(1,64)$ & $21,53(0,64)$ & $18,99(1,42)$ & $21,50(0,97)$ & $19,26(0,49)$ & $19,16(0,57)$ \\
\hline \multicolumn{7}{|c|}{ Índice de Resistência a Estouro, kPa.m²/g } \\
\hline PKEP & $1,83(0,16)$ & $2,64(0,19)$ & $2,00(0,21)$ & $2,39(0,48)$ & $1,68(0,17)$ & $2,34(0,21)$ \\
\hline PKPM & $2,96(0,24)$ & $3,03(0,27)$ & $2,66(0,30)$ & $3,56(0,30)$ & $2,73(0,21)$ & $2,74(0,33)$ \\
\hline
\end{tabular}

Nota: O número entre parênteses refere-se ao desvio padrão do ensaio.

De uma maneira geral, na Tabela 7.2 pode-se perceber que tanto com a adição de CNF quanto com as MFC, os índices de resistência mecânica aumentam na pasta PKEP. Na pasta PKPM a resistência à tração diminui e mantém, praticamente, constante a resistência ao rasgo e ao estouro.

Na pasta PKEP observa-se que nos índices de resistência a tração e estouro têm os maiores valores quando adicionados somente amido, cola e polímero. Isto é devido a que os aditivos de retenção catiônicos ajudam ao aumento das uniões entre fibras (HUBBE, 2005; HUBBE, 2007; KHOSRAVANI et al. 2010), aumentando as propriedades que dependem principalmente do potencial de união entre fibras, como tração e estouro e não aquelas que dependem, principalmente, da integridade das mesmas, como rasgo.

$\mathrm{Na}$ Tabela 7.2 observa-se que o uso de $1 \%$ de CNF aumenta, proporcionalmente, mais as propriedades de resistência que o uso de $1 \%$ de MFC. Adicionando nanoceluloses junto com amido, cola e polímero as propriedades mecânicas também aumentam, a exceção do índice de resistência a estouro quando se adicionam CNF e aditivos químicos. Se comparados as misturas de CNF ou MFC com aditivos, os incrementos são maiores quando usadas MFC. Na pasta PKPM, a diminuição dos índices de resistência é menor quando usadas MFC se comparados com o uso de CNF. 
Os maiores incrementos dos índices de resistência mecânica obtêm-se no índice de rasgo (31,6\%, CNF + aditivos; 36,6\%, MFC + aditivos) quando são usados aditivos de processo e nanoceluloses.

\subsubsection{Grau Schopper-Riegler da pasta pré-branqueada com nanoceluloses}

Para conhecer como o conteúdo de CNF ou de MFC afeta a drenagem, foi medido o grau Schopper-Riegler de uma suspensão de fibras da pasta prébranqueada em contato com $1 \%$ de CNF ou $1 \%$ de MFC. Na Tabela 7.3 apresentam-se os resultados.

Tabela 7.3: Grau Schopper-Riegler da pasta PKEP com 1\% de CNF e 1\% de MFC

\begin{tabular}{cccc}
\hline Pasta & $\begin{array}{c}\text { Referência } \\
\text { (Branco) }\end{array}$ & 1\% CNF & 1\% MFC \\
\hline PKEP & $34(1)$ & $35(1)$ & $36(1)$ \\
\hline
\end{tabular}

Nota: O número entre parênteses refere-se ao desvio padrão do ensaio.

Na Tabela 7.3 observa-se que, neste estudo, a adição de nanoceluloses não aumenta o grau Schopper-Riegler da pasta celulósica. Segundo autores, a adição de nanoceluloses na pasta celulósica diminui a drenagem e o desaguamento (KAJANTO e KOSONEN, 2012). Manninen (2011) observou que, com uma adição de $5 \%$ de MCF em pasta química, o tempo de drenagem de folhas manuais de laboratório quase se duplicou. Segundo Kajanto e Kosonen (2012) o aumento do tempo de drenagem tende a aumentar com quantidades maiores de nanocellulose.

Note-se que aqui estamos utilizando no máximo $2 \%$ de nanocelulose no delineamento de experimentos. Coerente com o exposto na revisão deste trabalho, no presente estudo 0 uso de um percentual pequeno de nanoceluloses com respeito à fibra não altera, significativamente, à resistência a drenagem.

\subsubsection{Resultados em propriedades físico-mecânicas com CNF}

O estudo aqui trata dos resultados da superfície de resposta, composto central das propriedades mecânicas (índices de tração, rasgo e estouro) das 
formações de folhas realizadas em pasta pré-branqueada com CNF, junto com os agentes de retenção e colagem (amido, cola e polímero de retenção). $\mathrm{Na}$ Tabela 7.4 apresentam-se os resultados obtidos para os índices de resistência mecânica nos ensaios realizados para fazer o planejamento de experimentos.

Tabela 7.4: Resultados dos testes realizados para os índices ${ }^{[23]}$ de tração, estouro e rasgo, com as diferentes adições de CNF

\begin{tabular}{|c|c|c|c|c|}
\hline $\begin{array}{c}\text { CNF, } \\
\%\end{array}$ & $\begin{array}{c}\text { Amido + Cola } \\
\%\end{array}$ & $\begin{array}{l}\text { Índice de Tração } \\
\text { (Tensile), N.m/g }\end{array}$ & $\begin{array}{l}\text { Índice de Estouro } \\
\text { (Burst), } \mathrm{kPa} \cdot \mathrm{m}^{2} / \mathrm{g}\end{array}$ & $\begin{array}{l}\text { Índice de Rasgo } \\
\text { (Tear), } \mathrm{mN} \cdot \mathrm{m}^{2} / \mathrm{g}\end{array}$ \\
\hline 0,3 & $0,15+0,02$ & 27,60 & 1,47 & 6,49 \\
\hline 1,7 & $0,15+0,02$ & 34,23 & 2,07 & 8,63 \\
\hline 0,3 & $0,85+0,01$ & 35,68 & 2,10 & 9,29 \\
\hline 1,7 & $0,85+0,01$ & 36,39 & 2,04 & 10,97 \\
\hline 0,0 & $0,50+0,06$ & 39,60 & 2,39 & 8,88 \\
\hline 2,0 & $0,50+0,06$ & 34,79 & 1,93 & 10,69 \\
\hline 1,0 & $0,00+0,00$ & 42,71 & 2,64 & 9,92 \\
\hline 1,0 & $1,00+0,12$ & 33,33 & 2,07 & 9,92 \\
\hline 1,0 & $0,50+0,06$ & 35,46 & 2,01 & 10,58 \\
\hline 1,0 & $0,50+0,06$ & 36,01 & 2,36 & 9,55 \\
\hline 1,0 & $0,50+0,06$ & 37,01 & 2,30 & 9,21 \\
\hline 1,0 & $0,50+0,06$ & 42,46 & 2,56 & 9,55 \\
\hline 1,0 & $0,50+0,06$ & 35,44 & 2,48 & 10,58 \\
\hline 1,0 & $0,85+0,10$ & 36,20 & 2,16 & 9,77 \\
\hline 1,0 & $0,15+0,02$ & 34,01 & 1,98 & 8,19 \\
\hline 0,3 & $0,50+0,06$ & 33,41 & 1,95 & 8,44 \\
\hline 1,7 & $0,50+0,06$ & 34,36 & 1,79 & 9,93 \\
\hline
\end{tabular}

Foi realizado o teste estatístico para os índices de tração, rasgo e estouro. Os resultados obtidos apresentam-se nas Tabelas 7.5, 7.6 e 7.7.

${ }^{23}$ Devido ao pouco espaço que fornece o software Minitab® para edição, nas Figuras e Tabelas seguintes os índices de resistência mecânica apresentam-se como: Tensile (Índice de tração), Tear (índice de rasgo) e Burst (índice de estouro). Da mesma forma, o percentual de ( amido + cola) apresenta-se como AMIDO. 
Tabela 7.5: Resultados estatísticos da análise da resposta do índice de tração (Tensile) usando CNF

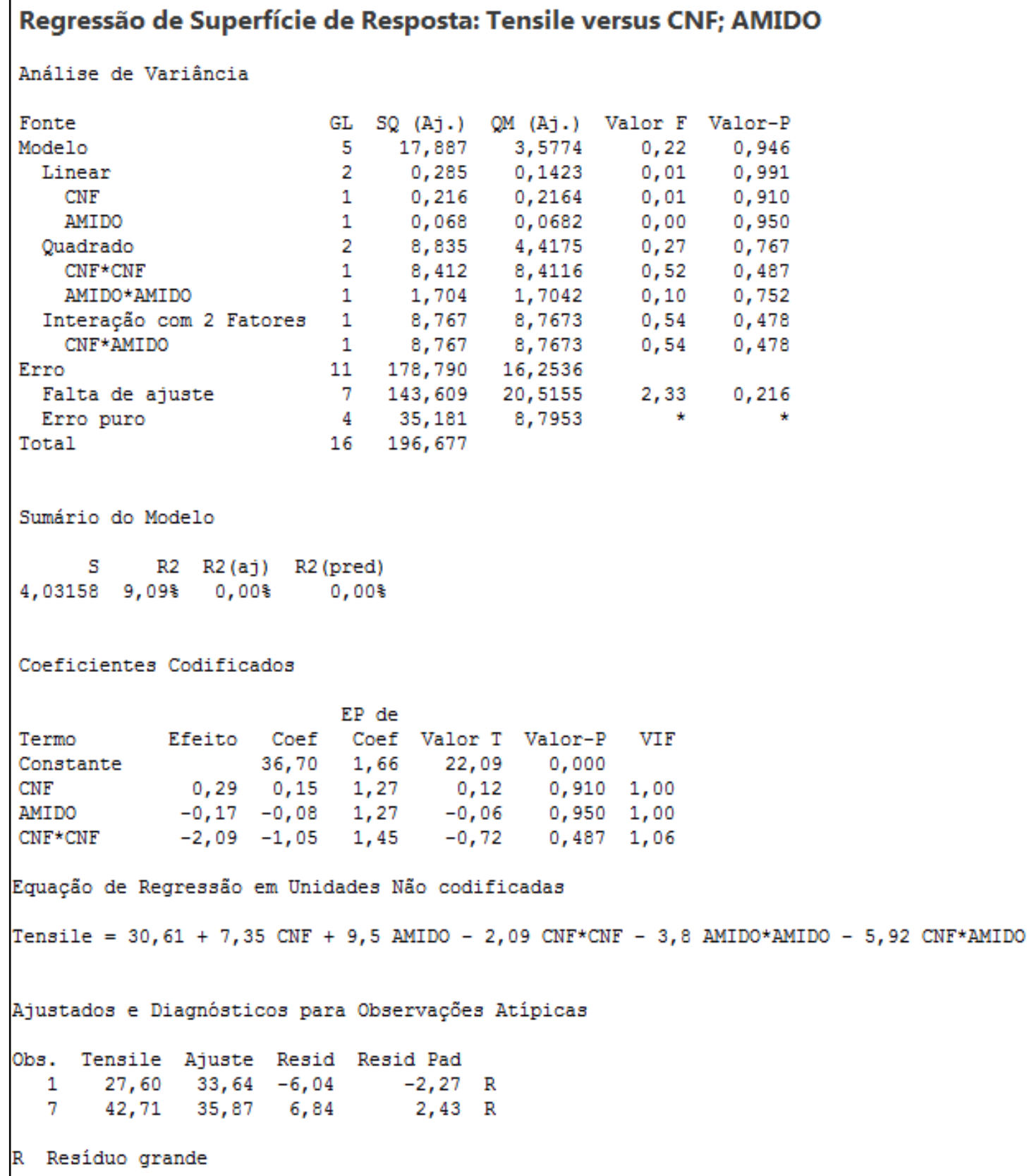


Tabela 7.6: Resultados estatísticos da análise da resposta do índice de rasgo (Tear) usando CNF

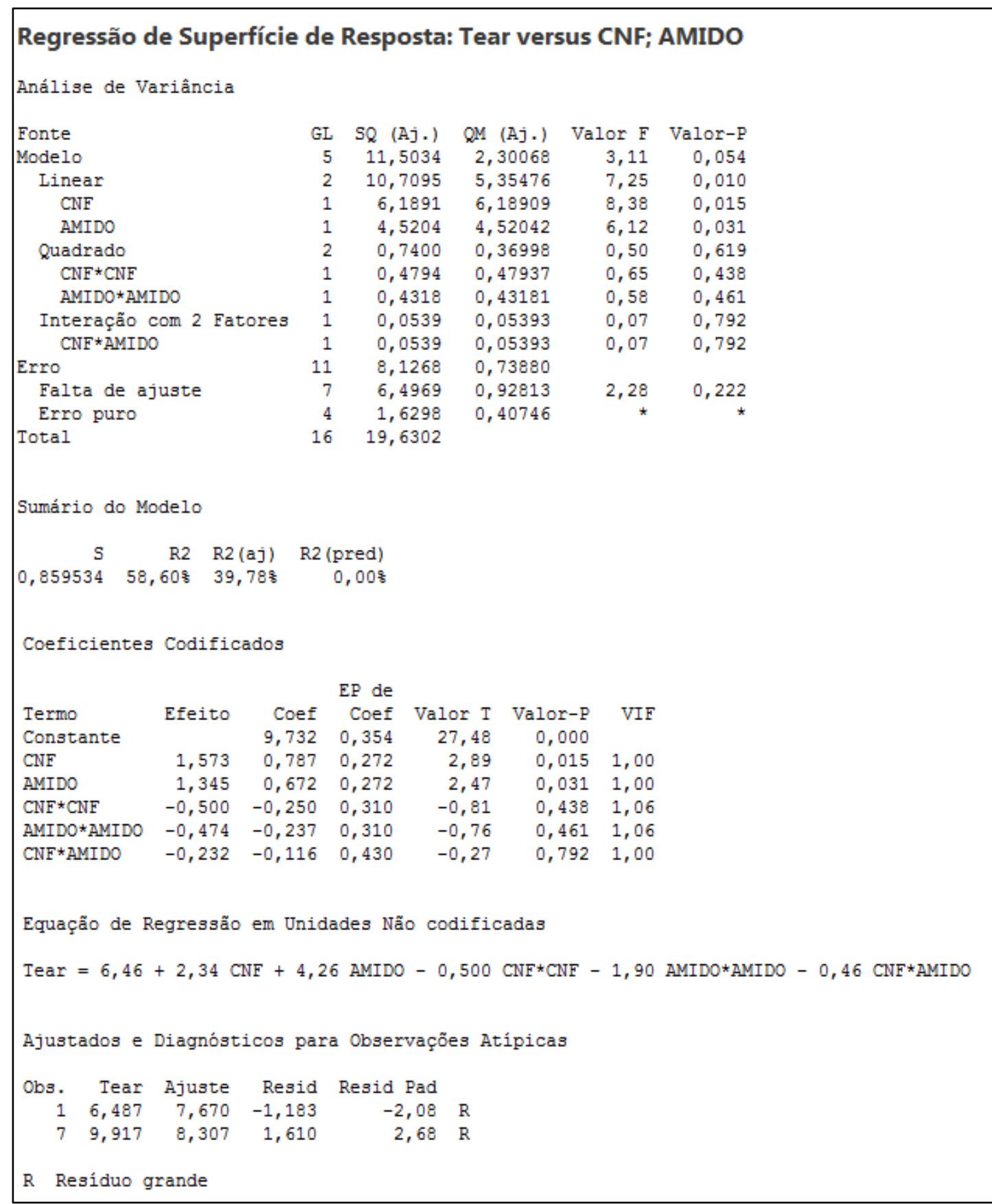


Tabela 7.7: Resultados estatísticos da análise da resposta do índice de estouro (Burst) usando CNF

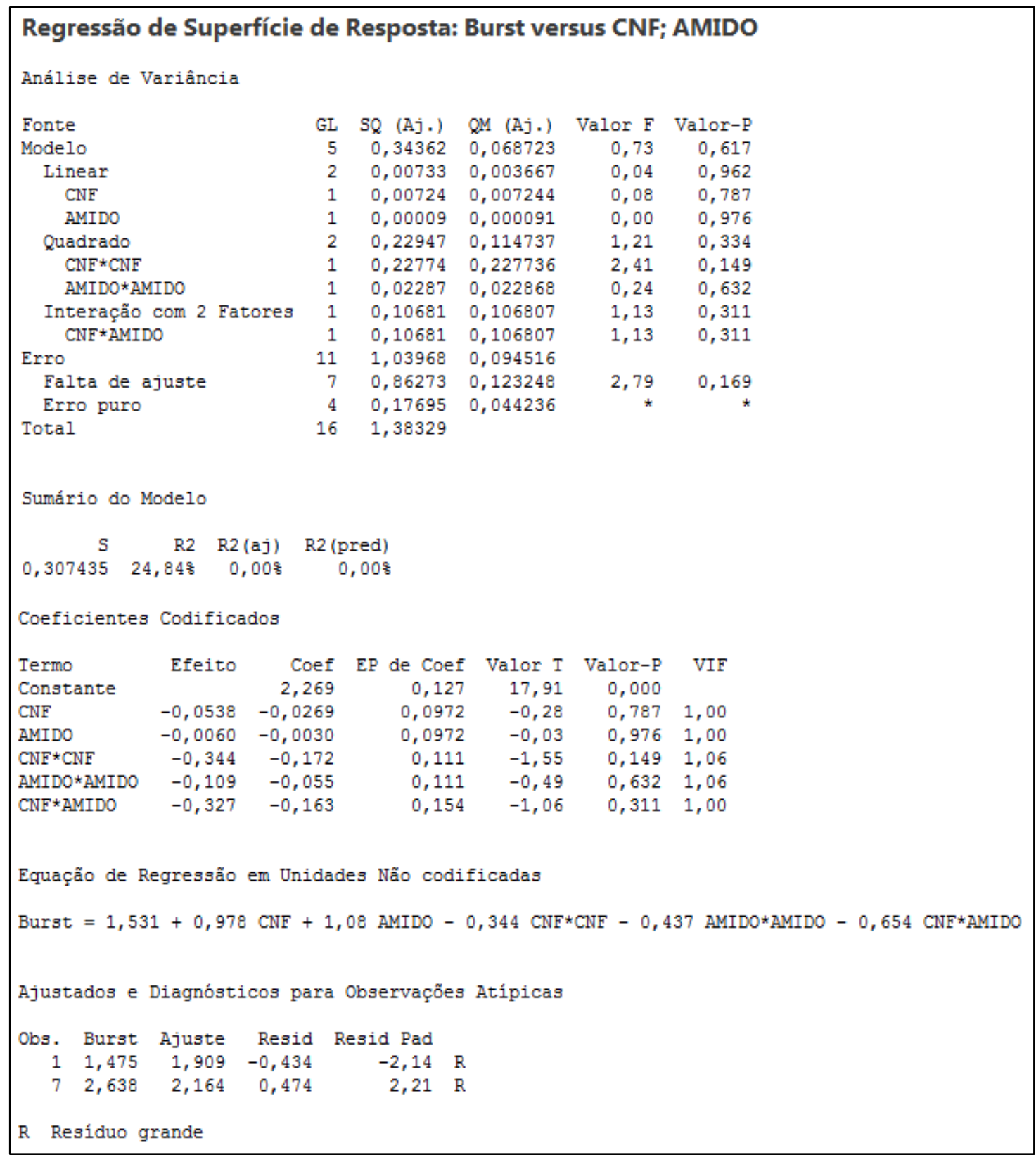

Para os dados dos índices de resistência a tração e estouro, as Tabelas 7.5 e 7.7 mostram o seguinte: 
- O valor de p para o conteúdo de CNF e o conteúdo de (amido + cola) (AMIDO) não é inferior a 0,05 . Portanto, não há nenhum efeito significativo. Consequentemente, as CNF ou AMIDO não tem efeito significativo individualmente;

- O modelo contém uma única interação de dois fatores (CNF*AMIDO). O valor da interação tem um valor de p>0,05, portanto também não é significativo;

- O modelo contém dois efeitos quadráticos $\left(\mathrm{CNF}^{*} \mathrm{CNF}\right.$ e AMIDO*AMIDO). Os termos quadráticos são usados para avaliar se há curvatura (quadrática) na superfície de resposta ou não. Os termos quadráticos podem-se identificar como não significativos na tabela de análise de variância $(p>0,05)$, implica que não se podem analisar os efeitos da CNF ou de (amido + cola) separadamente. Por outra parte, como os efeitos quadráticos têm um valor de $p>0,05$ a relação entre o conteúdo de CNF e o conteúdo de AMIDO, segue um modelo linear;

- Os VIFs estão todos próximos a 1, o que indicando que os preditores não são correlacionados.

Para os dados do índice de resistência a rasgo, a Tabela de 7.6 mostra o seguinte:

- O valor de p para o conteúdo de CNF e o conteúdo de (amido + cola) (AMIDO) é inferior a 0,05 . Portanto, há efeito significativo, implica que o valor do índice de resistência ao rasgo difere de acordo ao conteúdo de CNF e/ou de AMIDO;

- $O$ valor da interação $C N F^{\star} A M I D O$ tem um valor de $p>0,05$ não sendo significativo;

- Os termos quadráticos podem-se identificar como não significativos ( $p>0,05$ ), ao igual que nos índices de tração e estouro, implica que não se podem analisar os efeitos da CNF ou de AMIDO separadamente. Além disso, também segue um modelo linear;

- Ao igual que nos outros índices, os VIFs estão todos próximos a 1, indicando que os preditores não são correlacionados. 
Na Figura 7.24 apresentam-se os gráficos de contorno e os gráficos de superfície gerados para os índices de resistência à tração, rasgo e estouro, baseados nas seguintes equações de regressão (Equações 1, 2 e 3):

Índice de Tração $=30,61+7,35 *(\% C N F)+9,5 *(\%$ amido e cola $)-2,09 *$

$(\% C N F * \% C N F)-3,8 *(\%$ amido e cola $) *(\%$ amido e cola $)-5,92 *$

Equação 1

$(\% C N F) *(\%$ amido e cola $)$

Índice de Rasgo $=6,46+2,34 *(\% C N F)+4,26 *(\%$ amido e cola $)-0,5 *$

$(\% C N F * \% C N F)-1,9 *(\%$ amido e cola $) *(\%$ amido e cola $)-0,46 *$

Equação 2

$(\% C N F) *(\%$ amido e cola $)$

Índice de Estouro $=1,531+0,978 *(\% C N F)+1,08 *(\%$ amido e cola $)-$

$0,344 *(\% C N F * \% C N F)-0,437 *(\%$ amido e cola $) *(\%$ amido e cola $)-$

Equação 3

$0,654 *(\% C N F) *(\%$ amido e cola $)$

$\mathrm{Na}$ Figura 7.24 observa-se que a combinação dos parâmetros (CNF e AMIDO) nos níveis máximos ou mínimos influencia fortemente o resultado da função resposta (índice de tração - Tensile). Assim, os valores máximos para o índice de tração encontram-se quando o conteúdo de CNF ou o de (amido + cola) é máximo. $O$ aumento do valor do índice de resistência à tração com o aumento do conteúdo de CNF esta de acordo com a literatura pesquisada. Taipale et al. (2010) observaram incrementos de 39,9\% na resistência à tração ao adicionar CNF em folhas de laboratório na suspensão em massa. Toven et al. (2008), citado por Brodin et al. (2014), concluíram que o aumento do conteúdo de CNF em papéis supercalandrados aumenta a resistência mecânica dos papéis. No entanto, comparando com a referência (Tabela 7.2), o incremento do índice de resistência a tração é pouco significativa $(32,15$ N.m/g, referência). Por outra parte, observa-se na Figura 7.24 que usando uma quantidade inferior de CNF junto com (amido + cola) têm-se resultados semelhantes, usando menos materiais. 


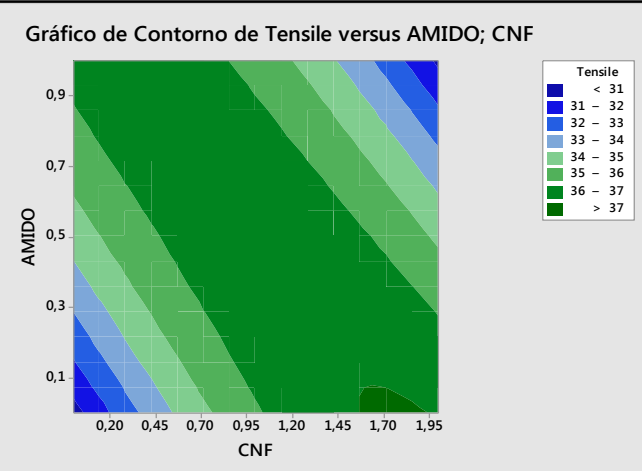

Gráfico de Contorno de Tear versus AMIDO; CNF

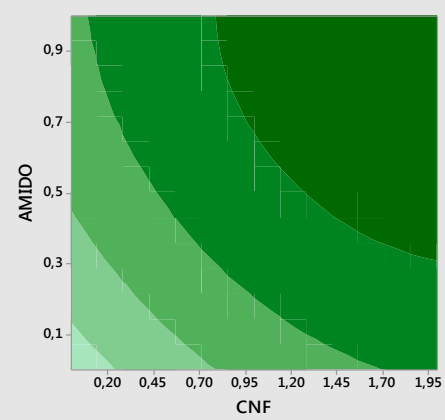

Gráfico de Contorno de Burst versus AMIDO; CNF
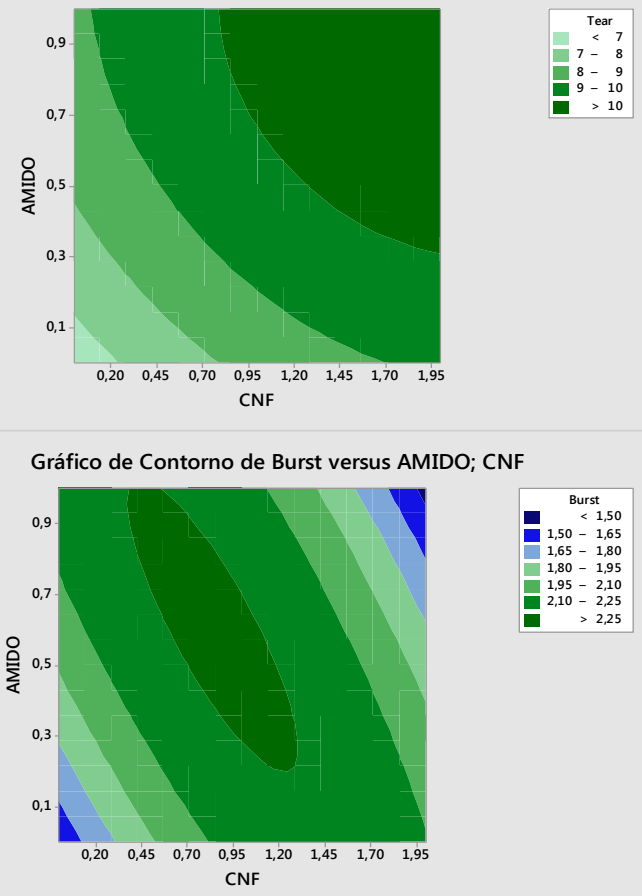

Gráfico de Superfície de Tensile versus AMIDO; CNF

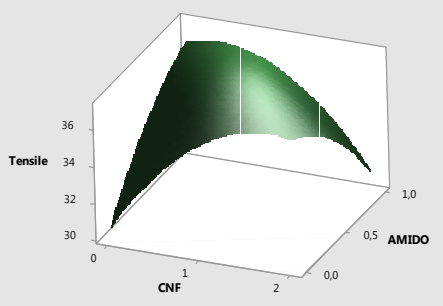

Gráfico de Superfície de Tear versus AMIDO; CNF

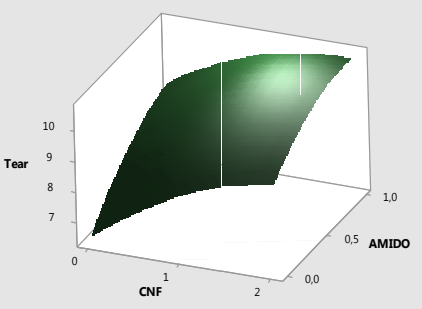

Gráfico de Superfície de Burst versus AMIDO; CNF

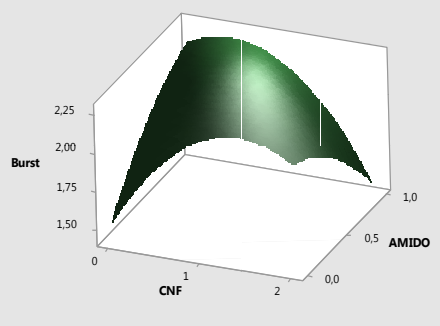

Figura 7.24: Gráficos de contorno e de superfície para os índices de resistência a tração (Tensile), rasgo (Tear) e estouro (Burst) com CNF

O gráfico de contorno e o gráfico de superfície do índice de resistência a rasgo mostram um valor máximo quando o valor de CNF e/ou amido é máximo. Porém, misturas intermédias de CNF e (amido + cola) obtém valores semelhantes. Conforme observado na Tabela 7.6, o conteúdo de CNF e de (amido + cola) têm significância estatística $(p<0,05)$, assim, ao contrario dos índices de resistência a tração e estouro, o aumento do índice de rasgo, sim, é significativo com respeito ao valor da referência $\left(7,24 \mathrm{mNm}^{2} / \mathrm{g}\right)$. 
Através do gráfico de contorno e de superfície, no índice de resistência a estouro, observa-se que os maiores valores têm-se para concentrações médias de CNF e baixas ou altas de (amido + cola). No entanto, similar ao índice de resistência à tração, o incremento do índice de resistência a estouro é relativamente pequeno.

Na Figura 7.25 apresentam-se o gráfico de otimização da resposta gerado para os índices de resistência à tração, rasgo e estouro.

\begin{tabular}{|c|c|c|c|c|c|c|c|c|c|}
\hline $\begin{array}{l}\text { Ótima } \\
\text { D: } 0,6780 \text { Superio } \\
\text { Predizer Inferio }\end{array}$ & $\begin{array}{c}\text { CNF } \\
2,0 \\
{[1,0303]} \\
0,0\end{array}$ & $\begin{array}{c}\text { AMIDO } \\
1,0 \\
{[0,6465]} \\
0,0\end{array}$ & $\begin{array}{l}\text { Otimiza } \\
\text { Parâmetro }\end{array}$ & ção da & Resposta: & Tear; Bu & Irst; Tensi & ile & \\
\hline $\begin{array}{l}\text { Composto } \\
\text { Desirability } \\
\text { D: } 0,6780\end{array}$ & & & $\begin{array}{l}\text { Resposta } \\
\text { Tear } \\
\text { Burst } \\
\text { Tensile }\end{array}$ & $\begin{array}{l}\text { Meta } \\
\text { Máximo } \\
\text { Máximo } \\
\text { Máximo }\end{array}$ & $\begin{array}{r}\text { Inferior } \\
6,4870 \\
1,4748 \\
27,6001\end{array}$ & $\begin{array}{r}\text { Alvo } \\
10,9660 \\
2,6378 \\
42,7135\end{array}$ & Superior & $\begin{array}{r}\text { Peso } \\
1 \\
1 \\
1\end{array}$ & $\begin{array}{r}\text { Importância } \\
1 \\
1 \\
1\end{array}$ \\
\hline $\begin{array}{c}\text { Tear } \\
\text { Máximo } \\
y=10,0015 \\
d=0,78466\end{array}$ & & & $\begin{array}{l}\text { Solução } \\
1\end{array}$ & $\begin{array}{l}\text { CNF } \\
1,03030\end{array}$ & $\begin{array}{l}\text { AMIDO } \\
0,646465\end{array}$ & $\begin{array}{r}\text { Tear } \\
\text { Ajuste } \\
10,0015\end{array}$ & $\begin{array}{r}\text { Burst } \\
\text { Ajuste } \\
2,25395\end{array}$ & $\begin{array}{l}\text { Tensile } \\
\text { Ajuste } \\
36,561\end{array}$ & $\begin{array}{rr}e & \text { Desirability } \\
\text { e } & \text { Composta } \\
4 & 0,678025\end{array}$ \\
\hline $\begin{array}{c}\text { Burst } \\
\text { Máximo } \\
y=2,2540 \\
d=0,66996\end{array}$ & & & $\begin{array}{l}\text { Predição } \\
\text { Variável } \\
\text { CNF } \\
\text { AMIDO }\end{array}$ & $\begin{array}{l}\text { de Múlti } \\
\text { Configu } \\
1,03030 \\
0,64646\end{array}$ & $\begin{array}{l}\text { plas Respo } \\
\text { rações } \\
5\end{array}$ & tas & & & \\
\hline $\begin{array}{c}\text { Tensile } \\
\text { Máximo } \\
y=36,5614 \\
d=0,59294\end{array}$ & & & $\begin{array}{l}\text { Resposta } \\
\text { Tear } \\
\text { Burst } \\
\text { Tensile }\end{array}$ & $\begin{array}{r}\text { Ajuste } \\
10,001 \\
2,254 \\
36,56\end{array}$ & $\begin{array}{r}\text { EP do } \\
\text { Ajustado } \\
0,342 \\
0,122 \\
1,60\end{array}$ & $\begin{array}{l}\quad \text { IC de } \\
(9,249 ; \\
(1,985 ; \\
(33,03 ;\end{array}$ & $\begin{array}{r}=95 \% \\
10,754) \\
2,523) \\
40,09)\end{array}$ & $\begin{array}{l}\quad \text { IP de } \\
(7,965 ; \\
(1,526 ; \\
(27,01 ;\end{array}$ & $\begin{array}{r}\text { e } 95 \% \\
12,038 \text { ) } \\
2,982) \\
46,11)\end{array}$ \\
\hline
\end{tabular}

Figura 7.25: Gráfico de otimização da quantidade de CNF e de (amido + cola) adicionar para os índices de tração (Tensile), rasgo (Tear) e estouro (Burst) com CNF

Na Figura 7.25 observa-se que:

- As melhores condições de dosagem de CNF e (amido + cola) são $1,03 \%$ e 0,6465\%, respectivamente, otimizando os valores os índices de resistência à tração, rasgo e estouro ao mesmo tempo. Aumentar ou diminuir o percentual de CNF e/ou de (amido + cola) pode aperfeiçoar o valor de cada índice individualmente, porém maximizar somente um índice faz que os outros diminuam;

- O índice de rasgo apresenta a maior resposta, isto é, o aumento do conteúdo de CNF e/ou (amido + cola) aproximam seu valor ao máximo. 
Embora o aumento da quantidade de CNF e de (amido + cola) incremente os índices de resistência mecânica, observando os resultados obtidos para os índices de tração, rasgo e estouro, a adição de CNF e de (amido + cola) temse uma maior significância no índice de rasgo. Tanto a CNF quanto o (amido + cola) não apresentam uma interação significativa nos índices de tração e estouro. A explicação mais provável é que as CNF estejam-se aderindo nas fibras celulósicas e não aumentando o numero de uniões fibra-fibra. Como explicado, o índice de resistência ao rasgo depende principalmente da integridade das fibras celulósicas individuais. A adesão CNF-fibra ajuda a manter a integridade estrutural das mesmas, porém não aumenta, significativamente, o número de pontes de hidrogênio inter-fibras. No entanto, isto não está de acordo com a floculação tipo patch ou mosaico (HUBBE, 2007). Segundo o modelo, de patch ou mosaico, os floculantes usados no sistema de retenção de partículas tais como amidos catiônicos, colas e polímeros de retenção fazem que a associação dos agentes de retenção (amido, cola de breu, etc.) com as fibras celulósicas aumentar a adesão das micro e nanopartículas (cargas, finos, microfibras, etc.), aumentando, o numero de enlaces de hidrogênio e, consequentemente, incrementam os índices de resistência à tração e estouro.

Como descrito na revisão, "patchs" ou mosaicos são regiões de carga oposta à superfície da partícula, criadas através da adsorção de polímeros (ALOI e TRKSAK, 1998; BLANCO et al., 2001; ROJAS e HUBBE, 2004). As fibras celulósicas absorvem os reagentes na superfície, isto é, o polímero é absorvido na superfície das fibras, promovendo as forças atrativas entre as fibras e as micro e nanopartículas. Conforme comentado anteriormente, possivelmente, o uso de CNF junto com amido, cola e polímeros fazem com que as CNF, devido a sua grande área específica, formem seus próprios aglomerados, os quais se aderem às fibras devido à atração que exercem os polímeros sobre elas, não aumentando assim o número de pontes de hidrogênio CNF-fibra como se esperaria. 


\subsubsection{Resultados em propriedades físico-mecânicas com MFC}

O estudo aqui trata dos resultados da superfície de resposta, com ponto central, relativa à simulação das propriedades mecânicas (índices de tração, rasgo e estouro) das formações de folhas realizadas em pasta prébranqueada com nanoceluloses (MFC), junto com os agentes de retenção e colagem (amido, cola e polímero de retenção). Na Tabela 7.8 apresentam-se os resultados obtidos para os índices de resistência mecânica nos ensaios realizados para fazer o planejamento de experimentos.

Tabela 7.8: Resultados dos testes realizados para os índices de tração, estouro e rasgo, com as diferentes adições de MFC (ou MCF)

\begin{tabular}{|c|c|c|c|c|}
\hline $\begin{array}{c}\text { MFC, } \\
\%\end{array}$ & $\begin{array}{c}\text { Amido + Cola } \\
\%\end{array}$ & $\begin{array}{c}\text { Índice de Tração } \\
\text { (Tensile), Nm/g }\end{array}$ & $\begin{array}{l}\text { Índice de Estouro } \\
\text { (Burst), } \mathrm{kPam}^{2} / \mathrm{g}\end{array}$ & $\begin{array}{l}\text { Índice de Rasgo } \\
\text { (Tear), } \mathrm{mNm}^{2} / \mathrm{g}\end{array}$ \\
\hline 0,3 & $0,15+0,02$ & 34,00 & 1,87 & 7,53 \\
\hline 1,7 & $0,15+0,02$ & 46,02 & 2,65 & 11,98 \\
\hline 0,3 & $0,85+0,01$ & 43,76 & 2,97 & 10,96 \\
\hline 1,7 & $0,85+0,01$ & 50,03 & 3,09 & 12,18 \\
\hline 0,0 & $0,50+0,06$ & 39,60 & 2,39 & 8,88 \\
\hline 2,0 & $0,50+0,06$ & 45,19 & 2,88 & 11,20 \\
\hline 1,0 & $0,00+0,00$ & 39,42 & 2,00 & 9,82 \\
\hline 1,0 & $1,00+0,12$ & 50,82 & 3,28 & 11,99 \\
\hline 1,0 & $0,50+0,06$ & 31,20 & 1,63 & 9,46 \\
\hline 1,0 & $0,50+0,06$ & 33,48 & 1,68 & 8,78 \\
\hline 1,0 & $0,50+0,06$ & 33,43 & 1,97 & 8,78 \\
\hline 1,0 & $0,50+0,06$ & 34,00 & 1,61 & 10,47 \\
\hline 1,0 & $0,50+0,06$ & 33,00 & 1,50 & 10,14 \\
\hline 1,0 & $0,85+0,10$ & 45,70 & 3,06 & 10,94 \\
\hline 1,0 & $0,15+0,02$ & 41,84 & 2,59 & 9,82 \\
\hline 0,3 & $0,50+0,06$ & 35,84 & 1,95 & 8,85 \\
\hline 1,7 & $0,50+0,06$ & 40,95 & 1,79 & 10,01 \\
\hline
\end{tabular}

Foi realizado o teste estatístico para os índices de tração, rasgo e estouro. Os resultados obtidos apresentam-se nas Tabelas 7.9, 7.10 e 7.11. 
Tabela 7.9: Resultados estatísticos da análise da resposta do índice de tração (Tensile) usando MFC (ou MCF)

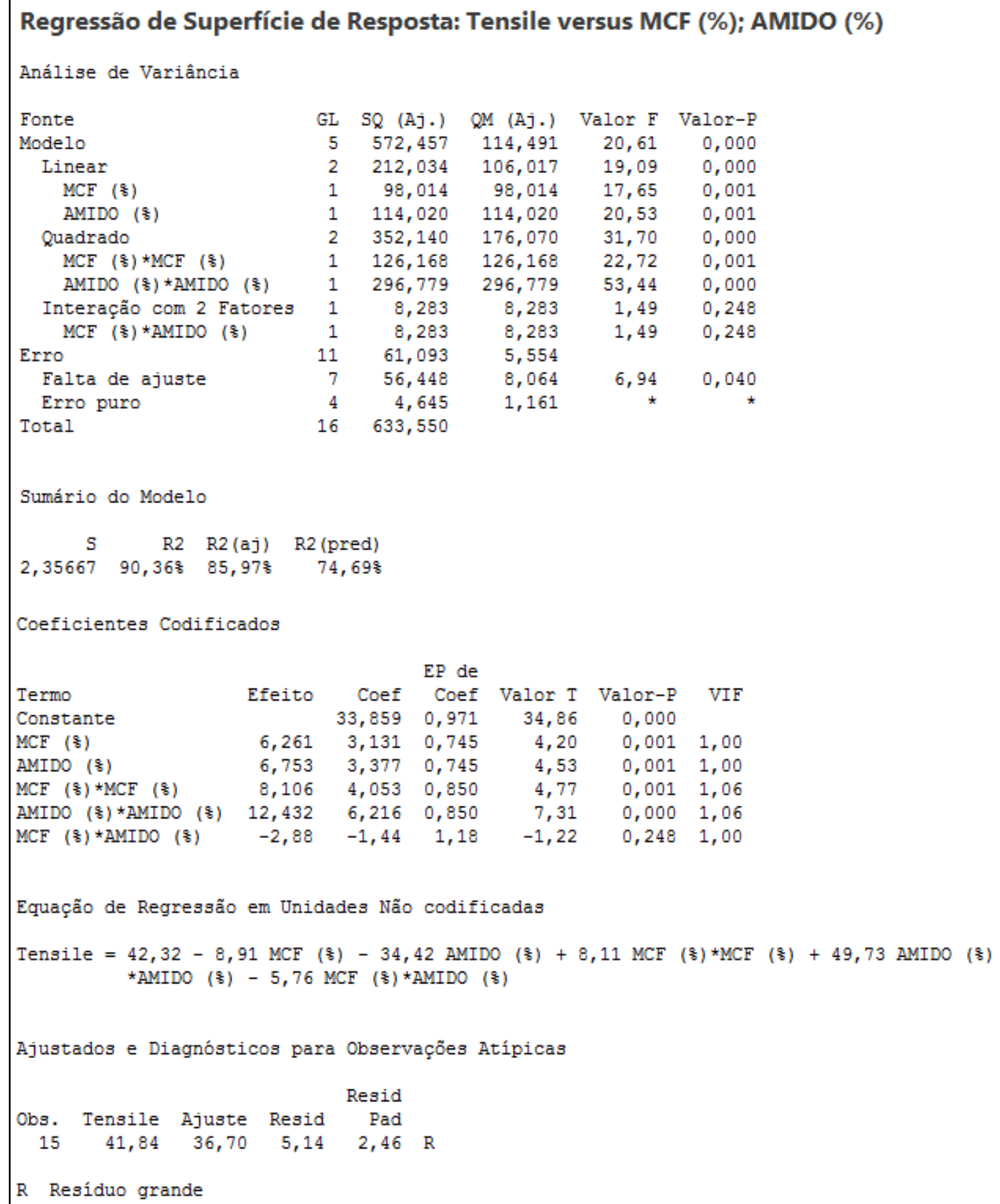


Tabela 7.10: Resultados estatísticos da análise da resposta do índice de rasgo (Tear) usando MFC (ou MCF)

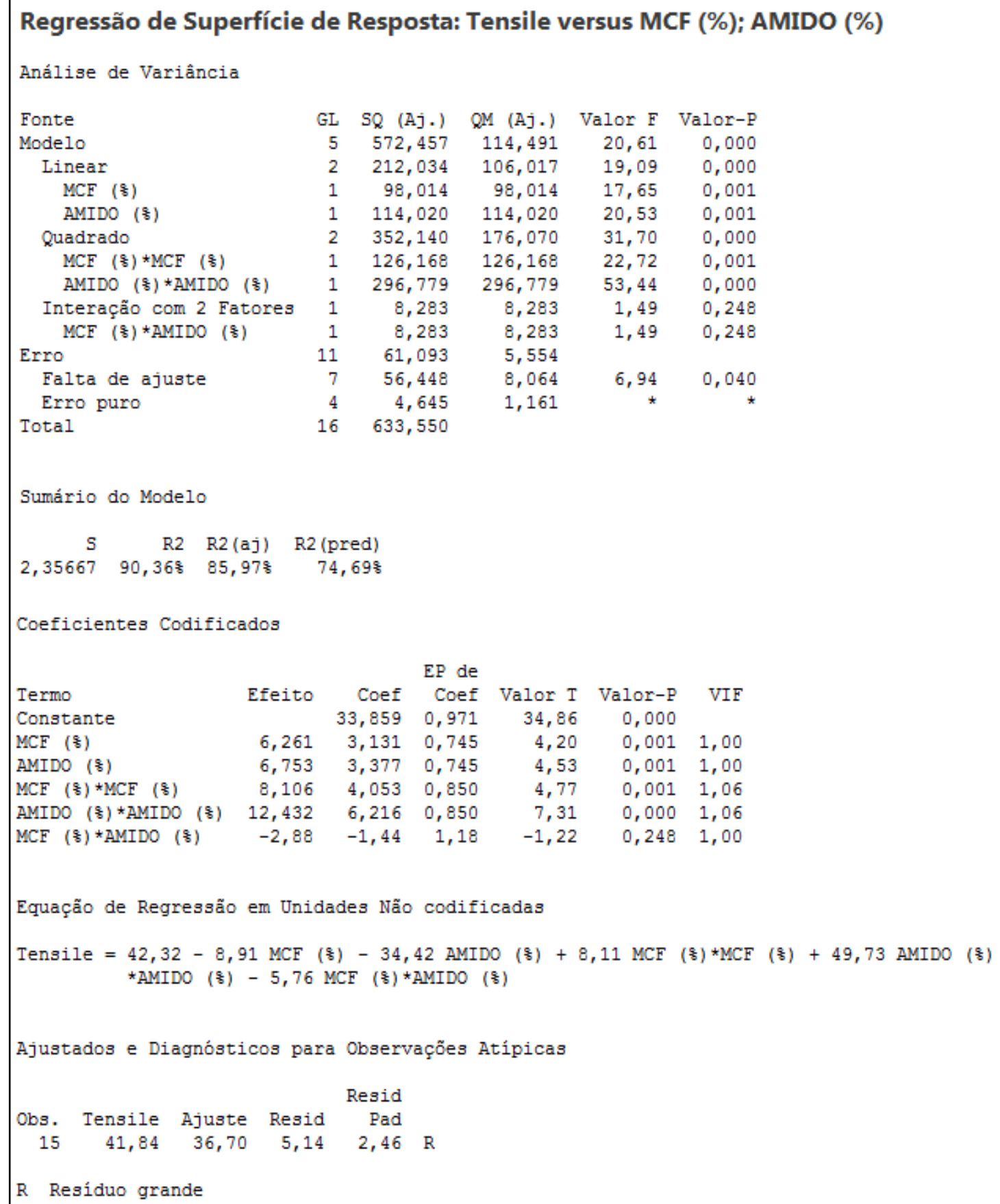


Tabela 7.11: Resultados estatísticos da análise da resposta do índice de estouro (Burst) usando MFC (ou MCF)

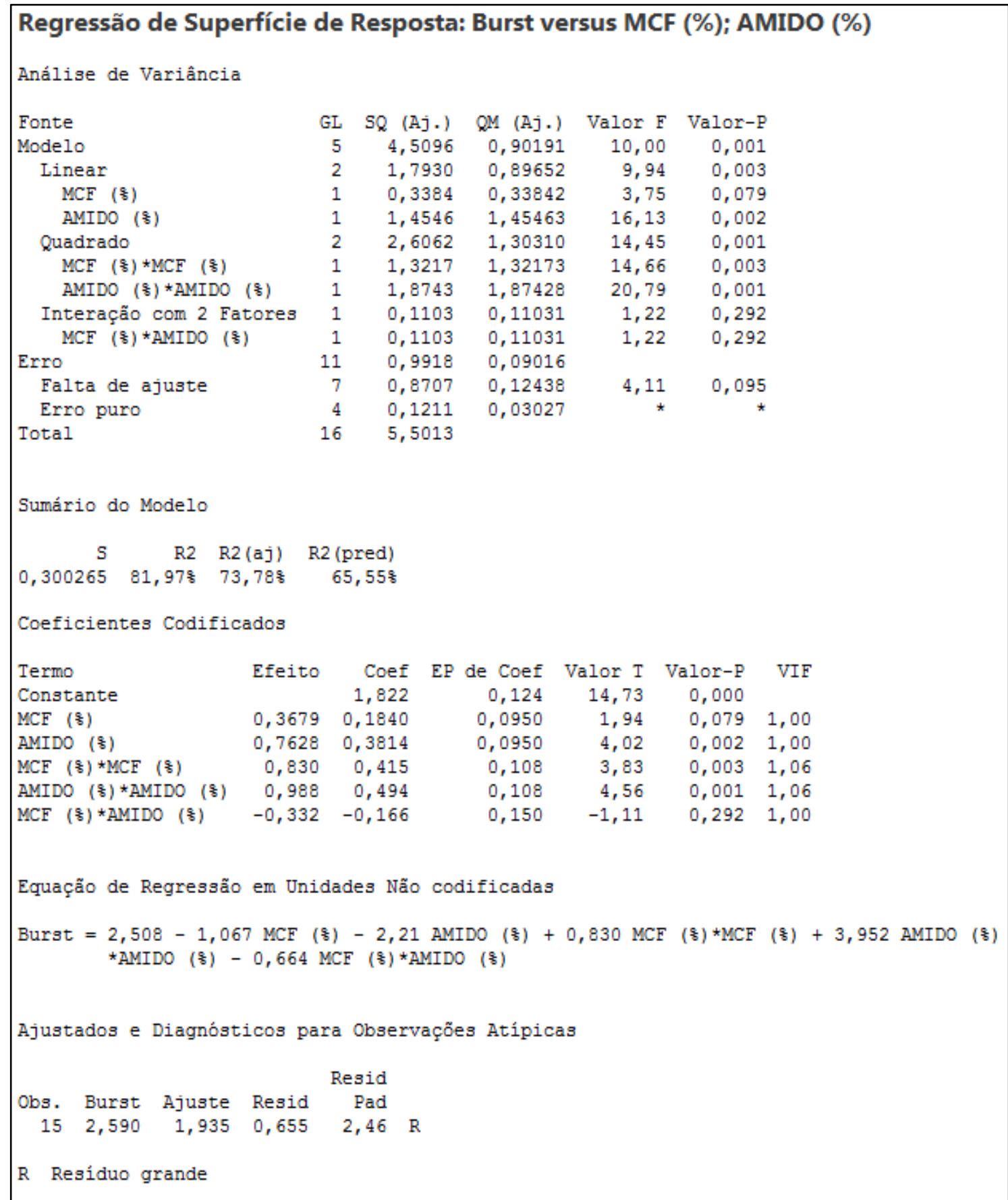

Para os dados dos índices de resistência a tração e rasgo, as Tabelas 7.9 e 7.11 mostram o seguinte: 
- O valor de p para o conteúdo de CNF e o conteúdo de (amido + cola) (AMIDO) é inferior a 0,05. Portanto, têm efeito significativo;

- O modelo contém uma única interação de dois fatores (CNF*AMIDO). O valor da interação tem um valor de $p>0,05$, portanto não é significativo;

- O modelo contém dois efeitos quadráticos $\left(\mathrm{CNF}^{*} \mathrm{CNF}\right.$ e AMIDO*AMIDO). Os termos quadráticos podem-se identificar como significativos na tabela de análise de variância $(p<0,05)$ implicam que pode-se analisar os efeitos da CNF ou de (amido + cola) separadamente. Por outra parte, como os efeitos quadráticos têm um valor de $p<0,05$ a relação entre o conteúdo de CNF e o conteúdo de (amido + cola), seguem uma linha curva;

- Os VIFs estão todos próximos a 1, o que indicando que os preditores não são correlacionados.

Para os dados do índice de resistência ao estouro, a Tabela de 7.10 mostra o seguinte:

- Ao igual que nos índices de tração e rasgo $p<0,05$, portanto tem um efeito significativo. No entanto, $p>0,05$ para (amido + cola), não há efeito significativo;

- $O$ valor da interação $C N F^{\star} A M I D O$ tem um valor de $p>0,05$ não sendo significativo;

- Observa-se que, ao igual que nos índices de tração e rasgo, os termos quadráticos podem-se identificar como significativos $(p<0,05)$.

- Ao igual que nos outros índices, os VIFs estão todos próximos a 1 , indicando que os preditores não são correlacionados.

$\mathrm{Na}$ Figura 7.26 apresentam-se os gráficos de contorno e os gráficos de superfície gerados para os índices de resistência à tração, rasgo e estouro, estes estão baseados nas seguintes equações de regressão (Equações 4, 5 e 6). 
Índice de Tração $=40,32+8,91 *(\% C N F)+34,42 *(\%$ amido e cola $)-$ $8,11 *(\% C N F * \% C N F)-49,73 *(\%$ amido e cola $) *(\%$ amido e cola $)-$ Equação 4 $5,76 *(\% C N F) *(\%$ amido e cola $)$

Índice de Rasgo $=42,32+8,91 *(\% C N F)+8,11 *(\%$ amido e cola $)-$ $49,73 *(\% C N F * \% C N F)-49,73 *(\%$ amido e cola $) *(\%$ amido e cola $)-$ $5,76 *(\% C N F) *(\%$ amido e cola $)$

Equação 5

Índice de Estouro =

$2,505+1,067 *(\% C N F)+0,830 *(\%$ amido e cola $)-3,952 *(\% C N F *$ $\% C N F)-3,952 *(\%$ amido e cola $) *(\%$ amido e cola $)-0,664 *(\% C N F) *$

Equação 6 (\%amido e cola)

Na Figura 7.26 observa-se que a combinação dos parâmetros (MFC e (amido + cola)) obtém uma resposta mínima para os índices de tração e estouro. Potulski et al. (2014) concluiu que o estouro e o rasgo têm a mesma tendência de crescimento com a adição de MFC. Para os mesmos índices, o uso da quantidade máxima de MFC ou de (amido + cola) têm-se os maiores valores. Adrndt et al. (2011) observou aumentos significativos do índice de tração em folhas de laboratório quando usadas 5\% de MFC e 0,25 de PEI (high molecular polyethylenimine). No entanto, os mesmos autores, ao usar concentrações de $1 \%$ de MFC, com ou sem PEl, obtiveram incrementos da tração pouco significativos. O uso moderado de MFC junto com (amido + cola) na formação do papel, sugere que é necessário saturar de químicos e de MFC a pasta celulósica, ao mesmo tempo, para que a mistura deles aumente significativamente as propriedades que dependem do potencial de união das fibras. Estudos com MFC usaram grandes quantidades de MFC, em proporção à pasta celulósica para ter aumentos importantes nas propriedades mecânicas. Missoum et al. (2013) fizeram folhas de laboratório com adição de 5\%, 10\%, 20\%, 30\% e 50\% de MFC em massa respeito à pasta celulósica.

O gráfico de contorno e o gráfico de superfície do índice de resistência a rasgo (Figura 7.26) mostram que o valor máximo quando o valor de MFC e/ou amido é máximo. Conforme observado na Tabela 7.5, o conteúdo de MFC 
e/ou de (amido + cola) têm significância estatística $(p<0,05)$, portanto 0 percentual usado dos mesmos influenciara significativamente o rasgo.

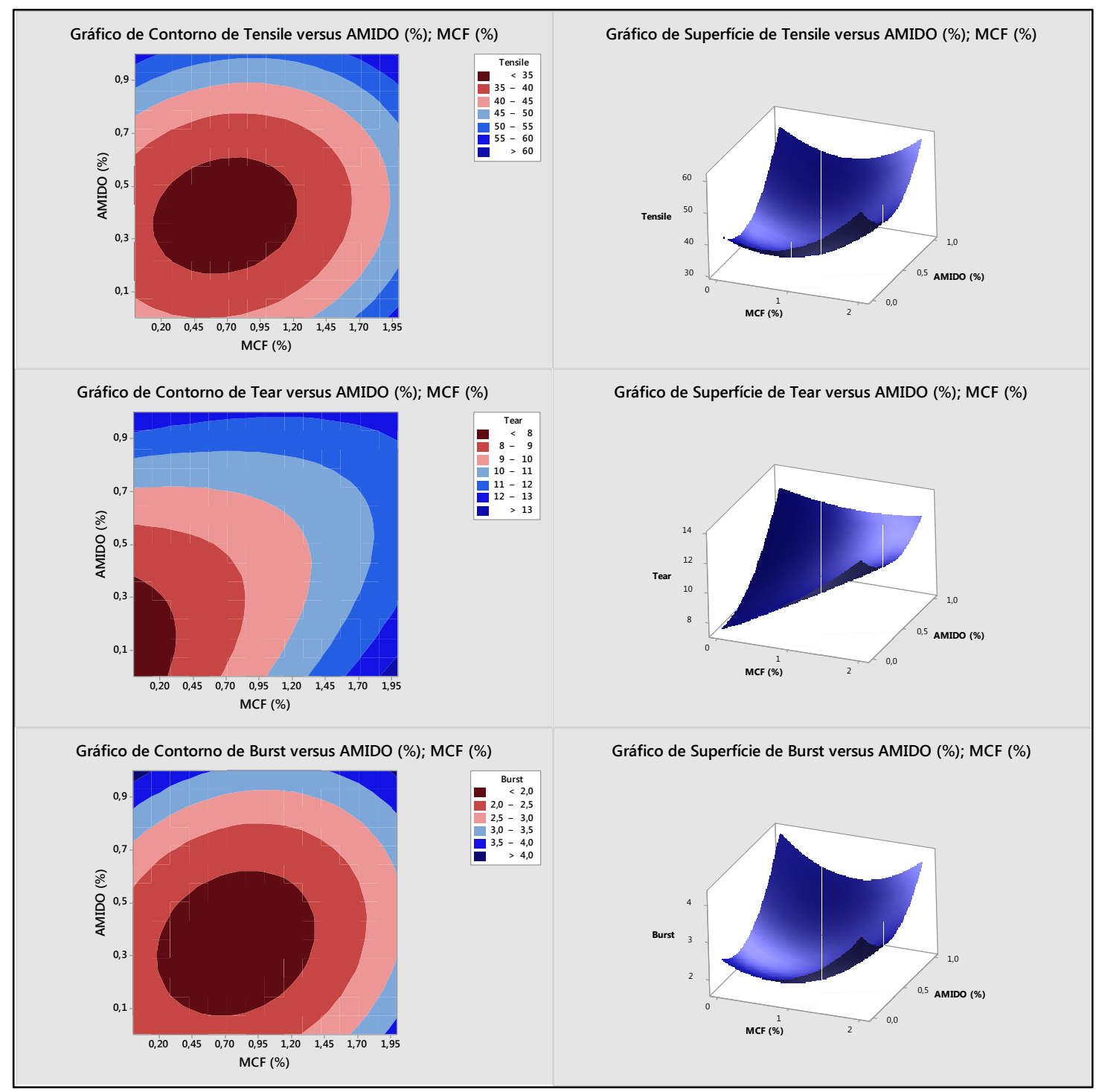

Figura 7.26: Gráficos de contorno e de superfície para os índices de resistência a tração (Tensile), rasgo (Tear) e estouro (Burst) com MFC (MCF)

Na Figura 7.27 apresentam-se o gráfico otimização gerado para os índices de resistência à tração, rasgo e estouro.

- As melhores condições de dosagem de MCF e (amido + cola) são 1\% e $0 \%$, respectivamente. Com estas dosagens aperfeiçoam-se os valores dos índices de resistência a tração, rasgo e estouro ao mesmo tempo. Aumentar o diminuir o percentual de CNF e/ou de (amido + 
cola) pode otimizar o valor de cada índice individualmente, porém maximizar somente um índice faz que os outros diminuam;

- O índice de rasgo apresenta a maior resposta, isto é, o aumento do conteúdo de MFC e/ou (amido + cola)r aproximam seu valor ao máximo. No entanto, isto faz que diminuam os índices de tração e estouro.

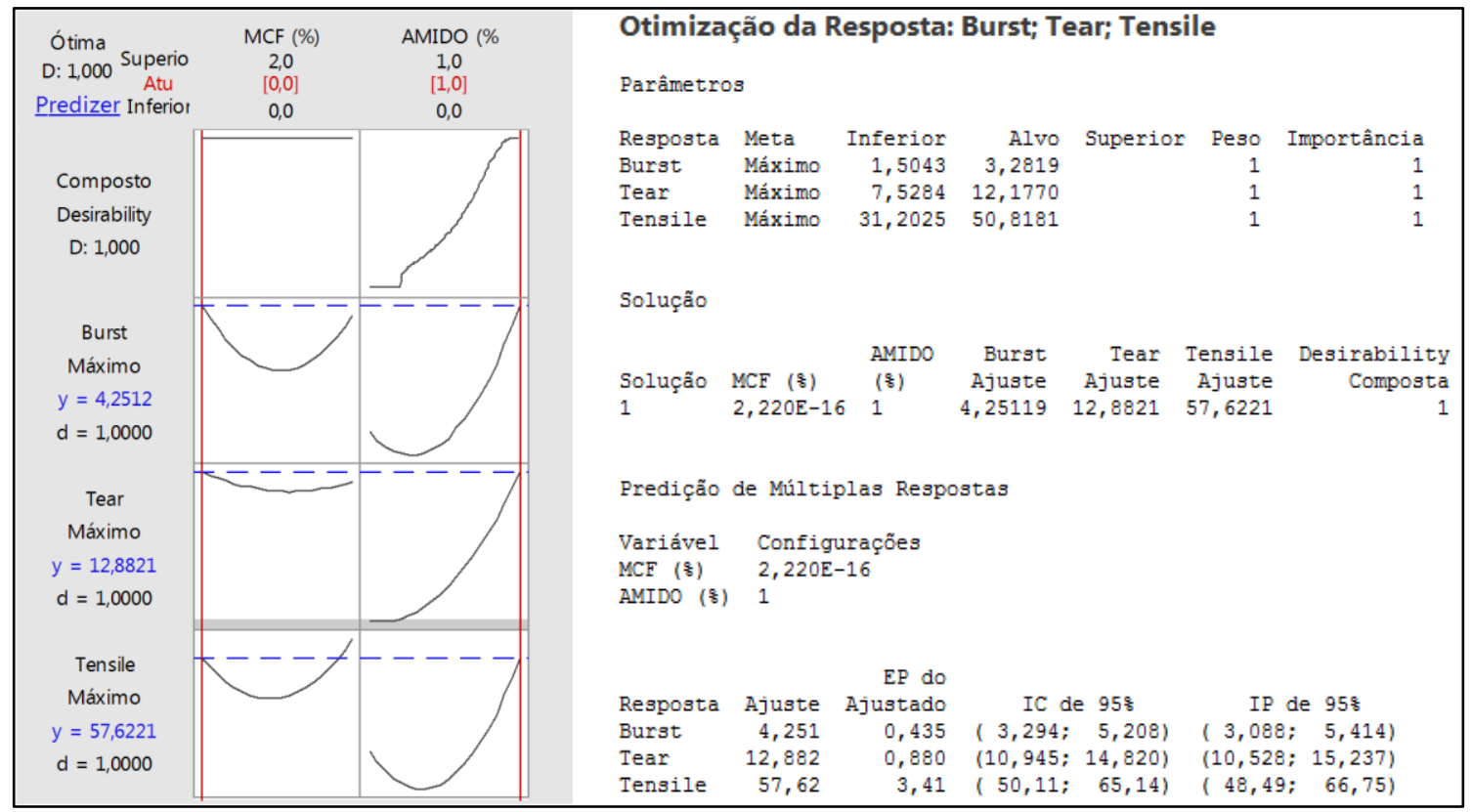

Figura 7.27: Gráfico de otimização da quantidade de CNF e de (amido + cola) adicionar para os índices de tração (Tensile), rasgo (Tear) e estouro (Burst) com MCF (MFC)

Da mesma forma que com a adição de CNF, a adição de MFC não cumpre os modelos tipo patch ou mosaico. loelovich (2008) conclui que para explicar as relações estrutura-propriedade de celulose nanoestruturada, leis da termodinâmica e físico-químicas para transformações de pequenas fases têm que ser consideradas. Essas leis permitem a interpretação de fenômenos como distorções e acessibilidade de nanocristalitos, e também os efeitos da agregação, a dissolução, a reatividade e transições térmicas de celuloses nanoestruturados e nanoceluloses.

O processo de fabricação de papel consiste em várias etapas: parte úmida, prensagem, secagem, e algumas outras. A fim de conseguir a formação de ligações de hidrogênio interfibra, devem ser fornecidos contatos diretos entre 
as fibras. Contudo, segundo autores (IOELOVICH e FIGOVSKY, 2010) a rugosidade das fibras de celulose e fibrilas impede a formação de tais contatos em um papel insuficientemente fibrilado. Segundo os mesmos para preencher as lacunas entre as fibras e fibrilas, nanopartículas hidrofílicas, de preferência da mesma natureza, isto é, finos, microfiras e nanofibras, devem ser adicionados à composição de papel. Os resultados obtidos com MFC concordam com dita explicação, quando adicionados somente MFC ou amido, cola e polímero ou quando a adição de valores de nanopartículas (MFC) e de compostos catiônicos são máximos, sendo, portanto não viável desde o ponto de vista da máquina de papel.

Pode-se concluir que partículas hidrofílicas (MFC) podem formar contatos adicionais com as fibrilas de celulose melhorando as propriedades físicas e mecânicas do papel final. No entanto, também se observa que ao misturar as MFC junto com eletrólitos catiônicos, a formação de fortes pontes de hidrogênio com a celulose diminui, e, portanto, as propriedades físicas e mecânicas do papel obtido diminuem.

Finalmente, fica aqui a seguinte observação: nas Tabelas 7.4 e 7.8 não se listou o desvio-padrão das medidas, porque o objetivo era mostrar os dados utilizados para geração das superfícies de resposta. Todas as réplicas de amostras e os erros calculados encontra-se nos Apêndices.

\subsection{Microscopia Eletrônica de Varredura (MEV)}

As Figuras 7.28 e 7.29 ilustram os pontos dos planejamentos de experimentos nas quais foram obtidas as imagens por Microscopia eletrônica de Transmissão (SEM). 


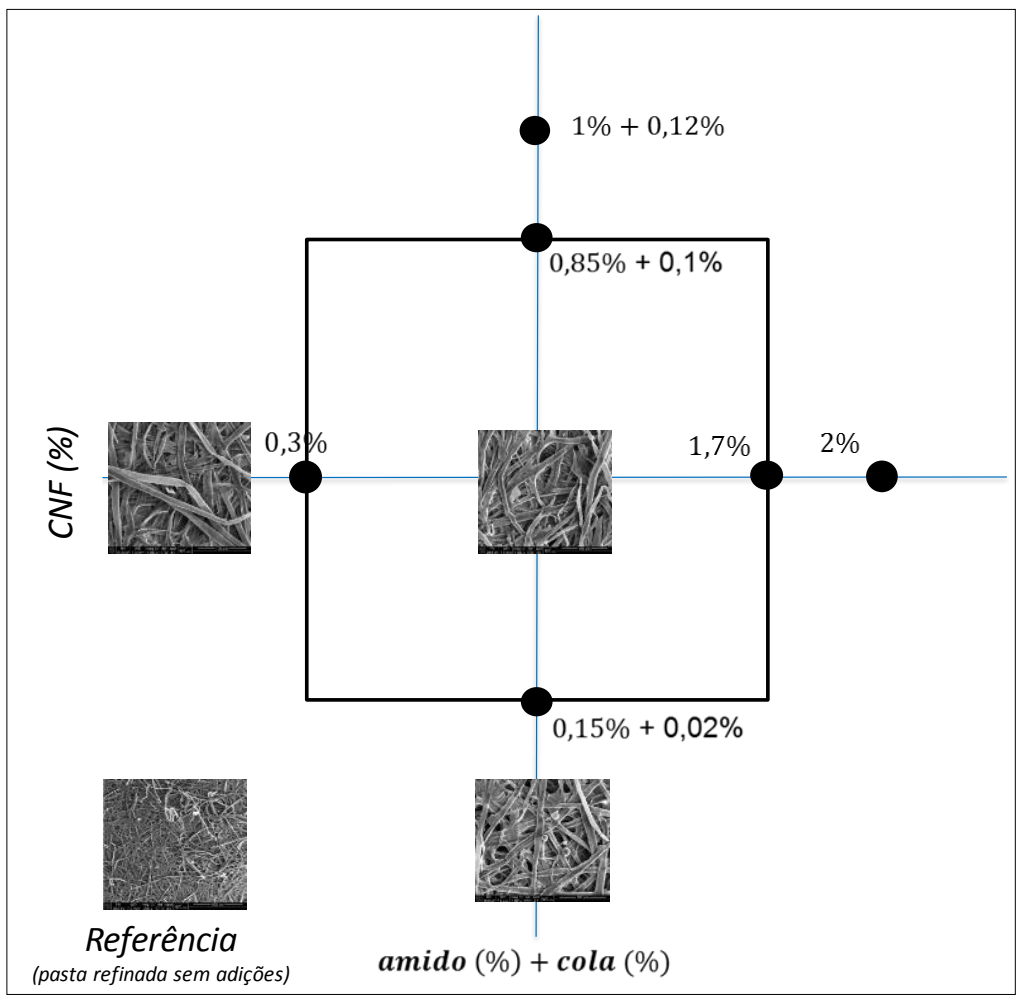

Figura 7.28: SEM realizados no planejamento de experimentos com CNF

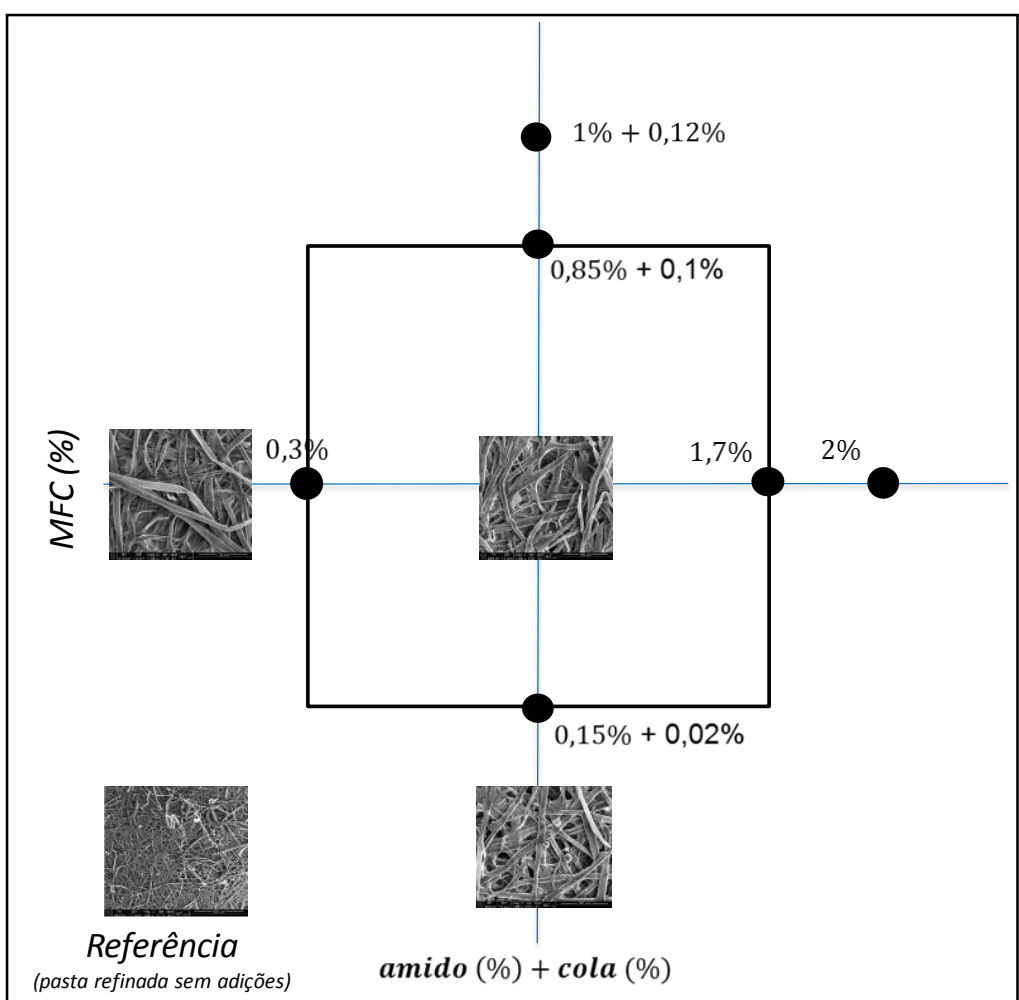

Figura 7.29: SEM realizados no planejamento de experimentos com MFC 
A Figura 7.30 apresenta as imagens obtidas por SEM de folhas de laboratório referência (branco) realizadas com a pasta de eucalipto pré-branqueada (PEKP), após refinação Valley (34 SR).

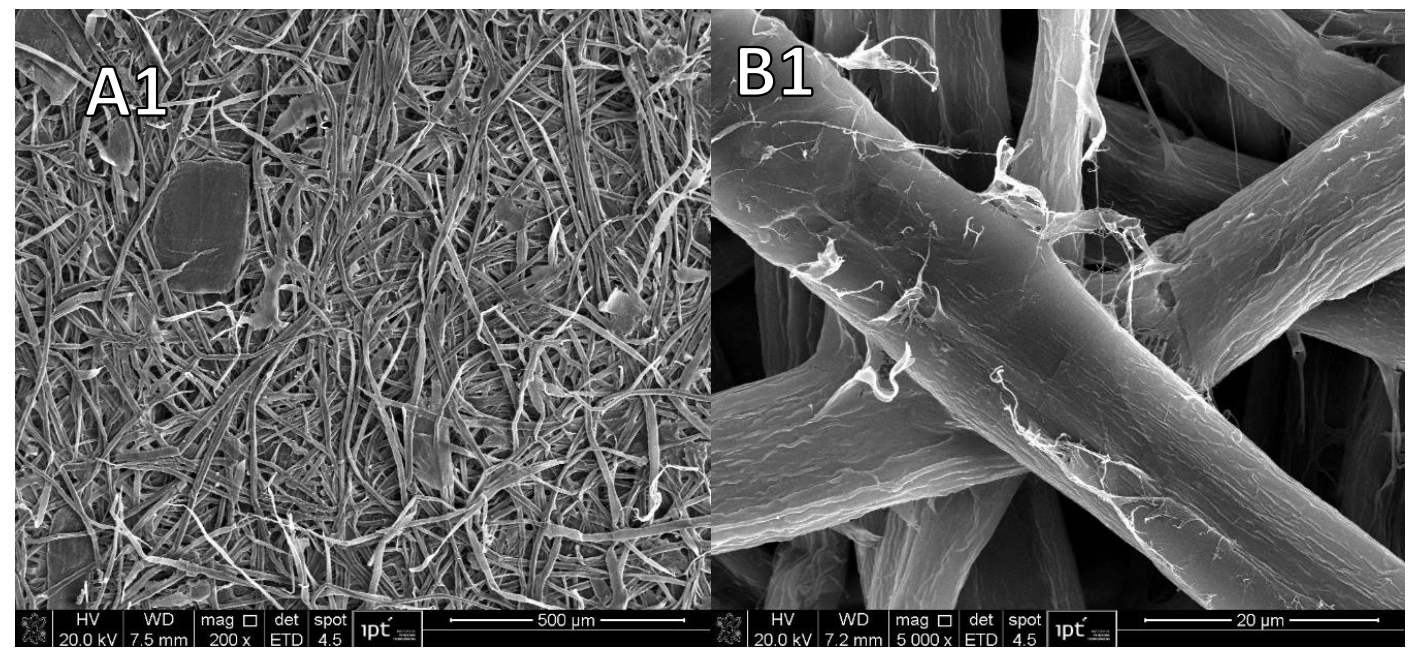

Figura 7.30: SEM de amostra referência (PKEP). A1: aumento de 200x; B1: aumento de 5000x

Na Figura 7.30 (A1), pode-se observar os efeitos da refinação com as alterações estruturais das fibras. Este refino faz as fibras se conformarem melhor entre si, aumentando a área superficial, e portanto, diminuindo a densidade, o volume específico e a porosidade do papel (BIERMAN, 1996). Por outro lado, na Figura 7.30 (B1) pode-se observar os cortes nas superfícies, que ocorrem devido à ação mecânica sobre as fibras, e que permite a entrada da água, determinante na fibrilação interna, além de visualizar a fibrilação externa.

Percebe-se na imagem da Fig. 7.30 (B1), a remoção parcial da camada $S 1$ da parede secundária, surgindo as fibrilas da camada $S 1$ na superfície destas fibras (fibrilação externa). As fibrilas aumentam o número de contato entre as fibras (enlaces fibra-fibra), aumentando as propriedades de resistência mecânica e diminuindo a drenagem.

A remoção da parede primária têm como consequência a formação de finos, os quais aumentam a densidade da folha e preenchem os espaços interfibras, diminuindo a porosidade. 
$\mathrm{Na}$ Figura 7.31 apresenta as imagens obtidas por SEM de folhas de laboratório realizadas com a pasta de eucalipto pré-branqueada (PEKP), após refinação Valley (34 SR) com adição de 0,5\% de amido, 0,06\% de cola e $0,02 \%$ de polímero de retenção sem nanocelulose.

Tal como na Figura 7.30, nesta Figura 7.31 pode-se observar os efeitos da refinação mecânica das fibras, com as análises similares das imagens. $\mathrm{Na}$ imagem da Figura 7.31(C2), ressaltam-se as partículas pequenas (indicado pela seta), provavelmente, são restos de (amido + cola) não dissolvidos totalmente na suspensão antes da formação de folhas.

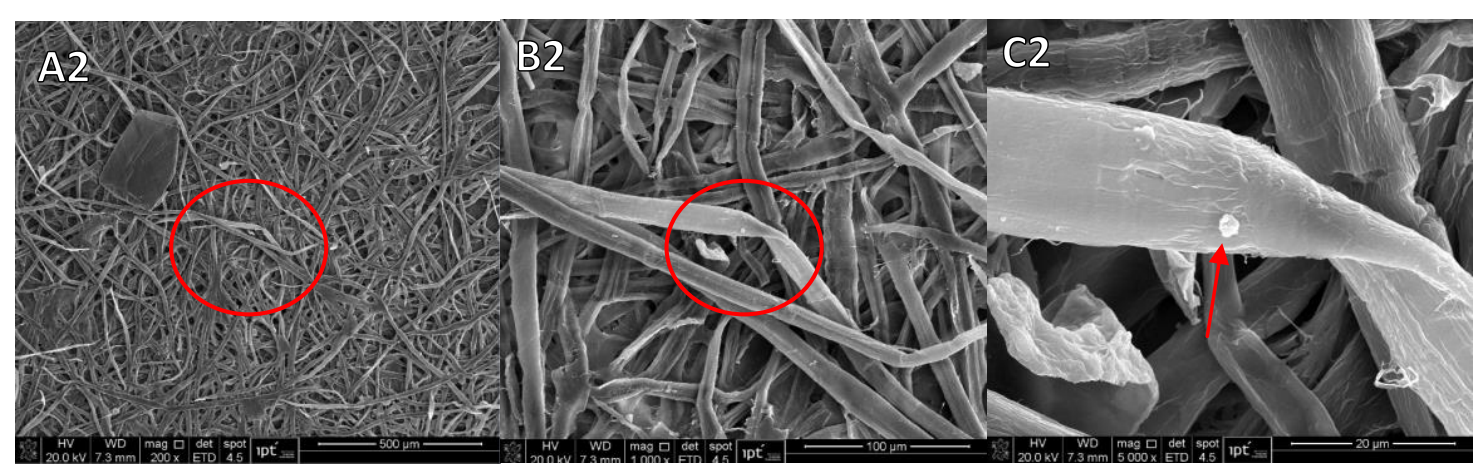

Figura 7.31: SEM PKEP realizada com adição de aditivo. A2: aumento de 200x; B2: aumento de 1000x; C3: aumento de 5000x

A Figura 7.32 apresenta as imagens obtidas por SEM das folhas de laboratório realizadas com a pasta de eucalipto pré-branqueada (PEKP), após refinação Valley (34 SR) com adição de 1\% de CNF em diferentes regiões.

Observa-se na Figura 7.32 (A3, B3 e C3) a formação de partículas "esféricas" de um tamanho, aproximado, de $5 \mu \mathrm{m}$ até $10 \mu \mathrm{m}$. Provavelmente, são aglomerados de nanocelulose que não se tem aderido às fibras e/ou não tem sido dispersos. Por outro lado, a formação de aglomerados de nanocelulose pode ser devido a que as CNF, ao ter uma grande área superficial em relação a seu tamanho, estejam se aderindo entre elas e não nas fibras. A grande área superficial faz com que as forças de atração entre as CNF sejam maiores que entre fibra-CNF, formando estes aglomerados esféricos de nanoceluloses. As CNF são aniônicas, portanto os agregados também, a falta de atração eletrostática faz que não sejam absorvidos pelas fibras. 


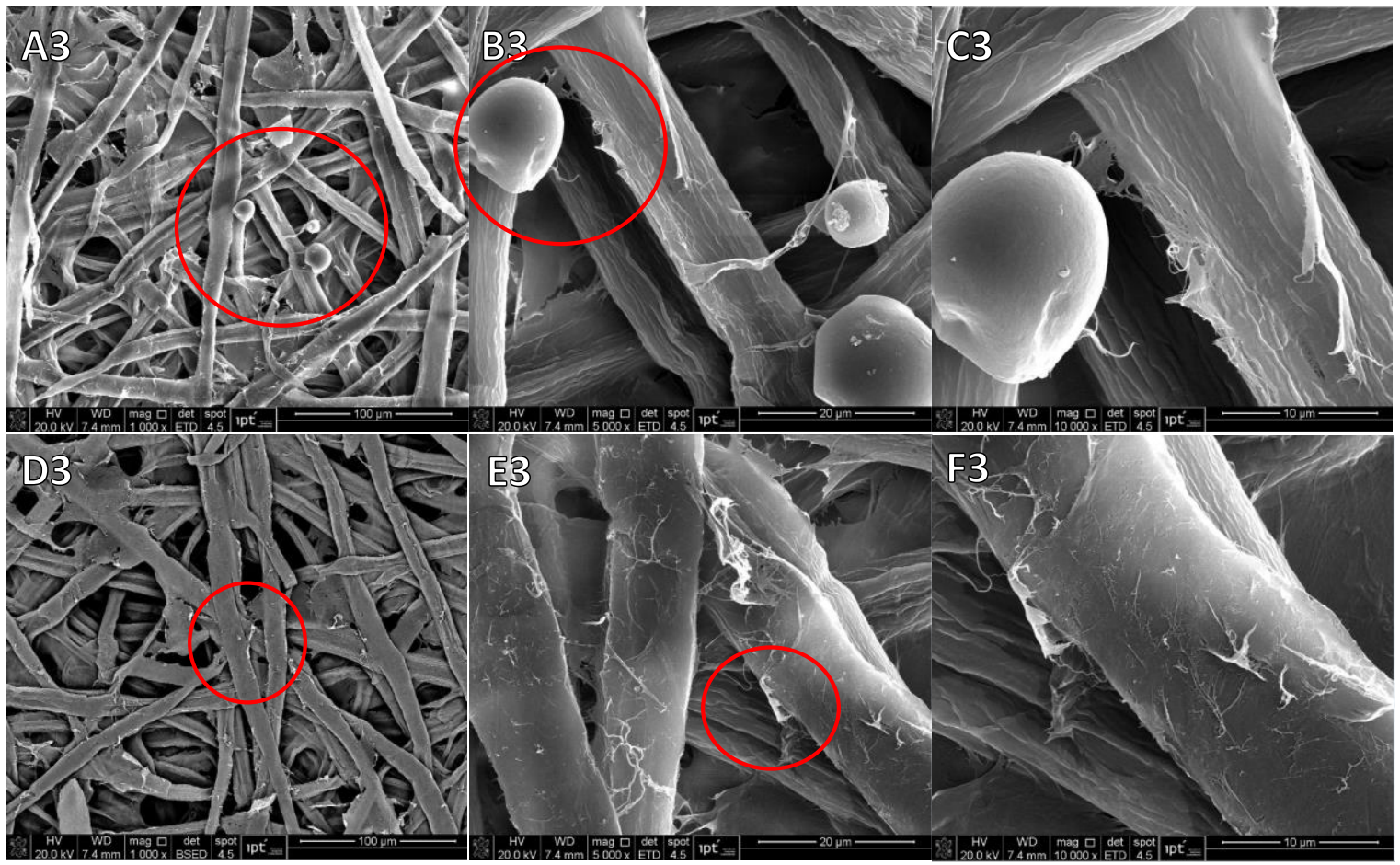

Figura 7.32: SEM de PKEP realizada com adição de CNF em duas regiões (A, B e C, e D,E e F). A4: aumento de 1000x, B4: aumento de 5000x e C4: aumento de 10000x. D3: aumento de 1000x; E3: aumento de 5000x; F3: aumento de 10000x

Na Figura 7.32 (D3, E3 e F3), aparentemente, o número de fibrilas observado é maior quando comparado com uma amostra sem adição de CNF (Figuras 7.30 e 7.31). Na mesma figura, observam-se também os pedaços de parede da fibra desprendidos, provavelmente, durante devidos à refinação da pasta celulósica.

Tanto nas imagens A3, B3 e C3 (Fig. 7.32) quanto nas imagens D3, E3 e F3, embora o número de nanofibras, microfibras e fibrilas tenha aumentado com adição de CNF, não se observa um aumento do número de enlaces fibrafibra, nem o enchimento dos espaços entre fibras, diferente da literatura (GONZÁLEZ et al., 2012; TAIPALE et al., 2010; AHOLA et al., 2010). O observado concorda com o exposto na revisão desta monografia: o pequeno percentual de nanocelulose utilizado na formação de folhas não afeta 0 preenchimento de vazios. 
A Figura 7.33 apresenta as imagens obtidas por SEM de folhas de laboratório realizadas com a pasta de eucalipto pré-branqueada (PEKP), após refinação Valley (34 SR) no ponto central do planejamento de experimentos.

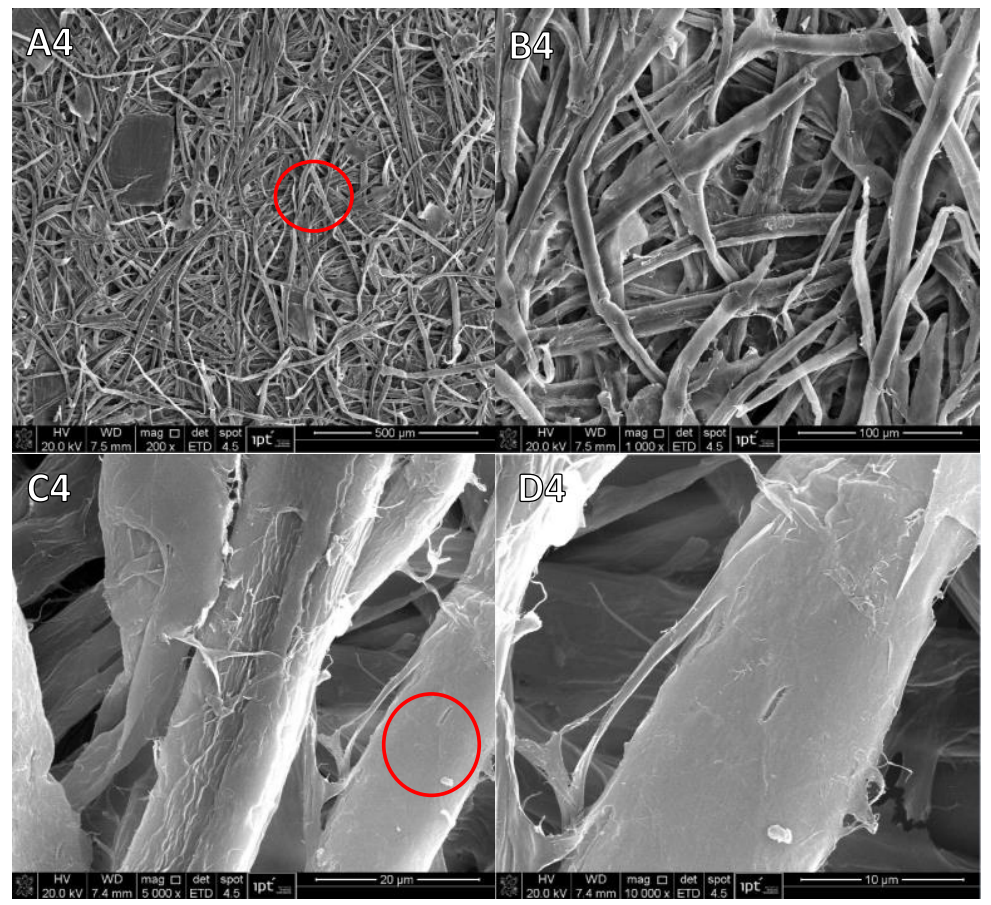

Figura 7.33: SEM de PKEP realizada com adição de aditivo e CNF. A4: aumento de 200x; B4: aumento de 1000x; C4: aumento de 5000x; D4; aumento de 10000x

Observando a Figura 7.33, tem-se:

- Como nas Figuras 7.30 e 7.31, nesta Figura 7.33 apreciam-se os efeitos do refino nas fibras celulósicas: corte das fibras, desprendimento da camada $\mathrm{S1}$, aumento do número de ligações entrefibras e fibrilação;

- Ao comparar com as imagens anteriores, na Figura 7.33 (C4 e D4), observa-se um aumento significativo de micro e nanofibras aderidas nas fibras celulósicas. Provavelmente as fibras celulósicas absorvem os reagentes na superfície, isto é, o polímero a cola e o amido é absorvido na superfície das fibras, promovendo as forças atrativas entre as fibras e as micro e nanofibras. 
A Figura 7.34 apresenta as imagens obtidas por SEM de folhas com a pasta de eucalipto pré-branqueada (PEKP), após refinação Valley (34 SR) com adição de $1 \%$ de MFC.

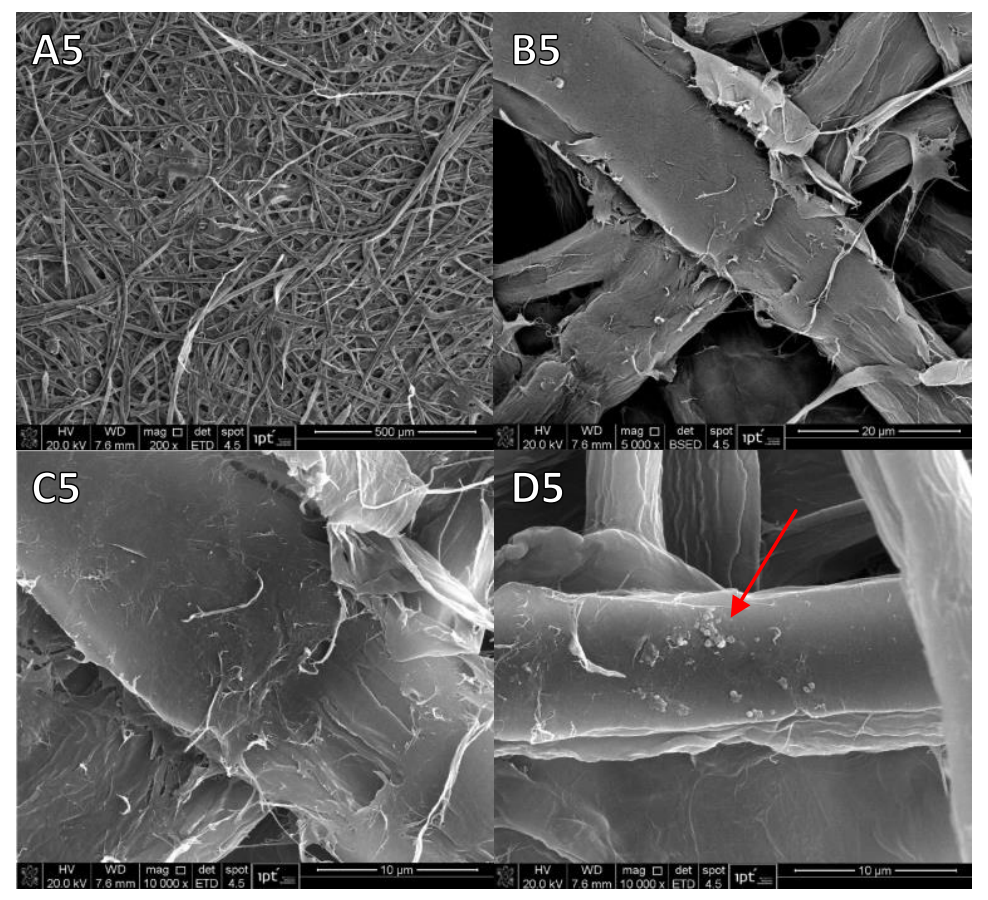

Figura 7.34: SEM de PKEP realizada com adição de MFC. A5: aumento de 200x, B5: aumento de 5000x e C5 e D5: aumento de 10000x

Observando a Figura 7.34 tem-se:

- Na Figura 7.34 (B5) aprecia-se o efeito de corte do refinador sob as fibras celulósicas, consequentemente existe um grande desprendimento da parede da fibra;

- Embora exista um aumento do número de microfibras pelo efeito da refinação, comparando-se a Figura 7.34 (C5 e D5) com a Figura 7.30, observa-se um aumento importante de material micro ou nanocrofibrilado, isto é, do número de micro e nanofibras;

- Observa-se na imagem D5 a formação de partículas esféricas de tamanho manométrico na superfície da fibra (indicadas pela seta). Uma explicação pode ser a formação de aglomerados de nanoceluloses devido à grande área superficial destas, as quais, posteriormente, se aderem na superfície da fibra, ao igual que na Figura 7.32. Turner et al. (2011), indica que as fibrilas de celulose têm 
uma estrutura fractal, por isso as estruturas observadas podem ser fibrilas adicionadas.

A Figura 7.35 apresenta as imagens obtidas por SEM de folhas de laboratório realizadas com a pasta de eucalipto pré-branqueada (PEKP), após refinação Valley (34 SR) no ponto central do planejamento de experimentos realizado com MFC. Observando a Figura 7.35, tem-se:

- Como anteriormente, apreciam-se os efeitos do refino nas fibras celulósicas;

- O número de material micro ou nanofibrilado têm aumentado, se comparados com a Figura 7.30. Provavelmente, isto deve-se às MFC adicionadas antes da formação das folhas, as quais aumentam 0 número de micro e nanofibras. No entanto, resulta difícil concluir, apenas por imagens, se as micro e nanofibras (inferiores a $5 \mu \mathrm{m}$ ) são devidas à adição de MFC ou se são os efeitos da refinação (fibrilação externa e interna).

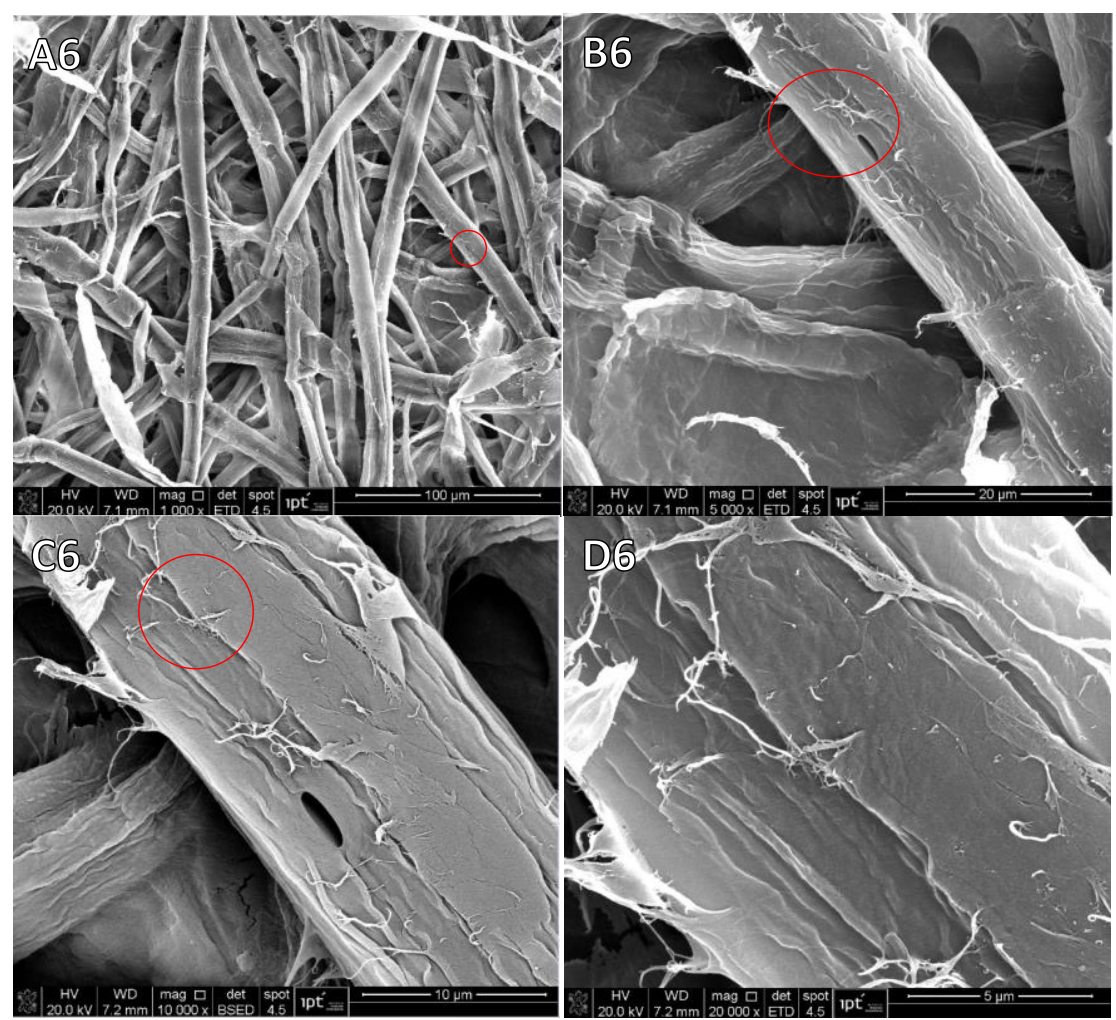

Figura 7.35: SEM de PKEP realizada com adição de aditivo e MFC. A6: aumento de 1000x; B6: aumento de 5000x; C6: aumento de 10000x; D6; aumento de 20000x 
A Figura 7.36 apresenta as imagens obtidas por SEM de folhas de laboratório realizadas com a pasta de pinus marrom (PKPM), com adição de CNF.

Observa-se a presença de traqueoides de pinus, os quais têm sofrido uma diminuição das dimensões, pelo efeito do refino, se comparados com a média dos traqueoides para diferentes espécies. Tomazello Filho (1987) observou um comprimento médio de $3,9 \mathrm{~mm}$ e diâmetro médio de $48 \mu \mathrm{m}$ para Pinus oocarpa. Nisgoski (2005) observou traqueóides com largura de 39,3 $\mu \mathrm{m}$ e 40,4 um para Pinus taeda de diferentes idades.

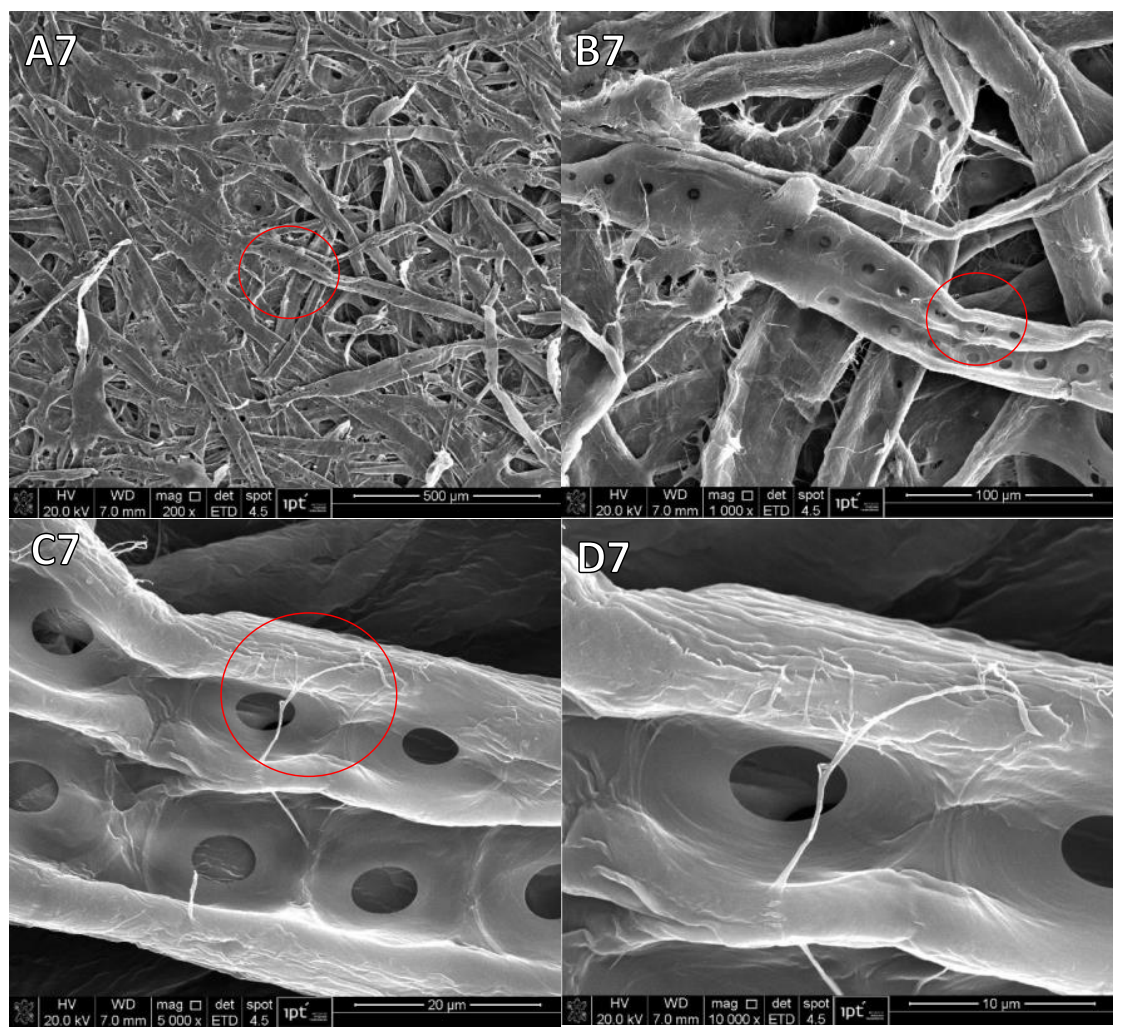

Figura 7.36: SEM de PKPM realizada com adição de 1\% CNF. A7: aumento de 200x, B7: aumento de 1000x e C7: aumento de 5000x. D7: aumento de $10000 x$

Na Figura 7.36 (C7 e D7), observa-se uma nanofibra de celulose aderida na fibra com largura aproximada de $17 \mu \mathrm{m}$. Sehaqui et al. (2011) descreve que o tamanho das CNF variam entre $5 \mu \mathrm{m}$ até $30 \mu \mathrm{m}$. Chinga-Carrasco (2011) explica que os pré-tratamentos (entre eles oxidação TEMPO), produzem nanofibras com tamanhos inferiores a $100 \mathrm{~nm}$. 
$\mathrm{Na}$ Figura 7.37 apresenta as imagens obtidas por SEM de folhas de laboratório realizadas com a pasta de pinus marrom (PKPM), com adição de $2 \%$ de CNF.

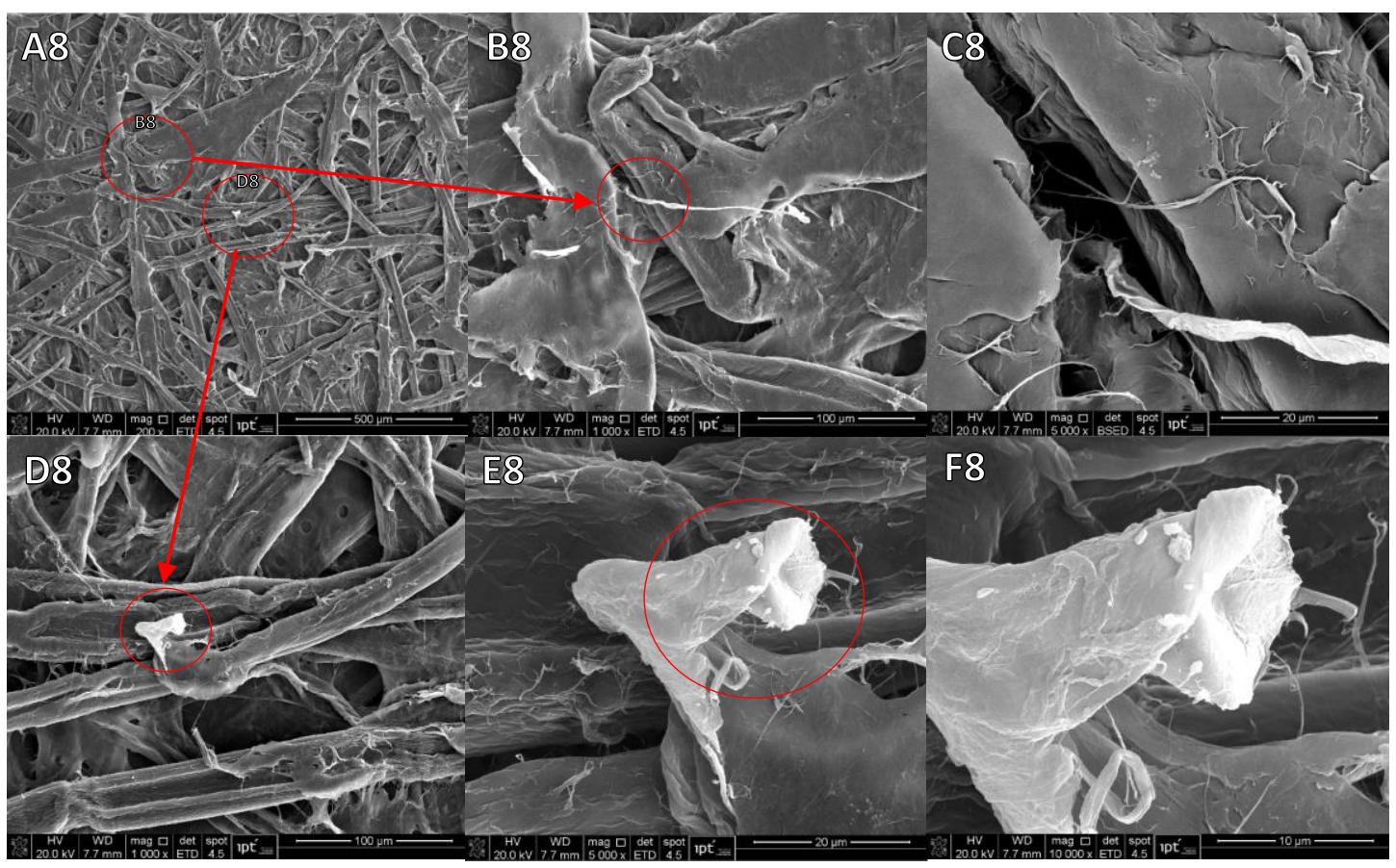

Figura 7.37: SEM de PKPM realizada com adição de $2 \%$ CNF em duas regiões. A8: aumento de 200x, B8: aumento de 1000x e C7: aumento de 5000x. D7: aumento de 1000x; E8: aumento de 1000x; F8: aumento de 10000x

Ao igual que na Figura 7.36, na Figura 7.37 observa-se material nanofibrilado inferior a $20 \mu \mathrm{m}$, possivelmente, devido à adição de $2 \%$ de CNF na pasta celulósica.

Nas Figuras 7.37 (D8, E8 e F8), observa-se uma partícula de forma irregular ampliada até 10000x. Podemos notar que está formada pela aglomeração de micro e nanofibras de tamanho inferior a $10 \mu \mathrm{m}$. A aglomeração de micro e nanofibras concorda com o observado anteriormente. As nanoceluloses estão se aglomerando entre elas e posteriormente grudam na superfície da parede da fibra celulósica. No entanto, as fibras de pinus utilizadas neste estudo não estão branqueadas, tendo um alto teor de lignina, a qual é aniônica. Como se comentou no apartado 7.3, ao adicionar CNF na pasta PKPM observou-se uma diminuição do índice de tração. Provavelmente, ao usar CNF, em pastas com elevado teor de lignina, as nanoceluloses se adiram entre si e não nas 
fibras. Devido à lignina estas aglomerações de CNF, não conseguem fazer ligações CNF-fibra, fazendo que a formação do papel seja afetada.

A Figura 7.38 apresenta as imagens obtidas por SEM de folhas de laboratório realizadas com a pasta de pinus marrom (PEPM), com adição de 1\% de MFC.

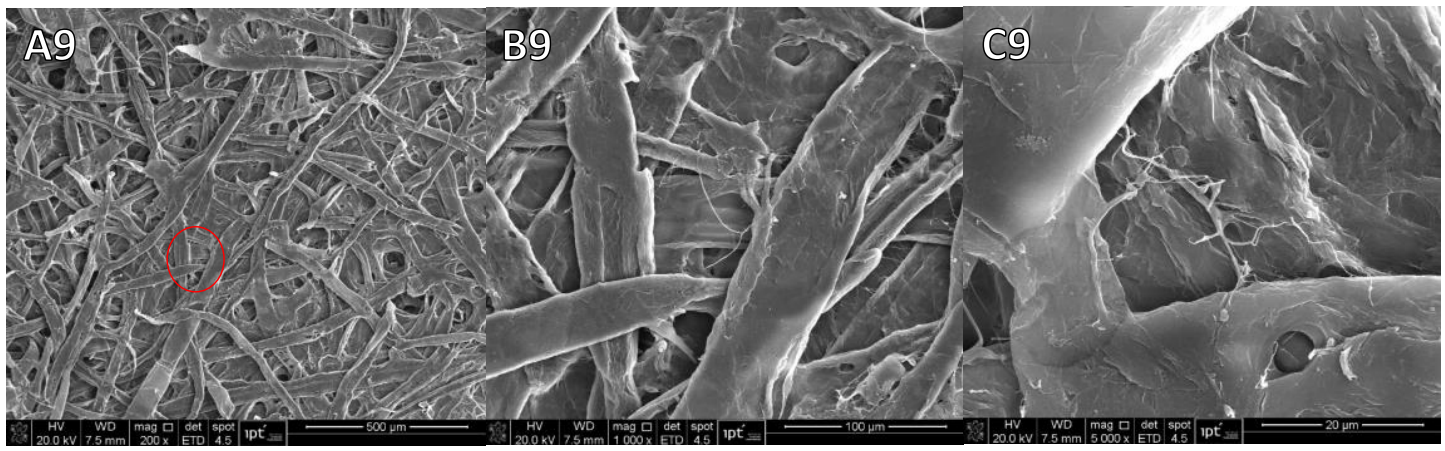

Figura 7.38: SEM de PKPM realizada com adição de MFC. A9: aumento de 200x; B9: aumento de 1000x; C9: aumento de 5000x

A Figura 7.39 apresenta as imagens obtidas por SEM de folhas de laboratório realizadas com a pasta branqueada de eucalipto (PKEB), com adição de 1\% de CNF.

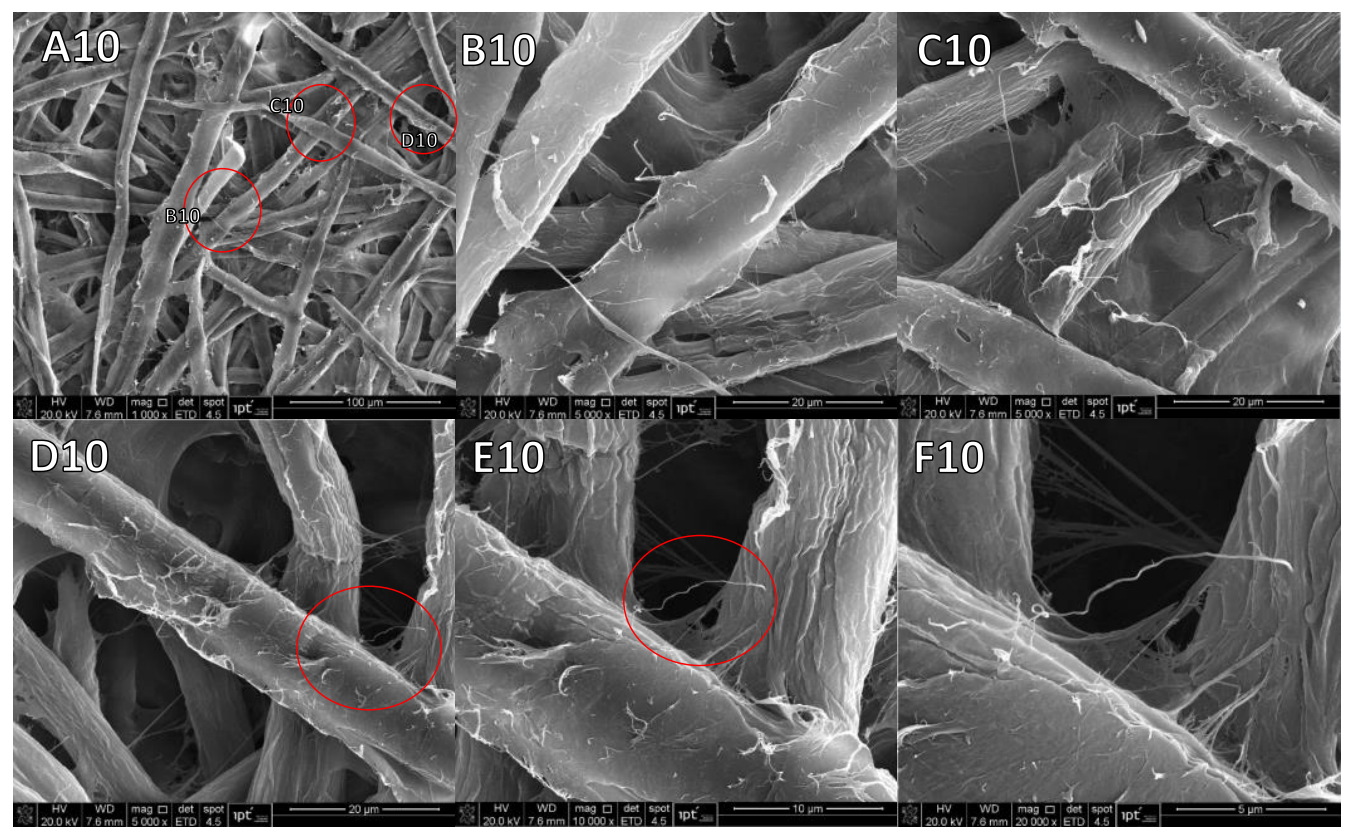

Figura 7.39: SEM de PKEB realizada com adição de 1\% de CNF em diferentes regiões. A10: aumento de 1000x, B10: aumento de 5000x e C10: aumento de 10000x. D10: aumento de 1000x; E10: aumento de 10000x; F10: aumento de 20000x. 
$\mathrm{Na}$ Figura 7.39 observa-se que pedaços de parede da fibra têm-se desprendido também, provavelmente por ação das forças mecânicas sobre as fibras durante a refinação das pastas celulósicas.

Conforme descrito na literatura, com adição de CNF podemos observar na Figura 7.39 um aumento do número de micro e nanofibras (GONZÁLEZ et al., 2012). No entanto, nas imagens continua não sendo observável a deposição das CNF entre as fibras. Nas imagens D10, E10 e F10 observam-se as ligações entre fibras devidas às micro e nanofibras. Nota-se que estas são das próprias fibras, isto é, por efeito da refinação mecânica. Aparentemente, as CNF estão se depositando acima das fibras e não entre elas.

Após as primeiras imagens, optou-se por repetir imagens de microscopia eletrônica de varredura nas folhas formadas com pasta pré-branqueada com $1 \%$ de CNF, $1 \%$ de MFC e nos pontos centrais do planejamento.

A Figura 7.40 apresenta imagens obtidas por SEM de folhas de laboratório realizadas com a pasta de eucalipto pré-branqueada (PEKP) e 1\% de CNF.

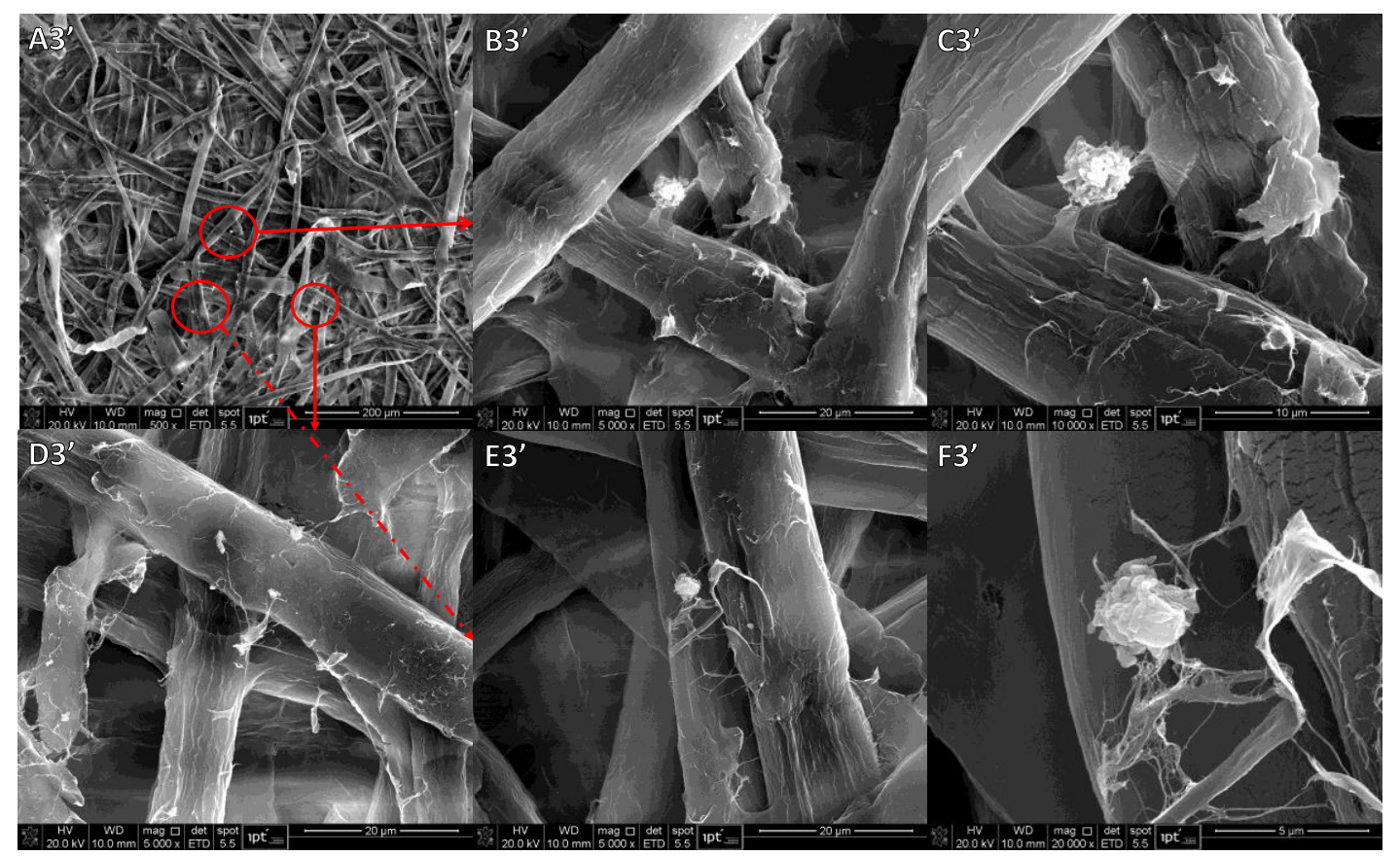

Figura 7.40: Repetição de SEM de PKEP realizada com adição de CNF. A3': aumento de 1000x, B3': aumento de 5000x e C3': aumento de 10000x. D3': aumento de 5000x; E3': aumento de 5000x; F3': aumento de 20000x 
Observa-se na Figura 7.40 a formação de aglomerados de CNF, tal como foram observados na Figura 7.32. Como indicado na literatura (GONZÁLEZ et al., 2012; TAIPALE et al., 2010; AHOLA et al., 2010) nota-se que as CNF formam uniões com as fibras, isto explica o aumento dos índices de resistência à tração e estouro quando usadas somente CNF como aditivo. As CNF têm uma grande área específica e uma quantidade elevada de grupos hidroxilo, os quais fazem ligação junto com as fibras celulósicas por meio de pontes de hidrogênio, aumentando, portanto, as propriedades de resistência mecânica.

Na Figura 7.40 (D3'), similar à Figura 7.32, observa-se que o número de fibrilas observado é maior quando comparado com uma amostra sem adição de CNF (Figuras 7.30 e 7.31).

A Figura 7.41 apresenta as imagens obtidas por SEM de folhas de laboratório realizadas com a pasta de eucalipto pré-branqueada (PEKP), após refinação Valley (34 SR) no ponto central do planejamento de experimentos realizado com $1 \%$ de CNF.

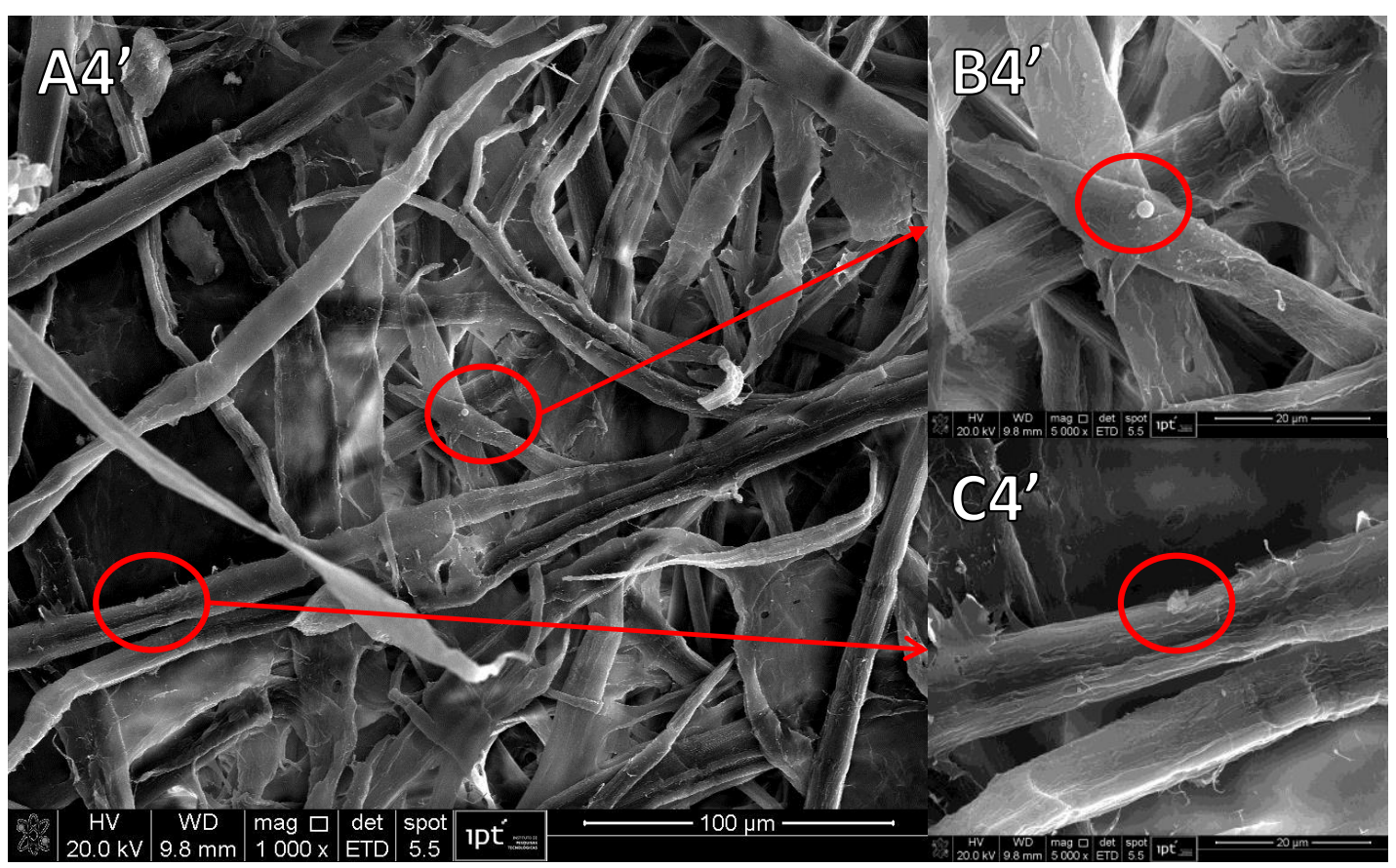

Figura 7.41: Repetição de SEM de PKEP realizada com adição de aditivo e CNF. A4': aumento de 1000x; B4': aumento de 5000x; C4': aumento de $5000 x$ 
Na Figura 7.41 é possível visualizar aglomerados de CNF, similar às Figuras 7.40 e 7.32. Concordando com o exposto anteriormente, as CNF tendem a formar aglomerados entre elas, possivelmente devido à grande área específica. No entanto, ao contrário da Figura 7.40, os aglomerados de CNF não se aderem aos espaços entre fibras (Figuras B4' e C4'), e aderem-se às paredes das fibras. Isto concorda com os resultados do planejamento de experimentos: a adesão CNF-fibra ajuda a manter a integridade estrutural das fibras (aumentando significativamente o rasgo), porém não aumenta, significativamente, o numero de pontes de hidrogênio inter-fibras, dos quais é dependente a tração, em maior medida, e o estouro. A grande área específica das CNF faz com que os polímeros catiônicos se adiram em maior medida nas CNF, aglomerando-as e, portanto, impedindo a formação de enlaces com as fibras.

A Figura 7.42 apresenta as imagens obtidas por SEM de folhas de laboratório realizadas com a pasta de eucalipto pré-branqueada (PEKP) e 1\% de CNF.

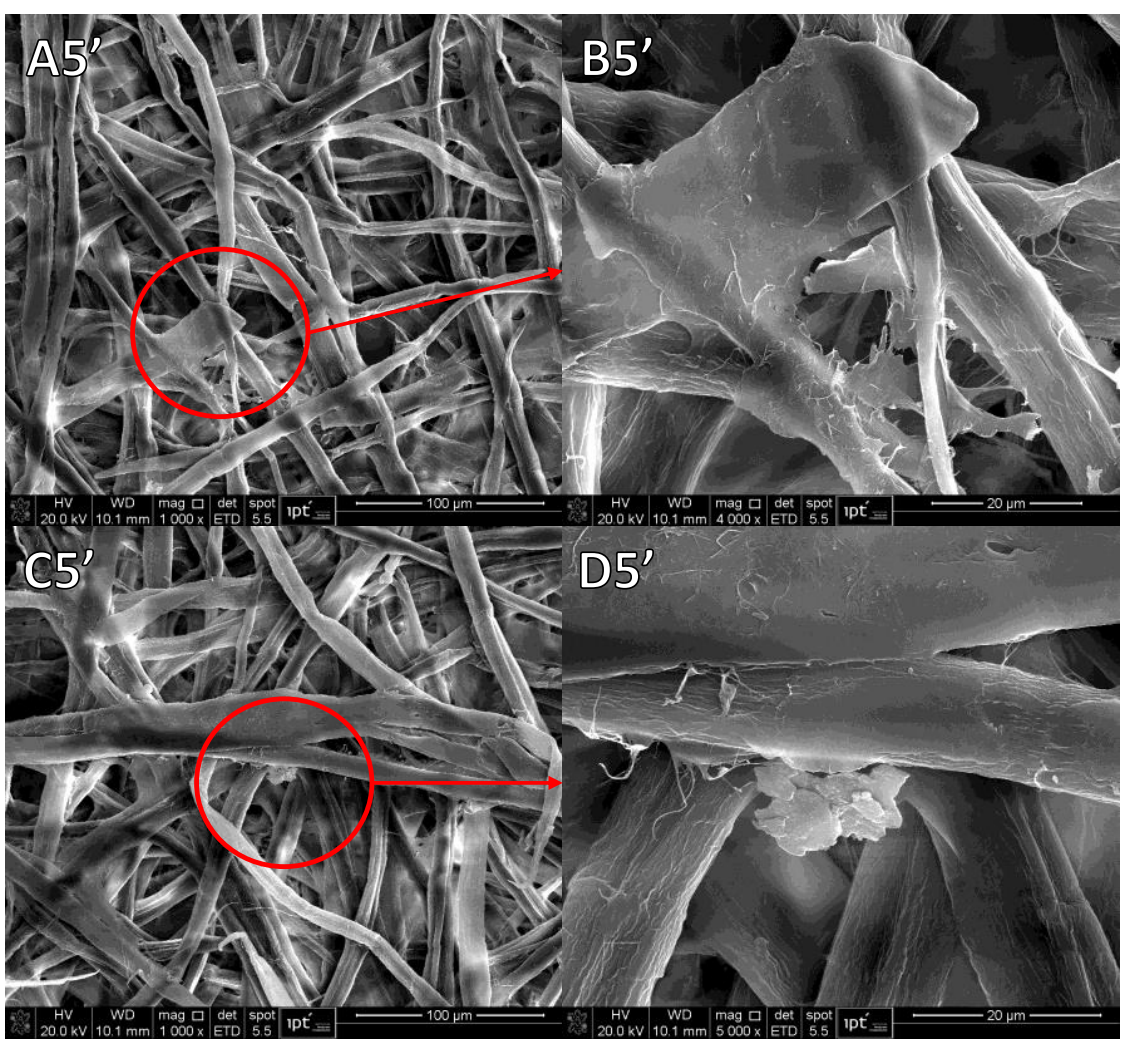

Figura 7.42: Repetição de SEM de PKEP realizada com adição de MFC. A5': aumento de 1000x, B5': aumento de 4000x e C5': aumento de 1000x. D5': aumento de 5000x 
Da mesma forma que com a adição de CNF, na Figura 7.42 observa-se que o número de micro e nanofibrilas é maior que em uma amostra sem adição de nanoceluloses (Figuras 7.30 e 7.31), de um modo óbvio, mas importante para ilustrar que a técnica de SEM está conduzida corretamente. Além disso, também se observa formação de aglomerados de MFC (C5' e D5'), estando de acordo com o exposto anteriormente.

A Figura 7.43 apresenta as imagens obtidas por SEM de folhas de laboratório realizadas com a pasta de eucalipto pré-branqueada (PEKP), após refinação Valley (34 SR) no ponto central do planejamento de experimentos realizado com $1 \%$ de MFC.

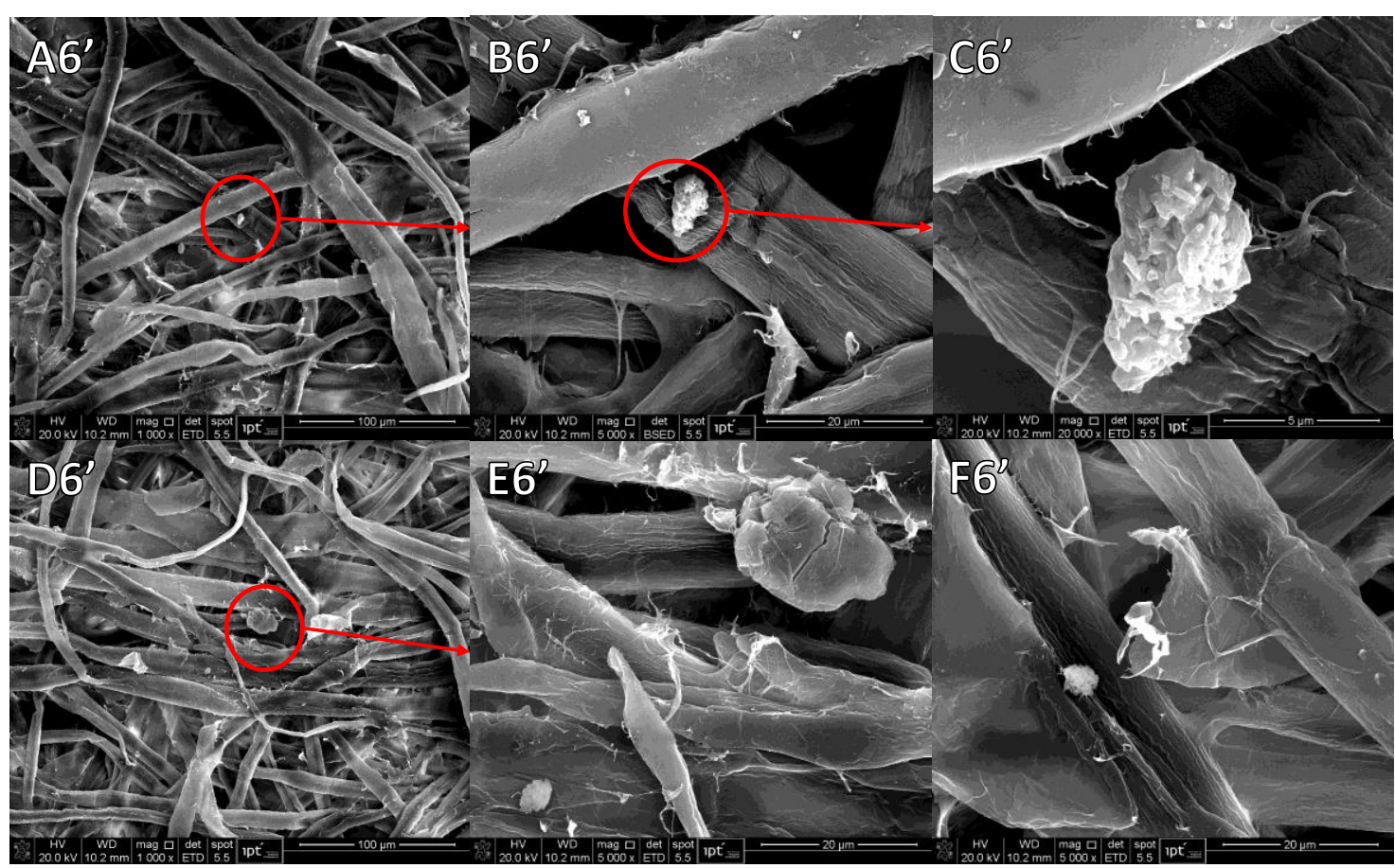

Figura 7.43: Repetição de SEM de PKEP realizada com adição de aditivo e MFC. A6': aumento de 1000x; B6': aumento de 5000x; C6': aumento de 20000x; D6'; aumento de 1000x; E6': aumento de 5000x; F6': aumento de $5000 x$

Tal como nas imagens com adição de CNF, na Figura 7.43 observa-se a formação de aglomerados de MFC, corroborando o anteriormente exposto. Por outro lado, tal como observado anteriormente (Fig. 7.37 e 7.42), os aglomerados de MFC aderem-se na superfície das fibras, não aumentando o numero de enlaces entre fibras, porém aumentando as propriedades dependentes da integridade das fibras, tais como o rasgo. 


\subsection{Discussão geral dos resultados obtidos}

Ao comparar as propriedades físico-mecânicas dos papéis realizados com pastas usadas neste estudo, em diferentes condições de formação, têm-se observado comportamentos diferentes dependendo do conteúdo de lignina. Na pasta Kraft de pinus marrom (PKPM), o uso de nanoceluloses diminui os índices de resistência mecânica. Após análise por SEM observou-se que as nanoceluloses não se aderem nas fibras, formam aglomerados. Quando os aditivos químicos usualmente aplicados na produção de papéis Kraftliner são adicionados com nanoceluloses, a ação dos primeiros ajuda o aumento das propriedades físico-mecânicas, especificamente em PKPM. Provavelmente, o elevado teor de lignina nesta pasta de fibras de pinho interfere a união das fibras com as nanoceluloses. Além disso, devido à grande área superficial das CNF e das MFC, os químicos usados fazem com que aumente a aglomeração das nanoceluloses entre elas.

Quando usadas em pastas com um teor de lignina menor (pasta Kraft de eucalipto pré-branqueada - PKEP), o uso de nanoceluloses aumenta consideravelmente os índices de resistência mecânica. $O$ uso de nanoceluloses junto com aditivo químico aumenta estes índices, mas em menor proporção. A quantidade a ser utilizada foi otimizada e percebeu-se que o índice de rasgo é aquele que obteve proporcionalmente o maior aumento. Ressalta-se novamente que a lignina de pastas mecânicas são diferentes da lignina Kraft de pasta marrom de pinus não branqueada, que por sua vez, é muito diferente da lignina residual da pasta de eucalipto após a deslignificação por oxigênio.

Nos resultados do delineamento de experimentos observou-se que, ainda que exista um aumento da quantidade de CNF e de (amido + cola), e estes incrementem os índices de resistência mecânica, a adição de CNF e de (amido + cola) tem uma maior significância no índice de rasgo. Tanto a CNF quanto $\circ$ (amido + cola) não apresentam uma interação significativa nos índices de tração e estouro. 
Nestas pastas PKEP, a adesão CNF-fibra ajuda a manter a integridade estrutural das mesmas, porém não aumenta, significativamente, o numero de pontes de hidrogênio inter-fibras, não concordando com a literatura nem com a floculação tipo patch ou mosaico (HUBBE, 2007). Após observação por SEM observa-se que as CNF e MFC não se depositam nos espaços entre fibras, depositam-se diretamente nas paredes das mesmas. Isto último pode ser o motivo do grande aumento (proporcionalmente) do rasgo e menos da tração e estouro. Tudo isto corrobora a hipótese descrita no item 7.4: o uso somente de CNF e/ou de MCF ou junto com (amido + cola) faz que as nanoceluloses se aglomerem entre si ou se adiram às fibras devido à atração que exercem os polímeros sobre elas.

Em pasta de eucalipto Kraft branqueada, o uso de CNF aumenta os índices de resistência mecânica. No entanto, o índice que mais aumento teve foi o rasgo, concordando com o anteriormente descrito. Com SEM observa-se também que as CNF depositam-se nas paredes das fibras, confirmando o exposto anteriormente.

\subsection{Avaliação econômica}

Para considerar as CNF e as MFC como uma alternativa real em escala industrial, é necessário estimar o custo destas em relação à matéria prima, a pasta de celulose, e o aumento do custo de sua adição na pasta celulósica.

$\mathrm{Na}$ literatura existem várias tentativas de estimar o custo de produção de CNF e de MFC. Jonoobi et al. (2012) avaliaram o custo da energia de produção de nanoceluloses obtidas mediante processo Masuko, produzidas a partir de pasta solúvel e de resíduo celulósico. Sem incluir a pasta solúvel na cotação, estimaram que custo energético de isolar nanofibras de celulose é de US\$ 148 por tonelada utilizando resíduo de finos primários como matéria-prima, e de US\$ 113 por tonelada, com a pasta branqueada sem incluir o custo desta matéria-prima. Delgado-Aguilar et al. (2015) estimaram o custo de produção de nanoceluloses obtidas mediante diferentes métodos em pasta Kraft de folhosa branqueada (BHKP). Concluem que o custo de produção de CNF 
obtidas por pré-tratamento com oxidação mediada por TEMPO, a pH 7 e pH 10 , é de $175,3911 € / \mathrm{kg}$ e $205,7328 € / \mathrm{kg}$, respectivamente, o que são valores muito diferentes de Jonoobi et al. (2012), com métodos de obtenção diferentes, e o custo de obtenção de CNF mediante pré-tratamento ácido, tratamento enzimático e tratamento mecânico é de $7,3294 € / \mathrm{kg}, 13,6561 € / \mathrm{kg}$ e 2,2472 €/kg, respectivamente. Alcalá et al. (2015) estimaram que o custo de produção de TOCN (2,2,6,6-tetramethylpiperidine-1-oxyl (TEMPO)-oxidized cellulose nanofibril), em diferentes níveis de oxidação, em aproximadamente de $25 € / \mathrm{kg}$. Verifica-se assim que não existe consenso sob o custo de obtenção de nanoceluloses.

Nelson et al. (2015) cita que a TAPPI Nanocellulose Division indica um preço de venda comercial de celulose nanocristalina (CNC) de 10 US $\$ /$ lb.-50 US $\$ / / \mathrm{lb}$., de nanocelulose obtida por processo mecânico de 4 US $\$ / \mathrm{lb}$. e de TOCN de 100 US\$/lb. No mercado, nanofibras podem ser compradas comercialmente, em preços que variam de 50 US $\$ / \mathrm{lb}$. até 800 US $\$ / \mathrm{lb}$., dependendo do tipo de nanoceluloses e do percentual de massa seca.

Embora, a produção de nanocelulose em laboratório tenha rendimentos de produção elevados, cerca de 95\% (JONOBI et al., 2012; ALCALÁ et al., 2015), tem que ser avaliado a relação de custo/rendimento. No presente estudo, obteve-se um rendimento de $78,7 \%$ na produção das CNF (Tabela 6.2). Nelson et al. (2015) apresentam rendimentos de obtenção de CNF de $45 \%$ por tonelada de biomassa original.

Para obter os custos de produção de nanoceluloses, consideram-se neste estudo os referidos rendimentos de $78,8 \%$ para CNF e de $95 \%$ para MFC. Não se consideram os custos de equipamentos, mão de obra, investimentos ou tratamentos de resíduos na obtenção de CNF ou MFC, ou seja, trata-se de uma estimativa geral, e não é uma avaliação rigorosa de CAPEX e OPEX (Capital Expenditure and Operational Expenditure). Na Tabela 7.12 apresentam-se os custos estimados de fabricação de $1 \mathrm{~kg}$ de CNF ou MFC. 
Tabela 7.12: Custo de obtenção das CNF e MFC

\begin{tabular}{lccccc}
\hline Nanocelulose & $\begin{array}{c}\text { Reagentes Químicos } \\
(\mathbf{U S} \mathbf{\$} / \mathbf{T})\end{array}$ & $\begin{array}{c}\text { Energia } \\
\mathbf{( k W h / T )}\end{array}$ & $\begin{array}{c}\text { Energia } \\
\mathbf{( k W h / U S \$ )}\end{array}$ & $\begin{array}{c}\text { Obtenção micro e } \\
\text { nanocelulose (US\$/T) }\end{array}$ & $\begin{array}{c}\text { Obtenção micro e } \\
\text { nanocelulose (US\$/kg) }\end{array}$ \\
\hline CNF & 74 & 570 & 60,250 & $94.949,0438$ & 949,490 \\
MFC & 0 & 2750 & 260,699 & $3.059,9989$ & 30,599 \\
\hline
\end{tabular}

O custo de produção foi estimado assumindo um custo de energia de US\$/MWh 105,7091 (R\$/MWh 369,98*), média do preço de compra industrial do ano 2015 no Brasil

Considera-se a cotação de 3,5 R \$/US\$, para efeitos de cálculo

Não se considera o custo da pasta celulósica. Neste estudo foi usado um rejeito industrial, portanto considera-se que o custo de matéria-prima é US\$0

* Nota: Fonte ANEEL, 2016. ${ }^{24]}$

Observa-se na Tabela 7.12 que os custos, no presente trabalho, para a obtenção de CNF e de MFC, são de 94,9490 US\$/kg e 3,0599 US\$/kg, respectivamente, semelhantes aos descritos por Nelson et al. (2015).

Para melhor estimativa do custo de produção de CNF e MFC, é necessário conhecer o custo de produção de $1 \mathrm{~kg}$ de pasta celulósica. Não existe no mercado pasta Kraft de eucalipto não branqueada. Por este motivo, considera-se o custo de produção de $1 \mathrm{~kg}$ de pasta Kraft de eucalipto não branqueada (UHKP - Unbleached Hardwood Kraft Pulp) igual ao de pasta Kraft de eucalipto branqueada (BHKP - Bleached Hardwood Kraft Pulp). Do mesmo modo, considera-se o custo de produção de $1 \mathrm{~kg}$ de pasta Kraft de pinus não branqueada (USKP- Unbleached Softwood Kraft Pulp) igual ao de pasta Kraft de pinus branqueada (BSKP- Bleached Softwood Kraft Pulp) apresentada na Tabela 7.13. Não são considerados custos de frete, marketing nem vendas (p.ex.: descontos).

Na Tabela 7.13 observa-se que o custo de produção de $1 \mathrm{~kg}$ de UHKP é de 0,174 US $\$ / \mathrm{kg}$ e de $1 \mathrm{~kg}$ de USKP é de 0,3375 US $\$ / \mathrm{kg}$. Nota-se que a obtenção de $1 \mathrm{~kg}$ de USKP tem, praticamente, o mesmo custo que o de produção $2 \mathrm{~kg}$ de UHKP.

24 AGÊNCIA NACIONAL DE ENERGIA ELÉTRICA - ANEEL. Tarifa Média por Classe de Consumo e por Região. Disponível em: <http://www.aneel.gov.br/> Acesso em 23 Maio de 2016. 
Tabela 7.13: Custos de Produção das Pastas

Modificado de Hawkins Wright (2015) ${ }^{[25]}$

\begin{tabular}{|c|c|c|c|c|c|c|c|c|}
\hline Pasta & $\begin{array}{c}\text { Madeira } \\
\text { (US\$/T) }\end{array}$ & $\begin{array}{l}\text { Químicos } \\
\text { (US\$/T) }\end{array}$ & $\begin{array}{l}\text { Energia } \\
\text { (US } \$ / T)\end{array}$ & $\begin{array}{l}\text { Trabalho** } \\
\text { (US\$/T) }\end{array}$ & $\begin{array}{l}\text { Manutenção } \\
\text { (US\$/T) }\end{array}$ & $\begin{array}{l}\text { Outros }{ }^{* * *} \\
\text { (US\$/T) }\end{array}$ & US\$/T & US\$/kg \\
\hline UHKP & 72 & 31 & 12 & 11 & 23 & 25 & 174 & 0,174 \\
\hline USKP* & 180,5 & 57 & 5,5 & 35,5 & 29,5 & 29,5 & 337,5 & 0,3375 \\
\hline \multicolumn{9}{|c|}{$\begin{array}{l}\text { "Nota 1: No Brasil não existe venda de USKP e/ou BSKP. Para efeitos de cálculo de considera a média do } \\
\text { custos de produção USKP de Argentina e de Chile }\end{array}$} \\
\hline \multicolumn{9}{|c|}{ **Nota 2: Custo dos salários pagos aos trabalhadores } \\
\hline
\end{tabular}

A Tabela 7.14 mostra o custo de adicionar $1 \%$ de CNF ou $1 \%$ de MFC na UHKP.

Tabela 7.14: Custo de $1 \mathrm{~kg}$ de pasta UHKP com $1 \%$ de CNF ou $1 \%$ de MFC adicionada

\begin{tabular}{|c|c|c|c|c|}
\hline Nanocelulose & $\begin{array}{l}\text { Custo } \\
\text { UHKP } \\
\text { (US\$/kg) }\end{array}$ & $\begin{array}{c}\text { Custo de micro e } \\
\text { nanocelulose adicionada } \\
(1 \%, w / w)(U S \$ / k g)\end{array}$ & $\begin{array}{c}\text { Total } \\
\text { (US\$/kg) }\end{array}$ & $\begin{array}{c}\text { Razão percentual do } \\
\text { custo de } 1 \% \text { de } \\
\text { nanocelulose (\%) }\end{array}$ \\
\hline CNF & 0,174 & 0,9494 & 1,1236 & 85 \\
\hline MFC & 0,174 & 0,0306 & 0,2046 & 15 \\
\hline
\end{tabular}

Observa-se na Tabela 7.14 que o custo para produzir pasta com $1 \%$ de CNF é de 1,1236 US $\$ / \mathrm{kg}$ e para produzir pasta com $1 \%$ de CMF é de 0,2046 US $\$ / K g$. Comparando com o custo de produção de $1 \mathrm{~kg}$ de USKP $(0,3375$ US\$ $/ \mathrm{kg}$ ), a produção de $1 \mathrm{~kg}$ de pasta UHKP com $1 \%$ adicional de CMF tem um custo de inferior $(0,2046 \mathrm{US} \$ / \mathrm{kg})$, o que é um resultado interessante. Por outro lado, o custo de produção de UHKP com $1 \%$ de CNF é muito maior que o da USKP. Embora o pré-tratamento de oxidação mediada com TEMPO diminua consideravelmente a energia de produção das CNF em relação a MFC (570 kWh/T para CNF e $2750 \mathrm{kWh} / \mathrm{T}$ ), o custo dos químicos necessários é bastante alto (Tabela 7.12) pelo que, atualmente, a utilização de CNF em pastas celulósicas não é competitiva quando comparada com a utilização de MFC. Pelo exposto, mostra-se a relevância de ter-se escolhido finos primários para a fabricação de nanocelulose no presente trabalho.

25 HAWKINS WRIGHT. The outlook for paper grade pulp demand, supply, cost and prices. Dezember, 2015. <http://www.hawkinswright.com> Relatórios desta empresa de consultpria independente de informação de negócios e inteligência de mercado são acessíveis para assinantes. 


\subsection{Formação de folhas em dupla camada}

Conforme descrito na metodologia, neste trabalho foi desenvolvida uma nova forma de adição de CNF ou MFC no papel, denominando-se formação em "dupla camada". Como explicado anteriormente, a formação em dupla camada consiste na adição de CNF ou MFC entre duas folhas de laboratório de $45 \mathrm{~g} / \mathrm{m}^{2}$, por aspersão, formando uma folha de gramatura de $90 \mathrm{~g} / \mathrm{m}^{2}$. Não se trata de inserção de uma camada de nanocelulose ou de um filme de nanocelulose entre folhas multiply, nem é realmente dupla camada, e sim de um spray de nanocelulose na mesma proporção definida no trabalho, $1 \%$ de CNF ou de MFC em massa em relação às fibras, que, ao consolidar a folha total, irá se distribuir uniformemente na direção CD e MD, mas apresentando perfil ao longo da direção $z$ com máximo no centro desse eixo. Está se reproduzindo na medida de possível essa condição em folha manual de laboratório, e nunca foi testado ou experimentado na literatura até o momento.

Na Tabela 7.15, apresentam-se os resultados obtidos para os índices de resistência a tração das folhas formadas realizadas em dupla camada (1\% CNF ou MFC, 0,5\% amido, $0,06 \%$ cola e $0,02 \%$ de polímero). Nesta Tabela, também se apresentam os resultados obtidos em outras condições de formação, assim como em pasta Kraft de pinus marrom para comparação de resultados. 
Tabela 7.15: Resultados obtidos para o índice de tração em folhas produzidas em dupla camada e em outras condições

\begin{tabular}{|c|c|c|c|c|}
\hline \multirow{3}{*}{ Condição de adição } & \multicolumn{4}{|c|}{ Índice de resistência à tração $(\mathrm{N} . \mathrm{m} / \mathrm{g})$} \\
\hline & \multirow[b]{2}{*}{ PKEP } & \multirow[b]{2}{*}{ PKPM } & \multicolumn{2}{|c|}{ Papel Kraftliner Industrial } \\
\hline & & & $\begin{array}{l}\text { Longitudinal } \\
\text { (CD) }\end{array}$ & $\begin{array}{c}\text { Transversal } \\
\text { (MD) }\end{array}$ \\
\hline Referência & $32,14(2,50)$ & $40,01(3,02)$ & \multirow{8}{*}{$95,15(6,85)$} & \multirow{8}{*}{$43,97(2,59)$} \\
\hline Aditivos Químicos* & $39,60(2,20)$ & $45,28(2,90)$ & & \\
\hline $1 \% \mathrm{CNF}$ & $42,71(3,99)$ & $34,14(1,98)$ & & \\
\hline $1 \% \mathrm{MCF}$ & $39,42(2,61)$ & $32,28(2,88)$ & & \\
\hline Aditivos Químicos* $+1 \%$ CNF & $33,02(1,08)$ & $32,68(1,20)$ & & \\
\hline Aditivos Químicos* $+1 \%$ MFC & $37,28(2,97)$ & $33,21(1,47)$ & & \\
\hline Dupla Camada - CNF & $52,58(2,39)$ & - & & \\
\hline Dupla Camada - MFC & $47,40(0,77)$ & - & & \\
\hline
\end{tabular}

*Nota: Aditivos Químicos equivale a: 0,5\% amido $+0,06 \%$ cola $+0,02 \%$ polímero.

O número entre parêntesis equivale ao desvio padrão do ensaio.

Analisando os resultados da Tabela 7.15 têm-se:

- Ao comparar os resultados obtidos das folhas produzidas em dupla camada com as outras condições de formação, para a PKEP, observase que os valores para os índices de resistência a tração são notavelmente superiores ao resto. Ao depositar um fino spray entre duas folhas de laboratório, esta se assenta no interior da folha total, ligado às duas folhas mediante pontes de hidrogênio dos grupos hidroxilo $\left(\mathrm{OH}^{-}\right)$. Filmes nanocelulósicos na literatura têm demonstrado umas excelentes propriedades mecânicas (EICHHORN et. al., 2010; BESBES et al. 2011; SPENCE et al., 2011). Por outra parte, as propriedades de tração e arrebentamento, dependem diretamente das ligações inter-fibras. Quanto menor é o tamanho das fibras, maior é o potencial de ligações interfibrilares e, portanto, maior a área de ligação entre elas;

- Comparando os valores de tração obtidos para as folhas produzidas em dupla camada com os resultados das folhas obtidas para PKPM (Figura 7.15), nota-se que os valores de tração são superiores aos 
obtidos na pasta de pinus, utilizada para fabricação de papéis Kraftliner.

- Se compararmos os valores obtidos para as folhas produzidas em dupla camada com CNF com as produzidas em dupla camada com MFC, observa-se que as produzidas com CNF têm uns valores do índice de tração superiores aos de CNF. Provavelmente, as CNF têm um grau de nanofibrilação maior que as MFC, portanto, menor o tamanho das fibras, o que implica maior área de ligação e maior tração.

$\mathrm{Na}$ Tabela 7.16, apresentam-se os resultados obtidos para os índices de resistência a rasgo das folhas formadas realizadas em dupla camada ( $1 \%$ CNF ou MFC, $0,5 \%$ amido, $0,06 \%$ cola e $0,02 \%$ de polímero). Nesta Tabela, também se apresentam os resultados obtidos em outras condições de formação, assim como em pasta Kraft de pinus marrom para comparação de resultados.

Analisando os resultados apresentado na Tabela 7.16 têm-se:

- Comparando a formação em dupla camada com outras condições de adição em PKEP, observa-se que similar aos valores apresentados para o índice de tração, a média do índice de rasgo é maior que em outras condições;

- Comparando os valores de tração obtidos para as folhas produzidas em dupla camada com os resultados das folhas obtidas para PKPM, observa-se que o valor do índice de rasgo é notavelmente superior na PKPM. O índice de rasgo depende, principalmente, da integralidade das fibras, do comprimento, do tamanho das paredes, da largura da fibra e do coarseness, entre outros, valores maiores nas fibras longas.

- Ao igual que na tração o valor do índice do rasgo é maior nas folhas em dupla camada produzidas com CNF que nas produzidas com MFC. 
Tabela 7.16: Resultados obtidos para o índice de rasgo em folhas produzidas em dupla camada e em outras condições

\begin{tabular}{|c|c|c|c|c|}
\hline \multirow{3}{*}{ Condição de adição } & \multicolumn{4}{|c|}{ Índice de resistência a rasgo $\left(\mathrm{mN} \cdot \mathrm{m}^{2} / \mathrm{g}\right)$} \\
\hline & \multirow[b]{2}{*}{ PKEP } & \multirow[b]{2}{*}{ PKPM } & \multicolumn{2}{|c|}{ Papel Kraftliner Industrial } \\
\hline & & & $\begin{array}{l}\text { Longitudinal } \\
\text { (CD) }\end{array}$ & $\begin{array}{c}\text { Transversal } \\
\text { (MD) }\end{array}$ \\
\hline Referência & $7,24(0,73)$ & $22,83(1,64)$ & \multirow{8}{*}{$11,46(0,70)$} & \multirow{8}{*}{$11,46(0,54)$} \\
\hline Aditivos Químicos* & $8,88(0,65)$ & $21,50(0,97)$ & & \\
\hline $1 \% \mathrm{CNF}$ & $9,92(1,08)$ & $21,53(0,64)$ & & \\
\hline $1 \% \mathrm{MCF}$ & $9,82(0,99)$ & $18,99(1,42)$ & & \\
\hline Aditivos Químicos* $+1 \%$ CNF & $9,53(0,77)$ & $19,26(0,49)$ & & \\
\hline Aditivos Químicos* $+1 \%$ MFC & $9,89(0,64)$ & $19,16(0,57)$ & & \\
\hline Dupla Camada - CNF & $11,27(0,68)$ & - & & \\
\hline Dupla Camada - MFC & $10,34(0,62)$ & - & & \\
\hline
\end{tabular}

*Nota: Aditivos Químicos equivale a: $0,5 \%$ amido $+0,06 \%$ cola $+0,02 \%$ polímero.

O número entre parêntesis equivale ao desvio padrão do ensaio.

$\mathrm{Na}$ Tabela 7.17, apresentam-se os resultados obtidos para os índices de resistência a estouro das folhas formadas realizadas em dupla camada ( $1 \%$ CNF ou MFC, 0,5\% amido, 0,06\% cola e 0,02\% de polímero). Nesta Tabela, também se apresentam os resultados obtidos em outras condições de formação, assim como em pasta Kraft de pinus marrom para comparação de resultados.

Pode-se observar na Tabela 7.17 os mesmos resultados obtidos para o índice de resistência a tração: valores superiores do índice de resistência a estouro na pasta PKEP que em todas as condições, independentemente da pasta usada. Pelo exposto, comparando formações em dupla camada (CNF com MFC), observa-se um valor superior quando usadas CNF.

$\mathrm{Na}$ revisão da literatura, expõe-se a pobre retenção de nanocelulose na matéria-prima fibrosa, isto é, no papel. A aglomeração e floculação das CNF e MFC observada neste trabalho põe-se de manifesto a perda destes nanomateríais durante a fabricação do papel. Realizando a formação em "dupla camada", pressupõe-se uma retenção total das nanocelulose, pelo qual se obtêm uns incrementos notavelmente superiores das propriedades 
mecânicas em comparação com a formação de folhas utilizando as nanoceluloses como aditivo em massa.

Tabela 7.17: Resultados obtidos para o índice de estouro em folhas produzidas em dupla camada e em outras condições

\begin{tabular}{|c|c|c|c|}
\hline \multirow{2}{*}{ Condição de adição } & \multicolumn{3}{|c|}{ Índice de resistência a estouro $\left(\mathrm{kPa} \cdot \mathrm{m}^{2} / \mathrm{g}\right)$} \\
\hline & PKEP & PKPM & Papel Kraftliner Industrial \\
\hline Referência & $7,24(0,73)$ & $22,83(1,64)$ & \multirow{8}{*}{$4,03(0,31)$} \\
\hline Aditivos Químicos* & $8,88(0,65)$ & $21,50(0,97)$ & \\
\hline $1 \% \mathrm{CNF}$ & $9,92(1,08)$ & $21,53(0,64)$ & \\
\hline $1 \% \mathrm{MCF}$ & $9,82(0,99)$ & $18,99(1,42)$ & \\
\hline Aditivos Químicos* $+1 \%$ CNF & $9,53(0,77)$ & $19,26(0,49)$ & \\
\hline Aditivos Químicos ${ }^{*}+1 \%$ MFC & $9,89(0,64)$ & $19,16(0,57)$ & \\
\hline Dupla Camada - CNF & $11,27(0,68)$ & - & \\
\hline Dupla Camada - MFC & $10,34(0,62)$ & - & \\
\hline
\end{tabular}

*Nota: Aditivos Químicos equivale a: 0,5\% amido + 0,06\% cola $+0,02 \%$ polímero.

O número entre parêntesis equivale ao desvio padrão do ensaio.

Expostos os resultados, pode-se concluir que a formação em dupla camada mostra-se como uma alternativa viável e econômica (quando usadas MFC), para substituição das fibras longas por fibras curtas. Exceto no rasgo, os valores das propriedades mecânicas são superiores aos obtidos em fibras longas. Além disso, provavelmente, ao colocar um filme de nanoceluloses entre camada, obteríamos propriedades de barreira de líquidos e gases, fazendo a formação em dupla camada ótima para seu uso em embalagens para alimentos.

Portanto, fica claro aqui que nessa retenção total de nanocelulose no interior da folha do papel, conseguiu-se as propriedades físicas com fibras curtas PKEP maiores do que as características medidas no papel PKPM, o que indica fortemente que ao se utilizar industrialmente esse desenvolvimento inovador, conseguir-se-á um papel superior ao Kraftliner industrial de pinus. 


\section{CONCLUSÔES E FUTUROS TRABALHOS}

Brasil é o maior produtor de fibras de eucalipto do mundo, consequentemente, dada a sua disponibilidade e preço menor em relação às fibras longas de coníferas, o presente trabalho teve interesse em desenvolver a substituição destas fibras na fabricação de papéis para embalagem, especificamente as folhas externas, ou capas, denominadas de Kraftliner.

Sabendo-se, pelas experiências industriais passadas, de que adição de fibras curtas em torno de $20 \%$ em relação às fibras longas alcançava as propriedades requeridas em processo tradicional, o presente trabalho se propôs a um desenvolvimento inovador com o uso de nanocelulose para fabricação com $100 \%$ de fibras curtas de pasta não branqueada.

Mostra-se no trabalho que as fibras tradicionalmente utilizadas em Kraftliner, fibras longas marrons (não branqueadas), não se obtém aumento das propriedades mecânicas, chegando a degradar algumas resistências mecânicas. Esse fato não provém de erro de condução experimental, pois estudo similar realizado independentemente em outro local com outra fábrica, também mostrou essa degradação de propriedades [26]. Mesmo com essa evidência experimental independente, mostra-se por outro lado, que não é suficiente fazer experimentos de fabricação, e que falta ainda muito desenvolvimento de teorias que expliquem os mecanismos de fabricação de papel que contenham alto teor de lignina.

Considerando que as fibras marrons de eucalipto utilizadas no presente trabalho eram após a deslignificação com oxigênio, que é considerada uma extensão da polpação, e ao mesmo tempo uma pré-etapa de branqueamento, portanto com teor e tipo de lignina muito diferente de lignina mecânica (que

${ }^{26}$ Comunicação pessoal em Paraná de testes em outras fábricas na fabricação de Sackliners. Para adição de nanocelulose em fibras marrons de pinus e eucalipto sem aditivos químicos para analisar a aolicação em papéis marrons, ver POTULSKI, D.C. Influência da Nanocelulose nas Propriedades Físicas Mecânicas de Papel Primário e Reciclado de Pinus e Eucalyptus. Curitiba, 97p. 2016. Tese (Doutorado em Engenharia Florestal) - Universidade Federal do Paraná, 2016, onde a autora apenas sugere em futuro, "Testar a aplicação de nanocelulose combinada com aditivos químicos sobre as propriedades físico-mecânicas do papel". 
tem alto grau de hidrofobicidade) e de Kraft logo após polpação com lignina residual (que tem alto teor de lignina condensada), previa-se que o uso de nanocelulose nessas pastas obteria resultados diferentes. De fato a aplicação de nanocelulose aumentou as propriedades mecânicas da pasta com eucalipto.

A fabricação de papel para embalagem requer o uso de agentes químicos, e a interação entre nanoceluloses e esses agentes, além dos finos, é muito mais complexa do que a literatura apresenta em relação às fibras branqueadas, onde se supõe simplesmente que aumento de teor de nanocelulose aumenta a resistência apesar de detrimento com a drenabilidade. Mostra-se no trabalho, portanto, que no caso de pastas marrom, em certas condições, chega-se a diminuir a resistência do papel devido a complexidade do meio com nanocelulose, finos e agentes químicos, o que significa que além dos estudos mais detalhados sobre ação entre nanocelulose e esses agentes, é igualmente necessário um estudo de desenvolvimento de teorias em relação aos finos com alto teor de lignina.

A literatura supõe que deveria se utilizar máximo permitido pela drenabilidade, porém os ensaios preliminares mostram que existe alguma forma de saturação evidenciada pelos mínimos e máximos de algumas propriedades. Assim o presente trabalho mostra que a faixa de sensibilidade está entre 0-3\% de nanocelulose. Portanto o delineamento de experimentos relata em seus resultados as condições requeridas para o uso de nanocelulose na presença de agentes químicos e com refino das fibras virgens. Mostra-se também que com o teor de nanocelulose até $3 \%$ no presente caso não se compromete a drenabilidade, portanto não compromete a operabilidade da máquina de papel.

Entretanto o sucesso do propósito inicial de fabricação de Kraftliner baseado totalmente em fibras virgens curtas deslignificadas com oxigênio ocorre no desenvolvimento do presente trabalho devido à percepção de que adição direta na parte úmida da fabricação fazia perder uma quantidade significativa de nanocelulose, lembrando-se de que estes são extremamente compatíveis 
com água e tem ação de pontes de hidrogênio em escala superior às fibras usuais devido às características das suas superfícies. Portanto, testou-se inclusão de nanocelulose por spray diretamente na parte intermediária do Kraftliner, chegando a propriedades mecânicas quase duas vezes superiores à adição na parte úmida, e ultrapassando as propriedades de Kraftliner de coníferas.

Como existem diferentes nanoceluloses, experimentou-se uma nanocelulose feita por homogeneização mecânica simples por esmerilhamento, considerada aqui como MCF ou MFC, e outra produzida com pré-tratamento químico via oxidação por TEMPO e posterior homogeneização por impacto, considerada aqui como CNF. Após testes preliminares de prospecção e delineamento de experimentos, escolheram-se CNF como o mais representativo para analisar ação de nanocelulose em fibras marrons de eucalipto. Para diminuir a discussão sobre os custos de produção de nanocelulose e criar mais valor agregado, apesar de ter-se produzido nanocelulose a partir de fibra virgem branqueada de eucalipto e de seus finos primários (portanto igualmente branqueados), escolheu-se CNF e MFC produzidas a partir de resíduos industriais para os estudos com delineamento de experimentos e discute-se o custo econômico para concluir que a produção e o uso destes nanoceluloses é extremamente viável.

A continuidade desse trabalho será desenvolver aplicação real em unidade piloto, do lado tecnológico. Necessita-se também rever totalmente as teorias coloidais aceitas na fabricação de papel com fibras branqueadas, porque se nanocelulose é extremamente diferente de fibras usuais e de matéria usual em estado coloidal (finos, lixos iônicos etc), devem ir pelos caminhos de mecanismos diferentes, e ainda a literatura sobre esse assunto é muito incipiente.

As propriedades analisadas a partir de delineamento dos experimentos requeriu um balanceamento entre os índices de resistência a tração, rasgo e estouro. Uma continuidade de análise será utilizar análise estatística multivariada para entender a correlação entre todas as propriedades medidas 
e a utilização de métodos de otimização multiobjetivo em lugar de simples balanço de compromisso entre essas diferentes propriedades de papel para embalagem, o que será mais coerente com a ideia global de extensibilidade requerida para papéis Kraftliner e Sackliner. 


\section{REFERÊNCIAS BIBLIOGRÁFICAS}

ABE, K.; IWAMOTO, S.; YANO, H. Obtaining Cellulose Nanofibers with a Uniform Width of $15 \mathrm{~nm}$ from Wood, Biomacromolecules, v.8, p.3276-3278, 2007.

ABE, K.; NAKATSUBO, F.; YAN, H. High-strength nanocomposite based onfibrillated chemi-thermomechanical pulp. Composites Science and Technology, v.69, p.2434-2437, 2009.

ADEL, A. M.; EL-GENDY, A.A.; DIAB, M.A.; ABOU-ZEID, R.E.; EL-ZAWAWY, W.K.; DUFRESNE, A. Microfibrillated cellulose from agricultural residues. Part I: Papermaking application. Part II. Strategic evaluation and market analysis for MFCE30. Industrial Crops and Products. 2016 (to be published)

ARNDT, T.; MEINL, G.; ERHARD, K; Behaviour of cellulose fine structures in papermaking test. In: COST, Fine Structure of Papermaking Fibres, p.247252, 2011.

AHOLA, S.; ÖSTERBERG, M.; LAINE, J. Cellulose nanofibrils - adsorption with poly(amideamine) epichlorohydrin studied by QCM-D and application as a paper strength additive, Cellulose, v.15, n.2, p.303-314, 2008.

ALCALA, M.; DELGADO-AGUILAR, M.; TARRÉS, Q.; PÈLACH, M.A.; VILASECA, F.; MUTJÉ, P. Approach to the costs production of cellulose nanofibers obtained by TEMPO-mediated oxidation. In: COST, European Cooperation in Science and Technology. Congress. 24 Maio 2015, Madri.

ALMEIDA, E.V.R.; FROLLINI, E.; CASTELLAN, A.; COMA, V. Chitosan, sisal cellulose, and biocomposite chitosan/sisal cellulose films prepared from thiourea/ $\mathrm{NaOH}$ aqueous solution. Carbohydrate Polymers, v. 80 , n. 3, p. 655664, 2010.

ÄMMÄLÄ, A.; LIIMATAINEN, H.; BURMEISTER, C.; NIINIMAKI, J. Effect of tempo and periodate-chlorite oxidized nanofibrils on ground calcium carbonate flocculation and retention in sheet forming and on the physical properties of sheets. Cellulose, v.20, p.2451-2460. 2013. 
ALOI, F.G.; TRKSAK, R.M. Retention in Neutral and Alkaline Papermaking. In: Retention of Fines and Fillers during Papermaking. Tappi Press. Cap 5. 1998.

ANDRESEN, M.; JOHANSSON, L.S.; TANEM, B.S.; STENIUS, P. Properties and characterization of hydrophobized microfibrillated cellulose. Cellulose, v.13, p.665-677, 2006.

ANTUNES, E.; GARCIA, F. A.; FERREIRA, P.; BLANCO, A.; NEGRO, C.; RASTEIRO, M. G. Use of new branched cationic polyacrylamides to improve retention and drainage in papermaking. Industrial \& Engineering Chemistry Research, v.47, n.23, p.9370-9375, 2008.

BARDET, R.; BRAS, J. Chapter 13. Cellulose nanofibers and their use in paper industry. in K. Oksman; A. P. Mathew; A. Bismarck (eds.) Handbook of Green Materials. Vol. 1. World Scientific. 2014.

BESBES, I.; VILAR, M.R.; BOUFI, S. Nanofibrillated cellulose from Alfa, Eucalyptus and Pine fibres: Preparation, characteristics and reinforcing potential. Carbohydrate Polymers, v.86, p.1198-1206, 2011.

BIERMANN, C.J. Handbook of pulping and papermaking. $2^{\text {nd }}$ ed. Academic Press, California, 1996.

BLANCO, A.; NEGRO, C.; TIJERO, J. Developments in flocculation: a literature review. UK: Pira International, 2001. 152p.

BLEDZKI, A.K.; GASSAN, J. Composites reinforced with cellulose-based fibres. Progress in polymer science., v.24, n.2, p.221-274, 1999.

BRODIN, F.W.; GREGERSEN, O.W.; SYVERUD, K. Cellulose nanofibrils: challenges and possibilities as a paper additive or coating material: a review. Nordic Pulp \& Paper Research Journal, v.29, n.1, p.156-166, 2014.

CAMPBELL, W. B. The mechanism of bonding. Tappi, v.42, n.12, p.999-1001, 1959. (obs: em lugar do trabalho original, foi acessado em diversos livros textos citados ao longo desse trabalho). 
CARRASCO, G.C. Cellulose fibres, nanofibrils and microfibrils: the morphological sequence of MFC components from a plant physiology and fibre technology point of view. Nanoscale Research Letter, v.6, n.1, p.417, 2011.

CHAUHAN, V.S.; CHAKRABARTI, S.K. Use of nanotechnology for high performance cellulosic and papermaking products. Cellulose Chemistry and Technology, v. 46, p. 389-400, 2012.

CHINGA-CARRASCO, G. Cellulose fibres, nanofibrils and microfibrils: The orphological sequence of MFC components from a plant physiology and fibre technology point of view. Nanoscale Research Letters, v.6, p.417. 2011.

COLODETTE, J.L.; GOMES, F.J.B.G. (eds.) Branqueamento de Polpa Celulósica. Editora UFV. 2015.

COLSON, J.; BAUER, W.; MAYR, M.; FISCHER; W., GINDL-ALTMUTTER, W. Morphology and rheology of cellulose nanofibrils derived from mixtures of pulp fibres and papermaking fines. Cellulose, v. 23, p. 2439-2448, 2016.

CRUCES-CERRO, J. Influencia del contenido de estuco en la reciclabilidad de los papeles de escribir. Tese de Licenciatura. E.U.I.T. Forestales de Madrid. Madri (Espanha), 2013.

CUBEROS-MARTINEZ, P.; PARK, S.W. Review of physical principles in low consistency refining. O Papel v.73, n. 8, p. 65-72, 2012

CUBEROS-MARTINEZ, P. Modelagem Matemática da Refinação de Polpa Celulósica em Baixa Consistência. São Paulo, 2005. 113p. Dissertação (Mestrado em Engenharia Quimica) - Escola Politêcnica, Universidade de São Paulo.

D’ALMEIDA, M.L.O. Capítulo 3. Composição química dos materiais lignocelulósicos. In: D’ALMEIDA, M.L.O. (org.). Celulose e Papel - Tecnologia de fabricação da pasta celulósica. Volume 1, 2.ed. São Paulo: IPT/SENAI, 1988.

DÉJARDIN, A.; LAURANS, F.; ARNAUD, D.; BRETON, C.; PILATE, G.; LEPLE, G.J. Wood formation in Angiosperms. Comptes Rendus Biologies, v.333, n.4, p. 325-334, 2010. 
DELGADO-AGUILAR, M.; GONZÁLEZ, I.; MANUEL ALCALÁ, Q.T.; PÈLACH, M.A.; MUTJÉ,P. Approaching a Low-Cost Production of Cellulose Nanofibers for Papermaking Applications. Bioresources, v.10, n.3, p.5345-5355, 2015.

EICHHORN, S.J.; DUFRESNE, A.; ARANGUREN, M.; MARCOVICH, N.E.; CAPADONA, J.R.; ROWAN, S.J.; WEDER, C.; THIELEMANS, W.; ROMAN, M.; RENNECKAR, S.; GINDL, W.; VEIGEL, S.; KECKES J.; YANO, H.; ABE, K.; NOGI, M.; NAKAGAITO, A.N.; MANGALAM, A.; SIMONSEN, J.. BENIGHT, A.S.; BISMARCK, A.; BERGLUNG, L.A.; PEIJS, T. Review: current international research into cellulose nanofibres and nanocomposites. Journal of Materials Science, v.45, p.1-10, 2010.

EK, M.; GELLERSTEDT, G.; HENRIKSSON, G. Pulp and paper chemistry and tecnology. 4 volumes. Berlin. De Gruyter, 2009.

El SEOUD, O.A.; FIDALE, L.C.; RUIZ, N.; D'ALMEIDA, M.L.O.; FROLLINI, E. Cellulose swelling by protic solvents: which properties of the biopolymer and the solvent matter? Cellulose, v.15, n.3, p.371-392, 2008.

ERIKSEN, Ø.; SYVERUD, K.; GREGERSEN, Ø. The use of microfibrillated celulose produced from Kraft pulp as strength enhancer in TMP. Nordic Pulp \& Paper Research Journal, v.23, n.3, p.299-3-4, 2008.

ESA, F.; TASIRIN, S.M.; RAHMAN, N.A. Overview of bacterial cellulose production and application. Agriculture and Agricultural Science Procedia, v.2, p.113119, 2014.

FERNANDES, E.T. Nanopartículas de sílica coloidal como agente da química da parte úmida na fabricação de papel. São Paulo, 2013. 154p. Dissertação (Mestrado em Engenharia Química) - Escola Politécnica, Universidade de São, 2013.

FERREIRA, P.J.T. Estudos de pastas Kraft de Eucalyptus globulus: características estruturais e aptidão papeleira. Coimbra, 2000. 361p. Tese (Doutor em Engenharia Química) - Faculdade de Ciência e Tecnologia, Universidade de Coimbra, 2000. 
FERREIRA, P.J.; MATOS, S.; FIGUEIREDO, M.M. Size characterization of fibres and fines in hardwood kraft pulps. Particle \& Particle Systems Characterization, v.16, n.1, p.20-24, 1999.

FERREIRA, P.J.; MARTINS, A.A.; FIGUEIREDO, M.M. Primary and secondary fines from Eucalyptus globulus Kraft pulps. Characterization and influence. Paperi Ja Puu - Paper and Timber, v.82, n.6, p.403-408, 2000

FRONE, A.N.; PANAITESCU, D.M.; DONESCU, D. Some aspects concerning the isolation of cellulose micro- and nano: fibers. UPB Scientific Bulletin, v.73, p.133- 152, 2011.

FUKUZUMI, H.; SAITO, T.; ISOGAI, A. Influence of TEMPO-oxidized cellulose nanofibril length on film properties. Carbohydrate Polymers, v.93, p.172-177, 2013.

GAMELAS, J.A.; PEDROSA, J.; LOURENÇO, A.F.; FERREIRA, P.J. Surface properties of distinct nanofibrillated celluloses assessed by inverse gas chromatography. Colloids and Surfaces A: Physicochemical and Engineering Aspects, v.469, p.36-41. 2015a.

GAMELAS, J.A.; PEDROSA, J.; LOURENÇO, A.F.; MUTJÉ, P.; GONZÁlEZ, I.; CHINGA-CARRASCO, G.; SINGH, G.; FERREIRA, P.J. On the morphology of cellulose nanofibrils obtained by TEMPO-mediated oxidation and mechanical treatment. Micron, v.72, p.28-33. 2015b.

GAO, W.H.; CHEN, K.F.; YANG, R.D.; YANG, F.; HAN, W.J. Properties of bacterial cellulose and its influence on the physical properties of paper. BioResources, v.6, n.1, p.144-153, 2010.

GARDNER, D.J.; OPORTO, G.S.; MILLS, R.; SAMIR, M.A.S.A. Adhesion and surface issues in cellulose and nanocellulose. Journal of Adhesion Science and Technology, v.22, p.545-567, 2008.

GHAREHKHANI, S.; SADEGHINEZHAD, E.; KAZI, S. N.; YARMAND, H.; BADARUDIN, A.; SAFAEI, M. R.; ZUBIR, M. N. M. Basic effects of pulp refining on fiber properties-A review. Carbohydrate polymers, v.115, p.785-803, 2015 
GIUDICI, R.; PARK, S.W. Kinetic Model For Kraft Pulping of Hardwood. Industrial and Engineering Chemistry Research, v.35, n.3, p.856-863, 1996.

GLOBUS, A.; BAILEY, D.; HAN, J.; JAFFE, R.; LEVIT, C.; MERKLE, R.; SRIVASTAVA, D. NASA applications of molecular nanotechnology. The Journal of the British Interplanetary Society, v.51, p.145-152, 1998.

GOMES, F.J.B.; GOMES, A.F.; COLODETTE, J.L.; GOMIDE, J.L.; CARVALHO, A.M.M.L.; TRUGILHO, P.F.; GOMES, C.M.; ROSADO, A.M. . Influência do teor e da relação $S / G$ da lignina da madeira no desempenho da polpação Kraft. 0 Papel, São Paulo, v. 69, p. 95-105, 2008.

GONZÁLEZ, I.; BOUFI, S.; PÈLACH, M.A.; ALCALÀ, M.; VILASECA, F.; MUTJÉ, P. Nanofibrillated cellulose as paper additive in eucalyptus pulps. BioResources, v.7, n.4, p.5167-5180, 2012.

GOTTUMUKKALA, L. D.; HAIGH, K.; COLLARD, F. X.; VAN RENSBURG, E.; GÖRGENS, J. Opportunities and prospects of biorefinery-based valorisation of pulp and paper sludge. Bioresource technology, v.215, p.37-49, 2016.

GULLICHSEN, J.; FOGELHOLM, C.J. Chemical Pulping. Papermaking Science and Technology Series. Book 6A. Finnish paper engineer's association and TAPPI Publ. 1999.

HAMADA, H.; BECKVERMIT, J.; BOUSFIELD, W.D. Nanofibrillated Cellulose with Fine Clay as a Coating Agent to Improve Print Quality. PaperCon 2010, Conference.

HASSAN, E.; HASSAN, M.; OKSMAN, K. Improving bagasse pulp paper sheet properties with microfibrillated cellulose isolated from xylanase-treated bagasse, Wood Fibre Sci., v. 43, n.1, p. 76-82, 2011.

HENRIKSSON, M.; BERGLUND, L.A.; ISAKSSON, P.; LINDSTRÖM, T. Cellulose nanopaper structures of high toughness. Biomacromolecules, v.9, p.15791585, 2008.

HII, C.; GREGERSEN, Ø.; CHINGA-CARRASCO, G; ERIKSEN, Ø. The effect of MFC on the pressability and paper properties of TMP and GCC based sheets, Nord. Pulp Paper Res. J., v.27, n.2, p.388-396, 2012. 
HUBBE, M.A. Prospects for maintaining strength of paper and paperboard products while using less forest resources: A review. BioResources, v.9, n.1, p.16341763, 2014.

HUBBE, M.A. Flocculation and redispersion of cellulosic fiber suspensions: A review of effects of hydrodynamic shear and polyelectrolytes. BioResources, v.2, n.2, p.296-331, 2007.

HUBBE, M.A. Nanotechnology in the Wet-End. In: Emerging Technologies in WetEnd Chemistry, TAPPI Press, Atlanta, 2005, cap 5.

IFUKU, S.; NOGI, M.; ABE, K.; YOSHIOKA, M.; MORIMOTO, M.; SAIMOTO, H.; YANO, $H$. Preparation of chitin nanofibers with a uniform width as $\alpha$-chitin from crab shells. Biomacromolecules, v.10, p.1584-1588, 2009.

IFUKU, S.; NOGI, M.; YOSHIOKA, M.; MORIMOTO, M.; YANO, H. Fibrillation of dried chitin into $10-20 \mathrm{~nm}$ nanofibers by a simple grinding method under acidic condition. Carbohydrate Polymers, v.81, p.134-139, 2010.

IOELOVICH, M. Cellulose as a nanostructured polymer: a short review. Nanostructured cellulose: review. BioResources, v.3, n.4, p.1403-1418, 2008.

IOELOVICH, M.; FIGOVSKY, O. Structure and properties of nanoparticles used in paper compositions. Mechanics of Composite Materials, v.46, n.4, p.435-442, 2010

ISOGAI, A.; SAITO, T.; FUKUZUM H. TEMPO-oxidized cellulose nanofibers. Nanoscale, v.3, p.71, 2011.

IWAMOTO, S.; KENTARO, A.; YANO, H. The effect of hemicelluloses on wood pulp nanofibrillation and nanofiber network characteristics. Biomacromolecules, v.9, p.1022-1026, 2008.

JARDIM, C.M.; COLODETTE, J.L.; Química do branqueamento. In: BRANQUEAMENTO de polpa celulósica. Viçosa: Universidade Federal de Viçosa, 2015. Seção 4, cap.1. 
JONOOBI, M.; MATHEW, A.P.; OKSMAN, K. Producing low-cost cellulose nanofiber from sludge as new source of raw materials. Industrial Crops and Products, v.40, p.232-238, 2012

JOSELEAU, J. P.; CHEVALIER-BILlOSTA, V.; RUEL, K. Interaction between microfibrillar cellulose fines and fibers: influence on pulp qualities and paper sheet properties. Cellulose, v.19, n.3, p.769-777, 2012.

JÚNIOR, D.L.; COLODETTE, J.L. Remoção de hemiceluloses da madeira por tratamento de auto-hidrólise. Ciência Florestal, Santa Maria, v.21, n.3, p.541550, 2011.

KAJANTO, I.; KOSONEN, M. The potencial use of micro- and nano-fibrrillated cellulose as a reinforcing element in paper. Journal of Science \& Technology for Forest Products and Processes, v.2, n.6, p.42-28, 2012.

KANGAS, H.; POHLER, T.; HEIKKURINEN, A.; KLEEN, M. Development of the mechanical pulp fibre surface as a function of refining energy. Journal of pulp and paper science, v.30, n.11, p.298-306, 2004.

KANGAS, H.; LAHTINEN, P.; SNECK, A.; SAARIAHO, A.M.; LAITINEN, O.; HELLÉN. E. Characterization of fibrillated celluloses. A short review and evaluation of characteristics with a combination of methods. Nordic Pulp \& Paper Research Journal, v.29, n.1, p.130-143, 2014

KIMURA, S.; LAOSINCHAI, W.; ITOH, T.; CUI, X.; LINDER, C.R.; BROWN JR., R.M. Immunogold labeling of rosette terminal cellulose-synthesizing complexesin the vascular plant Vigna angularis. The Plant Cell, v.11, p.2075-2086, 1999.

KIVIRANTA, A. Paperboard grades. In: PAPER and board grades. Helsinky (Finland), 2000. Cap.2.

KORHONEN, M.; LAINE, J. Effect of nanocelluloses on flocculation and retention of fillers. In: TAPPI International Conference on Nanotechnology 2013, Stockholm; Sweden; 24 June 2013 through 27 June 2013

KLEMM, D.; KRAMER, F.; MORITZ, S.; LINDSTRÖM, T.; ANKERFORS, M.; GRAY, D.; DORRIS, A. Nanocelluloses: a new family of nature-based materials. Angewandte Chemi International Edition, v.50, p.5438-5466, 2011. 
KOLAKOVIC, R.; PELTONEN, L.; LAAKSONEN, T.; PUTKISTO, K.; LAUKKANEN, A.; HIRVONEN, J. Spray-dried cellulose nanofibers as novel tablet excipient. American Association of Pharmaceutical Scientists, v.12, n.4, p.1366-1373, 2011.

KHOSRAVANI, A.; LATIBARI, A.J.; MIRSHOKRAEI S.A.; RAHMANINIA, M.; NAZAHD, M.M. Studying the effect of cationic starch-anionic nanosilica system on retention an drainage. BioResources, v.5, n.2, p.939-950, 2010.

KIMURA, S.; LAOSINCHAI, W.; ITOH, T.; CUI, X.; LINDER, C.R.; BROWN JR., R.M. Immunogold labeling of rosette terminal cellulose-synthesizing complexesin the vascular plant Vigna angularis. The Plant Cell, v.11, n. 11, p.2075-2086, 1999.

LAVOINE, N.; DESLOGES, I.; DUFRESNE, A.; BRAS, J. Microfibrillated cellulose Its barrier properties and applications in cellulosic materials: a review. Carbohydrate Polymers, v.90, p.735-764, 2012.

LEÃO, A.; CHERIAN,B.F.; DE SOUZA,S.F.; TOLEDO, M.A.S. Use of primary sludge from pulp and paper mills for nanocomposites Mol. Cryst. Liq. Cryst., v.556, n.1, p. 254-263, 2012.

LI, Q.; RAJ, P.; HUSAIN, F.A.; VARANASI, S.; RAINEY, T.; GARNIER, G.; BATCHELOR, W. Engineering cellulose nanofibre suspensions to control filtration resistance and sheet permeability. Cellulose, v.23, n.1, p.391-402, 2016.

LIN, T.; YIN, X.; RETULAINEN, E.; NAZHAD, M.M. Effect of chemical pulp fines on filler retention and paper properties. Appita v.60, n.6, p.469, 2007.

MAGNUSSON, M.S.; OSTLUND, S. Inter-fibre bond strength and combined normal and shear loading. In: Progress in Paper Physics Seminar, Graz, Austria, September 5-8, 2011.

MAHECHA, M.M.A.; BLÁCIDO, D.R.T.; MENEGALLI, F.C. Películas biodegradables: la incorporación de microfibras y nanofibras de celulosa obtenido a partir de fuentes vegetales. Publicaciones e Investigación, v.5, n.1, p.11-28, 2011.

MANNINEN, M.; KAJANTO, I.; HAPPONEN, J.; PALTAKARI, J. The Effect of Microfibrillated Cellulose Addition on Drying Shrinkage and Dimensional Stability 
of Wood-Free Paper, Nordic Pulp and Paper Research Journal, v.26, n.3, p.297-305, 2011.

MISSOUM, K.; MARTOÏA, F.; BELGACEM, M.N.; BRAS, J. Effect of chemically modified nanofibrillated cellulose addition on the properties of fiber-based materials. Industrial Crops and Products, v.48, p.98-105, 2013.

MÖRSEBURG, K.; CHINGA-CARRASCO, G. Assessing the combined benefits of clay and nanofibrillated cellulose in layered TMP-based sheets. Cellulose, v. 16, n. 5, p. 795-806, 2009.

MORSEBURG, K.; CHINGA-CARRASCO, G. Assessing the combined benefits of clay and nanofibrillated cellulose in layered TMP-based sheets. Cellulose, v.16, p. $795-806,2009$

NAKAGAITO, A.N.; YANO, H. Novel high-strength biocomposites based on microfibrillated cellulose having nano-order-unit web-like network structure. Applied Physics, v.80, p.155-159, 2005.

NECHYPORCHUK, O.; BELGACEM, M.N.; BRAS, J. Production of cellulose nanofibrils: A review of recent advances. Industrial Crops and Products. 2016. (to be published)

NELSON, K.; RETSINA, T.; IAKOVLEV, M.; HEININGEN, A.; DENG, Y.; SHATKIN, J.A.; MULYADI, A. American Process: Production of Low Cost Nanocellulose for Renewable, Advanced Materials Applications. In: Materials Reserch for Manufacturing. MADSEN, L.D.; SVEDBERRG, E.B. (Eds). Atlanta, Springer Series in Materials Science, 2015, cap. 9.

NISGOSKI, S. Espectroscopia no infravermelho próximo no estudo de características da madeira e papel de Pinus taeda L. Curitiba, 2005. 160 p. Tese (Doutorado em Engenharia Florestal) - Setor de Ciências Agrárias, Universidade Federal do Paraná, 2005.

NISKANEN, K. (ed.). Mechanics of paper products. Berlin. De Gruyter, 2012.

NOGI, M.; YANO, H. Optically transparent nanofiber sheets by deposition of transparent materials: a concept for a roll-to-roll processing. Applied Physics Letters, v.94, p.1-4, 2009. 
NUNES, T.; LOURENÇO, A.F.; GAMELAS, J.A.; FERREIRA, P.J. Cellulose nanofibrils in papermaking - Filler retention, wet web resistance and printability.In: ICNF2015 The Second Int. Conf, on natural Fibers. Açores, Portugal 27-29 April. 2015.

NUNES, T.; LOURENÇO, A.F.; AMARAL, J.L. GAMELAS, J.A.; FERREIRA, P.J. Influence of CNF and PCC on the wet-web resistance on papermaking. TECHNICELPA 2016 (to be published).

OSONG, S.H.; NORGREN, S.; ENGSTRAND, P. Processing of wood-based microfibrillated cellulose and nanofibrillated cellulose, and applications relating to papermaking: a review. Cellulose, v.23, n.1, p.93-123, 2016.

PÄÄKKÖ, M.; ANKERFORS, M.; KOSONEN, H.; NYKÄNEN, A.; AHOLA, S.; ÖSTERBERG, M.; RUOKOLAINEN, J.; LAINE, J.; LARSSON, P.T.; IKKALA, O.; LINDSTRÖM, T. Enzymatic hydrolysis combined with mechanical shearing and high pressure homogenization for nanoscale cellulose fibrils and strong gels. Biomacromolecules, v.8, n.6, p.1934-1941, 2007.

PARK, S.W.; PINTO, J.M.. Cinética de Polpação Kraft: Parte 1. A Evolução de Modelos Empíricos para Modelos Mecanísticos. In: 23 Congresso Anual de Celulose e Papel da ABTCP, 1990.

PEREZ, D.S.; MONTANARI, S.; VIGNON, M.R. TEMPO-Mediated Oxidation of Cellulose III. Biomacromolecules, v.4, p.1417-1425, 2003

POSTEK, M.T.; MOON, R.J.; RUDIE, A.W.; BILODEAU, M.A. Production and applications of cellulose nanomaterials. TAPPI Press, Atlanta. 2013.

POTULSKI, D.C.; MUNIZ, G.I.B.; KLOCK, U.; ANDRADE, A.S. The influence of incorporation of microfibrillated cellulose on mechanical strength properties of paper. Sci. For., Piracicaba, v.42, n.103, p.345-351, 2014.

RETULAINEN, E.; MOSS, P.; NIEMINEM, K. Effect of fines on the properties of fibre networks. In: Baker, C.F (ed): Products in papermaking, vol. 2. Transactions of the 10th Fundamental Research Symposium, Oxford, UK, September, 1993. PIRA International, Leatherhead, UK, p.727-769. 1993. 
ROJAS, O.J. Capítulo 3. Fibras y finos. In: QUÍMICA del papel. Cenpapel (Centro de Capacitación y Desarrollo Tecnológico para la Indústria Papelera), 2003. Colombia. (obs: não possui ISBN)

ROJAS, O.J.; HUBBE, M.A. The Dispersion Science of Papermaking. Journal of Dispersion Science and Technology, v.25, n.6, p.713-732, 2004.

SAITO, T.; HIROTA, M.; TAMURA, N.; KIMURA, S.; FUKUZUMI, H.; HEUX, L.; ISOGA, A. Individualization of nano-sized plant cellulose fibrils by direct surface carboxylation using TEMPO catalyst under neutral conditions. Biomacromolecules, v.10, p.1992-1996, 2009.

SAITO, T.; ISOGAI, A. TEMPO-Mediated Oxidation of Native Cellulose. The Effect of Oxidation Conditions on Chemical and Crystal Structures of the Water-Insoluble Fractions. Biomacromolecules, v.5, n.5, p. 1983-1989, 2004.

SAITO, T.; KIMURA, S.; NISHIYAMA, Y.; ISOGAI. A. Cellulose nanofibres prepared by TEMPO mediated oxidation of native cellulose. Biomacromolecules, v.8, p.2485-2491, 2007.

SANTOS, S.M.; CARBAJO, J.M.; QUINTANA, E.; IBARRA, D.; GOMEZ, N.; LADERO, M.; EUGENIO, M.E.; VILLAR, J.C. Characterization of purified bacterial cellulose focused on its use on paper restoration. Carbohydrate polymers, v.116, p.173-181, 2015.

SCOTT, W.E. Properties of paper: am introduction. Atlanta: Tappi Press, 1995. $192 p$.

SEHAQUI, H.; ALLAIS, M.; ZHOU, Q.; BERGLUND, L.A. Wood cellulose biocomposites with fibrous structures at micro- and nanoscale. Composites Science and Technology, v.71, p.382-387, 2011.

SEHAQUI, H.; ZHOU, Q.; LARS, BERGLUND, L.A. Nanofibrillated cellulose for enhancement of strength in high-density paper structures. Nord Pulp Pap Res J, v.28, n.2, p.182-189, 2013.

SETH, R.S. The measurement and significance of fines. Pulp \& Paper Canada, v. 104, n. 2, p. 41-44, 2003. 
SHINODA, R.; SAITO, T.; OKITA, Y.; ISOGAI, A. Relationship between length and degree of polymerization of TEMPO-oxidized cellulose nanofibrils. Biomacromolecules, v.13, p.842-849, 2012.

SIQUEIRA, G.; BRAS, J.; DUFRESNE, A. Cellulosic bionanocomposites: a review of preparation, properties and applications. Polymers, v.2, n.4, p.728-765, 2010.

SILVA, D.J. Química da parte úmida em processo de fabricação de papel Interações em interfaces sólido-líquido. São Paulo, 2010. 293p. Tese (Doutor em Engenharia Química) - Escola Politécnica, Universidade de São Paulo, 2010.

SILVA, D.J.; D’ALMEIDA, M.L.O. Cellulose whiskers. O Papel, v.70, n.7, p.34-52, 2009.

SILVA, M.G. Produtividade, idade e qualidade da madeira de Eucalyptus destinada à produção de pasta celulósica branqueada. Piracicaba, 2011. 94p. Dissertação (Mestrado em Recursos Florestais) - Escola Superior de Agricultura “Luiz de Queiroz", Universidade de São Paulo, 2011.

SIM, K.; LEE, J.; LEE, H.; YOUN, H.J. Flocculation behavior of cellulose nanofibrils under different salt conditions and its impact on network strength and dewatering ability. Cellulose, v.22, n.6, p.3689-3700, 2015

SIRÓ, I.; PLACKETT, D. Microfibrillated cellulose and new nanocomposite materials: a review. Cellulose, v.17, n.3, p.459-494, 2010.

SIXTA, H.; RUTKOWSKA, E.W. Comprehensive kinetic study on Kraft pulping of Eucalyptus globulus.. Part.1,2. O Papel v.68, n.2, p.54-67, p.68-81, 2007.

SIXTA, H. Handbook of Pulp. 2 volumes. Berlin. Wiley-VCH. 2006.

SJÖSTRÖM, E. Wood Chemistry. $2^{\text {nd }}$ Ed. Academic Press, NY. 1993.SJÖSTRÖM, E.; ALÉN, R. Analytical Methos in Wood Chemistry. $2^{\text {nd }}$ Ed. Springer, Berlin. 2010.

SPENCE, K.L.; VENDITTI, R.A.; ROJAS, O.; HABIBI, Y.; PAWLAK, J.J. A comparative study of energy consumption and physical properties of microfibrillated cellulose produced by different processing methods. Cellulose, v.18, p.1097-1111, 2011. 
SPENCE, K.L.; VENDITTI, R.A.; ROJAS, O.; HABIBI, Y.; PAWLAK, J.J. The effect of chemical composition on microfibrillar cellulose films from wood pulps: water interactions and physical properties for packaging applications. Cellulose, v.17, n.4, p.835-848, 2010.

STELTE, W.; SANADI, A.R. Preparation and characterization of cellulose nanofibers from two commercial hardwood and softwood pulps. Industrial \& Engineering Chemistry Research, v.48, p.11211-11219, 2009.

STENIUS, P. (ed.) Forest Products Chemistry. Papermaking Science and Technology Series. Book 3. Finnish paper engineer's association and TAPPI Publ. 2000.

SUBRAMANIAM, R. Engineering fine paper by utilizing the structural elements of the raw materials. Helsinky, 2008. 66p. Tese (Doutor em Ciencias) - Helsinki University of Technology, 2008.

SWANSON, J.W. Colloid Chemistry of Papermaking Materials. Atlanta: TAPPI Press, 2003. 278p.

SYVERUD, K.; CARRASCO, G.C.; TOLEDO, J.; TOLEDO, P.G. A comparative study of Eucalyptus and Branqueada radiata pulp fibres as raw materials for production of cellulose nanofibrils. Carbohydrate Polymers, v.84, p.1033-1038, 2011.

TAIPALE, T.; ÖSTERBERG, M.; NYKÄNEN, A.; RUOKOLAINEN, J.; LAINE, J. Effect of microfibrillated cellulose and fines on the drainage of kraft pulp suspension and paper strength, Cellulose, v.17, n.5, p.1005-1020, 2010.

TECHNICAL ASSOCIATION FOR PULP AND PAPER INDUSTRY - TAPPI. TAPPI UM 21: Kappa number of pulp. Atlanta, 2013. 9p.

TECHNICAL ASSOCIATION FOR PULP AND PAPER INDUSTRY - TAPPI. TAPPI/ANSI T 271 om-12: Fiber length of pulp and paper by automated optical analyzer using polarized light. Atlanta, 2012. 6p.

TOMAZELLO FILHO, M. Análise da madeira de compressão em Pinus oocarpa estrutura anatômica e quantificação, IPEF, Piracicaba, n.37, p.61-68, 1987. 
TONOLI, G.H.D.; TEIXEIRA, E. M.; CORRÊA, A.C.; MARCONCINI, J.M.; CAIXETA, L.A.; PEREIRA-DA-SILVA, M.A.; MATTOSO, L.H.C. Cellulose micro/nanofibres from Eucalyptus kraft pulp: preparation and properties. Carbohydrate Polymers, v.89, n.1, p.80-88, 2012.

TOVEN, K.; GORSKI, D.; GREGERSEN, Ø.W. Fracture resistance of reinforced SC paper, Progress in paper physics seminar 2008, Espoo Finland, June 2 - June 5 ,2008, p.109-112. (obs: em lugar do trabalho original, foi acessado em diversos textos).

TRIPATTHARANAN, T.; HUBBE, M.A.; HEITMANN, J.A.; VENDITTI, R.A. Effect of idealised flow conditions on retention aid performance. Part 2: polymer bridging, charged patches, and charge neutralization. Appita Journal, v.57, n.6, p.448454, 2004.

TURNER, P.; KOWALEZYK, M.; REYNOLDS, A. New insights into the micro-fibril architecture of the wood cell wall. In: Cost, Fine Structure of Papermaking Fiber, p.11-26, 2011.

UETANI, K.; YANO, H. Nanofibrillation of wood pulp using a high-speed blender. Biomacromolecules, v.12, p.348-353, 2011.

VALLEJOS, M.E.; FELISSIA, F.E.; AREA, M.C.; EHMAN, N.V.; TARRÉS, Q.; MUTJÉ, P. . Nanofibrillated cellulose (CNF) from eucalyptus sawdust as a dry strength agent of unrefined eucalyptus handsheets. Carbohydrate polymers, v.139, p.99-105, 2016.

VARTIAINEN, J.; PÖHLER, T.; SIROLA, K.; PYLKKÄNEN, L.; ALENIUS, H.; HOKKINEN, J.; TAPPER, U.; LAHTINEN, P.; KAPANEN, A.; PUTKISTO, K.; HIEKKATAIPALE, P.; ERONEN, P.; RUOKOLAINEN, J.; LAUKKANEN, A. Health and environmental safety aspects of friction grinding and spray drying of microfibrillated cellulose. Cellulose, v.18, p.775-786, 2011.

VERVERIS, C.; GEORGHIOU, K., CHRISTODOULAKIS, N., SANTAS, P.; SANTAS, R. Fiber dimensions, lignin and cellulose content of various plant materials and their suitability for paper production. Industrial Crops and Products, v.19, n.3, p.245-254, 2004. 
VIANA, L.C. Desenvolvimento de filmes celulósicos nanoestruturados a partir da polpa Kraft de Pinus sp. Curitiba, 2013. 128p. Tese (Doutor em Engenharia Florestal) - Setor de Ciências Agrárias, Universidade Federal do Paraná, 2013.

VISHTAL, A.; RETULAINEN, E. Boosting the extensibility potential of fibre networks: A review. BioResources, v.9, n.4, p.7951-8001, 2014.

WANG, H.; LI, D.; ZHANG, R. Preparation of ultralong cellulose nanofibers and optically transparent nanopapers derived from waste corrugated paper pulp. BioResources, v.8, n.1, p.1374-1384, 2013.

WANG, Z.L. Splendid one-dimensional nanostructures of zinc oxide: a new nanomaterial family for nanotechnology. ACS Nano, v.2, n.10, p.1987-1992, 2008.

YASUMURA, P.K. Caracterização de propriedades de papel para impressão por jato de tinta. São Paulo, 2012. 249p. Tese (Doutor em Engenharia Química) Escola Politécnica, Universidade de São Paulo, 2012.

YASUMURA, P.K.; D'ALMEIDA, M.L.O; PARK, S.W. Refining actions in PFI and in industrial disc refiner. O Papel, v. 69, n. 8, p.63-52, 2008.

YASUMURA, P.K.; D'ALMEIDA, M.L.O; PARK, S.W. Multivariate statistical evaluation of physical properties of pulp refined in a PFI mill. O Papel, v. 73, n. 3, p.59-65, 2012.

YASUMURA, P.K.; PARK, S.W. Comparison of methods for paper roughness and porosity assessment. In: VII Ciadicyp - Iberoamerican Congress on Pulp and Paper, São Paulo, 2012. 


\section{APÊNDICE A - DADOS DAS PROPRIEDADES DAS FOLHAS FORMADAS NO LABORATÓRIO}

A1. Dados das propriedades das folhas formadas no laboratório na Pasta Kraft de Eucalipto Branqueada

\begin{tabular}{|c|c|c|c|c|c|c|c|c|c|c|c|}
\hline \multicolumn{4}{|c|}{ Amostra: Pasta de Eucalipto Branqueada, 0 PFI } & & \multicolumn{4}{|c|}{ Porosidade } & & \multicolumn{2}{|c|}{ Opacidade } \\
\hline & & & & & $\begin{array}{l}\text { equaçăo de } \\
\text { correâo do }\end{array}$ & $\mathrm{a}$ & 1 & Volume corrigido & & 1 & 88.12 \\
\hline \multicolumn{4}{|c|}{ Resistência à tração } & \multirow{4}{*}{$\begin{array}{c}\text { Indice de } \\
\text { Resistência à } \\
\text { Traçăo, } \mathrm{Nm} / \mathrm{g}\end{array}$} & Tempo & b & 0 & 98.7096 & & 2 & 87.89 \\
\hline $\begin{array}{ll}\text { equaçăo de } \\
\text { corecăo }\end{array}$ & $\mathrm{a}$ & 0.995 & \multirow{3}{*}{$\begin{array}{l}\text { Resistência à } \\
\text { tração em N/m }\end{array}$} & & $\begin{array}{l}\text { equaçăo de } \\
\text { correço do }\end{array}$ & $\mathrm{a}$ & 0.9946 & \multirow{3}{*}{$\begin{array}{c}\text { Porosidade em } \\
\mu \mathrm{m} / \mathrm{Pa} . \mathrm{s}\end{array}$} & & 3 & 88.02 \\
\hline & $\mathrm{b}$ & 0.003 & & & $\begin{array}{l}\text { corlegao do } \\
\text { volume }\end{array}$ & $\mathrm{b}$ & -0.7504 & & & 4 & 87.83 \\
\hline Força & $\begin{array}{c}\begin{array}{c}\text { sem corregăo } \\
\text { em kgf }\end{array} \\
\end{array}$ & \begin{tabular}{|c|} 
com correção \\
em N
\end{tabular} & & & Tempo & \begin{tabular}{|l|}
$\begin{array}{c}\text { sem correção } \\
\text { em s }\end{array}$ \\
\end{tabular} & $\begin{array}{c}\text { com correçăo em } \\
\mathrm{s}\end{array}$ & & & 5 & 87.76 \\
\hline 1 & 2.53 & 24.6759 & 1645.0629 & 16.8563 & 1 & 1.4 & 1.3600 & 98.20153588 & & 6 & \\
\hline 2 & 2.92 & 28.4626 & 1897.5067 & 19.4430 & 2 & 1.3 & 1.3400 & 99.66723045 & & 7 & \\
\hline 3 & 2.70 & 26.3061 & 1753.7372 & 17.9699 & 3 & 1.7 & 1.6600 & 80.45427036 & & 8 & \\
\hline 4 & 2.83 & 27.6645 & 1844.3014 & 18.8979 & 4 & 1.3 & 1.3100 & 101.9496861 & & 9 & \\
\hline 5 & 2.59 & 25.2533 & 1683.5536 & 17.2507 & 5 & 1.6 & 1.5500 & 86.16392826 & & 10 & \\
\hline \multicolumn{2}{|c|}{ Largura em $\mathrm{mm}$} & média & 1764.83 & 18.08 & & média & 1.44 & 93.29 & & média & 87.9 \\
\hline \multicolumn{2}{|c|}{15} & D.P & 106.06 & 1.09 & & D.P & 0.15 & 9.42 & & D.P & 0.15 \\
\hline \multicolumn{4}{|c|}{ Resistênncia ao Rasgo } & & \multicolumn{3}{|c|}{ Resistência ao Arrebentamento } & & \multicolumn{3}{|c|}{ Espessura } \\
\hline \multirow{2}{*}{\begin{tabular}{|c|} 
equação de \\
correçấo força
\end{tabular}} & $\mathrm{a}$ & 1 & \multirow{3}{*}{$\begin{array}{c}\text { Resistência ao } \\
\text { rasgo } \mathrm{mN}\end{array}$} & \multirow{3}{*}{\begin{tabular}{|c|} 
Indice de \\
Resistência à à \\
Rasgo, \\
Nm2/g \\
\end{tabular}} & \multirow{3}{*}{\begin{tabular}{|l} 
equacăão de \\
correçāo \\
pressăo
\end{tabular}} & $\mathrm{a}$ & 0.998 & \multirow{3}{*}{$\begin{array}{c}\text { Indice de } \\
\text { Resistência } \\
\text { Arrebentamento, } \\
\text { kPam2/g } \\
\end{array}$} & \multirow{3}{*}{$\begin{array}{l}\text { equacăăo de } \\
\text { coreçăo } \\
\text { espessura }\end{array}$} & $\mathrm{a}$ & 1.0001 \\
\hline & $\mathrm{b}$ & 0 & & & & $\mathrm{~b}$ & 3.4335 & & & b & 0 \\
\hline Força & $\begin{array}{c}\text { sem correçăo } \\
\text { em gf }\end{array}$ & \begin{tabular}{|c|c|c|c|c|c|c|c|c|c|c|} 
em gf \\
\end{tabular} & & & & \begin{tabular}{|c|} 
sem correção \\
em kPa
\end{tabular} & $\begin{array}{c}\text { com correção em } \\
\mathrm{kPa}\end{array}$ & & & \begin{tabular}{|c|} 
sem correção \\
em mm
\end{tabular} & \begin{tabular}{|c|}
$\begin{array}{c}\text { com correção } \\
\text { em mm }\end{array}$ \\
\end{tabular} \\
\hline 1 & 10.0 & 10.0000 & 313.92 & 3.21662152 & 1 & 64.7 & 68.0141 & 0.696914989 & 1 & 0.1950 & 0.1950 \\
\hline 2 & 11.0 & 11.0000 & 345.312 & 3.538283672 & 2 & 70.7 & 73.9921 & 0.758169537 & 2 & 0.1990 & 0.1990 \\
\hline 3 & 10.0 & 10.0000 & 313.92 & 3.21662152 & 3 & 55.1 & 58.4433 & 0.598846355 & 3 & 0.1900 & 0.1900 \\
\hline 4 & 10.0 & 10.0000 & 313.92 & 3.21662152 & 4 & 52.7 & 56.0580 & 0.574405893 & 4 & 0.1950 & 0.1950 \\
\hline 5 & 10.0 & 10.0000 & 313.92 & 3.21662152 & 5 & 56.3 & 59.6409 & 0.611117717 & 5 & 0.1880 & 0.1880 \\
\hline número de folhas & Fator & média & 320.20 & 3.28 & & média & 63.23 & 0.65 & 6 & 0.1950 & 0.1950 \\
\hline \multirow[t]{2}{*}{5} & 16 & D.P & 14.04 & 0.14 & & D.P & 7.52 & 0.08 & 7 & 0.1850 & 0.1850 \\
\hline & & & & & & & & & 8 & 0.1860 & 0.1860 \\
\hline \multicolumn{5}{|c|}{ Gramatura } & & & & & 9 & 0.1860 & 0.1860 \\
\hline Area da folha & & massa 5 folhas & \multicolumn{2}{|l|}{14.1022} & & & & & 10 & 0.1880 & 0.1880 \\
\hline lado $(\mathrm{cm})$ & 0.17 & & & & & & & & & 0.197 & 0.1916 \\
\hline diâmetro $(\mathrm{cm})$ & & & & & & & & & & D.P & 0.005 \\
\hline & & & & & & & & & & & \\
\hline massa 5 folhas & 14.1022 & & & & & & & & & & \\
\hline 1 folha & 2.8204 & $g$ & & & & & & & & & \\
\hline lado & 0.1700 & $\mathrm{~m}$ & & & & & & & & & \\
\hline $\mathrm{m} 2$ & 0.0289 & & & & & & & & & & \\
\hline$g^{\prime / m} 2$ & 97.5931 & & & & & & & & & & \\
\hline
\end{tabular}




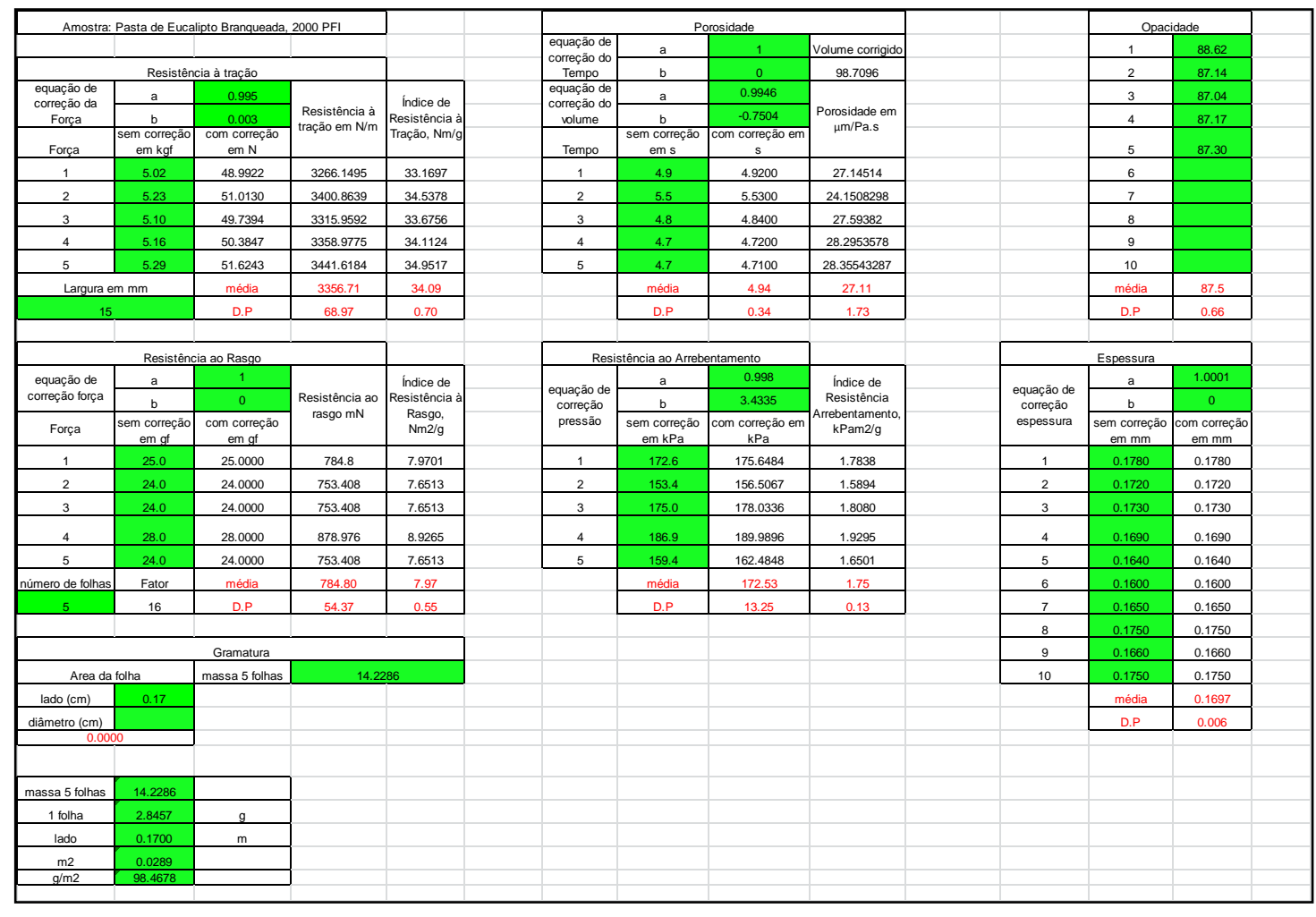

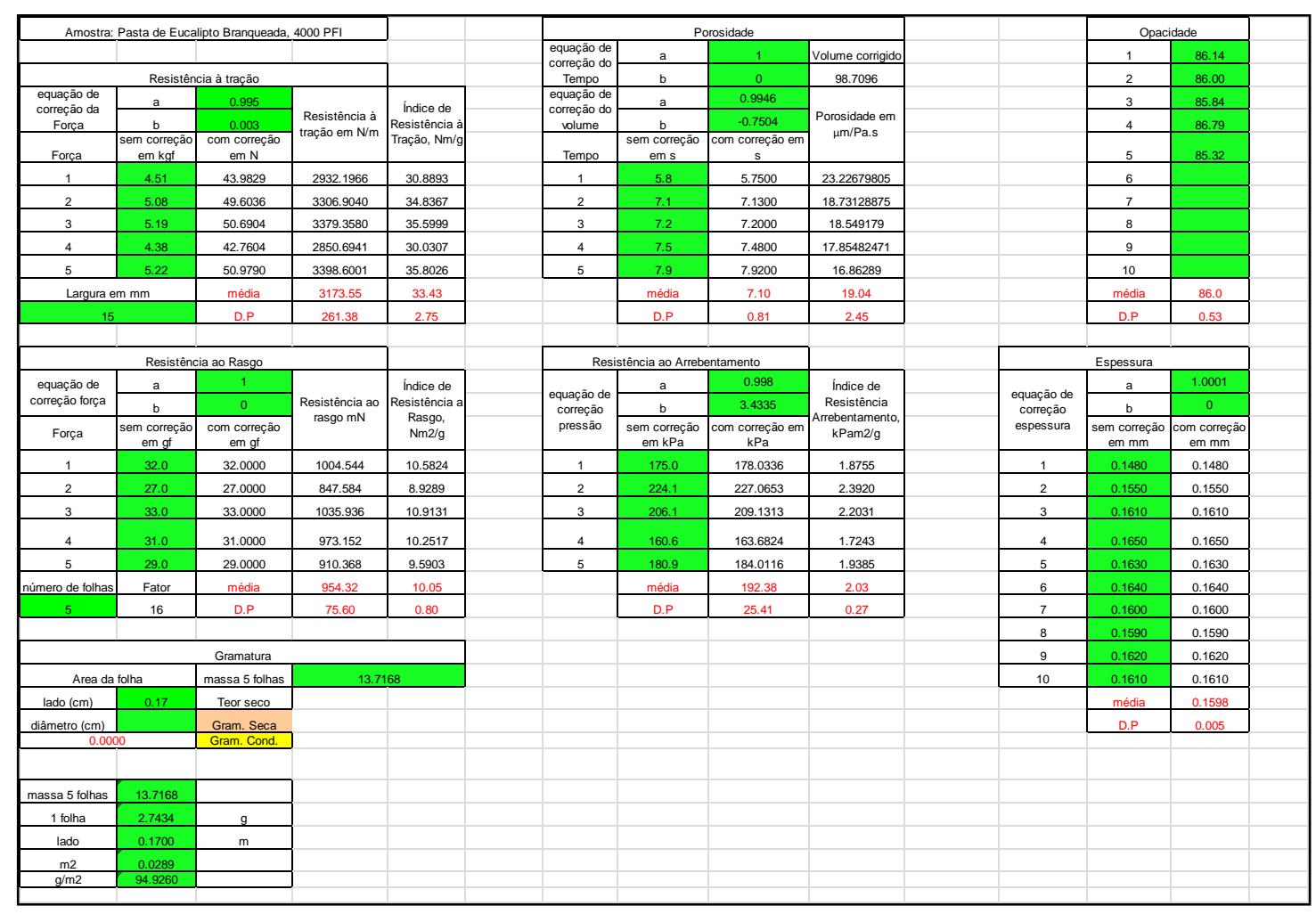




\begin{tabular}{|c|c|c|c|c|c|c|c|c|c|c|c|}
\hline \multicolumn{4}{|c|}{ Amostra: Pasta de Eucalipto Branqueada + $2 \%$ CNF } & & \multicolumn{4}{|c|}{ Porosidade } & & \multicolumn{2}{|c|}{ Opacidade } \\
\hline & & & & & \begin{tabular}{|l|l} 
equaçăo de \\
corecăo do
\end{tabular} & a & 1 & \begin{tabular}{|l|} 
Volume corrigido \\
\end{tabular} & & 1 & 85.57 \\
\hline \multicolumn{4}{|c|}{ Resistência à tração } & \multirow{4}{*}{$\left|\begin{array}{c|}\text { Indice de } \\
\text { Resistência à } \\
\text { Traçâo, Nm/g }\end{array}\right|$} & \multirow{3}{*}{$\begin{array}{c}\text { correceao do } \\
\text { Tempo } \\
\text { qeacuacáo de } \\
\text { correçáo do } \\
\text { volume } \\
\end{array}$} & b & 0 & 98.7096 & & 2 & 85.75 \\
\hline $\begin{array}{l}\text { equaçăoo de } \\
\text { correcă da }\end{array}$ & $\mathrm{a}$ & 0.995 & \multirow{3}{*}{$\begin{array}{l}\text { Resistência à } \\
\text { traçăo em N/m }\end{array}$} & & & $\mathrm{a}$ & 0.9946 & \multirow{3}{*}{$\begin{array}{c}\text { Porosidade em } \\
\mu \mathrm{m} / \mathrm{Pa} . \mathrm{s}\end{array}$} & & 3 & 84.81 \\
\hline Força & $\mathrm{b}$ & 0.003 & & & & $\mathrm{~b}$ & -0.7504 & & & 4 & 85.26 \\
\hline Força & $\begin{array}{c}\text { sem correçäo } \\
\text { em kgf }\end{array}$ & \begin{tabular}{|c|} 
com correçãa \\
em N N
\end{tabular} & & & Tempo & \begin{tabular}{|l} 
sem correção \\
em s
\end{tabular} & $\begin{array}{c}\text { com correçăo em } \\
\text { s }\end{array}$ & & & 5 & 85.60 \\
\hline 1 & 6.06 & 59.1184 & 3941.2239 & 42.4707 & 1 & 8.6 & 8.5900 & 15.54762384 & & 6 & \\
\hline 2 & 6.37 & 62.1927 & 4146.1805 & 44.6793 & 2 & 10.0 & 9.9900 & 13.36877766 & & 7 & \\
\hline 3 & 6.02 & 58.7480 & 3916.5305 & 42.2046 & 3 & 10.1 & 10.1400 & 13.17101467 & & 8 & \\
\hline 4 & 5.93 & 57.8590 & 3857.2690 & 41.5660 & 4 & 9.5 & 9.4800 & 14.08798405 & & 9 & \\
\hline 5 & 5.47 & 53.3958 & 3559.7187 & 38.3596 & 5 & 9.6 & 9.5600 & 13.97009297 & & 10 & \\
\hline \multicolumn{2}{|c|}{ Largura em mm } & média & 3884.18 & 41.86 & & média & 9.55 & 14.03 & & média & 85.4 \\
\hline \multicolumn{2}{|c|}{15} & D.P & 211.51 & 2.28 & & D.P & 0.61 & 0.93 & & D.P & 0.37 \\
\hline \multicolumn{4}{|c|}{ Resistência ao Rasgo } & & \multicolumn{3}{|c|}{ Resistência ao Arrebentamento } & & \multicolumn{3}{|c|}{ Espessura } \\
\hline \multirow{2}{*}{\begin{tabular}{c|} 
equacăa de \\
correçâo força
\end{tabular}} & $\mathrm{a}$ & 1 & \multirow{3}{*}{$\begin{array}{l}\text { Resistência ao } \\
\text { rasgo } \mathrm{mN}\end{array}$} & \multirow{3}{*}{\begin{tabular}{|c|} 
Indice de \\
Resistenciaia a \\
Rasso, \\
$\mathrm{Nm} 2 / \mathrm{g}$ \\
\end{tabular}} & \multirow{3}{*}{\begin{tabular}{|c|} 
equaçãa de \\
coreçăo \\
pressãa
\end{tabular}} & a & 0.998 & \multirow{3}{*}{\begin{tabular}{|c|} 
İndice de \\
Resistência \\
Arrebentamento, \\
$\mathrm{kPam} 2 / \mathrm{g}$
\end{tabular}} & \multirow{3}{*}{$\begin{array}{l}\text { equacăăo de } \\
\text { coreçăo } \\
\text { espessura }\end{array}$} & $\mathrm{a}$ & 1.0001 \\
\hline & b & 0 & & & & $\mathrm{~b}$ & 3.4335 & & & $\mathrm{~b}$ & 0 \\
\hline Força & \begin{tabular}{|c|} 
sem correção \\
em gf
\end{tabular} & 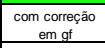 & & & & $\begin{array}{c}\text { sem correção } \\
\text { em kPa }\end{array}$ & $\begin{array}{c}\text { com correção em } \\
\mathrm{kPa}\end{array}$ & & & $\begin{array}{c}\begin{array}{c}\text { sem correção } \\
\text { em mm }\end{array} \\
\end{array}$ & 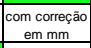 \\
\hline 1 & 29.0 & 29.0000 & 910.368 & 9.8101 & 1 & 206.1 & 209.1313 & 2.2536 & 1 & 0.1520 & 0.1520 \\
\hline 2 & 27.0 & 27.0000 & 847.584 & 9.1336 & 2 & 269.6 & 272.5143 & 2.9366 & 2 & 0.1450 & 0.1450 \\
\hline 3 & 29.0 & 29.0000 & 910.368 & 9.8101 & 3 & 239.7 & 242.6142 & 2.6144 & 3 & 0.1540 & 0.1540 \\
\hline 4 & 30.0 & 30.0000 & 941.76 & 10.1484 & 4 & 239.7 & 242.6142 & 2.6144 & 4 & 0.1580 & 0.1580 \\
\hline 5 & 31.0 & 31.0000 & 973.152 & 10.4867 & 5 & 182.1 & 185.2092 & 1.9958 & 5 & 0.1570 & 0.1570 \\
\hline número de folhas & Fator & média & 916.65 & 9.88 & & média & 230.42 & 2.48 & 6 & 0.1550 & 0.1550 \\
\hline 5 & 16 & D.P & 46.56 & 0.50 & & D.P & 33.79 & 0.36 & 7 & 0.1550 & 0.1550 \\
\hline & & & & & & & & & 8 & 0.1530 & 0.1530 \\
\hline \multicolumn{5}{|c|}{ Gramatura } & & & & & 9 & 0.1500 & 0.1500 \\
\hline \multicolumn{2}{|c|}{ Area da follha } & massa 5 folhas & \multicolumn{2}{|c|}{13.4094} & & & & & 10 & 0.1520 & 0.1520 \\
\hline lado (cm) & 0.168 & Teor seco & & & & & & & & média & 0.1531 \\
\hline diâmetro $(\mathrm{cm})$ & & Gram. Seca & & & & & & & & D.P & 0.004 \\
\hline 0.000 & & Gram. Cond. & & & & & & & & & \\
\hline massa 5 tolhas & 13.4094 & & & & & & & & & & \\
\hline 1 follha & 2.6819 & $g$ & & & & & & & & & \\
\hline lado & 0.1700 & $\mathrm{~m}$ & & & & & & & & & \\
\hline $\mathrm{m} 2$ & 0.0289 & & & & & & & & & & \\
\hline$g / m 2$ & 92.7986 & & & & & & & & & & \\
\hline
\end{tabular}


A2. Dados das propriedades das folhas formadas no laboratório na Pasta Kraft Marrom de Pinus

\begin{tabular}{|c|c|c|c|c|c|c|c|c|c|c|c|}
\hline \multicolumn{4}{|c|}{ Amostra: Pasta Pinus Marom, o PFI } & & \multicolumn{4}{|c|}{ Porosidade } & & \multicolumn{2}{|c|}{ Opacidade } \\
\hline \multirow{2}{*}{\multicolumn{4}{|c|}{ Resistência à traçăo }} & & \multirow{4}{*}{ 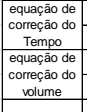 } & \multicolumn{2}{|r|}{1} & \multirow{2}{*}{$\begin{array}{c}\text { Volume corrigido } \\
98.7096\end{array}$} & & 1 & 99.49 \\
\hline & & & & & & b & 0 & & & 2 & 99.80 \\
\hline \multirow{2}{*}{ 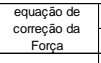 } & $\mathrm{a}$ & 0.995 & \multirow{3}{*}{$\begin{array}{l}\text { Resistência à } \\
\text { traçāo em N/m }\end{array}$} & \multirow{3}{*}{\begin{tabular}{|c|}
$\mid \begin{array}{c}\text { Indice de } \\
\text { Resistência a } \\
\text { Traạâo, Nm/g }\end{array}$ \\
\end{tabular}} & & a & & \multirow{3}{*}{$\begin{array}{c}\text { Porosidade em } \\
\mu \mathrm{m} / \mathrm{Pa} . \mathrm{s}\end{array}$} & & 3 & 99.72 \\
\hline & \multirow{2}{*}{\begin{tabular}{|c|} 
b \\
$\begin{array}{c}\text { sem correçäo } \\
\text { em kgf }\end{array}$ \\
\end{tabular}} & \multirow{2}{*}{\begin{tabular}{|c|c|c|}
0.003 \\
$\begin{array}{c}\text { com coreçăo } \\
\text { em N }\end{array}$
\end{tabular}} & & & & \multirow{2}{*}{$\begin{array}{l}\frac{b}{\text { sem correçäo }} \\
\text { em s }\end{array}$} & \multirow{2}{*}{ 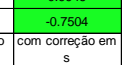 } & & & 4 & 100.21 \\
\hline Força & & & & & \begin{tabular}{|l|l} 
Tempo \\
\end{tabular} & & & & & 5 & 99.34 \\
\hline 1 & 6.44 & 62.8655 & 4191.0332 & 41.5338 & 1 & 12.9 & 12.9000 & 10.35303014 & & 6 & \\
\hline 2 & 6.53 & 63.7654 & 4251.0298 & 42.1284 & 2 & 13.9 & 13.8800 & 9.622052507 & & 7 & \\
\hline 3 & 5.39 & 52.5752 & 3505.0107 & 34.7352 & 3 & 12.5 & 12.4500 & 10.72723605 & & 8 & \\
\hline 4 & 6.42 & 62.6278 & 4175.1867 & 41.3768 & 4 & 16.8 & 16.8300 & 7.935477647 & & 9 & \\
\hline 5 & 6.25 & 60.9976 & 4066.5059 & 40.2997 & 5 & 5.7 & 5.6500 & 23.63789182 & & 10 & \\
\hline \multirow{2}{*}{\multicolumn{2}{|c|}{ Largura em mm }} & média & 4037.75 & 40.01 & & média & 12.34 & 12.46 & & média & 99.7 \\
\hline & & D.P & 305.17 & 3.02 & & D.P & 4.11 & 6.34 & & D.P & 0.33 \\
\hline \multirow{2}{*}{\multicolumn{4}{|c|}{ Resistência ao Rasgo }} & & \multirow{2}{*}{\multicolumn{3}{|c|}{ Resistência ao Arrebentamento }} & & \multirow{2}{*}{\multicolumn{3}{|c|}{ Espessura }} \\
\hline & & & & & & & & & & & \\
\hline \multirow{2}{*}{$\begin{array}{l}\text { equacăo de } \\
\text { correçâo força }\end{array}$} & $\mathrm{a}$ & 1 & \multirow{3}{*}{$\begin{array}{l}\text { Resistência ao } \\
\text { rasgo } \mathrm{mN}\end{array}$} & & & $\mathrm{a}$ & 0.998 & Indice de & & $\mathrm{a}$ & 1.0001 \\
\hline & b & 0 & & $\begin{array}{l}\text { Resistência a } \\
\text { Rasao. }\end{array}$ & 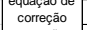 & $\mathrm{b}$ & 3.4335 & $\begin{array}{c}\text { Resistência } \\
\text { rrebentamento }\end{array}$ & $\begin{array}{l}\text { equachad oe } \\
\text { correçâ }\end{array}$ & $\mathrm{b}$ & 0 \\
\hline Força & $\begin{array}{c}\begin{array}{c}\text { sem correçāo } \\
\text { em gf }\end{array} \\
\end{array}$ & $\begin{array}{c}\text { com correçāo } \\
\text { em gf }\end{array}$ & & & & \begin{tabular}{|c|}
$\begin{array}{c}\text { sem correçāo } \\
\text { em kPa }\end{array}$ \\
\end{tabular} & $\begin{array}{c}\text { com correcăa em } \\
\mathrm{kPa}\end{array}$ & $\begin{array}{c}\text { Arreeentamento, } \\
\mathrm{kPam} / \mathrm{g}\end{array}$ & & $\begin{array}{c}\text { sem correçāo } \\
\text { em mm }\end{array}$ & $\begin{array}{l}\text { com correçāo } \\
\text { em mm }\end{array}$ \\
\hline 1 & 71.0 & 71.0000 & 2228.832 & 22.0881 & 1 & 292.4 & 295.2387 & 2.9259 & 1 & 0.2030 & 0.2030 \\
\hline 2 & 82.0 & 82.0000 & 2574.144 & 25.5102 & 2 & 323.5 & 326.3264 & 3.2339 & 2 & 0.2140 & 0.2140 \\
\hline 3 & 72.0 & 72.0000 & 2260.224 & 22.3992 & 3 & 294.8 & 297.6239 & 2.9495 & 3 & 0.1870 & 0.1870 \\
\hline 4 & 74.0 & 74.0000 & 2323.008 & 23.0214 & 4 & 309.2 & 311.9752 & 3.0917 & 4 & 0.2020 & 0.2020 \\
\hline 5 & 68.0 & 68.0000 & 2134.656 & 21.1548 & 5 & 258.8 & 261.7458 & 2.5939 & 5 & 0.2040 & 0.2040 \\
\hline número de folhas & Fator & média & 2304.17 & 22.83 & & média & 298.58 & 2.96 & 6 & 0.2090 & 0.2090 \\
\hline 5 & 16 & D.P & 165.52 & 1.64 & & D.P & 24.07 & 0.24 & 7 & 0.1800 & 0.1800 \\
\hline & & & & & & & & & 8 & 0.1880 & 0.1880 \\
\hline & & Gramatura & & & & & & & 9 & 0.2030 & 0.2030 \\
\hline Area da to & & massa 5 tolhas & 14.581 & 310 & & & & & 10 & 0.2080 & 0.2080 \\
\hline lado $(\mathrm{cm})$ & 0.168 & \begin{tabular}{|l|} 
Teor seco \\
\end{tabular} & & & & & & & & média & 0.1998 \\
\hline$\frac{\text { diâmetro }(\mathrm{cm})}{0.0000}$ & & Gram. Seca & & & & & & & & D.P & 0.011 \\
\hline & & Gram. Cond. & & & & & & & & & \\
\hline massa 5 folhas & 14.5810 & & & & & & & & & & \\
\hline 1 tollha & 2.9162 & $g$ & & & & & & & & & \\
\hline lado & 0.1700 & $\mathrm{~m}$ & & & & & & & & & \\
\hline $\mathrm{m} 2$ & 0.0289 & & & & & & & & & & \\
\hline$g^{\prime m} 2$ & 100.9066 & & & & & & & & & & \\
\hline
\end{tabular}

\begin{tabular}{|c|c|c|c|c|c|c|c|c|c|c|c|}
\hline \multicolumn{4}{|c|}{ Amostra: Pasta Pinus Marrom, $2000 \mathrm{PFI}$} & & \multicolumn{4}{|c|}{ Porosidade } & & \multicolumn{2}{|c|}{ Opacidade } \\
\hline & & & & & 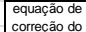 & $\mathrm{a}$ & 1 & Volume corrigido & & 1 & 99.82 \\
\hline \multicolumn{4}{|c|}{ Resistência à traçăo } & & Tempo & b & 0 & 98.7096 & & 2 & 99.43 \\
\hline \multirow{3}{*}{$\begin{array}{c}\begin{array}{c}\text { equaçăo de } \\
\text { correçăo da } \\
\text { Força }\end{array} \\
\text { Forca }\end{array}$} & $a$ & 0.995 & \multirow{3}{*}{$\begin{array}{l}\text { Resistência à } \\
\text { traçăo em N/m }\end{array}$} & \multirow{3}{*}{$\left|\begin{array}{c}\text { Indice de } \\
\text { Resistência à } \\
\text { Trą̧ăo, Nm/g }\end{array}\right|$} & \multirow{3}{*}{\begin{tabular}{|c|}
$\begin{array}{c}\text { equacăào de } \\
\text { correço do do } \\
\text { volume }\end{array}$ \\
Tempo \\
\end{tabular}} & $\mathrm{a}$ & 0.9946 & \multirow{3}{*}{$\begin{array}{c}\text { Porosidade em } \\
\mu \mathrm{m} / \mathrm{Pa} \text { as }\end{array}$} & & 3 & 99.58 \\
\hline & $\mathrm{b}$ & 0.003 & & & & $\mathrm{~b}$ & -0.7504 & & & 4 & 99.72 \\
\hline & $\begin{array}{c}\text { sem começăo } \\
\text { em kgf }\end{array}$ & \begin{tabular}{|c|} 
com correçăo \\
em N
\end{tabular} & & & & \begin{tabular}{|c|}
$\begin{array}{c}\text { sem correção } \\
\text { em s }\end{array}$ \\
\end{tabular} & $\begin{array}{c}\text { com correçăo em } \\
\text { s }\end{array}$ & & & 5 & 99.65 \\
\hline 1 & 9.87 & 96.3174 & 6421.1609 & 64.9133 & 1 & 211.6 & 211.5600 & 0.631282326 & & 6 & \\
\hline 2 & 10.29 & 100.3758 & 6691.7215 & 67.6485 & 2 & 171.3 & 171.3100 & 0.779604745 & & 7 & \\
\hline 3 & 8.18 & 79.7783 & 5318.5511 & 53.7667 & 3 & 151.1 & 151.0600 & 0.884112861 & & 8 & \\
\hline 4 & 10.11 & 98.6438 & 6576.2557 & 66.4812 & 4 & 127.7 & 127.7200 & 1.045678741 & & 9 & \\
\hline 5 & 9.00 & 87.8610 & 5857.4019 & 59.2141 & 5 & 126.6 & 126.6400 & 1.054596406 & & 10 & \\
\hline \multicolumn{2}{|c|}{ Largura em $\mathrm{mm}$} & média & 6173.02 & 62.40 & & média & 157.66 & 0.88 & & média & 99.6 \\
\hline \multicolumn{2}{|c|}{15} & D.P & 575.10 & 5.81 & & D.P & 35.33 & 0.18 & & D.P & 0.15 \\
\hline \multicolumn{4}{|c|}{ Resistência ao Rasgo } & & \multicolumn{3}{|c|}{ Resistência ao Arrebentamento } & & \multicolumn{3}{|c|}{ Espessura } \\
\hline \multirow{2}{*}{\begin{tabular}{|c|} 
equação de \\
correçấo força
\end{tabular}} & $\mathrm{a}$ & 1 & \multirow{3}{*}{$\begin{array}{l}\text { Resistência ao } \\
\text { rasgo } \mathrm{mN}\end{array}$} & \multirow{3}{*}{\begin{tabular}{|c|} 
Indice de \\
Resistência a \\
Rasgoo \\
$\mathrm{Nm} 2 / 9$ \\
\end{tabular}} & \multirow{3}{*}{\begin{tabular}{|l} 
equacăâo de \\
correção \\
pressão
\end{tabular}} & $\mathrm{a}$ & 0.998 & \multirow{3}{*}{$\begin{array}{c}\text { Indice de } \\
\text { Resistência } \\
\text { Arrebentamento, } \\
\mathrm{kPam} 2 / \mathrm{g} \\
\end{array}$} & \multirow{3}{*}{$\begin{array}{l}\text { equacăăo de } \\
\text { correçăo } \\
\text { espessura }\end{array}$} & $\mathrm{a}$ & 1.0001 \\
\hline & $\mathrm{b}$ & 0 & & & & $b$ & 3.4335 & & & $\mathrm{~b}$ & 0 \\
\hline Força & $\begin{array}{c}\begin{array}{c}\text { sem correçäo } \\
\text { em gf }\end{array} \\
\end{array}$ & \begin{tabular}{|l|} 
com correçăo \\
em gf
\end{tabular} & & & & \begin{tabular}{|l}
$\begin{array}{c}\text { sem correçäo } \\
\text { em kPa }\end{array}$ \\
\end{tabular} & $\begin{array}{c}\text { com correção em } \\
\mathrm{kPa}\end{array}$ & & & \begin{tabular}{|c|}
$\begin{array}{c}\text { sem correçăo } \\
\text { em mm }\end{array}$ \\
\end{tabular} & $\begin{array}{c}\text { com correçăc } \\
\text { em mm }\end{array}$ \\
\hline 1 & 65.0 & 65.0000 & 2040.48 & 20.6278 & 1 & 496.1 & 498.5413 & 5.0399 & 1 & 0.1600 & 0.1600 \\
\hline 2 & 62.0 & 62.0000 & 1946.304 & 19.6757 & 2 & 500.9 & 503.3217 & 5.0882 & 2 & 0.1570 & 0.1570 \\
\hline 3 & 59.0 & 59.0000 & 1852.128 & 18.7237 & 3 & 464.9 & 467.4436 & 4.7255 & 3 & 0.1670 & 0.1670 \\
\hline 4 & 61.0 & 61.0000 & 1914.912 & 19.3584 & 4 & 512.9 & 515.2778 & 5.2091 & 4 & 0.1690 & 0.1690 \\
\hline 5 & 60.0 & 60.0000 & 1883.52 & 19.0410 & 5 & 547.8 & 550.0880 & 5.5610 & 5 & 0.1670 & 0.1670 \\
\hline número de folhas & Fator & média & 1927.47 & 19.49 & & média & 506.93 & 5.12 & 6 & 0.1660 & 0.1660 \\
\hline \multirow[t]{2}{*}{5} & 16 & D.P & 72.27 & 0.73 & & D.P & 29.90 & 0.30 & 7 & 0.1750 & 0.1750 \\
\hline & & & & & & & & & 8 & 0.1610 & 0.1610 \\
\hline \multicolumn{5}{|c|}{ Gramatura } & & & & & 9 & 0.1680 & 0.1680 \\
\hline \multicolumn{2}{|c|}{ Area da follha } & massa 5 folhas & \multicolumn{2}{|c|}{14.2938} & & & & & 10 & 0.1660 & 0.1660 \\
\hline lado $(\mathrm{cm})$ & 0.168 & Teor seco & & & & & & & & média & 0.1656 \\
\hline diâmetro $(\mathrm{cm})$ & & Gram. Seca & & & & & & & & D.P & 0.005 \\
\hline & & Gram. Cond. & & & & & & & & & \\
\hline massa 5 folhas & 14.2938 & & & & & & & & & & \\
\hline 1 folha & 2.8588 & $g$ & & & & & & & & & \\
\hline lado & 0.1700 & $\mathrm{~m}$ & & & & & & & & & \\
\hline $\mathrm{m} 2$ & 0.0289 & & & & & & & & & & \\
\hline$g / m 2$ & 98.9190 & & & & & & & & & & \\
\hline
\end{tabular}




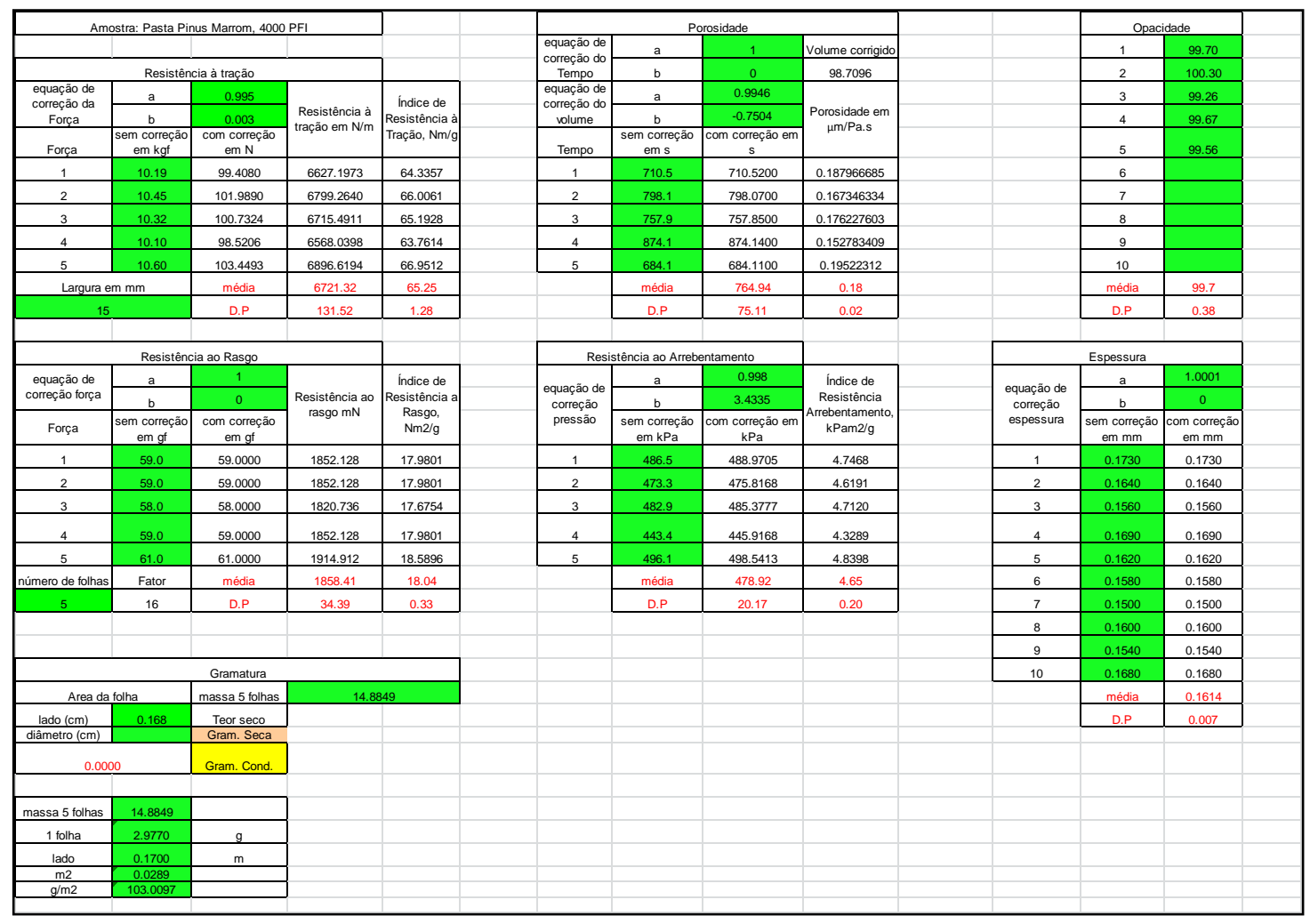

\begin{tabular}{|c|c|c|c|c|c|c|c|c|c|c|c|}
\hline \multicolumn{4}{|c|}{ Amostra: Pasta Pinus Marrom $1 \%$ CNF } & & \multicolumn{4}{|c|}{ Porosidade } & & \multicolumn{2}{|c|}{ Opacidade } \\
\hline \multirow{2}{*}{\multicolumn{4}{|c|}{ Resistência à tração }} & & $\begin{array}{ll}\text { equaçăo de } \\
\text { corecăodo }\end{array}$ & $\mathrm{a}$ & 1 & Volume corrigido & & 1 & 99.81 \\
\hline & & & & & $\begin{array}{l}\text { Correçao do } \\
\text { Tempo } \\
\text { The }\end{array}$ & $\mathrm{b}$ & 0 & 98.7096 & & 2 & 99.73 \\
\hline \multirow{3}{*}{$\begin{array}{c}\begin{array}{c}\text { equaçăo de } \\
\text { correção da } \\
\text { Força }\end{array} \\
\end{array}$} & $\mathrm{a}$ & 0.995 & \multirow{3}{*}{$\begin{array}{l}\text { Resistência à } \\
\text { trą̧ăo em N/m }\end{array}$} & \multirow{3}{*}{$\left|\begin{array}{c}\text { Indice de } \\
\text { Resistência à } \\
\text { Traa̧âa, Nm/g }\end{array}\right|$} & \begin{tabular}{|l|l} 
equacăão de \\
correăo do
\end{tabular} & $\mathrm{a}$ & 0.9946 & \multirow{3}{*}{ 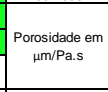 } & & 3 & 99.22 \\
\hline & \multirow{2}{*}{\begin{tabular}{|c|} 
b \\
sem correçāo \\
em kgf
\end{tabular}} & \multirow{2}{*}{\begin{tabular}{|c|}
0.003 \\
$\begin{array}{c}\text { com coreçắo } \\
\text { em N }\end{array}$ \\
\end{tabular}} & & & $\begin{array}{c}\text { cortegao dum } \\
\text { volume }\end{array}$ & $\mathrm{b}$ & -0.7504 & & & 4 & 99.85 \\
\hline & & & & & Tempo & $\begin{array}{c}\begin{array}{c}\text { sem correção } \\
\text { em s }\end{array} \\
\end{array}$ & $\begin{array}{c}\text { com correçăo em } \\
\mathrm{s}\end{array}$ & & & 5 & 99.72 \\
\hline 1 & 5.36 & 52.2846 & 3485.6385 & 37.2317 & 1 & 6.0 & 6.0200 & 22.18506458 & & 6 & \\
\hline 2 & 4.60 & 44.8951 & 2993.0064 & 31.9697 & 2 & 5.4 & 5.3800 & 24.82418007 & & 7 & \\
\hline 3 & 4.81 & 46.8953 & 3126.3547 & 33.3941 & 3 & 4.8 & 4.8400 & 27.59382 & & 8 & \\
\hline 4 & 4.81 & 46.9138 & 3127.5842 & 33.4072 & 4 & 6.6 & 6.5500 & 20.38993722 & & 9 & \\
\hline 5 & 4.99 & 48.7102 & 3247.3498 & 34.6865 & 5 & 6.6 & 6.5500 & 20.38993722 & & 10 & \\
\hline \multicolumn{2}{|c|}{ Largura em $\mathrm{mm}$} & média & 3195.99 & 34.14 & & média & 5.87 & 23.08 & & média & 99.7 \\
\hline \multicolumn{2}{|c|}{15} & D.P & 185.25 & 1.98 & & D.P & 0.75 & 3.11 & & D.P & 0.26 \\
\hline & & & & & & & & & & & \\
\hline \multicolumn{4}{|c|}{ Resistência ao Rasgo } & & \multicolumn{3}{|c|}{ Resistência ao Arrebentamento } & & \multicolumn{3}{|c|}{ Espessura } \\
\hline \multirow{2}{*}{\begin{tabular}{c|} 
equaçăo de \\
correçâo força
\end{tabular}} & $\mathrm{a}$ & 1 & \multirow{3}{*}{$\begin{array}{c}\text { Resistência ao } \\
\text { rasgo } \mathrm{mN}\end{array}$} & \multirow{3}{*}{\begin{tabular}{|c|} 
Indice de \\
Resistência a \\
Rasgoo: \\
Nm2/g \\
\end{tabular}} & \multirow{3}{*}{$\begin{array}{l}\text { equacăâo de } \\
\text { coreçăo } \\
\text { pressão }\end{array}$} & $\mathrm{a}$ & 0.998 & \multirow{3}{*}{\begin{tabular}{|c} 
Indice de \\
Resistência \\
Arrebentamento, \\
$\mathrm{kPam} 2 / \mathrm{g}$ \\
\end{tabular}} & \multirow{3}{*}{$\begin{array}{l}\text { equaçấo de } \\
\text { correcăo } \\
\text { espessura }\end{array}$} & $\mathrm{a}$ & 1.0001 \\
\hline & $\mathrm{b}$ & 0 & & & & $\mathrm{~b}$ & 3.4335 & & & $\mathrm{~b}$ & 0 \\
\hline Força & $\begin{array}{c}\text { sem correçäo } \\
\text { em gf }\end{array}$ & 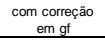 & & & & \begin{tabular}{|c|} 
sem correção \\
em kPa
\end{tabular} & $\begin{array}{c}\text { com correção em } \\
\mathrm{kPa}\end{array}$ & & & \begin{tabular}{|c} 
sem correção \\
em mm
\end{tabular} & $\begin{array}{c}\text { com correção } \\
\text { em mm }\end{array}$ \\
\hline 1 & 65.0 & 65.0000 & 2040.48 & 21.7953 & 1 & 279.2 & 282.0751 & 3.0130 & 1 & 0.1930 & 0.1930 \\
\hline 2 & 61.0 & 61.0000 & 1914.912 & 20.4541 & 2 & 300.8 & 303.6020 & 3.2429 & 2 & 0.2080 & 0.2080 \\
\hline 3 & 66.0 & 66.0000 & 2071.872 & 22.1306 & 3 & 306.8 & 309.5800 & 3.3068 & 3 & 0.1950 & 0.1950 \\
\hline 4 & 65.0 & 65.0000 & 2040.48 & 21.7953 & 4 & 275.6 & 278.4923 & 2.9747 & 4 & 0.2220 & 0.2220 \\
\hline 5 & 64.0 & 64.0000 & 2009.088 & 21.4600 & 5 & 242.1 & 245.0094 & 2.6171 & 5 & 0.2300 & 0.2300 \\
\hline número de folhas & Fator & média & 2015.37 & 21.53 & & média & 283.75 & 3.03 & 6 & 0.2520 & 0.2520 \\
\hline \multirow[t]{2}{*}{5} & 16 & D.P & 60.38 & 0.64 & & D.P & 25.46 & 0.27 & 7 & 0.2280 & 0.2280 \\
\hline & & & & & & & & & 8 & 0.2120 & 0.2120 \\
\hline \multicolumn{5}{|c|}{ Gramatura } & & & & & 9 & 0.2300 & 0.2300 \\
\hline \multicolumn{2}{|c|}{ Area da folha } & massa 5 follhas & \multicolumn{2}{|c|}{13.5281} & & & & & 10 & 0.2350 & 0.2350 \\
\hline lado $(\mathrm{cm})$ & 0.167 & Teor seco & & & & & & & & média & 0.2205 \\
\hline$\frac{\text { diâmetro }(\mathrm{cm})}{0.000}$ & & \begin{tabular}{|l} 
Gram. Seca \\
Gram. Cond.
\end{tabular} & & & & & & & & D.P & 0.018 \\
\hline & & & & & & & & & & & \\
\hline massa 5 folhas & 13.5281 & & & & & & & & & & \\
\hline 1 folha & 2.7056 & $g$ & & & & & & & & & \\
\hline lado & 0.1700 & $\mathrm{~m}$ & & & & & & & & & \\
\hline $\mathrm{m} 2$ & 0.0289 & & & & & & & & & & \\
\hline $\mathrm{g} / \mathrm{m} 2$ & 93.6201 & & & & & & & & & & \\
\hline
\end{tabular}




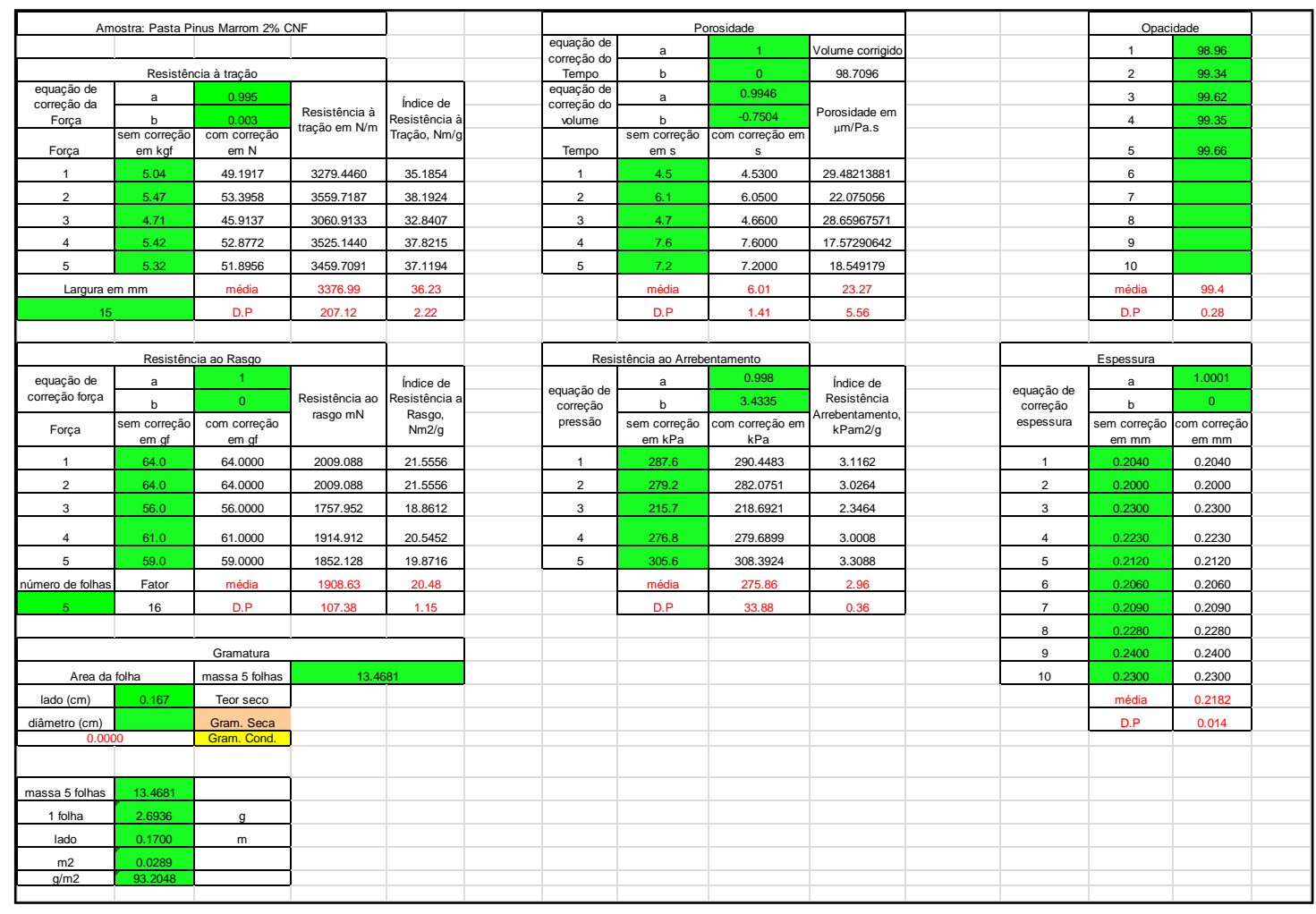

\begin{tabular}{|c|c|c|c|c|c|c|c|c|c|c|c|}
\hline \multirow{2}{*}{\multicolumn{4}{|c|}{ Amostra: Pasta Pinus Marrom 3\% CNF }} & & \multicolumn{4}{|c|}{$\begin{array}{l}\text { Porosidade } \\
\end{array}$} & & \multicolumn{2}{|c|}{ Opacidade } \\
\hline & & & & & 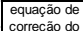 & $a$ & 1 & \begin{tabular}{|l|l|l|l|l} 
Volue corrigido \\
\end{tabular} & & 1 & 99.73 \\
\hline & Resistên & cia à traçăo & \multirow{4}{*}{$\begin{array}{l}\text { Resistência à } \\
\text { traçăo em Nmm }\end{array}$} & \multirow{4}{*}{ 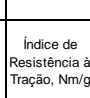 } & $\begin{array}{l}\text { Touteda ou } \\
\text { Tempo } \\
\end{array}$ & $\mathrm{b}$ & 0 & 98.7096 & & 2 & 99.46 \\
\hline 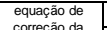 & $a$ & 0.995 & & & 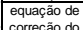 & $\mathrm{a}$ & 0.9946 & \multirow{3}{*}{$\begin{array}{c}\text { Porosidade em } \\
\text { um/Pa.s }\end{array}$} & & 3 & 100.09 \\
\hline Força & $\mathrm{b}$ & 0.003 & & & $\begin{array}{l}\text { curegaciou } \\
\text { volume }\end{array}$ & $\mathrm{b}$ & -0.7504 & & & 4 & 99.68 \\
\hline Força & $\begin{array}{l}\text { em correçat } \\
\text { em kgft }\end{array}$ & $\begin{array}{l}\text { om correçăo } \\
\text { em N }\end{array}$ & & & Tempo & $\begin{array}{c}\text { sem ocreacâa } \\
\text { em s }\end{array}$ & 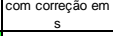 & & & 5 & 99.10 \\
\hline 1 & 5.51 & 53.7846 & 3585.6415 & 38.9953 & 1 & 7.8 & 7.8400 & \begin{tabular}{|l|l|}
17.03496031 \\
\end{tabular} & & 6 & \\
\hline 2 & 5.13 & 50.0807 & 3338.7140 & 35.7512 & 2 & 7.4 & 7.4300 & \begin{tabular}{|l|}
17.9749783 \\
\end{tabular} & & 7 & \\
\hline 3 & 5.00 & 48.8398 & 3255.9885 & 34.8653 & 3 & 4.4 & 4.3600 & \begin{tabular}{|l|}
30.63167174 \\
\end{tabular} & & 8 & \\
\hline 4 & 5.48 & 53.4884 & 3565.8920 & 38.1838 & 4 & 7.8 & 7.7500 & 17.23278565 & & 9 & \\
\hline 5 & 4.73 & 46.1174 & 3074.4959 & 32.9219 & 5 & 4.7 & 4.7300 & \begin{tabular}{|l|l|}
28.23553674 \\
\end{tabular} & & 10 & \\
\hline \multirow{2}{*}{\multicolumn{2}{|c|}{$\begin{array}{l}\text { Largura em } \mathrm{mm} \\
15\end{array}$}} & média & 3364.15 & 36.02 & & média & 6.42 & 22.22 & & média & 99.6 \\
\hline & & D.P & 215.64 & 2.31 & & D.P & 1.73 & 6.65 & & D.P & 0.36 \\
\hline \multirow{2}{*}{\multicolumn{4}{|c|}{ Resistência ao Rasgo }} & & \multirow{2}{*}{\multicolumn{3}{|c|}{ Resisteñncia ao Arreber }} & & \multirow{2}{*}{\multicolumn{3}{|c|}{ Espessura }} \\
\hline & & & & \multirow{3}{*}{ 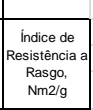 } & & & nento 0.998 & \multirow{3}{*}{ 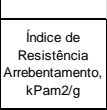 } & \multirow{3}{*}{$\begin{array}{l}\text { equacago de } \\
\text { corecajo } \\
\text { espessurat }\end{array}$} & & 1.0001 \\
\hline 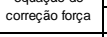 & $\mathrm{b}$ & 0 & \multirow{2}{*}{$\begin{array}{l}\text { Resistência ao } \\
\text { rassgo } \mathrm{mN}\end{array}$} & & \multirow{2}{*}{\begin{tabular}{|c|}
$\begin{array}{c}\text { equacão de } \\
\text { coreçăo } \\
\text { pressão }\end{array}$ \\
\end{tabular}} & b & 3.4335 & & & $\mathrm{~b}$ & 0 \\
\hline Força & $\begin{array}{c}\text { sem correçäo } \\
\text { em gf }\end{array}$ & $\begin{array}{l}\text { com correçâa } \\
\text { em gf }\end{array}$ & & & & $\begin{array}{l}\text { sem correçăo } \\
\text { em KRa }\end{array}$ & $\begin{array}{l}\text { com conceăa em } \\
\text { kPa }\end{array}$ & & & $\begin{array}{c}\text { sem correçáa } \\
\text { em mm }\end{array}$ & $\begin{array}{c}\text { com coreceáa } \\
\text { em mm }\end{array}$ \\
\hline 1 & 65.0 & 65.0000 & 2004.48 & 21.8496 & 1 & 278.0 & 280.8875 & 3.0078 & 1 & 0.2240 & 0.2240 \\
\hline 2 & 61.0 & 61.0000 & 1914.912 & 20.5050 & 2 & 282.8 & 285.6679 & 3.0590 & 2 & 0.2280 & 0.2280 \\
\hline 3 & 56.0 & 56.0000 & 1757.952 & 18.8243 & 3 & 258.8 & 261.7458 & 2.8028 & 3 & 0.2010 & 0.2010 \\
\hline 4 & 64.0 & 64.0000 & 2009.088 & 21.5134 & 4 & 266.0 & 268.9215 & 2.8796 & 4 & 0.2140 & 0.2140 \\
\hline 5 & 61.0 & 61.0000 & 1914.912 & 20.5050 & 5 & 275.6 & 278.4923 & 2.9821 & 5 & 0.2230 & 0.2230 \\
\hline numero de tolhas & Fator & média & 1927.47 & 20.64 & & média & 275.14 & 2.95 & 6 & 0.2110 & 0.2110 \\
\hline 5 & 16 & D.P & 110.10 & 1.18 & & D.P & 9.66 & 0.10 & 7 & 0.2270 & 0.2270 \\
\hline \multirow{2}{*}{\multicolumn{5}{|c|}{ Gramatura }} & & & & & 8 & 0.2000 & 0.2000 \\
\hline & & & \multirow{2}{*}{\multicolumn{2}{|c|}{13.4945}} & & & & & 9 & 0.2400 & 0.2400 \\
\hline \multicolumn{2}{|c|}{ Area da folha } & massa 5 follas & & & & & & & 10 & 0.2180 & 0.2180 \\
\hline lado (cm) & 0.169 & Teor seco & & & & & & & & média & 0.2186 \\
\hline diâmetro $(\mathrm{cm})$ & & $\begin{array}{l}\text { Gram. Seca } \\
\text { Gram. }\end{array}$ & & & & & & & & D.P & 0.012 \\
\hline & & & & & & & & & & & \\
\hline massa 5 tollas & 13.4945 & & & & & & & & & & \\
\hline 1 folha & 2.6989 & 9 & & & & & & & & & \\
\hline lado & 0.1700 & $m$ & & & & & & & & & \\
\hline $\begin{array}{l}\mathrm{m} 2 \\
\mathrm{~g} / \mathrm{l} 2\end{array}$ & 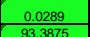 & $2=$ & & & & & & & & & \\
\hline
\end{tabular}




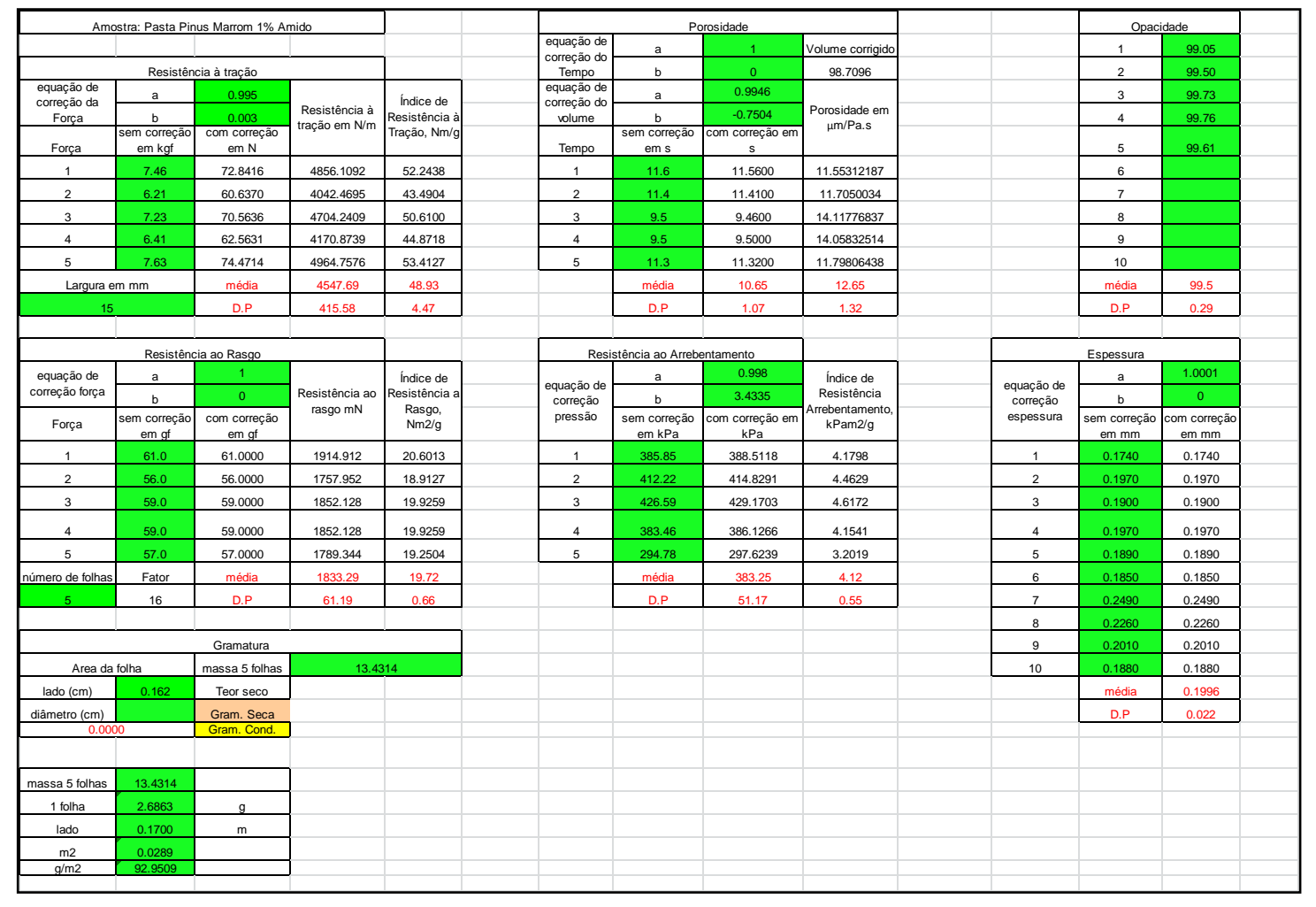

\begin{tabular}{|c|c|c|c|c|c|c|c|c|c|c|c|}
\hline \multirow{2}{*}{\multicolumn{4}{|c|}{ Amostra: Pasta Pinus Marom 0,5\% amido }} & & \multicolumn{4}{|c|}{$\begin{array}{l}\text { Porosidade } \\
\end{array}$} & & \multicolumn{2}{|c|}{ Opacidade } \\
\hline & & & & & 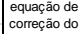 & $\mathrm{a}$ & 1 & 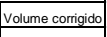 & & 1 & 99.56 \\
\hline & Resister & cia a traçăo & \multirow{4}{*}{ 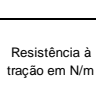 } & \multirow{4}{*}{ 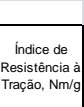 } & \begin{tabular}{|l|l|} 
Tempo \\
equariac de
\end{tabular} & $\mathrm{b}$ & (50) & 98.7096 & & 2 & 98.44 \\
\hline $\begin{array}{l}\text { equacăâd o } \\
\text { correcáo da }\end{array}$ & $\mathrm{a}$ & 0.995 & & & 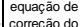 & $a$ & 0.9946 & \multirow{3}{*}{ Porosidade em } & & 3 & 99.49 \\
\hline Forca a & $b$ & 0.003 & & & volume & $b$ & -0.7504 & & & 4 & 99.63 \\
\hline Forga & $\begin{array}{l}\text { em correça } \\
\text { em kgf }\end{array}$ & 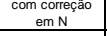 & & & Tempo & $\begin{array}{c}\substack{s e m \text { conoce } \\
\text { ems }} \\
\end{array}$ & $\begin{array}{l}\text { corregá } \\
\text { sato }\end{array}$ & & & 5 & 98.95 \\
\hline 1 & 6.78 & 66.1374 & 4409.1626 & 47.4821 & 1 & 111.0 & 10.9800 & \begin{tabular}{|l|}
12.16395607 \\
\end{tabular} & & 6 & \\
\hline 2 & 6.72 & 65.5448 & 4369.6505 & 47.0566 & 2 & 14.9 & 14.8600 & \begin{tabular}{|l|l|}
8.9874899152 \\
\end{tabular} & & 7 & \\
\hline 3 & 6.63 & 64.6928 & 4312.2544 & 46.4449 & 3 & 8.1 & 8.0800 & 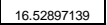 & & 8 & \\
\hline 4 & 5.76 & 56.2293 & 3748.6206 & 40.3687 & 4 & 9.1 & 9.1100 & \begin{tabular}{|l|l|}
14.66016342 \\
\end{tabular} & & 9 & \\
\hline 5 & 6.43 & 62.7668 & 4184.4500 & 45.0622 & 5 & 11.7 & 11.7000 & 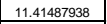 & & 10 & \\
\hline \multirow{2}{*}{\multicolumn{2}{|c|}{$\begin{array}{c}\text { Largura em mm } \\
\frac{15}{15}\end{array}$}} & média & 4204.95 & 45.28 & & média & 10.95 & 12.75 & & média & 99.2 \\
\hline & & D.P & 268.85 & 2.90 & & D.P & 2.62 & 2.92 & & D.P & 0.51 \\
\hline \multicolumn{4}{|c|}{ Resistetencia ao Rasgo } & & \multirow{2}{*}{\multicolumn{3}{|c|}{ Resistếncia ao Arrebentamento }} & & \multicolumn{3}{|c|}{ Espessura } \\
\hline equaçăo de & $a$ & & \multirow{3}{*}{$\begin{array}{l}\text { Resistência ao } \\
\text { rasgo mN }\end{array}$} & Indice de & \multirow{3}{*}{ 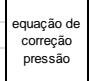 } & & 0.998 & Indice de & \multirow{3}{*}{\begin{tabular}{|c|c|} 
equacăa de \\
coreceáo \\
espessura
\end{tabular}} & $\mathrm{a}$ & 1.0001 \\
\hline correçấo força & $\mathrm{b}$ & 0 & & & & $\mathrm{~b}$ & 3.4335 & \begin{tabular}{l|l} 
Resisitência \\
\end{tabular} & & b & 0 \\
\hline Força & $\begin{array}{l}\text { sem corregăa } \\
\text { em of }\end{array}$ & $\begin{array}{l}\text { com correăa } \\
\text { em of }\end{array}$ & & 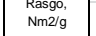 & & \begin{tabular}{|l|l} 
sem correcaáo \\
em $\mathrm{kPa}$
\end{tabular} & $\begin{array}{c}\text { com correcăa em } \\
\text { kPa }\end{array}$ & $\begin{array}{l}\text { rrebentamento, } \\
\mathrm{kPam} / \mathrm{g}\end{array}$ & & 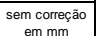 & $\begin{array}{l}\text { tom correâà } \\
\text { em mm }\end{array}$ \\
\hline 1 & 68.0 & 68.0000 & 2134.656 & 22.9880 & 1 & 30.8 & 309.5800 & 3.3339 & 1 & 0.2180 & 0.2180 \\
\hline 2 & 60.0 & 60.0000 & 1883.52 & 20.2835 & 2 & 346.3 & 349.0509 & 3.7599 & 2 & 0.1950 & 0.1950 \\
\hline 3 & 63.0 & 63.0000 & 1977.696 & 21.2977 & 3 & 300.3 & 303.1429 & 3.2645 & 3 & 0.2010 & 0.2010 \\
\hline 4 & 63.0 & 63.0000 & 1977.696 & 21.2977 & 4 & 320.0 & 322.7436 & 3.4756 & 4 & 0.2090 & 0.2090 \\
\hline 5 & 64.0 & 64,0000 & 2009.088 & 21.6558 & 5 & 366.7 & 369.3801 & 3.9778 & 5 & 0.2070 & 0.2070 \\
\hline nummero de folhas & Fator & média & 1996.53 & 21.50 & & média & 330.78 & 3.56 & 6 & 0.2180 & 0.2180 \\
\hline 5 & 16 & D.P & 90.44 & 0.97 & & D.P & 27.85 & 0.30 & 7 & 0.2110 & 0.2110 \\
\hline \multirow{2}{*}{\multicolumn{5}{|c|}{ Gramatura }} & & & & & 8 & 0.2090 & 0.2090 \\
\hline & & & & & & & & & 9 & 0.1960 & 0.1960 \\
\hline \multicolumn{2}{|c|}{ Area da folha } & massa 5 tolhas & \multicolumn{2}{|c|}{13.4182} & & & & & 10 & 0.2010 & 0.2010 \\
\hline lado (cm) & 0.162 & Teor seco & & & & & & & & média & 0.2065 \\
\hline diâmetro $(\mathrm{cm})$ & & $\begin{array}{l}\text { Gram. Seca } \\
\text { Sim. Sord }\end{array}$ & & & & & & & & D.P & 0.008 \\
\hline & - & Gatant. Oura. & & & & & & & & & \\
\hline massa 5 tolhas & 13.4182 & & & & & & & & & & \\
\hline 1 folha & 2.6836 & $g$ & & & & & & & & & \\
\hline lado & 0.1700 & $\mathrm{~m}$ & & & & & & & & & \\
\hline$\frac{\mathrm{m} 2}{\mathrm{~g} / \mathrm{m} 2}$ & \begin{tabular}{|l|l|}
0.02299 \\
9828559
\end{tabular} & 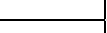 & & & & & & & & & \\
\hline
\end{tabular}




\begin{tabular}{|c|c|c|c|c|c|c|c|c|c|c|c|c|}
\hline \multicolumn{4}{|c|}{ Amostra: Pasta Pinus Marrom $2 \% \mathrm{CNF}+1 \%$ amido } & & \multicolumn{4}{|c|}{ Porosidade } & & \multicolumn{2}{|c|}{ Opacidade } & \\
\hline \multirow{2}{*}{\multicolumn{4}{|c|}{ Resistência à tracạo }} & & \begin{tabular}{|l|}
$\begin{array}{l}\text { equacăâo de } \\
\text { corraca do }\end{array}$ \\
\end{tabular} & $\mathrm{a}$ & 1 & \begin{tabular}{|l|} 
Volume corrigido \\
\end{tabular} & & 1 & 100.03 & \\
\hline & & & & & 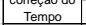 & $\mathrm{b}$ & 0 & 98.7096 & & 2 & 99.48 & \\
\hline \multirow{3}{*}{$\begin{array}{c}\begin{array}{c}\text { equacăāo de } \\
\text { correçăo da } \\
\text { Força }\end{array} \\
\text { Forca }\end{array}$} & \multirow{2}{*}{\begin{tabular}{|c|}
$a$ \\
sem correçä \\
\end{tabular}} & \multirow{2}{*}{0.995} & \multirow{3}{*}{$\begin{array}{r}\text { Resistência à } \\
\text { trą̧áo em N/m }\end{array}$} & \multirow{3}{*}{\begin{tabular}{|c|} 
Indice de \\
Resistência à \\
Traçâ, Nm/g
\end{tabular}} & \multirow{2}{*}{ 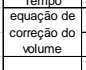 } & $\mathrm{a}$ & 0.9946 & \multirow{3}{*}{$\begin{array}{c}\text { Porosidade em } \\
\mu \mathrm{m} / \mathrm{Pa} . \mathrm{s}\end{array}$} & & 3 & 99.43 & \\
\hline & & & & & & \multirow{2}{*}{ 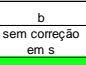 } & \multirow{2}{*}{\begin{tabular}{l|c} 
& -0.7504 \\
& com correçăo em \\
$\mathrm{s}$
\end{tabular}} & & & 4 & 99.76 & \\
\hline & $\begin{array}{c}\begin{array}{c}\text { sem correçăo } \\
\text { em kgf }\end{array} \\
\end{array}$ & $\begin{array}{l}\text { om correção } \\
\text { em N }\end{array}$ & & & Tempo & & & & & 5 & 99.31 & \\
\hline 1 & 7.42 & 72.3601 & 4824.0065 & 52.5967 & 1 & 11.4 & 11.4100 & 11.7050034 & & 6 & & \\
\hline 2 & 6.62 & 64.6002 & 4306.6811 & 46.9562 & 2 & 11.8 & 11.7600 & 11.3566402 & & 7 & & \\
\hline 3 & 7.65 & 74.6566 & 4977.1043 & 54.2659 & 3 & 9.9 & 9.8800 & 13.51762032 & & 8 & & \\
\hline 4 & 6.43 & 62.7112 & 4180.7486 & 45.5832 & 4 & 10.4 & 10.4300 & 12.80480238 & & 9 & & \\
\hline 5 & 6.02 & 58.7110 & 3914.0651 & 42.6755 & 5 & 8.7 & 8.6600 & 15.42195021 & & 10 & & \\
\hline \multicolumn{2}{|c|}{ Largura em $\mathrm{mm}$} & média & 4440.52 & 48.42 & & média & 10.43 & 12.96 & & média & 99.6 & \\
\hline \multicolumn{2}{|c|}{$\begin{array}{l}\text { Largura em mim } \\
15\end{array}$} & D.P & 446.52 & 4.87 & & D.P & 1.24 & 1.62 & & D.P & 0.29 & \\
\hline \multirow{2}{*}{\multicolumn{4}{|c|}{ Resistência ao Rasgo }} & & & & & & & & & \\
\hline & & & & & \multicolumn{3}{|c|}{ Resistência ao Arrebentamento } & & \multicolumn{4}{|c|}{ Espessura } \\
\hline \multirow{2}{*}{\begin{tabular}{|c|}
$\begin{array}{c}\text { equacăà de } \\
\text { correçâ força }\end{array}$ \\
\end{tabular}} & a & 1 & \multirow{3}{*}{$\begin{array}{c}\text { Resistência ao } \\
\text { rasgo } \mathrm{mN}\end{array}$} & \multirow{3}{*}{\begin{tabular}{|c|} 
Indice de \\
Resistência a a \\
Rasgoo \\
Nm2/g \\
\end{tabular}} & & $\mathrm{a}$ & 0.998 & indice de & equacăào de & & $\mathrm{a}$ & 1.0001 \\
\hline & b & \begin{tabular}{|c|}
0 \\
\end{tabular} & & & 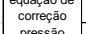 & $\mathrm{b}$ & \begin{tabular}{|l|}
3.4335 \\
\end{tabular} & Resistência & 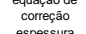 & & \begin{tabular}{|c|}
$b$ \\
\end{tabular} & 0 \\
\hline Força & $\begin{array}{c}\text { sem correçāo } \\
\text { em gf }\end{array}$ & $\begin{array}{c}\text { com correçāo } \\
\text { em gf }\end{array}$ & & & & $\begin{array}{l}\text { sem correcaāo } \\
\text { em kPa }\end{array}$ & com correçăo em & & espessura & & $\left|\begin{array}{c}\text { sem coneçāao } \\
\text { em mm }\end{array}\right|$ & $\begin{array}{c}\text { com correçāo } \\
\text { em mm }\end{array}$ \\
\hline 1 & 61.0 & 61.0000 & 1914.912 & 20.8785 & 1 & 320.0 & 322.7436 & 3.5189 & 1 & & 0.1970 & 0.1970 \\
\hline 2 & 59.0 & 59.0000 & 1852.128 & 20.1940 & 2 & 348.7 & 351.4461 & 3.8319 & 2 & & 0.1940 & 0.1940 \\
\hline 3 & 58.0 & 58.0000 & 1820.736 & 19.8517 & 3 & 330.7 & 333.5020 & 3.6362 & 3 & & 0.1950 & 0.1950 \\
\hline 4 & 58.0 & 58.0000 & 1822.736 & 19.8517 & 4 & 322.3 & 325.1288 & 3.5449 & 4 & & 0.1950 & 0.1950 \\
\hline 5 & 56.0 & 56.0000 & 1757.952 & 19.1671 & 5 & 281.6 & 284.4703 & 3.1016 & 5 & & 0.2040 & 0.2040 \\
\hline número de follhas & Fator & média & 1833.29 & 19.99 & & média & 323.46 & 3.53 & 6 & & 0.1790 & 0.1790 \\
\hline 5 & 16 & D.P & 57.03 & 0.62 & & D.P & 24.53 & 0.27 & 7 & & 0.1790 & 0.1790 \\
\hline & & & & & & & & & 8 & & 0.1910 & 0.1910 \\
\hline & & Gramatura & & & & & & & 9 & & 0.1860 & 0.1860 \\
\hline Area da & tolha & \begin{tabular}{|l|} 
massa 5 folhas \\
\end{tabular} & 13.25 & & & & & & 10 & & 0.1810 & 0.1810 \\
\hline lado $(\mathrm{cm})$ & 0.163 & \begin{tabular}{|l|} 
Teor seco \\
\end{tabular} & & & & & & & & & média & 0.1901 \\
\hline diâmetro $(\mathrm{cm})$ & & Gram. Seca & & & & & & & & & D.P & 0.009 \\
\hline & & Gram. Cond. & & & & & & & & & & \\
\hline & & & & & & & & & & & & \\
\hline massa 5 folhas & 13.2531 & & & & & & & & & & & \\
\hline 1 folha & 2.6506 & $g$ & & & & & & & & & & \\
\hline lado & 0.1700 & $\mathrm{~m}$ & & & & & & & & & & \\
\hline$\frac{\mathrm{m} 2}{\mathrm{~g} / \mathrm{m}^{2}}$ & 0.0289 & & & & & & & & & & & \\
\hline $\mathrm{g}^{\prime / m} 2$ & I 91.7170 & & & & & & & & & & & \\
\hline
\end{tabular}

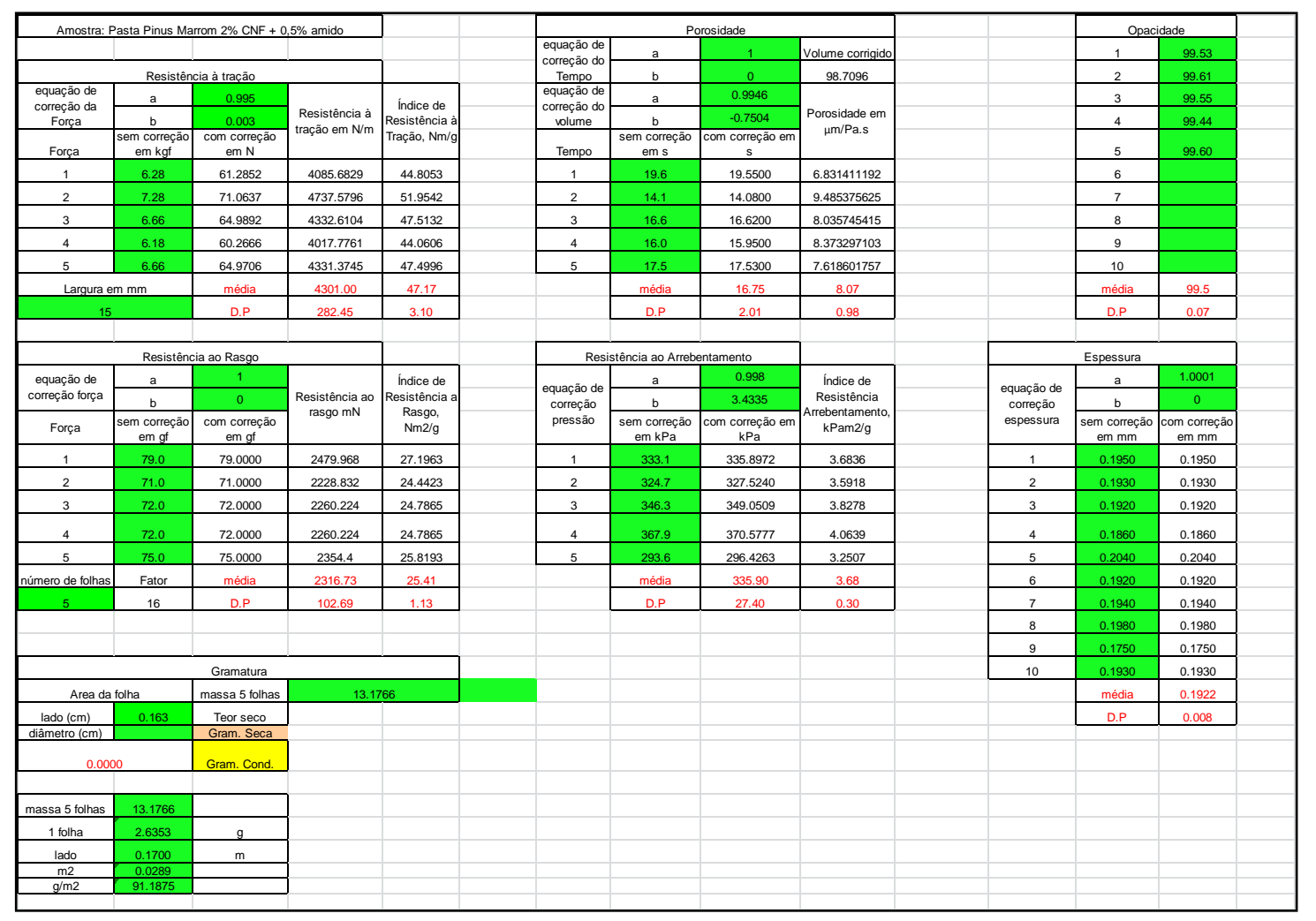



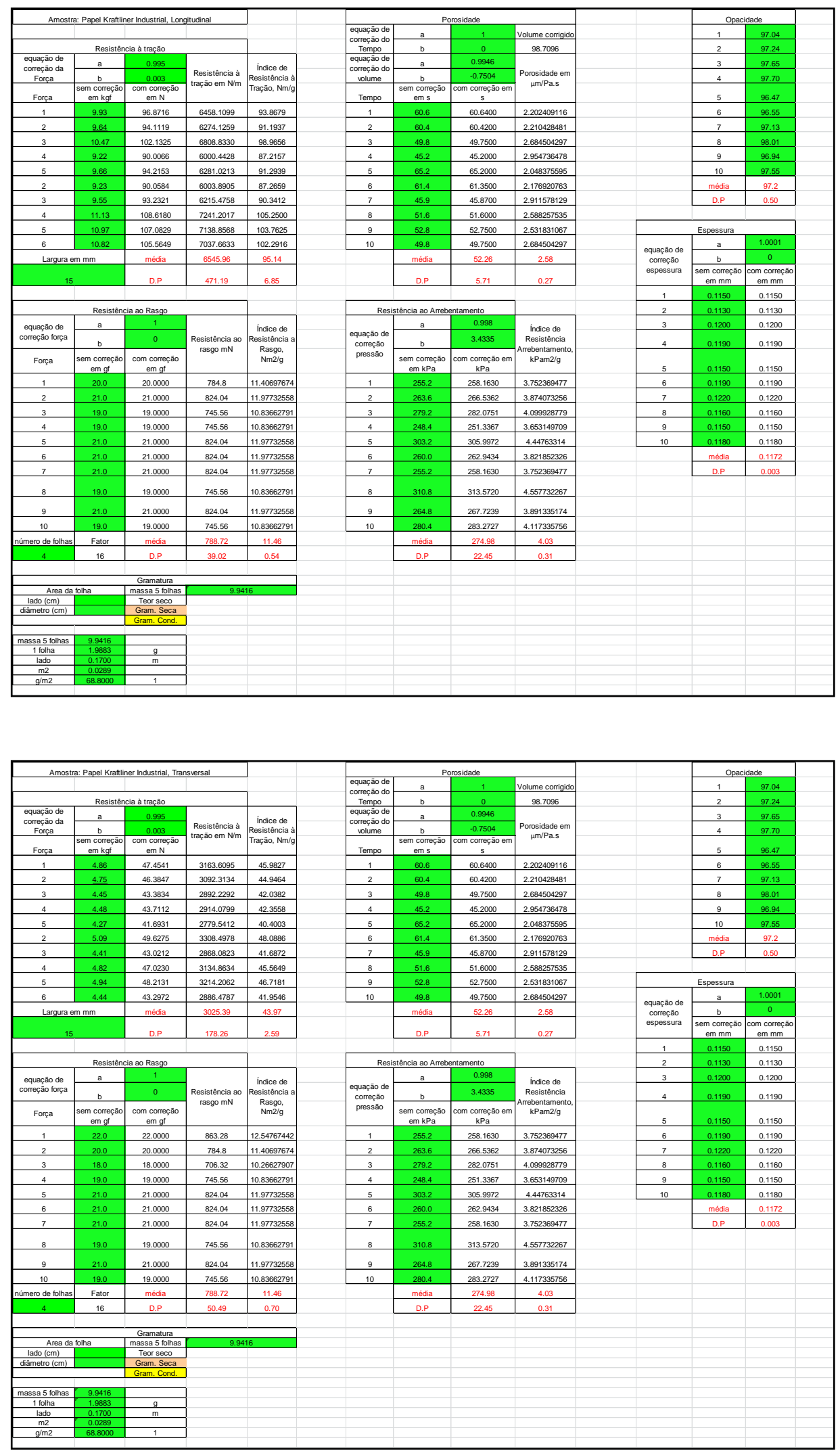


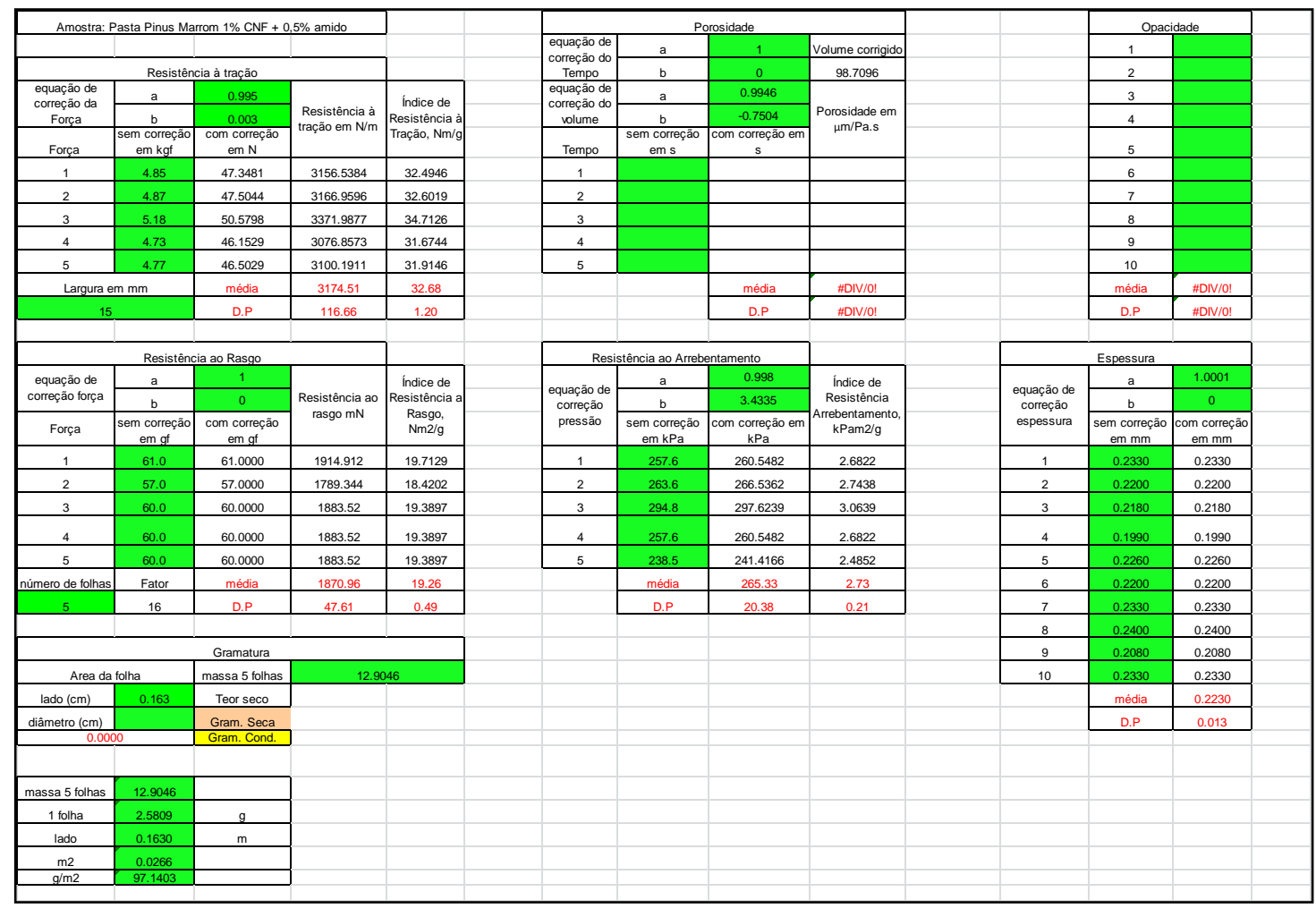

\begin{tabular}{|c|c|c|c|c|c|c|c|c|c|c|c|}
\hline \multicolumn{4}{|c|}{ Amostra: Pasta Pinus Marom 1\% MFC } & & \multicolumn{4}{|c|}{$\begin{array}{l}\text { Porosidade } \\
\end{array}$} & & \multicolumn{2}{|c|}{ Opacidade } \\
\hline & & & & & 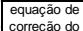 & $\mathrm{a}$ & 1 & \begin{tabular}{|l|l|l|l} 
Volume corrigido \\
\end{tabular} & & 1 & \\
\hline & Resistên & cia ̀ traçấ & \multirow{4}{*}{$\begin{array}{l}\text { Resistência à̀ } \\
\text { trąăao em N/m }\end{array}$} & \multirow{4}{*}{$\begin{array}{c}\text { Indicice de } \\
\text { Resistencià } \\
\text { Traģa, Nm/g }\end{array}$} & Tenpo & $\mathrm{b}$ & 0 & & & 2 & \\
\hline $\begin{array}{l}\text { equacăáo de } \\
\text { corceáo oa }\end{array}$ & $\mathrm{a}$ & 0.995 & & & 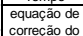 & $a$ & 0.9946 & \multirow{3}{*}{ 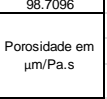 } & & 3 & \\
\hline Forģa & $\mathrm{b}$ & 0.003 & & & 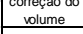 & $\mathrm{b}$ & -0.7504 & & & 4 & \\
\hline Força & $\begin{array}{l}\text { em correçat } \\
\text { em kgft }\end{array}$ & $\begin{array}{l}\text { om correçăo } \\
\text { em N }\end{array}$ & & & Tempo & $\begin{array}{c}\text { sem correcăo } \\
\text { ems }\end{array}$ & 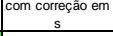 & & & 5 & \\
\hline 1 & 4.95 & 48.2565 & 3217.1010 & 34.0275 & 1 & & & & & 6 & \\
\hline 2 & 4.69 & 45.7284 & 3048.5601 & 32.2449 & 2 & & & & & 7 & \\
\hline 3 & 3.99 & 38.9669 & 2597.7949 & 27.4771 & 3 & & & & & 8 & \\
\hline 4 & 5.07 & 49.4852 & 3299.0133 & 34.8939 & 4 & & & & & 9 & \\
\hline 5 & 4.76 & 46.4209 & 3094.7268 & 32.7332 & 5 & & & & & 10 & \\
\hline \multirow{2}{*}{\multicolumn{2}{|c|}{$\begin{array}{l}\text { Largura em mm } \\
15\end{array}$}} & média & 3051.44 & 32.28 & & & média & $\# D|V| 0 !$ & & média & \#DIV/o! \\
\hline & & D.P & 272.22 & 2.88 & & & D.P & \#DIV/0! & & D.P & \#DIV/0! \\
\hline \multirow{2}{*}{\multicolumn{4}{|c|}{ Resistência ao Rasgo }} & & \multirow{2}{*}{\multicolumn{3}{|c|}{ Resistência ao Arrebenn }} & & \multirow{2}{*}{\multicolumn{2}{|c|}{ Espessura }} & \\
\hline & & & & \multirow{3}{*}{ 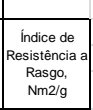 } & & & ento 0.998 & \multirow{3}{*}{ 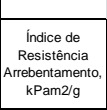 } & \multirow{3}{*}{$\begin{array}{l}\text { equacăa de } \\
\text { coregáa } \\
\text { espessurara }\end{array}$} & & 1.0001 \\
\hline 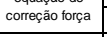 & $\mathrm{b}$ & 0 & \multirow{2}{*}{$\begin{array}{l}\text { Resistência ao } \\
\text { rasgo } \mathrm{mNN}\end{array}$} & & \multirow{2}{*}{\begin{tabular}{|c|}
$\begin{array}{c}\text { equacão de } \\
\text { coreçăo } \\
\text { pressão }\end{array}$ \\
\end{tabular}} & $\mathrm{b}$ & 3.4335 & & & $\mathrm{~d}$ & 0 \\
\hline Força & $\begin{array}{c}\text { sem correçäo } \\
\text { em gf }\end{array}$ & $\begin{array}{l}\text { com correçâa } \\
\text { em gf }\end{array}$ & & & & $\begin{array}{l}\text { sem correcăo } \\
\text { em kPa }\end{array}$ & $\begin{array}{c}\text { com corceăa em } \\
\text { kPa }\end{array}$ & & & $\begin{array}{c}\text { sem correçáa } \\
\text { em mm }\end{array}$ & $\begin{array}{c}\text { com coreceáa } \\
\text { em mm }\end{array}$ \\
\hline 1 & 57.0 & 57.0000 & 1789.344 & 18.9260 & 1 & 276.8 & 279.6899 & 2.9583 & 1 & 0.2080 & 0.2080 \\
\hline 2 & 62.0 & 62.0000 & 1946.304 & 20.5862 & 2 & 202.5 & 205.5385 & 2.1740 & 2 & 0.1960 & 0.1960 \\
\hline 3 & 61.0 & 61.0000 & 1914.912 & 20.2542 & 3 & 262.4 & 265.3386 & 2.8065 & 3 & 0.2280 & 0.2280 \\
\hline 4 & 53.0 & 53.0000 & 1663.776 & 17.5979 & 4 & 245.7 & 248.5922 & 2.6294 & 4 & 0.2120 & 0.2120 \\
\hline 5 & 53.0 & 53.0000 & 1663.776 & 17.5979 & 5 & 255.2 & 258.1630 & 2.7306 & 5 & 0.2220 & 0.2220 \\
\hline numero de tolhas & Fator & média & 1795.62 & 18.99 & & média & 251.46 & 2.66 & 6 & 0.2130 & 0.2130 \\
\hline 5 & 16 & D.P & 133.92 & 1.42 & & D.P & 28.07 & 0.30 & 7 & 0.2140 & 0.2140 \\
\hline \multirow{2}{*}{\multicolumn{5}{|c|}{ Gramatura }} & & & & & 8 & 0.2260 & 0.2260 \\
\hline & & & & & & & & & 9 & 0.1990 & 0.1990 \\
\hline \multicolumn{2}{|c|}{ Area da tolha } & massa 5 follas & \multicolumn{2}{|c|}{12.5597} & & & & & 10 & 0.1890 & 0.1890 \\
\hline lado (cm) & 0.163 & Teor seco & & & & & & & & média & 0.2107 \\
\hline diâmetro $(\mathrm{cm})$ & & $\begin{array}{l}\text { Gram. Seca } \\
\text { Gram. }\end{array}$ & & & & & & & & D.P & 0.013 \\
\hline & & & & & & & & & & & \\
\hline massa 5 tollas & 12.5597 & & & & & & & & & & \\
\hline 1 folha & 2.5119 & $g$ & & & & & & & & & \\
\hline lado & 0.1630 & $m$ & & & & & & & & & \\
\hline$\frac{\mathrm{m} 2}{\mathrm{~g} / \mathrm{m} 2}$ & \begin{tabular}{|l|l|}
.0266 \\
045440
\end{tabular} & 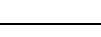 & & & & & & & & & \\
\hline
\end{tabular}




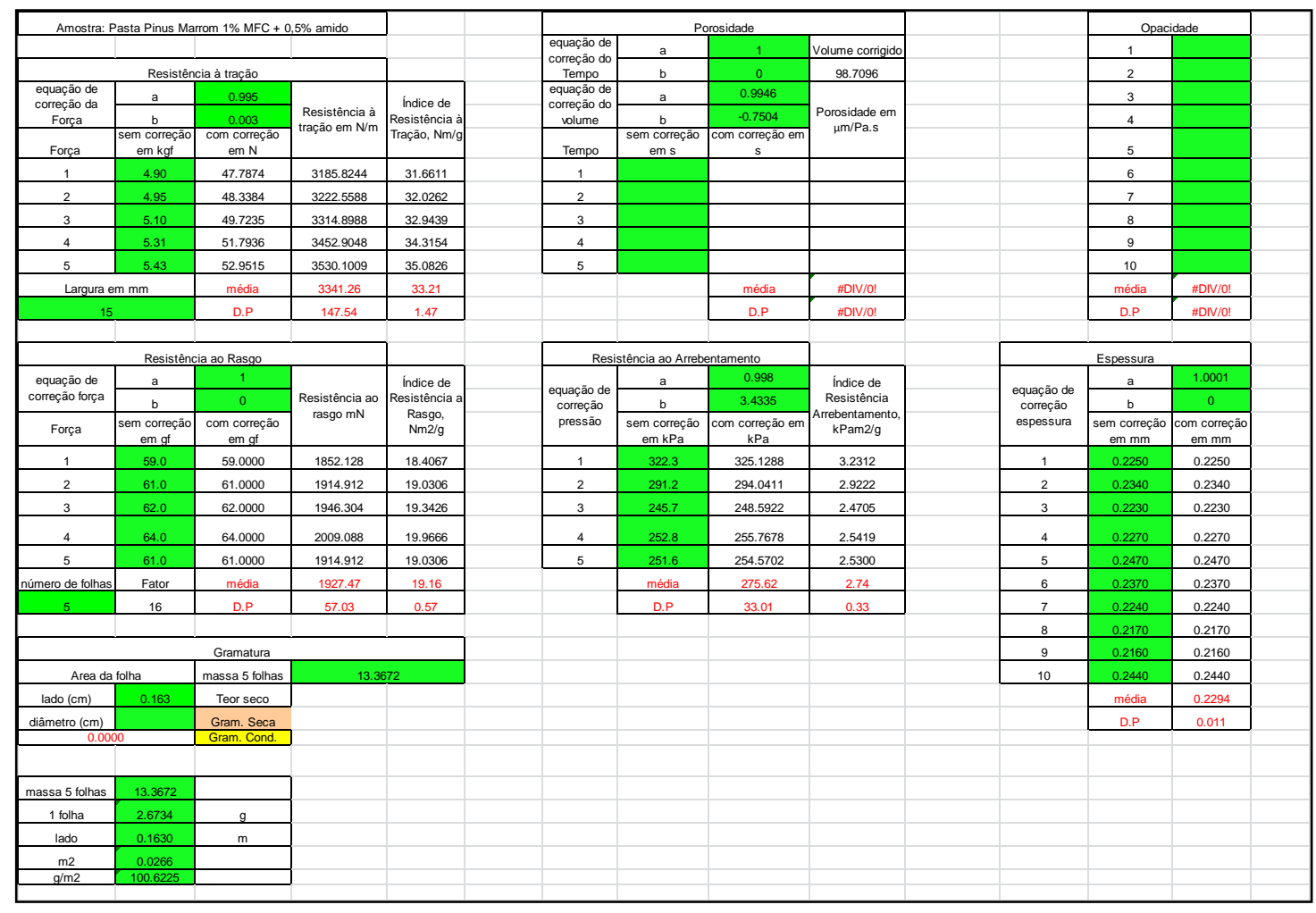


A3. Dados das propriedades das folhas formadas no laboratório na Pasta Kraft de Eucalipto Pré-branqueada

\begin{tabular}{|c|c|c|c|c|c|c|c|c|c|c|c|}
\hline \multicolumn{4}{|c|}{ Amostra: Pasta Pré-branqueada de eucalipto, 0 PFI } & & \multicolumn{4}{|c|}{ Porosidade } & & \multicolumn{2}{|c|}{ Opacidade } \\
\hline & & & & & \begin{tabular}{|l|}
$\begin{array}{l}\text { equaçăo de } \\
\text { correcăo do }\end{array}$ \\
\end{tabular} & $\mathrm{a}$ & 1 & Volume corrigido & & 1 & 97.54 \\
\hline \multicolumn{4}{|c|}{ Resistência à tração } & \multirow{4}{*}{$\mid$\begin{tabular}{c|} 
Indice de \\
Resistência à \\
Traçăo, Nm/g
\end{tabular}} & Tempo & b & 0 & 98.7096 & & 2 & 97.30 \\
\hline \multirow{3}{*}{$\begin{array}{c}\begin{array}{c}\text { equacăa de } \\
\text { correcáa da } \\
\text { Força }\end{array} \\
\end{array}$} & a & 0.995 & \multirow{3}{*}{$\begin{array}{l}\text { Resistência à } \\
\text { tração em N/m }\end{array}$} & & \begin{tabular}{|l|l} 
equaçắo de \\
\end{tabular} & & 0.9946 & \multirow{3}{*}{$\begin{array}{c}\text { Porosidade em } \\
\mu \mathrm{m} / \mathrm{Pa} . \mathrm{s}\end{array}$} & & 3 & 97.34 \\
\hline & $\mathrm{b}$ & 0.003 & & & & & -0.7504 & & & 4 & 97.31 \\
\hline & $\begin{array}{c}\text { sem correçăo } \\
\text { em kgf }\end{array}$ & $\begin{array}{c}\text { com correção } \\
\text { em N }\end{array}$ & & & \begin{tabular}{|l|} 
Tempo \\
\end{tabular} & $\begin{array}{l}\begin{array}{c}\text { sem correção } \\
\text { em s sate }\end{array} \\
\end{array}$ & $\begin{array}{c}\text { com correģão em } \\
\mathrm{s}\end{array}$ & & & 5 & 97.32 \\
\hline 1 & 2.69 & 26.2721 & 1751.4735 & 17.7523 & 1 & S.N. & \#VALOR! & \#VALOR! & & 6 & \\
\hline 2 & 2.60 & 25.3552 & 1690.3449 & 17.1328 & 2 & & & & & 7 & \\
\hline 3 & 2.49 & 24.2684 & 1617.8910 & 16.3984 & 3 & & & & & 8 & \\
\hline 4 & 2.83 & 27.6136 & 1840.9057 & 18.6588 & 4 & & & & & 9 & \\
\hline 5 & 2.62 & 25.5759 & 1705.0595 & 17.2819 & 5 & & & & & 10 & \\
\hline \multicolumn{2}{|c|}{ Largura em mm } & média & 1721.13 & 17.44 & & & média & \#VALOR! & & média & 97.4 \\
\hline \multicolumn{2}{|c|}{15} & D.P & 82.36 & 0.83 & & & D.P & \#VALOR! & & D.P & 0.10 \\
\hline \multirow{2}{*}{\multicolumn{4}{|c|}{ Resistência ao Rasgo }} & & & & & & & & \\
\hline & & & & & \multicolumn{3}{|c|}{ Resistência ao Arrebentamento } & & \multicolumn{3}{|c|}{ Espessura } \\
\hline \multirow{2}{*}{$\begin{array}{c}\text { equação de } \\
\text { correçăa força }\end{array}$} & $\mathrm{a}$ & 1 & \multirow{3}{*}{$\begin{array}{l}\text { Resistência ao } \\
\text { rasgo } \mathrm{mN}\end{array}$} & \multirow{3}{*}{\begin{tabular}{|c|} 
Índice de \\
Resistência a a \\
Rasgo, \\
$\mathrm{Nm} 2 / \mathrm{g}$
\end{tabular}} & \multirow{3}{*}{$\begin{array}{l}\text { equação de } \\
\text { coreçăo } \\
\text { pressaão }\end{array}$} & $\mathrm{a}$ & 0.998 & \multirow{3}{*}{\begin{tabular}{|c|} 
Indice de \\
Resistência \\
Arrebentamento, \\
$\mathrm{kPam} 2 / \mathrm{g}$
\end{tabular}} & \multirow{3}{*}{$\begin{array}{l}\text { equacăão de } \\
\text { coreção } \\
\text { espessura }\end{array}$} & $\mathrm{a}$ & 1.0001 \\
\hline & $\mathrm{b}$ & 0 & & & & $\mathrm{~b}$ & 3.4335 & & & $\mathrm{~b}$ & 0 \\
\hline Força & $\begin{array}{c}\begin{array}{c}\text { sem correçăo } \\
\text { em gf }\end{array} \\
\end{array}$ & \begin{tabular}{|c|} 
com correção \\
em gf
\end{tabular} & & & & \begin{tabular}{|c} 
sem correcão \\
em kPa
\end{tabular} & $\begin{array}{c}\text { com correcăo em } \\
\mathrm{KPa}\end{array}$ & & & \begin{tabular}{|c|}
$\begin{array}{c}\text { sem correçăo } \\
\text { em mm }\end{array}$ \\
\end{tabular} & $\begin{array}{c}\text { com correção } \\
\text { em mm }\end{array}$ \\
\hline 1 & 12.0 & 12.0000 & 376.704 & 3.818142334 & 1 & 70.7 & 73.9921 & \begin{tabular}{|l|}
0.749958507 \\
\end{tabular} & 1 & 0.2110 & 0.2110 \\
\hline 2 & 14.0 & 14.0000 & 439.488 & \begin{tabular}{|l|l|}
4.45449939 \\
\end{tabular} & 2 & 69.5 & 72.7945 & \begin{tabular}{|l|}
0.737820045 \\
\end{tabular} & 2 & 0.2190 & 0.2190 \\
\hline 3 & 14.0 & 14.0000 & 439.488 & \begin{tabular}{|l|l|}
4.45449939 \\
\end{tabular} & 3 & 76.7 & 79.9701 & 0.810549664 & 3 & 0.2150 & 0.2150 \\
\hline 4 & 14.0 & 14.0000 & 439.488 & 4.45449939 & 4 & 81.5 & 84.7505 & 0.859002359 & 4 & 0.2140 & 0.2140 \\
\hline 5 & 13.0 & 13.0000 & 408.096 & \begin{tabular}{|l|l|} 
& 4.136320862 \\
\end{tabular} & 5 & 50.3 & 53.6628 & \begin{tabular}{|l|} 
\\
\end{tabular} & 5 & 0.2010 & 0.2010 \\
\hline número de folhas & Fator & média & 420.65 & 4.26 & & média & 73.03 & 0.74 & 6 & 0.2100 & 0.2100 \\
\hline \multirow[t]{2}{*}{5} & 16 & D.P & 28.08 & 0.28 & & D.P & 11.85 & 0.12 & 7 & 0.2220 & 0.2220 \\
\hline & & & & & & & & & 8 & 0.2130 & 0.2130 \\
\hline \multicolumn{4}{|c|}{ Gramatura } & & & & & & 9 & 0.2230 & 0.2230 \\
\hline \multicolumn{2}{|c|}{ Area da folha } & \begin{tabular}{|l|} 
massa 5 follhas \\
\end{tabular} & \multicolumn{2}{|c|}{14.2566} & & & & & 10 & 0.2200 & 0.2200 \\
\hline lado $(\mathrm{cm})$ & 0.17 & Teor seco & & & & & & & & média & 0.2148 \\
\hline diâmetro $(\mathrm{cm})$ & & \begin{tabular}{|l|} 
Gram. Seca \\
\end{tabular} & & & & & & & & D.P & 0.007 \\
\hline & & & & & & & & & & & \\
\hline massa 5 folhas & 14.2566 & & & & & & & & & & \\
\hline 1 folha & 2.8513 & $g$ & & & & & & & & & \\
\hline lado & 0.1700 & $\mathrm{~m}$ & & & & & & & & & \\
\hline $\mathrm{m} 2$ & 0.0289 & & & & & & & & & & \\
\hline $\mathrm{g} / \mathrm{m} 2$ & 98.6616 & & & & & & & & & & \\
\hline
\end{tabular}

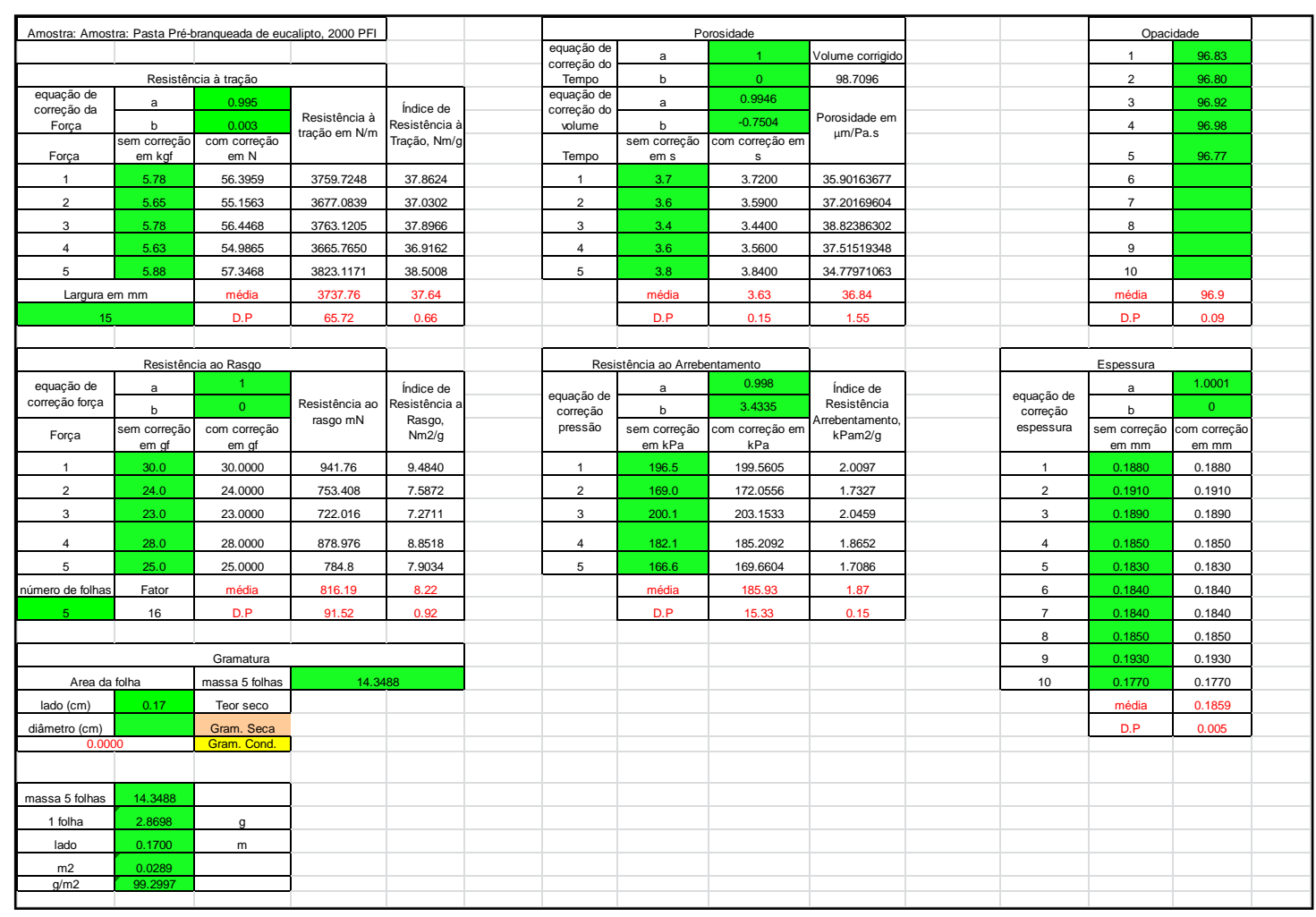



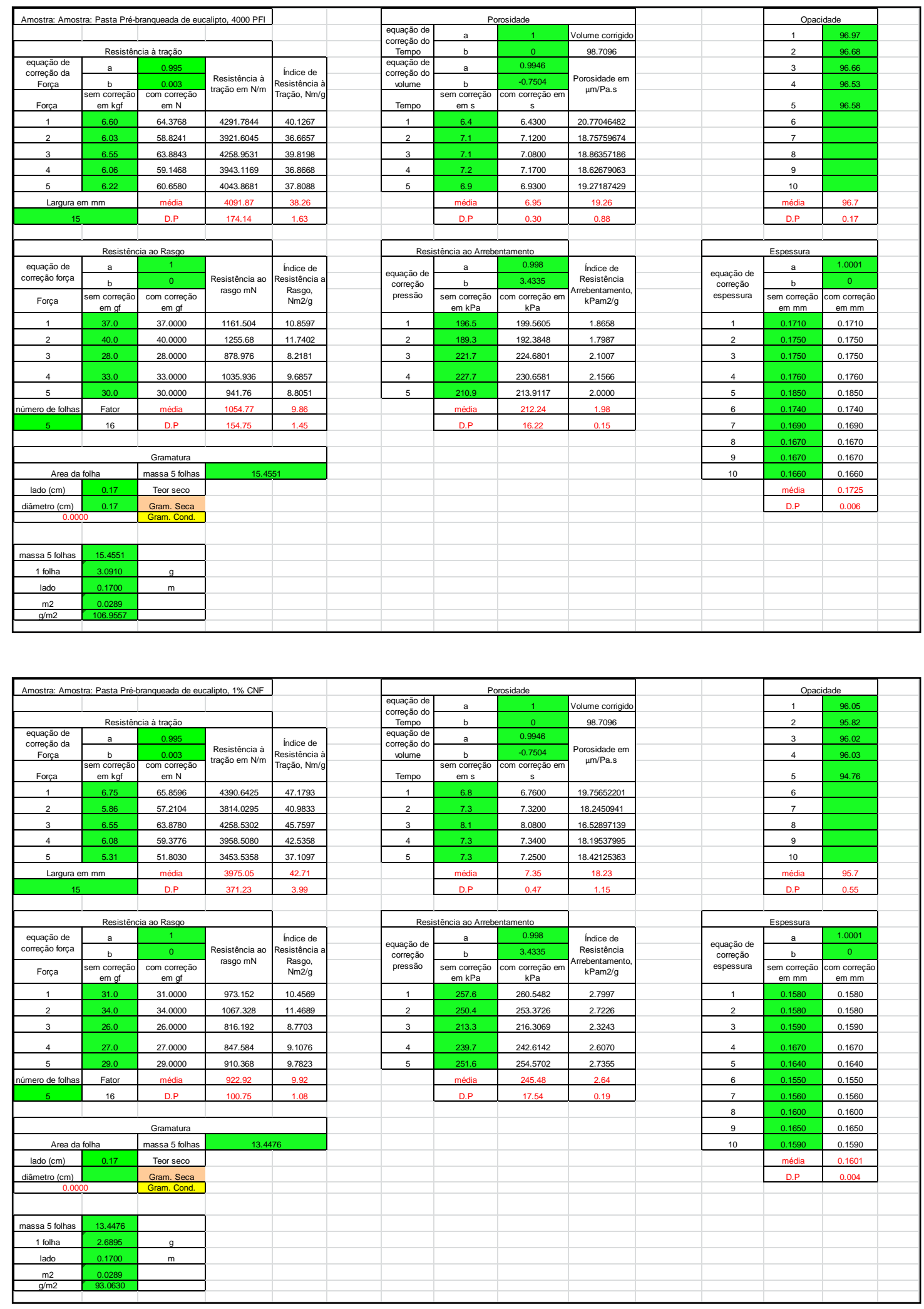


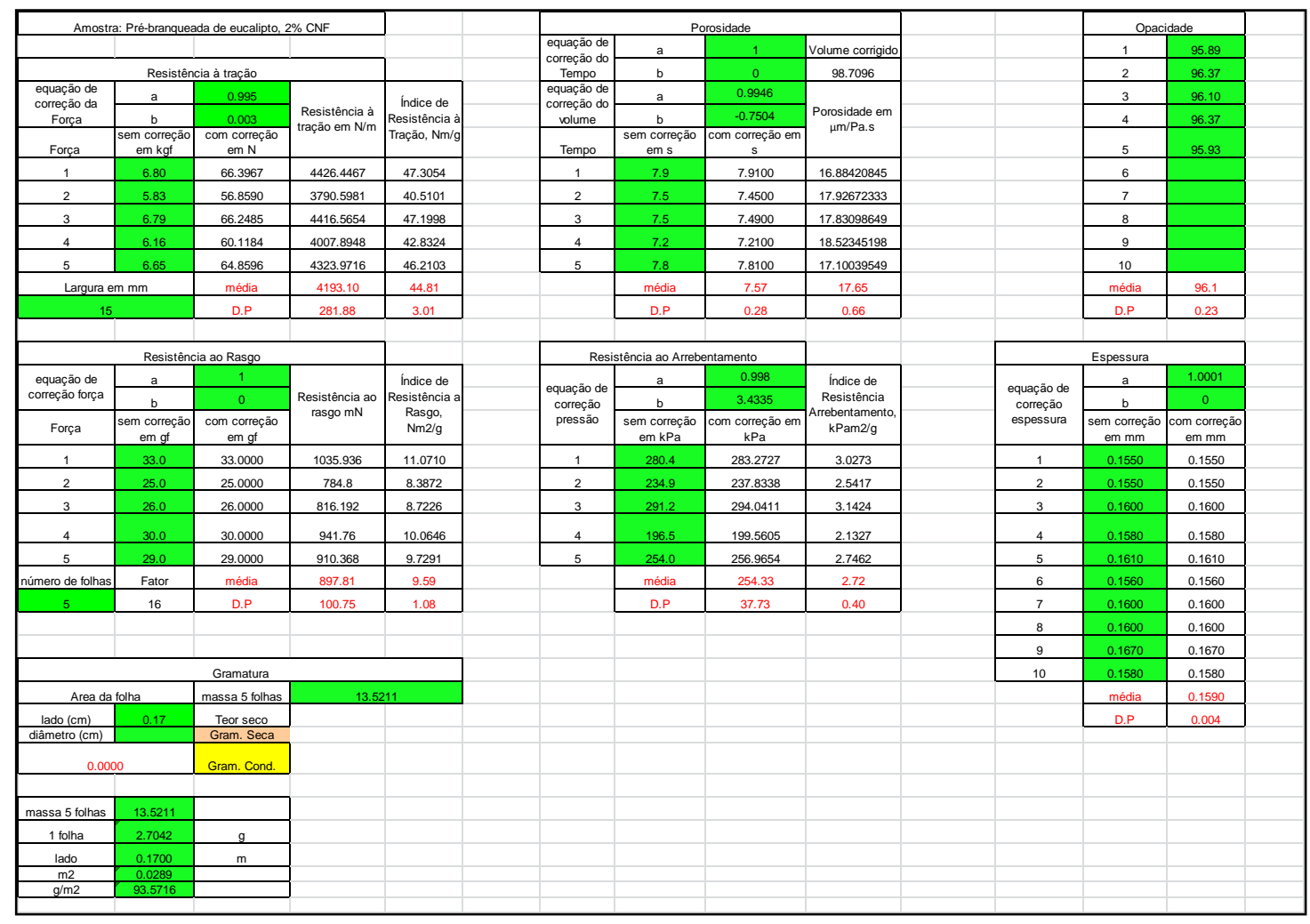

\begin{tabular}{|c|c|c|c|c|c|c|c|c|c|c|c|}
\hline \multirow{2}{*}{\multicolumn{4}{|c|}{ Amostra: Préb-brangueada de eucalipto, $3 \%$ CNF }} & & \multicolumn{4}{|c|}{ Porosidade } & & \multicolumn{2}{|c|}{ Opacidade } \\
\hline & & & & & 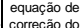 & $\mathrm{a}$ & 1 & Volume corrigido & & 1 & 96.00 \\
\hline & Resisteter & cia à traçăo & \multirow{4}{*}{$\begin{array}{l}\text { Resitstonia à } \\
\text { tragá em Nmm }\end{array}$} & \multirow{4}{*}{$\left|\begin{array}{c}\text { Indice de } \\
\text { Resitíncia a } \\
\text { Traắa, Nm/gat }\end{array}\right|$} & Tempo & $\mathrm{b}$ & 0 & 98.7096 & & 2 & 96.07 \\
\hline $\begin{array}{ll}\text { equacăo de } \\
\text { de }\end{array}$ & a & 0.995 & & & equacắo de & $\mathrm{a}$ & 0.9946 & \multirow{3}{*}{$\begin{array}{l}\text { Porsididad em } \\
\text { pumpa.s }\end{array}$} & & 3 & 9624 \\
\hline 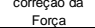 & $\mathrm{b}$ & 0.003 & & & $\begin{array}{c}\text { corcegaco or } \\
\text { volume }\end{array}$ & $\mathrm{b}$ & 0.7504 & & & 4 & $\begin{array}{ll}66.28 \\
\end{array}$ \\
\hline Forca & $\begin{array}{l}\text { m correceca } \\
\text { em kgfi }\end{array}$ & 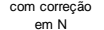 & & & Tempo & $\begin{array}{l}\text { em correçăo } \\
\text { em s }\end{array}$ & $s$ & & & 5 & 96 \\
\hline 1 & 6.81 & $\begin{array}{ll}66.4522 \\
\end{array}$ & 4430.1481 & $\begin{array}{ll}47.1991 \\
\end{array}$ & 1 & 9.2 & 9.2000 & \begin{tabular}{|l|l|}
14.51674878 \\
\end{tabular} & & 6 & \\
\hline 2 & 6.23 & 60.7666 & 4051 1083 & 43.1608 & 2 & 88 & 8.8200 & 15.14218694 & & 7 & \\
\hline 3 & $5.67 \mathrm{C}$ & 55.3402 & 3689.3499 & 39.3066 & 3 & 8.3 & 8.3000 & \begin{tabular}{|l|l|}
16.09085407 \\
\end{tabular} & & 8 & \\
\hline 4 & 6.34 & 61.8778 & 4125.1885 & 43.9500 & 4 & 8.5 & 8.5200 & \begin{tabular}{|l|l|}
15.67536254 \\
\end{tabular} & & 9 & \\
\hline 5 & 6.69 & 65.3040 & 4353.6024 & 46.3836 & 5 & 8.4 & 8.4200 & \begin{tabular}{|l|l|}
15.86153074 \\
\end{tabular} & & 10 & \\
\hline \multirow{2}{*}{\multicolumn{2}{|c|}{ 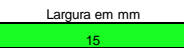 }} & média & 4129.88 & 44.00 & & média & 8.65 & 15.46 & & média & 96.1 \\
\hline & & D.P & 291.76 & 3.11 & & D.P & 0.36 & 0.63 & & D.P. & 0.12 \\
\hline \multirow{2}{*}{\multicolumn{4}{|c|}{ Resistência ao Rasgo }} & \multirow{4}{*}{$\begin{array}{c}\text { Indice de } \\
\text { Resistencia a } \\
\text { Rasgo: } \\
\text { Nm2/g }\end{array}$} & \multirow{2}{*}{\multicolumn{3}{|c|}{ Resistência ao Arrebentamento }} & \multirow{4}{*}{$\begin{array}{c}\text { Indice de } \\
\text { Resistência } \\
\text { Arrebentamento. } \\
\text { kPam2/g }\end{array}$} & \multicolumn{3}{|c|}{ Espessura } \\
\hline equacăo de & & & \multirow{3}{*}{$\begin{array}{l}\text { Resistência ao } \\
\text { rassgo } \mathrm{mNN}\end{array}$} & & \multirow{3}{*}{\begin{tabular}{|c|}
$\begin{array}{c}\text { equacăo de } \\
\text { corecaca } \\
\text { pressâa }\end{array}$ \\
\end{tabular}} & & 0.998 & & \multirow{3}{*}{ 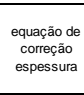 } & a & 1.0001 \\
\hline corrȩ̣ắo força & & 0 & & & & $\mathrm{~b}$ & 3.4335 & & & $\mathrm{~b}$ & 0 \\
\hline Força & sem correçăo & com correçấo & & & & $\begin{array}{l}\text { sem coreseăa } \\
\text { enk } \mathrm{Pa} a\end{array}$ & om correcăo em & & & sem correcắa & com corregăo \\
\hline 1 & 33.0 & 33.0000 & $\begin{array}{l}1035.936 \\
\end{array}$ & $\mid 11.03692809$ & 1 & 263.6 & 266.5362 & 2.8397 & 1 & 0.1670 & 0.1670 \\
\hline 2 & 27.0 & 27.0000 & 847.584 & 9.030213892 & 2 & 267.2 & 270.1191 & 2.8779 & 2 & 0.1680 & 0.1680 \\
\hline 3 & 32.0 & 32.0000 & 1004.544 & 10.70247572 & 3 & 254.0 & 256.965 & 2.7377 & 3 & 0.1640 & 0.1640 \\
\hline 4 & 33.0 & 33.0000 & 1035.936 & 11.03692809 & 4 & 242.1 & 245.0094 & 2.6103 & 4 & 0.1640 & 0.1640 \\
\hline 5 & 33.0 & 33.0000 & 1035.936 & 11.03692809 & 5 & 263.6 & 266.5362 & 2.8397 & 5 & 0.1660 & 0.1660 \\
\hline número de folhas & Fator & média & 991.99 & 10.57 & & media & 261.03 & 2.78 & 6 & 0.1680 & 0.1680 \\
\hline 5 & 16 & D.P & 81.86 & 0.87 & & D.P & 10.20 & 0.11 & 7 & 0.1640 & 0.1640 \\
\hline \multirow{2}{*}{\multicolumn{5}{|c|}{ Gramatura }} & & & & & 8 & 0.1630 & 0.1630 \\
\hline & & & \multirow{2}{*}{\multicolumn{2}{|c|}{13.5629}} & & & & & 9 & 0.1650 & 0.1650 \\
\hline \multicolumn{2}{|c|}{ Area da tolna } & massa 5 follas & & & & & & & 10 & 0.1610 & 0.1610 \\
\hline $\operatorname{lado}(\mathrm{cm})$ & 0.169 & Teor seco & & & & & & & & media & 0.1650 \\
\hline diâmetro $(\mathrm{cm})$ & & $\begin{array}{l}\text { Gram. Seca } \\
\text { Gram. Cond }\end{array}$ & & & & & & & & D.P & 0.002 \\
\hline & & & & & & & & & & & \\
\hline massa 5 tolhas & 13.5629 & & & & & & & & & & \\
\hline 1 tolha & 2.7126 & $g$ & & & & & & & & & \\
\hline lado & 0.1700 & $\mathrm{~m}$ & & & & & & & & & \\
\hline$\frac{\mathrm{m} 2}{\mathrm{~g} / \mathrm{m} 2}$ & 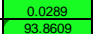 & 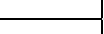 & & & & & & & & & \\
\hline
\end{tabular}




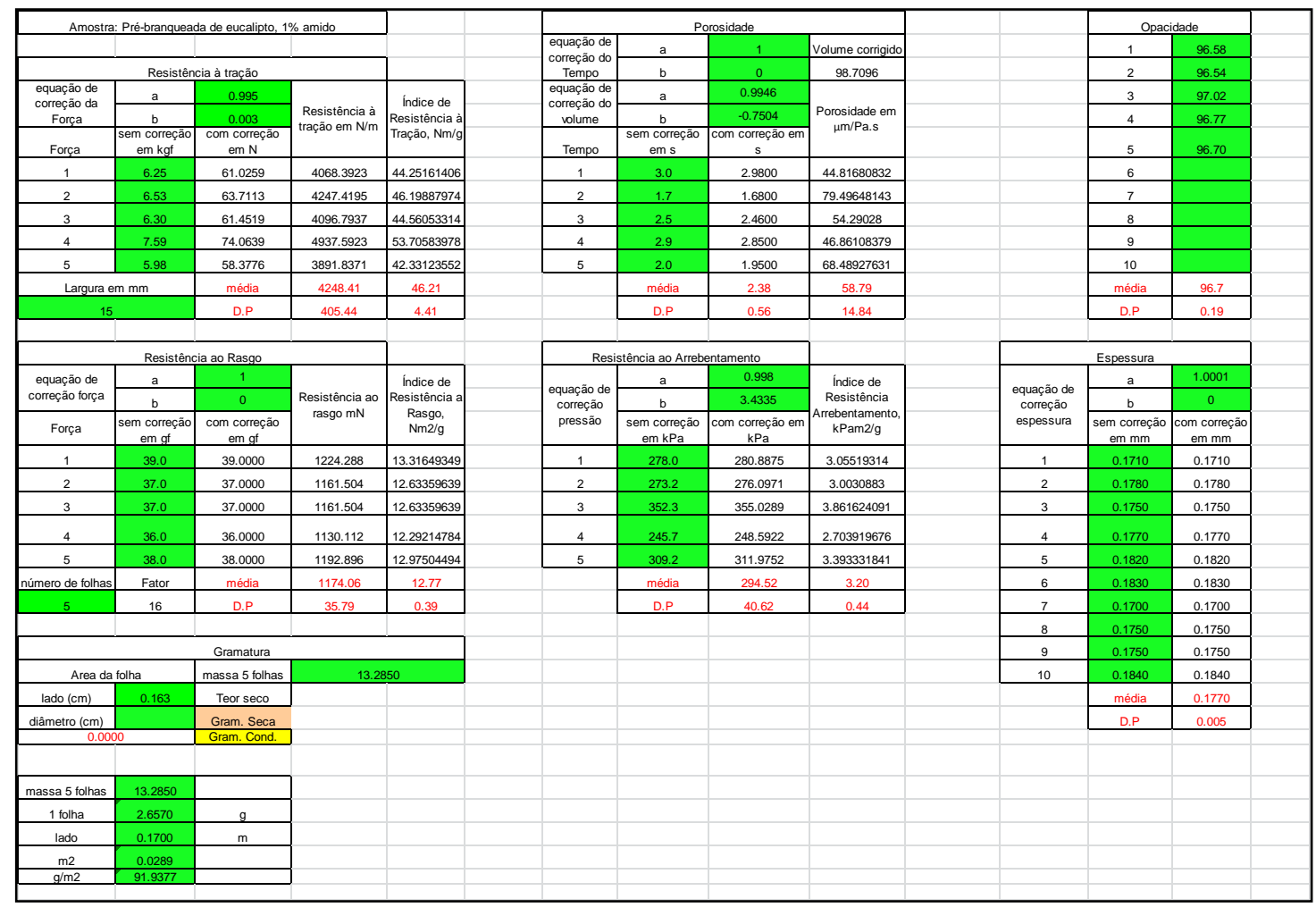

\begin{tabular}{|c|c|c|c|c|c|c|c|c|c|c|c|}
\hline \multirow{2}{*}{\multicolumn{4}{|c|}{ Amostra: Prébranqueada de eucalipto, $0.5 \%$ amido }} & & \multicolumn{4}{|c|}{ Porosidade } & & \multicolumn{2}{|c|}{ Opacidade } \\
\hline & & & & & $\begin{array}{l}\text { equacăco od } \\
\text { correcáa do do }\end{array}$ & $\mathrm{a}$ & 1 & Volume corigido & & 1 & 96.94 \\
\hline & Resistên & cia à tração & & & Tempo & $\mathrm{b}$ & 0 & 98.7096 & & 2 & 96.83 \\
\hline equaçăo de & a & 0.995 & \multirow{3}{*}{ 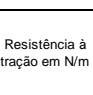 } & \multirow{3}{*}{ 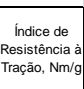 } & equacáá de & $\mathrm{a}$ & 0.9946 & \multirow{3}{*}{$\begin{array}{c}\text { Porosidade em } \\
\text { mm/Pa.s }\end{array}$} & & 3 & 96.65 \\
\hline 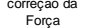 & $\mathrm{b}$ & 0.003 & & & 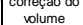 & $\mathrm{b}$ & $\begin{array}{l}-0.7504 \\
\end{array}$ & & & 4 & 9694 \\
\hline Fore & $\begin{array}{l}m \text { coorecegà } \\
\text { em kft }\end{array}$ & $\begin{array}{l}\text { com correçăo } \\
\text { em N }\end{array}$ & & & Tenpons & sem correçãa & com correção em & & & ${ }_{5}$ & 2078 \\
\hline 1 & 6.10 & 59.5444 & 3969.6252 & 43.18491619 & 1 & 1.7 & 1.6600 & \begin{tabular}{|l|}
8.45427036 \\
\end{tabular} & & 6 & \\
\hline 2 & 5.27 & 51.3956 & 3426.3704 & 37.27493404 & 2 & 2.2 & 2.1600 & 61.83059667 & & 7 & \\
\hline 3 & 5.46 & 53.3216 & 3554.7748 & $38.67182476-$ & 3 & 2.0 & 2.0200 & 66.11588554 & & 8 & \\
\hline 4 & 5.53 & 53.9514 & 3596.7588 & 39.12856181 & 4 & & & & & 9 & \\
\hline 5 & 5.62 & 54.8032 & 3653.5484 & 39.74636697 & 5 & & & & & 10 & \\
\hline \multirow{2}{*}{\multicolumn{2}{|c|}{$\begin{array}{l}\text { Largura em } \mathrm{mm} \\
15\end{array}$}} & média & 3640.22 & 39.60 & & média & 1.95 & 69.47 & & média & 96.8 \\
\hline & & D.P & 202.24 & 2.20 & & D.P & 0.26 & 9.75 & & D.P & 0.12 \\
\hline \multirow{2}{*}{\multicolumn{4}{|c|}{ Resistência ao Rasgo }} & & \multirow{2}{*}{\multicolumn{3}{|c|}{ Resistência ao Arrebentamento }} & & \multirow{2}{*}{\multicolumn{3}{|c|}{ Espessura }} \\
\hline equacăo de & & & \multirow{3}{*}{$\begin{array}{l}\begin{array}{l}\text { Resistência ao } \\
\text { rasgo } \mathrm{mN}\end{array} \\
\text { a }\end{array}$} & & & & entamento & \multirow{3}{*}{ 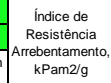 } & & & 1.0001 \\
\hline 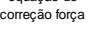 & $\frac{a}{b}$ & 0 & & 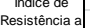 & \multirow{2}{*}{ 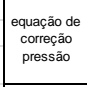 } & $\frac{a}{b}$ & 3.4335 & & \multirow{2}{*}{$\begin{array}{l}\text { equarăa de } \\
\text { ouregąu } \\
\text { espessura }\end{array}$} & $\frac{a}{b}$ & 0 \\
\hline Força & sem correçăo & com correçāo & & 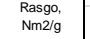 & & sem correção & com correçăo em & & & sem correçãa & iom correçäo \\
\hline 1 & 15.0 & 15.0000 & 784.8 & 8.537713311 & 1 & 267.2 & 270.1191 & 2.938581924 & 1 & 0.1850 & 0.1850 \\
\hline 2 & 17.0 & 17.0000 & 889.44 & 9.676075085 & 2 & 194.1 & 197.1653 & 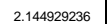 & 2 & 0.1860 & 0.1860 \\
\hline 3 & 16.0 & 16.0000 & 837.12 & 9.106894198 & 3 & 188.1 & 191.1872 & \begin{tabular}{|l|}
2.079895316 \\
\end{tabular} & 3 & 0.1950 & 0.1950 \\
\hline 4 & 16.0 & 16.0000 & 837.12 & 9.106894198 & 4 & & & & 4 & 0.1910 & 0.1910 \\
\hline 5 & 14.0 & 14.0000 & 732.48 & 7.968532423 & 5 & & & & 5 & 0.1890 & 0.1890 \\
\hline úmero de folhas & Fator & média & 816.19 & 8.88 & & média & 219.49 & 2.39 & 6 & 0.1870 & 0.1870 \\
\hline & 16 & D.P & 59.65 & 0.65 & & D.P & 43.95 & 0.48 & 7 & & \\
\hline & & & & & & & & & 8 & & \\
\hline & & & & & & & & & 9 & & \\
\hline \multicolumn{3}{|r|}{ Gramatura } & & & & & & 10 & & \\
\hline \multicolumn{2}{|c|}{ Area da folha } & massa 5 tollas & & & & & & & & média & 0.1889 \\
\hline$\frac{\text { lado }(\mathrm{cm})}{\text { dîmetro }(\mathrm{cm})}$ & 0.163 & $\begin{array}{l}\text { Teor seco } \\
\text { Gram Seca } \\
\end{array}$ & 7.9696 & & & & & & & D.P & 0.004 \\
\hline \multirow{2}{*}{\multicolumn{2}{|c|}{0.0000}} & Gram. Cond. & & & & & & & & & \\
\hline & & & & & & & & & & & \\
\hline & & & & & & & & & & & \\
\hline penas 3 tollhas & 7.9696 & & & & & & & & & & \\
\hline 1 tolha & $\frac{2.6565}{0.1700}$ & $\frac{9}{m}$ & & & & & & & & & \\
\hline Iado & $\frac{0.1700}{0.0299}$ & $m$ & & & & & & & & & \\
\hline $\mathrm{g} / \mathrm{m} 2$ & 91.9216 & 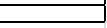 & & & & & & & & & \\
\hline
\end{tabular}



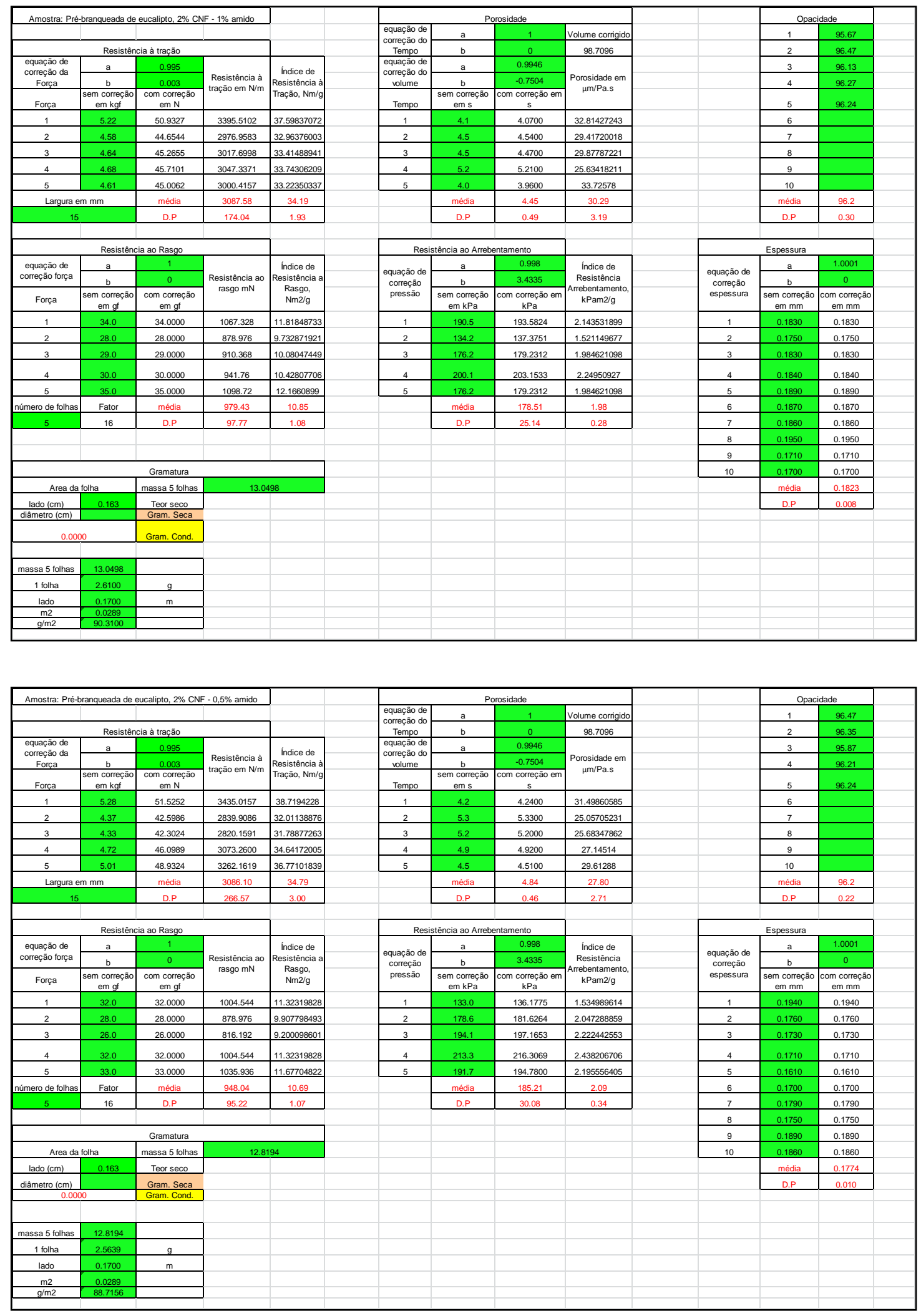


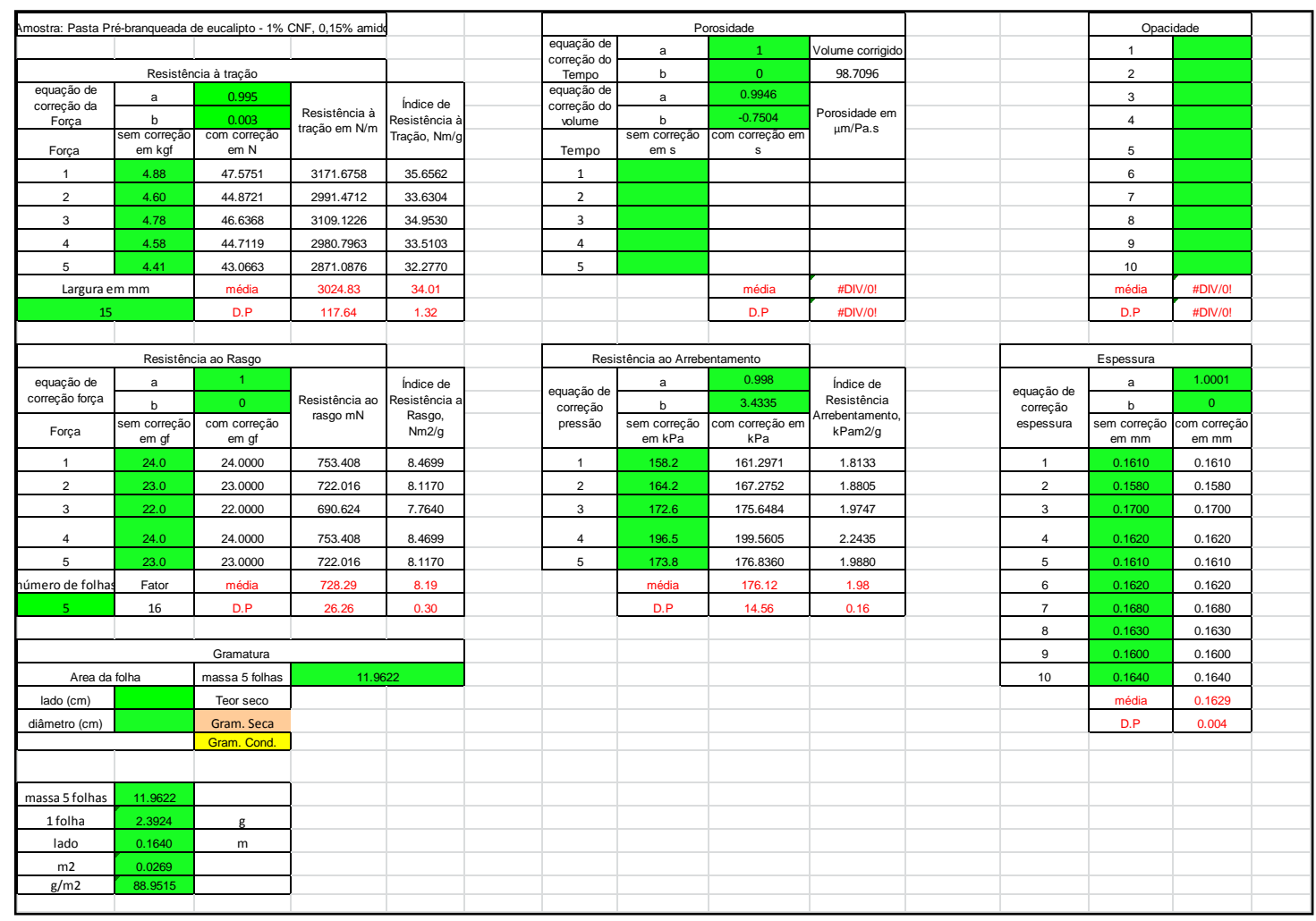

\begin{tabular}{|c|c|c|c|c|c|c|c|c|c|c|c|}
\hline mostra: Pasta Pré & tranqueadada $d$ & eucalipto $-1,7 \%$ & CNF, $0,85 \%$ ami & & & & rosidade & & & & \\
\hline & & & & & equacăâ de & $\mathrm{a}$ & 1 & Volume corrigido & & 1 & \\
\hline & Resistân & cia à tracāo & & & 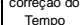 & $\mathrm{b}$ & 0 & 98.7096 & & 2 & \\
\hline $\begin{array}{l}\text { equaçăo de } \\
\text { correço de }\end{array}$ & $\mathrm{a}$ & 0.995 & & Indice de & 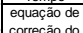 & $\mathrm{a}$ & 0.9946 & & & 3 & \\
\hline $\begin{array}{l}\text { Forca } \\
\text { Foracoa }\end{array}$ & $\mathrm{b}$ & 0.003 & $\begin{array}{c}\text { Resistência à } \\
\text { trataço }\end{array}$ & Resistência à & $\begin{array}{c}\text { corferaca oo } \\
\text { volume }\end{array}$ & b & -0.7504 & Prosidade em & & 4 & \\
\hline Forga & $\begin{array}{c}\text { sem o corecequa } \\
\text { en kgft }\end{array}$ & 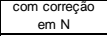 & & & Tempo & 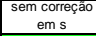 & $\begin{array}{c}\text { Com corregáa } \\
\mathrm{s}\end{array}$ & & & 5 & \\
\hline & 4.45 & 43.4498 & 2896.6527 & 31.4245 & 1 & & & & & 6 & \\
\hline 2 & 5.39 & 52.5867 & 3505.7783 & 38.0327 & 2 & & 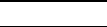 & & & 7 & \\
\hline 3 & 5.48 & 53.4988 & 3566.5881 & 38.6924 & 3 & & & & & 8 & \\
\hline 4 & 5.32 & 51.8755 & 3458.3690 & 37.5184 & 4 & & . & & & 9 & \\
\hline 5 & 5.14 & 50.1740 & 3344.9329 & 36.2878 & 5 & & & & & 10 & \\
\hline Largura e & $\mathrm{nmm}$ & $\begin{array}{l}\text { média } \\
\end{array}$ & 3354.46 & 36.39 & & & $\begin{array}{l}\text { média } \\
\text { mate }\end{array}$ & \#DII/O!! & & média & \#DIV/o! \\
\hline 15 & & D.P & 268.50 & 2.91 & & & D.P & \#DIV/O1 & & D.P & \#DIV/0! \\
\hline & & & & & & & & & & & \\
\hline & Resistênn & jia ao Rasgo & & & & stênnia ao Arreb & ntamento & & & Espessura & \\
\hline 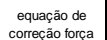 & $a$ & 1 & & 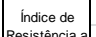 & equacăa de & $a$ & 0.998 & $\begin{array}{l}\text { Indice de } \\
\text { Resistóngia }\end{array}$ & equacăâ de & $a$ & 1.0001 \\
\hline Fora & bem corres & & $\begin{array}{l}\text { rasgo } \mathrm{mN} \\
\text { rev }\end{array}$ & $\begin{array}{l}\text { Pasgo, } \\
\text { Rasto }\end{array}$ & \begin{tabular}{|l|l} 
corregáa \\
poressaio
\end{tabular} & \begin{tabular}{|c} 
b \\
sem correão
\end{tabular} & & $\begin{array}{l}\text { Resitseñia } \\
\text { arebentamento, }\end{array}$ & 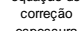 & $\frac{b}{\text { sem corecăo }}$ & 0 \\
\hline Forrça & em gt & em gf & & $\mathrm{Nm} 2 / \mathrm{g}$ & & em kPa & $\mathrm{kPa}$ & $\mathrm{kPam} / \mathrm{g}$ & & $\begin{array}{c}\text { sem correceata } \\
\text { em mm }\end{array}$ & 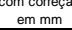 \\
\hline 1 & 34.0 & 34.0000 & 1067.328 & 11.5790 & 1 & 158.2 & 1661.2971 & 1.7498 & 1 & 0.1750 & 0.1750 \\
\hline 2 & 34.0 & 34.0000 & 1067.328 & 11.5790 & 2 & 154.6 & 157.7043 & 1.7109 & 2 & 0.1600 & 0.1600 \\
\hline 3 & 29.0 & 29.0000 & 910.368 & 9.8762 & 3 & 165.4 & 168.4728 & 1.8277 & 3 & 0.1640 & 0.1640 \\
\hline 4 & 34.0 & 34.0000 & 1067.328 & 11.5790 & 4 & 222.9 & 225.8677 & 2.4503 & 4 & 0.1580 & 0.1580 \\
\hline 5 & 30.0 & 30.0000 & 941.76 & 10.2168 & 5 & 221.7 & 224.6801 & 2.4375 & 5 & 0.1630 & 0.1630 \\
\hline úmero de folha: & Fator & média & 1010.82 & 10.97 & & média & 187.60 & 2.04 & 6 & 0.1700 & 0.1700 \\
\hline 5 & 16 & D.P & 78.17 & 0.85 & & D.P & 34.61 & 0.38 & 7 & 0.1610 & 0.1610 \\
\hline & & & & & & & & & 8 & 0.1590 & 0.1590 \\
\hline & & & & & & & & & 9 & 0.1610 & 0.1610 \\
\hline & & Gramatura & & & & & & & 10 & 0.1590 & 0.1590 \\
\hline Area da & & massa 5 follas & 12.39 & & & & & & & média & 0.1630 \\
\hline lado (cm) & 0.164 & Teor seco & & & & & & & & D.P & 0.005 \\
\hline diâmetro (cm) & & Gram. Seca & & & & & & & & & \\
\hline 0.000 & & Gram. Cond. & & & & & & & & & \\
\hline massa 5 folhas & 12.3961 & & & & & & & & & & \\
\hline 1 folha & 2.4792 & $\mathrm{~g}$ & & & & & & & & & \\
\hline Iado & 0.1640 & $\mathrm{~m}$ & & & & & & & & & \\
\hline $\begin{array}{c}\mathrm{m} 2 \\
\mathrm{~g} / \mathrm{m} 2\end{array}$ & 0.0269 & & & & & & & & & & \\
\hline
\end{tabular}




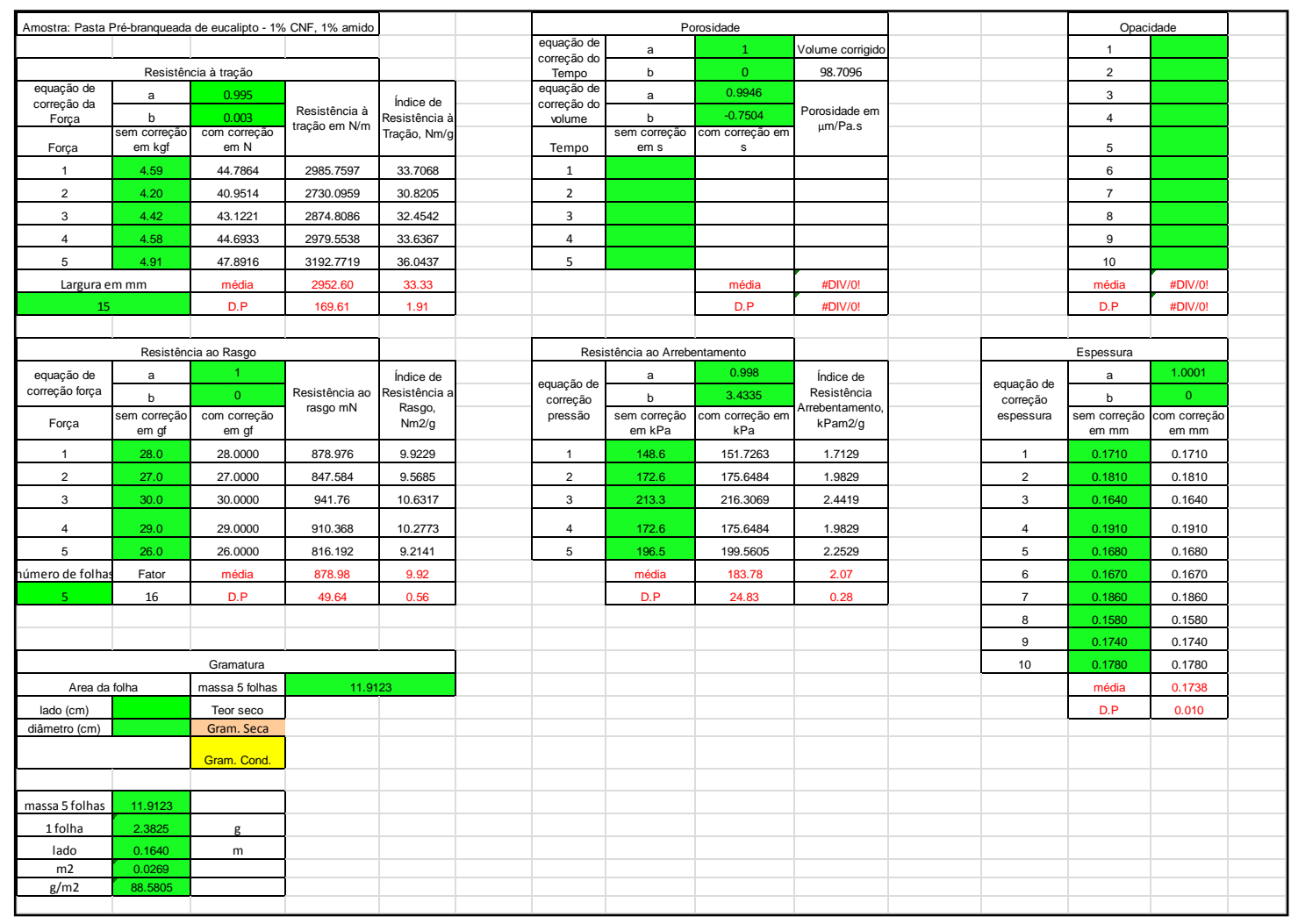

\begin{tabular}{|c|c|c|c|c|c|c|c|c|c|c|c|}
\hline Amostra: Pasta Pr & branqueada & eucalipto - $1 \%$ & CNF, $0,3 \%$ a amido & & & & rosidade & & & & \\
\hline & & & & & 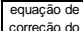 & $a$ & 1 & 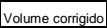 & & 1 & \\
\hline & Resistên & ia à tração & & & Terpo & $\mathrm{b}$ & 0 & 98.7096 & & 2 & \\
\hline 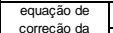 & $\mathrm{a}$ & 0.995 & & Indice de & 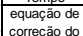 & $a$ & 0.9946 & & & 3 & \\
\hline 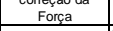 & $\mathrm{b}$ & 0.003 & 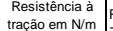 & Resistência à & $\begin{array}{l}\text { Doregaciou } \\
\text { volume }\end{array}$ & b & $\begin{array}{l}-0.7504 \\
0.700\end{array}$ & $\begin{array}{l}\text { Dorosidada em em } \\
\text { um/Pa.s }\end{array}$ & & 4 & \\
\hline Força & 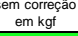 & $\begin{array}{l}\text { m corocea } \\
\text { em N }\end{array}$ & & & Tempo & $\begin{array}{l}\text { sem oorecegaj } \\
\text { ems }\end{array}$ & $\begin{array}{l}\text { mogega } \\
\text { s }\end{array}$ & & & 5 & \\
\hline 1 & 5.09 & 49.6341 & 3308.9401 & 36.1111 & 1 & & & & & 6 & \\
\hline 2 & 5.10 & 49.7645 & 3317.6310 & 36.2059 & 2 & & & & & 7 & \\
\hline 3 & 5.76 & 56.1796 & 3745.3095 & 40.8733 & 3 & & & & & 8 & \\
\hline 4 & 5.02 & 48.9714 & 3264.7574 & 35.6289 & 4 & & & & & 9 & \\
\hline 5 & 5.59 & 54.5935 & 3639.5689 & 39.7193 & 5 & & & & & 10 & \\
\hline Larguraen & & média & 3455.24 & 37.71 & & & média & \#DIV/0! & & média & $\#$ \#DIV/ \\
\hline 15 & & $D . P$ & 220.65 & 2.41 & & & D.P & \#DIV/0! & & D.P & \#DIVI0! \\
\hline & & & & & & & & & & & \\
\hline & Resistênn & a a o Rasgo & & & Res & istência a a Arrebe & entamento & & & Espessura & \\
\hline $\begin{array}{c}\text { equacă de } \\
\text { coreráa forge }\end{array}$ & $\mathrm{a}$ & $\frac{1}{0}$ & & $\begin{array}{c}\text { Indice ede } \\
\text { Reristénnia }\end{array}$ & equacăâo de & $a$ & \begin{tabular}{|l|l|}
0.998 \\
3.4335
\end{tabular} & $\begin{array}{l}\text { Indice de } \\
\text { Resistência }\end{array}$ & equaçăo de & $a$ & $\frac{1.0001}{0}$ \\
\hline & & com correção & rasgo $\mathrm{mN}$ & Rasgo, & \begin{tabular}{|c|} 
correcáa \\
pressáa
\end{tabular} & & & rebentamento, & $\begin{array}{l}\text { correção } \\
\text { essessusur }\end{array}$ & semerea & 0 \\
\hline Força & em gf & em gf & & & & em kPa & $\mathrm{kPa}$ & $\mathrm{kPam} 2 / \mathrm{g}$ & & $\begin{array}{c}\text { en mm } \\
\text { em }\end{array}$ & $\begin{array}{l}\text { em correcao } \\
\text { em mm }\end{array}$ \\
\hline 1 & 36.0 & 36.0000 & 1130.112 & 12.3331 & 1 & 252.8 & 255.7678 & 2.7912 & 1 & 0.1730 & 0.1730 \\
\hline 2 & 31.0 & 31.0000 & 973.152 & 10.6202 & 2 & 230.1 & 233.0434 & 2.5432 & 2 & 0.1850 & 0.1850 \\
\hline 3 & 32.0 & 32.0000 & 1004.544 & 10.9628 & 3 & 188.1 & 191.1872 & 2.0865 & 3 & 0.1710 & 0.1710 \\
\hline 4 & 30.0 & 30.0000 & 941.76 & 10.2776 & 4 & 177.4 & 180.4288 & 1.9691 & 4 & 0.1680 & 0.1680 \\
\hline 5 & 31.0 & 31.0000 & 973.152 & 10.6202 & 5 & 219.3 & 222.2849 & 2.4258 & 5 & 0.1730 & 0.1730 \\
\hline púmero de follha: & Fator & média & 1004.54 & 10.96 & & média & 216.54 & 2.36 & 6 & 0.1750 & 0.1750 \\
\hline 5 & 16 & D.P & 73.62 & 0.80 & & D.P & 30.79 & 0.34 & 7 & 0.1700 & 0.1700 \\
\hline & & & & & & & & & 8 & 0.1760 & 0.1760 \\
\hline & & & & & & & & & 9 & 0.1800 & 0.1800 \\
\hline & & Gramatura & & & & & & & 10 & 0.1770 & 0.1770 \\
\hline Area dat & & massa 5 folhas & 12.322 & & & & & & & média & 0.1748 \\
\hline 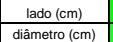 & & $\begin{array}{l}\text { Teor seco } \\
\text { Gram Secolo }\end{array}$ & & & & & & & & D.P & 0.005 \\
\hline 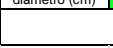 & & Gram. Cond. & & & & & & & & & \\
\hline massas follhas & & & & & & & & & & & \\
\hline massas ffolhas & 12.3227 & & & & & & & & & & \\
\hline$\frac{1}{\text { ladina }}$ & $\begin{array}{l}2.4645 \\
0.1640\end{array}$ & $\mathrm{~g}$ & & & & & & & & & \\
\hline $\mathrm{m} 2$ & 0.0269 & & & & & & & & & & \\
\hline $\mathrm{g} / \mathrm{m} 2$ & 91.6322 & & & & & & & & & & \\
\hline
\end{tabular}



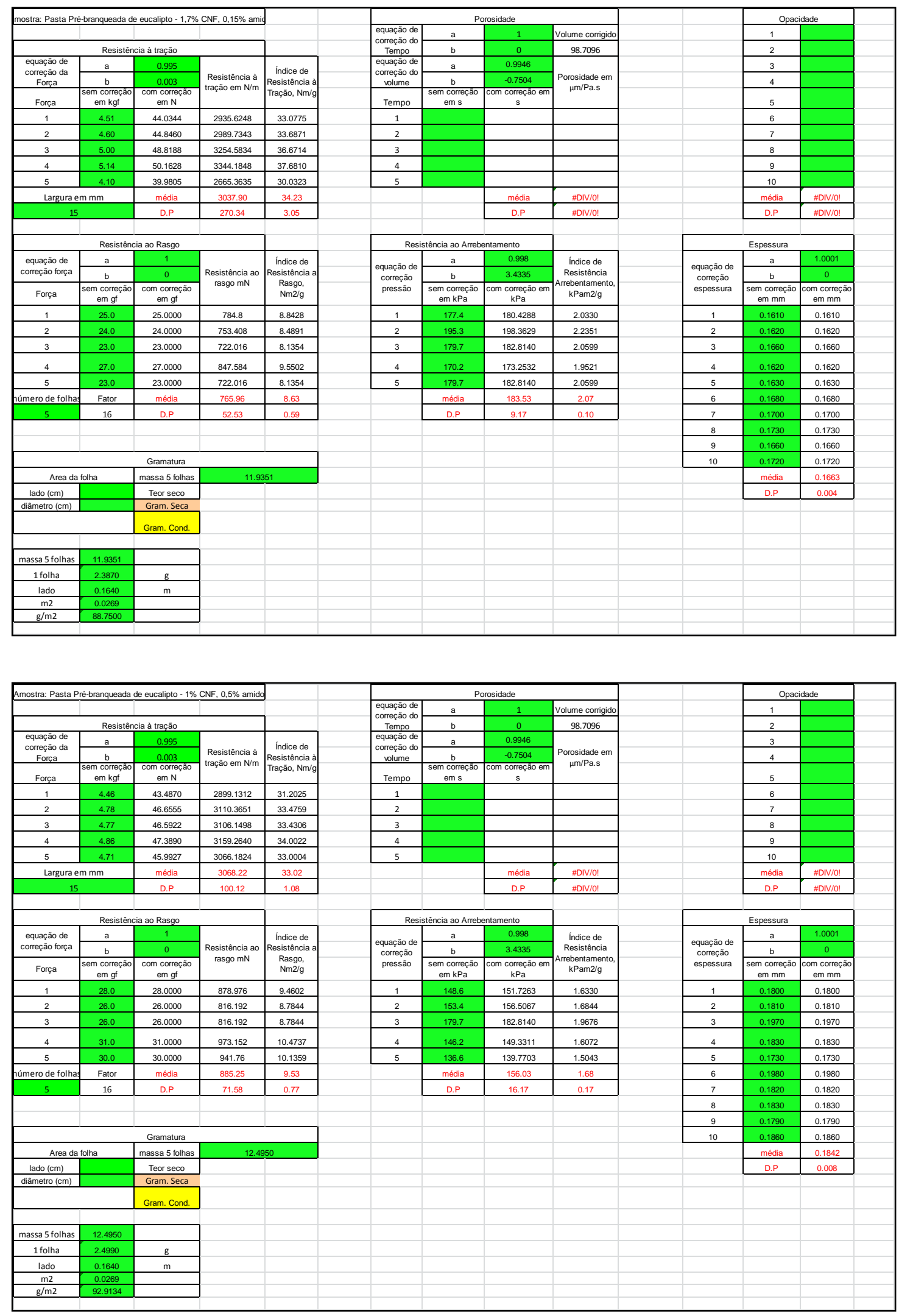


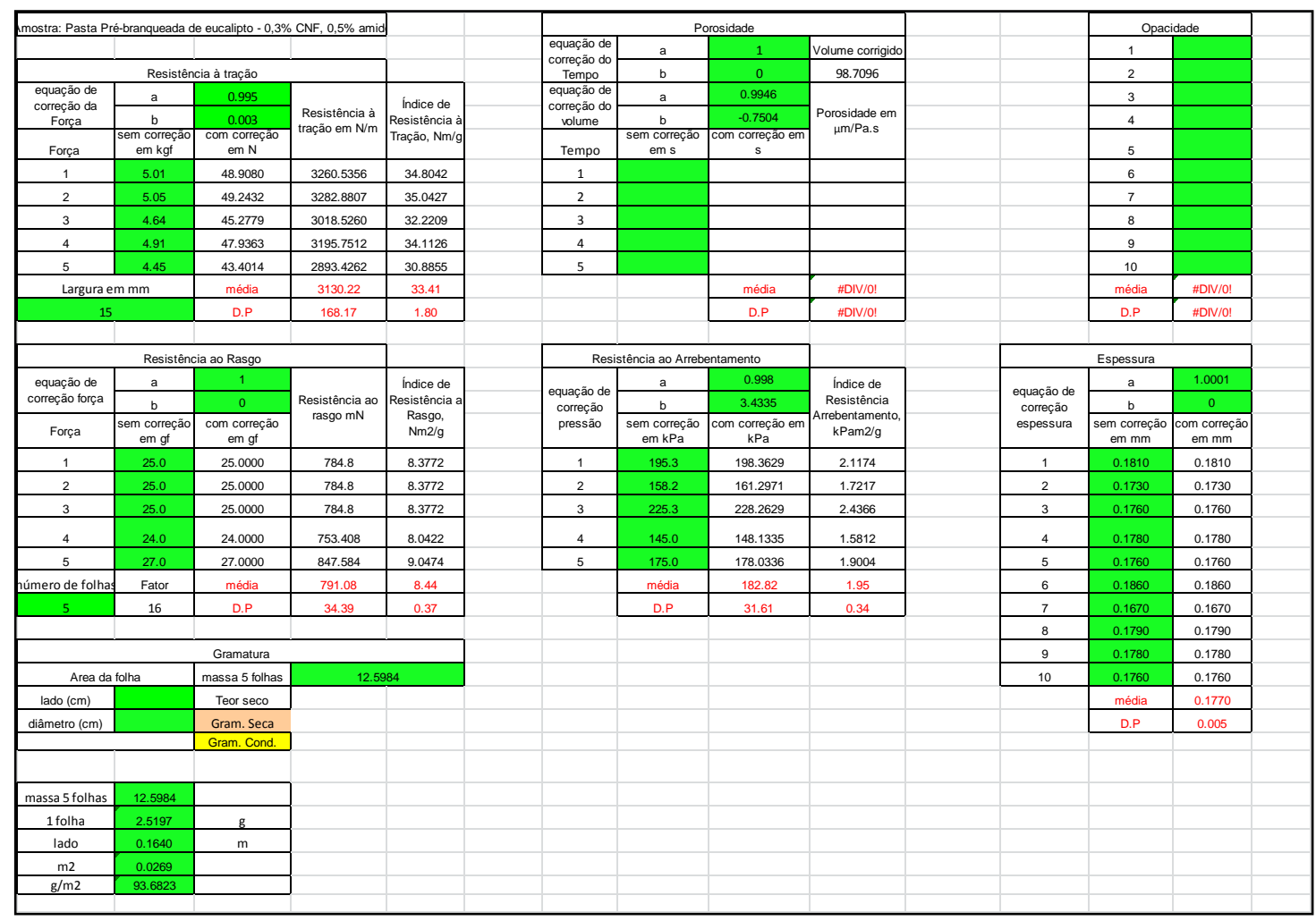

\begin{tabular}{|c|c|c|c|c|c|c|c|c|c|c|c|}
\hline \multirow{2}{*}{\multicolumn{5}{|c|}{ mostra: Pasta Prébranqueada de eucalipto - $1,7 \%$ CNF, $0,5 \%$ amid }} & \multicolumn{4}{|c|}{$\begin{array}{l}\text { Porosidade } \\
\end{array}$} & & \multicolumn{2}{|c|}{ Opacidade } \\
\hline & & & & & $\begin{array}{l}\text { equacăa de } \\
\text { correcáa do }\end{array}$ & $\mathrm{a}$ & 1 & \begin{tabular}{|l|} 
Volume corrigido \\
\end{tabular} & & 1 & \\
\hline \multicolumn{4}{|c|}{ Resistência à traçāo } & \multirow{4}{*}{ 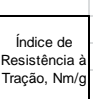 } & Tempo & b & 0 & 98.7096 & & 2 & \\
\hline $\begin{array}{l}\text { equacăâo od } \\
\text { correcáa da }\end{array}$ & $a$ & 0.995 & \multirow{3}{*}{$\begin{array}{l}\text { Resistếncia à } \\
\text { traçâ em } \mathrm{Nmm}\end{array}$} & & 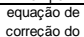 & $\mathrm{a}$ & 0.9946 & \multirow{3}{*}{$\begin{array}{c}\text { Porosidade em } \\
\text { mmpa.s }\end{array}$} & & 3 & \\
\hline 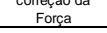 & $\mathrm{b}$ & 0.003 & & & volume & $\mathrm{b}$ & -0.7504 & & & 4 & \\
\hline Forca & $\begin{array}{l}\text { sem correcáa } \\
\text { em kgt }\end{array}$ & $\begin{array}{l}\text { me correģa } \\
\text { em N }\end{array}$ & & & Tempo & $\begin{array}{l}\begin{array}{l}\text { sem corocesáo } \\
\text { em s }\end{array}\end{array}$ & 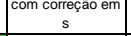 & & & 5 & \\
\hline 1 & 4.79 & 46.7002 & 3113.3445 & 33.5075 & 1 & & & & & 6 & \\
\hline 2 & 4.95 & 48.2676 & 3217.8426 & 34.6321 & 2 & & & & & 7 & \\
\hline 3 & 4.90 & 47.8395 & 3189.2981 & 34.3249 & 3 & & & & & 8 & \\
\hline 4 & 4.91 & 47.9401 & 3196.0049 & 34.3971 & 4 & & & & & 9 & \\
\hline 5 & 4.99 & 48.6660 & 3244.4029 & 34.9180 & 5 & & & & & 10 & \\
\hline \multirow{2}{*}{\multicolumn{2}{|c|}{$\begin{array}{l}\text { Largura em } \mathrm{mm} \\
15\end{array}$}} & média & 3192.18 & 34.36 & & & média & \#DIV/0! & & média & \#DIV/0! \\
\hline & & D.P & 49.05 & 0.53 & & & D.P & \#DIV/0! & & D.P & \#DIV/0! \\
\hline & & & & & & & & & \multirow{2}{*}{\multicolumn{3}{|c|}{ Espessura }} \\
\hline \multicolumn{4}{|c|}{ Resisitência ao Rasgo } & & \multicolumn{3}{|c|}{ Resistếncia ao Arrebentamento } & & & & \\
\hline 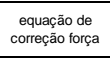 & $a$ & 1 & \multirow{2}{*}{$\begin{array}{c}\begin{array}{c}\text { Resistência ao } \\
\text { rasgo } \mathrm{mN}\end{array} \\
\text { f }\end{array}$} & \multirow{2}{*}{$\begin{array}{c}\text { Indice de } \\
\text { Resistencicia a } \\
\text { Rasago, } \\
\text { Nm2/g }\end{array}$} & \multirow{2}{*}{$\begin{array}{l}\text { equacăo de } \\
\text { coreça } \\
\text { pressäa }\end{array}$} & $a$ & 0.998 & \multirow{2}{*}{ 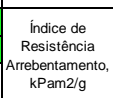 } & \multirow{2}{*}{$\begin{array}{l}\text { equacăa de } \\
\text { coreacao } \\
\text { espessura }\end{array}$} & $\mathrm{a}$ & 1.0001 \\
\hline Força & $\begin{array}{l}\frac{b}{\text { Sem coreçầ }} \\
\text { em gf }\end{array}$ & $\begin{array}{l}0 \\
\begin{array}{c}\text { com correçōo } \\
\text { em of }\end{array}\end{array}$ & & & & $\begin{array}{c}\text { b } \\
\begin{array}{c}\text { sem correcäo } \\
\text { em } \mathrm{KPa}\end{array}\end{array}$ & 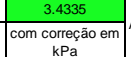 & & & $\begin{array}{c}\text { b } \\
\text { sem correçấo } \\
\text { em mm }\end{array}$ & $\begin{array}{c}\text { com correção } \\
\text { em mm }\end{array}$ \\
\hline 1 & 35.0 & 35.0000 & 1098.72 & 11.8250 & 1 & 152.2 & 155.3091 & 1.6715 & 1 & 0.1670 & 0.1670 \\
\hline 2 & 30.0 & 30.0000 & 941.76 & 10.1357 & 2 & 185.7 & 188.8020 & 2.0320 & 2 & 0.1650 & 0.1650 \\
\hline 3 & 26.0 & 26.0000 & 816.192 & 8.7843 & 3 & 182.1 & 185.2092 & 1.9933 & 3 & 0.1770 & 0.1770 \\
\hline 4 & 29.0 & 29.0000 & 910.368 & 9.7979 & 4 & 115.0 & 118.2434 & 1.2726 & 4 & 0.1780 & 0.1780 \\
\hline 5 & 27.0 & 27.0000 & 847.584 & 9.1222 & 5 & 180.9 & 184.0116 & 1.9804 & 5 & 0.1730 & 0.1730 \\
\hline úmero de folha & Fator & média & 922.92 & 9.93 & & mécia & 166.32 & 1.79 & 6 & 0.1690 & 0.1690 \\
\hline 5 & 16 & D.P & 110.10 & 1.18 & & D.P & 30.03 & 0.32 & 7 & 0.1700 & 0.1700 \\
\hline \multirow{2}{*}{\multicolumn{5}{|c|}{ Gramatura }} & & & & & 8 & 0.1730 & 0.1730 \\
\hline & & & & & & & & & 9 & 0.1770 & 0.1770 \\
\hline \multicolumn{2}{|c|}{ Area da follha } & massa 5 tolhas & \multicolumn{2}{|c|}{12.4952} & & & & & 10 & 0.1760 & 0.1760 \\
\hline lado $(\mathrm{cm})$ & & Teor seco & & & & & & & & média & 0.1725 \\
\hline diâmetro (cm) & & Gram. Seca & & & & & & & & D.P & 0.005 \\
\hline & & Gram. Cond. & & & & & & & & & \\
\hline & & & & & & & & & & & \\
\hline massa 5 folhas & 12.4952 & & & & & & & & & & \\
\hline 1 folha & 2.4990 & $\mathrm{~g}$ & & & & & & & & & \\
\hline lado & 0.1640 & $\mathrm{~m}$ & & & & & & & & & \\
\hline $\mathrm{m} 2$ & 0.0269 & & & & & & & & & & \\
\hline $\mathrm{g} / \mathrm{m} 2$ & 92.9149 & & & & & & & & & & \\
\hline
\end{tabular}




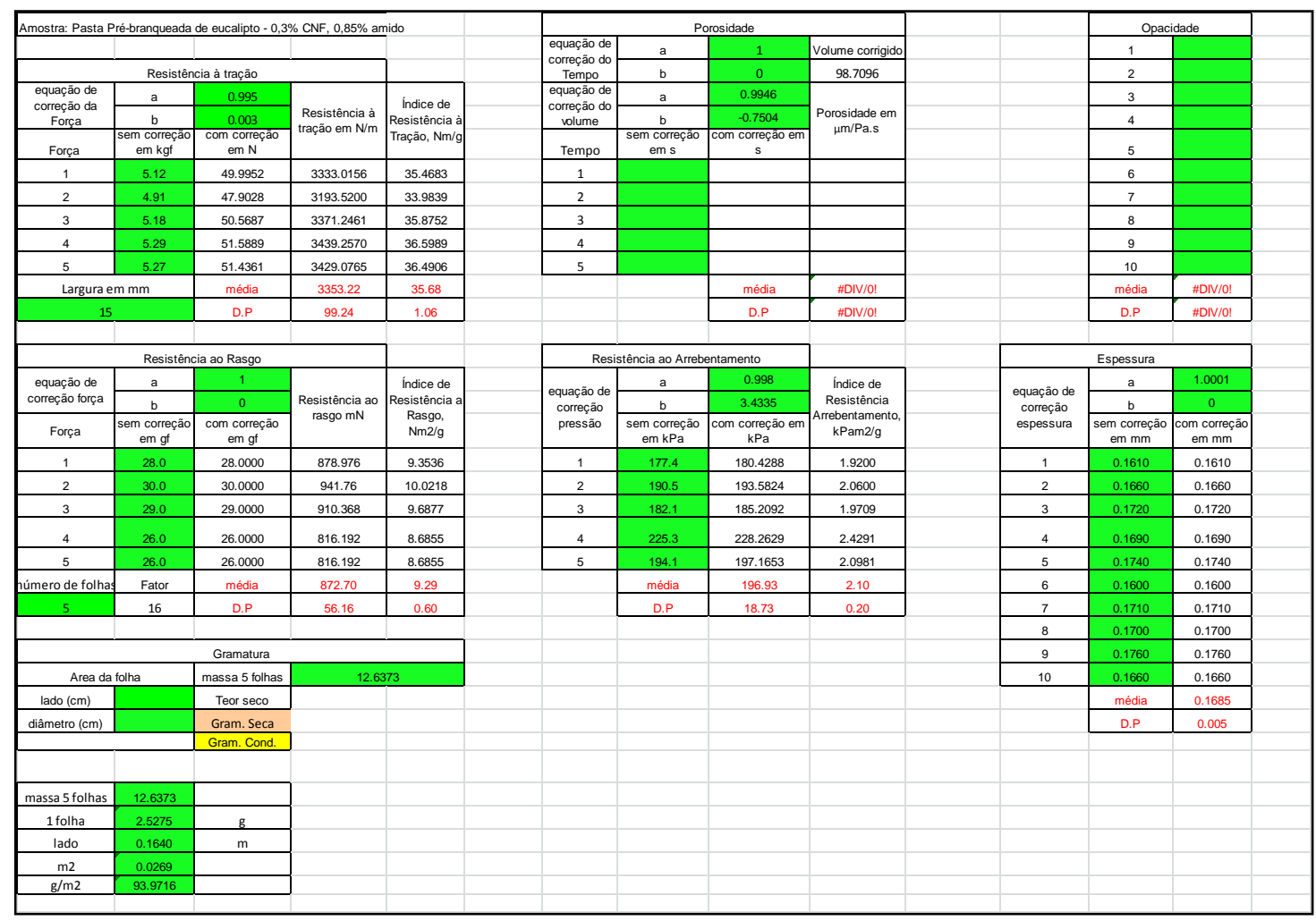

\begin{tabular}{|c|c|c|c|c|c|c|c|c|c|c|c|}
\hline \multicolumn{4}{|c|}{ Amostra: Referênncia } & & \multicolumn{4}{|c|}{ Porosidade } & & \multicolumn{2}{|c|}{ Opacidade } \\
\hline & & & & & $\begin{array}{l}\text { equacăo de } \\
\text { corceác do }\end{array}$ & $\mathrm{a}$ & 1 & \begin{tabular}{|l|l|l|l} 
Volume corrigido \\
\end{tabular} & & 1 & \\
\hline \multicolumn{4}{|c|}{ Resistência à traăâa } & \multirow{4}{*}{ 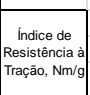 } & $\begin{array}{l}\text { Tumbaciou } \\
\text { Tempo }\end{array}$ & $\mathrm{b}$ & 0 & \multirow{4}{*}{$\begin{array}{c}\text { Porosidade em } \\
\mu \mathrm{m} / \mathrm{Pas}\end{array}$} & & 2 & \\
\hline $\begin{array}{l}\text { equacăo de } \\
\text { correcáo da }\end{array}$ & $\mathrm{a}$ & 0.995 & \multirow{3}{*}{$\begin{array}{l}\text { Resistênciai à } \\
\text { traçao em N/m }\end{array}$} & & equacăẩ de & $a$ & 0.9946 & & & 3 & \\
\hline $\begin{array}{c}\text { conreçac oa } \\
\text { Força }\end{array}$ & $\mathrm{b}$ & 0.003 & & & $\begin{array}{l}\text { corlegaco oo } \\
\text { volume }\end{array}$ & $\mathrm{b}$ & -0.7504 & & & 4 & \\
\hline Forca & $\begin{array}{l}\text { meoreagá } \\
\text { em kgfi }\end{array}$ & $\begin{array}{l}m \text { corocesăa } \\
\text { em N }\end{array}$ & & & Tempo & 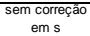 & $\begin{array}{l}\text { começắo } \\
\text { cal }\end{array}$ & & & 5 & \\
\hline 1 & 4.56 & 44.5407 & 2969.3799 & 32.604 & 1 & & & & & 6 & \\
\hline 2 & 4.71 & 45.9927 & 3066.1824 & 33.6632 & 2 & & & & & 7 & \\
\hline 3 & 4.44 & 43.3046 & 2886.9731 & $\begin{array}{l}31.6957 \\
\end{array}$ & 3 & & & & & 8 & \\
\hline 4 & 3.94 & 38.4048 & 2560.3190 & 28.1094 & 4 & & & & & 9 & \\
\hline 5 & 4.85 & 47.2885 & 3152.5638 & 34.6115 & 5 & & & & & 10 & \\
\hline \multirow{2}{*}{\multicolumn{2}{|c|}{$\begin{array}{l}\text { Largura em } \mathrm{mm} \\
15\end{array}$}} & média & 2927.08 & 32.14 & & & 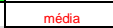 & \#DIV/0! & & $\begin{array}{l}\text { média } \\
\text { nof }\end{array}$ & $\#$ DIV $/ 0 !$ \\
\hline & & D.P & 228.09 & 2.50 & & & D.P & \#DIV/O! & & D.P & \#DNV!! \\
\hline \multicolumn{4}{|c|}{ Resistência ao Rasgo } & & \multicolumn{3}{|c|}{ Resistência ao Arrebentamento } & & \multicolumn{3}{|c|}{ Espessura } \\
\hline equacăa de & $\mathrm{a}$ & 1 & \multirow{3}{*}{ 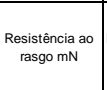 } & \multirow{3}{*}{ 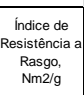 } & \multirow{3}{*}{ 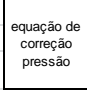 } & $\mathrm{a}$ & 0.998 & \multirow{3}{*}{ 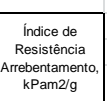 } & \multirow{3}{*}{$\begin{array}{l}\text { equacăa de } \\
\text { conceaca } \\
\text { espessura }\end{array}$} & $\mathrm{a}$ & 1.0001 \\
\hline correçắo orç̣a & 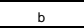 & 0 & & & & $\mathrm{~b}$ & 3.4335 & & & $b$ & 0 \\
\hline Força & $\begin{array}{l}m \text { correcta } \\
\text { em of }\end{array}$ & $\begin{array}{l}\text { com correăa } \\
\text { em of }\end{array}$ & & & & $\begin{array}{l}\text { sem coreceâá } \\
\text { em maa }\end{array}$ & $\begin{array}{c}\text { correcăo em } \\
\text { ka }\end{array}$ & & & $\begin{array}{l}\text { sem correcấa } \\
\text { em mm }\end{array}$ & $\begin{array}{l}\text { om correcáă } \\
\text { em mm }\end{array}$ \\
\hline 1 & 24.0 & 24.0000 & 753.408 & 8.2716 & 1 & 153.4 & 156.5067 & 1.7183 & 1 & 0.1660 & 0.1660 \\
\hline 2 & 21.0 & 21.0000 & 659.232 & 7.2376 & 2 & 177.4 & 180.4288 & 1.9809 & 2 & 0.1720 & 0.1720 \\
\hline 3 & 19.0 & 19.0000 & 596.448 & 6.5483 & 3 & 177.4 & 180.4288 & 1.9809 & 3 & 0.1660 & 0.1660 \\
\hline 4 & 19.0 & 19.0000 & 596.448 & 6.5483 & 4 & 143.8 & 146.9459 & 1.6133 & 4 & 0.1710 & 0.1710 \\
\hline 5 & 22.0 & 22.0000 & 690.624 & 7.5823 & 5 & 166.6 & 169.6604 & 1.8627 & 5 & 0.1740 & 0.1740 \\
\hline Imero de folhas & Fator & média & 659.23 & 7.24 & & média & $\begin{array}{l}166.79 \\
\end{array}$ & \begin{tabular}{|l|l|l}
1.83 \\
\end{tabular} & 6 & 0.1680 & 0.1680 \\
\hline 5 & 16 & D.P & 66.59 & 0.73 & & D.P & 14.83 & 0.16 & 7 & 0.1720 & 0.1720 \\
\hline \multirow{2}{*}{\multicolumn{5}{|c|}{ Gramatura }} & & & & & 8 & 0.1700 & 0.1700 \\
\hline & & & & & & & & & 9 & 0.1680 & 0.1680 \\
\hline \multicolumn{2}{|c|}{$\begin{array}{l}\text { Area da folha } \\
\text { lado }(\mathrm{cm})\end{array}$} & massa 5 tollas & \multicolumn{2}{|c|}{12.2490} & & & & & 10 & 0.1700 & 0.1700 \\
\hline lado $(\mathrm{cm})$ & & Teor seco & & & & & & & & média & 0.1697 \\
\hline diâmetro (cm) & & Gram. Seca & & & & & & & & D.P & 0.003 \\
\hline & & Gam. Cond. & & & & & & & & & \\
\hline massa 5 folhas & 12.2490 & & & & & & & & & & \\
\hline 1 folha & 2.4498 & $\mathrm{~g}$ & & & & & & & & & \\
\hline lado & 0.1640 & $\mathrm{~m}$ & & & & & & & & & \\
\hline $\mathrm{m} 2$ & 0.0269 & & & & & & & & & & \\
\hline $\mathrm{g} / \mathrm{m} 2$ & 91.0842 & & & & & & & & & & \\
\hline
\end{tabular}




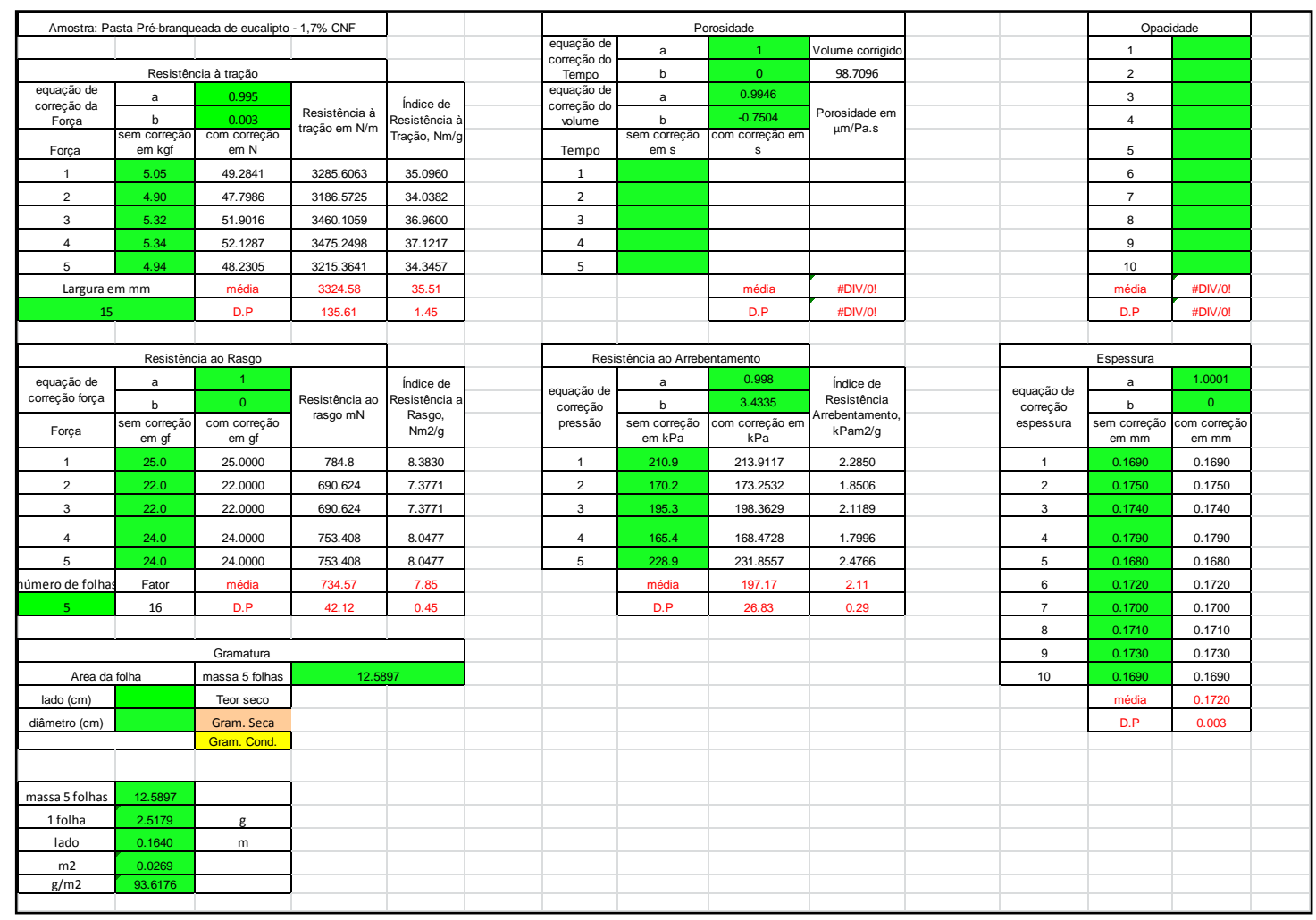

\begin{tabular}{|c|c|c|c|c|c|c|c|c|c|c|c|}
\hline \multirow{2}{*}{\multicolumn{5}{|c|}{ mostra: Pasta Prébrannueada de eucalipto - $0,3 \%$ CNF, $0,15 \%$ amic }} & \multicolumn{4}{|c|}{ Porosidade } & & \multicolumn{2}{|c|}{ Opacidade } \\
\hline & & & & & 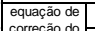 & a & 1 & \begin{tabular}{|l|l|l|l} 
Volume corrigido \\
\end{tabular} & & & \\
\hline \multicolumn{3}{|c|}{ Resistência àtracăo } & \multirow{4}{*}{$\begin{array}{l}\text { Resistência à } \\
\text { traçăo em N/m }\end{array}$} & & $\begin{array}{c}\text { correçáa do } \\
\text { Tempo }\end{array} \mid$ & $\mathrm{b}$ & 0 & 98.7096 & & 2 & \\
\hline $\begin{array}{l}\text { equacăa de } \\
\text { corceăo da }\end{array}$ & $\mathrm{a}$ & 0.995 & & \multirow{3}{*}{ 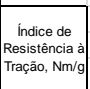 } & 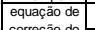 & $\mathrm{a}$ & 0.9946 & \multirow{3}{*}{ 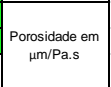 } & & 3 & \\
\hline 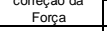 & $\mathrm{b}$ & 0.003 & & & $\begin{array}{c}c \\
\text { ondume } \\
\text { volume }\end{array}$ & $\mathrm{b}$ & -0.7504 & & & 4 & \\
\hline Forga & 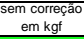 & $\begin{array}{l}\text { mo corecgà } \\
\text { emen N }\end{array}$ & & & Tетро & 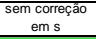 & $\begin{array}{ccc}\text { com coregega } \\
\mathrm{s}\end{array}$ & & & 5 & \\
\hline 1 & 4.48 & 43.7625 & 2917.5016 & 27.4038 & 1 & & & & & 6 & \\
\hline 2 & 4.41 & 43.0700 & 2871.3348 & 26.9702 & 2 & & & & & 7 & \\
\hline 3 & 4.69 & 45.7657 & 3051.0450 & 28.6582 & 3 & & & & & 8 & \\
\hline 4 & 4.42 & 43.1445 & 2876.2982 & 27.0168 & 4 & & & & & 9 & \\
\hline 5 & 4.57 & 44.6375 & 2975.8329 & 27.9517 & 5 & & & & & 10 & \\
\hline \multirow{2}{*}{\multicolumn{2}{|c|}{$\begin{array}{l}\text { Largura em } \mathrm{mm} \\
15\end{array}$}} & média & 2938.40 & 27.60 & & & média & \#DIV/0! & & média & \#DIV/0! \\
\hline & & D.P & 75.63 & 0.71 & & & D.P & \#DIV/0! & & D.P & \#DIV/0! \\
\hline \multirow{2}{*}{\multicolumn{4}{|c|}{ Resistência ao Rasgo }} & & \multirow{2}{*}{\multicolumn{3}{|c|}{ Resistência ao Arrebentamento }} & & \multirow{2}{*}{\multicolumn{3}{|c|}{ Espessura }} \\
\hline & & & & & & & & \multirow{4}{*}{ 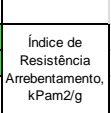 } & & & \\
\hline 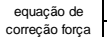 & $\mathrm{a}$ & $\frac{1}{0}$ & \multirow{3}{*}{$\begin{array}{l}\text { Resisteñnia ao } \\
\text { rasgo mN }\end{array}$} & $\begin{array}{c}\text { Indice de } \\
\text { Resistencia }\end{array}$ & \multirow{3}{*}{\begin{tabular}{|c|} 
equacăa de de \\
coraçâa \\
pressão
\end{tabular}} & a & 0.998 & & \multirow{3}{*}{$\begin{array}{c}\text { equacă de } \\
\text { concenaj } \\
\text { espessurar }\end{array}$} & $\mathrm{a}$ & 1.0001 \\
\hline Forca & $\frac{b}{m \text { correct. }}$ & com correção & & Rasgo, & & $\frac{\text { b }}{\text { sem correcão }}$ & & & & sem correcão & \\
\hline Forçą & em gf & em gf & & $\mathrm{Nm} 2 / \mathrm{g}$ & & em kPa & $\mathrm{kPa}$ & & & $\begin{array}{c}\text { Sem mm } \\
\text { em }\end{array}$ & $\begin{array}{c}\text { em mm } \\
\end{array}$ \\
\hline 1 & 24.0 & 24.0000 & 753.408 & 7.0767 & 1 & 151.0 & 154.1211 & 1.4476 & 1 & 0.1750 & 0.1750 \\
\hline 2 & 22.0 & 22.0000 & 690.624 & 6.4870 & 2 & 121.0 & 124.2214 & 1.1668 & 2 & 0.1730 & 0.1730 \\
\hline 3 & 22.0 & 22.0000 & 690.624 & 6.4870 & 3 & 145.0 & 148.1335 & 1.3914 & 3 & 0.1680 & 0.1680 \\
\hline 4 & 21.0 & 21.0000 & 659.232 & 6.1921 & 4 & 172.6 & 175.6484 & 1.6498 & 4 & 0.1720 & 0.1720 \\
\hline 5 & 21.0 & 21.0000 & 659.232 & 6.1921 & 5 & $\begin{array}{ll}179.8 \\
\end{array}$ & 182.9138 & 1.7181 & 5 & 0.1650 & 0.1650 \\
\hline úmero de follhas & Fator & média & 690.62 & 6.49 & & média & 157.01 & 1.47 & 6 & 0.1730 & 0.1730 \\
\hline 5 & 16 & D.P & 38.45 & 0.36 & & D.P & 23.35 & 0.22 & 7 & 0.1880 & 0.1880 \\
\hline \multirow{2}{*}{\multicolumn{5}{|c|}{ Gramatura }} & & & & & 8 & 0.1600 & 0.1600 \\
\hline & & & & & & & & & 9 & 0.1690 & 0.1690 \\
\hline Area dat & & massa 5 follhas & \multirow{2}{*}{\multicolumn{2}{|c|}{14.3172}} & & & & & 10 & 0.1720 & 0.1720 \\
\hline lado (cm) & & Teor seco & & & & & & & & média & 0.1715 \\
\hline diâmetro $(\mathrm{cm})$ & & Gram. Seca & & & & & & & & D.P & 0.007 \\
\hline & 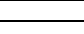 & Gram. Cond. & & & & & & & & & \\
\hline & & & & & & & & & & & \\
\hline massa 5 folhas & 14.3172 & & & & & & & & & & \\
\hline 1 folha & 2.8634 & $\mathrm{~g}$ & & & & & & & & & \\
\hline lado & 0.1640 & $\mathrm{~m}$ & & & & & & & & & \\
\hline $\mathrm{m} 2$ & 0.0269 & & & & & & & & & & \\
\hline $\mathrm{g} / \mathrm{m} 2$ & 106.4634 & & & & & & & & & & \\
\hline
\end{tabular}




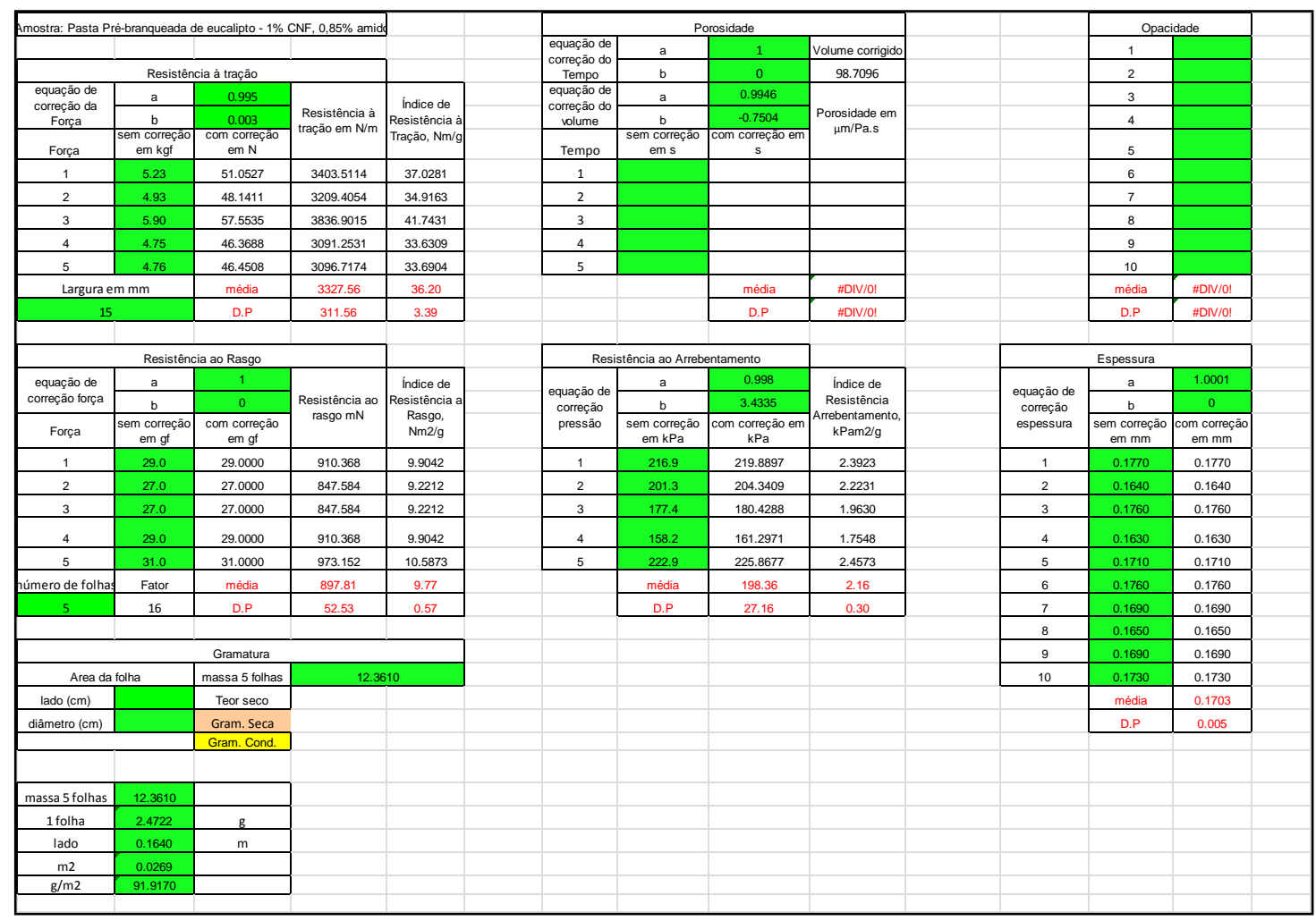

\begin{tabular}{|c|c|c|c|c|c|c|c|c|c|c|c|}
\hline \multirow{2}{*}{\multicolumn{4}{|c|}{ Amostra: Dupla Camada - CNF }} & & \multicolumn{4}{|c|}{ Porosidade } & & \multicolumn{2}{|c|}{ Opacidade } \\
\hline & & & & & $\begin{array}{l}\text { equacăo de } \\
\text { corceác do }\end{array}$ & $\mathrm{a}$ & 1 & \begin{tabular}{|l|l|l|l} 
Volume corrigido \\
\end{tabular} & & 1 & \\
\hline \multicolumn{4}{|c|}{ Resistênncia à tração } & \multirow{4}{*}{$\begin{array}{l}\text { Indice de } \\
\text { Resistancia a } \\
\text { Traça, Nam/g }\end{array}$} & $\begin{array}{l}\text { Tumbaciou } \\
\text { Tempo }\end{array}$ & $\mathrm{b}$ & 0 & 98.7096 & & 2 & \\
\hline $\begin{array}{l}\text { equacăo de } \\
\text { correcáo da }\end{array}$ & $\mathrm{a}$ & 0.995 & \multirow{3}{*}{$\begin{array}{l}\text { Resistência à } \\
\text { traçâo em N/m }\end{array}$} & & equacăẩ de & $\mathrm{a}$ & 0.9946 & \multirow{3}{*}{$\begin{array}{c}\text { Porosidade em } \\
\mu m \text { Pa.s. }\end{array}$} & & 3 & \\
\hline $\begin{array}{c}\text { conreçac oa } \\
\text { Força }\end{array}$ & $\mathrm{b}$ & 0.003 & & & $\begin{array}{l}\text { corlegaco oo } \\
\text { volume }\end{array}$ & $\mathrm{b}$ & -0.7504 & & & 4 & \\
\hline Forca & $\begin{array}{l}\text { Sem correcáa } \\
\text { en mgta }\end{array}$ & $\begin{array}{l}m \text { corocesăa } \\
\text { em N }\end{array}$ & & & Tempo & $\begin{array}{l}\text { sem comerect } \\
\text { em s }\end{array}$ & $\begin{array}{l}\text { começắo } \\
\text { cal }\end{array}$ & & & 5 & \\
\hline 1 & 7.04 & 68.6973 & 4579.8177 & 51.7079 & 1 & & & & & 6 & \\
\hline 2 & 7.67 & 74.8369 & 4989.1257 & 56.3292 & 2 & & & & & 7 & \\
\hline 3 & 6.78 & 66.1245 & 4408.2974 & 49.7714 & 3 & & & & & 8 & \\
\hline 4 & 7.18 & 70.1009 & 4673.3937 & 52.7644 & 4 & & & & & 9 & \\
\hline 5 & 7.13 & 69.5275 & 46355.1696 & 52.3329 & 5 & & & & & 10 & \\
\hline \multirow{2}{*}{\multicolumn{2}{|c|}{ Largura em mm }} & média & 4657.16 & 52.58 & & & 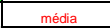 & \#DIV/0! & & $\begin{array}{l}\text { média } \\
\text { nof }\end{array}$ & $\#$ DIV $/ 0 !$ \\
\hline & & D.P & 211.46 & 2.39 & & & D.P & \#DIV/O! & & D.P & \#DNV!! \\
\hline \multicolumn{4}{|c|}{ Resistência ao Rasgo } & & \multicolumn{3}{|c|}{ Resistência ao Arrebentamento } & & \multicolumn{3}{|c|}{ Espessura } \\
\hline equaçăo de & $\mathrm{a}$ & 1 & \multirow{3}{*}{ 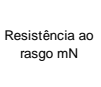 } & \multirow{3}{*}{ 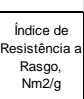 } & \multirow{3}{*}{ 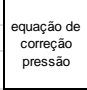 } & $\mathrm{a}$ & 0.998 & \multirow{3}{*}{ 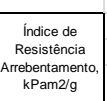 } & \multirow{3}{*}{$\begin{array}{l}\text { equacăa de } \\
\text { conceaca } \\
\text { espessura }\end{array}$} & $\mathrm{a}$ & 1.0001 \\
\hline correçắo orç̣a & 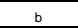 & 0 & & & & $\mathrm{~b}$ & 3.4335 & & & $\mathrm{~b}$ & 0 \\
\hline Força & $\begin{array}{l}\text { m corregăa } \\
\text { em of }\end{array}$ & $\begin{array}{l}\text { com correçáa } \\
\text { em of }\end{array}$ & & & & 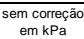 & $\begin{array}{c}\text { correcăo em } \\
\text { ka }\end{array}$ & & & $\begin{array}{l}\text { sem correcấa } \\
\text { em mm }\end{array}$ & $\begin{array}{l}\text { om correcáă } \\
\text { em mm }\end{array}$ \\
\hline 1 & 35.0 & 35.0000 & 1098.72 & 12.4050 & 1 & 263.6 & 266.5362 & 3.0093 & 1 & 0.1500 & 0.1500 \\
\hline 2 & 32.0 & 32.0000 & 1004.544 & 11.3417 & 2 & 269.6 & 272.5143 & 3.0768 & 2 & 0.1630 & 0.1630 \\
\hline 3 & 31.0 & 31.0000 & 973.152 & 10.9873 & 3 & 273.2 & 276.0971 & 3.1772 & 3 & 0.1470 & 0.1470 \\
\hline 4 & 30.0 & 30.0000 & 941.76 & 10.6328 & 4 & 311.6 & 314.3704 & 3.5494 & 4 & 0.1520 & 0.1520 \\
\hline 5 & 31.0 & 31.0000 & 973.152 & 10.9873 & 5 & 286.4 & 289.2507 & 3.2658 & 5 & 0.1640 & 0.1640 \\
\hline Imero de folhas & Fator & média & \begin{tabular}{l|l}
998.27 \\
\end{tabular} & $\begin{array}{lll}11.27 \\
\end{array}$ & & média & 283.75 & 3.20 & 6 & 0.1560 & 0.1560 \\
\hline 5 & 16 & D.P & 60.38 & 0.68 & & D.P & 19.03 & 0.21 & 7 & 0.1560 & 0.1560 \\
\hline \multirow{2}{*}{\multicolumn{5}{|c|}{ Gramatura }} & & & & & 8 & 0.1490 & 0.1490 \\
\hline & & & & & & & & & 9 & 0.1570 & 0.1570 \\
\hline \multirow{2}{*}{\multicolumn{2}{|c|}{$\begin{array}{l}\text { Area da folha } \\
\text { lado }(\mathrm{cm})\end{array}$}} & massa 5 tollas & \multirow{2}{*}{\multicolumn{2}{|c|}{12.2033}} & & & & & 10 & 0.1590 & 0.1590 \\
\hline & & Teor seco & & & & & & & & média & 0.1553 \\
\hline diâmetro (cm) & & Gram. Seca & & & & & & & & D.P & 0.006 \\
\hline & & Gram. Cond. & & & & & & & & & \\
\hline & & & & & & & & & & & \\
\hline massa 5folhas & 12.2033 & & & & & & & & & & \\
\hline 1 follha & 2.4407 & $\mathrm{~g}$ & & & & & & & & & \\
\hline lado & 0.1660 & $\mathrm{~m}$ & & & & & & & & & \\
\hline $\mathrm{m} 2$ & 0.0276 & & & & & & & & & & \\
\hline $\mathrm{g} / \mathrm{m} 2$ & 88.5709 & & & & & & & & & & \\
\hline
\end{tabular}



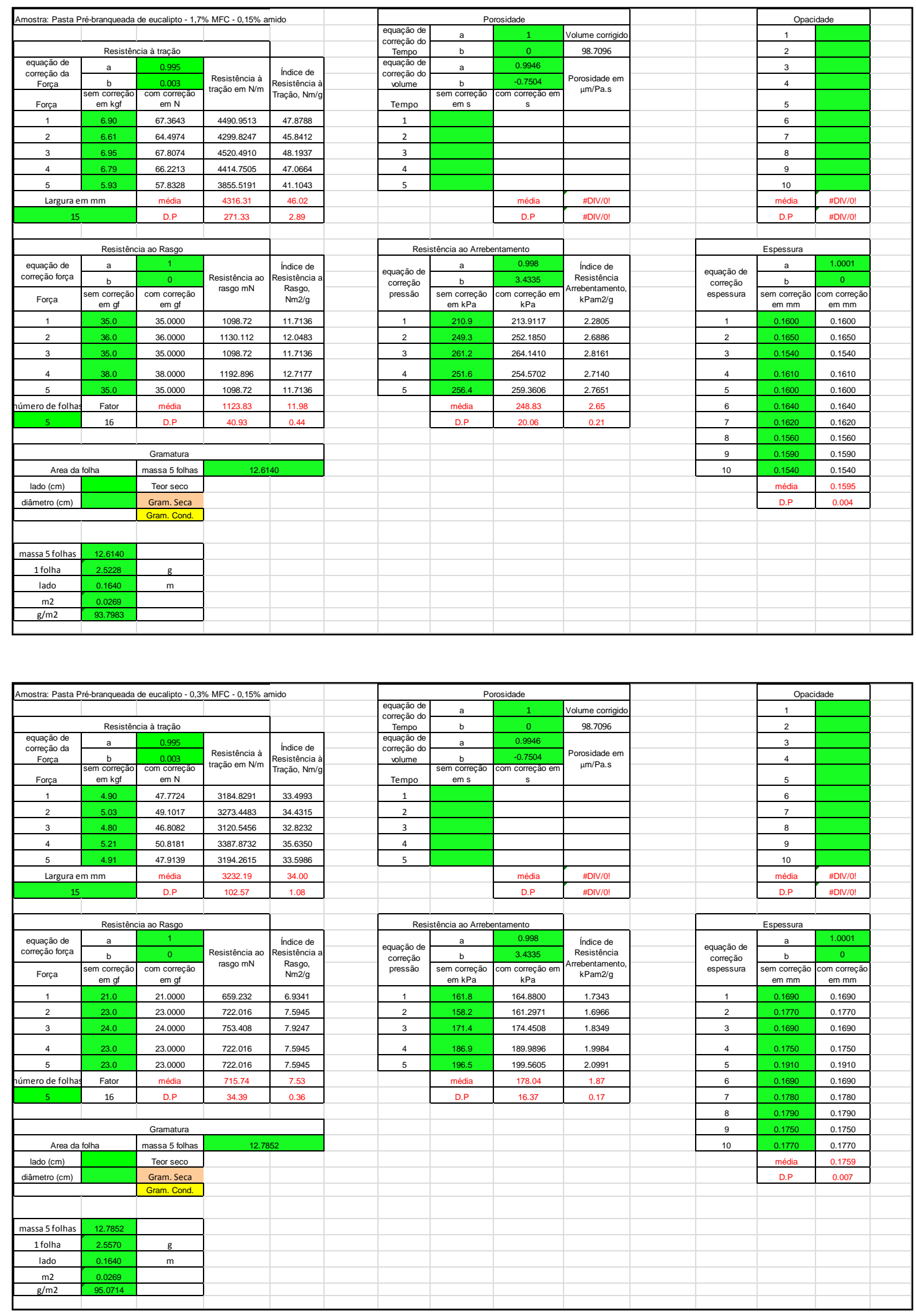

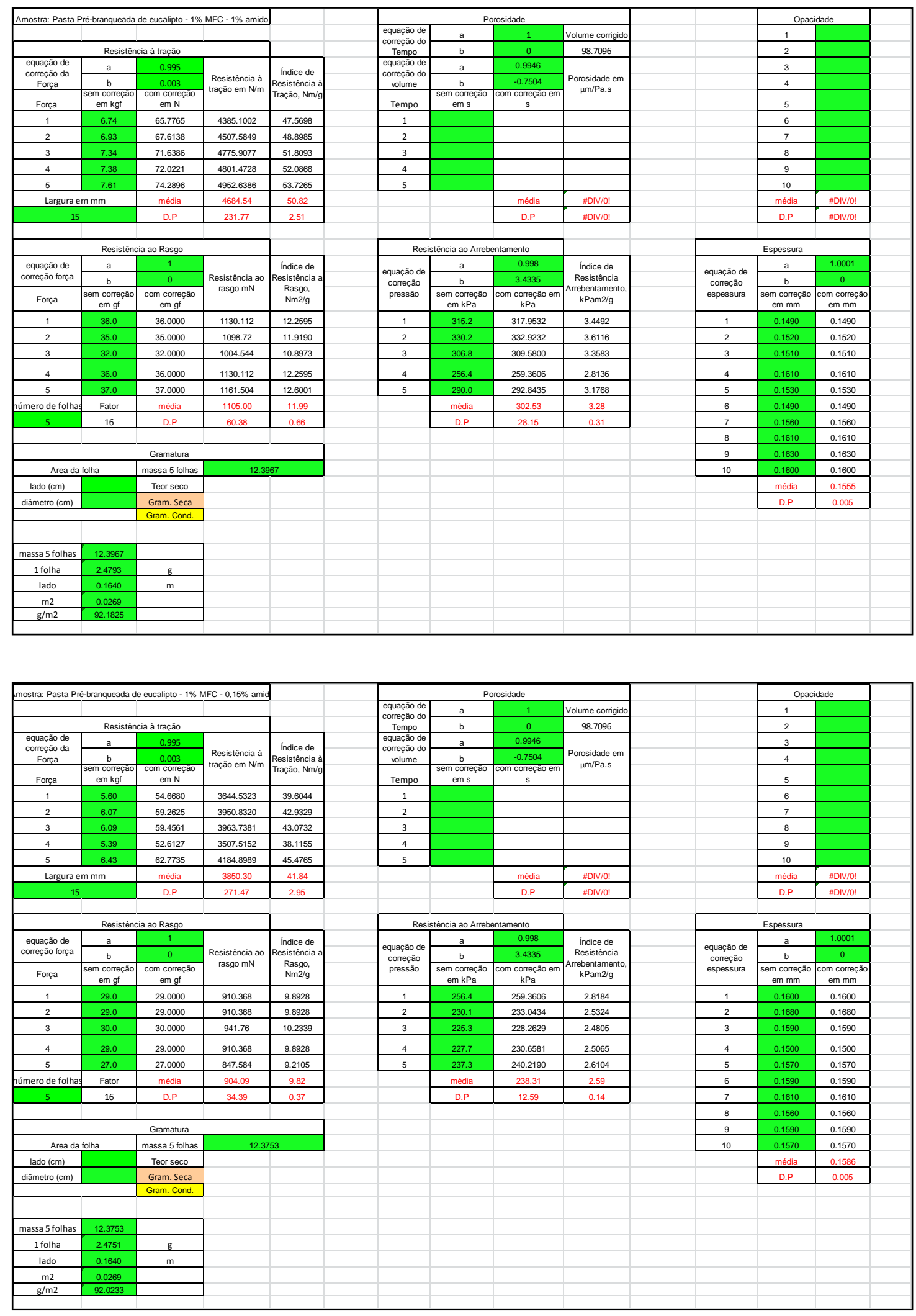

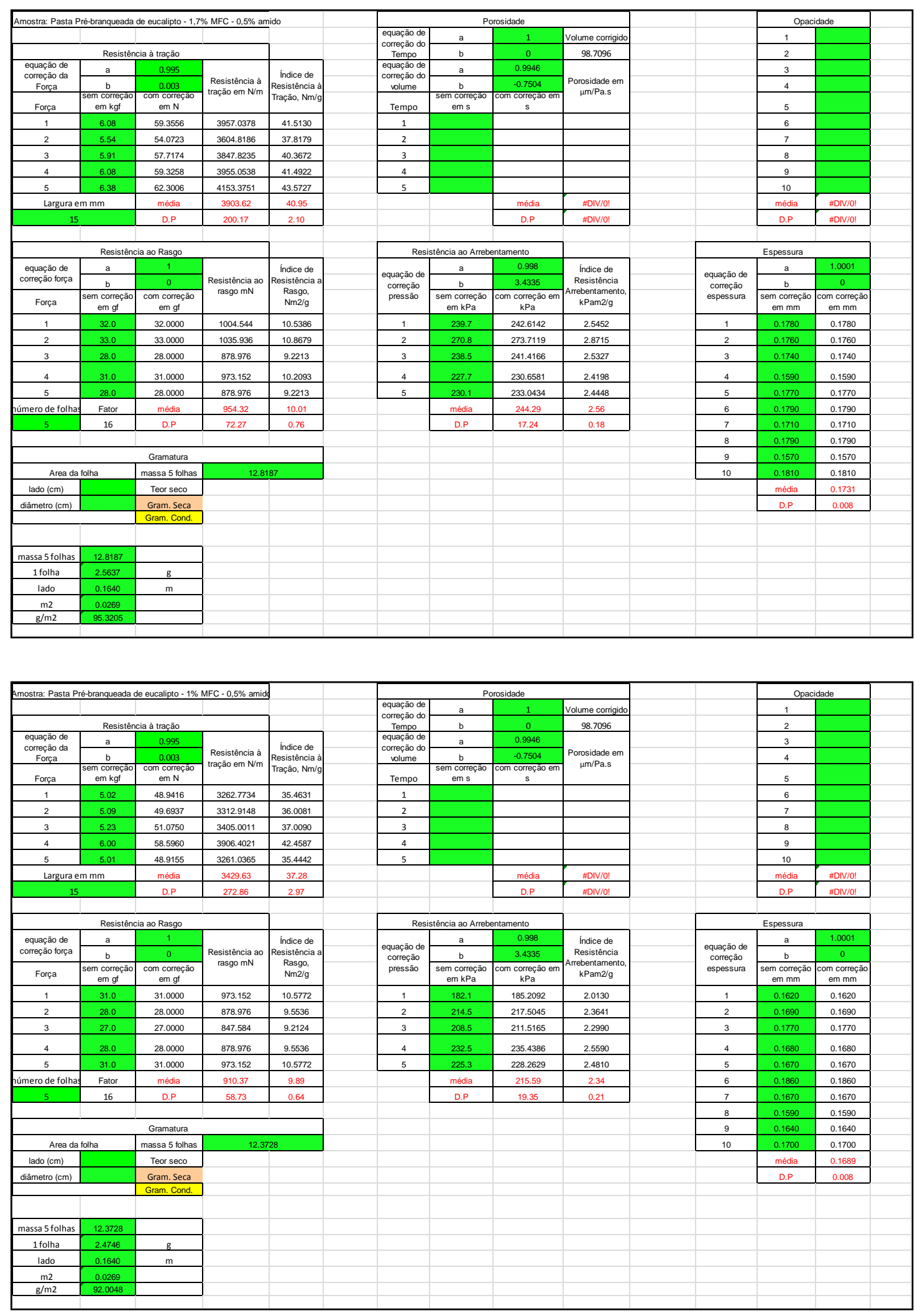

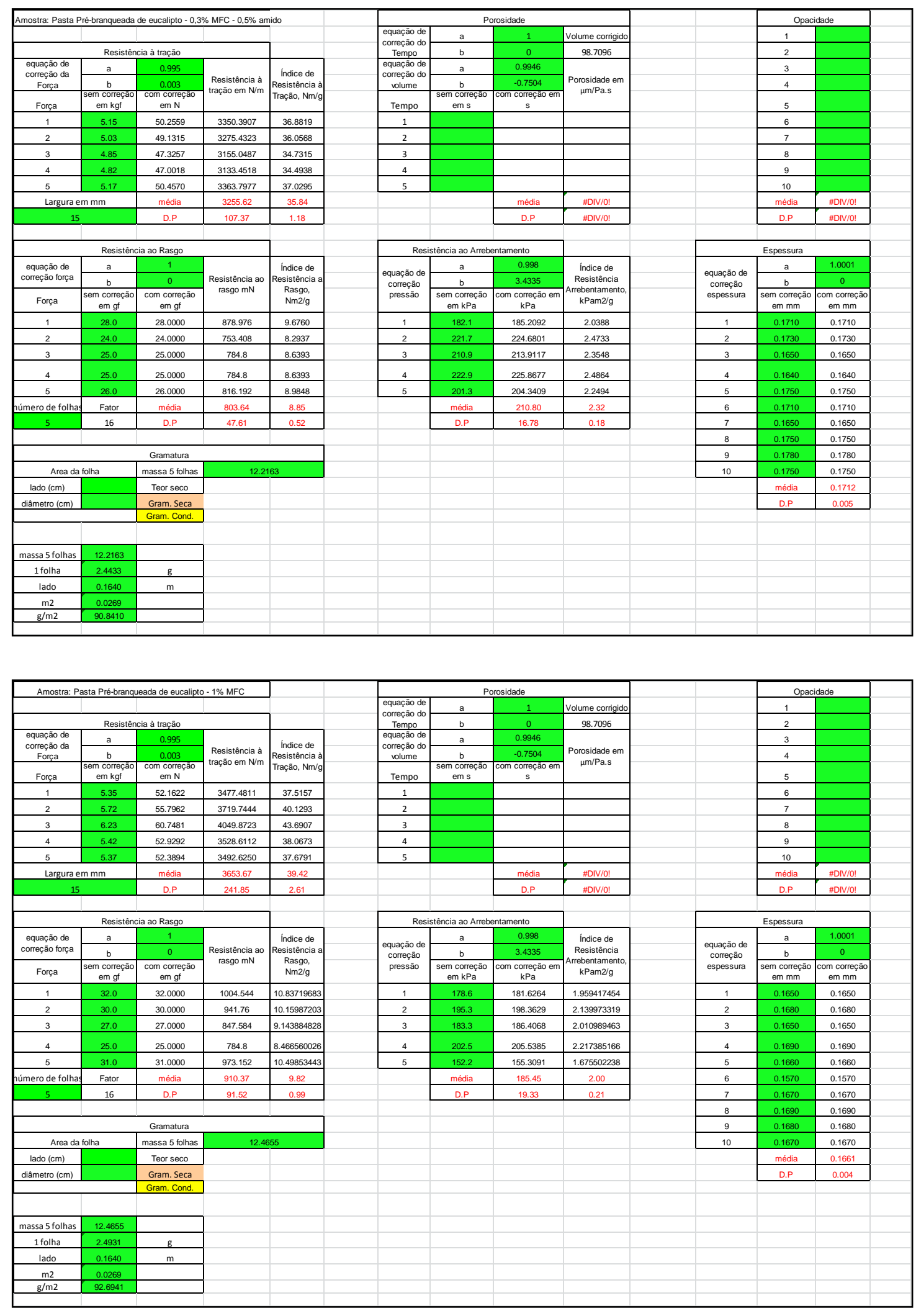

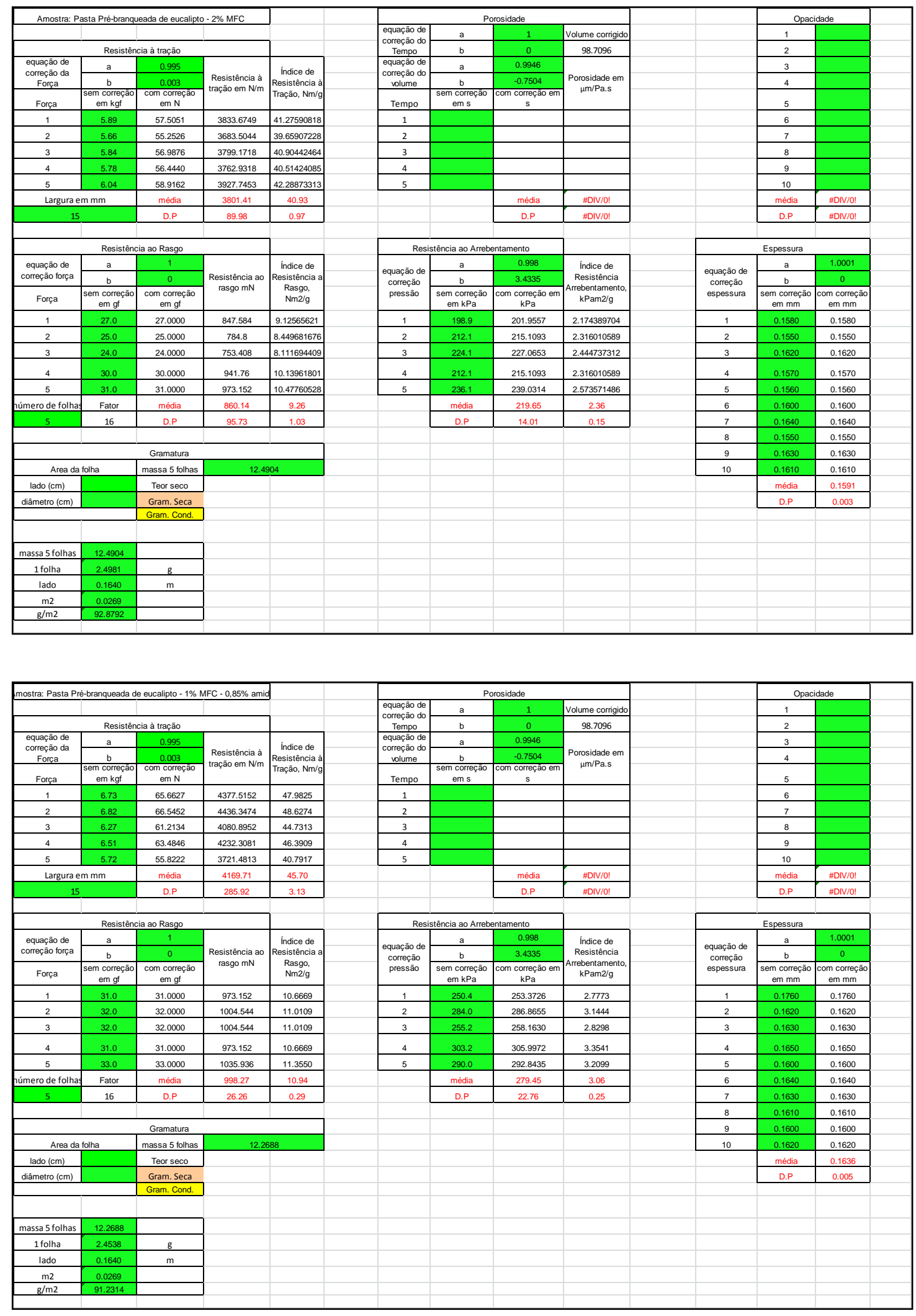

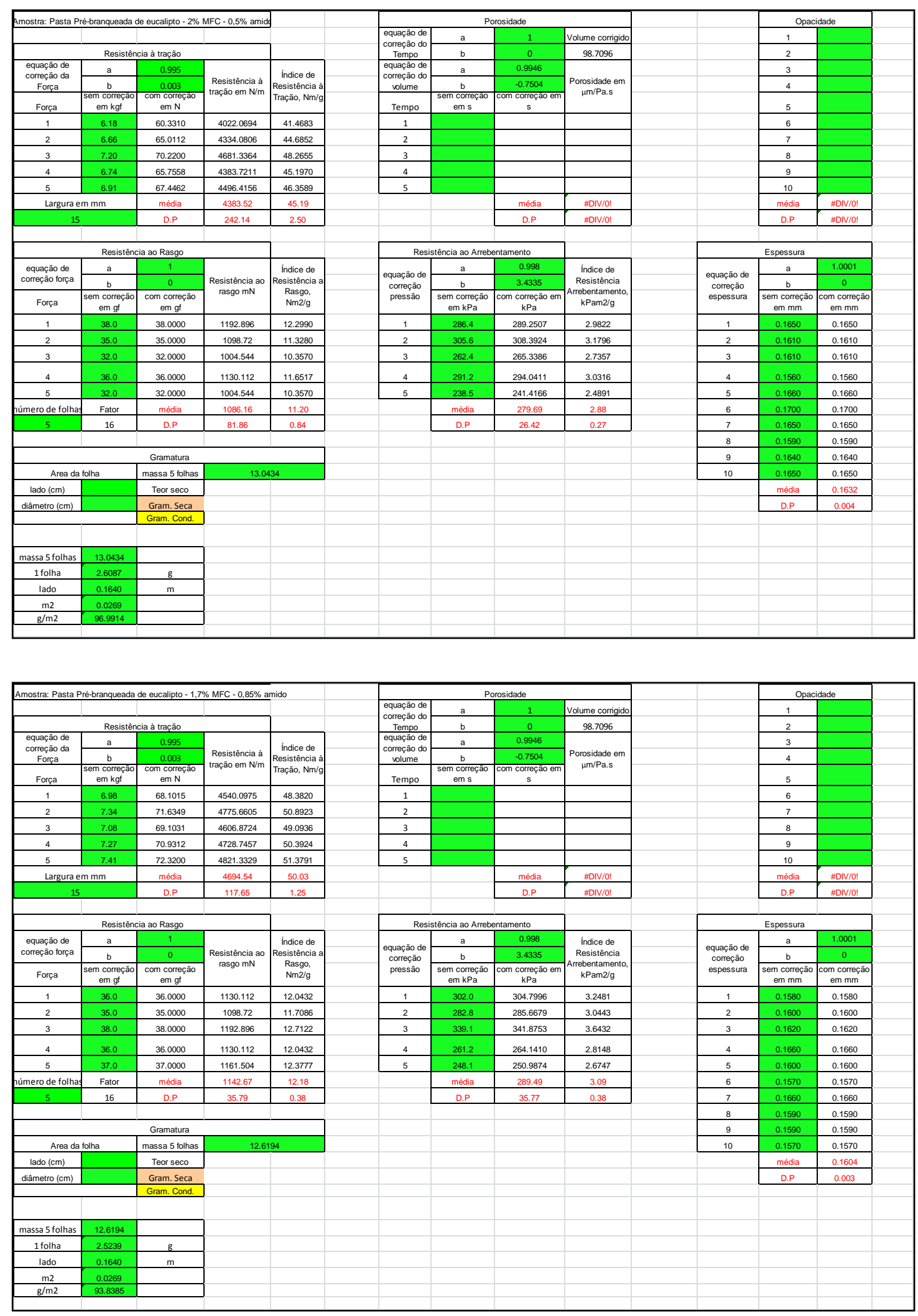


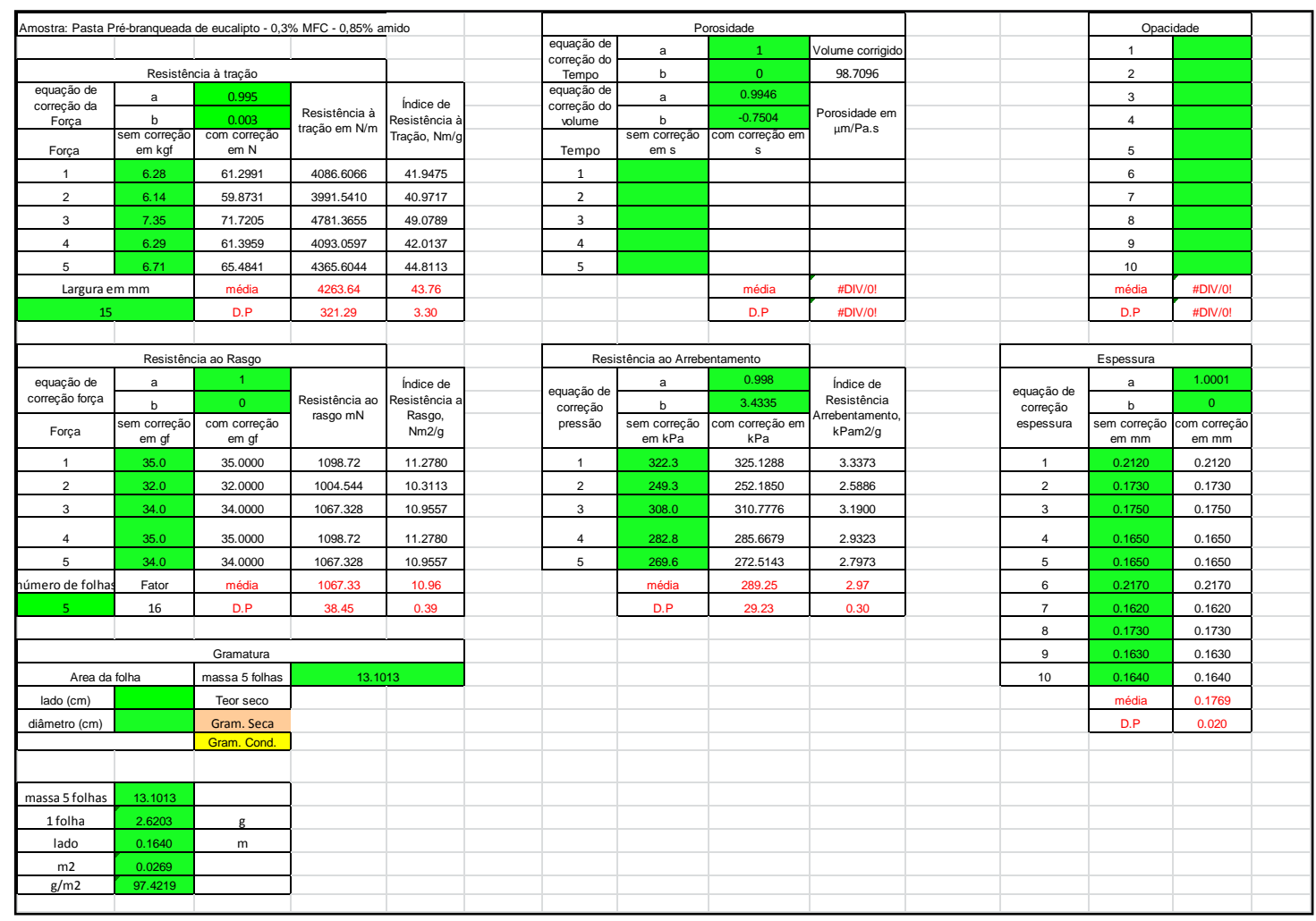

\begin{tabular}{|c|c|c|c|c|c|c|c|c|c|c|c|}
\hline \multirow{2}{*}{\multicolumn{4}{|c|}{ Amostra: Dupla Camada - MFC }} & & \multicolumn{4}{|c|}{ Porosidade } & & \multicolumn{2}{|c|}{ Opacidade } \\
\hline & & & & & $\begin{array}{l}\text { equacăo de } \\
\text { corceác do }\end{array}$ & $\mathrm{a}$ & 1 & \begin{tabular}{|l|l|l|l} 
Volume corrigido \\
\end{tabular} & & 1 & \\
\hline \multicolumn{4}{|c|}{ Resistênncia à tração } & \multirow{4}{*}{$\begin{array}{l}\text { Indice de } \\
\text { Resistencia a } \\
\text { Traça, Nam/g }\end{array}$} & $\begin{array}{l}\text { Tumbaciou } \\
\text { Tempo }\end{array}$ & $\mathrm{b}$ & 0 & 98.7096 & & 2 & \\
\hline $\begin{array}{l}\text { equacăo de } \\
\text { correcáo da }\end{array}$ & $\mathrm{a}$ & 0.995 & \multirow{3}{*}{$\begin{array}{l}\text { Resistênciai à } \\
\text { traçao em N/m }\end{array}$} & & 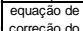 & $\mathrm{a}$ & 0.9946 & \multirow{3}{*}{$\begin{array}{c}\text { Porosidade em } \\
\mu m \text { Pa.s. }\end{array}$} & & 3 & \\
\hline $\begin{array}{c}\text { conreçac oa } \\
\text { Força }\end{array}$ & $\mathrm{b}$ & 0.003 & & & $\begin{array}{l}\text { corlegaco oo } \\
\text { volume }\end{array}$ & $\mathrm{b}$ & -0.7504 & & & 4 & \\
\hline Forca & $\begin{array}{l}\text { Sem correcáa } \\
\text { en mgta }\end{array}$ & $\begin{array}{l}m \text { corocesăa } \\
\text { em N }\end{array}$ & & & Tempo & $\begin{array}{l}\text { sem comerect } \\
\text { em s }\end{array}$ & $\begin{array}{c}\text { corregéti } \\
s\end{array}$ & & & 5 & \\
\hline 1 & 6.63 & 64.7319 & 4315.4630 & 47.6942 & 1 & & & & & 6 & \\
\hline 2 & 6.66 & 64.9852 & 4332.3437 & 47.8808 & 2 & & & & & 7 & \\
\hline 3 & 6.59 & 64.3261 & 4288.4082 & 47.3952 & 3 & & & & & 8 & \\
\hline 4 & 6.41 & 62.5464 & 4169.7615 & 46.0839 & 4 & & & & & 9 & \\
\hline 5 & 6.67 & 65.0931 & 4339.5384 & 47.9603 & 5 & & & & & 10 & \\
\hline \multirow{2}{*}{\multicolumn{2}{|c|}{$\begin{array}{l}\text { Largura em } \mathrm{mm} \\
15\end{array}$}} & média & 4289.10 & 47.40 & & & 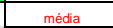 & \#DIV/0! & & $\begin{array}{l}\text { média } \\
\text { nof }\end{array}$ & $\#$ DIV $/ 0 !$ \\
\hline & & D.P & 69.55 & 0.77 & & & D.P & \#DIV/O! & & D.P & \#DNV!! \\
\hline \multicolumn{4}{|c|}{ Resistência ao Rasgo } & & \multicolumn{3}{|c|}{ Resistência ao Arrebentamento } & & \multicolumn{3}{|c|}{ Espessura } \\
\hline equacăa de & $a$ & 1 & \multirow{3}{*}{ 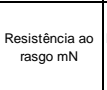 } & \multirow{3}{*}{ 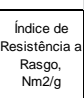 } & \multirow{3}{*}{ 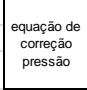 } & $\mathrm{a}$ & 0.998 & \multirow{3}{*}{ 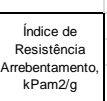 } & \multirow{3}{*}{$\begin{array}{l}\text { equacăa de } \\
\text { conceaca } \\
\text { espessura }\end{array}$} & $\mathrm{a}$ & 1.0001 \\
\hline correçắo orç̣a & 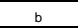 & 0 & & & & $\mathrm{~b}$ & 3.4335 & & & $b$ & 0 \\
\hline Força & $\begin{array}{l}m \text { correquă } \\
\text { em of }\end{array}$ & $\begin{array}{l}\text { com correăa } \\
\text { em of }\end{array}$ & & & & 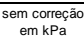 & $\begin{array}{c}\text { correcăo em } \\
\text { ka }\end{array}$ & & & $\begin{array}{l}\text { sem correcấa } \\
\text { em mm }\end{array}$ & $\begin{array}{l}\text { om correcáă } \\
\text { em mm }\end{array}$ \\
\hline 1 & 30.0 & 30.0000 & 941.76 & 10.4083 & 1 & 285.2 & 288.0631 & 3.1837 & 1 & 0.1650 & 0.1650 \\
\hline 2 & 31.0 & 31.0000 & 973.152 & 10.7552 & 2 & 254.0 & 256.9654 & 2.8400 & 2 & 0.1650 & 0.1650 \\
\hline 3 & 28.0 & 28.0000 & 878.976 & 9.7144 & 3 & 239.7 & 242.6142 & 2.6814 & 3 & 0.1580 & 0.1580 \\
\hline 4 & 28.0 & 28.0000 & 878.976 & 9.7144 & 4 & 262.4 & 265.3386 & 2.9325 & 4 & 0.1610 & 0.1610 \\
\hline 5 & 32.0 & 32.0000 & 1004.544 & 11.1022 & 5 & 225.3 & 228.2629 & 2.5227 & 5 & 0.1630 & 0.1630 \\
\hline Imero de folhas & Fator & média & $\begin{array}{l}935.48 \\
\end{array}$ & 10.34 & & média & 256.25 & $\begin{array}{ll}2.83 \\
\end{array}$ & 6 & 0.1600 & 0.1600 \\
\hline 5 & 16 & $D . P$ & 56.16 & 0.62 & & D.P & 22.72 & 0.25 & 7 & 0.1620 & 0.1620 \\
\hline \multirow{2}{*}{\multicolumn{5}{|c|}{ Gramatura }} & & & & & 8 & 0.1650 & 0.1650 \\
\hline & & & & & & & & & 9 & 0.1600 & 0.1600 \\
\hline \multicolumn{2}{|c|}{$\begin{array}{l}\text { Area da folha } \\
\text { lado }(\mathrm{cm})\end{array}$} & massa 5 tollas & \multicolumn{2}{|c|}{12.4666} & & & & & 10 & 0.1660 & 0.1660 \\
\hline lado $(\mathrm{cm})$ & & Teor seco & & & & & & & & média & 0.1625 \\
\hline diâmetro (cm) & & Gram. Seca & & & & & & & & D.P & 0.003 \\
\hline & & Gram. Cond. & & & & & & & & & \\
\hline massa 5 folhas & 12.4666 & & & & & & & & & & \\
\hline 1 folha & 2.4933 & $\mathrm{~g}$ & & & & & & & & & \\
\hline lado & 0.1660 & $\mathrm{~m}$ & & & & & & & & & \\
\hline $\mathrm{m} 2$ & 0.0276 & & & & & & & & & & \\
\hline $\mathrm{g} / \mathrm{m} 2$ & 90.4819 & & & & & & & & & & \\
\hline
\end{tabular}




\section{APÊNDICE B - MORFOLOGÍA DAS FIBRAS DAS PASTAS CELULÓSICAS UTILIZADAS}

B1. Morfologia das fibras da Pasta Kraft de Eucalipto Branqueada Refinação Valley

\begin{tabular}{|c|c|c|c|c|c|c|c|}
\hline & \multicolumn{3}{|c|}{ Fiber tester } & & & \multirow{2}{*}{\begin{tabular}{||c||} 
Media massa \\
0.10315 \\
\end{tabular}} & \multirow{2}{*}{$\begin{array}{l}\text { massas } \\
01012\end{array}$} \\
\hline & M1 & M2 & Média & $\begin{array}{c}\text { Dados } \\
\text { Convertidos } \\
\end{array}$ & Conversão & & \\
\hline Vessel per gram & 42726 & $47>37$ & 45231.5 & 45231.50 & - & & 01051 \\
\hline Mean Vessel area & 00453 & 00455 & 0.0454 & 2053.51 & $\begin{array}{c}\text { àrea de } 1 \text { vaso } x \\
\text { quantidade de vasos/g }\end{array}$ & & \\
\hline$N^{\circ}$ Fiber in sample & 215489 & 23318 & 2243363.5 & 21.75 & \begin{tabular}{|c|}
$\begin{array}{c}\text { Dividir pela massa e } \\
\text { por } 1000000\end{array}$ \\
\end{tabular} & & \\
\hline Length arithm, mm & 0637 & 0634 & 0.6355 & 0.64 & - & & \\
\hline Length weighted in length, $\mathrm{mm}$ & 0816 & 0817 & 0.8165 & 0.82 & - & & \\
\hline Width, $\mu \mathrm{m}$ & 7000 & 17000 & 17 & 17.00 & - & & \\
\hline Fração parede, \% & 38.476 & 36.380 & 37.42801007 & 37.43 & - & & \\
\hline Diâmetro do lumen, $\mu \mathrm{m}$ & 10.459 & 10.815 & 10.63723829 & 10.64 & - & & \\
\hline Coarseness, $\mathrm{mg} / \mathrm{m}$ & 61600 & 59000 & 60.3 & 6.03 & dividir por 10 & & \\
\hline Mean Kink angle, ${ }^{\circ}$ & 48500 & 49400 & 48.95 & 131.05 & 180 - kink angle & & \\
\hline$N^{0}$ of Kinks per fibers, $\%$ & 0586 & 0588 & 0.587 & 58.70 & multiplicar por 100 & & \\
\hline \begin{tabular}{|cc} 
Curl, $\%$ & $\begin{array}{c}\text { Dado de entrada } \\
\text { Shape }\end{array}$ \\
\end{tabular} & 8600 & 8400 & 89.5 & 11.73 & $((100 /$ shape $)-1) \star 100$ & & \\
\hline Fine Elements, \% aritmethic & 22600 & 23300 & 22.95 & 22.95 & - & & \\
\hline Percentage of fine elts, \% in area & 3900 & 4100 & 4 & 4.00 & - & & \\
\hline
\end{tabular}


B2. Morfologia das fibras da Pasta Kraft Marrom de Pinus

\begin{tabular}{|c|c|c|c|c|c|c|c|}
\hline & \multicolumn{3}{|c|}{ Fiber tester } & & & \multirow{2}{*}{\begin{tabular}{||c||} 
Media massa \\
0.1575 \\
\end{tabular}} & \multirow{2}{*}{$\begin{array}{r}\text { massas } \\
0157\end{array}$} \\
\hline & M1 & M2 & Média & $\begin{array}{c}\text { Dados } \\
\text { Convertidos }\end{array}$ & Conversão & & \\
\hline Vessel per gram & 23961 & 25170 & 24565.5 & 24565.50 & - & & 0158 \\
\hline Mean Vessel area & 02038 & 01988 & 0.2013 & 4945.04 & \begin{tabular}{|c||} 
àrea de 1 vaso $x$ \\
quantidade de vasos $/ 9$
\end{tabular} & & \\
\hline$N^{\circ}$ Fiber in sample & 300868 & 308100 & 304484 & 1.93 & \begin{tabular}{|c|} 
Dividir pela massa e \\
por 1000000
\end{tabular} & & \\
\hline Length arithm, mm & 1146 & 1167 & 1.1565 & 1.16 & - & & \\
\hline Length weighted in length, $\mathrm{mm}$ & 2641 & 2680 & 2.6605 & 2.66 & - & & \\
\hline Width, $\mu \mathrm{m}$ & 34600 & 34900 & 34.75 & 34.75 & - & & \\
\hline Fração parede, \% & 36.055 & 36.652 & 36.3531978 & 36.35 & - & & \\
\hline Diâmetro do lumen, $\mu \mathrm{m}$ & 22.125 & 22.109 & 22.11681623 & 22.12 & - & & \\
\hline Coarseness, $\mathrm{mg} / \mathrm{m}$ & 242700 & 250100 & 246.4 & 24.64 & dividir por 10 & & \\
\hline Mean Kink angle, ${ }^{\circ}$ & 51100 & 51300 & 51.2 & 128.80 & 180 - kink angle & & \\
\hline$N^{\circ}$ of Kinks per fibers, $\%$ & 0766 & 0770 & 0.768 & 76.80 & multiplicar por 100 & & \\
\hline \begin{tabular}{|cc} 
Curl, $\%$ & Dado de entrada \\
Shape
\end{tabular} & 85800 & 85700 & 85.75 & 16.62 & $((100 / \text { shape })-1)^{\star} 100$ & & \\
\hline Fine Elements, \% aritmethic & 75100 & 73600 & 74.35 & 74.35 & - & & \\
\hline Percentage of fine elts, $\%$ in area & 4600 & 4400 & 4.5 & 4.50 & - & & \\
\hline
\end{tabular}

\begin{tabular}{|c|c|c|c|c|c|c|c|}
\hline & \multicolumn{3}{|c|}{ Fiber tester } & \multirow[b]{2}{*}{$\begin{array}{c}\text { Dados } \\
\text { Convertidos }\end{array}$} & \multirow[b]{2}{*}{ Conversão } & \multirow{2}{*}{\begin{tabular}{|c||} 
Media massa \\
0.12835 \\
\end{tabular}} & \multirow{2}{*}{$\begin{array}{l}\text { massas } \\
01303\end{array}$} \\
\hline & M1 & M2 & Média & & & & \\
\hline Vessel per gram & 20903 & $18 \div 68$ & 10460.634 & 10460.63 & - & & 01264 \\
\hline Mean Vessel area & 02844 & 0412 & 0.3467 & 3626.70 & $\begin{array}{c}\text { àrea de } 1 \text { vaso } x \\
\text { quantidade de vasos } / 9\end{array}$ & & \\
\hline$N^{\circ}$ Fiber in sample & 312342 & 269430 & 290886 & 2.27 & \begin{tabular}{|c|}
$\begin{array}{c}\text { Dividir pela massa e } \\
\text { por } 1000000\end{array}$ \\
\end{tabular} & & \\
\hline Length arithm, mm & 1233 & 197 & 1.215 & 1.22 & - & & \\
\hline Length weighted in length, $\mathrm{mm}$ & 2657 & 2634 & 2.6455 & 2.65 & - & & \\
\hline Width, $\mu \mathrm{m}$ & 35500 & 34800 & 35.15 & 35.15 & - & & \\
\hline Fração parede, \% & 8.329 & 19.292 & 13.81037736 & 13.81 & - & & \\
\hline Diâmetro do lumen, $\mu \mathrm{m}$ & 32.543 & 28.086 & 30.31483804 & 30.31 & - & & \\
\hline Coarseness, $\mathrm{mg} / \mathrm{m}$ & 69000 & 144800 & 106.9 & 10.69 & dividir por 10 & & \\
\hline Mean Kink angle, & 52900 & 51600 & 52.25 & 127.75 & 180 - kink angle & & \\
\hline$N^{\circ}$ of Kinks per fibers, \% & 093 & 0913 & 0.953 & 95.30 & multiplicar por 100 & & \\
\hline 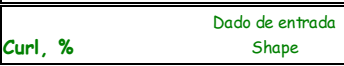 & 85300 & 85800 & 85.55 & 16.89 & $((100 / \text { shape })-1)^{\star} 100$ & & \\
\hline Fine Elements, \% aritmethic & 78100 & 80600 & 79.35 & 79.35 & - & & \\
\hline Percentage of fine elts, $\%$ in area & 4500 & 4800 & 4.65 & 4.65 & - & & \\
\hline
\end{tabular}




\section{B3. Morfologia das fibras da Pasta Kraft de Eucalipto Pré-branqueada}

\begin{tabular}{|c|c|c|c|c|c|c|}
\hline & \multicolumn{3}{|c|}{ Fiber tester } & \multirow[b]{2}{*}{$\begin{array}{c}\begin{array}{c}\text { Dados Convertidos- } \\
\text { Resultados }\end{array} \\
\end{array}$} & \multirow{2}{*}{\begin{tabular}{|c|} 
Media massa \\
0.09825 \\
\end{tabular}} & \multirow{2}{*}{$\begin{array}{r}\text { massas } \\
0.0973 \\
\end{array}$} \\
\hline & A1 & A2 & Média & & & \\
\hline Vessel per gram & 5575 & 57651 & 56703 & 56703.00 & & 00992 \\
\hline Mean Vessel area & 005 & 00745 & 0.06625 & 3756.57 & & \\
\hline$N^{\circ}$ Fiber in sample & 1912021 & 1971935 & 1941978 & 19.77 & & \\
\hline Length arithm, mm & 0700 & 0697 & 0.6985 & 0.70 & & \\
\hline Length weighted in length, $\mathrm{mm}$ & 0868 & 0875 & 0.8715 & 0.87 & & \\
\hline Width, $\mu \mathrm{m}$ & 18100 & 18000 & 18.05 & 18.05 & & \\
\hline Fração parede, \% & 33.252 & 33.310 & 33.2808871 & 33.28 & & \\
\hline Diâmetro do lumen, $\mu \mathrm{m}$ & 12.081 & 12.004 & $\mid 12.0428145$ & 12.04 & & \\
\hline Coarseness, $\mathrm{mg} / \mathrm{m}$ & 62300 & 61700 & 62 & 6.20 & & \\
\hline Mean Kink angle, ${ }^{\circ}$ & 51900 & 52100 & 52 & 128.00 & & \\
\hline$N^{\circ}$ of Kinks per fibers, $\%$ & 0540 & 0538 & 0.539 & 53.90 & & \\
\hline $\begin{array}{l}\text { Dado de } \\
\text { entrada } \\
\end{array}$ & 90400 & 90400 & 90.4 & 10.62 & & \\
\hline Fine Elements, \% aritmethic & 19000 & 19400 & 19.2 & 19.20 & & \\
\hline Percentage of fine elts, $\%$ in area & 200 & 3000 & 2.95 & 2.95 & & \\
\hline
\end{tabular}

\section{B1. Morfologia das fibras da Pasta Pré-branqueada de Eucalipto - Refinação Valley}

\begin{tabular}{|c|c|c|c|c|c|c|c|}
\hline & \multicolumn{3}{|c|}{ Fiber tester } & & & \multirow{2}{*}{\begin{tabular}{||c||} 
Media massa \\
0.10355 \\
\end{tabular}} & \multirow{2}{*}{$\begin{array}{r}\text { massas } \\
0105 \\
\end{array}$} \\
\hline & M1 & M2 & Média & $\begin{array}{c}\text { Dados } \\
\text { Convertidos }\end{array}$ & Conversão & & \\
\hline Vessel per gram & 73516 & 66913 & 70214.5 & 70214.50 & - & & 01014 \\
\hline Mean Vessel area & 00539 & 00548 & 0.05435 & 3816.16 & \begin{tabular}{|c||} 
àrea de 1 vaso $x$ \\
quantidade de vasos $/ g$
\end{tabular} & & \\
\hline$N^{\circ}$ Fiber in sample & 2191608 & 2132994 & 2162301 & 20.88 & \begin{tabular}{|c||} 
Dividir pela massa e \\
por 1000000
\end{tabular} & & \\
\hline Length arithm, mm & 0662 & 0664 & 0.663 & 0.66 & - & & \\
\hline Length weighted in length, $\mathrm{mm}$ & 0884 & 0851 & 0.8675 & 0.87 & - & & \\
\hline Width, $\mu \mathrm{m}$ & 17500 & 17500 & 17.5 & 17.50 & - & & \\
\hline Fração parede, \% & 34.958 & 34.448 & 34.70284594 & 34.70 & - & & \\
\hline Diâmetro do lumen, $\mu \mathrm{m}$ & 11.382 & 11.472 & 11.42700196 & 11.43 & - & & \\
\hline Coarseness, $\mathrm{mg} / \mathrm{m}$ & 60600 & 59000 & 60.25 & 6.03 & dividir por 10 & & \\
\hline Mean Kink angle, ${ }^{\circ}$ & 48000 & 48600 & 48.3 & 131.70 & 180 - kink angle & & \\
\hline$N^{\circ}$ of Kinks per fibers, $\%$ & 0491 & 0498 & 0.4945 & 49.45 & multiplicar por 100 & & \\
\hline \begin{tabular}{|cc} 
Curl, \% & Dado de entrada \\
Shape
\end{tabular} & 91000 & 90900 & 90.95 & 9.95 & $((100 /$ shape $)-1) \star 100$ & & \\
\hline Fine Elements, \% aritmethic & 22600 & 22400 & 22.5 & 22.50 & - & & \\
\hline Percentage of fine elts, $\%$ in area & 3700 & 300 & 3.75 & 3.75 & - & & \\
\hline
\end{tabular}




\section{APÊNDICE C - LAVAGEM PASTA KRAFT DE EUCALIPTO PRÉ-BRANQUEADA}

\begin{tabular}{|c|c|c|c|c|c|c|}
\hline 1) CONSISTÊNCIA & & & & & & \\
\hline \multicolumn{7}{|l|}{ antes da lavagem } \\
\hline Determinação & Peso Filtro (g) & $\begin{array}{l}\text { Alíquota da } \\
\text { amostra (g) }\end{array}$ & $\begin{array}{l}\text { Peso seco } \\
\text { (filtro+amostra) }\end{array}$ & Amostra (g) & $\begin{array}{l}\text { Consistência } \\
\text { (gfibra/100g) }\end{array}$ & \\
\hline 1 & 1.076 & 102 & 1.602 & 0.526 & 0.516 & \\
\hline 2 & 1.07 & 98.8 & 1.598 & 0.528 & 0.534 & \\
\hline 3 & 1.062 & 101.14 & 1.597 & 0.535 & 0.529 & \\
\hline & & & & Média & 0.526 & \\
\hline \multicolumn{7}{|l|}{ depois da lavagem } \\
\hline Determinação & Peso Filtro (g) & $\begin{array}{l}\text { Alíquota da } \\
\text { amostra (g) }\end{array}$ & $\begin{array}{l}\text { Peso seco } \\
\text { (filtro+amostra) }\end{array}$ & Amostra (g) & $\begin{array}{l}\text { Consistência } \\
\text { (gfibra/100g) }\end{array}$ & \\
\hline 1 & 1.05 & 98.37 & 1.592 & 0.542 & 0.551 & \\
\hline 2 & 1.048 & 101.08 & 1.613 & 0.565 & 0.559 & \\
\hline 3 & 1.049 & 98.01 & 1.579 & 0.53 & 0.541 & \\
\hline & & & & Média & 0.550 & \\
\hline \multicolumn{7}{|l|}{ 2) FINOS } \\
\hline \multicolumn{7}{|l|}{ antes da lavagem } \\
\hline Determinação & Peso Filtro (g) & $\begin{array}{l}\text { Alíquota da } \\
\text { amostra (g) }\end{array}$ & Amostra total (g) & \begin{tabular}{|l} 
Peso seco \\
(filtro+amostra)
\end{tabular} & Retido DDJ (g) & Teor de finos (\%) \\
\hline 1 & 1.07 & 99.29 & 0.523 & 1.558 & 0.488 & 6.62 \\
\hline 2 & 1.07 & 98.6 & 0.519 & 1.547 & 0.477 & \\
\hline 3 & 1.056 & 97.24 & 0.512 & 1.539 & 0.483 & 5.63 \\
\hline 4 & 1.087 & 101 & 0.532 & 1.591 & 0.504 & 5.20 \\
\hline 5 & 1.064 & 102.04 & 0.537 & 1.583 & 0.519 & \\
\hline & & & & & Média & 5.82 \\
\hline & & & & & Desvio & 0.73 \\
\hline \multicolumn{7}{|l|}{ depois da lavagem } \\
\hline Determinação & Peso Filtro (g) & $\begin{array}{l}\text { Alíquota da } \\
\text { amostra (g) }\end{array}$ & Amostra total (g) & $\begin{array}{l}\text { Peso seco } \\
\text { (filtro+amostra) }\end{array}$ & Retido DDJ (g) & Teor de finos (\%) \\
\hline 1 & 1.049 & 102.39 & 0.563 & 1.596 & 0.547 & 2.91 \\
\hline 2 & 1.046 & 103.47 & 0.569 & 1.594 & 0.548 & 3.75 \\
\hline 3 & 1.041 & 102.65 & 0.565 & 1.523 & 0.482 & \\
\hline 4 & 1.056 & 100.24 & 0.552 & 1.581 & 0.525 & 4.81 \\
\hline \multirow[t]{3}{*}{5} & 1.042 & 98.1 & 0.540 & 1.603 & 0.561 & \\
\hline & & & & & Média & 3.82 \\
\hline & & & & & Desvio & 0.96 \\
\hline
\end{tabular}




\section{APÊNDICE D - CARACTERÍSTICAS DAS CNF}

\begin{tabular}{|c|c|c|c|c|c|c|c|c|c|c|c|}
\hline \multicolumn{5}{|c|}{ Amostra } & \multirow{3}{*}{$\begin{array}{c}\text { Consistência, } \\
\%\end{array}$} & \multirow{2}{*}{\multicolumn{2}{|c|}{ Rendimento, \% }} & \multirow{3}{*}{$\begin{array}{c}\text { Concentração } \\
\text { de grupos } \\
\text { carboxálicos, } \\
\text { mmol/g }\end{array}$} & \multirow{3}{*}{$\begin{array}{l}\text { Potencial } \\
\text { zeta } \mathrm{my}\end{array}$} & \multirow{2}{*}{\multicolumn{2}{|c|}{$\begin{array}{l}\text { Distribuiç̃ố de tamanho } \\
\text { de particula (IDS), nm }\end{array}$}} \\
\hline & & & Tratamento & mecânico & & & & & & & \\
\hline Código & $\begin{array}{l}\text { Oglgem ud } \\
\text { fibra }\end{array}$ & $\begin{array}{l}\text { quimico, } \\
\mathrm{mmol} / \mathrm{g}\end{array}$ & Passsagens & $\begin{array}{c}\begin{array}{c}\text { Pressão, } \\
\text { bar }\end{array} \\
\end{array}$ & & $\begin{array}{c}\text { De } \\
\text { producão }\end{array}$ & $\begin{array}{c}\text { De } \\
\text { nanofibrilarã̃o }\end{array}$ & & & $\begin{array}{c}\text { Z-Average } \\
\text { (d) } \mathrm{nm}\end{array}$ & $\begin{array}{cc}10 & 20 \\
\text { Pico } & \text { Picoo } \\
\end{array}$ \\
\hline $\begin{array}{l}\text { 2PFR } \\
\text { fibraPt }\end{array}$ & & 5 & 2 & $\begin{array}{l}1 \times 500+ \\
1 \times 000 \\
\end{array}$ & 1.00 & $71.5 \%$ & $88 \pm 2$ & 1.10 & 39 & 1723 & 243.923 .51 \\
\hline $\begin{array}{l}2 \mathrm{PSR} \\
\text { fibrabr }\end{array}$ & & 5 & 2 & $\begin{array}{l}\times 500+ \\
1 \times 1000 \\
\end{array}$ & 1.15 & $78.7 \%$ & $89 \pm 1$ & 1.18 & -59 & 1692 & 335.044 .57 \\
\hline $\begin{array}{c}2 \mathrm{PSB} \\
\text { finosir }\end{array}$ & & 5 & 2 & $\begin{array}{l}1 \times 500+ \\
1 \times 1000\end{array}$ & 1.11 & $p 8.7 \%$ & $86 \pm 1$ & 1.56 & -82 & 1751 & 307.042 .23 \\
\hline
\end{tabular}


APÊNDICE E - MICROSCOPIA ELECTRÔNICA DE VARREDURA (SEM)

\section{E1. SEM das CNF}
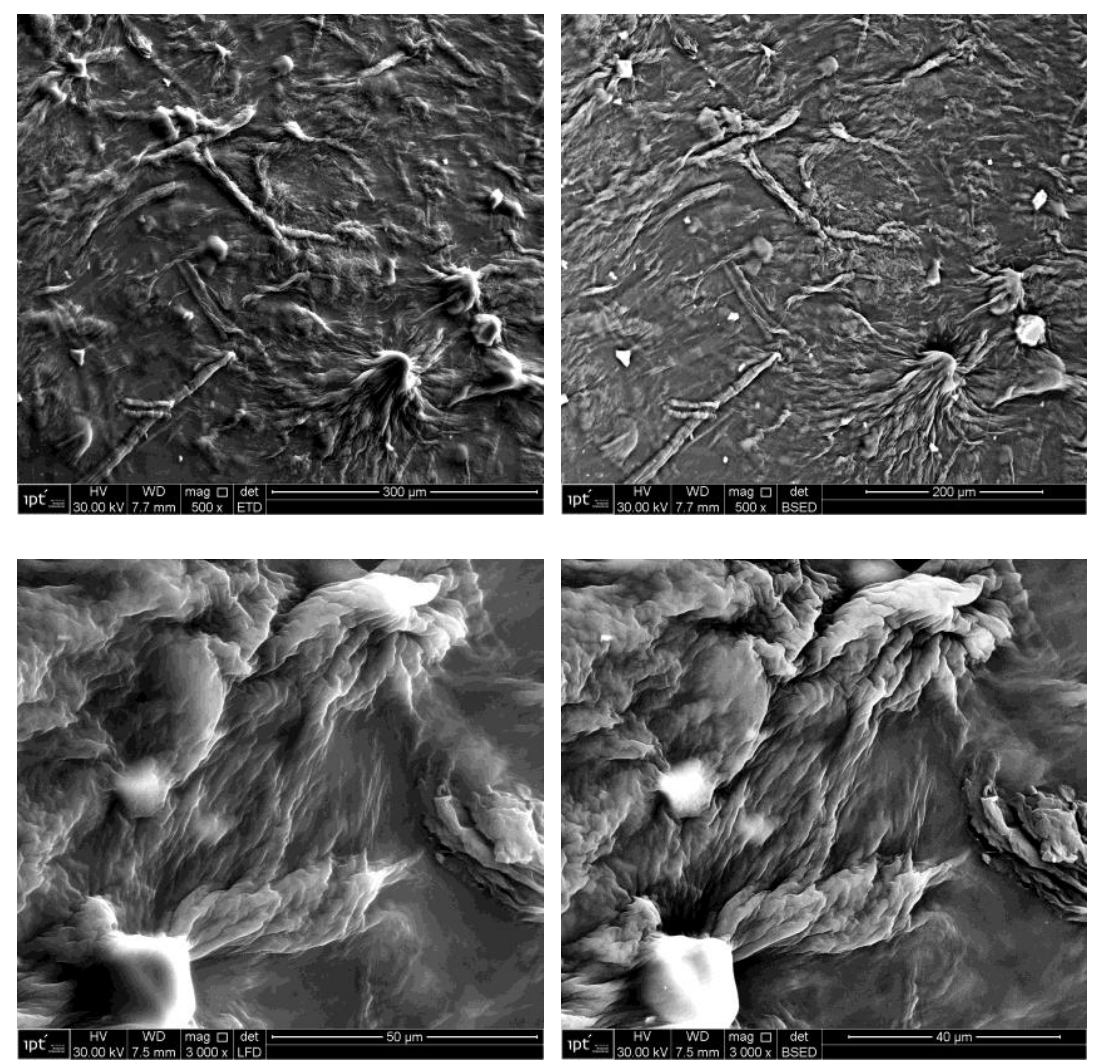


\section{E2. SEM das folhas de laboratório}

1) Amostra - Pasta Kraft de Eucalipto Pré-branqueada - Referência
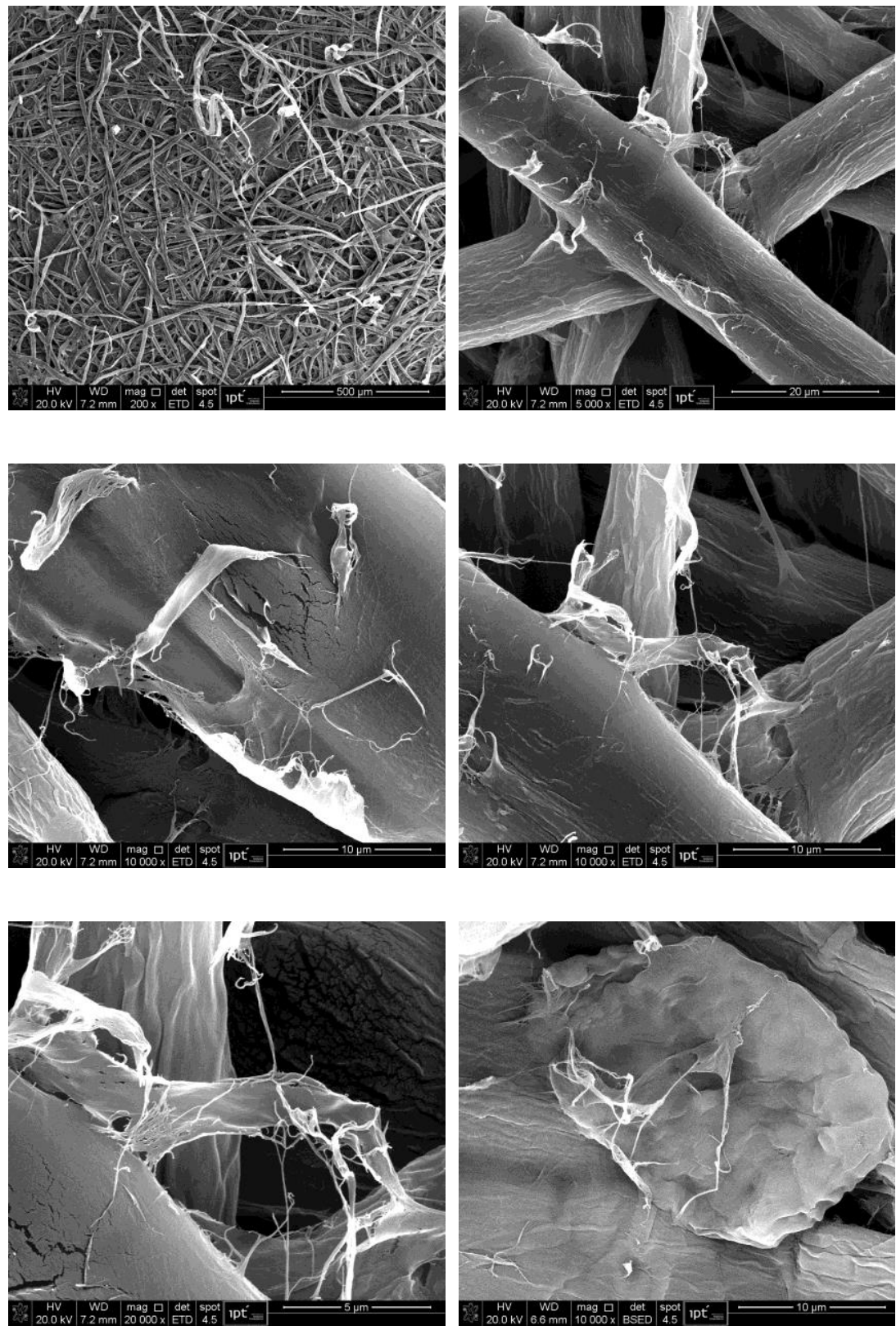
Continuação... Amostra - Pasta Kraft de Eucalipto Pré-branqueada Referência

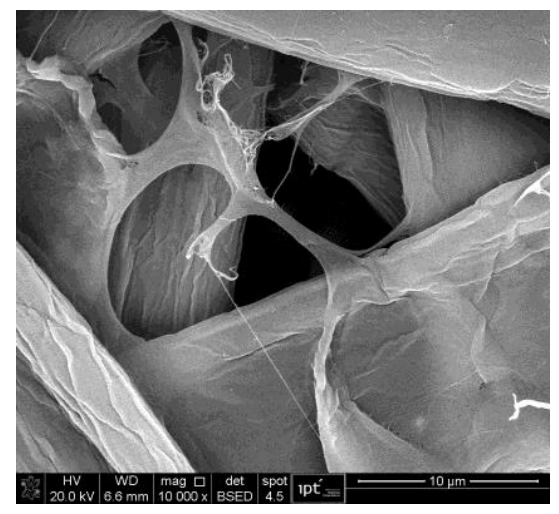

1) Amostra - Pasta Kraft de Eucalipto Pré-branqueada - 0,05\% amido, 0,06\% cola e $0,02 \%$ polímero de retenção
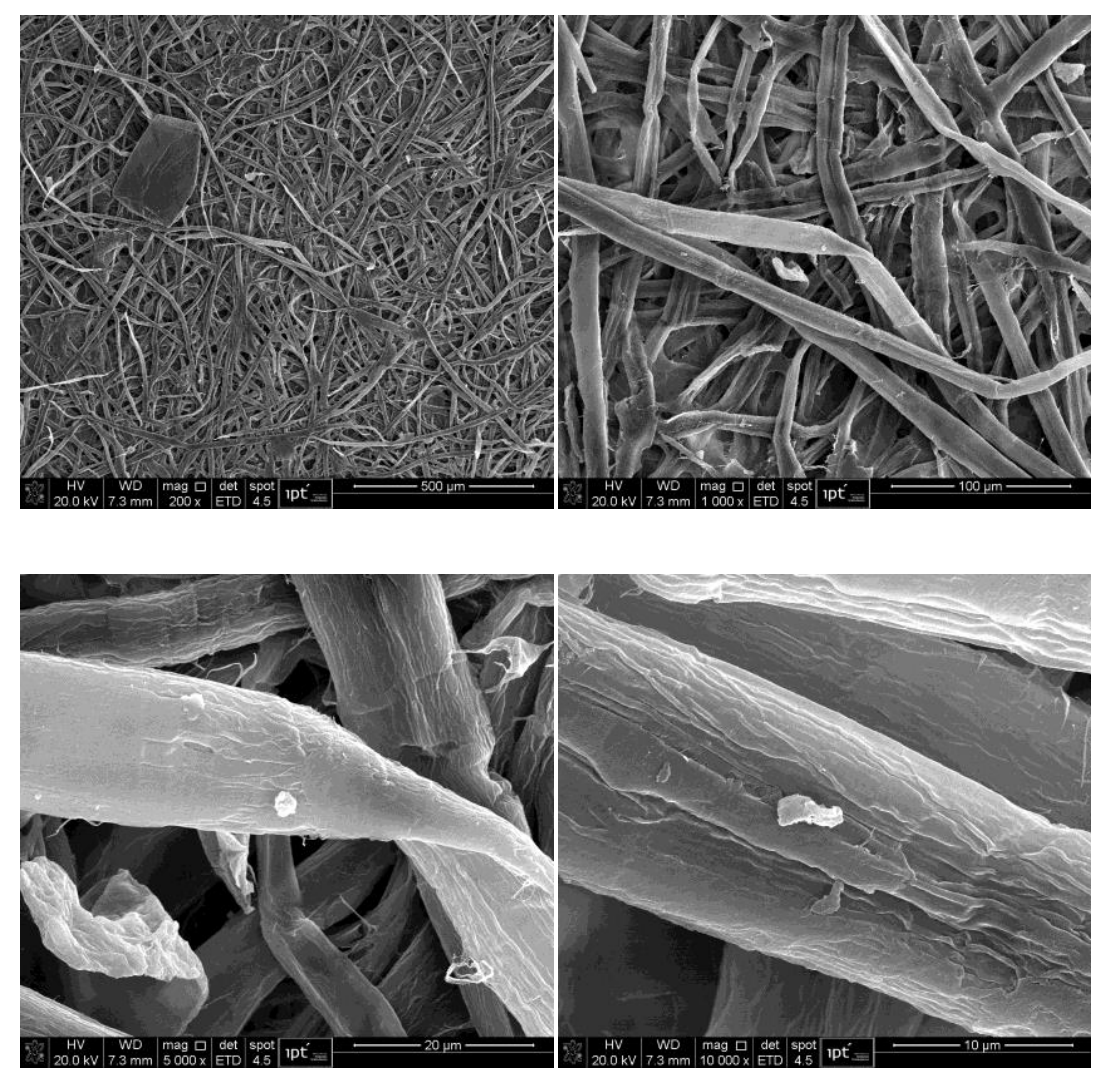
Continuação... Amostra - Pasta Kraft de Eucalipto Pré-branqueada - 0,05\% amido, $0,06 \%$ cola e $0,02 \%$ polímero de retenção

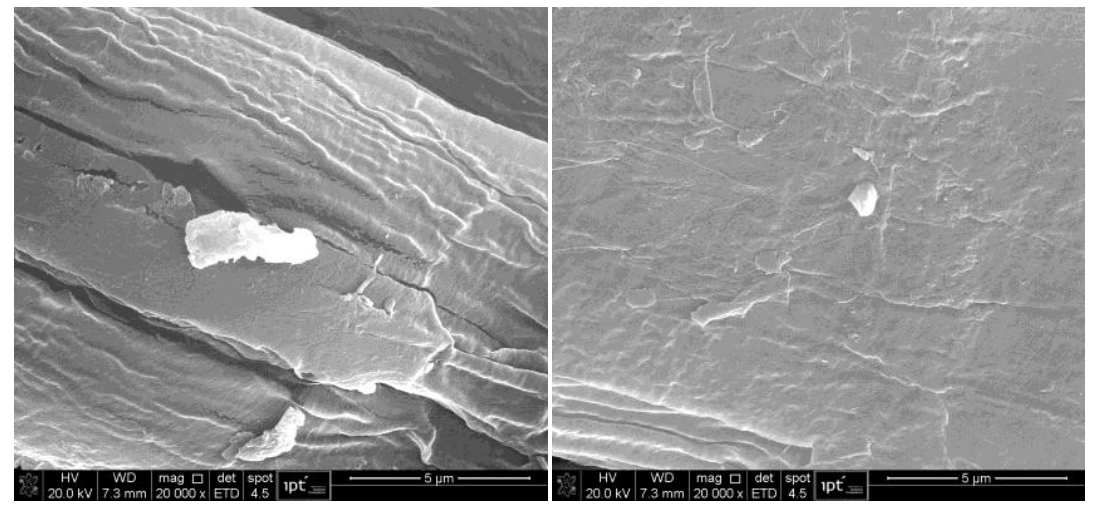

2) Amostra - Pasta Kraft de Eucalipto Pré-branqueada - 1\% CNF
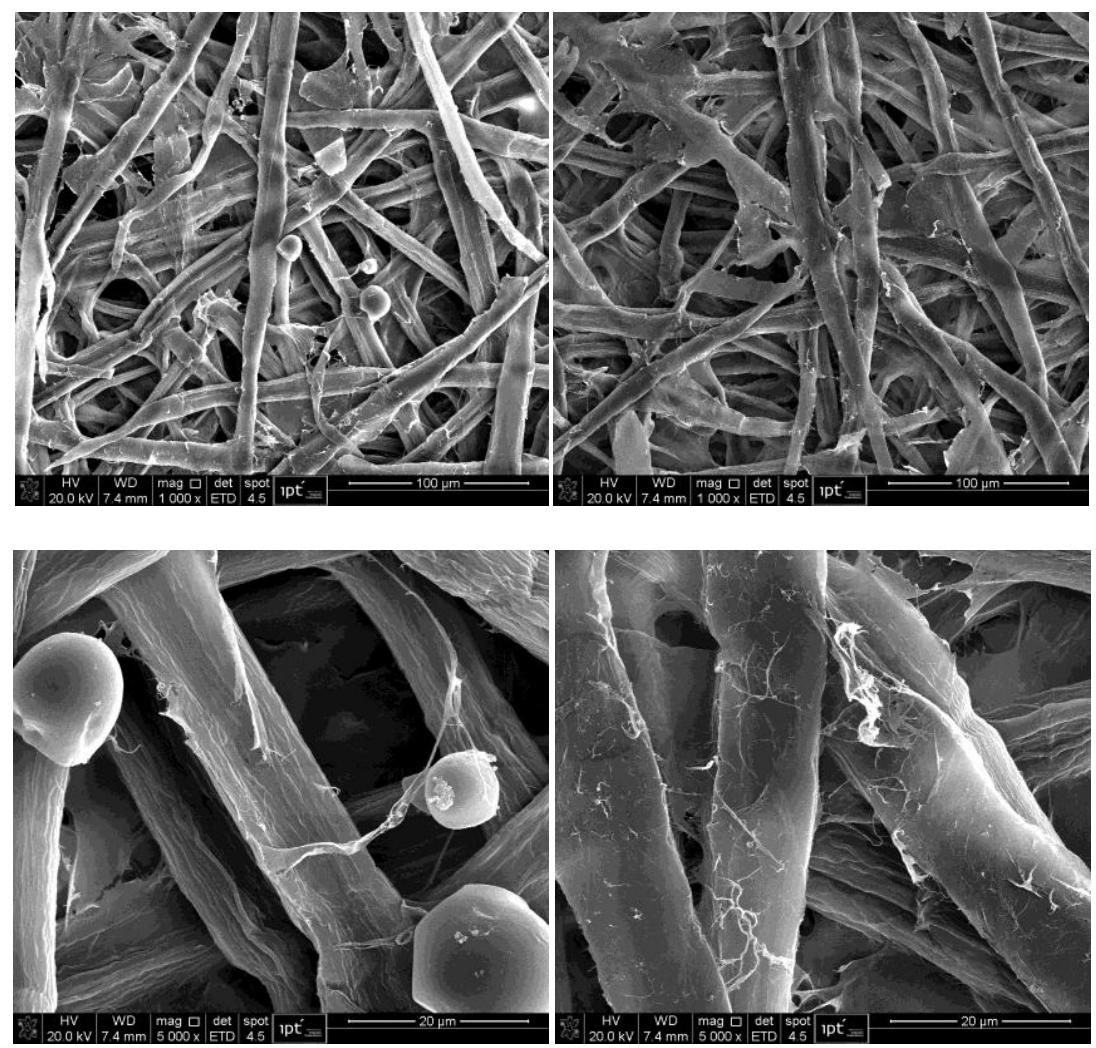
Continuação... Amostra - Pasta Kraft de Eucalipto Pré-branqueada - 1\% CNF
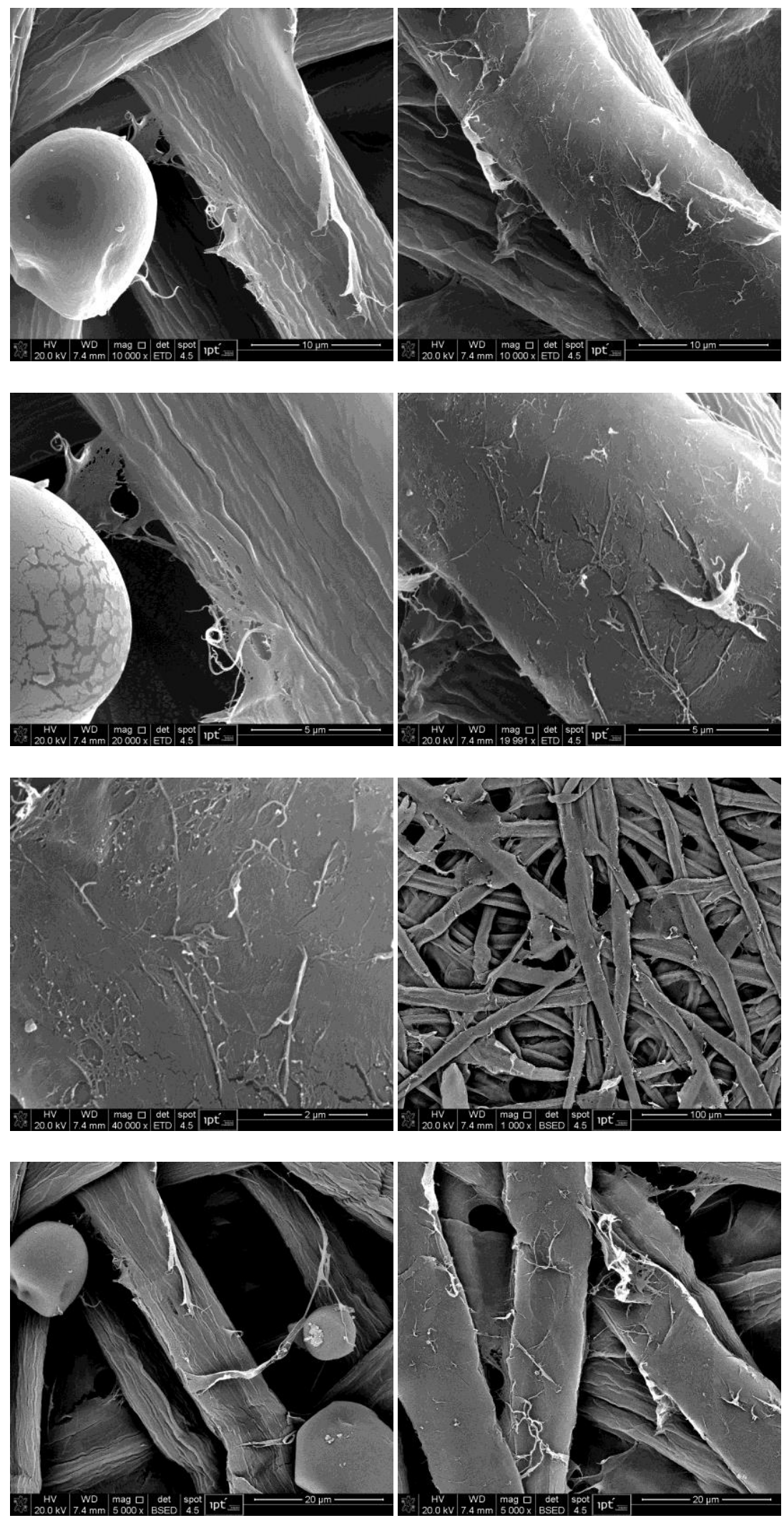
Continuação... Amostra - Pasta Kraft de Eucalipto Pré-branqueada - 1\% CNF
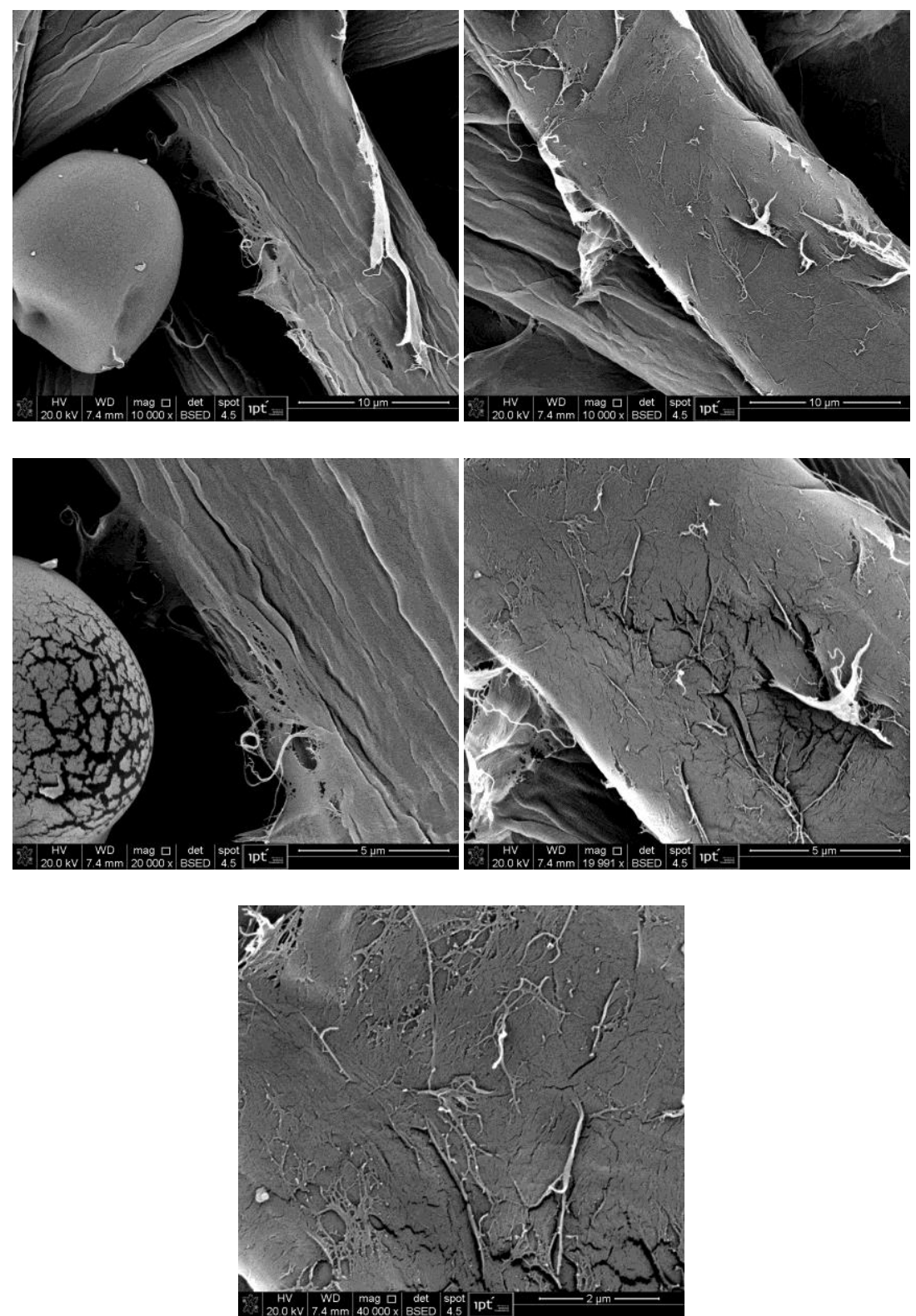
3) Amostra - Pasta Kraft de Eucalipto Pré-branqueada - Ponto Central do planejamento com CNF
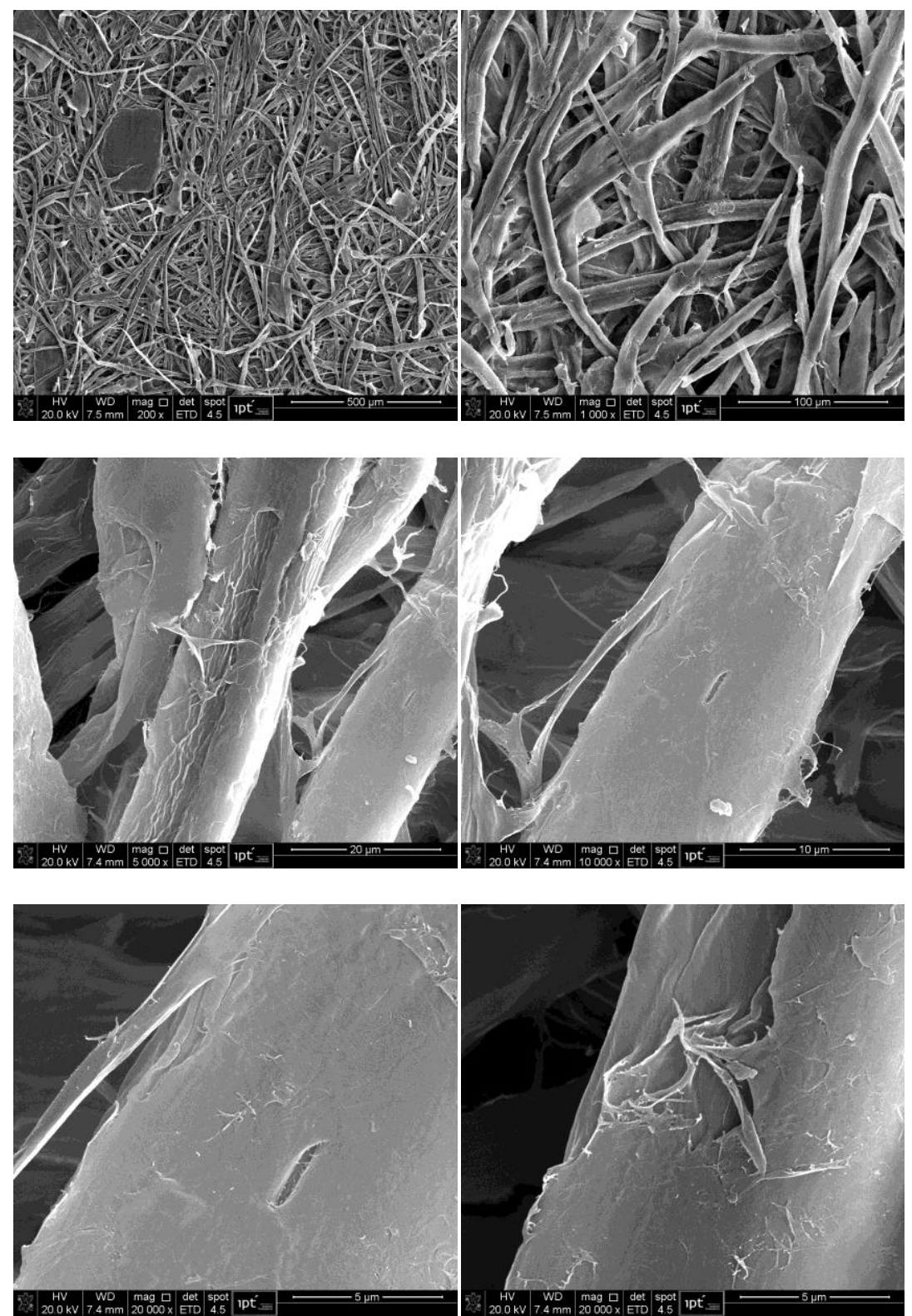
Continuação... Amostra - Pasta Kraft de Eucalipto Pré-branqueada - Ponto Central do planejamento com CNF
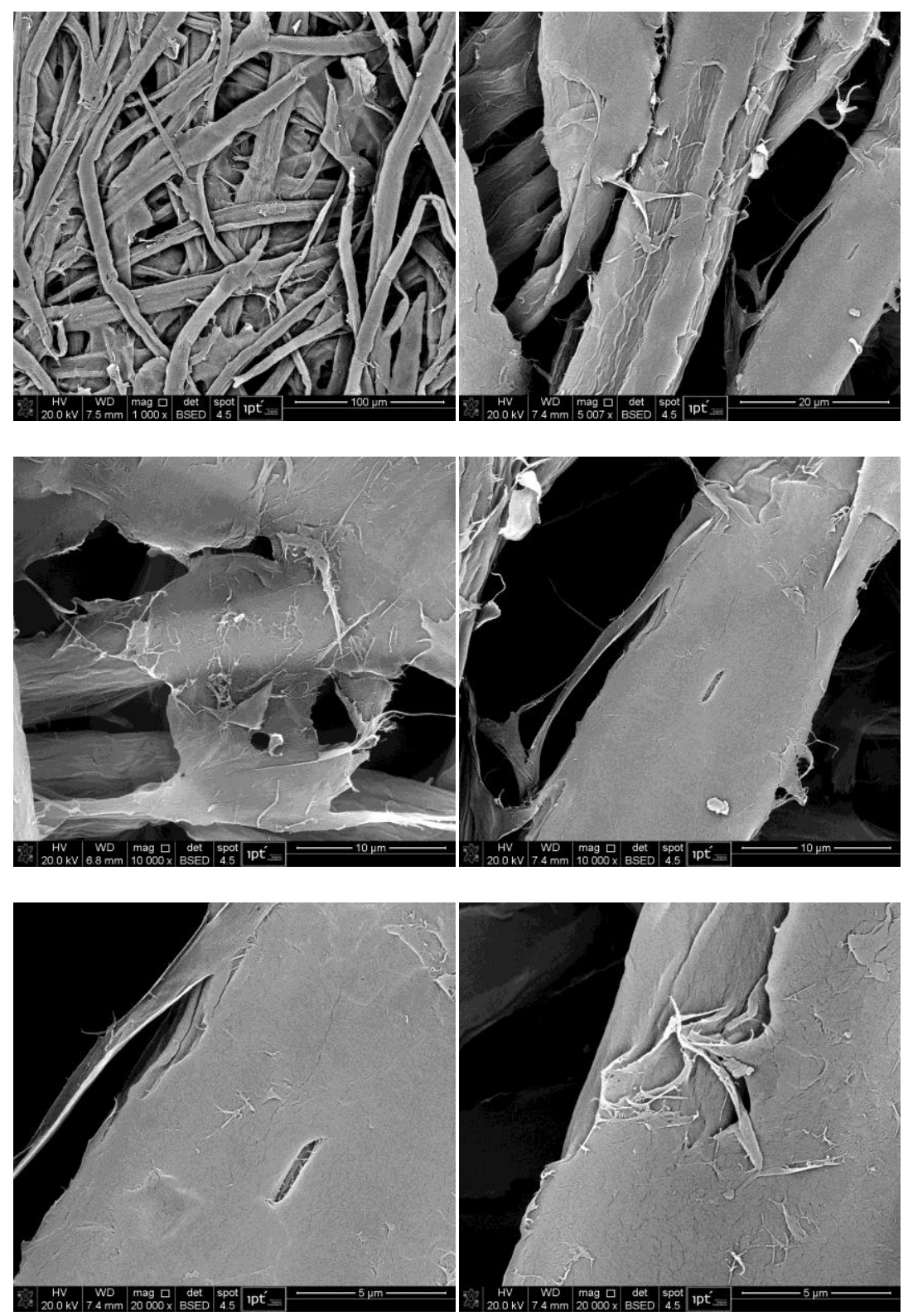
4) Amostra - Pasta Kraft de Eucalipto Pré-branqueada - 1\% MFC
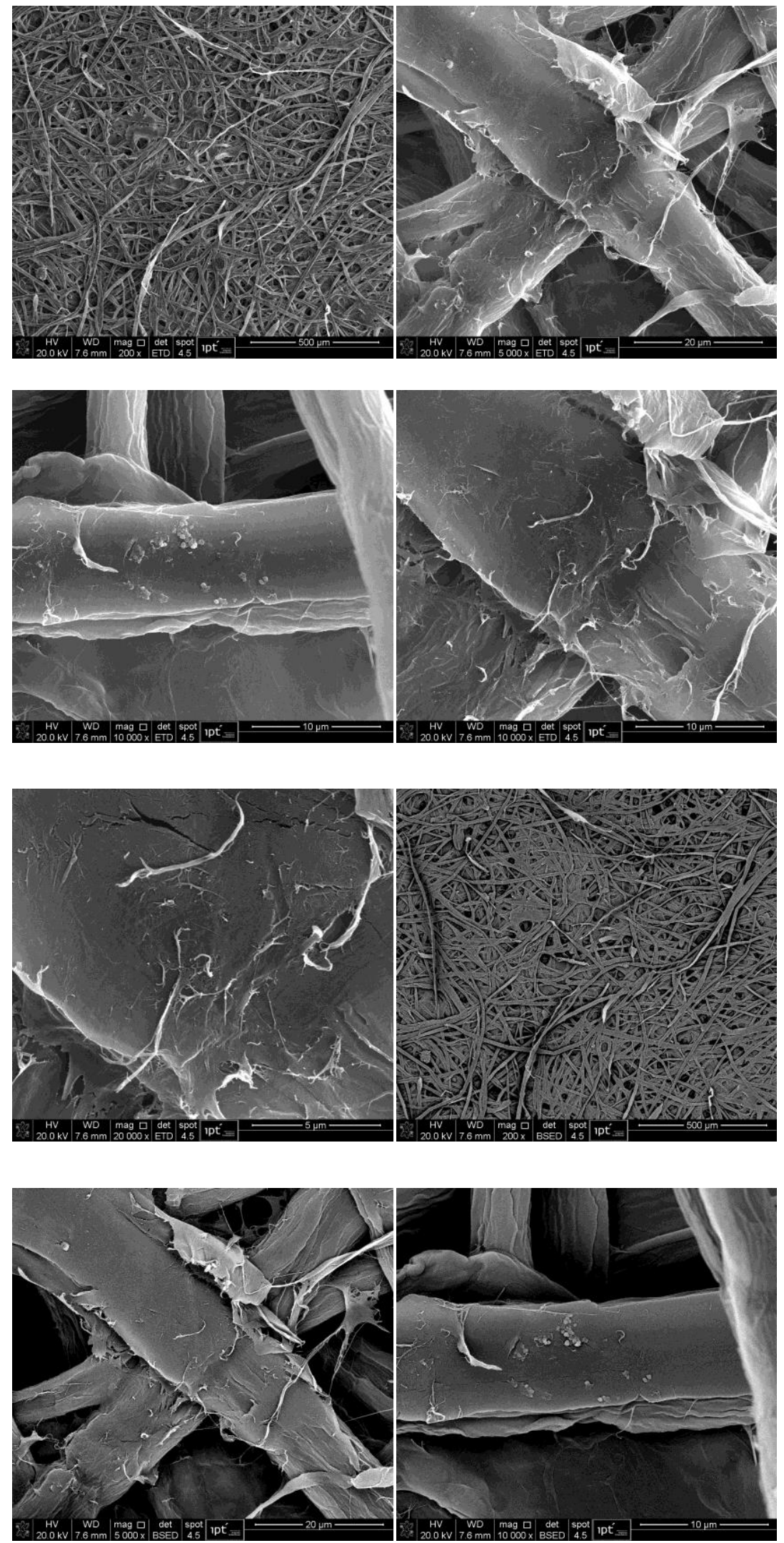
Continuação... Amostra - Pasta Kraft de Eucalipto Pré-branqueada - 1\% MFC

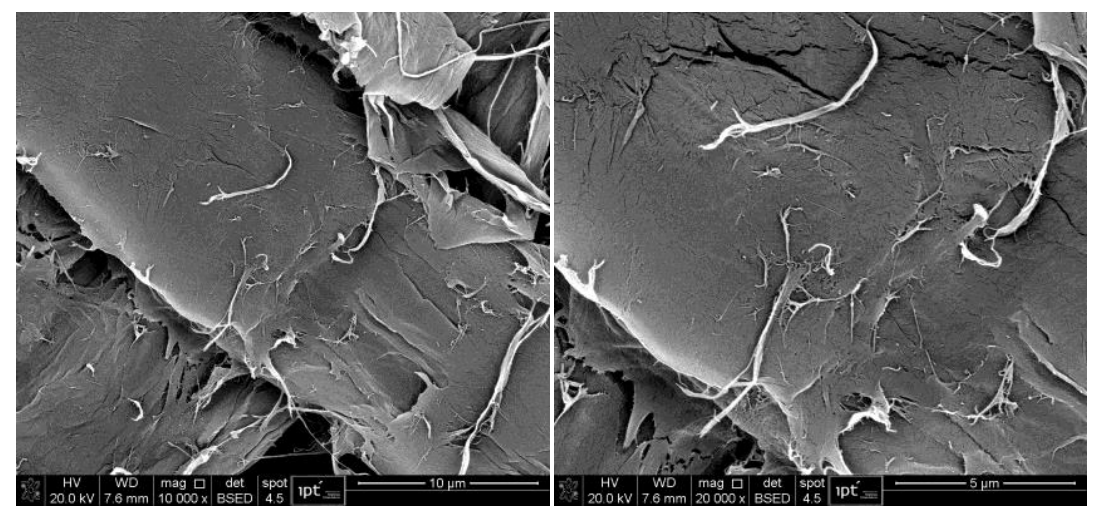

5) Amostra - Pasta Kraft de Eucalipto Pré-branqueada - Ponto Central do planejamento com MFC
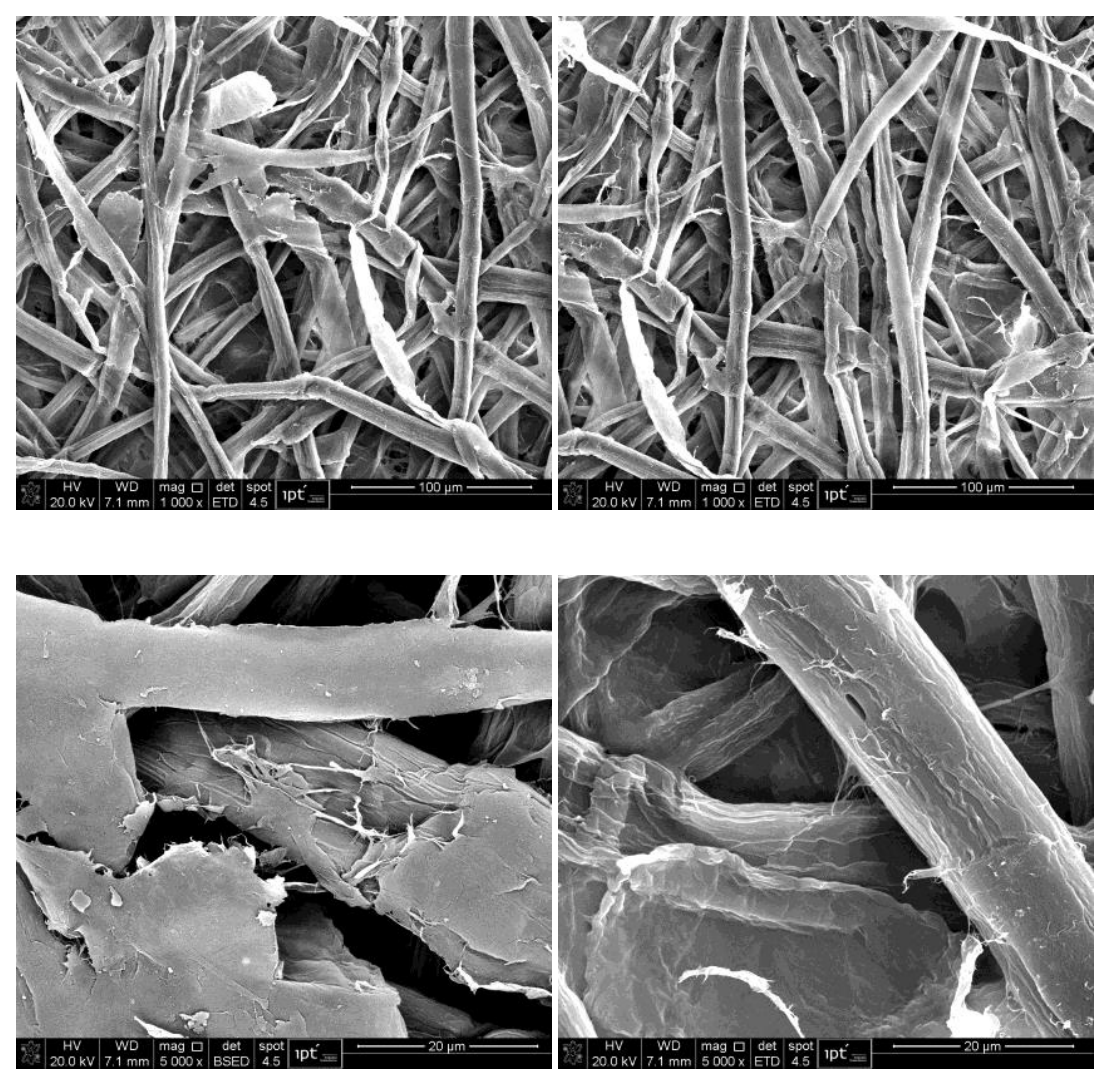
Continuação... Amostra - Pasta Kraft de Eucalipto Pré-branqueada - Ponto Central do planejamento com MFC
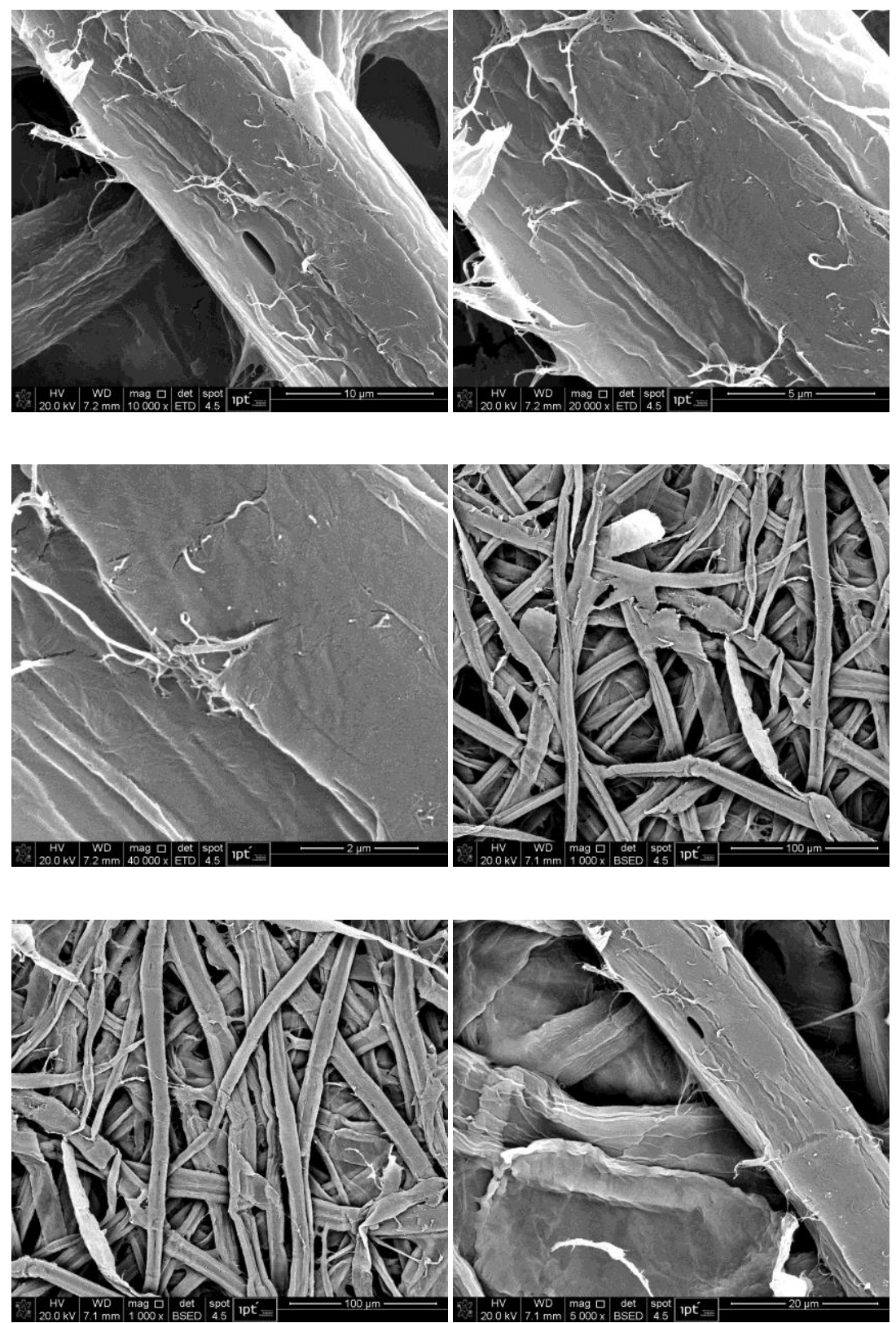
Continuação... Amostra - Pasta Kraft de Eucalipto Pré-branqueada - Ponto Central do planejamento com MFC
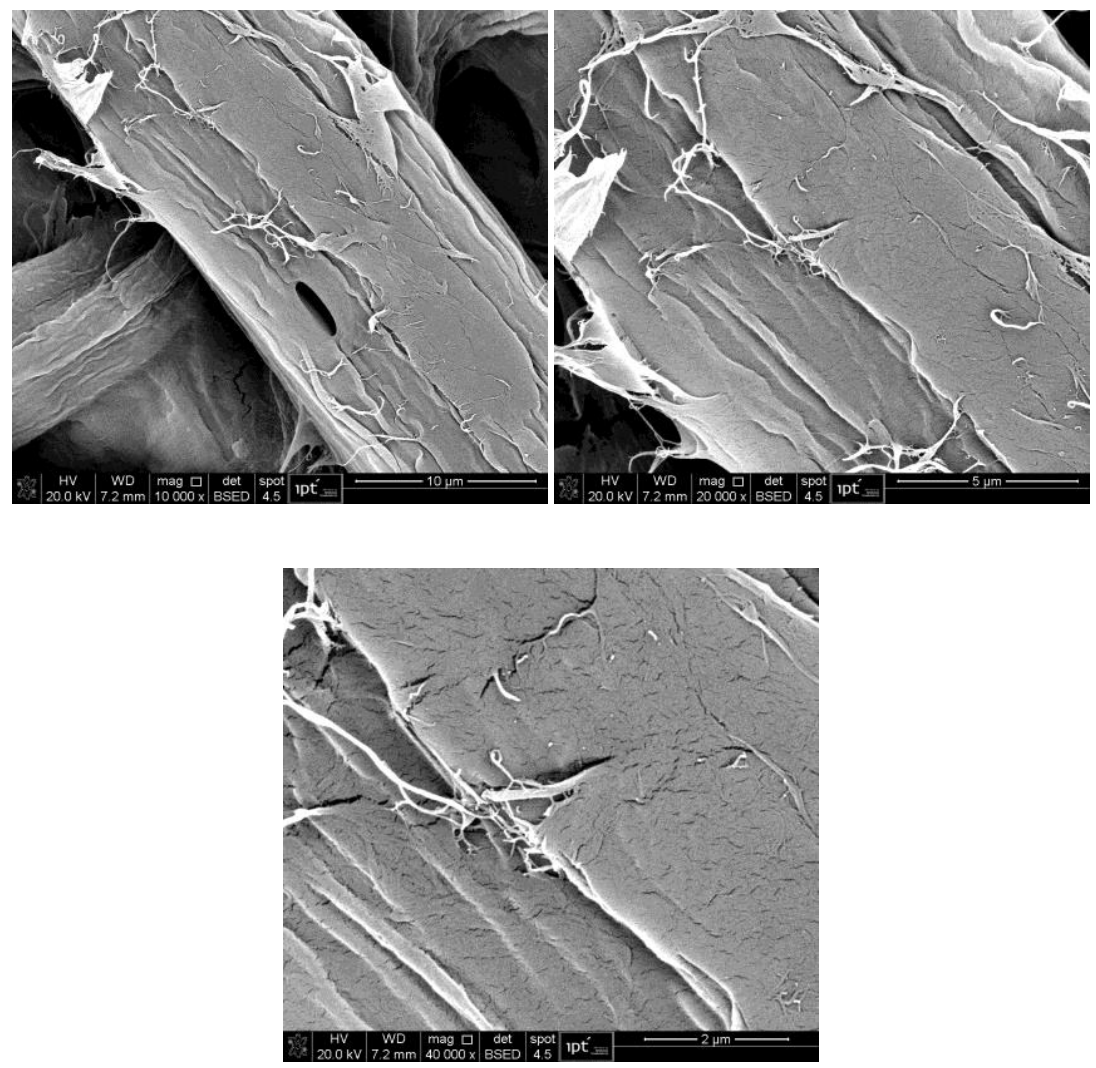

6) Amostra - Pasta Kraft de Eucalipto Branqueada - $2 \%$ CNF - Lado Fieltro

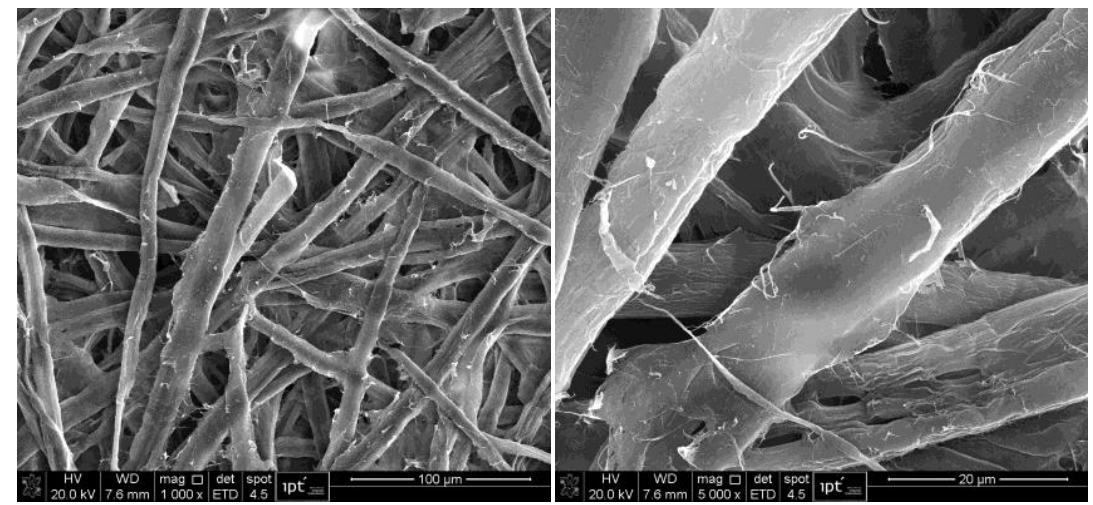


Continuação... Amostra - Pasta Kraft de Eucalipto Branqueada - 2\% CNF — Lado Fieltro
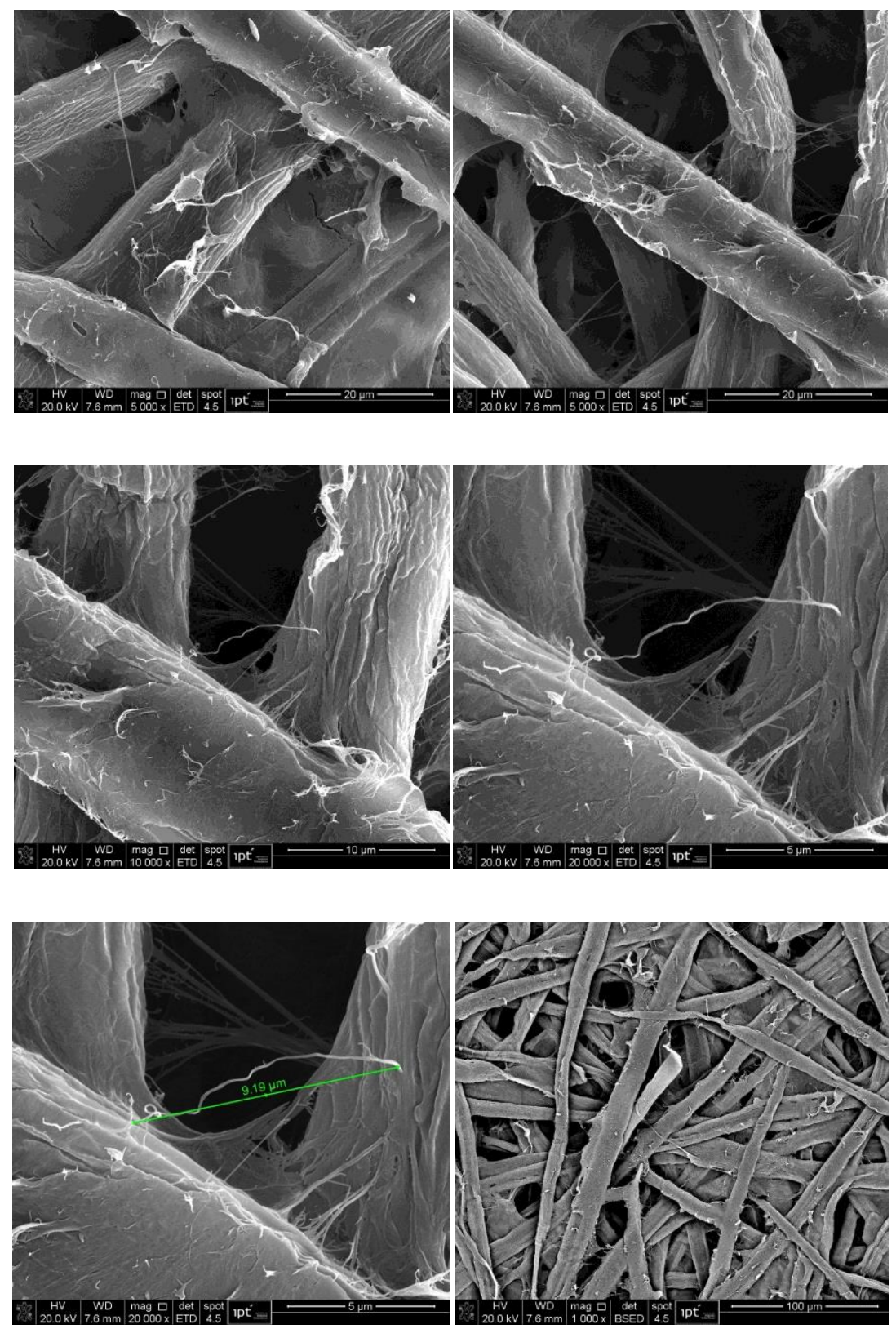
Continuação... Amostra - Pasta Kraft de Eucalipto Branqueada - 2\% CNF — Lado Fieltro
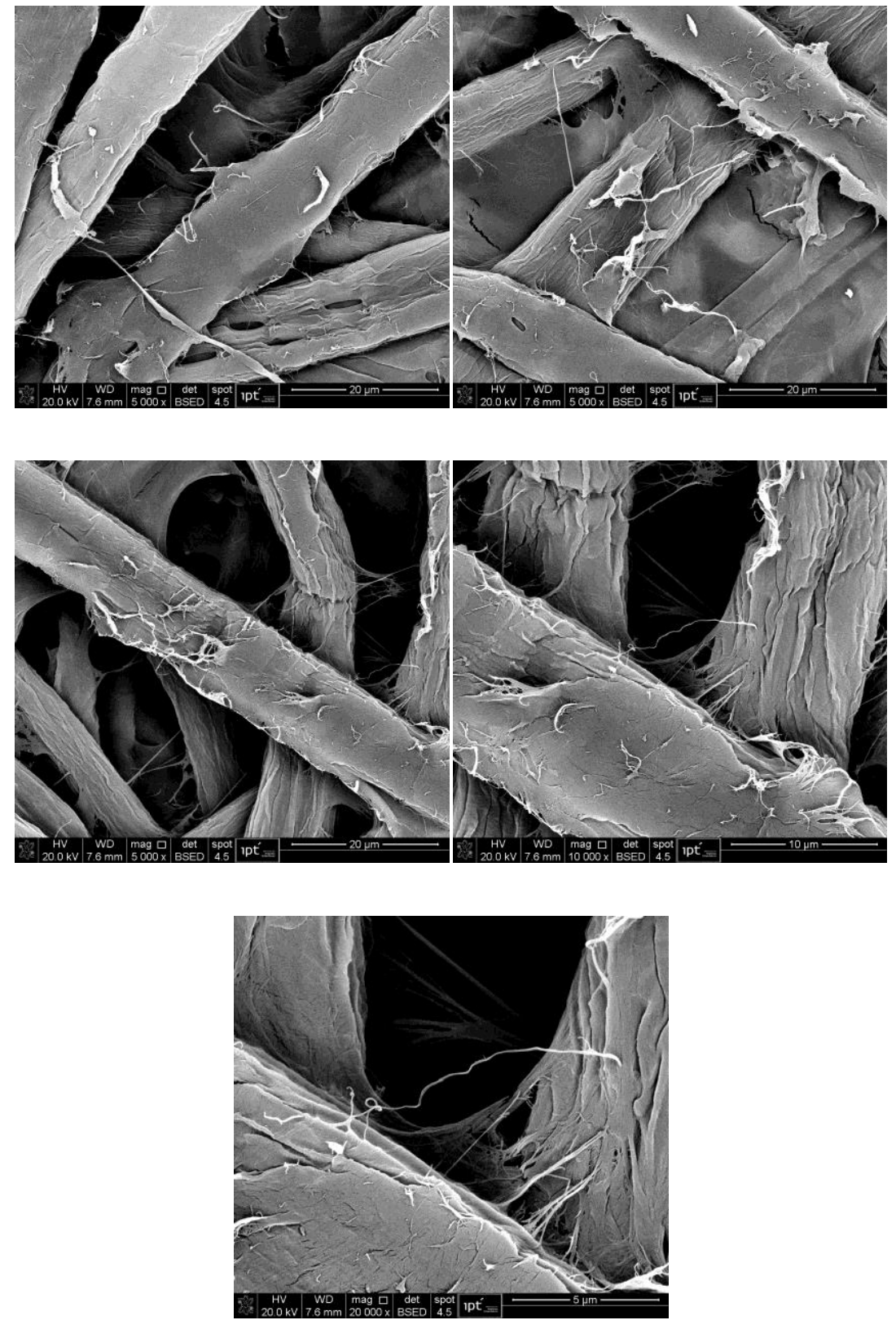
7) Amostra - Pasta Kraft de Eucalipto Branqueada - 2\% CNF - Lado Tela
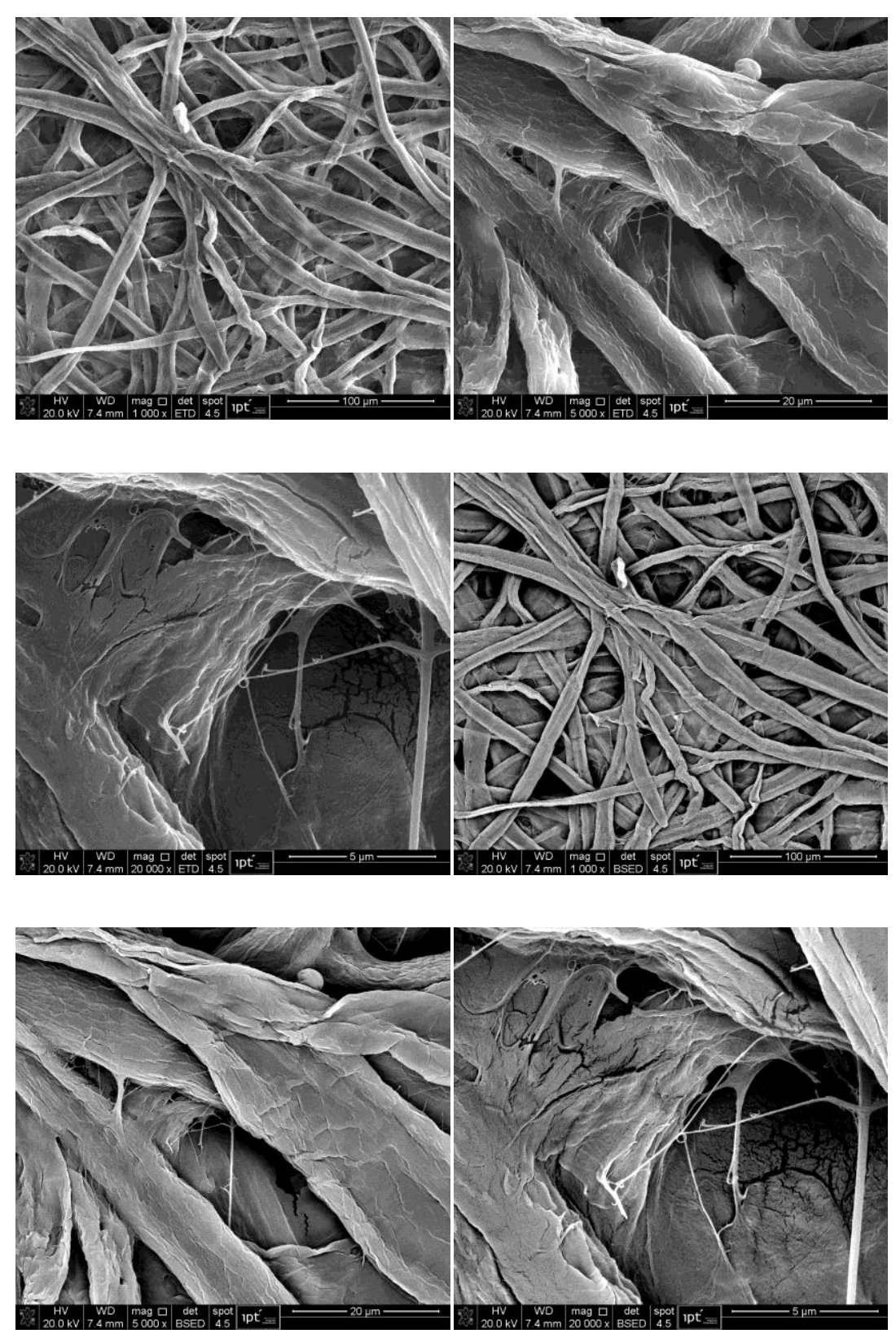
8) Amostra - Pasta Kraft Marrom de Pinus - 1\% CNF
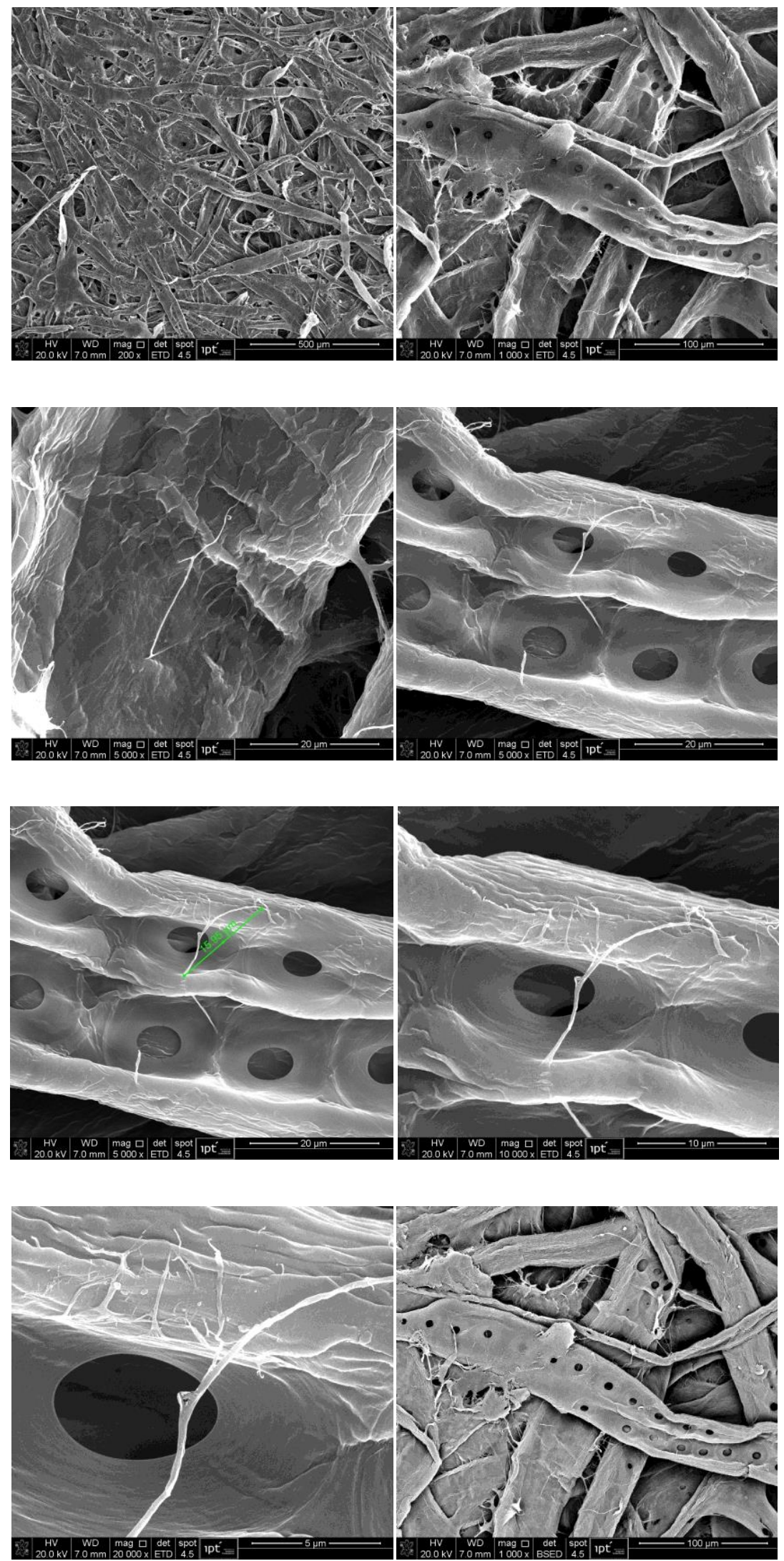
Continuação... Amostra - Pasta Kraft Marrom de Pinus - 1\% CNF
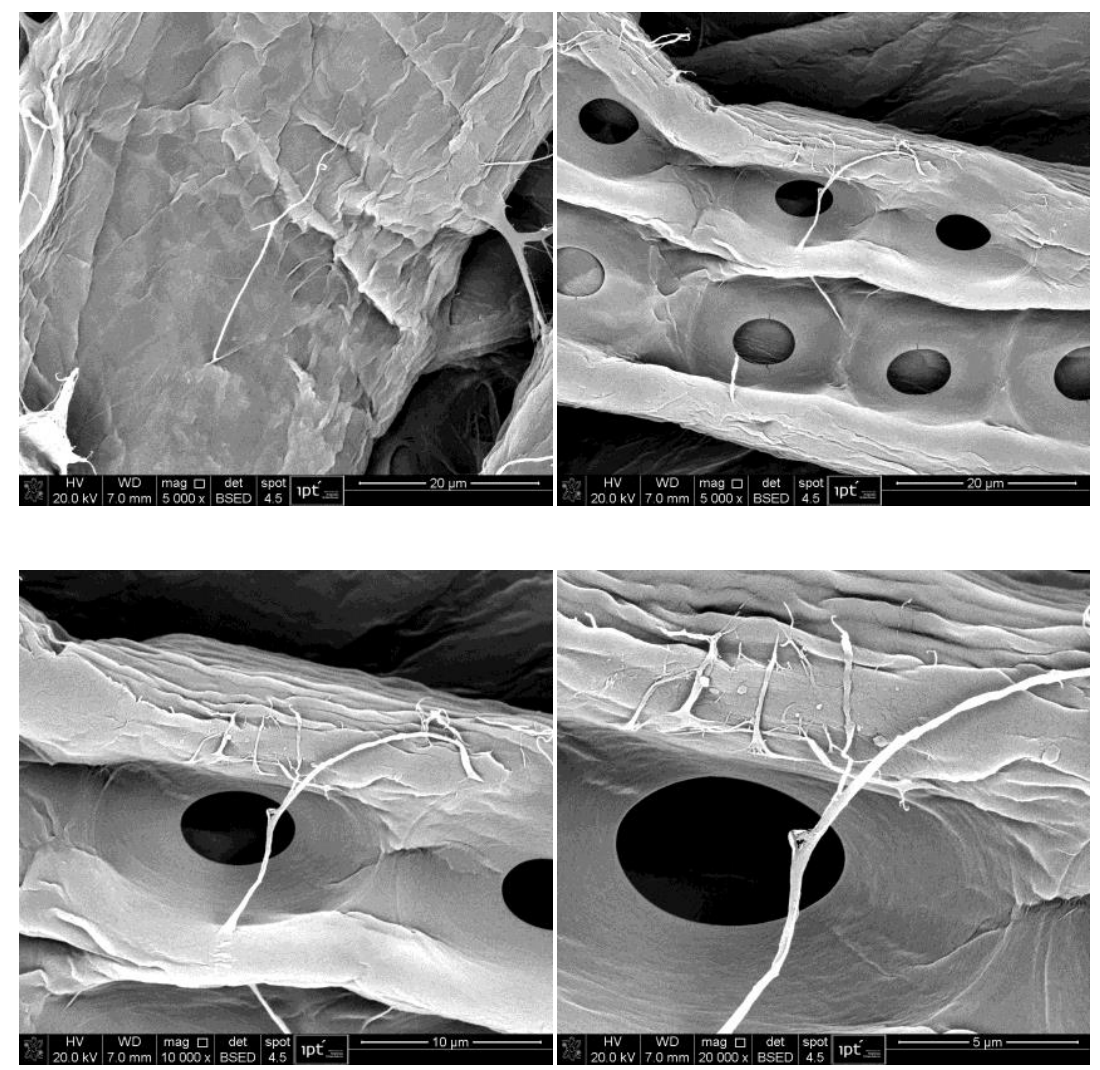

9) Amostra - Pasta Kraft Marrom de Pinus - 2\% CNF
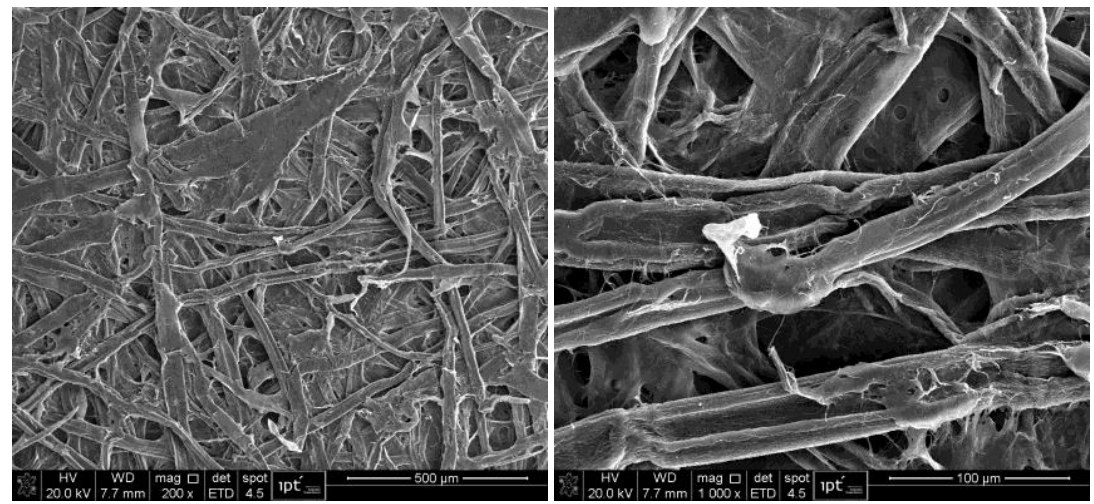
Continuação... Amostra - Pasta Kraft Marrom de Pinus - 2\% CNF
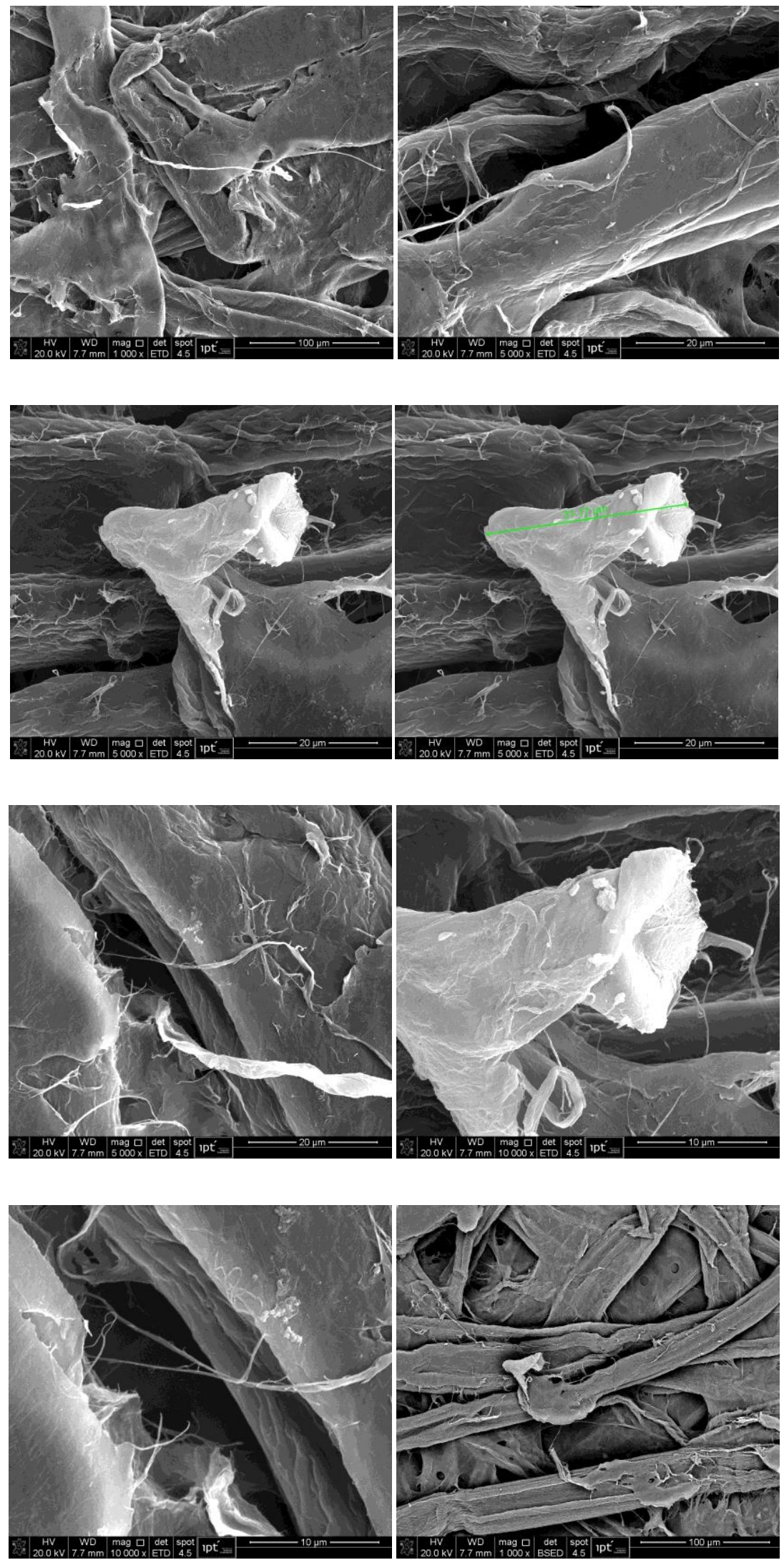
Continuação... Amostra - Pasta Kraft Marrom de Pinus - 2\% CNF
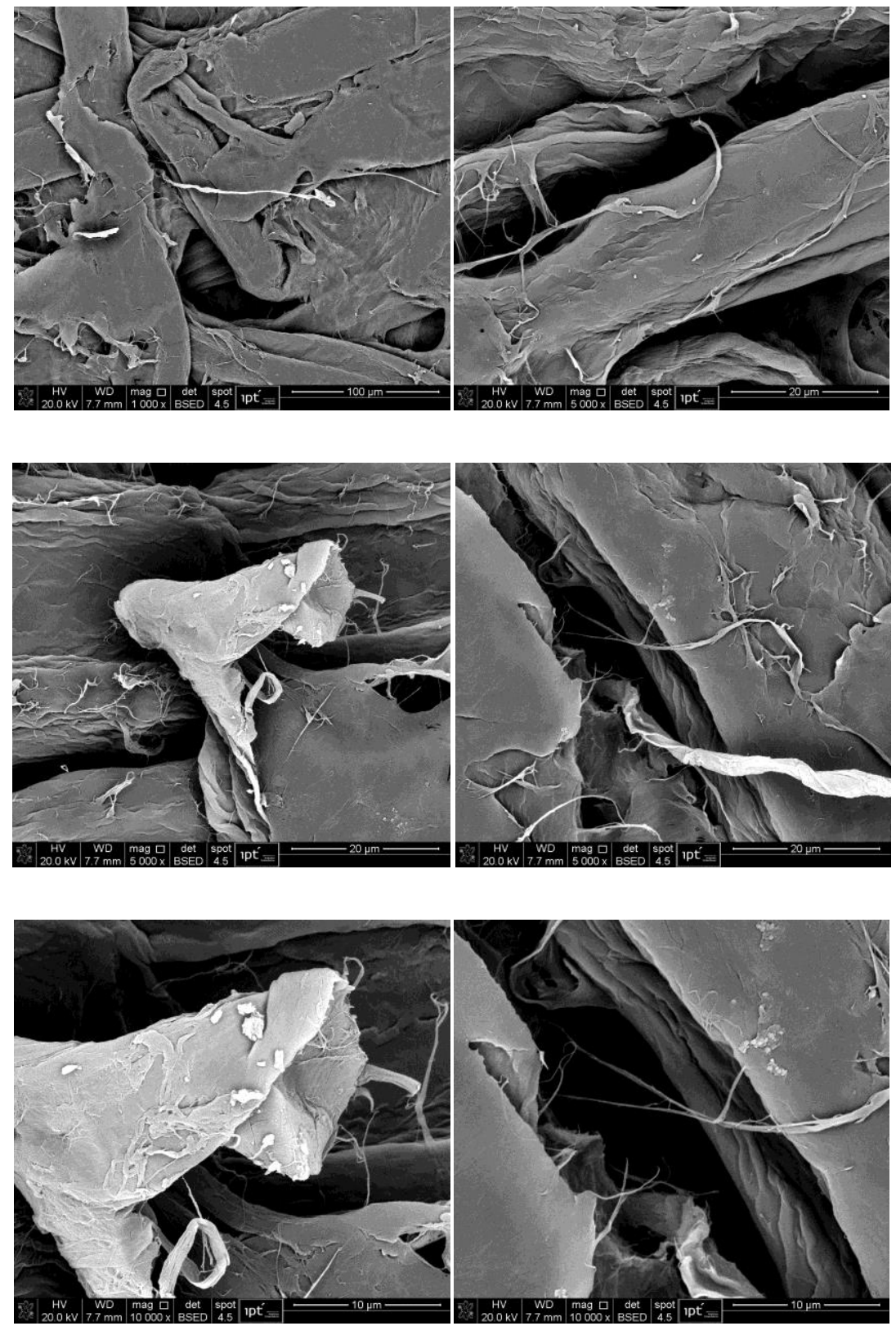
10) Amostra - Pasta Kraft Marrom de Pinus - 1\% MFC
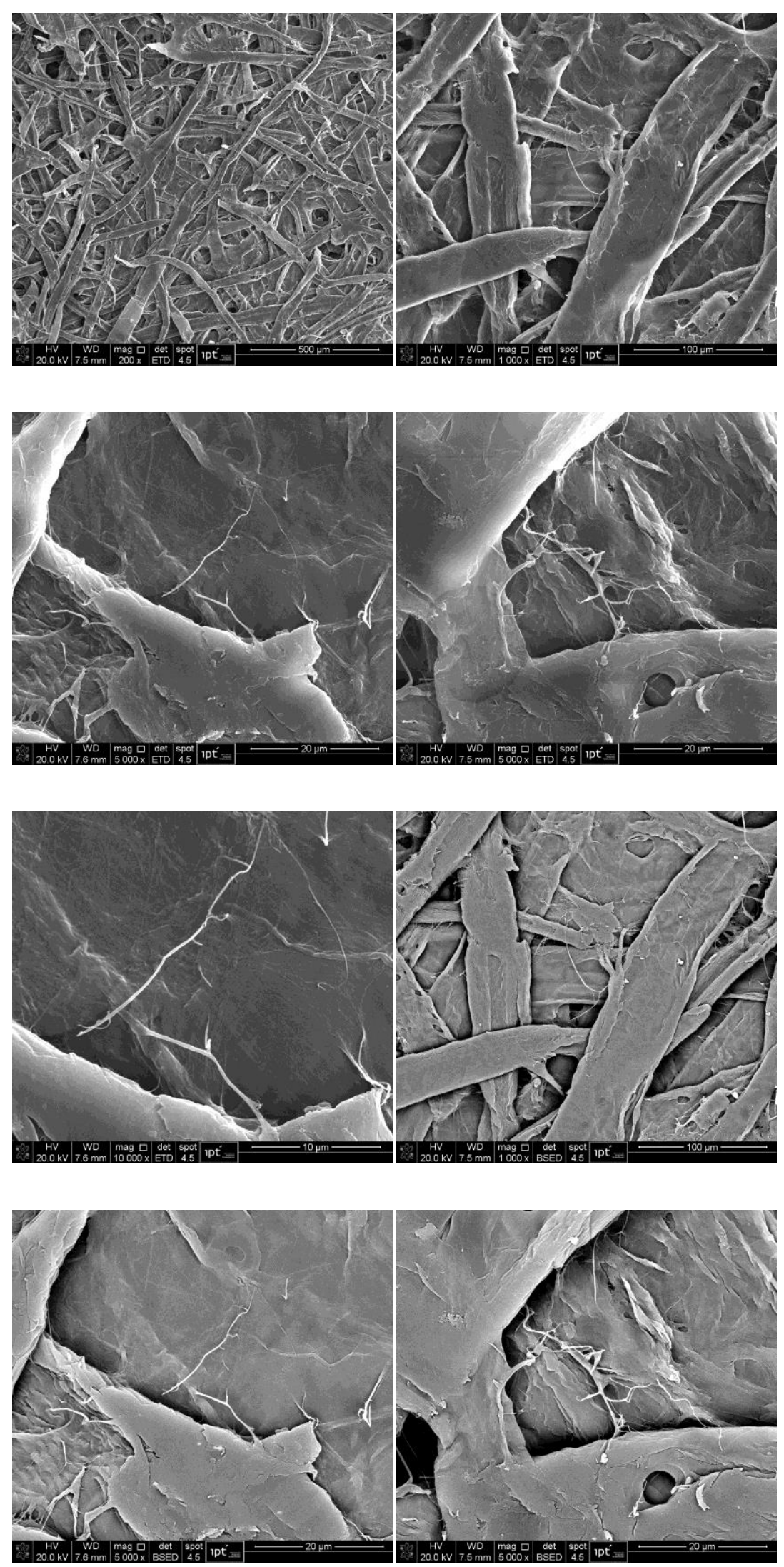
Continuação... Amostra - Pasta Kraft Marrom de Pinus - 1\% MFC

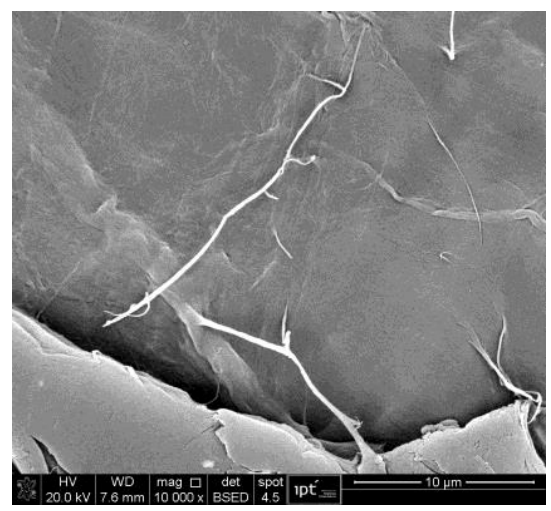

11) Amostra - Pasta Kraft de Eucalipto Pré-branqueada - 1\% CNF - Repetição
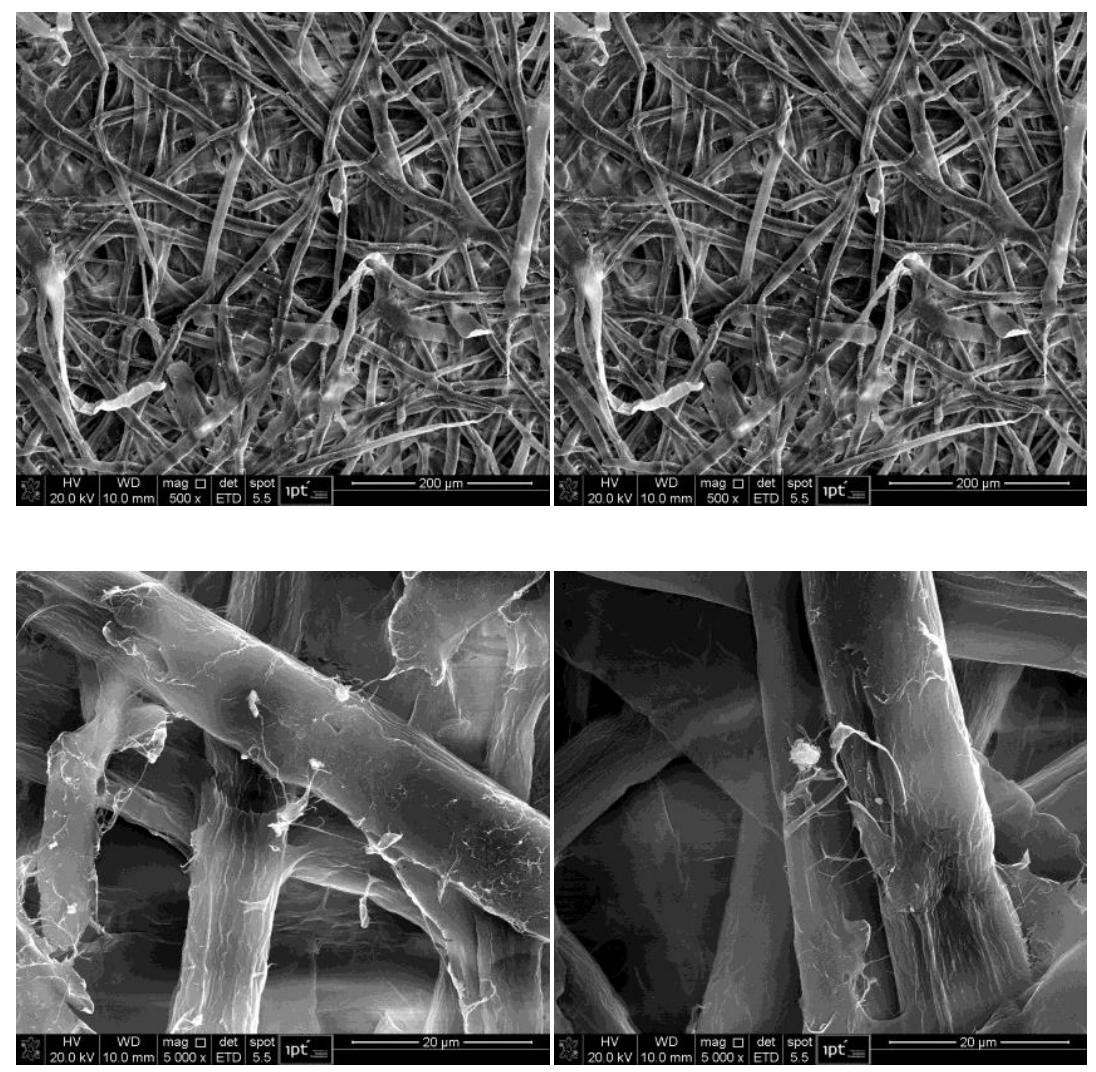
Continuação... Amostra - Pasta Kraft de Eucalipto Pré-branqueada - 1\% CNF

- Repetição
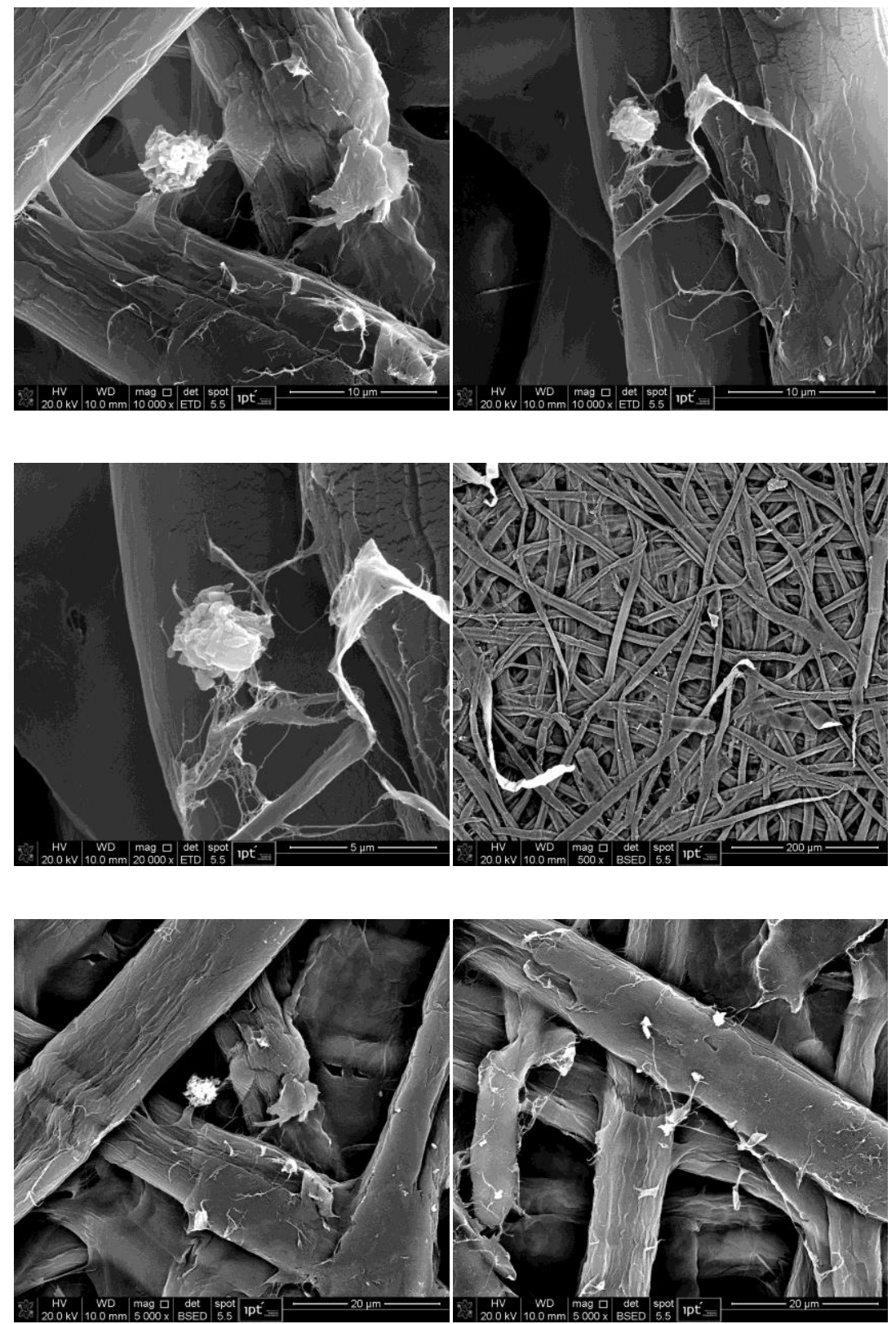
Continuação... Amostra - Pasta Kraft de Eucalipto Pré-branqueada - 1\% CNF

- Repetição
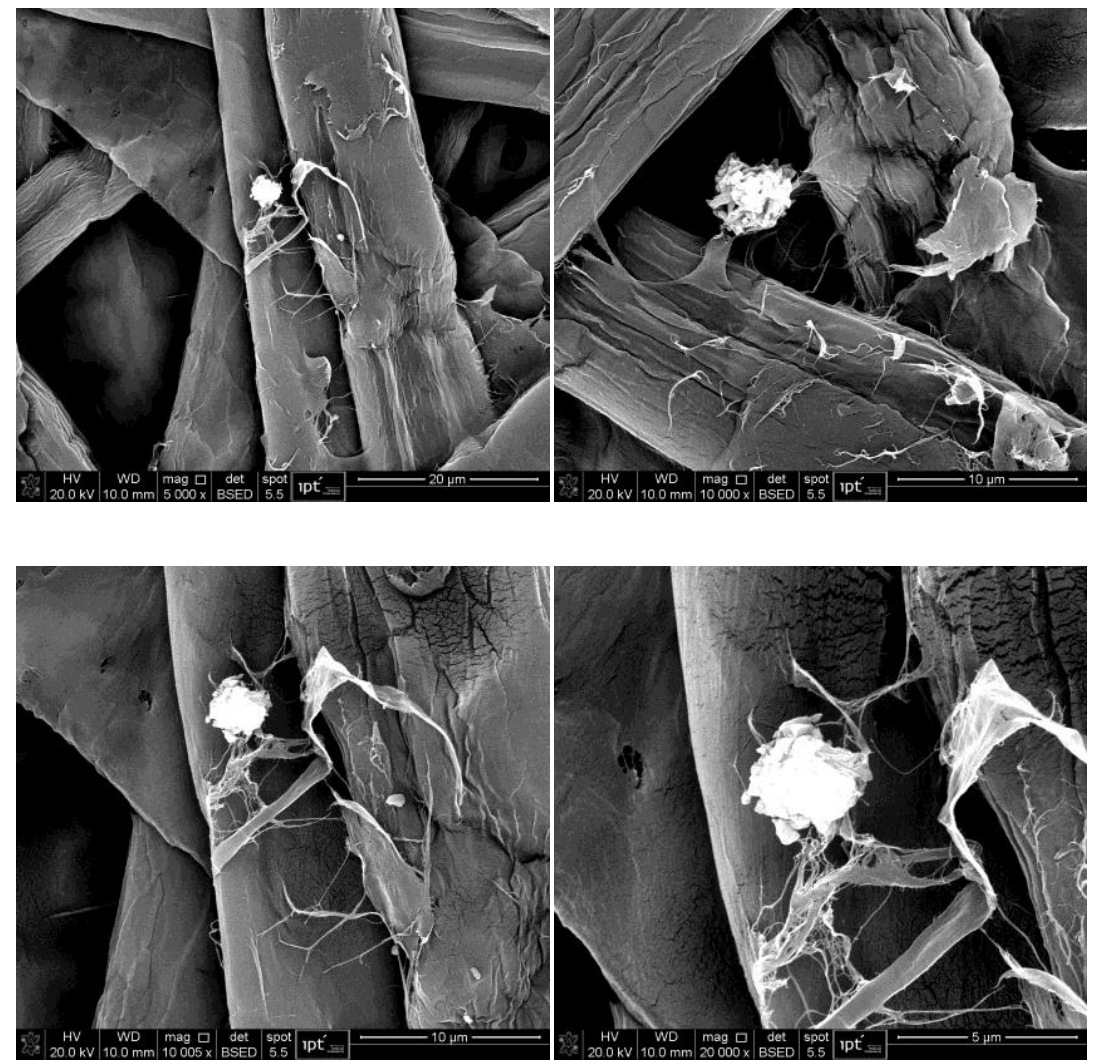

12) Amostra - Pasta Kraft de Eucalipto Pré-branqueada - Ponto Central do planejamento com CNF - Repetição

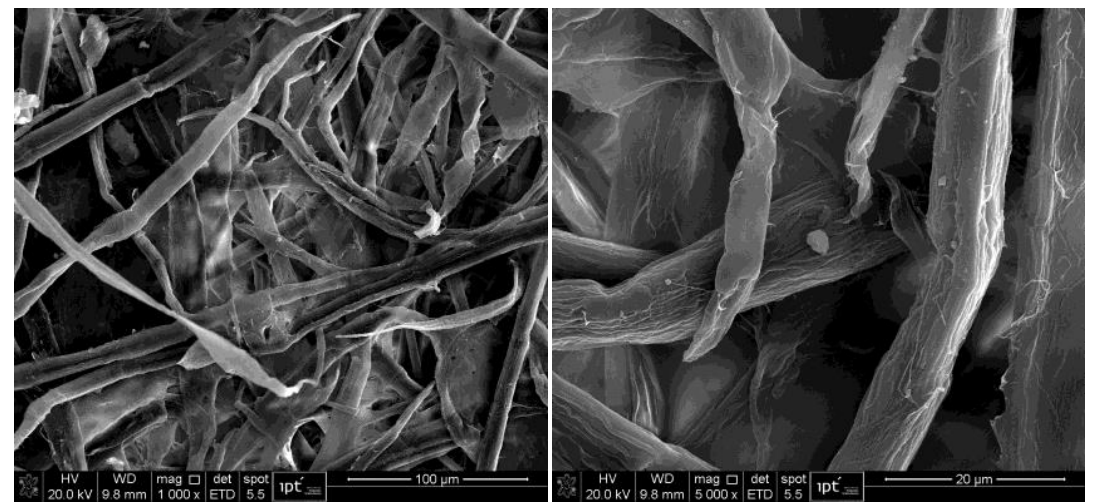


Continuação... Amostra - Pasta Kraft de Eucalipto Pré-branqueada - Ponto Central do planejamento com CNF - Repetição
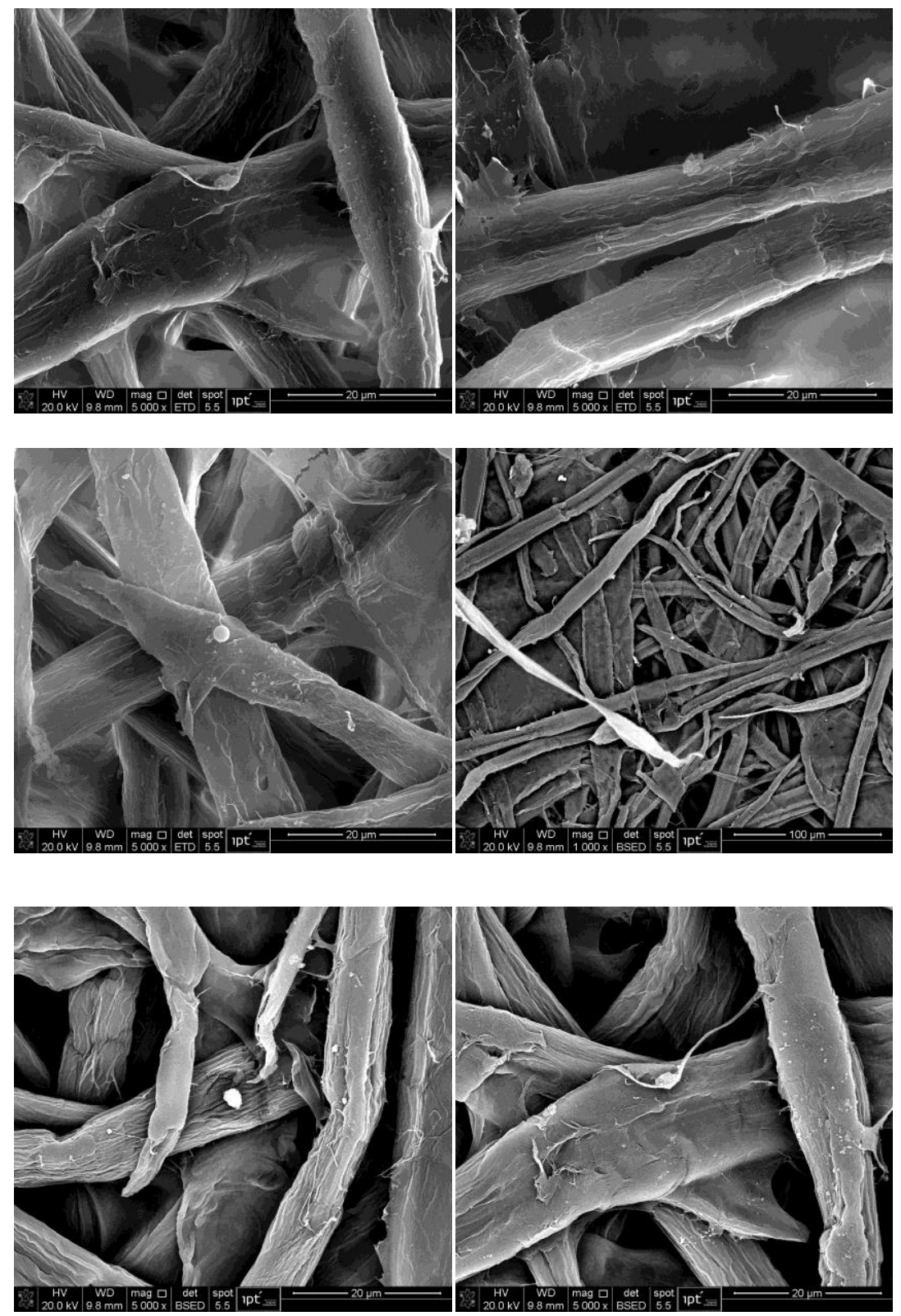
Continuação... Amostra - Pasta Kraft de Eucalipto Pré-branqueada - Ponto Central do planejamento com CNF - Repetição

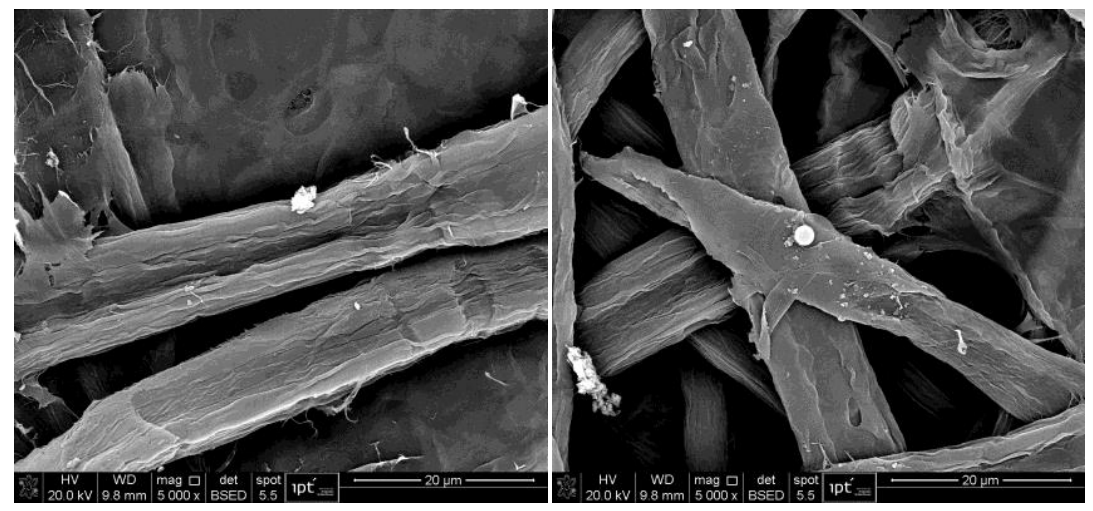

13) Amostra - Pasta Kraft de Eucalipto Pré-branqueada - 1\% MFC - Repetição
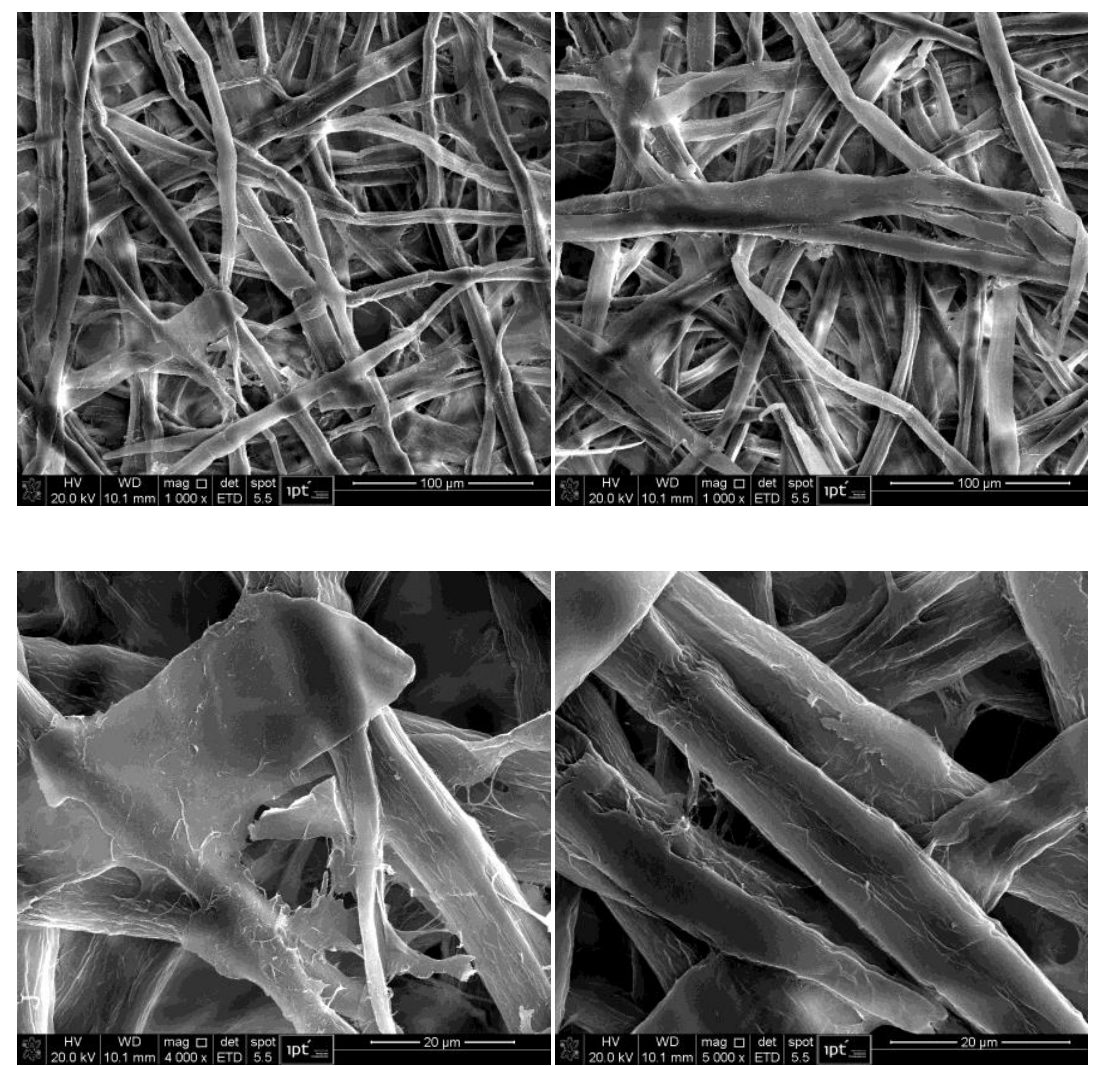
Continuação... Amostra - Pasta Kraft de Eucalipto Pré-branqueada - 1\% MFC - Repetição
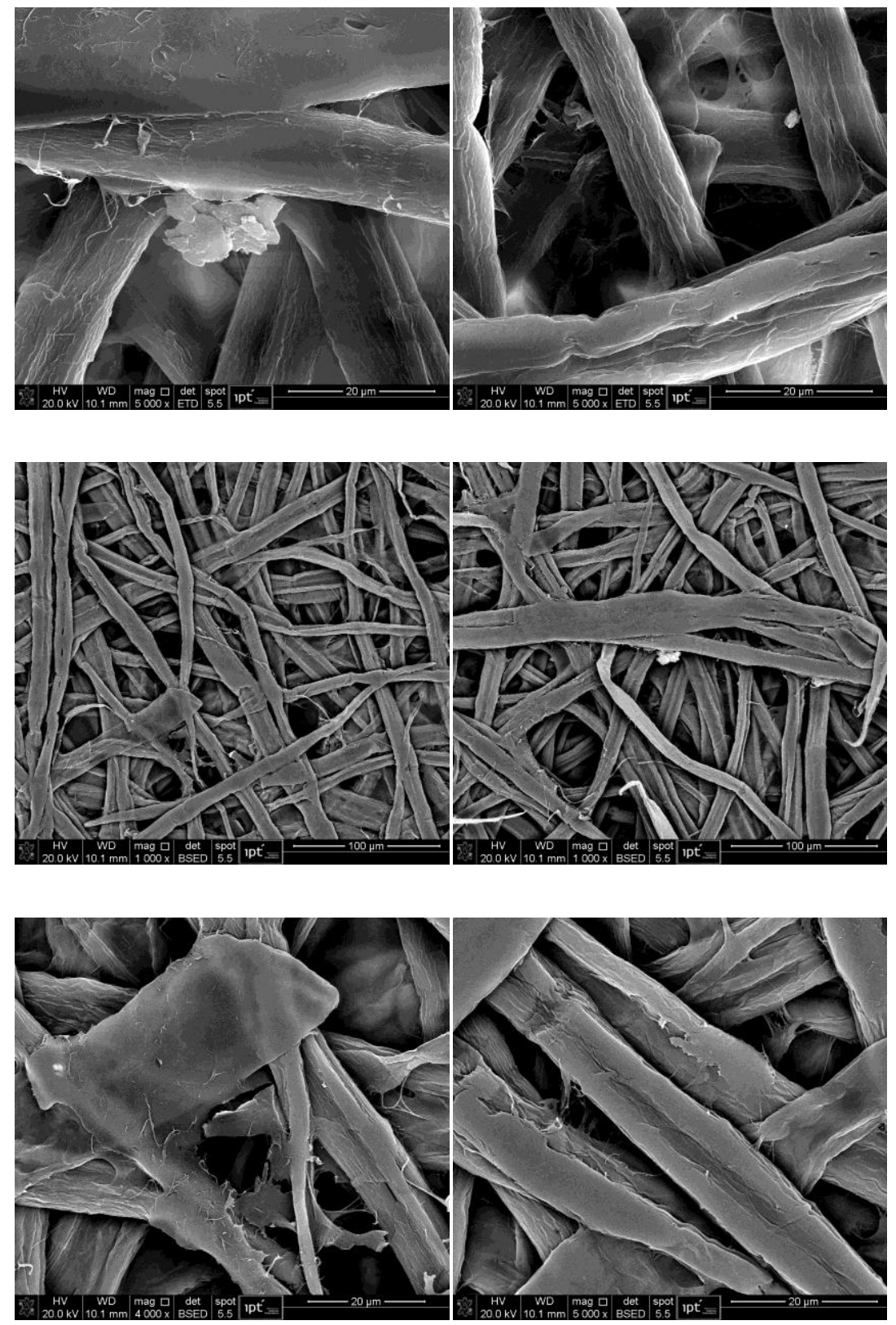
Continuação... Amostra - Pasta Kraft de Eucalipto Pré-branqueada - 1\% MFC - Repetição

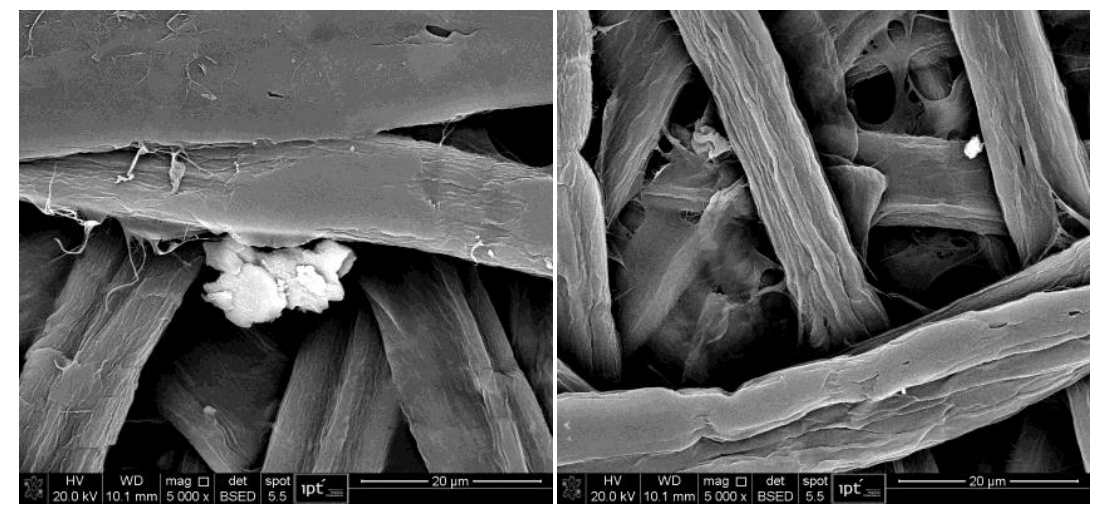

14) Amostra - Pasta Kraft de Eucalipto Pré-branqueada - Ponto Central do planejamento com MFC - Repetição

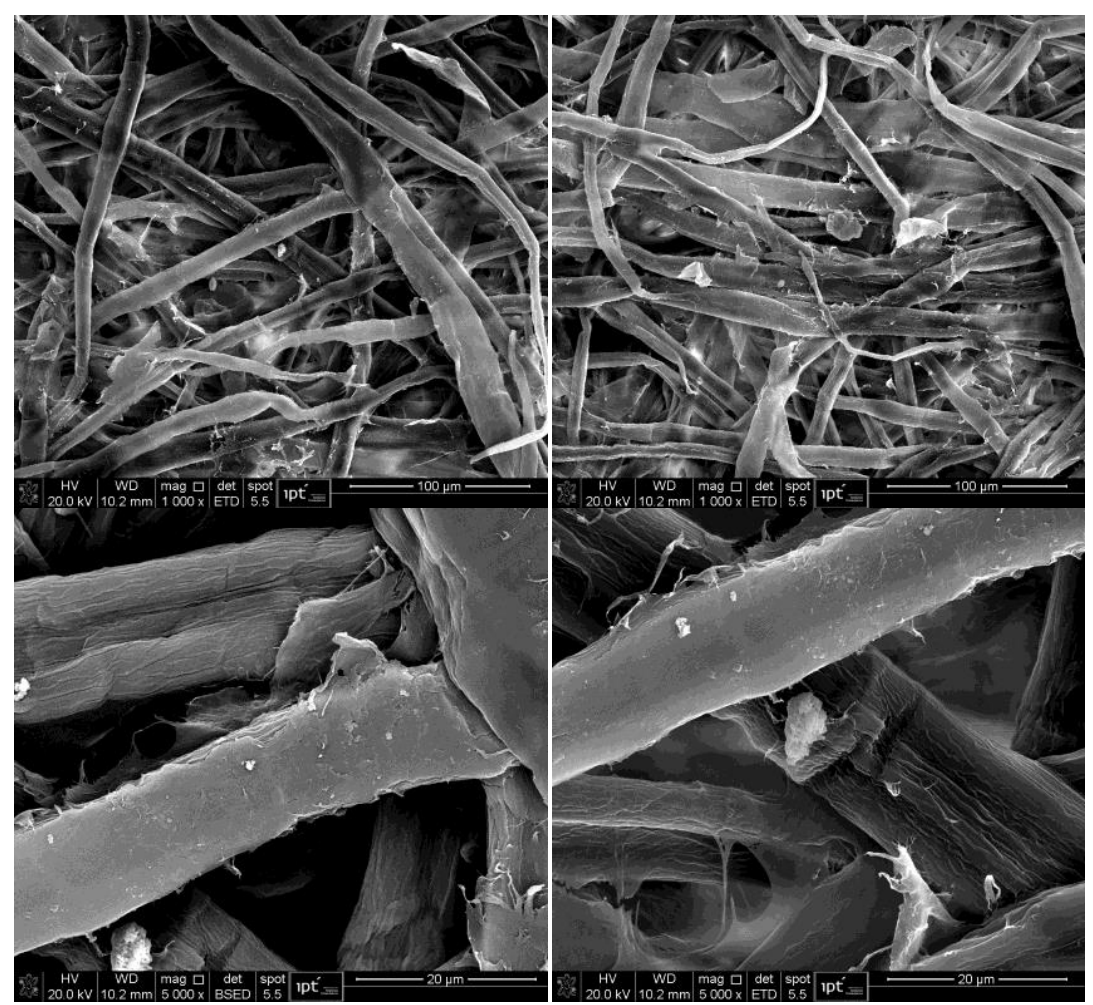


Continuação... Amostra - Pasta Kraft de Eucalipto Pré-branqueada Ponto Central do planejamento com MFC - Repetição
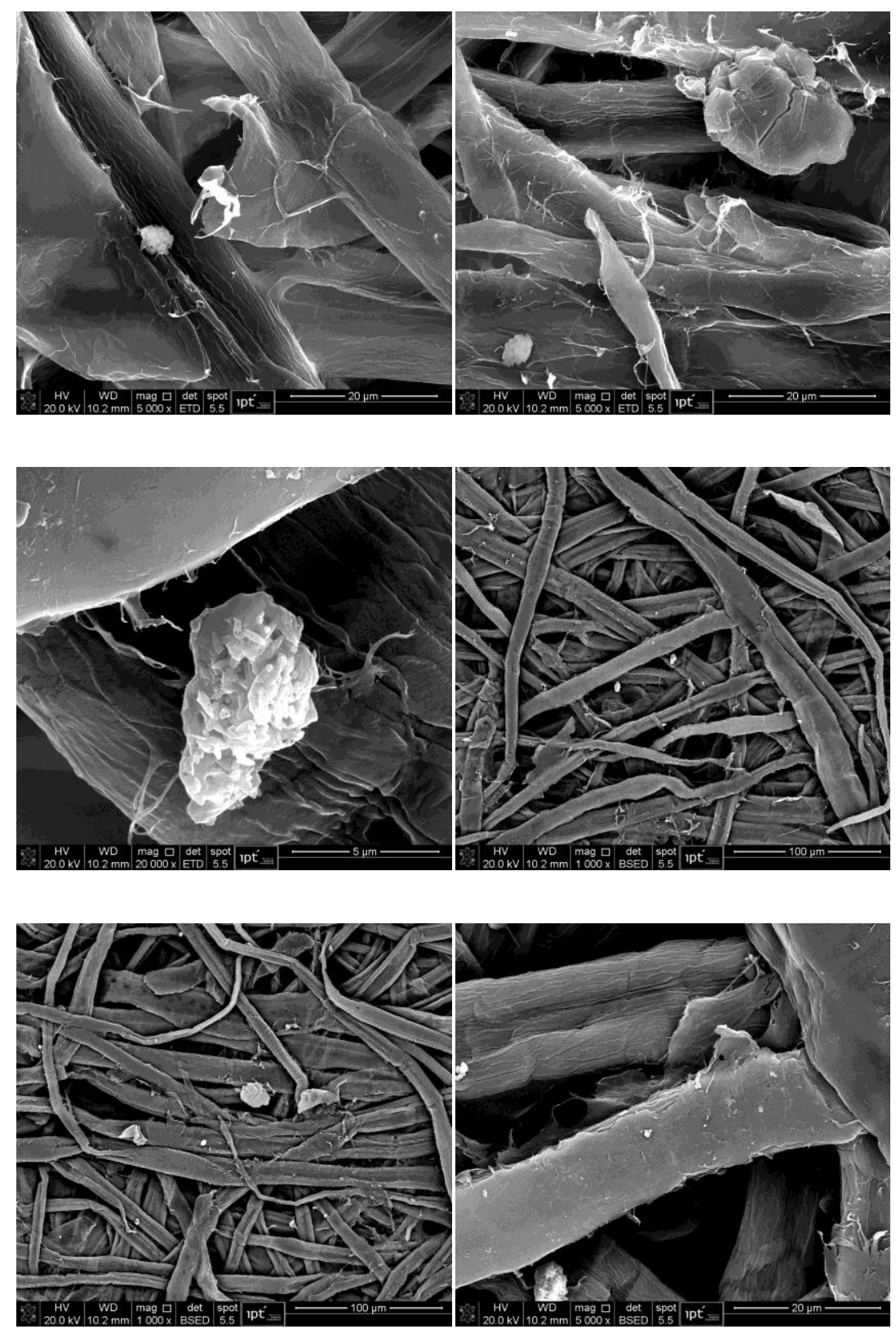
Continuação... Amostra - Pasta Kraft de Eucalipto Pré-branqueada Ponto Central do planejamento com MFC - Repetição
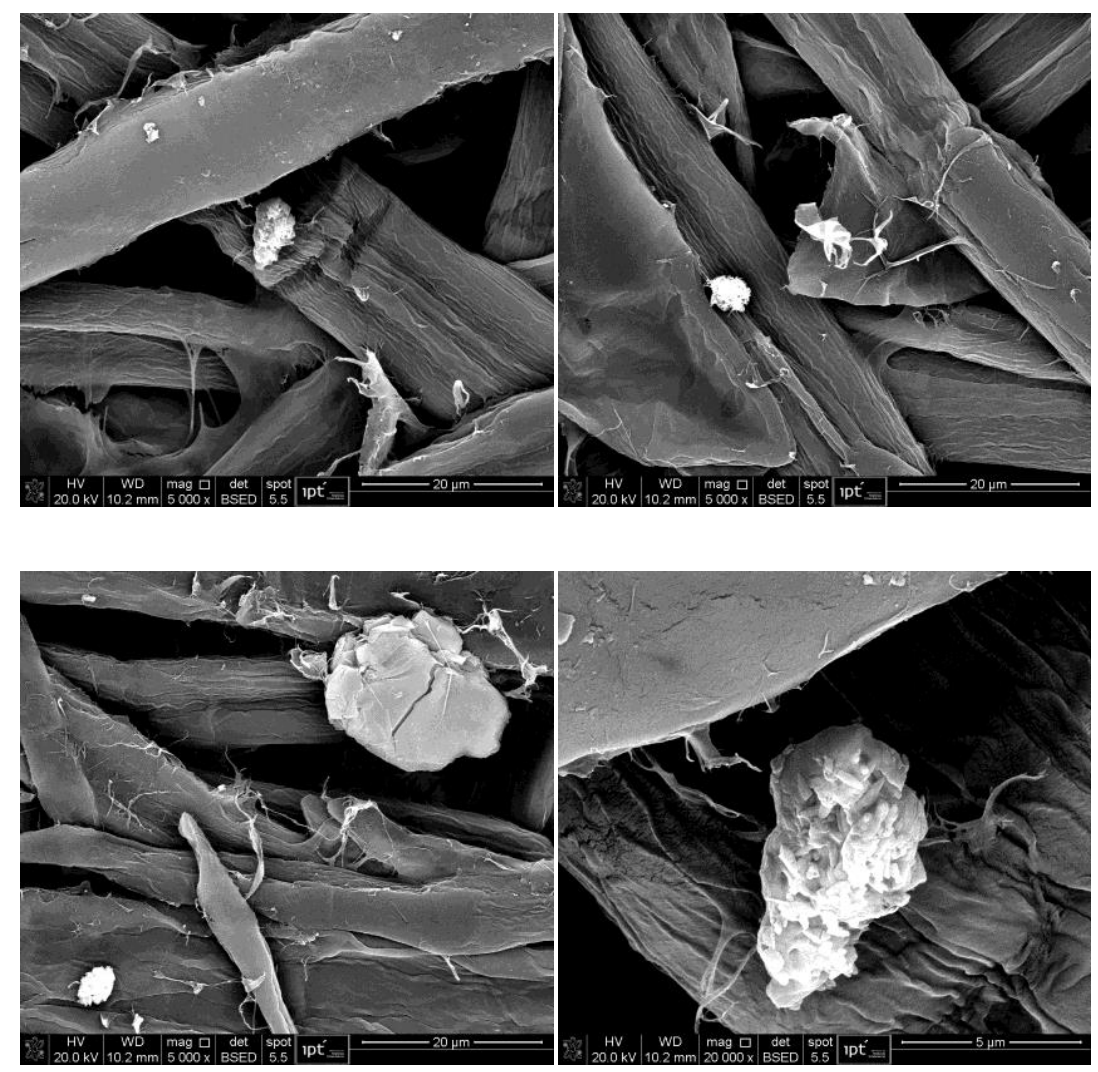


\section{BIOGRAFIA}

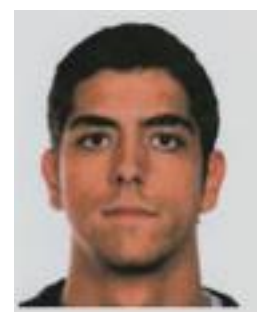

Formado em Engenharia Florestal na especialidade "Indústrias dos Produtos Florestais", pela "Escuela Politécnica de Madrid" (UPM), em 2013, Jorge Cruces Cerro desempenha atividades técnicas no Setor de Papel e Celulose desde agosto de 2011.

O autor começou os trabalhos no "Centro de Investigación Forestal - Instituto Nacional de Investigación y Tecnologia Agrária y Alimentaria" (CIFOR-INIA) de Madri (Espanha), onde foi estagiário no Laboratório de Papel e Celulose, tendo atuado, na área de pesquisa, em estudos da melhoria em reciclado de papéis.

Em meados de 2013, como resultado de uma colaboração entre a USP (Escola Politécnica da Universidade de São Paulo), o IPT (Instituto de Pesquisas Tecnológicas do Estado de São Paulo) e o CIFOR-INIA, veio a São Paulo com o auxilio de bolsas do programa da Fundação de Apoio ao IPT (FIPT) e do programa SMILE Magalhães, da UPM, para desenvolver estudos de aproveitamento de resíduos florestais na área da Biorrefinaria até Julho de 2014.

Com o início de seu trabalho em São Paulo, e com a formação da rede científica: "Productos de Valor Agregado a partir de Residuos Agro y Forestoindustriales" (PROVALOR-Cyted) de cooperação internacional, atuou como secretário financeiro e de logística para a mobilidade das reuniões internacionais em Iberoamérica desta rede.

Em meados de 2014, começou os trabalhos como bolsista na empresa Eldorado Brasil Celulose S.A., na área de Desenvolvimento Técnico, desempenhando serviços de laboratório, no desenvolvimento técnico-comercial em pastas de celuloses e papéis, voltado às necessidades específicas dos clientes nos mercados nacionais e internacionais, com especial ênfase em Brasil, Ásia, Europa e Norte América. Também, desenvolveu tarefas de "Customer Service" na área de pré e pós-venda de celulose, área de reclamações e atendimento aos requisitos dos clientes em apoio técnico e legal de produto, considerando áreas tais como a origem da madeira, sistema de gestão da qualidade e informações sobre desempenho ambiental.

Ao longo de sua carreira, o autor acumulou experiência na área Florestal e Industrial, desenvolvendo estudos em reciclado, biorrefinaria lignocelulósica, pastas celulósicas e papéis, além de testes de homologação em operação industrial do uso da celulose em máquina de papel com recomendações para obtenção de melhores resultados na redução de custos e consumo de energia, e ações para melhoria da qualidade do produto final. 